\title{
Interventions for preventing oral mucositis for patients with cancer receiving treatment (Review)
}

Worthington HV, Clarkson JE, Bryan G, Furness S, Glenny AM, Littlewood A, McCabe MG, Meyer S, Khalid T, Riley $\mathrm{P}$

Worthington HV, Clarkson JE, Bryan G, Furness S, Glenny A-M, Littlewood A, McCabe MG, Meyer S, Khalid T, Riley P. Interventions for preventing oral mucositis for patients with cancer receiving treatment.

Cochrane Database of Systematic Reviews 2011, Issue 4. Art. No.: CD000978.

DOI: 10.1002/14651858.CD000978.pub5.

www.cochranelibrary.com 
TABLE OF CONTENTS

HEADER

ABSTRACT

PLAIN LANGUAGE SUMMARY

SUMMARY OF FINDINGS

BACKGROUND

OBJECTIVES

METHODS

RESULTS

Figure 1.

Figure 2.

DISCUSSION

AUTHORS' CONCLUSIONS

ACKNOWLEDGEMENTS

REFERENCES

CHARACTERISTICS OF STUDIES

DATA AND ANALYSES

Analysis 1.1. Comparison 1: Allopurinol versus placebo/no treatment, Outcome 1: Mucositis (any)

Analysis 1.2. Comparison 1: Allopurinol versus placebo/no treatment, Outcome 2: Mucositis (moderate plus severe) …...........

Analysis 1.3. Comparison 1: Allopurinol versus placebo/no treatment, Outcome 3: Mucositis (severe)

Analysis 2.1. Comparison 2: Aloe vera versus placebo, Outcome 1: Mucositis (moderate plus severe)

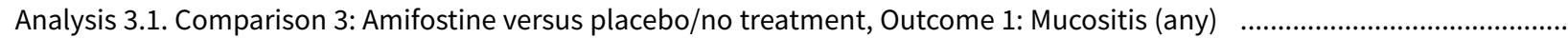

Analysis 3.2. Comparison 3: Amifostine versus placebo/no treatment, Outcome 2: Mucositis (moderate plus severe) …...........

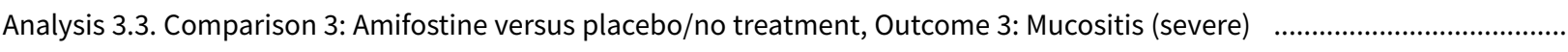

Analysis 4.1. Comparison 4: Chlorhexidine versus placebo/no treatment, Outcome 1: Mucositis (any) ...................................

Analysis 4.2. Comparison 4: Chlorhexidine versus placebo/no treatment, Outcome 2: Mucositis (moderate plus severe) .........

Analysis 4.3. Comparison 4: Chlorhexidine versus placebo/no treatment, Outcome 3: Mucositis (severe) ……….....................

Analysis 5.1. Comparison 5: Cryotherapy versus no treatment, Outcome 1: Mucositis (any)

Analysis 5.2. Comparison 5: Cryotherapy versus no treatment, Outcome 2: Mucositis (moderate plus severe) ….....................

Analysis 5.3. Comparison 5: Cryotherapy versus no treatment, Outcome 3: Mucositis (severe)

Analysis 6.1. Comparison 6: Glutamine versus placebo, Outcome 1: Mucositis (any)

Analysis 6.2. Comparison 6: Glutamine versus placebo, Outcome 2: Mucositis (moderate plus severe)

Analysis 6.3. Comparison 6: Glutamine versus placebo, Outcome 3: Mucositis (severe)

Analysis 7.1. Comparison 7: G-CSF versus placebo or no treatment, Outcome 1: Mucositis (any)

Analysis 7.2. Comparison 7: G-CSF versus placebo or no treatment, Outcome 2: Mucositis (severe)

Analysis 8.1. Comparison 8: GM-CSF versus no treatment/placebo, Outcome 1: Mucositis (any)

Analysis 8.2. Comparison 8: GM-CSF versus no treatment/placebo, Outcome 2: Mucositis (moderate plus severe) ...................

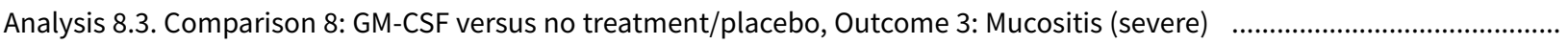

Analysis 9.1. Comparison 9: Honey versus control, Outcome 1: Mucositis (any)

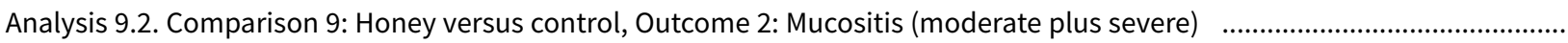

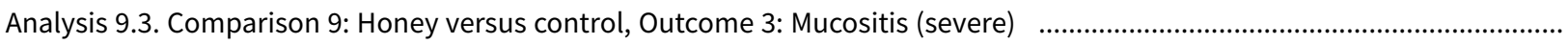

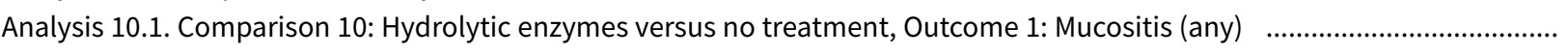

Analysis 10.2. Comparison 10: Hydrolytic enzymes versus no treatment, Outcome 2: Mucositis (moderate plus severe) ….......

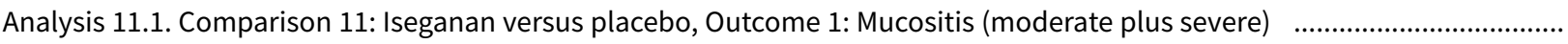

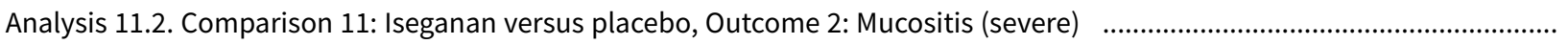

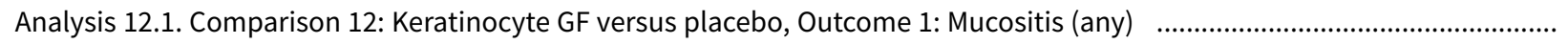

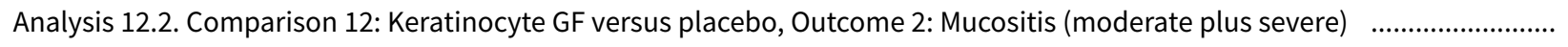

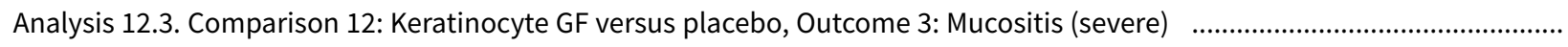

Analysis 13.1. Comparison 13: Laser versus no treatment, Outcome 1: Mucositis (any)

213

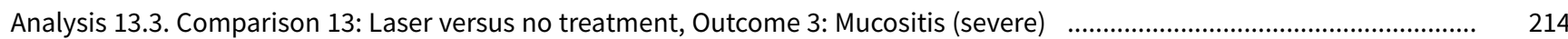

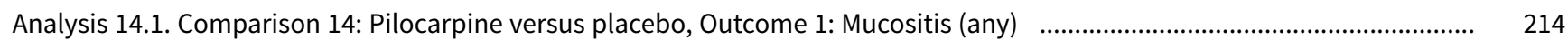




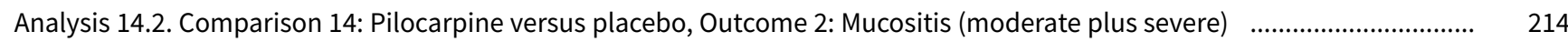

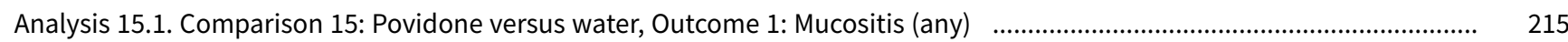

Analysis 15.2. Comparison 15: Povidone versus water, Outcome 2: Mucositis (moderate plus severe) ........................................ 215

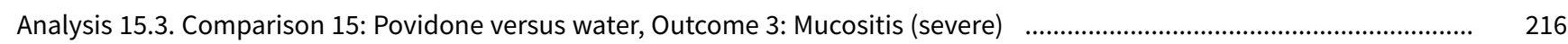

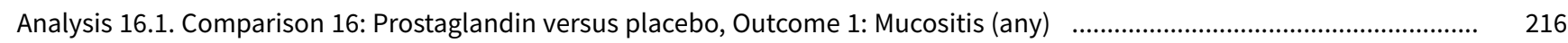

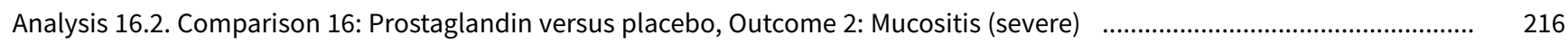

Analysis 17.1. Comparison 17: PTA antibiotic pastille or paste versus placebo/no treatment, Outcome 1: Mucositis (any) $\quad$........ $\quad 217$

Analysis 17.2. Comparison 17: PTA antibiotic pastille or paste versus placebo/no treatment, Outcome 2: Mucositis (severe) $\quad$.... 217

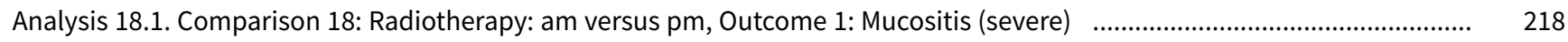

Analysis 19.1. Comparison 19: Sucralfate versus placebo/usual care, Outcome 1: Mucositis (any) .......................................... 218

Analysis 19.2. Comparison 19: Sucralfate versus placebo/usual care, Outcome 2: Mucositis (moderate plus severe) $\quad$................ 219

Analysis 19.3. Comparison 19: Sucralfate versus placebo/usual care, Outcome 3: Mucositis (severe) ....................................... 219

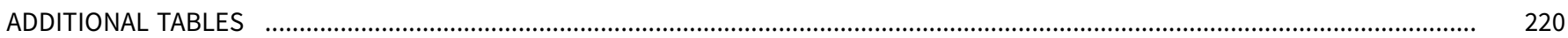

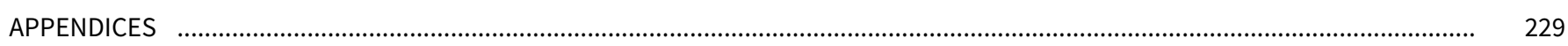

WHAT'S NEW

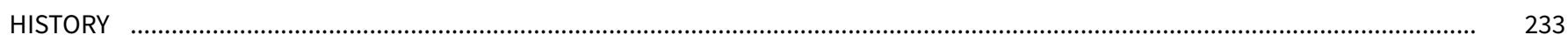

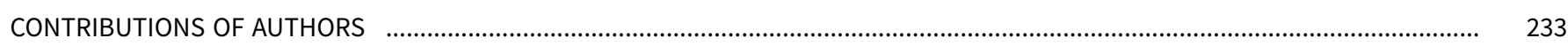

DECLARATIONS OF INTEREST

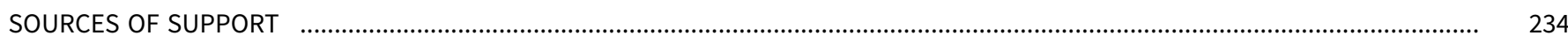

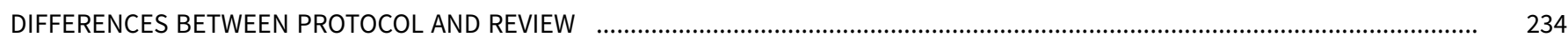

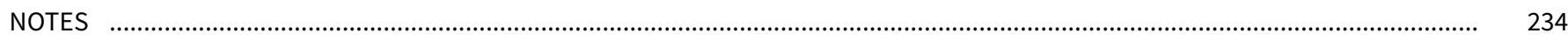

INDEX TERMS 
[Intervention Review]

\section{Interventions for preventing oral mucositis for patients with cancer receiving treatment}

Helen V Worthington ${ }^{1}$, Janet E Clarkson 1 , Gemma Bryan², Susan Furness ${ }^{3}$, Anne-Marie Glenny ${ }^{4}$, Anne Littlewood ${ }^{1}$, Martin G McCabe ${ }^{5}$, Stefan Meyer 6 , Tasneem Khalid 7 , Philip Riley ${ }^{1}$

${ }^{1}$ Cochrane Oral Health, Division of Dentistry, School of Medical Sciences, Faculty of Biology, Medicine and Health, The University of Manchester, Manchester, UK. ${ }^{2}$ Cochrane Oral Health Group, School of Dentistry, The University of Manchester, Manchester, UK. ${ }^{3}$ Cochrane Oral Health, Division of Dentistry, School of Medical Sciences, Faculty of Biology, Medicine and Health, The University of Manchester, Manchester, New Zealand. ${ }^{4}$ Division of Dentistry, School of Medical Sciences, Faculty of Biology, Medicine and Health, The University of Manchester, Manchester, UK. ${ }^{5}$ Division of Cancer Sciences, The University of Manchester, Manchester, UK. ${ }^{6}$ Paediatric and Adolescent Oncology, Royal Manchester Children's and Christie Hospital, School of Cancer and Enabling Sciences, Manchester Academic Health Science Centre, The University of Manchester, Manchester, UK. 7Department of Haematology/Oncology, Royal Manchester Children's Hospital, Manchester, UK

Contact address: Helen V Worthington, helen.worthington@manchester.ac.uk.

Editorial group: Cochrane Oral Health Group.

Publication status and date: Stable (no update expected for reasons given in 'What's new'), published in Issue 3, 2021.

Citation: Worthington HV, Clarkson JE, Bryan G, Furness S, Glenny A-M, Littlewood A, McCabe MG, Meyer S, Khalid T, Riley P. Interventions for preventing oral mucositis for patients with cancer receiving treatment. Cochrane Database of Systematic Reviews 2011, Issue 4. Art. No.: CD000978. DOI: 10.1002/14651858.CD000978.pub5.

Copyright @ 2011 The Cochrane Collaboration. Published by John Wiley \& Sons, Ltd.

\section{A B S T R A C T}

\section{Background}

Treatment of cancer is increasingly more effective but is associated with short and long term side effects. Oral side effects remain a major source of illness despite the use of a variety of agents to prevent them. One of these side effects is oral mucositis (mouth ulcers).

\section{Objectives}

To evaluate the effectiveness of prophylactic agents for oral mucositis in patients with cancer receiving treatment, compared with other potentially active interventions, placebo or no treatment.

\section{Search methods}

Electronic searches of Cochrane Oral Health Group and PaPaS Trials Registers (to 16 February 2011), CENTRAL (The Cochrane Library 2011, Issue 1), MEDLINE via OVID (1950 to 16 February 2011), EMBASE via OVID (1980 to 16 February 2011), CINAHL via EBSCO (1980 to 16 February 2011), CANCERLIT via PubMed (1950 to 16 February 2011), OpenSIGLE (1980 to 2005) and LILACS via the Virtual Health Library (1980 to 16 February 2011) were undertaken. Reference lists from relevant articles were searched and the authors of eligible trials were contacted to identify trials and obtain additional information.

\section{Selection criteria}

Randomised controlled trials of interventions to prevent oral mucositis in patients receiving treatment for cancer.

\section{Data collection and analysis}

Information regarding methods, participants, interventions, outcome measures, results and risk of bias were independently extracted, in duplicate, by two review authors. Authors were contacted for further details where these were unclear. The Cochrane Collaboration statistical guidelines were followed and risk ratios calculated using random-effects models. 


\section{Main results}

A total of 131 studies with 10,514 randomised participants are now included. Overall only $8 \%$ of these studies were assessed as being at low risk of bias. Ten interventions, where there was more than one trial in the meta-analysis, showed some statistically significant evidence of a benefit (albeit sometimes weak) for either preventing or reducing the severity of mucositis, compared to either a placebo or no treatment. These ten interventions were: aloe vera, amifostine, cryotherapy, granulocyte-colony stimulating factor (G-CSF), intravenous glutamine, honey, keratinocyte growth factor, laser, polymixin/tobramycin/amphotericin (PTA) antibiotic pastille/paste and sucralfate.

\section{Authors' conclusions}

Ten interventions were found to have some benefit with regard to preventing or reducing the severity of mucositis associated with cancer treatment. The strength of the evidence was variable and implications for practice include consideration that benefits may be specific for certain cancer types and treatment. There is a need for further well designed, and conducted trials with sufficient numbers of participants to perform subgroup analyses by type of disease and chemotherapeutic agent.

\section{PLAIN LANGUAGE SUMMARY}

\section{Interventions for preventing oral mucositis for patients with cancer receiving treatment}

Treatment for cancer (including bone marrow transplant) can cause oral mucositis (severe ulcers in the mouth). This painful condition can cause difficulties in eating, drinking and swallowing, and may also be associated with infections which may require the patient to stay longer in hospital. Different strategies are used to try and prevent this condition, and the review of trials found that some of these are effective. Two interventions, cryotherapy (ice chips) and keratinocyte growth factor (palifermin ${ }^{\circledR}$ ) showed some benefit in preventing mucositis. Sucralfate is effective in reducing the severity of mucositis, and a further seven interventions, aloe vera, amifostine, intravenous glutamine, granulocyte-colony stimulating factor (G-CSF), honey, laser and antibiotic lozenges containing polymixin/tobramycin/amphotericin (PTA) showed weaker evidence of benefit. These were evaluated in patients with different types of cancer, undergoing different types of cancer treatment. Benefits may be restricted to the disease and treatment combinations evaluated. 


\begin{tabular}{|c|c|c|c|c|c|c|}
\hline \multicolumn{7}{|c|}{ treatment for preventing oral muc } \\
\hline \multicolumn{7}{|c|}{ Cryotherapy versus no treatment for preventing oral mucositis for patients with cancer receiving treatment } \\
\hline \multicolumn{7}{|c|}{$\begin{array}{l}\text { Patient or population: preventing oral mucositis for patients with cancer receiving treatment } \\
\text { Settings: } \\
\text { Intervention: Cryotherapy versus no treatment }\end{array}$} \\
\hline \multirow[t]{3}{*}{ Outcomes } & \multicolumn{2}{|c|}{ Illustrative comparative risks* $(95 \% \mathrm{Cl})$} & \multirow{3}{*}{$\begin{array}{l}\text { Relative effect } \\
(95 \% \mathrm{CI})\end{array}$} & \multirow{3}{*}{$\begin{array}{l}\text { No of Partici- } \\
\text { pants } \\
\text { (studies) }\end{array}$} & \multirow{3}{*}{$\begin{array}{l}\text { Quality of the } \\
\text { evidence } \\
\text { (GRADE) }\end{array}$} & \multirow[t]{3}{*}{ Comments } \\
\hline & Assumed risk & Corresponding risk & & & & \\
\hline & Control & Cryotherapy versus no treatment & & & & \\
\hline \multirow{4}{*}{$\begin{array}{l}\text { Mucositis (any) } \\
0-4 \text { scale } \\
\text { Follow-up: median } 28 \\
\text { days }\end{array}$} & Low risk popu & & \multirow{4}{*}{$\begin{array}{l}\text { RR } \mathbf{0 . 7 4} \\
-(0.57 \text { to } 0.95)\end{array}$} & \multirow{4}{*}{$\begin{array}{l}472 \\
\text { (5 studies) }\end{array}$} & \multirow{4}{*}{$\begin{array}{l}\oplus \oplus \ominus \ominus \\
\operatorname{low}^{2,3}\end{array}$} & \\
\hline & 600 per 1000 & $\begin{array}{l}\mathbf{4 4 4} \text { per } 1000 \\
(342 \text { to } 570)\end{array}$ & & & & \\
\hline & \multicolumn{2}{|c|}{ High risk population 1} & & & & \\
\hline & 950 per 1000 & $\begin{array}{l}\mathbf{7 0 3} \text { per } 1000 \\
\text { (541 to } 902)\end{array}$ & & & & \\
\hline \multirow{4}{*}{$\begin{array}{l}\text { Mucositis (severe) } \\
0-4 \text { scale } \\
\text { Follow-up: median } 28 \\
\text { days }\end{array}$} & Low risk popu & & \multirow{4}{*}{$\begin{array}{l}\text { RR } 0.36 \\
(0.17 \text { to } 0.77)\end{array}$} & \multirow{4}{*}{$\begin{array}{l}472 \\
\text { (5 studies) }\end{array}$} & \multirow{4}{*}{$\begin{array}{l}\oplus \oplus \ominus \ominus \\
\text { low } 2,5\end{array}$} & \\
\hline & 300 per 1000 & $\begin{array}{l}\mathbf{1 0 8} \text { per } 1000 \\
(51 \text { to } 231)\end{array}$ & & & & \\
\hline & \multicolumn{2}{|c|}{ High risk population 4} & & & & \\
\hline & 650 per 1000 & $\begin{array}{l}234 \text { per } 1000 \\
\text { (111 to } 501)\end{array}$ & & & & \\
\hline
\end{tabular}

*The basis for the assumed risk (e.g. the median control group risk across studies) is provided in footnotes. The corresponding risk (and its $95 \%$ confidence interval) is based on the assumed risk in the comparison group and the relative effect of the intervention (and its $95 \% \mathrm{Cl}$ ).

Cl: Confidence interval; RR: Risk ratio;

GRADE Working Group grades of evidence

High quality: Further research is very unlikely to change our confidence in the estimate of effect.

Moderate quality: Further research is likely to have an important impact on our confidence in the estimate of effect and may change the estimate. 


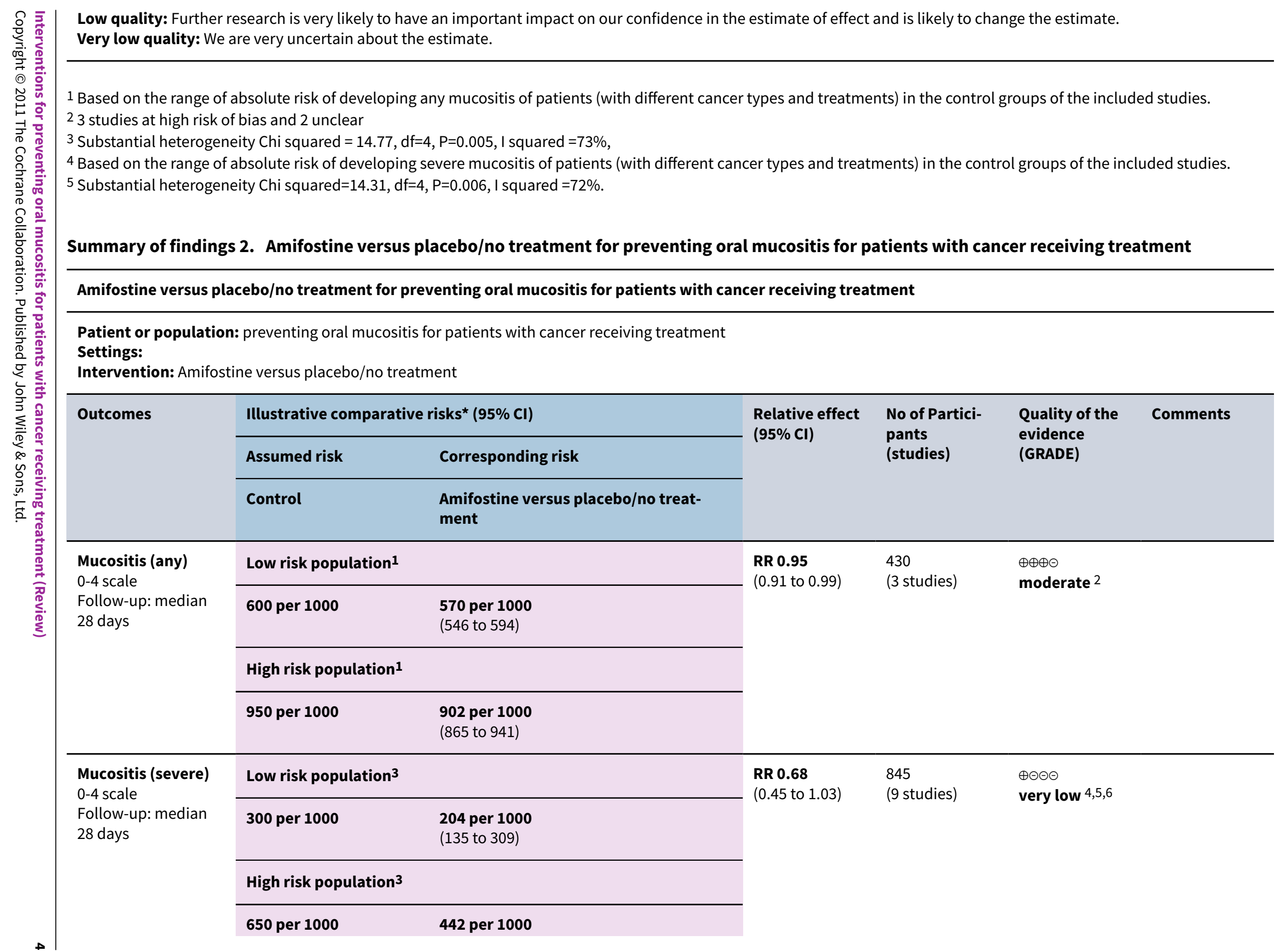




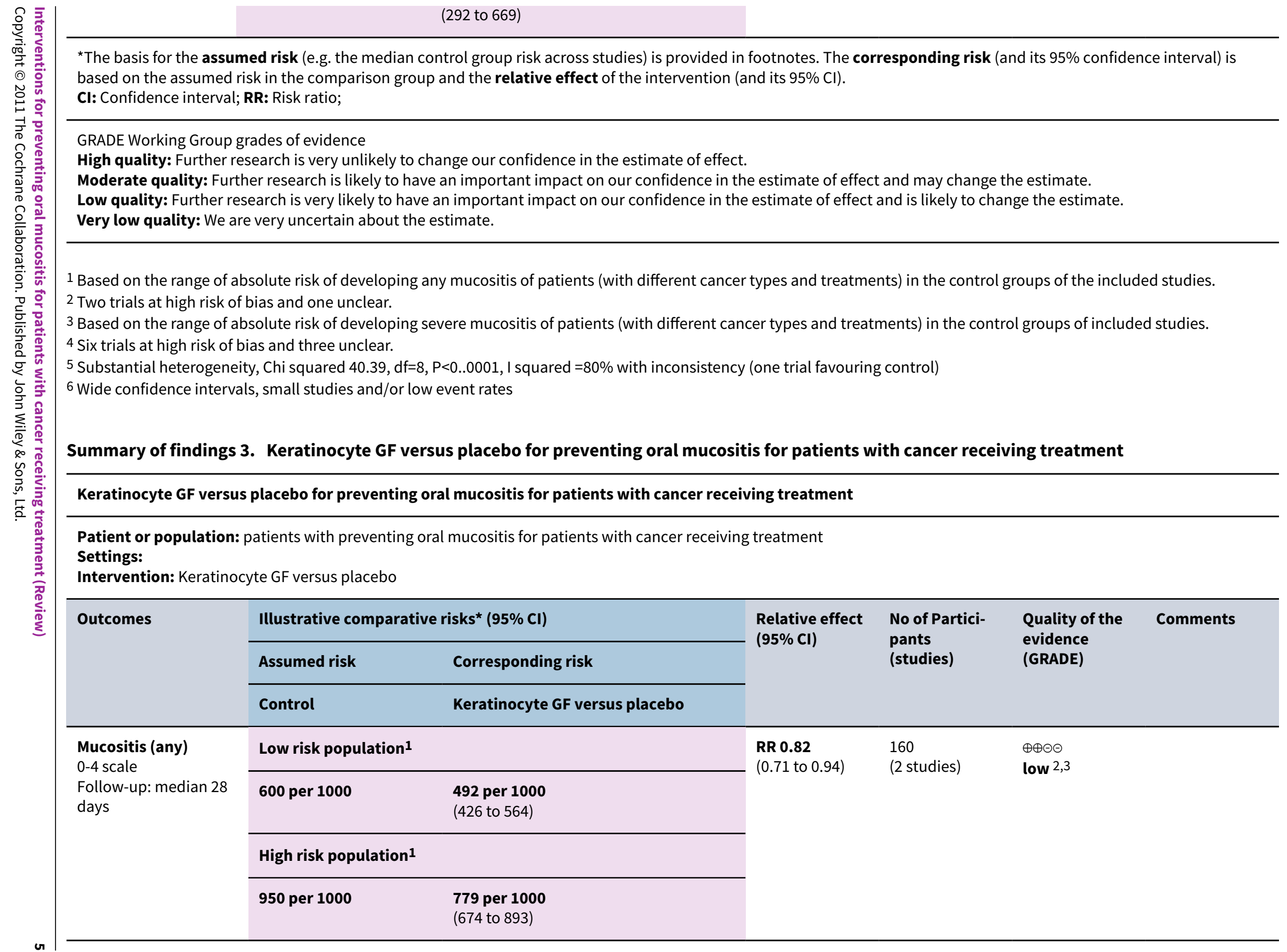

3 Based on the range of absolute risk of developing severe mucositis of patients (with different cancer types and treatments) in the control groups of included studies.

5 Substantial heterogeneity, Chi squared $40.39, \mathrm{df}=8, \mathrm{P}<0 . .0001$, I squared $=80 \%$ with inconsistency (one trial favouring control)

6 Wide confidence intervals, small studies and/or low event rate

Summary of findings 3. Keratinocyte GF versus placebo for preventing oral mucositis for patients with cancer receiving treatment

Keratinocyte GF versus placebo for preventing oral mucositis for patients with cancer receiving treatment

Patient or population: patients with preventing oral mucositis for patients with cancer receiving treatment 


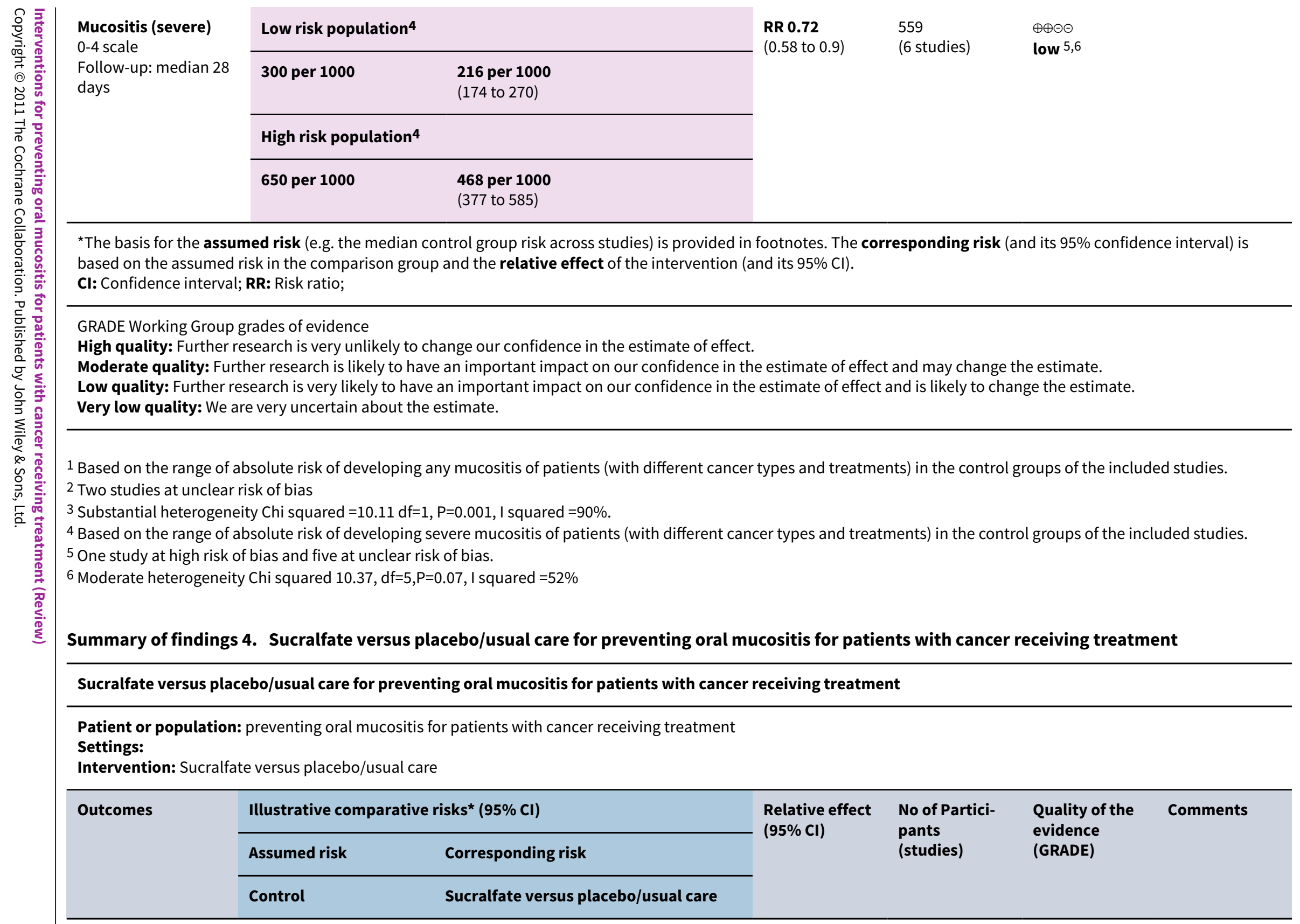




\begin{tabular}{|c|c|c|c|c|c|}
\hline \multirow{4}{*}{ 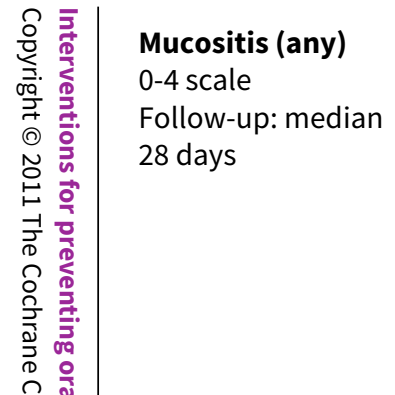 } & \multicolumn{2}{|c|}{ Low risk population 1} & \multirow{4}{*}{$\begin{array}{l}\text { RR } 0.98 \\
\text { (0.88 to } 1.1)\end{array}$} & \multirow{4}{*}{$\begin{array}{l}222 \\
\text { (3 studies) }\end{array}$} & \multirow{4}{*}{$\begin{array}{l}\oplus \oplus \oplus \ominus \\
\text { moderate } 2\end{array}$} \\
\hline & 600 per 1000 & $\begin{array}{l}\mathbf{5 8 8} \text { per } \mathbf{1 0 0 0} \\
\text { (528 to } 660)\end{array}$ & & & \\
\hline & \multicolumn{2}{|c|}{ High risk population 1} & & & \\
\hline & 950 per 1000 & $\begin{array}{l}\mathbf{9 3 1} \text { per } \mathbf{1 0 0 0} \\
(836 \text { to } 1000)\end{array}$ & & & \\
\hline \multirow{4}{*}{$\begin{array}{l}\text { Mucositis (severe) } \\
0-4 \text { scale } \\
\text { Follow-up: median } \\
28 \text { days }\end{array}$} & \multicolumn{2}{|c|}{ Low risk population 3} & \multirow{4}{*}{$\begin{array}{l}\text { RR } 0.67 \\
\text { (0.48 to } 0.92 \text { ) }\end{array}$} & \multirow{4}{*}{$\begin{array}{l}428 \\
\text { (7 studies) }\end{array}$} & \multirow{4}{*}{$\begin{array}{l}\oplus \oplus \oplus \ominus \\
\text { moderate 4 }\end{array}$} \\
\hline & 300 per 1000 & $\begin{array}{l}201 \text { per } 1000 \\
\text { (144 to } 276)\end{array}$ & & & \\
\hline & \multicolumn{2}{|c|}{ High risk population 3} & & & \\
\hline & 650 per 1000 & $\begin{array}{l}\mathbf{4 3 5} \text { per } \mathbf{1 0 0 0} \\
\text { (312 to } 598)\end{array}$ & & & \\
\hline
\end{tabular}

${ }^{*}$ The basis for the assumed risk (e.g. the median control group risk across studies) is provided in footnotes. The corresponding risk (and its $95 \%$ confidence interval) is based on the assumed risk in the comparison group and the relative effect of the intervention (and its $95 \% \mathrm{Cl}$ ).

Cl: Confidence interval; RR: Risk ratio;

GRADE Working Group grades of evidence

High quality: Further research is very unlikely to change our confidence in the estimate of effect.

Moderate quality: Further research is likely to have an important impact on our confidence in the estimate of effect and may change the estimate.

Low quality: Further research is very likely to have an important impact on our confidence in the estimate of effect and is likely to change the estimate.

Very low quality: We are very uncertain about the estimate.

1 Based on the range of absolute risk of developing any mucositis of patients (with different cancer types and treatments) in the control groups of the included studies.

2 All studies at unclear risk of bias

3 Based on the range of absolute risk of developing severe mucositis of patients (with different cancer types and treatments) in the control groups of the included studies.

4 One study at low risk of bias and six at unclear risk of bias

\section{Summary of findings 5. Chlorhexidine versus placebo/no treatment for preventing oral mucositis for patients with cancer receiving treatment}

\section{Chlorhexidine versus placebo/no treatment for preventing oral mucositis for patients with cancer receiving treatment}

Patient or population: preventing oral mucositis for patients with cancer receiving treatment

Settings: 
Intervention: Chlorhexidine versus placebo/no treatment

\begin{tabular}{|c|c|c|c|c|c|c|}
\hline \multirow[t]{3}{*}{ Outcomes } & \multicolumn{2}{|c|}{ Illustrative comparative risks ${ }^{\star}(95 \% \mathrm{Cl})$} & \multirow{3}{*}{$\begin{array}{l}\text { Relative effect } \\
(95 \% \mathrm{Cl})\end{array}$} & \multirow{3}{*}{$\begin{array}{l}\text { No of Partici- } \\
\text { pants } \\
\text { (studies) }\end{array}$} & \multirow{3}{*}{$\begin{array}{l}\text { Quality of the } \\
\text { evidence } \\
\text { (GRADE) }\end{array}$} & \multirow[t]{3}{*}{ Comments } \\
\hline & Assumed risk & Corresponding risk & & & & \\
\hline & Control & $\begin{array}{l}\text { Chlorhexidine versus placebo/no treat- } \\
\text { ment }\end{array}$ & & & & \\
\hline \multirow{4}{*}{$\begin{array}{l}\text { Mucositis (any) } \\
0-4 \text { scale } \\
\text { Follow-up: median } \\
28 \text { days }\end{array}$} & Low risk population 1 & & \multirow{4}{*}{$\begin{array}{l}\text { RR } 0.76 \\
(0.47 \text { to } 1.24)\end{array}$} & \multirow{4}{*}{$\begin{array}{l}454 \\
\text { (4 studies) }\end{array}$} & \multirow{4}{*}{$\begin{array}{l}\oplus \oplus \ominus \ominus \\
\text { low 2,3 }\end{array}$} & \\
\hline & 600 per 1000 & $\begin{array}{l}\mathbf{4 5 6} \text { per } \mathbf{1 0 0 0} \\
\text { (282 to } 744)\end{array}$ & & & & \\
\hline & \multicolumn{2}{|l|}{ High risk population 1} & & & & \\
\hline & 950 per 1000 & $\begin{array}{l}722 \text { per } 1000 \\
(446 \text { to } 1000)\end{array}$ & & & & \\
\hline \multirow{4}{*}{$\begin{array}{l}\text { Mucositis (severe) } \\
0-4 \text { scale } \\
\text { Follow-up: median } \\
28 \text { days }\end{array}$} & Low risk population 4 & & \multirow{4}{*}{$\begin{array}{l}\text { RR } \mathbf{0 . 8 2} \\
(0.54 \text { to } 1.23)\end{array}$} & \multirow{4}{*}{$\begin{array}{l}244 \\
\text { (4 studies) }\end{array}$} & \multirow{4}{*}{$\begin{array}{l}\oplus \oplus \odot \ominus \\
\text { low } 5,6\end{array}$} & \\
\hline & 300 per 1000 & $\begin{array}{l}246 \text { per } 1000 \\
\text { (162 to } 369)\end{array}$ & & & & \\
\hline & \multicolumn{2}{|l|}{ High risk population 4} & & & & \\
\hline & 650 per 1000 & $\begin{array}{l}\mathbf{5 3 3} \text { per } \mathbf{1 0 0 0} \\
\text { (351 to } 800)\end{array}$ & & & & \\
\hline
\end{tabular}

${ }^{\star}$ The basis for the assumed risk (e.g. the median control group risk across studies) is provided in footnotes. The corresponding risk (and its $95 \%$ confidence interval) is based on the assumed risk in the comparison group and the relative effect of the intervention (and its $95 \% \mathrm{Cl}$ ).

Cl: Confidence interval; RR: Risk ratio;

GRADE Working Group grades of evidence

High quality: Further research is very unlikely to change our confidence in the estimate of effect.

Moderate quality: Further research is likely to have an important impact on our confidence in the estimate of effect and may change the estimate.

Low quality: Further research is very likely to have an important impact on our confidence in the estimate of effect and is likely to change the estimate.

Very low quality: We are very uncertain about the estimate.

1 Based on the range of absolute risk of developing any mucositis of patients (with different cancer types and treatments) in the control groups of the included studies.

2 One study at low risk of bias and three unclear.

3 Substantial heterogeneity Chi squared $30.49, \mathrm{df}=3, \mathrm{P}<0.0001$, I squared $=90 \%$.

${ }^{4}$ Based on the range of absolute risk of developing severe mucositis of patients (with different cancer types and treatments) in the control groups of the included studies. 
One high risk of bias, two unclear and one low

6 Moderate heterogeneity Chi squared $7.44, \mathrm{df}=3, \mathrm{P}=0.06$, I squared $=60 \%$, with some inconsistency (only one study, at unclear risk of bias, showing benefit)

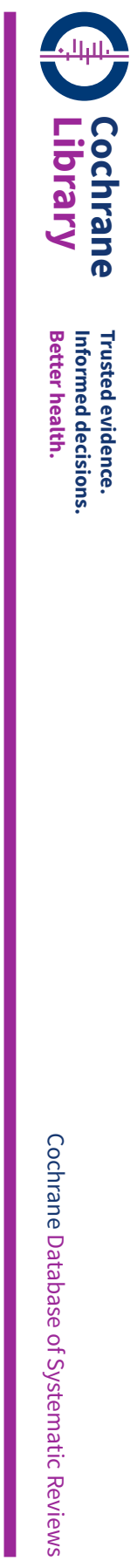




\section{B A C K G R O U N D}

\section{Description of the condition}

Treatment for malignancies with cytotoxic chemotherapy or radiotherapy or both are becoming increasingly effective but are associated with short and long term side effects. Among the clinically important acute side effects is the disruption in the function and integrity of the mouth. The consequences of this include severe ulceration (mucositis) and fungal infection of the mouth (oral candidiasis, thrush). These disease and treatment induced complications may also produce oral discomfort or pain, poor nutrition, delays in cancer treatment, increased hospital stays and costs and, in some patients, life threatening infection (septicaemia).

\section{Description of the intervention}

Oral complications remain a major source of illness despite the use of a plethora of prophylactic agents, many of which are not evidence based. Individual cancer centres use different mouth care regimens to prevent mucositis (Glenny 2004), frequently with scant evidence of efficacy. Given the costs to patients and their clinicians of mucositis-related morbidity it is surprising that a uniform approach to mucositis prevention, backed by a strong evidence base, is lacking. There are variations in usage between cancer centres in terms of the mouth care regimen used. Compliance with recommended use of product is variable and there are conflicting reports of the effectiveness of prophylactic agents. The qualitative and quantitative benefits, side effects and costs of oral therapies are of importance to the cancer teams responsible for the treatment of patients.

There have been several traditional reviews published and most of these present a general discussion for both chemotherapy and radiotherapy induced oral side effects (Andreassen 2003; Chang 2003; De Pauw 1997; Denning 1992; Duncan 2003; Lortholary 1997; Savarese 2003; Stevens 1995; Symonds 1998; Verdi 1993; White 1993). The conclusions drawn and recommendations made vary from advocating a particular therapy to recommending oral care procedures that have not been systematically investigated. Three systematic reviews have focused on the prevention of oral mucositis in patients with cancer (Kowanko 1998; Stokman 2006; Sunderland 2001). Kowanko and colleagues concluded that for most strategies reviewed there was insufficient evidence to draw any conclusions regarding their effectiveness (Kowanko 1998). Sunderland and colleagues focused exclusively on patients with head and neck cancer. Their main analysis combined all the interventions in one meta-analysis and found a beneficial effect of prophylactic interventions (Sunderland 2001). The most recent published review (Stokman 2006) considered eight different interventions and found four that showed a statistically significant effect in preventing the development or severity of mucositis.

Since the previous update of this review the most significant development in this field has been the publication of a review of evidence and the development of clinical practice guidelines by the Mucositis Study Section of the Multinational Association of Supportive Care in Cancer and the International Society for Oral Oncology (Keefe 2007; Rubenstein 2004; Sonis 2004). The development of clinical practice guidelines highlights the fact that preventing and managing mucositis in cancer patients worldwide is imperative. However, given the large number of clinical trials identified in this systematic review, it is important that researchers work co-operatively to maintain up to date systematic reviews, which can then be used to provide the evidence base for clinical guidelines, which can be adapted at the local level to take account of policy and resources.

A previous version of this Cochrane review looked at the use of prophylactic agents for the prevention of oral mucositis and oral candidiasis in patients with cancer treated by chemotherapy (Clarkson 2000). The review concluded that there was some evidence that using ice chips during the chemotherapy treatment was effective in preventing mucositis. The review was updated in 2003 (Clarkson 2003a) and this update broadened the oral mucositis part of the initial review and looked at the prevention of oral mucositis in patients receiving any treatment for cancer, including patients with all types of cancer, as well as head and neck cancer, and including comparisons between any interventions for prevention. A second review update was carried out in 2006 (Worthington 2006) and reviews on the prevention of oral candidiasis have also been published in The Cochrane Library (Clarkson 2007a; Worthington 2004a). The third prevention review update was carried out in 2007 (Worthington 2007).These reviews form part of a series of Cochrane reviews on the prevention and treatment of oral mucositis, oral candidiasis (Clarkson 2007b; Worthington 2007a); xerostomia (Tavender 2004) and herpes simplex in patients receiving cancer therapy (Glenny 2009).

\section{How the intervention might work}

Mucositis presents a particular challenge due to its complex biological nature and the range of interventions tested have included mucosal surface protectants, anti-inflammatory formulations, antimicrobials, growth factors and a plethora of other miscellaneous agents.

\section{Why it is important to do this review}

The Cochrane Oral Health Group undertook an extensive prioritisation exercise in 2014 to identify a core portfolio of titles that were the most clinically important ones to maintain on the Cochrane Library (Worthington 2015). This review was identified as a priority title by the oral medicine expert panel (Cochrane OHG priority review portfolio).

\section{OB JECTIVES}

To evaluate the effectiveness of interventions (which may include placebo or no treatment) for the prevention of oral mucositis in patients with cancer receiving radiotherapy, chemotherapy or targeted therapies.

We also investigated the following secondary outcomes for benefits or harms provided there were three or more trials or one trial with more than 100 participants, otherwise we recorded outcomes reported:

- Oral hygiene measures

- Relief of pain/use of analgesia

- Duration or severity of dysphagia

- Use of parenteral nutrition or feeding tube

- Incidence of systemic infection or use of antibiotics

- Febrile episodes

- Blood changes 
- Treatment interruption

- Days of stay in hospital

- Toxicity (nausea/vomiting/constipation/diarrhoea)

- Toxicity - skin changes

- Toxicity - unspecific

- Xerostomia

- Cost of care

- Patient quality of life

- Death

- Weight loss/gain

- Caloric intake by oral nutrition

- Eating/drinking difficulty

- Overall health

- Recurrence of cancer.

The following subgroup analyses were proposed:

- Cancer type (leukaemia, head and neck, other solid tumours and mixed)

- Cancer treatment (specific, for example 5-fluorouracil (5-FU))

- Age group (adults, children or both).

\section{METHODS}

\section{Criteria for considering studies for this review}

\section{Types of studies}

Only randomised controlled trials (RCTs) were eligible for inclusion in this review, including both cross-over and parallel group studies.

\section{Types of participants}

Anyone with cancer who received radiotherapy, chemotherapy or targeted therapies.

\section{Types of interventions}

(This review did not include studies of different cancer treatments when the primary outcome was survival or cure with mucositis as a toxicity.)

Active agents: any agent prescribed as prophylaxis for oral mucositis.

Control: may be placebo or no treatment, or another active intervention.

\section{Types of outcome measures}

\section{Primary outcome}

- Mucositis (at all levels of severity) (ulcers). Mucositis measured on a 0 to 4 point scale (none to severe) was used and this was dichotomised as any mucositis ( 0 versus $1+$ ), moderate plus severe mucositis ( 0 to 1 versus $2+$ ), severe mucositis ( 0 to 2 versus $3+$ ).

- Trials where mucositis is measured using a scale which individually grades multiple components of oral health such as teeth or plaque (Eilers 1988), are excluded. It is acknowledged that these oral effects are important, but it is not possible to separate the 'mucositis only' score, from the total score, so this review will not include studies which evaluate mucositis using such component scores.

\section{Secondary outcomes}

- Oral hygiene measures

- Relief of pain/use of analgesia

- Duration or severity of dysphagia

- Use of parenteral nutrition or feeding tube

- Incidence of systemic infection or use of antibiotics

- Febrile episodes

- Blood changes

- Treatment interruption

- Days of stay in hospital

- Toxicity (nausea/vomiting/constipation/diarrhoea)

- Toxicity - skin changes

- Toxicity - unspecific

- Xerostomia

- Cost of care

- Patient quality of life

- Death

- Weight loss/gain

- Caloric intake by oral nutrition

- Eating/drinking difficulty

- Overall health

- Recurrence of cancer.

\section{Search methods for identification of studies}

This review is part of a series of four reviews on the prevention and treatment of oral candidiasis and oral mucositis in patients with cancer, and the same search strategies were used for all four reviews.

The searches attempted to identify all relevant trials irrespective of language. Papers not in English were translated by members of The Cochrane Collaboration. Sensitive search strategies were developed for each database using a combination of free text and MeSH terms. The MEDLINE and CANCERLIT searches combined the subject search with the Cochrane Highly Sensitive Search Strategy (CHSSS) for identifying randomised trials in MEDLINE: sensitivity maximising version (2009 revision) as referenced in Chapter 6.4.11.1 and detailed in boxes 6.4.a and 6.4.c of the Cochrane Handbook for Systematic Reviews of Interventions version 5.0.2 (updated September 2009) (Higgins 2009). The EMBASE and CINAHL searches were combined with sensitive search strategies developed by the Cochrane Oral Health Group for identifying randomised controlled trials (RCTs). The LILACs subject search was combined with the Brazilian Cochrane Centre search strategy for identifying RCTs in LILACS.

\section{Electronic searches}

The databases searched were:

- Cochrane Oral Health Group Trials Register (to 16 February 2011) (Appendix 1)

- Cochrane Pain, Palliative and Supportive Care (PaPaS) Group Trials Register (to 16 February 2011) (Appendix 1)

- Cochrane Central Register of Controlled Trials (CENTRAL) (The Cochrane Library 2011, Issue 1) (Appendix 2)

- MEDLINE via OVID (1950 to 16 February 2011) (Appendix 3) 
- EMBASE via OVID (1980 to 16 February 2011) (Appendix 4)

- CANCERLIT via PubMed (1950 to 16 February 2011) (Appendix 5)

- OpenSIGLE (1980 to 2005) (Appendix 6)

- LILACS via The Virtual Health Library (to 16 February 2011) (Appendix 7)

- CINAHL via EBSCO (1980 to 16 February 2011) (Appendix 8).

Only handsearching carried out by The Cochrane Collaboration was included in the search (see master list www.cochrane.org).

The controlled trials database (www.controlled-trials.com) was also searched to identify ongoing and completed trials and to contact trialists for further information about these trials.

The review will be updated every 2 years using the Cochrane Oral Health Group Trials Register, CENTRAL, MEDLINE, EMBASE, CINAHL, CANCERLIT and LILACS. The search of OpenSIGLE was discontinued as this database ceased being updated in 2005.

\section{Searching other resources}

The reference list of related review articles and all articles obtained were checked for further trials. Authors of trial reports and specialists in the field known to the review authors were written to concerning further published and unpublished trials.

\section{Data collection and analysis}

\section{Selection of studies}

The titles and abstracts (when available) of all reports identified through the electronic searches were scanned independently by two review authors. For studies appearing to meet the inclusion criteria, or for which there were insufficient data in the title and abstract to make a clear decision, the full report was obtained. The full reports, containing names of the authors, institutions, journal of publication and results, obtained from all the electronic and other methods of searching were assessed independently by two authors with expertise in this content area, to establish whether the studies met the inclusion criteria or not. Disagreements were resolved by discussion. Where resolution was not possible, a third review author was consulted. All studies meeting the inclusion criteria then underwent validity assessment and data extraction. Studies rejected at this or subsequent stages were recorded in the 'Characteristics of excluded studies' table, and reasons for exclusion recorded.

\section{Data extraction and management}

Data were extracted by two review authors independently using specially designed data extraction forms. The characteristics of the trial participants, interventions and outcomes in the included trials are presented in the study tables. Mucositis may be dichotomised at different levels of severity. In order to maximise the availability of similar outcome data we recorded the number of patients in each category of mucositis. We planned to form three dichotomies of mucositis: absent versus present ( 0 versus $1+)$, mild versus moderate/severe ( 0 to 1 versus $2+$ ) and moderate versus severe ( 0 to 2 versus $3+$ ). Pain was assessed on visual analogue scales (0 to 100), the means and standard deviations for each group were recorded. The duration of trials and timing of assessments were recorded in order to make a decision about which to include for commonality. We also recorded the country where the trial was conducted and whether a dentist was involved in the investigation. Some of the authors were contacted for clarification or for further information.

\section{Assessment of risk of bias in included studies}

For any relevant studies identified, two review authors independently graded the relevant trials following the domain-based evaluation described in the Cochrane Handbook for Systematic Reviews of Interventions 5.0.2 (updated September 2009) (http://archie.cochrane.org/sections/ documents/view?

document=8D67D37282E26AA201AA9B4D54ED9EBC\&format=REVMAN\#REFHiggins-2009\#REF-Higgins-2009). The review authors then compared evaluations, discussed and resolved any disagreements and reported their assessments in a risk of bias in included studies table in Review Manager (RevMan) software.

An assessment of the overall risk of bias involved the consideration of the relative importance of different domains and studies were to be categorised as low, high or unclear risk of bias.

The review authors were to assess the following domains as 'Yes' (i.e. low risk of bias), 'Unclear' (i.e. uncertain risk of bias) or 'No' (i.e. high risk of bias):

1. adequate sequence generation;

2. allocation concealment;

3. blinding (of participants, carers and outcome assessors);

4. incomplete outcome data addressed;

5. free of selective outcome reporting;

6. free of other bias.

These risk of bias assessments were then for each study across all domains. Adequate allocation concealment and blinding of outcome assessors were designated as key domains for this assessment.

Overall risk of bias was categorised according to the following:

- Low risk of bias (plausible bias unlikely to seriously alter the results) for all key domains;

- Unclear risk of bias (plausible bias that raises some doubt about the results) if one or more key domains were assessed as unclear; or

- High risk of bias (plausible bias that seriously weakens confidence in the results) if one or more key domains were assessed to be at high risk of bias.

\section{Measures of treatment effect}

For dichotomous outcomes, the estimate of effect of an intervention was expressed as risk ratios (RR) together with 95\% confidence intervals (Cls). For continuous outcomes, mean differences and standard deviations were used to summarise the data for each group using mean differences and 95\% Cls. Appropriate data were extracted from the cross-over studies and the generic inverse variance method was used to enter this into RevMan.

\section{Unit of analysis issues}

The patient was the unit of analysis in all trials. 


\section{Dealing with missing data}

All authors were contacted to retrieve missing data from authors of trials.

The analysis will generally include only the available data (ignoring missing data) however methods for estimating missing standard deviations in Section 7.7.3 of the Cochrane Handbook for Systematic Reviews of Interventions 5.0.2 (Higgins 2009) were to be used. Otherwise we do not intend to undertake any imputations nor to use statistical methods to allow for missing data.

\section{Assessment of heterogeneity}

The significance of any discrepancies in the estimates of the treatment effects from the different trials was to be assessed by means of Cochran's test for heterogeneity and heterogeneity would have been considered significant if $\mathrm{P}<0.1$ (Higgins 2009).

The $1^{2}$ statistic, which describes the percentage total variation across studies that is due to heterogeneity rather than chance, was used to quantify heterogeneity with 12 over $50 \%$ being considered substantial heterogeneity (Higgins 2009 Section 9.5.2). In order to assist in the readers in the interpretation of heterogeneity we would still have included the pooled meta-analysis in the forest plot because the $\mathrm{I}^{2}$ and $\mathrm{Chi}^{2}$ statistics are helpful. With substantial heterogeneity pooling the data may not be appropriate and this will be considered in the results for each intervention.

\section{Assessment of reporting biases}

If there had been sufficient numbers of trials (more than 10) in any meta-analysis, publication bias would have been assessed according to the recommendations on testing for funnel plot asymmetry (Egger 1997) as described in the Cochrane Handbook for Systematic Reviews of Interventions 5.0.2 (Higgins 2009). If asymmetry were identified we would have examined possible causes.

\section{Data synthesis}

A meta-analysis would have only be conducted if there were studies of similar comparisons reporting the same mucositis outcome measures. Single studies would not be entered into forest plots. Risk ratios were to be combined for dichotomous data, and mean differences for continuous data, using random-effect models provided there were more than three studies in the meta-analysis.

It is possible to conduct cross-over trials in this area as patients may be receiving several chemotherapy sessions, any mucositis completely healing in the periods between the sessions. The treatment effects from cross-over trials were combined with those from parallel group trials where appropriate, using the data from both periods of the cross-over studies (Elbourne 2002). The generic inverse variance method incorporated in RevMan was used for all analyses. Where data for the cross-tabulation of pairs were not available, all possible paired comparisons for each study were calculated, giving rise to the same risk ratios values with different confidence intervals. The widest confidence interval was used in the analysis.

\section{Subgroup analysis and investigation of heterogeneity}

Clinical heterogeneity was to be assessed by examining the types of participants and interventions for all outcomes in each study.
We proposed a priori to conduct subgroup analyses for different cancer types (leukaemia, head and neck, other solid tumours and mixed), cancer treatment (for example 5-fluorouracil (5-FU)) and age groups (children, adults and both). However, there were insufficient trials by intervention type to do this.

\section{Sensitivity analysis}

It was planned to undertake sensitivity analyses to examine the effect of the study quality assessment on the overall estimates of effect. In addition, the effect of including unpublished literature on the review's findings was also to be examined. There were too few trials to undertake these analyses.

\section{Summary of findings and assessment of the certainty of the evidence}

We described the results for the main outcome in 'Summary of findings' tables and assessed the certainty of the evidence for each comparison and the main outcome. We used GRADE criteria to judge the evidence as having high, moderate, low or very low certainty.

\section{RES U LTS}

\section{Description of studies}

\section{Results of the search}

Three hundred and eighty-three reports of trials were initially identified as eligible according to the defined inclusion criteria for this review with regard to study design, participants, interventions and outcomes. From this list, the total number of included trials was 131 , there were 10 duplicate reports and 176 studies were excluded. Due to changes in the inclusion criteria for studies in this review, some previously excluded studies are being reconsidered for inclusion in the next update. Information about these studies is in Characteristics of studies awaiting classification.

\section{Included studies}

\section{Characteristics of the trial settings and investigators}

Of the 131 included trials 124 were designed as parallel group studies and seven as cross-over studies (Anderson 1998; Chi 1995; Dozono 1989; Jebb 1994; Loprinzi 1990; Mahood 1991; Pfeiffer 1990). None of the published reports of cross-over studies reported the 'paired' data in an appropriate form to be used in a meta-analysis. All the authors were contacted and replies were received supplying data for three studies (Anderson 1998; Loprinzi 1990; Mahood 1991). Data from the other cross-over studies were extracted as outlined in the methods section.

Of the 131 included trials all included data on assessment of mucositis. Ninety-two (70\%) of the 131 included trials were conducted at a single site. Thirty-two of these trials were conducted in Europe, 20 in the USA, seven in China, five in India, four in Canada, three in Brazil and Japan, two in Iran, Israel, Thailand, Taiwan and Turkey, and one in each of the following countries: Argentina, Egypt, Hong Kong, Malaysia, Mexico, South Africa, South Korea, and Uruguay. Thirty-six trials were multicentre studies. Ten of these were conducted in the USA (Blazar 2006; Crawford 1999; Dodd 1996; Freytes 2004; Giles 2004; Hanson 1995; Mahood 1991; Meropol 2003; Scarantino 2006; Spielberger 2004), three in the USA and Canada (Epstein 2001; Foote 1994; Nemunaitis 1995), two in the USA and European countries (Brizel 2000; Buentzel 2006), two 
in European countries alone (Castagna 2001; Vokurka 2005), one in the USA, Canada and Europe (Trotti 2004), one in the USA and Australia (Rosen 2006) and one in the USA, Australia and Canada (Brizel 2008). Two studies were conducted in Australia (Spencer 2005; Veness 2006), Canada (Bjarnason 2009; El Sayed 2002), France (Bensadoun 1999 Gandemer 2007), Iran (Abbasi-Nazari 2007; Motallebnejad 2008) and Taiwan (Chi 1995; Lin 2006), and one in each of the following countries: China (Tu 1998), Germany (Dorr 2007), Italy (Gori 2007), South Korea (Wu 2009), Russia (Peterson 2009) and Thailand (Veerasarn 2006). It was unclear whether the remaining three studies were conducted at a single site or were multisite studies (Bubley 1989; Lievens 1998; Qin 2007).

Eighty-one studies (62\%) provided funding information. Thirtyseven $(28 \%)$ trials were funded by the pharmaceutical industry. Twenty-three studies received government funding. Whilst an additional nine trials were funded by a combination of funding sources (Anderson 1998; Blazar 2006; Cerchietti 2006; Dodd 1996; Ferretti 1988; Foote 1994; Makkonen 1994; Sornsuvit 2008; van der Lelie 2001). Five studies were funded by charities (Bjarnason 2009; Dickson 2000; Franzen 1995; Lilleby 2006; Lockhart 2005). Four trials reported that they received university funding (Biswal 2003; Madan 2008; Motallebnejad 2008; Yuen 2001). Three studies were funded by other sources (Gori 2007; Lin 2006; Oberbaum 2001). The remaining $50(38 \%)$ studies reported either none, or insufficient information about funding sources. A dentist was involved in 26 $(20 \%)$ of the trials.

\section{Characteristics of the participants}

One hundred and fourteen (87\%) of the included trials recruited only adult patients, 13 included both adults and children (with a difference in age as large as 1 to 70 years) and three trials were conducted solely on paediatric patients (Cruz 2007; Gandemer 2007; Shenep 1988), the age group being unclear in one trial (Mahood 1991). The type of cancer for which patients were being treated was exclusively head and neck cancer in 69 trials (53\%), leukaemia in 13 trials, solid tumours in 22 trials and a combination of haematological and solid tumours in 21 trials, the cancer type being unclear in six trials. The radiotherapy and/or chemotherapy regimen was described in most of the trials though the chemotherapeutic agents were not always described in full detail. Twenty-nine trials included patients who were undergoing a bone marrow transplant. The chemotherapy regimen included 5fluorouracil (5-FU) in 25 trials. In 13 of these trials the patients had solid tumours, in six trials patients had head and neck cancer, in two trials patients had mixed cancers and in four trials the cancer type was unclear. It was not always clear if the dose was in a bolus or continuous form. Trials in which patients received radiotherapy generally gave information about the total and daily or weekly dose. Total radiotherapy for head and neck cancer was generally 60 to $74 \mathrm{~Gy}$ and the Karnofsky performance $>60$.

\section{Characteristics of the interventions}

All of the 131 trials provided a clear description of the interventions including the dose and method of administration for the test and control groups. The dosage of the test agents varied for similar products. Thirty-six trials compared an active intervention with no treatment and 87 trials used a placebo control. In some trials the placebo was matched in taste and appearance to the active intervention and in others the following interventions were described as placebo: water, albumin, glycine, sugar solution, polycal, saline. Two trials included in the no treatment control group tested different oral care protocols and in each case one group received limited oral hygiene (usual care) (Borowski 1994; Shieh 1997). A further three trials included in the placebo control group included both a placebo control and a direct comparison (Freytes 2004 - two different doses of keratinocyte growth factor, Madan 2008 - chlorhexidine versus povidone iodine versus salt \& soda, and Sorensen 2008 chlorhexidine mouthwash versus ice chips).

A further two trials (Huang 2003; Wang 2002) compared Chinese medicine to a control described as Dobell's solution, which is "a solution of sodium borate, sodium bicarbonate, phenol, and glycerol, used as a wash for mucous membranes" (Merck Index 2010). Two trials compared patients receiving radiotherapy in the morning with patients receiving radiotherapy in the afternoon (Bjarnason 2009; Goyal 2009). Another four trials compared two active interventions: ice chips sucked for different time periods (30 minutes versus 60 minutes) (Rocke 1993), granulocyte/macrophage colony-stimulating factor (GM-CSF) versus sucralfate (Saarilahti 2002), chlorhexidine versus laser (Arun Maiya 2006) and polaprezinc versus azulene (Watanabe 2010).

The interventions for the 131 studies assessing oral mucositis were:

- aciclovir (Bubley 1989)

- allopurinol mouthrinse (Abbasi-Nazari 2007; Dozono 1989; Loprinzi 1990; Panahi 2009)

- aloe vera (Puataweepong 2009; Su 2004;)

- amifostine (Antonadou 2002; Bourhis 2000; Brizel 2000; Buentzel 2006; Buntzel 1998; Haddad 2009; Hartmann 2001; Koukourakis 2000; Spencer 2005; Vacha 2003; Veerasarn 2006)

- antibiotic pastille or paste (El Sayed 2002)

- antibiotic systemic (clarithromycin) (Yuen 2001)

- azulene (Watanabe 2010*)

- benzydamine (Epstein 1989; Epstein 2001; Kazemian 2009; Prada 1987)

- beta carotene (Mills 1988)

- chamomile (Fidler 1996)

- chewing gum (Gandemer 2007)

- Chinese herbs (details of herbs used are given in Characteristics of included studies table) (Huang 2003*; Wang 2002*)

- chlorhexidine (Arun Maiya 2006*; Dodd 1996; Ferretti 1988; Foote 1994; Madan 2008*; McGaw 1985; Pitten 2003; Sorensen 2008; Spijkervet 1989; Wahlin 1989)

- cryotherapy (Cascinu 1994; Gori 2007; Lilleby 2006; Mahood 1991; Rocke 1993*; Svanberg 2007; Sorensen 2008*)

- dental stent (Qin 2007)

- epidermal growth factor (Wu 2009)

- glutamine (Anderson 1998; Cerchietti 2006; Choi 2007; Dickson 2000; He 2008; Huang 2000; Jebb 1994; Li 2006; Okuno 1999; Sornsuvit 2008)

- granulocyte colony-stimulating factor (G-CSF) (Crawford 1999; Katano 1995; Schneider 1999; Su 2006)

- granulocyte/macrophage colony-stimulating factor (GM-CSF) (Cartee 1995; Chi 1995; Dazzi 2003; Ifrah 1999; Makkonen 2000; McAleese 2006; Nemunaitis 1995; Saarilahti 2002*; van der Lelie 2001)

- histamine gel (Elad 2006) 
- honey (Biswal 2003; Motallebnejad 2008; Rashad 2008)

- hydrolytic enzymes (details of enzymes used are given in Characteristics of included studies table) (Dorr 2007; Gujral 2001; Kaul 1999)

- indigo wood root (You 2009)

- intestinal trefoil factor (Peterson 2009)

- iseganan (Giles 2004; Trotti 2004)

- keratinocyte growth factor (GF) (Blazar 2006; Brizel 2008; Freytes 2004*; Meropol 2003; Rosen 2006; Spielberger 2004; Vadhan-Raj 2010)

- laser (Antunes 2007; Arun Maiya 2006*; Bensadoun 1999; Chor 2010; Cruz 2007; Schubert 2007)

- non-steroidal anti-inflammatory drug (Pillsbury 1986)

- oral care (Borowski 1994; Shieh 1997)

- pentoxifylline (Attal 1993)

- pilocarpine (Lockhart 2005; Scarantino 2006)

- PTA (polymixin/tobramycin/amphotericin) lozenges/paste (Stokman 2003; Symonds 1996; Wijers 2001)

- polaprezinc (Watanabe 2010*)

- povidone iodine (Arun Maiya 2006; Madan 2008*; Rahn 1997; Vokurka 2005)

- prednisone (Leborgne 1997)

- propantheline anticholinergic (Ahmed 1993)

- prostaglandin (Duenas 1996; Hanson 1995; Labar 1993; Pillsbury 1986; Veness 2006)

- radiation: morning versus evening (Bjarnason 2009*, Goyal $\left.2009^{*}\right)$

- shenqi-fanghou (Hu 2005)

- superoxide dismutase (SOD) (Tu 1998)

- sucralfate (Carter 1999; Castagna 2001; Cengiz 1999; Epstein 1994; Evensen 2001; Franzen 1995; Lievens 1998; Makkonen 1994; Nottage 2003; Pfeiffer 1990; Saarilahti 2002*; Scherlacher 1990; Shenep 1988)

- traumeel (Oberbaum 2001)

- yangygin-humo decoctalion (Dai 2009)

- zinc sulphate (Ertekin 2004; Lin 2006).

* studies with two or more different active treatments.

Characteristics of outcome measures

\section{Mucositis}

All trials used a graded scale to record the severity of mucositis. Most described the index used or referred to published criteria, mainly World Health Organization (WHO) or European Organization for Research and Treatment of Cancer (EORTC). Scales were similar to the 5-point WHO scale ranging from 0 (normal) to 4 (severe). The categories initially relate to visible changes in the mucosa and gradually record pain and inability to eat solid foods. The duration of the trials varied from a few days up to a year after treatment. The interval during which mucositis was recorded varied from 5 to 90 days or until the end of the radiotherapy, or the leukocyte count was above $8000 \mathrm{~mm}^{3}$. Several studies presented data at different time points, with the median time point being 28 days. The nearest assessment to 28 days was used for all studies.

\section{Secondary outcomes}

There was little consistency on the other outcome measures reported.

- Oral hygiene measures (Biswal 2003; Cruz 2007; Dodd 1996; El Sayed 2002; Elad 2006; Ertekin 2004; Evensen 2001; Ferretti 1988; Foote 1994; Gandemer 2007; Kazemian 2009; Leborgne 1997; Lockhart 2005; Makkonen 1994; Makkonen 2000; McGaw 1985; Rahn 1997; Rashad 2008; Scherlacher 1990; Spijkervet 1989; Stokman 2003; Symonds 1996; Vadhan-Raj 2010; Vokurka 2005; Wahlin 1989; Wijers 2001; Wu 2009).

- Relief of pain/use of analgesia (morphine) (Antunes 2007; Arun Maiya 2006; Attal 1993; Bensadoun 1999; Blazar 2006; Brizel 2008; Carter 1999; Castagna 2001; Cengiz 1999; Cerchietti 2006; Cruz 2007; Dazzi 2003; Dorr 2007; El Sayed 2002; Epstein 1989; Epstein 1994; Epstein 2001; Ertekin 2004; Ferretti 1988; Franzen 1995; Freytes 2004; Gandemer 2007; Giles 2004; Hanson 1995; Lilleby 2006; Lockhart 2005; Makkonen 2000; Meropol 2003; Nottage 2003; Oberbaum 2001; Peterson 2009; Pfeiffer 1990; Prada 1987; Puataweepong 2009; Rosen 2006; Saarilahti 2002; Schubert 2007; Shenep 1988; Shieh 1997; Spencer 2005; Spielberger 2004; Su 2004; Svanberg 2007; Trotti 2004; Tu 1998; Vadhan-Raj 2010; van der Lelie 2001; Veness 2006; Vokurka 2005; Watanabe 2010; Wijers 2001; Wu 2009).

- Duration or severity of dysphagia (Antonadou 2002; Bensadoun 1999; Bjarnason 2009; Bourhis 2000; Brizel 2008; Buntzel 1998; Castagna 2001; Cengiz 1999; Choi 2007; Dorr 2007; El Sayed 2002; Elad 2006; Epstein 1994; Fidler 1996; Franzen 1995; Giles 2004; Goyal 2009; Gujral 2001; Haddad 2009; Hartmann 2001; Kaul 1999; Lievens 1998; Lilleby 2006; Lockhart 2005; McAleese 2006; Oberbaum 2001; Prada 1987; Rosen 2006; Scarantino 2006; Scherlacher 1990; Spielberger 2004; Su 2006; Symonds 1996; Trotti 2004; Vadhan-Raj 2010; Veerasarn 2006; You 2009).

- Use of parenteral nutrition or feeding tube (Bjarnason 2009; Bourhis 2000; Brizel 2008; Carter 1999; Cerchietti 2006; Cruz 2007; Dickson 2000; El Sayed 2002; Evensen 2001; Foote 1994; Franzen 1995; Gandemer 2007; Haddad 2009; Hanson 1995; Hartmann 2001; Leborgne 1997; Lilleby 2006; Lockhart 2005; Rashad 2008; Saarilahti 2002; Shenep 1988; Spencer 2005; Spielberger 2004; Stokman 2003; Su 2006; Symonds 1996; Trotti 2004; Vadhan-Raj 2010; van der Lelie 2001; Yuen 2001).

- Incidence of systemic infection or use of antibiotics (Antunes 2007; Attal 1993; Blazar 2006; Borowski 1994; Brizel 2008; Bubley 1989; Buntzel 1998; Castagna 2001; Cerchietti 2006; Crawford 1999; Cruz 2007; Duenas 1996; El Sayed 2002; Ertekin 2004; Ferretti 1988; Freytes 2004; Gandemer 2007; Hanson 1995; Hartmann 2001; Ifrah 1999; Jebb 1994; Labar 1993; McGaw 1985; Pitten 2003; Puataweepong 2009; Shenep 1988; Sornsuvit 2008; Spencer 2005; Spielberger 2004; Su 2004; Symonds 1996; Trotti 2004; Tu 1998; Vadhan-Raj 2010; van der Lelie 2001; Vokurka 2005; Wahlin 1989; Yuen 2001).

- Febrile episodes (Ahmed 1993; Anderson 1998; Attal 1993; Borowski 1994; Brizel 2000; Chi 1995; Chor 2010; Crawford 1999; Duenas 1996; Ferretti 1988; Freytes 2004; Ifrah 1999; Katano 1995; Labar 1993; McGaw 1985; Nemunaitis 1995; Pitten 2003; Shenep 1988; Spencer 2005; Spielberger 2004; van der Lelie 2001; Vokurka 2005; Wahlin 1989; Yuen 2001).

- Blood changes (Ahmed 1993; Antonadou 2002; Attal 1993; Blazar 2006; Brizel 2000; Buentzel 2006; Buntzel 1998; Cartee 1995; Cascinu 1994; Cerchietti 2006; Chi 1995; Crawford 1999; Dazzi 
2003; Dickson 2000; Dorr 2007; Duenas 1996; Elad 2006; Epstein 2001; Ertekin 2004; Ferretti 1988; Franzen 1995; Freytes 2004; Hartmann 2001; Huang 2003; Ifrah 1999; Katano 1995; Labar 1993; Li 2006; Lilleby 2006; Lin 2006; Mahood 1991; Makkonen 2000; Meropol 2003; Nemunaitis 1995; Pitten 2003; Rocke 1993; Rosen 2006; Saarilahti 2002; Schneider 1999; Shenep 1988; Sorensen 2008; Sornsuvit 2008; Spencer 2005; Spielberger 2004; Svanberg 2007; van der Lelie 2001; Veerasarn 2006; Vokurka 2005; Wahlin 1989; Wu 2009; You 2009).

- Treatment interruption (Antonadou 2002; Biswal 2003; Bjarnason 2009; Bourhis 2000; Brizel 2000; Brizel 2008; Carter 1999; Dazzi 2003; El Sayed 2002; Foote 1994; Franzen 1995; Haddad 2009; Huang 2003; Ifrah 1999; Koukourakis 2000; Leborgne 1997; Makkonen 1994; Makkonen 2000; Pfeiffer 1990; Puataweepong 2009; Saarilahti 2002; Trotti 2004; van der Lelie 2001; Vadhan-Raj 2010; Veness 2006; Wu 2009; You 2009).

- Days of stay in hospital (Antonadou 2002; Attal 1993; Cerchietti 2006; Chor 2010; Dickson 2000; Duenas 1996; Ifrah 1999; Lilleby 2006; McGaw 1985; Saarilahti 2002; Sornsuvit 2008; van der Lelie 2001).

- Toxicity - nausea/vomiting/constipation/diarrhoea (Antonadou 2002; Blazar 2006; Bourhis 2000; Brizel 2000; Brizel 2008; Bubley 1989; Buentzel 2006; Cascinu 1994; Castagna 2001; Cengiz 1999; Dickson 2000; Duenas 1996; El Sayed 2002; Elad 2006; Epstein 1994; Epstein 2001; Ertekin 2004; Fidler 1996; Freytes 2004; Gandemer 2007; Giles 2004; Gujral 2001; Haddad 2009; Hartmann 2001; He 2008; Kazemian 2009; Labar 1993; Li 2006; Lievens 1998; Lockhart 2005; Mahood 1991; Meropol 2003; Nottage 2003; Oberbaum 2001; Okuno 1999; Peterson 2009; Pfeiffer 1990; Rocke 1993; Rosen 2006; Scarantino 2006; Shenep 1988; Sornsuvit 2008; Spencer 2005; Trotti 2004; Tu 1998; Vadhan-Raj 2010; Yuen 2001).

- Toxicity - skin changes (Antonadou 2002; Blazar 2006; Bourhis 2000; Buntzel 1998; Choi 2007; Dickson 2000; Dorr 2007; El Sayed 2002; Evensen 2001; Giles 2004; Goyal 2009; Gujral 2001; Haddad 2009; Kaul 1999; Lievens 1998; Lin 2006; Meropol 2003; Rosen 2006; Scarantino 2006; Shenep 1988; Spielberger 2004; Tu 1998; Vacha 2003; Yuen 2001).

- Toxicity - unspecific (Buentzel 2006; Cerchietti 2006; Chi 1995; Duenas 1996; El Sayed 2002; Epstein 1994; Fidler 1996; Freytes 2004; Giles 2004; Gujral 2001; Mahood 1991; Makkonen 1994; Makkonen 2000; Okuno 1999; Puataweepong 2009; Spielberger 2004; Su 2006; Tu 1998).

- Xerostomia (Antonadou 2002; Bourhis 2000; Brizel 2000; Brizel 2008; Buentzel 2006; Buntzel 1998; Castagna 2001; Cengiz 1999; Dazzi 2003; Elad 2006; Epstein 1994; Epstein 2001; Goyal 2009; Hartmann 2001; Koukourakis 2000; Lockhart 2005; Makkonen 2000; McAleese 2006; Meropol 2003; Nottage 2003; Oberbaum 2001; Saarilahti 2002; Scarantino 2006; Spencer 2005; Vacha 2003; Veerasarn 2006; Watanabe 2010).

- Cost (Bourhis 2000; Brizel 2000; Buentzel 2006; Buntzel 1998; Choi 2007; Dodd 1996; Haddad 2009; Hartmann 2001; Hu 2005; Huang 2000; Koukourakis 2000; Makkonen 2000; McAleese 2006; Nemunaitis 1995; Nottage 2003; Sornsuvit 2008; Su 2006; Yuen 2001).

- Patient quality of life (Bjarnason 2009; Brizel 2000; McAleese 2006; Nottage 2003; Scarantino 2006; Spielberger 2004; Veness 2006).

- Death (Ahmed 1993; Attal 1993; Bjarnason 2009; Blazar 2006; Brizel 2008; Dickson 2000; Dodd 1996; Epstein 2001; Ertekin
2004; Ferretti 1988; Giles 2004; Gujral 2001; Kazemian 2009; Leborgne 1997; Madan 2008; Mills 1988; Oberbaum 2001; Rahn 1997; Rosen 2006; Schubert 2007; Spielberger 2004).

- Weight loss/gain (Antonadou 2002; Biswal 2003; Bjarnason 2009; Brizel 2000; Buentzel 2006; Buntzel 1998; Carter 1999; Cengiz 1999; Cerchietti 2006; El Sayed 2002; Elad 2006; Ertekin 2004; Foote 1994; Freytes 2004; Haddad 2009; Hanson 1995; He 2008; Hu 2005; Huang 2000; Koukourakis 2000; Leborgne 1997; Lievens 1998; Lilleby 2006; Lin 2006; Makkonen 2000; Motallebnejad 2008; Nottage 2003; Pillsbury 1986; Puataweepong 2009; Qin 2007; Shenep 1988; Sornsuvit 2008; Stokman 2003; Su 2004; Su 2006; Symonds 1996; Trotti 2004; Vacha 2003; Veerasarn 2006; Veness 2006; Wu 2009; You 2009).

- Caloric intake by oral nutrition (Castagna 2001; Cruz 2007; Dickson 2000; Freytes 2004; Hartmann 2001; He 2008; Lilleby 2006; Pfeiffer 1990; Shenep 1988; Spencer 2005; Watanabe 2010).

- Eating/drinking difficulty (Anderson 1998; Carter 1999; Cengiz 1999; Cerchietti 2006; Dickson 2000; El Sayed 2002; Evensen 2001; Franzen 1995; Freytes 2004; Jebb 1994; Lilleby 2006; Lockhart 2005; Nottage 2003; Oberbaum 2001; Pfeiffer 1990; Prada 1987; Rashad 2008; Rosen 2006; Scarantino 2006; Shenep 1988; Sornsuvit 2008; Spielberger 2004; Stokman 2003; Symonds 1996; Vadhan-Raj 2010).

- Overall health (Antonadou 2002; Bourhis 2000; Brizel 2000; Buentzel 2006; Elad 2006; Ertekin 2004; Haddad 2009; Ifrah 1999; Jebb 1994; Lilleby 2006; Makkonen 2000; McAleese 2006; Nemunaitis 1995; Rosen 2006; Shenep 1988; Su 2004; Su 2006; Wu 2009).

- Recurrence of cancer (Ahmed 1993; Attal 1993; Bjarnason 2009; Blazar 2006; Brizel 2000; Brizel 2008; Cerchietti 2006; Chi 1995; Dickson 2000; Duenas 1996; Goyal 2009; Gujral 2001; Leborgne 1997; Li 2006; Makkonen 2000; Mills 1988; Okuno 1999; Pillsbury 1986; Rosen 2006; Saarilahti 2002; Schneider 1999; Spielberger 2004; Vadhan-Raj 2010; Watanabe 2010).

\section{Excluded studies}

See Characteristics of excluded studies table for further information on each excluded study. In summary, studies were excluded for the following reasons.

- Abstracts only available, insufficient information to include study in the review (36 studies: Antonadou 1998; Buentzel 1999; Castro 2009; Clarke 2001; Collova 2004; Colombat 1995; Costa 1999; Gabison 1995; Goldberg 2003; Gordon 1993; Harris 1995; He 2004; Kante 1995; Klocke 2006; Lavendag 1998; Le 2008; Leong 1995; Lozada 1998; Marcial 1994; Merte 1999; Papas 1984; Pouli 1999; Radmard 2002; Robustelli 1999; Schwerkoske 1999; Sharma 2009; Shea 2007; Shidfar 2008; Spadaro 1991; Spielberger 2001; Throuvalas 1995; Valcárcel 1997; Vesole 1999; Villar 2009; Vitello 2000; Wagner 2002).

- Comparing different cancer treatments including radiotherapy regimens (29 trial reports: Andersen 1987; Ardizzoni 2002; Awada 2002; Awwad 2002; Bensadoun 2006; Bentzen 2001; Bleehen 1996; Bourhis 2006; Calais 2000; Cassidy 2002; Cunningham 1995; Damon 2004; De Boer 2002; Denham 1999; Dobrowsky 1998; Doroshow 1987; Erkisi 1996; Erlichman 1988; Ezzat 2005; Falcone 2001; Giles 2003a; Giles 2003b; Gladkov 2007; Lee 1989; Levi 1997; Mahmoud 1996; Pyrhonen 1995; Rabinovitch 2006; Rocci 2005). 
- Not a randomised controlled trial (64 study reports: Aisa 2005; Altmann 1999; Arora 2008; Awada 2004; Baydar 2005; Calais 2004; Cheng 2001; Cheng 2002; Colella 2010; Costa 2003; Dreicer 1997; Edelman 1998; Eisen 2003; El-Sayed 2002a; Fahlke 1999; Fay 1994; Foncuberta 2001; Gandara 1997; Gutierrez 1996; Horsley 2007; Hu 2003; Hunter 2007; Inagaki 2006; Ito 2002; Johnson 2002; Ju 2009; Karacetin 2004; Khouri 2009; Kuriakose 2002; Labbate 2003; Luglié 2002; Maddocks-Jennings 2009; Madero 1999; Malaker 1991; Mantovani 2003; Martin 2006; Matejka 1990; Mills 1995; Mori 2006; Nicolatou-Galitis 2006; Okutomi 2000; Papadeas 2007; Penpattanagul 2007; Peters 1993; Phillips 2002; Putwatana 2009; Sato 1997; Sato 2006; Schuster 2008; Shabanloei 2009; Simoes 2009; Stokman 2004; Thieblemont 2002; Tiemann 2006; Toubai 2003; Uchiyama 2005; Wang 2002a; Ward 2007; Weiss 1990; Whelan 2002; Whelan 2004; Wollina 2002; Wymenga 1999; Yokomizo 2004).

- Multicomponent oral assessment instruments (which included voice, teeth etc) - specifically excluded in methods section of review (16 trial reports: Aquino 2005; Cowen 1997; Dudjak 1987; Epstein 1992; Etiz 2000; Feber 1995; Feber 1996; Grotz 2001; Jebb 1995; Kenny 1990; Mcllroy 1996; Nikoletti 2005; Piccirillo 2003; Pytlik 2002; Rothwell 1990; Verdi 1995).

- Some mucositis present at baseline (12 trial reports: Anderson 1998b; Barasch 1995; Djuric 2006; Ferretti 1990; GenotKlastersky 2008; Kuhn 2009; Lanzos 2010; Loo 2010; Masucci 2005; Prada 1985; Ryu 2007; Valcarcel 2002).

- Mucositis prevention not purpose of study (one trial report: Jham 2007).

- Data presented as episodes rather than patients, where patients were re-entered into the study, so data not independent (seven trial reports: Abramoff 2008; Awidi 2001; Hickey 1982; Karthaus 1998; Lorusso 2003; Rojas 2001; van Zaanen 1994).

- Major change to protocol half way through study, blinded and unblinded patient data combined (one trial report: Okuno 1997).

- Unclear if mucositis present at baseline (one trial report: Cheng 2006).

- Unclear if randomised (four trial reports: Apaydin 1996; Howell 1983; Teshima 1986; Zanin 2010).

- No mucositis data - study stopped early because preset stooping rule triggered (two trial reports: Antin 2002; Rades 2004).

- No clear mucositis data presented and unable to contact authors (two trial reports: Niibe 1985; Rutkauskas 1993).

- Design flaw - confounded interventions (one trial report: Papas 2003).

\section{Risk of bias in included studies}

Eleven studies were assessed at low overall risk of bias (8\%) (Cartee 1995 Dazzi 2003 Foote 1994; Madan 2008; Oberbaum 2001; Pitten 2003; Saarilahti 2002; Schneider 1999; Shenep 1988; Stokman 2003; Su 2006), 82 (63\%) were described as unclear and the remaining 38 studies $(29 \%)$ were defined as being at high overall risk of bias (Antonadou 2002; Antunes 2007; Biswal 2003; Bjarnason 2009; Borowski 1994; Bourhis 2000; Brizel 2000; Buntzel 1998; Cascinu 1994; Chi 1995; Choi 2007; Dai 2009; Dozono 1989; Gandemer 2007; Gori 2007; Gujral 2001; Haddad 2009; Hartmann 2001; Huang 2000; Katano 1995; Kaul 1999; Koukourakis 2000; Lilleby 2006; Makkonen 2000; Mills 1988; Rahn 1997; Rashad 2008; Rocke 1993; Shieh 1997; Spencer 2005; Svanberg 2007; Vacha 2003; Vadhan-Raj 2010; Veerasarn 2006; Wahlin 1989; Watanabe 2010; Wu 2009; Yuen 2001). See Figure 1 and Figure 2.

\section{Figure 1. Risk of bias assessment graph: review authors' judgements about each risk of bias domain presented as percentages across all included studies.}

Random sequence generation (selection bias)

Allocation concealment (selection bias)

Blinding (performance bias and detection bias): Carers

Blinding (performance bias and detection bias): Patients

Blinding (performance bias and detection bias): Outcome assessors

Incomplete outcome data (attrition bias): All outcomes

Selective reporting (reporting bias)

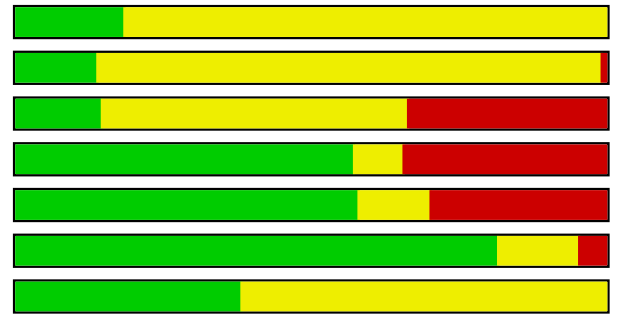

Other bias

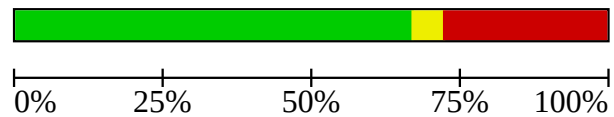

Low risk of bias

Unclear risk of bias

High risk of bias 
Figure 2. (Continued)

Cerchietti 2006

Chi 1995

Choi 2007

Chor 2010

Crawford 1999

Cruz 2007

Dai 2009

Dazzi 2003

Dickson 2000

Dodd 1996

Dorr 2007

Dozono 1989

Duenas 1996

Elad 2006

El Sayed 2002

Epstein 1989

Epstein 1994

Epstein 2001

Ertekin 2004

Evensen 2001

Ferretti 1988

Fidler 1996

Foote 1994

Franzen 1995

Freytes 2004

Gandemer 2007

Giles 2004

Gori 2007

Goyal 2009

Gujral 2001

Haddad 2009

Hanson 1995

Hartmann 2001

He 2008

Hu 2005

Huang 2000

Huang 2003

Ifrah 1999

Jebb 1994

Katano 1995

Kaul 1999

Kazemian 2009

Koukourakis 2000

Labar 1993

Leborgne 1997

Li 2006

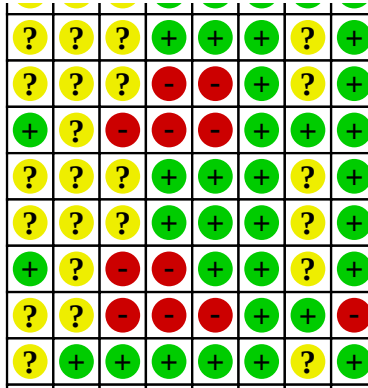

\begin{tabular}{l|l|l|l|l|l|l|l}
\hline$?$ & $?$ & $?$ & + & + & + & $?$ & + \\
\hline
\end{tabular}

\begin{tabular}{llll|lll}
\hline$?$ & $?$ & + & + & + & ? & +
\end{tabular}

\begin{tabular}{llllllllll}
+ & ? & $?$ & + & + & + & ? & + \\
\hline
\end{tabular}

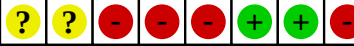

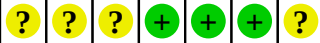

\begin{tabular}{ll|c|c|c|c|}
\hline$?$ & $?$ & + & + & $?$ & $?$
\end{tabular}

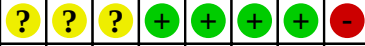

\begin{tabular}{lllll|l|l|l|l|}
\hline$?$ & $?$ & $?$ & + & + & + & $?$ & + \\
\hline
\end{tabular}

\begin{tabular}{lllllllll}
\hline$?$ & $?$ & $?$ & + & + & + & $?$ & + \\
\hline
\end{tabular}

\begin{tabular}{lll|l|l|l|l|l|l|}
\hline$?$ & $?$ & $?$ & $?$ & $?$ & + & $?$ & + \\
\hline
\end{tabular}

\begin{tabular}{lllllllllll}
\hline$?$ & $?$ & $?$ & $?$ & $?$ & + & + & + \\
\hline
\end{tabular}

\begin{tabular}{lllllllll}
\hline$?$ & $?$ & $?$ & + & + & + & + & ? \\
\hline
\end{tabular}

\begin{tabular}{lllllllllll}
\hline$?$ & $?$ & $?$ & + & + & $?$ & $?$ & + \\
\hline
\end{tabular}

\begin{tabular}{llllllll}
\hline$?$ & $?$ & $?$ & + & + & + & + & + \\
\hline
\end{tabular}

\begin{tabular}{llllllll}
\hline$?$ & + & + & + & + & + & - \\
\hline
\end{tabular}

\begin{tabular}{ll|l|l|l|l|l|l|}
\hline$?$ & $?$ & $?$ & + & + & $?$ & $?$ & + \\
\hline
\end{tabular}

\begin{tabular}{lll|lllll}
\hline & $?$ & $?$ & + & + & + & ?
\end{tabular}

\begin{tabular}{llllllll}
\hline & + & - & - & - & + & $?$ & +
\end{tabular}

\begin{tabular}{llllllllll}
\hline ? & ? & ? & + & + & ? & ? & + \\
\hline
\end{tabular}

\begin{tabular}{llllllll}
\hline ? & ? & - & - & - & + & + & + \\
\hline
\end{tabular}

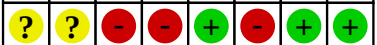

\begin{tabular}{llllllll}
\hline ? & ? & - & - & - & + & + & + \\
\hline
\end{tabular}

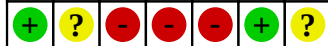

\begin{tabular}{llllllll}
\hline ? & ? & + & + & + & + & ?
\end{tabular}

\begin{tabular}{|l|l|lllllll}
\hline$?$ & $?$ & - & - & - & + & $?$ & + \\
\hline
\end{tabular}

\begin{tabular}{lll|l|l|l|l|l}
\hline$?$ & $?$ & $?$ & $?$ & $?$ & + & $?$ \\
\hline
\end{tabular}

? $3-\odot-\odot+C$

\begin{tabular}{lll|lllll}
\hline$?$ & $?$ & $?$ & + & - & + & + & + \\
\hline
\end{tabular}

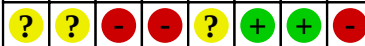

\begin{tabular}{lllllllll}
\hline ? & $?$ & $?$ & + & + & + & ? & - \\
\hline
\end{tabular}

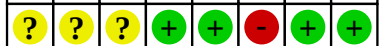

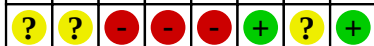

\begin{tabular}{ll|l|l|l|l|l|l|l|l}
\hline$?$ & $?$ & - & - & - & - & $?$
\end{tabular}

\begin{tabular}{llllllllll}
\hline$?$ & $?$ & $?$ & + & + & + & ? & + \\
\hline
\end{tabular}

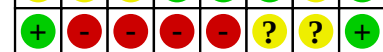

\begin{tabular}{llllllllll}
+ & $?$ & $?$ & + & + & $?$ & $?$ & + \\
\hline
\end{tabular}

\begin{tabular}{|l|l|l|l|l|l|l|l|}
\hline$?$ & $?$ & $?$ & + & + & + & + & - \\
\hline
\end{tabular}

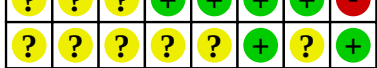


Figure 2. (Continued)

Li 2006

Lievens 1998

Lilleby 2006

Lin 2006

Lockhart 2005

Loprinzi 1990

Madan 2008

Mahood 1991

Makkonen 1994

Makkonen 2000

McAleese 2006

McGaw 1985

Meropol 2003

Mills 1988

Motallebnejad 2008

Nemunaitis 1995

Nottage 2003

Oberbaum 2001

Okuno 1999

Panahi 2009

Peterson 2009

Pfeiffer 1990

Pillsbury 1986

Pitten 2003

Prada 1987

Puataweepong 2009

Qin 2007

Rahn 1997

Rashad 2008

Rocke 1993

Rosen 2006

Saarilahti 2002

Scarantino 2006

Scherlacher 1990

Schneider 1999

Schubert 2007

Shenep 1988

Shieh 1997

Sorensen 2008

Sornsuvit 2008

Spencer 2005

Spielberger 2004

Spijkervet 1989

Stokman 2003

Su 2004

Su 2006

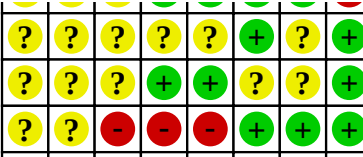

\begin{tabular}{|l|l|l|l|l|l|l|l}
\hline & $?$ & $?$ & + & $?$ & + & $?$ & + \\
\hline
\end{tabular}

\begin{tabular}{|l|l|l|l|l|l|l|l|}
\hline & $?$ & $?$ & + & + & + & $?$ & + \\
\hline
\end{tabular}

\begin{tabular}{llllllllll}
\hline & $?$ & $?$ & + & + & + & + & - \\
\hline
\end{tabular}

\begin{tabular}{llllllll}
\hline$?$ & + & + & + & + & + & ? & + \\
\hline
\end{tabular}

\begin{tabular}{llllllllll}
\hline$?$ & $?$ & - & $\odot$ & $?$ & ? & + & + \\
\hline
\end{tabular}

\begin{tabular}{lllllllll}
\hline & ? & ? & + & + & + & + & - \\
\hline
\end{tabular}

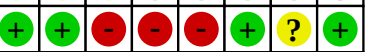

\begin{tabular}{lllllllll}
\hline & $?$ & $?$ & - & + & + & + & + \\
\hline
\end{tabular}

\begin{tabular}{llllllllll}
\hline$?$ & $?$ & $?$ & + & + & + & ? & + \\
\hline
\end{tabular}

$\begin{array}{lllllllll} & ? & ? & ? & + & + & + & \text { ? } & +\end{array}$

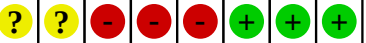

\begin{tabular}{llllllll}
\hline$?$ & $?$ & $?$ & - & + & + & ? & + \\
\hline
\end{tabular}

\begin{tabular}{lll|l|l|l|l|l}
\hline$?$ & $?$ & + & + & + & $?$ & \\
\hline
\end{tabular}

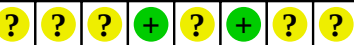

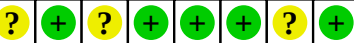

\begin{tabular}{llllllllll}
\hline$?$ & $?$ & $?$ & + & + & + & + & - \\
\hline
\end{tabular}

\begin{tabular}{lllllllll}
\hline$?$ & $?$ & $?$ & + & + & + & + & + \\
\hline
\end{tabular}

\begin{tabular}{lllllllll}
\hline ? & $?$ & + & + & + & + & + & + \\
\hline
\end{tabular}

\begin{tabular}{lllllllll}
\hline & $?$ & $?$ & + & + & - & $?$ & - \\
\hline
\end{tabular}

\begin{tabular}{llllllllll}
\hline$?$ & $?$ & $?$ & + & + & + & ? & + \\
\hline
\end{tabular}

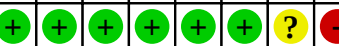

\begin{tabular}{ll|l|l|l|lll} 
& ? & $?$ & + & + & $?$ & ? & - \\
\hline
\end{tabular}

\begin{tabular}{llllllllll}
\hline$?$ & $?$ & $?$ & + & + & + & + & - \\
\hline
\end{tabular}

\begin{tabular}{lllllllll}
\hline ? & ? & $?$ & ? & ? & + & + & - \\
\hline
\end{tabular}

\begin{tabular}{|llllllll}
\hline$?$ & $?$ & - & - & - & + & + & + \\
\hline
\end{tabular}

\begin{tabular}{|l|l|llllll}
\hline$?$ & $?$ & - & - & - & + & + & ? \\
\hline
\end{tabular}

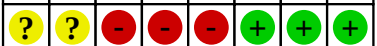

\begin{tabular}{lllllllllll}
\hline$?$ & $?$ & $?$ & + & + & + & + & + \\
\hline
\end{tabular}

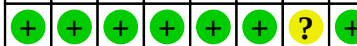

\begin{tabular}{llllllllll}
\hline$?$ & $?$ & $?$ & + & + & + & $?$ & ? \\
\hline
\end{tabular}

\begin{tabular}{|l|l|l|l|l|l|l}
\hline$?$ & $?$ & $?$ & $?$ & $?$ & $?$ & ? \\
\hline
\end{tabular}

? +++++ ?

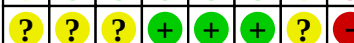

\begin{tabular}{|l|l|llllll}
\hline ? & + & + & + & + & + & ? & + \\
\hline
\end{tabular}

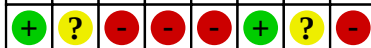

\begin{tabular}{|l|l|lllllll}
\hline$?$ & $?$ & $?$ & + & + & + & + & + \\
\hline
\end{tabular}

\begin{tabular}{|l|l|l|l|l|l|l|l|}
\hline$?$ & $?$ & $?$ & $?$ & $?$ & + & ? & + \\
\hline
\end{tabular}

\begin{tabular}{|llllllll}
\hline$?$ & $?$ & - & - & - & + & $?$ & + \\
\hline
\end{tabular}

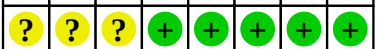

\begin{tabular}{llllllllll}
\hline$?$ & $?$ & $?$ & + & + & + & ? & + \\
\hline
\end{tabular}

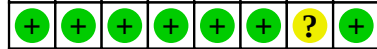

\begin{tabular}{llllllll}
+ & ? & ? & + & + & ? & ? & + \\
\hline
\end{tabular}

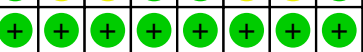


Figure 2. (Continued)

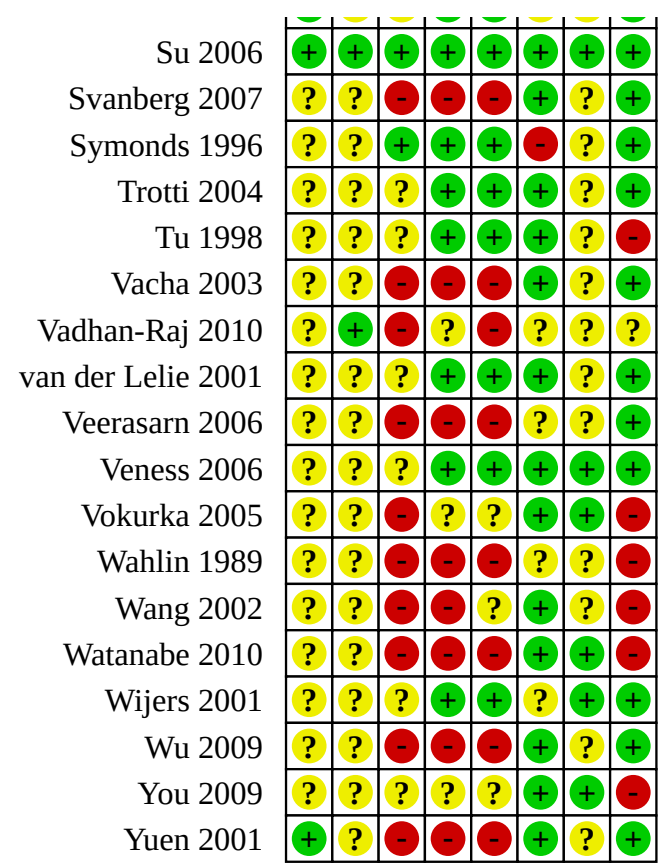

\section{Allocation}

\section{Random sequence generation}

Twenty-seven studies (21\%) were deemed to have adequate sequence generation, and therefore were classified as being at low risk of bias for this domain. Thirteen of these studies employed computer-based sequence generation; while, four studies employed minimization. Four studies did not provide enough information about the randomisation process; however it was the opinion of the assessors that the setting of these trials made adequate randomisation likely. These studies were conducted at the Dana Faber cancer institute (Haddad 2009), the Memorial Sloan Kettering Cancer Centre (Su 2004), the Duke Centre (Cartee 1995) and the Finish cancer registry (Makkonen 2000). One study used biased coin randomisation (Su 2004). Of the remaining five studies, three used a table of random numbers (Huang 2003 Koukourakis 2000; Pitten 2003), and two studies provided limited information but made reference to appropriate literature concerning randomisation (Brizel 2000 Shieh 1997). Those studies considered to use an inappropriate method of randomisation were excluded; therefore no studies were given a decision of no for this category. The remaining 104 studies (79\%) were judged as 'unclear'. The majority of these unclear studies gave no more information than that they were 'randomised'. Four studies stated that they employed the "closed envelope" method of randomisation. However, no information was provided about whether these envelopes were shuffled prior to the patient being randomised. They were therefore classified as "unclear".

\section{Allocation concealment}

Nineteen studies (14\%) employed adequate methods of allocation concealment and were therefore classified as being at low risk of bias. Central randomisation was mentioned in 15 studies, with eight studies employing pharmacy controlled randomisation,

six studies communicating by telephone, and one study by fax (Gandemer 2007). Two studies employed sequentially numbered drug containers which were identical in appearance (Foote 1994 Madan 2008). Two studies (1.5\%) used open number tables without concealment and were therefore deemed to be at high risk of bias (Huang 2003 Koukourakis 2000). The remaining 111 studies were classified as unclear.

\section{Blinding}

Blinding was assessed for three different groups: patients, carers and outcome assessors.

Carer blinding: Nineteen studies (15\%) described some method of blinding and were therefore deemed to be at low risk of bias for carer blinding. Forty-five studies (34\%) were classified as being at high risk of bias, as no blinding was employed. Sixty-seven (51\%) studies were classified as 'unclear'.

Patient blinding: Forty-five studies were classified as being at high risk of bias for patient blinding. The majority of these were studies which employed no blinding, however one study was described by its authors as double blind, but then went on to state that a patient withdrew from the study because they were not allocated the intervention of interest (Wu 2009). The assessors were concerned that this suggested a failure in the blinding of patients in this study, and therefore decided to characterise the study at high risk of bias for all three blinding categories. Seventyfive studies (58\%) were deemed to be at low risk of bias for patient blinding. Eleven studies (8\%) were classified as unclear. Of these studies, four were deemed unclear as they employed the use of a placebo control, and therefore blinding could not be discounted, while three studies were assessed for risk of bias from a data collection sheet provided by a translator without any additional information. Of the remaining four 'unclear' studies, one study which compared povidone-iodine to saline was described as 'blind' 
to patients, however, this was considered by the assessors to be an inappropriate control as presumably the iodine solution would differ in colour from the saline (Vokurka 2005). Another which investigated zinc in head and neck patients receiving a mix of radiotherapy and chemoradiotherapy (Ertekin 2004), was classified as unclear for two reasons: firstly, because the study authors described the need for a double blind study in the introduction, and then failed to provide any information about blinding in the remainder of the text, and secondly, because the authors used empty capsules as the control, and the assessors were concerned that this would be noticeable to the patients. The third study (Vadhan-Raj 2010) was deemed unclear because the authors stated that adverse events associated with the intervention (keratinocyte growth factor) may have affected the integrity of the blinding. The remaining trial (Ahmed 1993) only stated that "trial drugs were administered blind", without any additional information.

Outcome assessor blinding: Seventy-seven studies (59\%) were deemed to describe any method of outcome assessor blinding adequately and were considered to be at low risk of bias. Sixteen studies (12\%) were classified as unclear and 38 studies (29\%) were given a decision of 'no' and were therefore considered to be at high risk of bias in this category. In a subanalysis of those studies providing blinding information, only 19 studies gave specific information regarding the blinding of an outcome assessor. The remaining 58 studies were only described as "double blind" by the authors.

\section{Incomplete outcome data}

One hundred and six studies (82\%) were considered to be at low risk of bias for this category. Seventeen studies (13\%) were given a decision of unclear and eight were considered to be at high risk of bias. These seven studies experienced a high rate of drop out.

\section{Selective reporting}

Forty-nine $(37 \%)$ studies were deemed to be free of selective reporting for mucositis grade, which was determined prior to assessment as the outcome of interest for this category. These studies were therefore deemed to be at a low risk of bias. The remaining 82 studies were classified as unclear. These studies tended to only provide subsets of data for severe mucositis (grade > 2) rather than all the information of interest. No studies were given a decision of 'no', and consequently classified at high risk of bias, as studies which did not provide mucositis information for at least one of the dichotomies of interest could not be included in the review.

\section{Other potential sources of bias}

Thirty-five studies (27\%) were deemed to be at high risk of bias in the final 'other' category. A baseline imbalance was reported by 11 studies. Three studies reported gender imbalances (Abbasi-Nazari 2007 Makkonen 1994; Puataweepong 2009), while three studies reported age imbalances (Bensadoun 1999; Ifrah 1999; Makkonen 1994). Two or more baseline imbalances were reported by four studies (Bensadoun 1999; Ifrah 1999 Makkonen 1994; Puataweepong 2009). Puataweepong 2009 reported baseline imbalances in both patient gender $(P=0.03)$ and previous surgery $(P=0.04)$. Meanwhile, in the Ifrah 1999 study, patients randomised to receive GM-CSF in the intervention arm of the study, were older $(P=0.04)$ and more likely to have the Philadelphia chromosomal re-arrangement $(P=0.026)$. Baseline imbalances in age and gender were reported by Makkonen and colleagues (Makkonen 1994).
Bensadoun and colleagues reported imbalances in the number of patients receiving supplementary application of laser to the neck, which was hypothesised to exert a distant beneficial effect. In this study patients in the intervention group also tended to be older. However, no $P$ values were presented by the authors for this imbalance (Bensadoun 1999). Risk of bias was assessed for eight studies from a data collection form completed by a translator. Loprinzi and colleagues initially aimed to recruit 120 patients into their allopurinol study, however, the power calculation was rerun after 77 patients and as the results were found to favour the intervention, the study was terminated and the data published (Loprinzi 1990). In the Duenas and colleagues study (Duenas 1996), an interim analysis conducted in the 16 patients recruited into the study showed a significant different in favour of the placebo, and the authors therefore decided to cease recruitment. Epstein and colleagues also report the results of an interim analysis, in this case a trial of 33 patients which compared sucralfate to placebo. This trial was terminated after an interim analysis suggested that the impact of sucralfate on mucositis prevention was minimal (Epstein 1994).

\section{Effects of interventions}

See: Summary of findings 1 Cryotherapy versus no treatment for preventing oral mucositis for patients with cancer receiving treatment; Summary of findings 2 Amifostine versus placebo/no treatment for preventing oral mucositis for patients with cancer receiving treatment; Summary of findings 3 Keratinocyte GF versus placebo for preventing oral mucositis for patients with cancer receiving treatment; Summary of findings 4 Sucralfate versus placebo/usual care for preventing oral mucositis for patients with cancer receiving treatment; Summary of findings 5 Chlorhexidine versus placebo/no treatment for preventing oral mucositis for patients with cancer receiving treatment

\section{Interventions with more than one trial}

\section{Allopurinol versus placebo/no treatment (Analysis 1.1; Analysis 1.2; Analysis 1.3)}

There were four trials (Abbasi-Nazari 2007; Dozono 1989; Loprinzi 1990; Panahi 2009), two designed as cross-over studies (Dozono 1989; Loprinzi 1990), which compared allopurinol mouthrinse with placebo or no treatment. Three of these studies were conducted in patients undergoing treatment with chemotherapy for solid tumours. One study was conducted in patients receiving radiotherapy $+/$ - chemotherapy for head and neck cancer (AbbasiNazari 2007). Data were provided for all three outcome categories.

All trials provided data for the outcome category of any mucositis, and there was no statistically significant difference between allopurinol and control, risk ratio (RR) 0.77 ( $95 \%$ confidence interval (CI) 0.50 to $1.19, \mathrm{P}=0.24$, Analysis 1.1 ). Two trials, both assessed as being at unclear risk of bias, provided data for the moderate plus severe and severe outcome categories (Abbasi-Nazari 2007; Panahi 2009). There was substantial heterogeneity in both the moderate plus severe meta-analysis $\left(\mathrm{Chi}^{2}=8.24\right.$, degrees of freedom $(\mathrm{df})=1$, $\mathrm{P}=0.004, \mathrm{I}^{2}=88 \%$, Analysis 1.2 ) and the severe meta-analysis ( $\mathrm{Chi}^{2}$ $=13.14, \mathrm{df}=1, \mathrm{P}=0.0003, \mathrm{I}^{2}=92 \%$, Analysis 1.3 ), probably due to differences with regard to the type of tumour and cancer treatment in the trials. The effect estimates from these trials are inconsistent; the risk of bias is unclear and there is substantial heterogeneity. 
Overall, there is weak inconsistent evidence which is insufficient to indicate a benefit of allopurinol in the prevention of mucositis.

\section{Aloe vera solution versus placebo (Analysis 2.1)}

Two trials (Puataweepong 2009; Su 2004), comprising a total of 119 patients with head and neck cancer undergoing radiotherapy or chemoradiotherapy compared aloe vera with placebo. Both trials were found to be at unclear risk of bias. Both provided data for the outcome category of prevention of moderate plus severe mucositis and showed a statistically significant benefit in favour of aloe vera, RR $0.74(95 \% \mathrm{Cl} 0.58$ to $0.96, \mathrm{P}=0.02$, Analysis 2.1$)$ with moderate heterogeneity $\left(\mathrm{Chi}^{2}=2.42, \mathrm{df}=1(\mathrm{P}=0.12) ; \mathrm{I}^{2}=59 \%\right)$.

Su 2004 found a statistically significant reduction in severe mucositis in the aloe vera group but Puataweepong 2009 found no difference between the groups with regard to the prevention of any mucositis (Additional Table 1).

Overall, there is weak unreliable evidence that aloe vera may be beneficial in the prevention of moderate to severe mucositis.

\section{Amifostine versus placebo/no treatment (Analysis 3.1; Analysis 3.2; Analysis 3.3)}

Eleven trials compared amifostine with no treatment (Antonadou 2002; Bourhis 2000; Brizel 2000; Buntzel 1998; Haddad 2009; Hartmann 2001; Koukourakis 2000; Spencer 2005; Vacha 2003; Veerasarn 2006) or a placebo (Buentzel 2006). Most of the trials recruited adults with head and neck cancer being treated with radiotherapy (Bourhis 2000; Brizel 2000; Veerasarn 2006) or chemoradiotherapy (Antonadou 2002; Buentzel 2006; Buntzel 1998; Haddad 2009; Vacha 2003). Two trials (Hartmann 2001; Spencer 2005) included patients having bone marrow transplants, and one trial (Koukourakis 2000) included adults with solid tumours receiving radiotherapy. Eight trials were found to be at high risk of bias (Antonadou 2002; Bourhis 2000; Brizel 2000; Haddad 2009; Koukourakis 2000; Spencer 2005; Vacha 2003; Veerasarn 2006) and three trials were found to be at unclear risk of bias (Buentzel 2006; Buntzel 1998; Hartmann 2001).

Three trials provided data for the outcome of any mucositis. There was a significant but small benefit for amifostine preventing mucositis in this outcome category with RR $=0.95(95 \% \mathrm{Cl} 0.91$ to $0.99, \mathrm{P}=0.007$, Analysis 3.1).

Six heterogeneous trials provided data for moderate plus severe mucositis demonstrating a benefit for amifostine compared with placebo or no treatment, $\mathrm{RR}=0.75(95 \% \mathrm{Cl} 0.58$ to $0.96, \mathrm{P}=$ 0.02 , Analysis 3.2). However, this meta-analysis showed substantial heterogeneity: $\mathrm{Chi}^{2}=25.86, \mathrm{df}=5, \mathrm{P}<0.0001, \mathrm{I}^{2}=81 \%$, which is not explained by cancer treatment (radiotherapy or chemotherapy) or dose of amifostine.

Nine trials provided data for severe mucositis and the pooled metaanalysis showed weak evidence of a possible benefit for amifostine in the prevention of severe mucositis, $\mathrm{RR}=0.68(95 \% \mathrm{Cl} 0.45$ to 1.03 , $\mathrm{P}=0.07$, Analysis 3.3).

A further trial (Vacha 2003) at high risk of bias provided a graph of weekly mean mucositis scores and the text indicated that there was a statistically significant difference in favour of amifostine compared to no treatment at 2 weeks, however no overall result was given in this paper (Additional Table 2).
The results from these 11 studies indicate that there is weak unreliable evidence that amifostine may prevent oral mucositis in adults.

\section{Benzydamine versus placebo}

Four studies compared benzydamine mouthwash (marketed as Difflam $^{\circledR}$ ) with placebo, in a combined total of 332 patients. Kazemian 2009 found a statistically significant reduction in severe mucositis and Prada 1987 found a statistically significant reduction in the development of any mucositis associated with benzydamine (Additional Table 1). Both studies were assessed as being at unclear risk of bias.

Two further studies (Epstein 1989; Epstein 2001), both assessed as being at unclear risk of bias, compared benzydamine with placebo and used other mucositis indices to evaluate the outcome. Both trials reported statistically significant differences in favour of benzydamine (Additional Table 2).

There is weak unreliable evidence that the use of benzydamine may reduce the development of mucositis.

\section{Chlorhexidine versus placebo/no treatment (Analysis 4.1; Analysis 4.2; Analysis 4.3)}

Nine trials, with a total of 692 participants, compared chlorhexidine mouthwash with either a placebo or no treatment control group. Four trials (Dodd 1996; Ferretti 1988; Foote 1994; Sorensen 2008) provided data for the first outcome category (any mucositis), three trials (Foote 1994; Pitten 2003; Sorensen 2008 ) provided data for the second outcome level, moderate plus severe mucositis, and four trials (Foote 1994; Sorensen 2008; Spijkervet 1989; Wahlin 1989) provided data for severe mucositis (grade 3 or greater).

Madan 2008 compared three active treatments: chlorhexidine, povidone iodine, and salt/soda mouthwashes with placebo, and McGaw 1985 compared chlorhexidine mouthwash with placebo, and both these studies presented data as mean mucositis scores for each group (Additional Table 1 ).

Three studies were found to be at low risk of bias (Foote 1994; Pitten 2003; Madan 2008), one study was found to be at high risk of bias (Wahlin 1989). The remaining five studies were found to be at unclear risk of bias (Dodd 1996; Ferretti 1988; McGaw 1985; Sorensen 2008; Spijkervet 1989).

There was substantial heterogeneity in the meta-analysis of any mucositis $\left(\mathrm{Chi}^{2}=30.49, \mathrm{df}=3, \mathrm{P}<0.00001, \mathrm{I}^{2}=90 \%\right.$, Analysis 4.1) and moderate plus severe $\left(\mathrm{Chi}^{2}=10.84 \mathrm{df}=2, \mathrm{P}=0.004\right.$, $1^{2}=82 \%$, Analysis 4.2) mucositis levels which may be partly due to clinical differences between the studies in terms of the cancer type and treatment. In one trial (Foote 1994) patients received radiotherapy for head and neck cancer, in three trials (Dodd 1996; Pitten 2003; Sorensen 2008) patients received chemotherapy for either solid tumours or mixed cancers and in the fifth study (Ferretti 1988) patients were undergoing chemotherapy conditioning prior to bone marrow transplant.

There was no evidence that chlorhexidine was more effective than placebo or no treatment for any of the outcomes evaluated (Analysis 4.1; Analysis 4.2; Analysis 4.3). 
Two further trials (Madan 2008; McGaw 1985) at low and unclear risk of bias respectively, reported statistically significant differences in mean mucositis scores in each group which favoured chlorhexidine over placebo (Additional Table 2).

Overall, there is no evidence of a benefit for chlorhexidine compared with placebo or no treatment, for the prevention of mucositis.

\section{Cryotherapy (ice chips) versus no treatment (Analysis 5.1; Analysis 5.2; Analysis 5.3)}

Six trials (Cascinu 1994; Gori 2007; Lilleby 2006; Mahood 1991; Sorensen 2008; Svanberg 2007) compared cryotherapy (ice chips) with either no treatment or placebo (saline) control. Five trials used a parallel group design and one (Mahood 1991) was a cross-over trial. Three of these studies investigated the use of cryotherapy in patients receiving chemotherapy with 5-FU (Cascinu 1994; Mahood 1991; Sorensen 2008); participants in the trial by Gori 2007 received methotrexate, in Lilleby 2006 they were receiving melphalan conditioning in preparation for stem cell transplantation, and in Svanberg 2007 patients received either chemotherapy or total body irradiation prior to bone marrow or stem cell transplantation. Four of these studies were found to be at high risk of bias, and two studies was found to be at unclear risk of bias (Mahood 1991; Sorensen 2008). Five trials presented data in a format suitable for inclusion in meta-analysis.

There was evidence of a benefit associated with the use of ice chips for each of the three outcome categories of mucositis, with RRs of $0.74(95 \% \mathrm{Cl} 0.57$ to $0.95, \mathrm{P}=0.02$, Analysis 5.1), $0.53(95 \% \mathrm{Cl} 0.31$ to $0.91, \mathrm{P}=0.02$, Analysis 5.2$)$ and $0.36(95 \%$ $\mathrm{Cl} 0.17$ to $0.77, \mathrm{P}=0.008$, Analysis 5.3 ) respectively. However, substantial heterogeneity, likely to be related to the diversity of clinical conditions and treatments, was also identified in each meta-analysis: $\mathrm{Chi}^{2}=14.77, \mathrm{df}=4, \mathrm{P}=0.005, \mathrm{I}^{2}=73 \%$ for any mucositis (Analysis 5.1), $\mathrm{Chi}^{2}=19.02, \mathrm{df}=4, \mathrm{P}=0.0008, \mathrm{I}^{2}=79 \%$ for moderate plus severe (Analysis 5.2), and $\mathrm{Chi}^{2}=14.31, \mathrm{df}=4, \mathrm{P}=$ $0.006,12=72 \%$ for the severe outcome category (Analysis 5.3).

The trial by Svanberg 2007 also found that cryotherapy reduced the development of mucositis and oral pain requiring treatment with opioids (Additional Table 2).

Overall, these six heterogeneous trials provide some evidence, with substantial risk of bias, that ice chips are effective in preventing or reducing the severity of mucositis in patients receiving chemotherapy and/or radiotherapy.

\section{Glutamine versus placebo/usual care (Analysis 6.1; Analysis 6.2; Analysis 6.3)}

Ten trials (Anderson 1998; Cerchietti 2006; Choi 2007; Dickson 2000; He 2008; Huang 2000; Jebb 1994; Li 2006; Okuno 1999; Sornsuvit 2008) evaluating 433 patients compared the use of glutamine with either a placebo (nine trials) or best supportive care (Choi 2007). Two of these trials were designed as cross-over studies (Anderson 1998; Jebb 1994) and both had data from more than $40 \%$ of randomised participants missing from the outcome evaluation. The remaining eight trials used a parallel group design. The smallest trial evaluated only 13 patients (Anderson 1998) and the largest evaluated 124 patients (Okuno 1999). Three trials were conducted in the USA (Anderson 1998; Dickson 2000; Okuno 1999), two in China (He 2008; Li 2006), and one each in Argentina (Cerchietti 2006), Korea (Choi 2007), Taiwan (Huang 2000), Thailand (Sornsuvit 2008), and the UK (Jebb 1994). Two trials were conducted in head and neck cancers undergoing radiation (Huang 2000) or chemoradiation (Cerchietti 2006). Five studies were conducted in patients with solid cancers receiving radiotherapy (Anderson 1998; Choi 2007; He 2008; Jebb 1994; Li 2006). The remaining three studies were conducted in patients with cancers of the blood receiving chemotherapy (Sornsuvit 2008), a group of patients with mixed cancers receiving a mix of radiotherapy and chemotherapy (Dickson 2000) and a group of patients, with unclear cancer type, receiving chemotherapy.

Three trials used a glutamine suspension and instructed patients to either swish it around the mouth and swallow, twice daily (Anderson 1998; Okuno 1999) or swish and then expectorate (Huang 2000). A further four trials compared oral supplementation with 30 grams of glutamine daily (Choi 2007; Dickson 2000; Li 2006) or 15 grams per day (Jebb 1994).

For all three levels of mucositis prevention (any mucositis, moderate to severe or severe), there was no evidence that oral glutamine was different from placebo in the groups of five studies which reported each level of mucositis ( $R R=0.78,95 \% \mathrm{Cl} 0.57$ to $1.08, \mathrm{P}=0.13$, Analysis $6.1 ; \mathrm{RR}=0.88,95 \% \mathrm{Cl} 0.69$ to $1.12, \mathrm{P}=0.31$, Analysis 6.2; and RR $=0.69,95 \% \mathrm{Cl} 0.37$ to $1.29, \mathrm{P}=0.24$, Analysis 6.3 respectively. There was substantial heterogeneity between these studies, in part due to the lower dose in two studies (Jebb 199415 $\mathrm{g} /$ day, Huang 2000 swish and expectorate) and the lack of a placebo control in another study which was assessed as being at high risk of bias (Choi 2007). The risk of bias was assessed as high in Huang 2000 and unclear in the other five studies, but it should be noted that both the cross-over studies (Anderson 1998; Jebb 1994) had in excess of $40 \%$ loss to follow-up.

The remaining three studies compared intravenous (IV) glutamine supplementation with placebo using approximately 30 grams/ day (Cerchietti 2006; Sornsuvit 2008) or 20 grams/day added to parenteral nutrition (He 2008). These trials were small (16 to 48 participants) and all are assessed as being at unclear risk of bias. Only one trial reported the prevention of any grade of mucositis or moderate to severe mucositis and found no difference between glutamine and placebo (Sornsuvit 2008). All three trials (including a total of 93 participants) reported the outcome of prevention of severe mucositis, and found a statistically significant $75 \%$ decrease in severe mucositis associated with IV glutamine supplementation $(\mathrm{RR}=0.25,95 \% \mathrm{Cl} 0.10$ to $0.62, \mathrm{P}=0.002$, Analysis 6.3). This result should be interpreted with caution as it is based on small numbers of participants in studies at unclear risk of bias.

Overall, there is no evidence of a benefit for oral glutamine supplementation in the prevention of mucositis but there is weak evidence, from small trials at unclear risk of bias, that intravenous glutamine supplementation may be beneficial for the prevention of severe mucositis.

\section{G-CSF (Analysis 7.1; Analysis 7.2)}

Three trials, ranging in size from 14 to 195 patients, compared granulocyte colony-stimulating factor (G-CSF) with placebo (Crawford 1999; Schneider 1999; Su 2006) (total $n=249$ ) and one compared G-CSF with no treatment (Katano 1995) ( $n=14)$, for the prevention of mucositis associated with chemotherapy (Crawford 1999; Katano 1995) for solid tumours, or chemoradiotherapy 
(Schneider 1999) or radiotherapy (Su 2006) for head and neck cancers. Of the four studies in this group, Crawford 1999 has unclear risk of bias, Katano 1995 has high risk of bias, and both Su 2006 and Schneider 1999 were found to be at low risk of bias. However, the data presented in the Schneider 1999 paper are from an interim analysis after the trial was stopped early for reasons that are unclear. In Analysis 7.1 two trials show a benefit associated with G-CSF in the prevention of any mucositis and two do not. As well as substantial clinical heterogeneity with regard to the primary tumours and cancer treatments, there is a very high level of statistical heterogeneity $\left(\mathrm{Chi}^{2}=20.48, \mathrm{df}=3, \mathrm{P}=0.0001, \mathrm{I}^{2}=85 \%\right.$ ) among these four trials such that combining the results by metaanalysis is not appropriate. There was a statistically significant reduction in the incidence of severe mucositis in the G-CSF groups compared to placebo ( $R R 0.36,95 \% \mathrm{Cl} 0.15$ to $0.86, \mathrm{P}=0.02$, Analysis 7.2) in two homogenous trials (Schneider 1999; Su 2006). However, Su 2006 found no statistically significant difference between G-CSF and placebo in the prevention of moderate plus severe mucositis.

Overall there is weak evidence that G-CSF may be beneficial in the prevention of severe mucositis in patients with head and neck cancer undergoing radiotherapy.

\section{GM-CSF versus placebo/no treatment (Analysis 8.1; Analysis 8.2; Analysis 8.3)}

Eight trials compared granulocyte/macrophage colony-stimulating factor (GM-CSF) with a placebo or no treatment control group. Five trials were placebo controlled (Cartee 1995; Dazzi 2003; Ifrah 1999; Nemunaitis 1995; van der Lelie 2001) and three trials had a no treatment control group (Chi 1995; Makkonen 2000; McAleese 2006). Three studies were conducted in patients receiving chemotherapy (Chi 1995) or radiotherapy for head and neck cancer (Makkonen 2000; McAleese 2006). Two studies were conducted in patients with solid cancers receiving chemotherapy (Cartee 1995; Dazzi 2003). The remaining studies were conducted in patients with a mix of cancers receiving either radiotherapy (van der Lelie 2001) or chemotherapy (Ifrah 1999), or a mix of different therapies (Nemunaitis 1995).

Two trials were found to be at low risk of bias (Cartee 1995; Dazzi 2003), two trials were found to be at high risk of bias (Chi 1995; Makkonen 2000) and the remaining four studies were assessed as being at unclear risk of bias.

Two trials provided data for any mucositis, and moderate to severe mucositis outcome categories, with six trials providing data for the severe mucositis outcome category. There was no statistically significant difference between GM-CSF and control for any of the outcome categories (Analysis 8.1; Analysis 8.2; Analysis 8.3).

In the trial by Makkonen 2000 all patients in both groups developed mucositis and "there was no significant difference in the frequency or degree of radiation-induced mucositis between GM-CSF and the control groups". Chi 1995 reported a cross-over study of 20 patients, assessed as being at high risk of bias, which showed some period effect from the first treatment period to the second. The study reports a statistically significant benefit favouring GM-CSF.

Based on these eight trials of 433 patients there is no evidence that GM-CSF is different from either placebo or no treatment in the prevention of mucositis.

\section{Honey versus no treatment control (Analysis 9.1; Analysis 9.2; Analysis 9.3)}

Three trials (Biswal 2003; Motallebnejad 2008; Rashad 2008), each with 40 randomised patients, compared honey with a no treatment control for the prevention of mucositis. In Biswal 2003, 20 patients in Malaysia with head and neck cancer, who were undergoing radiotherapy, smeared honey on their mouth, and then swallowed slowly to coat the mucosa, both prior to and after radiotherapy. Patients in the control group received radiotherapy only. This intervention was replicated some 4 years later in Iran (Motallebnejad 2008) in another group of 40 patients undergoing radiotherapy for head and neck cancer and also in Egypt (Rashad 2008) in a group of patients undergoing chemoradiotherapy for head and neck cancer. In Motallebnejad 2008 outcome assessors were blinded to treatment allocation and risk of bias in this study was assessed as unclear, and in the other two studies there was no blinding or allocation concealment and risk of bias is assessed as high. None of these trials provided any information on compliance with treatment and none recorded any drop outs or losses to followup.

There is weak unreliable evidence from these three small trials that honey is associated with a moderate benefit with regard to the prevention of any mucositis (RR $0.70,85 \% \mathrm{Cl} 0.56$ to $0.88, \mathrm{P}=0.002$ ), moderate to severe mucositis (RR $0.48,95 \% \mathrm{Cl}$ 0.31 to $0.74, \mathrm{P}=0.0009$ ) and severe mucositis (RR $0.26,95 \% \mathrm{Cl}$ 0.13 to $0.52, P=0.0002$ ). However, in view of the considerable statistical heterogeneity and high risk of bias these results should be interpreted with caution.

\section{Hydrolytic enzymes versus no treatment (Analysis 10.1; Analysis 10.2)}

Three trials (Dorr 2007; Gujral 2001; Kaul 1999) compared hydrolytic enzymes with either a placebo (Dorr 2007) or radiotherapy only control, in a total of 210 patients receiving radiotherapy for head and neck cancers. Dorr 2007 was double blind, but overall risk of bias was unclear, and Gujral 2001 and Kaul 1999 were assessed as being at high risk of bias overall.

Two trials reported the outcome category of any mucositis (Gujral 2001; Kaul 1999) with conflicting results (Analysis 10.1) and considerable statistical heterogeneity, so these data were not pooled.

All three trials provided data for the prevention of moderate plus severe mucositis. There was considerable heterogeneity identified so these data were not pooled. The placebo controlled study found no difference between the groups (Dorr 2007) but the other two studies, both at high risk of bias, found a benefit favouring hydrolytic enzymes with radiotherapy compared to radiotherapy alone which was not statistically significant.

The three trials also had some differences with regard to the ingredients in the hydrolytic enzyme intervention. Dorr 2007 and Gujral 2001 used a preparation containing papain $100 \mathrm{mg}$, trypsin $40 \mathrm{mg}$ and chymotrypsin $40 \mathrm{mg}$, and Kaul 1999 used a preparation containing papain, trypsin, chymotrypsin, pancreatin, rutin and bromelain.

In summary, the evidence from these three trials is conflicting, and all trials are at some risk of bias. There is insufficient evidence that the use of hydrolytic enzymes to prevent mucositis associated with 
radiotherapy for head and neck cancers is significantly different from placebo or no treatment.

\section{Iseganan versus placebo (Analysis 11.1; Analysis 11.2)}

Two studies (Giles 2004; Trotti 2004), comprising a total of 1013 patients, both at unclear risk of bias, compared iseganan with placebo for different outcome categories of mucositis. One study was conducted in patients with a mix of cancers receiving a range of different cancer treatments (Giles 2004). The other study was conducted in patients with head and neck cancers receiving a mix of cancer therapies (Trotti 2004). These studies provided data for the moderate plus severe and severe outcome categories of mucositis, and both meta-analyses showed no evidence of a difference between iseganan and placebo (Analysis 11.1; Analysis 11.2).

Overall there is no evidence from these trials that iseganan is more or less effective than placebo.

\section{Keratinocyte GF versus placebo (Analysis 12.1; Analysis 12.2; Analysis 12.3)}

Seven trials compared keratinocyte growth factor (GF) (marketed as either Palifermin ${ }^{\circledR}$ or Velafermin ${ }^{\circledR}$ ) with placebo (Blazar 2006;
Brizel 2008; Freytes 2004; Meropol 2003; Rosen 2006; Spielberger 2004; Vadhan-Raj 2010). Six studies were judged to be at unclear risk of bias. One study was judged to be at high risk of bias (Vadhan-Raj 2010). Two provided data for any mucositis, seven for moderate plus severe and six for severe. All three mucositis outcome categories showed evidence of a benefit associated with keratinocyte GF with RR $0.82(95 \% \mathrm{Cl} 0.71$ to $0.94, \mathrm{P}=0.005$, Analysis 12.1) for any mucositis, RR $0.74(95 \% \mathrm{Cl} 0.62$ to $0.89, \mathrm{P}=0.002$, Analysis 12.2) for moderate plus severe mucositis and RR 0.72 (95\% $\mathrm{Cl} 0.58$ to $0.90, \mathrm{P}=0.004$, Analysis 12.3 ) for severe mucositis.

However, there is substantial heterogeneity in the any mucositis $\left(\mathrm{Chi}^{2}=10.11, \mathrm{df}=1, \mathrm{P}=0.001, \mathrm{I}^{2}=90 \%\right.$, Analysis 12.1$)$ and moderate to severe mucositis outcome categories (Chi2 $=50.75, \mathrm{df}=6, \mathrm{P}<$ $0.00001,1^{2}=88 \%$, Analysis 12.2 ). From the table below there is no evidence that this heterogeneity can be explained by differences between the studies in terms of cancer type, cancer treatment, dose or type of keratinocyte GF.

From these seven trials there is some evidence that keratinocyte growth factor is effective in the prevention of mucositis.

\begin{tabular}{llllll}
\hline Author & $\begin{array}{l}\text { Type } \\
\text { of ker- } \\
\text { atinocyte }\end{array}$ & $\begin{array}{l}\text { Dose } \\
\text { of ker- } \\
\text { atinocyte }\end{array}$ & Schedule & $\begin{array}{l}\text { Number } \\
\text { and gen- } \\
\text { der of pa- } \\
\text { tients }\end{array}$ & $\begin{array}{l}\text { Cancer } \\
\text { type }\end{array}$ \\
\hline
\end{tabular}

Blazar 2006 Palifermin $40 \mu \mathrm{g} / \mathrm{kg}$ or Cohort 1: patients randomised

\section{0 (58M/ Leukaemia, Allogeneic stem cell \\ lymphoma, transplant.} to placebo or palifermin at ei- $42 \mathrm{~F}$ ) ther $40 \mu \mathrm{g}$ (8 patients, total dose $240 \mu \mathrm{g})$ or $60 \mu \mathrm{g}(10 \mathrm{pa}$ tients, total dose $360 \mu \mathrm{g}$ ) per day for 3 days before conditioning (days -11 to -9 ) and for 3 days after transplant (days 0 , 1 and 2).

Cohort 2: 14 patients received palifermin at $60 \mu \mathrm{g} /$ day, for 3 days before conditioning (day -11 to -9 ) and then for 6 days after transplant (days $0-2$ and then days 7-9) (9 doses total). Total dose of palifermin received was $540 \mu \mathrm{g}$.

Cohort 3: 37 patients received palifermin at $60 \mu \mathrm{g} /$ day for 3 days before conditioning (day -11 to -9 ) and then for 9 days after transplant (days 0-2, 7-9 and 14-16) (12 doses total). Total dose of palifermin received was $720 \mu \mathrm{g}$ myelodysplastic syn- Cyclophosphamide 60 drome $\mathrm{mg} / \mathrm{kg}$ per day, TBI total dose = 13.2 Gy (fractionated as 165 Gy twice daily for 4 days)

or

busulfan $1 \mathrm{mg} / \mathrm{kg}$ per dose given 4 times daily for 4 days then cyclophosphamide 60 $\mathrm{mg} / \mathrm{kg}$ per day for 2 days

\begin{tabular}{llllll}
\hline Brizel 2008 Palifermin & $\begin{array}{l}60 \mu \mathrm{gg}(67 \\
\text { patients) }\end{array}$ & $\begin{array}{l}1 \text { dose administered weekly } \\
\text { on the Friday before the first } \\
\text { week of chemotherapy (then } \\
\text { continued each Friday for } 7\end{array}$ & $\begin{array}{l}99 \\
(82 \mathrm{M} / 17 \mathrm{~F})\end{array}$ & $\begin{array}{l}\text { Head and } \\
\text { neck }\end{array}$ & $\begin{array}{l}\text { Chemotherapy (cis- } \\
\text { platin } 20 \mathrm{mg} / \mathrm{m}^{2} / \mathrm{d} \text { IV } \\
\text { bolus and fluorouracil } \\
1000 \mathrm{mg} / \mathrm{m}^{2} / \mathrm{d} \mathrm{contin} \text { - }\end{array}$
\end{tabular}


consecutive weeks). 2 additional doses given weeks 8 and 9 uous infusion) administered for first 4 days of the first and fifth weeks of radiotherapy.

Radiotherapy (daily fractions of 2 Gy until 70 Gy)

or

hyperfractionated radiotherapy (1.25 Gy twice daily until $72 \mathrm{~Gy}$ )

\begin{tabular}{lll}
\hline Freytes & Repifermin & $25 \mu \mathrm{g} / \mathrm{kg}$ or \\
2004 & & $50 \mu \mathrm{g} / \mathrm{kg}$
\end{tabular}

Cohort 1: $25 \mu \mathrm{g} / \mathrm{kg}$ repifermin.

42

Cohort 2: $50 \mu \mathrm{g} / \mathrm{kg}$ repifermin

(31M/11F)

Haemato- Autologous stem cell logic malig- transplant.

nancies or lymphoma

Cyclophosphamide, etoposide and carmustine, or

melphalan monotherapy, or melphalan combination, or cyclophosphamide $+\mathrm{TBI}$ or

thiotepa + TBI or cyclophosphamide + busulfan

\begin{tabular}{|c|c|c|c|c|c|c|}
\hline $\begin{array}{l}\text { Meropol } \\
2003\end{array}$ & Palifermin & $\begin{array}{l}1 \mu \mathrm{g} / \mathrm{kg} / \mathrm{d} \\
\text { or } 10 \mu \mathrm{g} / \\
\mathrm{kg} / \mathrm{d} \text { or } 20 \\
\mu \mathrm{g} / \mathrm{kg} / \mathrm{d} \text { or } \\
40 \mu \mathrm{gg} / \mathrm{kg} / \\
\mathrm{d} \text { or } 60 \mu \mathrm{g} / \\
\mathrm{kg} / \mathrm{d} \text { or } 80 \\
\mu \mathrm{g} / \mathrm{kg} / \mathrm{d}\end{array}$ & $\begin{array}{l}\text { All cohorts received palifermin } \\
\text { on days } 1 \text { to } 3 \text { of each cycle. } \\
\text { Cohort } 1: 1 \mu \mathrm{g} / \mathrm{kg} / \mathrm{d} \text { palifermin } \\
\text { Cohort 2: } 10 \mu \mathrm{g} / \mathrm{kg} / \mathrm{d} \text { palifer- } \\
\text { min } \\
\text { Cohort 3: } 20 \mu \mathrm{g} / \mathrm{kg} / \mathrm{d} \text { palifer- } \\
\text { min } \\
\text { Cohort 4: } 40 \mu \mathrm{g} / \mathrm{kg} / \mathrm{d} \text { palifer- } \\
\text { min } \\
\text { Cohort 4: } 60 \mu \mathrm{gg} / \mathrm{kg} / \mathrm{d} \text { palifer- } \\
\text { min } \\
\text { Cohort 5: } 80 \mu \mathrm{g} / \mathrm{kg} / \mathrm{d} \text { palifer- } \\
\text { min. } \\
27 \text { placebo patients (ran- } \\
\text { domised } 1: 1 \text { in cohort } 1 \text { and } \\
\text { 2:1 in all other cohorts) }\end{array}$ & $81(47 \mathrm{M} / 34 \mathrm{~F})$ & $\begin{array}{l}\text { Metastatic } \\
\text { colorectal } \\
\text { cancer }\end{array}$ & $\begin{array}{l}\text { Leucovorin } 20 \mathrm{mg} / \mathrm{m}^{2} \\
\text { by IV followed immedi- } \\
\text { ately by } 425 \mathrm{mg} / \mathrm{m}^{2} \text { for } \\
5 \text { consecutive days on } \\
\text { days } 4 \text { to } 8 \text { of each } 28 \\
\text { day cycle }\end{array}$ \\
\hline Rosen 2006 & Palifermin & $\begin{array}{l}40 \mu \mathrm{g} / \mathrm{kg} \\
\text { per day ( } 28 \\
\text { patients) }\end{array}$ & $\begin{array}{l}3 \text { consecutive days before } \\
\text { chemotherapy }\end{array}$ & $\begin{array}{l}64 \\
(42 \mathrm{M} / 22 \mathrm{~F})\end{array}$ & $\begin{array}{l}\text { Solid tu- } \\
\text { mours } \\
\text { (colon and } \\
\text { rectum) }\end{array}$ & $\begin{array}{l}\text { Chemotherapy } \\
\text { (5-FU } 425 \mathrm{mg} / \mathrm{m}^{2} / \text { day } \\
\text { IV for } 5 \text { days, leucov- } \\
\text { orin } 20 \mathrm{mg} / \mathrm{m}^{2} / \text { day for } 5 \\
\text { days) }\end{array}$ \\
\hline $\begin{array}{l}\text { Spielberger } \\
2004\end{array}$ & Palifermin & $\begin{array}{l}60 \mu \mathrm{g} / \mathrm{kg} \\
\text { per day }\end{array}$ & $\begin{array}{l}3 \text { consecutive days (starting } 3 \\
\text { days before } \mathrm{TBI} \text { ) and } 3 \text { consec- }\end{array}$ & $\begin{array}{l}212 \\
(131 \mathrm{M} / 81 \mathrm{~F})\end{array}$ & $\begin{array}{l}\text { Lym- } \\
\text { phoma, }\end{array}$ & $\begin{array}{l}\text { Autologous stem cell } \\
\text { transplant. }\end{array}$ \\
\hline
\end{tabular}


utive doses after transplanta-

tion (day 0 , day 1 , day 2 ) leukaemia and multiple myeloma
TBI (total 1200 Gy)

chemotherapy included etoposide $(60 \mathrm{mg} / \mathrm{kg})$ and cyclophosphamide (100 mg/kg)

$\begin{array}{llll}\begin{array}{l}\text { Vadhan-Raj Palifermin } 180 \mu \mathrm{g} / \mathrm{kg} \\ 2010\end{array} & \begin{array}{l}\text { 1 dose 3 days before } \\ \text { chemotherapy }\end{array} & \begin{array}{l}48 \\ (25 \mathrm{M} / 23 \mathrm{~F})\end{array} & \begin{array}{l}\text { Sarcoma } \\ \text { Chemotherapy }\end{array} \\ \text { (doxorubicin } 90 \mathrm{mg} / \\ \mathrm{m}^{2} \text { over } 72 \text { hours, ifos- } \\ \text { famide } 10 \mathrm{~m} / \mathrm{m}^{2} 3 \text { hour } \\ \text { infusion for } 4 \text { days) }\end{array}$

\section{Laser versus placebo or sham control (Analysis 13.1; Analysis 13.2; Analysis 13.3)}

Five studies (Antunes 2007; Bensadoun 1999; Chor 2010; Cruz 2007; Schubert 2007), comprising a total of 234 patients, compared laser with a sham laser placebo or no treatment control. Data were provided for all three outcome categories of mucositis. Four of these trials were found to be at unclear risk of bias (Bensadoun 1999; Chor 2010; Cruz 2007; Schubert 2007) and one was assessed to be at high risk of bias (Antunes 2007). Two trials were conducted in patients with a mix of cancers (Antunes 2007; Cruz 2007), one in patients with head and neck cancer undergoing radiotherapy (Bensadoun 1999), one in patients with haematological malignancies undergoing a range of treatments (Schubert 2007) and in the remaining study, the type of cancer and cancer treatment was unclear (Chor 2010).

There was no evidence of a difference in the incidence of any mucositis (RR $0.91,95 \% \mathrm{Cl} 0.71$ to $1.17, \mathrm{P}=0.47$, Analysis 13.1) or moderate plus severe mucositis (RR $0.64,95 \% \mathrm{Cl} 0.38$ to $1.08, \mathrm{P}=$ 0.10 , Analysis 13.2) between the laser and control, but there was a statistically significant $80 \%$ reduction in the incidence of severe mucositis in the laser group compared to sham or no treatment control (RR $0.20,95 \% \mathrm{Cl} 0.06$ to $0.62, \mathrm{P}=0.006$, Analysis 13.3 ).

There was substantial heterogeneity in both the moderate plus severe $\left(\mathrm{Chi}^{2}=4.62, \mathrm{df}=1, \mathrm{P}<0.03, \mathrm{I}^{2}=78 \%\right.$, Analysis 13.2$)$ and severe outcome categories $\left(\mathrm{Chi}^{2}=3.20, \mathrm{df}=1, \mathrm{P}=0.07, \mathrm{I}^{2}=69 \%\right.$, Analysis 13.3), which may be partly explained by a variation in the laser wavelengths used in the trials: one trial used a wavelength of $660 \mathrm{~nm}$ (Antunes 2007) while the other study used a wavelength of $780 \mathrm{~nm}$ (Cruz 2007). In addition, Cruz 2007 recruited children, while Antunes 2007 recruited adults. Both studies were conducted in patients undergoing stem cell transplantation.

The study by Bensadoun 1999 reported the outcome in terms of a mean grade of mucositis in each group over the duration of radiotherapy, and found a statistically significant difference favouring laser (Additional Table 2). Schubert 2007 compared two different lasers (650 $\mathrm{nm}$ and $780 \mathrm{~nm}$ ) with a placebo arm in patients undergoing myeloablative therapy prior to bone marrow transplantation. Mean mucositis scores using the oral mucositis index were reported every 3 days over the 21 day treatment period. "The peak severity of mucositis that generally occurs during the second week of transplant was reduced in the $650 \mathrm{~nm}$ laser group" (Additional Table 2).
Overall there is weak evidence from two small studies at some risk of bias that low energy laser application may be beneficial in preventing severe mucositis.

\section{Oral care protocol versus none (Additional Table 1)}

Two studies (Borowski 1994; Shieh 1997) compared an intense oral care protocol with none (usual care). Borowski 1994 included 166 patients both adults and children undergoing bone marrow transplantation (study has unclear risk of bias) and Shieh 1997 included 30 adults undergoing radiotherapy for head and neck cancers (study at high risk of bias).

Borowski 1994 found no evidence of a difference between the groups with regard to the prevention of moderate plus severe or severe mucositis, but Shieh 1997 found a statistically significant difference favouring the oral care protocol in the prevention of any mucositis (Additional Table 1).

Based on these two studies there is no evidence that specific oral care protocols are any different from usual care with regard to the prevention of mucositis.

\section{Pilocarpine versus placebo (Analysis 14.1; Analysis 14.2; Additional Table 1)}

Two trials, both found to be at unclear risk of bias, compared pilocarpine versus placebo in patients with mixed cancers receiving a range of therapies (Lockhart 2005) and patients with head and neck cancer receiving radiotherapy (Scarantino 2006). The two trials showed inconsistent results and no evidence of benefit was found with regard to the prevention of mucositis for any of the outcome categories (Analysis 14.1; Analysis 14.2; Additional Table $1)$.

Therefore there is no evidence from these two studies that pilocarpine is more or less effective than placebo in preventing mucositis.

\section{Povidone versus water (Analysis 15.1; Analysis 15.2; Analysis 15.3)}

Two trials compared povidone with water or saline (Rahn 1997; Vokurka 2005). One of these studies was found to be at unclear (Vokurka 2005) risk of bias, and the other study was found to be at high risk of bias (Rahn 1997). No statistically significant differences were found for any of the outcome categories (Analysis 15.1; Analysis 15.2; Analysis 15.3). 
There is no evidence from these two studies that povidone is more or less effective than placebo in preventing mucositis.

\section{Prostaglandin versus placebo (Analysis 16.1; Analysis 16.2)}

Four trials, all found to be at unclear risk of bias, compared prostaglandin with a placebo (Duenas 1996; Hanson 1995; Labar 1993; Veness 2006). Participants (total of 228) had a range of cancers including head and neck (Hanson 1995; Veness 2006), haematological (Labar 1993) and mixed locations (Duenas 1996), treated by radiotherapy, radiotherapy and/or chemotherapy, and chemotherapy respectively. There was no statistically significant difference between prostaglandin and placebo for the prevention of any mucositis (Analysis 16.1), or the prevention of severe mucositis (Analysis 16.2). The trial by Hanson 1995 reported conflicting results for results for the two study centres (Additional Table 1).

There is no evidence from these four trials that prostaglandin is different from placebo in the prevention of mucositis.

\section{PTA antibiotic pastille or paste versus placebo (Analysis 17.1; Analysis 17.2)}

Two trials compared antibiotic + antifungal pastilles (containing polymixin, tobramycin and amphotericin (PTA)) with a placebo (Stokman 2003; Symonds 1996) and one trial compared PTA antibiotic paste with a placebo (Wijers 2001). In total 356 patients, all undergoing radiotherapy for head and neck cancers, were included in the trials. Stokman 2003 was assessed as being at low risk of bias and the other two trials at unclear risk of bias.

Two trials provided data for any mucositis (Symonds 1996; Wijers 2001) and the pooled estimate showed evidence of a benefit favouring PTA for the prevention of any mucositis (RR $0.87,95 \% \mathrm{Cl}$ 0.78 to $0.96, P=0.008$, Analysis 17.1 ). With regard to the prevention of severe mucositis there was evidence of a difference between PTA and placebo in the two studies that provided data for this outcome (Stokman 2003; Wijers 2001; Analysis 17.2). Likewise there was no statistically significant difference with regard to moderate plus severe mucositis in the only study that provided data for this outcome category (Wijers 2001; Additional Table 1).

In summary there is some weak evidence that the use of PTA applied locally may prevent mucositis in adults with head and neck cancer undergoing radiotherapy, but further high quality trials are required to confirm this.

\section{Radiation: morning versus afternoon (Analysis 18.1)}

Two trials (Bjarnason 2009; Goyal 2009), with a total of 428 patients, compared radiotherapy delivered in the morning to administration of radiotherapy in the evening, in patients with head and neck cancers. One of these studies was found to be at high risk of bias (Bjarnason 2009) and the other study was assessed as being at unclear risk of bias (Goyal 2009). No evidence of a difference was found for the prevention of severe mucositis (Analysis 18.1) from the two studies, nor for the prevention of moderate plus severe mucositis in Goyal 2009 (Additional Table 3).

From these two studies there is no evidence that the time of day that radiotherapy treatment is delivered makes a difference with regard to the prevention of mucositis.
Sucralfate versus placebo/usual care (Analysis 19.1; Analysis 19.2; Analysis 19.3)

Twelve parallel group trials evaluated the use of sucralfate; 10 compared sucralfate mouthwash with placebo (Carter 1999; Castagna 2001; Cengiz 1999; Epstein 1994; Franzen 1995; Lievens 1998; Makkonen 1994; Nottage 2003; Pfeiffer 1990; Shenep 1988), and one compared sucralfate mouthwash with usual care (Scherlacher 1990). The remaining trial in this group compared sucralfate mouthwash with placebo, but also instructed all participants to apply sucralfate gel to the skin on one side of the radiation area (resulting in possible contamination of the placebo group) (Evensen 2001). Four trials were conducted in Scandinavia (Evensen 2001 Franzen 1995; Makkonen 1994; Pfeiffer 1990), four in Europe (Castagna 2001; Cengiz 1999; Lievens 1998; Scherlacher 1990), two in the USA (Carter 1999; Shenep 1988), and two in Canada (Epstein 1994; Nottage 2003). Only one of these studies was found to be at low risk of bias (Shenep 1988). All other studies were assessed as being at unclear risk of bias.

Most of the trials recruited participants with head and neck cancer undergoing radiotherapy (Cengiz 1999; Epstein 1994; Evensen 2001; Franzen 1995; Lievens 1998; Makkonen 1994; Scherlacher 1990;) and of the remainder two recruited participants with head and neck cancer undergoing either chemotherapy or combined treatments (Carter 1999; Pfeiffer 1990) and three recruited patients with both a range of cancers and treatment regimens. Patients were instructed to swish the solution in their mouths for 5 minutes, three or four times a day and either swallow the solution or expectorate.

Because the intervention and comparison in Evensen 2001 are unique in this sucralfate group, the results are reported in Additional Table 1. There was no evidence from this study, at unclear risk of bias, that sucralfate mouthwash plus sucralfate gel applied to the skin is different from sucralfate gel alone in the prevention of mucositis.

There was no evidence of a difference between the sucralfate group and the placebo group in the proportion of patients who developed any mucositis in the three trials, all at unclear risk of bias, that reported this outcome $(\mathrm{RR} 1.00,95 \% \mathrm{Cl} 0.91$ to $1.10, \mathrm{P}=0.93$, Analysis 19.1).

However there was some evidence that sucralfate may be beneficial in the prevention of moderate plus severe mucositis in the four trials that reported this outcome $(\mathrm{RR} 0.75,95 \% \mathrm{Cl} 0.54$ to $1.04, \mathrm{P}=$ 0.08 , Analysis 19.2). One of these trials was at low risk of bias and the remaining three were assessed as unclear.

Seven trials, one at low and six at unclear risk of bias, provide evidence that sucralfate was effective in the prevention of severe mucositis, with a $33 \%$ reduction in severe mucositis in the sucralfate group compared to placebo (RR $0.67,95 \% \mathrm{Cl} 0.48$ to 0.92 , $P=0.01$, Analysis 19.3).

A further two trials (Epstein 1994; Lievens 1998) reported outcome data in a different format, but neither found a statistically significant difference between sucralfate and placebo in the prevention of mucositis (Additional Table 1).

From 9 trials including a total of 516 participants, which compared sucralfate mouthwash with placebo, and provided data for metaanalysis, there is some evidence that sucralfate may prevent 
moderate plus severe mucositis and stronger evidence of a $33 \%$ reduction in severe mucositis.

\section{Zinc sulphate versus placebo}

Two trials (Ertekin 2004; Lin 2006) including a total of 127 patients with head and neck cancer undergoing chemotherapy and/or radiotherapy compared oral zinc supplementation with placebo. Both trials were assessed as being at unclear risk of bias.

Ertekin 2004 found no statistically significant difference between zinc supplementation and placebo with regard to the prevention of any mucositis, but a statistically significant difference favouring zinc supplementation in the prevention of moderate plus severe and severe mucositis (Additional Table 1). The other study evaluating this comparison (Lin 2006) presented results in graphs and stated that there was no statistically significant difference between the groups (Additional Table 2).

There is conflicting evidence from these two studies and more research is necessary to determine whether zinc supplementation is better than placebo with regard to the prevention of mucositis.

\section{Comparisons evaluated by a single study}

Additional Table 1 presents the data from the comparisons for which there was only one trial evaluating a comparison or only one trial reporting data for one or more of the mucositis outcome categories.

We have summarised the data from the single trials below, indicating where a statistically significant difference is shown (detailed data given in Additional Table 1).

- Aciclovir versus placebo - Bubley 1989: no statistically significant difference for the prevention of any mucositis. Study assessed as being at unclear risk of bias.

- BCoG (bacitracin, cotrimoxazole, gentamicin) antibiotic pastilles - El Sayed 2002: no statistically significant difference between antibiotic and placebo for any of the outcome categories. Study assessed as being at unclear risk of bias.

- Beta carotene versus no treatment control - Mills 1988: no statistically significant difference for severe mucositis. Study assessed as being at high risk of bias.

- Camomile versus placebo - Fidler 1996: no statistically significant difference for all levels of mucositis. Study assessed as being at unclear risk of bias.

- Chewing gum versus no chewing gum - Gandemer 2007: no statistically significant difference for any or severe mucositis. Study assessed as being at high risk of bias.

- Clarithromycin (systemic antibiotic) versus no treatment - Yuen 2001: no statistically significant difference for moderate plus severe mucositis. Study assessed as being at high risk of bias.

- Dental stent versus no treatment control - Qin 2007: no statistically significant difference for moderate plus severe or severe mucositis. Study assessed as being at unclear risk of bias.

- Epidermal growth factor versus placebo - Wu 2009: statistically significant benefit for prevention of moderate plus severe mucositis. Study judged at high risk of bias.

- Histamine gel versus placebo - Elad 2006: no statistically significant difference for any or severe mucositis. Study assessed as being at unclear risk of bias.
- Indomethacin versus placebo - Pillsbury 1986: no statistically significant difference for the prevention of moderate plus severe mucositis. Study assessed as being at unclear risk of bias.

- Indigo wood root versus saline - You 2009: no statistically significant difference for moderate to severe mucositis. Significant benefit for the prevention of severe mucositis. Study assessed as being at unclear risk of bias.

- Intestinal trefoil factor versus placebo - Peterson 2009: statistically significant benefit for prevention of any mucositis and moderate plus severe mucositis, no statistically significant difference for severe only mucositis. Study assessed as being at unclear risk of bias.

- Pentoxifylline versus no treatment - Attal 1993: no statistically significant difference for moderate to severe mucositis. Study assessed as being at unclear risk of bias.

- Prednisone versus placebo - Leborgne 1997: no statistically significant difference for all levels of mucositis. Study assessed as being at unclear risk of bias.

- Propantheline versus placebo - Ahmed 1993: no statistically significant difference for any mucositis. Study assessed as being at unclear risk of bias.

- Shenqi-fanghou versus no treatment - Hu 2005: statistically significant benefit for the prevention of any, moderate plus severe and severe mucositis. Study assessed as being at unclear risk of bias.

- Superoxide dismutase (SOD) versus placebo - Tu 1998: no statistically significant difference for the prevention of any mucositis. Study assessed as being at unclear risk of bias.

- Traumeel versus placebo - Oberbaum 2001: no statistically significant difference was found for any mucositis. Study assessed as being at low risk of bias.

\section{Comparisons of two active interventions for preventing mucositis}

Most of the studies compared an active intervention to either placebo or no treatment. However, two trials (Freytes 2004; Sorensen 2008) had three comparative treatment arms (two active plus placebo) and the results of the direct comparisons are included in Additional Table 3 and summarised below. A further two of these trials (Bjarnason 2009; Goyal 2009) evaluated morning versus afternoon delivery of radiotherapy and the results are described in the section 'Interventions with more than one trial' because both studies used the same interventions. Further details are in Analysis 18.1 and Additional Table 3.

A further seven trials directly compared two active interventions only (Arun Maiya 2006; Dai 2009; Huang 2003; Rocke 1993; Saarilahti 2002; Wang 2002; Watanabe 2010). The data reported in these trials are recorded in Additional Table 3 , and the outcomes are summarised in the list below.

- Chinese herbs (mix of six types) versus Dobell's solution (Wang 2002: significant benefit for prevention of any and moderate plus severe mucositis. Study judged at unclear risk of bias).

- Chinese herbs (mix of 11 types) versus Dobell's solution (Huang 2003: significant benefit for the prevention of moderate plus severe and severe mucositis. Study judged at unclear risk of bias).

- Chlorhexidine verus cryotherapy (Sorensen 2008: no statistically significant difference for all levels of mucositis). 
- Cryotherapy 30 versus 60 minutes (Rocke 1993: no statistically significant difference for all levels of mucositis).

- GM-CSF versus sucralfate (Saarilahti 2002: no statistically significant difference for moderate plus severe and severe mucositis).

- Keratinocyte growth factor 50 versus 25 mg (Freytes 2004: no statistically significant difference for moderate plus severe and severe only mucositis).

- Laser versus povidone (Arun Maiya 2006: statistically significant for moderate plus severe, and severe only mucositis. Study judged at unclear risk of bias).

- Polaprezinc versus azulene (Watanabe 2010: statistically significant benefit for polaprezinc for moderate plus severe, and severe only mucositis).

- Yangyin humo decoctalion versus 'traditional Western medicine' (Dai 2009: significant benefit for the prevention of moderate plus severe mucositis. Study judged at high risk of bias).

Where there was no statistically significant difference between the interventions compared, it is acknowledged that this could be because the interventions were either equally effective or equally ineffective.

This review proposed to conduct subgroup analyses for different cancer types, cancer treatments and age groups. We were unable to undertake this as there were insufficient numbers of studies in the subgroups. However we did look at whether the heterogeneity was explained by different cancer types or treatments for amifostine and keratinocyte growth factor, by undertaking a sensitivity analysis and this is reported under these interventions in the section above.

We prepared summary of findings tables for those interventions where there was a substantial body of evidence comprising a combined total of at least 550 participants in at least three trials. Selection of interventions to be included in summary of findings tables was not influenced by the results of the trials. Five interventions with a substantial body of evidence were identified. For four interventions there was a substantial body of evidence showing some effectiveness: cryotherapy (Summary of findings 1 ), amifostine (Summary of findings 2), keratinocyte growth factor (Summary of findings 3) and sucralfate (Summary of findings 4). The body of evidence concerning chlorhexidine (Summary of findings 5) showed no evidence that chlorhexidine was different from placebo or no treatment in the prevention of mucositis.

\section{DISCUSSION}

\section{Summary of main results}

This update has identified a further 42 included trials which have been published in less than 3 years, bringing the total number of included studies up to 131 . The trials included in this review have evaluated 43 different interventions and recruited a total of 10,514 patients.

There is some evidence of a benefit for cryotherapy (ice chips) and keratinocyte growth factor based on a body of evidence comprising at least 6 trials and at least 550 participants for each of these interventions. However all these trials were assessed as being at either high or unclear risk of bias.
- Cryotherapy was found to be beneficial in the prevention of all the outcome categories of mucositis. Specifically the prevention of any mucositis RR $=0.74(95 \% \mathrm{Cl} 0.57$ to $0.95, \mathrm{P}=0.02)$, moderate plus severe mucositis $\mathrm{RR}=0.53(95 \% \mathrm{Cl} 0.31$ to 0.91 , $\mathrm{P}=0.02)$, and severe mucositis $\mathrm{RR}=0.36(95 \% \mathrm{Cl} 0.17$ to $0.77, \mathrm{P}$ $=0.008$ ).

- Keratinocyte Growth Factor was found to be beneficial for the prevention of all the outcome categories of mucositis, with RR $=0.82(95 \% \mathrm{Cl} 0.71$ to $0.94, \mathrm{P}=0.005)$ for any mucositis, $\mathrm{RR}=$ $0.74(95 \% \mathrm{Cl} 0.62$ to $0.89, \mathrm{P}=0.002)$ for moderate plus severe mucositis and $\mathrm{RR}=0.72(95 \% \mathrm{Cl} 0.58$ to $0.90, \mathrm{P}=0.004)$ for severe mucositis.

There is weak unreliable evidence of a benefit for the following eight interventions based on a smaller body of evidence ( 2 to 5 trials) involving 90 to 350 participants. Most of the trials in this group are assessed as being at either high or unclear risk of bias.

- Aloe vera: weak unreliable evidence that solution was beneficial for the prevention of moderate to severe mucositis: RR $=0.74$ ( $95 \% \mathrm{Cl} 0.58$ to 0.96 ; $\mathrm{P}=0.02$ ).

- Amifostine ${ }^{\star \star}$ : weak unreliable evidence from 11 low quality trials ( 8 trials high risk of bias and 3 unclear risk of bias) that amifostine is beneficial for the prevention of any mucositis: RR $=0.95(95 \% \mathrm{Cl} 0.91$ to $0.99, \mathrm{P}=0.007)$ and moderate to severe mucositis: $\mathrm{RR}=0.75(95 \% \mathrm{Cl} 0.58$ to $0.96, \mathrm{P}=0.02)$.

- Glutamine (intravenous): weak unreliable evidence that glutamine administered intravenously is beneficial for the prevention of severe mucositis ( $\mathrm{RR}=0.25,95 \% \mathrm{Cl} 0.10$ to 0.62 ).

- Granulocyte - Colony Stimulating Factor *: (G-CSF) weak evidence that G-CSF is effective for the prevention of severe mucositis ( $R R=0.36,95 \% \mathrm{Cl} 0.15$ to $0.86, \mathrm{P}=0.02$ ) based on two small trials at low risk of bias

- Honey: weak unreliable evidence, with substantial heterogeneity, that honey may be beneficial in the prevention of any mucositis ( $R R=0.70,85 \% \mathrm{Cl} 0.56$ to $0.88, \mathrm{P}=0.002$ ), moderate to severe mucositis ( $R R=0.48,95 \% \mathrm{Cl} 0.31$ to $0.74, \mathrm{P}$ $=0.0009)$ and severe mucositis ( $R R=0.26,95 \% \mathrm{Cl} 0.13$ to $0.52, \mathrm{P}$ $=0.0002$ ).

- Laser: weak unreliable evidence that laser is beneficial for the prevention of severe mucositis: $\mathrm{RR}=0.20(95 \% \mathrm{Cl} 0.06$ to $0.62, \mathrm{P}$ $=0.006$ ).

- Polymixin/Tobramycin/Amphotericin (PTA) lozenges/paste *: weak unreliable evidence that PTA lozenges may be beneficial for the prevention of any mucositis: RR $=0.87(95 \% \mathrm{Cl} 0.78$ to $0.96, P=0.008$ ).

- Sucralfate: evidence that sucralfate is effective in the prevention of severe mucositis, with a $33 \%$ reduction in severe mucositis in the sucralfate group compared to placebo $(\mathrm{RR}=$ $0.67,95 \% \mathrm{Cl} 0.48$ to $0.92, \mathrm{P}=0.01$ )

${ }^{\star}$ Conclusions based on at least one trial with a low risk of bias.

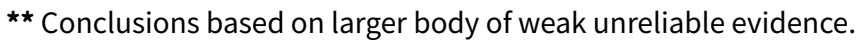

The mechanisms by which these ten interventions act to either prevent mucositis or reduce the severity of mucositis in cancer patients receiving treatment, is not clearly established. There are various explanations put forward in the literature, as to how the 'effective' interventions listed above might mitigate the effects of 
cancer treatment on the oral mucosa, but it is beyond the scope of this systematic review to comment further.

Overall, three interventions (aloe vera, PTA antibiotics and honey) were investigated almost exclusively in patients with head and neck cancer undergoing radiotherapy. Cryotherapy was investigated solely in patients with haematological malignancies undergoing chemotherapy or stem cell transplantation. Sucralfate was investigated mostly in patients with head and neck cancer undergoing radiotherapy, with a minority of trials including participants with other cancer types.The remainder (amifostine, granulocyte-colony stimulating factor, intravenous glutamine, keratinocyte growth factor, and laser treatment) were tested in combinations of patients with head and neck cancer, other solid tumours and haematological malignancies undergoing radiotherapy, stem cell transplantation, non-myeloablative chemotherapy or a combination.

Of the chemotherapeutic agents used to treat cancer, 5-fluouracil was the most frequently reported. However, a wide variety of different agents and schedules were examined, precluding analysis specific to a particular chemotherapy regimen.

It is important to note that a substantial body of evidence concerning chlorhexidine, has clearly shown no evidence of a benefit compared to either placebo or no treatment.

- Chlorhexidine - no evidence of a benefit for chlorhexidine based on 9 trials including a total of more than 650 participants. Risk of bias was assessed as low in 3 trials, high in one trial, and unclear in the remaining five trials.

In conclusion, there is some evidence of the effectiveness of cryotherapy and keratinocyte growth factor, and weaker evidence of a benefit associated with aloe vera, amifostine, glutamine (intravenous), granulocyte-colony stimulating factor, honey, laser, PTA antibiotic pastille/paste and sucralfate. There is no evidence of a benefit associated with the use of chlorhexidine.

\section{Overall completeness and applicability of evidence}

The number and range of interventions studied and reported in this review indicate the importance of this condition to clinicians and patients and the lack of a well-defined and effective means of prevention of oral mucositis in cancer patients. The presumed modes of action of the different interventions are very varied and include free radical scavenging (amifostine), local vasoconstriction (cryotherapy), reductions in concurrent mucosal infection (antibiotic pastilles) and enhancement of wound healing (honey, keratinocyte growth factor). Nine of the 43 interventions examined were found to have some evidence of a benefit, albeit sometimes weak, in preventing or reducing the severity of mucositis.

Despite the large number of trials included in the review few interventions were studied by several independent groups. This has led to limitations in the strength and generalisability of the evidence and several groups have highlighted the need for a coordinated research agenda (Wright 2003). The eligible trials varied in their setting, design, country of conduct, financial support and quality. The majority (79\%) were conducted primarily by medical teams who did not report the involvement of dental practitioners. It was unfortunate that many studies presented data in a format unsuitable for meta-analysis in this review. The use of structured abstracts and adherence to the Consolidated Standards of Reporting Trials (CONSORT) guidelines would greatly improve the conduct and reporting of randomised controlled trials (RCTs), allowing a greater number to be included in future meta-analyses (Begg 1996; Moher 2001).

With respect to publication bias, several negative studies for mucositis have been reported and we congratulate the authors and editors for doing so. It was not possible to detect any existing publication bias, as there were insufficient studies in each metaanalysis investigating the same interventions. This review has focused heavily on the prevention of mucositis in adults due to a lack of true RCTs conducted in paediatric populations, highlighting the difficulties of conducting research in this patient population.

\section{Quality of the evidence}

All studies included in this update of the review were assessed for risk of bias in six categories: adequate sequence generation, adequate allocation concealment, blinding (of patients, carers and outcome assessors), incomplete outcome data addressed, free of selective reporting and free of other bias. Overall risk of bias was described for each included study. Studies were deemed to be at low risk of overall bias if they were assessed as being at low risk for both allocation concealment and outcome assessor blinding. Only 10 studies (7.6\%) met both criteria. Eighty-three studies (63.4\%) were described as being at unclear overall risk of bias. The remaining 38 studies (29\%) were found to be at high overall risk of bias. In general, methods of allocation concealment were not reported in publications, or poorly described by authors, which prevented the study being described as at low risk of bias for this category. The use of adequate allocation concealment, together with the publication of full descriptions of any methods used, needs to be incorporated into future trials. Of the 77 studies described as double blind, only 19 studies specifically stated that the outcome assessor was blinded. Adequate outcome assessor blinding is crucial to obtain unbiased assessments, even with the most objective of assessment instruments. It is both possible and highly desirable that future trials employ adequate outcome assessor blinding, even where blinding of patients or support staff to the intervention is impossible.

Although there was general consistency among the included studies in the number of categories of mucositis severity, scoring systems were not always clearly defined. The most frequently used assessment instrument in this review was the World Health Organization (WHO) score, followed by the Radiation Therapy Oncology Group (RTOG) instrument. Since our last review update, a systematic review has been published (Gibson 2010) which identified 54 oral assessment instruments in the literature. In order for the results of future studies to be synthesised with others, it is recommended that authors should employ a 'simple' assessment, in addition to any multicomponent instrument, to allow for data to be dichotomised.

The appearances of mucositis and oral candidiasis can be similar, and moreover, the two frequently co-exist. Consequently, if the assessors were lacking experience in the differential diagnosis of these oral lesions, the validity of mucositis scores may have been compromised. Candidiasis was not routinely screened for or reported in the trials included in this review, and the addition of candidiasis screening may assist in the differential diagnosis and treatment of the two conditions. 
The reporting of secondary outcomes other than mucositis severity was variable and these outcomes were mentioned more frequently in trials published within the last 5 years. The types of outcome reported have changed to reflect characteristics of greater clinical relevance to clinicians and patients (Bellm 2002; Chang 2003; Sonis 2004; Wright 2003). In addition to reporting mucositisrelated outcomes some groups reported known side effects of the interventions. For some trials these side effects were reported only in the intervention group and it was not clear if there were any events in the control group. In future trials these side effects should be measured and reported on all patients in both groups in a consistent manner. This adverse event data should be presented per patient and not per episode.

\section{Potential biases in the review process}

The meta-analyses in this review include only studies where mucositis outcomes were graded on a 0-4 scale. The most recent update of the review has also included a further 13 studies where the outcomes are recorded in Additional Table 2, and the results are incorporated into the text of the review. However, 16 trial reports were excluded from this systematic review because the authors collected outcome data using an instrument which individually graded components of oral health, to produce a composite score (Eilers 1988). As such instruments include in the total score categories such as teeth and voice, the scores are not comparable with scales that measure only mucositis.

A further 16 trials are awaiting classification pending further information being made available by the authors of the papers and it is hoped that these trials may be included in future updates of this review.

\section{Agreements and disagreements with other studies or reviews}

This updated systematic review has identified nine interventions for the prevention of mucositis for which there is evidence of effectiveness. Four of these interventions: amifostine, locally applied antibiotic (PTA), cryotherapy and keratinocyte growth factor, have also been identified as having some evidence of effectiveness by practice guidelines and other systematic reviews (Keefe 2007; McDonnell 2007; Sasse 2006; Stokman 2006). We have also found weak evidence to support the effectiveness of the use of aloe vera, granulocyte-colony stimulating factor and honey for the prevention of oral mucositis, but we are not aware of other systematic reviews which support the use of these interventions.

Regarding the use of laser for the prevention of mucositis there is evidence based on two studies that laser reduces the incidence of severe mucositis, a finding which is supported by a Cochrane review on the treatment of oral mucositis which found that laser treatment was effective in reducing the severity of established mucositis (Clarkson 2010).

Our systematic review includes a small study by Oberbaum 2001 $(n=32)$ which is also included in another systematic review by Kassab 2009 which evaluated homeopathic interventions for the adverse effects of cancer treatments. In their review, Kassab et al reported the mucositis outcome as mean area under the curve for each group, and found a statistically significant difference favouring traumeel, the homeopathic intervention. In our systematic review we used a different outcome category: prevention of any mucositis, and found no statistically significant difference between traumeel and placebo. Both reviews assessed this study as being at low risk of bias. We agree with Kassab et al that further research is required to confirm any benefit of this intervention.

Our updated systematic review has found some weak evidence for the effectiveness of intravenous glutamine in the prevention of severe oral mucositis, based on three trials that have been published since 2006, but this intervention is not recommended by the current Multinational Association of Supportive Care in Cancer (MASCC) guidelines, based on a single study from 2002 (Keefe 2007). There are plans to update these guidelines in the near future.

\section{AUTHORS' CONCLUSIONS}

\section{Implications for practice}

Cryotherapy (ice chips) and Keratinocyte Growth Factor (Palifermin ${ }^{\circledR}$ ) have shown some evidence of benefit in the prevention of mucositis. There is weaker less reliable evidence of a benefit associated with aloe vera, amifostine, intravenous glutamine supplementation, granulocyte-colony stimulating factor, honey, laser, polymixin/tobramycin/amphotericin (PTA) lozenges and sucralfate.

There is no evidence that chlorhexidine is more effective that placebo and this intervention should not be used in the prevention of mucositis.

The patient groups studied were diverse, the associated treatment modalities were varied and the strength of the evidence of effectiveness was variable. As some interventions were studied exclusively in certain patient groups receiving specific treatment modalities generalisation of the results to other tumour types and treatment modalities must be done with caution as some benefits may be specific to certain cancer types and treatments.

\section{Implications for research}

There is a need for well designed and conducted trials of interventions to prevent mucositis induced by chemotherapy, radiotherapy or targeted therapies. Such trials should be reported according to the Consolidated Standards of Reporting Trials (CONSORT) guidelines with sufficient numbers of participants to perform subgroup analyses by type of disease and chemotherapeutic agent. This review has highlighted several interventions (aloe vera, amifostine, G-CSF, PTA antibiotic pastille/ paste, cryotherapy, intravenous glutamine, honey, keratinocyte growth factor and laser therapy) with evidence of effectiveness from more than one trial included in a meta-analysis. Further research into the benefits and harms of these interventions and whether these results can be generalized to other forms of cancer and its treatment should be conducted. In addition, as several agents were reported to show efficacy in a single trial, further well designed, adequately powered randomised controlled trials of these and other novel agents for mucositis prevention should be undertaken. The concurrent use of two or more interventions, with different modes of action, may be worth evaluating in well conducted, adequately powered randomised controlled trials.

We recognise the importance of multicomponent indices for oral health. However, to facilitate comparison between interventions for preventing mucositis it would be helpful if researchers used a simple mucositis index with a 0-4 scale (e.g. World Health 
Organization (WHO), Radiation Therapy Oncology Group (RTOG), National Cancer Institute - Common Toxicity Criteria ( $\mathrm{NCl}-\mathrm{CTC})$ ) as part of their outcome evaluation.

\section{ACKN OWLEDGEMENTS}

Thanks go to Luisa Fernandez Mauleffinch (Managing Editor, Cochrane Oral Health Group) and Phil Riley (Assistant Managing Editor) their help with the administration of the review, for locating all the articles, sending out letters to authors and helping collate the information for the review.

The help and expertise of the following is gratefully acknowledged: Marco Esposito (Italian translations, The University of Manchester); Tatiana Macfarlane (Russian translations, University of Aberdeen); Malgorzata Bala (Polish translations, Jagiellonian University Medical College, Poland), Joannna Zakrzewska (Polish translations, Eastman Dental Hospital), Valeria Marinho (Spanish/Portuguese translations, Queen Mary's School of Medicine and Dentistry); Shi Zongdao, Xie Huixu, Wang Ping, Yifan Zhang, Chunjie Li and Wu Jiapei (Chinese translations, Sichuan University); Mikako Hayashi and Kumiko Kasashi (Japanese translations, University of Osaka) and Toru Naito (Japanese translations, Fukuoka Dental College) for providing translations of the trial reports and completing the data extraction forms.

We would also like to thank the following investigators who replied to our request for additional information about their trials: HS Antunes, G Bjarnason, S Cascinu, D Cella, L Cruz, MJ Dodd, GA Ferretti, T Feyerabend, $\mathrm{P}$ Gotzshe, $\mathrm{CL}$ Loprinzi, $\mathrm{S}$ Wang and Drs PM Anderson, B Bensinger, BM Biswal, C Bokemeyer, J Bourhis, $\mathrm{H}$ Brincker, J Buentzel, L Cerchietti, LWC Chow, L Damon, C Dazzi, TC Dickson, P Dietrich, A Duenas-Gonzalez, S El Sayed, S Elad, MV Ertkin, GA Ferretti, R Foote, L Frazen, C Freytes, J Hartmann, M Heydt, R Haddad, E Huang, N Ifrah, SA Jebb, M Katano, J Leborgne, P Lockhart, G Masucci, M Motallebneja, SH Okuno, DE Peterson, N Piccirillo, HC Pillsbury, R Rahn, K Saarilahti, C Scarantino, JL Shenep, JA Sloan, A Spencer, R Spielberger, C Sportes, M Stokman, C Su, RP Symonds, A Trotti, S Vadhan-Raj, YB Wahlin, and H Whelan.

We would also like to thank those who have provided comments and editorial input into this review.

The administration of this review has been aided by a USA NIDCR grant, reference 1 R03 DE0 16950-01. 


\section{R E F E R E N C E S}

\section{References to studies included in this review}

Abbasi-Nazari 2007 \{published data only\}

Abbasi Nazari M, Sadrolhefazi B, Nikoofar A, Erfan M, Azizian H, Alamy M. Allopurinol mouthwash for prevention or alleviation radiotherapy induced oral mucositis: a randomized, placebocontrolled trial. Daru 2007;15(4):227-30.

\section{Ahmed 1993 \{published data only\}}

Ahmed T, Engelking C, Szalyga J, Helson L, Coombe N, Cook P et al. Propantheline prevention of mucositis from etoposide. Bone Marrow Transplantation 1993;12(2):131-2.

\section{Anderson 1998 \{published and unpublished data\}}

Anderson PM, Schroeder G, Skubitz KM. Oral glutamine reduces the duration and severity of stomatitis after cytotoxic cancer chemotherapy. Cancer 1998;83(7):1433-9.

\section{Antonadou 2002 \{published data only\}}

Antonadou D, Pepelassi M, Synodinou M, Puglisi M, Throuvalas N. Prophylactic use of amifostine to prevent radiochemotherapy-induced mucositis and xerostomia in headand-neck cancer. International Journal of Radiation Oncology, Biology and Physics 2002;52(3):739-47.

\section{Antunes 2007 \{published data only\}}

Antunes HS, de Azevedo AM, da Silva Bouzas LF, Adao CA, Pinheiro CT, Mayhe R et al. Low-power laser in the prevention of induced oral mucositis in bone marrow transplantation patients: a randomized trial. Blood 2007;109(5):2250-5.

\section{Arun Maiya 2006 \{published data only\}}

Arun Maiya G, Sagar MS, Fernandes D. Effect of low level heliumneon (He-Ne) laser therapy in the prevention \& treatment of radiation induced mucositis in head \& neck cancer patients. [see comment]. The Indian Journal of Medical Research 2006;124(4):399-402.

\section{Attal 1993 \{published data only\}}

Attal M, Huguet F, Rubie H, Charlet J-P, Schlaifer D, Huynh A et al. Prevention of regimen-related toxicities after bone marrow transplantation by pentoxifylline: A prospective, randomized trial. Blood 1993;82(3):732-6.

\section{Bensadoun 1999 \{published data only\}}

Bensadoun R, Cowen D, Nguyen TD, Ciais G, Franquin JC, Dassonville $\mathrm{O}$ et al. Low energy laser in the prevention of radiation-induced mucositis: A phase III randomized multicentric study in patients with head and neck cancer. In: Fifth International Congress on Anti-Cancer Chemotherapy. 1995.

Bensadoun R, Franquin J, Benezery K, Ciais G, Tardieu C, Dejou $\mathrm{J}$ et al. Low energy $\mathrm{He} / \mathrm{Ne}$ laser in the prevention of radiation induced mucositis: A multicenter phase III double blind study for patients with head and neck cancer. In: Proceedings of ASCO. 1999.

Bensadoun RJ, Ciais G, Darcourt V, Franquin JC, Cheynet C, Cowen $D$ et al. Low energy laser in the prevention of radiation induced mucositis: a phase II randomized multicentre study for patients with head and neck cancer. Supportive Care in Cancer 1999;7:SO-13.

* Bensadoun RJ, Franquin JC, Ciais G, Darcourt V, Schubert MM, Viot $\mathrm{M}$ et al. Low-energy $\mathrm{He} / \mathrm{Ne}$ laser in the prevention of radiation-induced mucositis. A multicentre phase III randomized study in patients with head and neck cancer. Supportive Care in Cancer 1999;7(4):244-52.

Biswal 2003 \{published data only\}

* Biswal BM, Zakaria A, Ahmad NM. Topical application of honey in the management of radiation mucositis: a preliminary study. Supportive Care in Cancer 2003;11(4):242-8.

Biswal BM, Zakaria A, Nik Min A. Topical application of honey in the management of radiation mucositis: A randomized study. International Journal of Cancer 2002;100 Supp 13:480 (Abstract 1109).

\section{Bjarnason 2009 \{published data only\}}

Bjarnason GA, MacKenzie RG, Nabid A, Hodson ID, El-Sayed S, Grimard $L$ et al. Comparison of toxicity associated with early morning versus late afternoon radiotherapy in pateints with head and neck cancer: a prospective randomized trial of the National Cancer Institute of the Canada Clinical Trials Group (HN3). International Journal of Radiation Oncology, Biology, Physics 2009;73(1):166-72.

\section{Blazar 2006 \{published data only\}}

Blazar BR, Weisdorf DJ, Defor T, Goldman A, Braun T, Silver S et al. Phase $1 / 2$ randomized, placebo-control trial of palifermin to prevent graft-versus-host disease (GVHD) after allogeneic hematopoietic stem cell transplantation (HSCT). Blood 2006;108(9):3216-22.

\section{Borowski 1994 \{published data only\}}

Borowski B, Benhamou E, Pico JL, Laplanche A, Margainaud JP, Hayat M. Prevention of oral mucositis in patients treated with high-dose chemotherapy and bone marrow transplantation: a randomised controlled trial comparing two protocols of dental care. European Journal of Cancer. Part B, Oral Oncology 1994;30B(2):93-7.

\section{Bourhis 2000 \{published data only\}}

* Bourhis J, De Crevoisier R, Abdulkarim B, Deutsch E, Lusinchi A, Luboinski $B$ et al. A randomized study of very accelerated radiotherapy with and without amifostine in head and neck squamous cell carcinoma. International Journal of Radiation Oncology, Biology, Physics 2000;46(5):1105-8.

Bourhis J, Rosine D. Radioprotective effect of amifostine in patients with head and neck squamous cell carcinoma. Seminars in Oncology 2002;29(6 Supp 19):61-2.

\section{Brizel 2000 \{published data only\}}

Brizel DM, Wasserman TH, Henke H, Strnad V, Rudat V, Monnier A et al. Phase III randomized trial of amifostine as a radioprotector in head and neck cancer. Journal of Clinical Oncology 2000;18(19):3339-45. 
Brizel 2008 \{published data only\}

Brizel DM, Murphy BA, Rosenthal DI, Pandya KJ, Gluck S, Brizel HE et al. Phase Il study of palifermin and concurrent chemoradiation in head and neck squamous cell carcinoma. Journal of Clinical Oncology 2008;26(15):2489-96.

Bubley 1989 \{published data only\}

Bubley GJ, Chapman B, Chapman SK, Crumpacker CS, Schnipper LE. Effect of acyclovir on radiation- and chemotherapy-induced mouth lesions. Antimicrobial Agents and Chemotherapy 1989;33(6):862-5.

\section{Buentzel 2006 \{published data only\}}

Buentzel J, Micke O, Adamietz IA, Monnier A, Glatzel M, de Vries A. Intravenous amifostine during chemoradiotherapy for head-and-neck cancer: a randomized placebo-controlled phase III study. International Journal of Radiation Oncology, Biology, Physics 2006;64(3):684-91.

\section{Buntzel 1998 \{published data only\}}

Bennett CL, Lane D, Stinson T, Glatzel M, Buntzel J. Economic analysis of amifostine as adjunctive support for patients with advanced head and neck cancer: Preliminary results from a randomized phase II clinical trial from Germany. Cancer Investigation 2001;19(2):107-13.

Buntzel J, Glatzel M, Kuttner K, Weinaug R, Frohlich D. Amifostine in simultaneous radiochemotherapy of advanced head and neck cancer. Seminars in Radiation Oncology 2002;12(1 Supp 1):4-13.

Buntzel J, Kuttner K, Frohlich D, Glatzel M. Selective cytoprotection with amifostine in concurrent radiochemotherapy for head and neck cancer. Annals of Oncology 1998;9(5):505-9.

* Buntzel J, Schuth J, Kuttner K, Glatzel M. Radiochemotherapy with amifostine cytoprotection for head and neck cancer. Supportive Care in Cancer 1998;6(2):155-60.

\section{Cartee 1995 \{published data only\}}

Cartee L, Petros WP, Rosner GL, Gilbert C, Moore S, Affronti $M L$ et al. Evaluation of GM-CSF mouthwash for prevention of chemotherapy-induced mucositis: a randomized, double-blind, dose-ranging study. Cytokine 1995;7(5):471-7.

\section{Carter 1999 \{published data only\}}

Carter DL, Hebert ME, Smink K, Leopold KA, Clough RL, Brizel DM. Double blind randomized trial of sucralfate vs placebo radial radiotherapy for head and neck cancers. Head and Neck 1999;21(8):760-6.

\section{Cascinu 1994 \{published and unpublished data\}}

Cascinu S, Fedeli A, Fedeli SL, Catalano G. Oral cooling (cryotherapy), an effective treatment for the prevention of 5fluorouracil-induced stomatitis. European Journal of Cancer. Part B, Oral Oncology 1994;30B(4):234-6.

\section{Castagna 2001 \{published data only\}}

Castagna L, Benhamou E, Pedraza E, Luboinski M, Forni M, Brandes I et al. Prevention of mucositis in bone marrow transplantation: a double blind randomised controlled trial of sucralfate. Annals of Oncology 2001;12(7):953-5.

\section{Cengiz 1999 \{published data only\}}

Cengiz M, Ozyar E, Ozturk D, Akyol F, Atahan IL, Hayran M. Sucralfate in the prevention of radiation-induced oral mucositis. Journal of Clinical Gastroenterology 1999;28(1):40-3.

\section{Cerchietti 2006 \{published data only\}}

Cerchietti LC, Navigante AH, Lutteral MA, Castro MA, Kirchuk R, Bonomi $\mathrm{M}$ et al. Double-blinded, placebo-controlled trial on intravenous L-alanyl-L-glutamine in the incidence of oral mucositis following chemoradiotherapy in patients with headand-neck cancer. International Journal of Radiation Oncology, Biology, Physics 2006;65(5):1330-7.

Chi 1995 \{published data only\}

* Chi KH, Chen CH, Chan WK, Chow KC, Chen SY, Yen SH et al. Effect of granulocyte-macrophage colony-stimulating factor on oral mucositis in head and neck cancer patients after cisplatin, fluorouracil and leucovorin chemotherapy. Journal of Clinical Oncology 1995;13(10):2620-8.

Chi KH, Chen $\mathrm{CH}$, Chan WK, Yen SH, Liang MJ, Chou KC et al. Effect of granulocyte-macrophage colony-stimulating factor (GH-CFS) on oral mucositis in head and neck cancer patients after cisplatin, 5-FU and leucovorin chemotherapy. In: Proceedings of Annual Meeting American Society of Clinical Oncology. Vol. 13. 1994:Abstract 1469.

\section{Choi 2007 \{published data only\}}

Choi K, Lee SS, Oh SJ, Lim SY, Lim SY, Jeon WK et al. The effect of oral glutamine on 5-flurouracil/ leucovorin-induced mucositis/ stomatitis assessed by intestinal permeability test. Clinical Nutrition 2007;26(1):57-62.

\section{Chor 2010 \{published data only\}}

Chor A, Torres SR, Maiolino A, Nucci M. Low-power laser to prevent oral mucositis in autologous hematopoietic stem cell transplantation. European Journal of Haematology 2010;84(2):178-9.

\section{Crawford 1999 \{published data only\}}

Crawford J, Glaspy J, Vincent M, Tomita D, Mazanet R. Effect of filgrastim ( $r$-metHug-CSF) on oral mucositis in patients with small cell lung cancer (SCLC) receiving chemotherapy (cyclophosphamide, doxorubicin and etoposide, CAE). In: Proceedings of Annual Meeting of American Society Clinical Oncology. Vol. 13. 1994:Abstract A1523.

* Crawford J, Tomita DK, Mazanet R, Glaspy J, Ozer H. Reduction of oral mucositis by filgrastim ( $r$-metHuG-CSF) in patients receiving chemotherapy. Cytokines, Cellular and Molecular Therapy 1999;5(4):187-93.

\section{Cruz 2007 \{published data only\}}

Cruz LB, Ribeiro AS, Rech A, Rosa LG, Castro CG Jr, Brunetto $A L$ et al. Influence of low-energy laser in the prevention of oral mucositis in children with cancer receiving chemotherapy. Pediatric Blood \& Cancer 2007;48(4):435-40. 
Dai 2009 \{published data only\}

Dai AW, Li ZY, Wang LH, Li SY, Yang H. Effect of Yangyin Humo Decoction on oral mucomembranous reaction to radiotherapy. Chinese Journal of Integrative Medicine 2009;15(4):303-6.

\section{Dazzi 2003 \{published data only\}}

* Dazzi C, Cariello A, Giovanis P, Monti M, Vertogen B, Leoni M et al. Prophylaxis with GM-CSF mouthwashes does not reduce frequency and duration of severe oral mucositis in patients with solid tumors undergoing high-dose chemotherapy with autologous peripheral blood stem cell transplantation rescue: a double blind, randomized, placebo-controlled study. Annals of Oncology 2003;14(4):559-63.

Dazzi C, Cariello A, Monti M, Giovanis P, Vertogen B, Nanni O et al. Prophylaxis with GM-CSF mouthwash does not reduce frequency and duration of severe oral mucositis in patients with solid tumors undergoing high dose chemotherapy with autogous PBPC rescue: A double blind randomized placebocontrolled study. Annals of Oncology 2002;13 Suppl 5:167 (Abstract 617).

\section{Dickson 2000 \{published data only\}}

Coghlin Dickson TM, Wong RM, Offrin RS, Shizuru JA, Johnston LJ, Hu WW et al. Effect of oral glutamine supplementation during bone marrow transplantation. Journal of Parenteral and Enteral Nutrition 2000;24(2):61-6.

Dodd 1996 \{published and unpublished data\}

Dodd MJ, Larson PJ, Dibble SL, Miaskowski C, Greenspan D, MacPhail $L$ et al. Randomized clinical trial of chlorhexidine versus placebo for prevention of oral mucositis in patients receiving chemotherapy. Oncological Nursing Forum 1996;23(6):921-7.

\section{Dorr 2007 \{published data only\}}

Dorr W, Herrmann T, Study Group. Efficacy of Wobe-Mugos E for reduction of oral mucositis after radiotherapy: results of a prospective, randomized, placebo-controlled, triple-blind phase III multicenter study. Strahlentherapie und Onkologie 2007;183(3):121-7.

\section{Dozono 1989 \{published data only\}}

Dozono H, Nakamura K, Motoya T, Nakamura S, Shinmura R, Miwa $\mathrm{K}$ et al. Prevention of stomatitis induced by anti-cancer drugs. Gan-to-kagaku-ryoho 1989;16(10):3449-51.

\section{Duenas 1996 \{published and unpublished data\}}

Duenas-Gonzalez A, Sobrevilla-Calvo P, Frias-Mendivil M, Gallardo-Rincon D, Lara-Medina F, Aguilar-Ponce L et al. Misoprostol prophylaxis for high-dose chemotherapy-induced mucositis: a randomized double-blind study. Bone Marrow Transplantation 1996;17(5):809-12.

\section{Elad 2006 \{published data only\}}

Elad S, Ackerstein A, Bitan M, Shapira MY, Resnick I, Gesundheit $B$ et al. A prospective, double-blind phase II study evaluating the safety and efficacy of a topical histamine gel for the prophylaxis of oral mucositis in patients post hematopoietic stem cell transplantation. Bone Marrow Transplantation 2006;37(8):757-62.

\section{El Sayed 2002 \{published data only\}}

Duncan GG, Epstein JB, Tu D, El Sayed S, Bezjak A, Ottaway J et al. Quality of life, mucositis, and xerostomia from radiotherapy for head and neck cancers: a report from the NCIC CTG HN2 randomized trial of an antimicrobial lozenge to prevent mucositis. Head \& Neck 2005;27(5):421-8.

* El-Sayed S, Nabid A, Shelley W, Hay J, Balogh J, Gelinas $M$ et al. Prophylaxis of radiation-associated mucositis in conventionally treated patients with head and neck cancer: a double-blind, phase III, randomized, controlled trial evaluating the clinical efficacy of an antimicrobial lozenge using a validated mucositis scoring system. Journal of Clinical Oncology 2002;20(19):3956-63.

\section{Epstein 1989 \{published data only\}}

Epstein JB, Stevenson-Moore P, Jackson S, Mohamed JH, Spinelli JJ. Prevention of oral mucositis in radiation therapy: a controlled study with benzydamine hydrochloride rinse. International Journal of Radiation Oncology, Biology, Physics 1989;16(6):1571-5.

\section{Epstein 1994 \{published data only\}}

Epstein JB, Wong FLW. The efficacy of sucralfate suspension in the prevention of oral mucositis due to radiation therapy. International Journal of Radiation Oncology, Biology, Physics 1994;28(3):693-8.

\section{Epstein 2001 \{published data only\}}

Epstein J, Silverman S Jr, Pagerino D, Lockhart P, Schubert M, Crockett R. Benzydamine HCL for prophylaxis of irradiation induced oral mucositis: a randomized double-blind, multicenter study. Supportive Care in Cancer 1999;7:Abstract 0-18.

* Epstein JB, Silverman S Jr, Paggiarino DA, Crockett S, Schubert MM, Senzer NN et al. Benzydamine $\mathrm{HCl}$ for prophylaxis of radiation-induced oral mucositis: results from a multicenter, randomized, double-blind, placebo-controlled clinical trial. Cancer 2001;92(4):875-85.

\section{Ertekin 2004 \{published data only\}}

Ertekin MV, Koc M, Karslioglu I, Sezen O. Zinc sulfate in the prevention of radiation-induced oropharyngeal mucositis: a prospective, placebo-controlled, randomized study. International Journal of Radiation Oncology, Biology, Physics 2004;58(1):167-74.

\section{Evensen 2001 \{published data only\}}

Evensen JF, Bjordal K, Jacobsen AB, Lokkevik E, Tausjo JE. Effects of Na-sucrose octasulfate on skin and mucosa reactions during radiotherapy of head and neck cancers--a randomized prospective study. Acta Oncologica 2001;40(6):751-5.

\section{Ferretti 1988 \{published and unpublished data\}}

Ferretti G, Largent B, Brown A, Lillich T, Ash R. The effect of chlorhexidine mouthrinse on mucositis, plaque, gingivitis and stain in bone marrow transplant patients. Journal of Dental Research 1985;64:235 (Abstract 546).

Ferretti GA, Ash RC, Brown AT, Largent BM, Kaplan A, Lillich TT. Chlorhexidine for prophylaxis against oral infections and associated complications in patients receiving bone marrow 
transplants. Journal of the American Dental Association 1987;114(4):461-7.

* Ferretti GA, Ash RC, Brown AT, Parr MD, Romond EH, Lillich TT. Control of oral mucositis and candidiasis in marrow transplantation: a prospective, double-blind trial of chlorhexidine digluconate oral rinse. Bone Marrow Transplantation 1988;3(5):483-93.

\section{Fidler 1996 \{published data only\}}

* Fidler P, Loprinzi CL, O'Fallon JR, Leitch JM, Lee JK, Hayes $\mathrm{DL}$ et al. Prospective evaluation of a chamomile mouthwash for prevention of 5-FU-induced oral mucositis. Cancer 1996;77(3):522-5.

Fidler P, Loprinzi CL, O'Fallon JR, Michalak J, Novotny P, Hayes D. A controlled evaluation of chamomile for preventing stomatitis in patients receiving 5-fluorouracil based chemotherapy: A North Central Cancer Treatment Group trial. In: Proceedings of the American Society of Clinical Oncology. Vol. 14. 1995:534 (Abstract 1765).

\section{Foote 1994 \{published data only\}}

Foote RL, Loprinzi CL, Frank AR, O'Fallon JR, Gulavita S, Tewfik $\mathrm{HH}$ et al. Randomized trial of a chlorhexidine mouthwash for alleviation of radiation-induced mucositis. Journal of Clinical Oncology 1994;12(12):2630-3.

\section{Franzen 1995 \{published data only\}}

Franzen L, Henriksson R, Littbrand B, Zackrisson B. Effects of sucralfate on mucositis during and following radiotherapy of malignancies in the head and neck region. Acta Oncologica 1995;34(2):219-23.

\section{Freytes 2004 \{published data only\}}

Freytes CO, Ratanatharathorn V, Taylor C, Abboud C, Chesser N, Restrepo $\mathrm{A}$ et al. Phase $\mathrm{I} / \mathrm{II}$ randomized trial evaluating the safety and clinical effects of repifermin administered to reduce mucositis in patients undergoing autologous hematopoietic stem cell transplantation. Clinical Cancer Research 2004;10(24):8318-24.

\section{Gandemer 2007 \{published data only\}}

* Gandemer V, Le Deley MC, Dollfus C, Auvrignon A, BonnaureMallet M, Duval $M$ et al. Multicenter randomized trial of chewing gum for preventing oral mucositis in children receiving chemotherapy. Journal of Pediatric Hematology/Oncology 2007;29(2):86-94.

Suc A, Gandemer V, Le Deley MC, Schmitt C, Pichard-Leandri E, French Group. Gum98: Preventing mucositis with chewing gum in children receiving chemotherapy, a multicentric trial. Supportive Care in Cancer 1999;7S:180 (Abstract P-60).

\section{Giles 2004 \{published data only\}}

Giles FJ, Rodriguez R, Weisdorf D, Wingard JR, Martin PJ, Fleming TR et al. A phase III, randomized, double-blind, placebo-controlled, study of iseganan for the reduction of stomatitis in patients receiving stomatotoxic chemotherapy. Leukemia Research 2004;28(6):559-65.
Gori 2007 \{published data only\}

Gori E, Arpinati M, Bonifazi F, Errico A, Mega A, Alberani F et al. Cryotherapy in the prevention of oral mucositis in patients receiving low-dose methotrexate following myeloablative allogeneic stem cell transplantation: a prospective randomized study of the Gruppo Italiano Trapianto di Midollo Osseo nurses group. Bone Marrow Transplantation 2007;39(6):347-52.

\section{Goyal 2009 \{published data only\}}

Goyal M, Shukla P, Gupta D, Bisht SS, Dhawan A, Gupta S et al. Oral mucositis in morning vs. evening irradiated patients: a randomised prospective study. International Journal of Radiation Biology 2009;85(6):504-9.

\section{Gujral 2001 \{published data only\}}

Gujral MS, Patnaik PM, Kaul R, Daftary GV, Parikh HK, Tamhankar $\mathrm{CP}$ et al. Oral enzymes preventing side effects of radiation therapy in patients with head and neck cancers. European Journal of Cancer 1999;35 Suppl 4:168 (Abstract 634).

* Gujral MS, Patnaik PM, Kaul R, Parikh HK, Conradt C, Tamhankar CP et al. Efficacy of hydrolytic enzymes in preventing radiation therapy-induced side effects in patients with head and neck cancers. Cancer Chemotherapy and Pharmacology 2001;47 Suppl:S23-8.

\section{Haddad 2009 \{published data only\}}

Haddad R, Sonis S, Posner M, Wirth L, Costello R, Braschayko $P$ et al. Randomised phase 2 study of concomitant chemoradiotherapy using weekly carboplatin/paclitaxel with or without daily subcutaneous amifostine in patients with locally advanced head and neck cancer. Cancer 2009;115(19):4514-23.

\section{Hanson 1995 \{published data only\}}

Hanson WR, Marks JE, Reddy SP, Simon S, Mihalo WE, Tova Y. Protection from radiation-induced oral mucositis by a mouth rinse containing the prostaglandin $\mathrm{E} 1$ analog, misoprostol: a placebo controlled double blind clinical trial. Advances in Experimental Medicine and Biology 1997;400B:811-8.

* Hanson WR, Marks JE, Reddy SP, Simon S, Mihalo WE, Tova Y. Protection from radiation-induced oral mucositis by misoprostol, a prostaglandin E(1) analog: a placebo-controlled, double-blind clinical trial. American Journal of Therapeutics 1995;2(11):850-7.

\section{Hartmann 2001 \{published data only\}}

Hartmann J, von Vangerow A, Knop S, Brugger W, Fels L, Stolte $\mathrm{H}$ et al. A randomized trial comparing the toxicity and the treatment costs of HD-VIC plus PBSC transplantation with or without amifostine (AMI) in patients with solid tumors. European Journal of Cancer 1999;35 Suppl 4:361 (Abstract 1464).

* Hartmann JT, von Vangerow A, Fels LM, Knop S, Stolte H, Kanz $L$ et al. A randomized trial of amifostine in patients with high-dose VIC chemotherapy plus autologous blood stem cell transplantation. British Journal of Cancer 2001;84(3):313-20.

\section{He 2008 \{published data only\}}

He Y-F, Chen J, Wang G, Sun Y-B, Wang Y, Du J-P et al. Randomised controlled trial on application of parenteral alanyl- 
glutamine dipeptide in chemotherapy of advanced patients with esophageal and cardiac carcinoma. Chinese Journal of Cancer Prevention and Treatment 2008;15(12):936-8.

\section{Hu 2005 \{published data only\}}

Hu YR, Wu CQ, Liu YJ, Wang Y, Li X, Zhong $\mathrm{H}$ et al. Clinical observation on effect of shenqi fanghou recipe in preventing and treating radiation injury in patients with head and neck tumor. Zhongguo Zhong xi yi jie he za zhi Zhongguo Zhongxiyi jiehe zazhi 2005;25(7):623-5.

\section{Huang 2000 \{published data only\}}

Huang EY, Leung SW, Wang CJ, Chen HC, Sun LM, Fang FM et al. Oral glutamine to alleviate radiation-induced oral mucositis: a pilot randomized trial. International Journal of Radiation Oncology, Biology, Physics 2000;46(3):535-9.

\section{Huang 2003 \{published data only\}}

Huang GX, Zhao C, Han F, Zhang B, Qiu HJ, Xu BP et al. Clinical study in prophylactic use of chinese medicine to prevent chemoradiotherapy induced mucositis in nasopharyngeal carcinoma. Ai Zheng 2003;22(10):1084-7.

\section{Ifrah 1999 \{published data only\}}

Ifrah N, Witz F, Jouet JP, Francois S, Lamy T, Linassier C et al. Intensive short term therapy with granulocyte-macrophagecolony stimulating factor support, similar to therapy for acute myeloblastic leukemia, does not improve overall results for adults with acute lymphoblastic leukemia. American Cancer Society 1999;86(8):1496-505.

\section{Jebb 1994 \{published and unpublished data\}}

Jebb SA, Osborne RJ, Maughan TS, Mohideen N, Mack P, Mort D et al. 5-fluorouracil and folinic acid-induced mucositis: no effect of oral glutamine supplementation. British Journal of Cancer 1994;70(4):732-5.

\section{Katano 1995 \{published data only\}}

Katano M, Nakamura M, Matsuo T, Iyama A, Hisatsugu T. Effect of granulocyte colony-stimulating factor (G-CSF) on chemotherapy-induced oral mucositis. Surgery Today 1995;25(3):202-6.

\section{Kaul 1999 \{published data only\}}

* Kaul R, Mishra BK, Sutradar P, Choudhary V, Gujral MS. The role of Wobe-Mugos in reducing acute sequele of radiation in head and neck cancers - a clinical phase-III randomized trial. Indian Journal of Cancer 1999;36(2-4):141-8.

Kaul RVC. To evaluate the effect of Wobe mugos hydrolytic enzyme therapy on inflammation induced by external radiotherapy in patients of head and neck cancers. Bahrain Medical Bulletin 2001;23(3):116-8.

\section{Kazemian 2009 \{published data only\}}

Kazemian A, Kamian S, Aghili M, Hashemi FA, Haddad P. Benzydamine for prophylaxis of radiation-induced oral mucositis in head and neck cancers: a double-blind placebocontrolled randomized clinical trial. European Journal of Cancer Care 2009;18(2):174-8.
Koukourakis 2000 \{published data only\}

Koukourakis MI, Kyrias G, Kakolyris S, Kouroussis C, Frangiadaki C, Giatromanolaki A et al. Subcutaneous administration of amifostine during fractionated radiotherapy: a randomized phase II study. Journal of Clinical Oncology 2000;18(11):2226-33.

\section{Labar 1993 \{published data only\}}

* Labar B, Mrsic M, Pavletic Z, Bogdanic V, Nemet D, Aurer l et al. Prostaglandin E2 for prophylaxis of oral mucositis following BMT. Bone Marrow Transplantation 1993;11(5):379-82.

Labar B, Pavletic Z, Bogdanic V, Nemet D, Aurer I, Jakie J. Prostaglandin E2 for prevention of oral mucositis in patients with leukaemia undergoing bone marrow transplantation: a randomized double-blind clinical trial. Experimental Hematology 1990;18:700.

\section{Leborgne 1997 \{published and unpublished data\}} Leborgne JH, Leborgne F, Zubizarreta E, Ortega B, Mezzera J. Corticosteroids and radiation mucositis in head and neck cancer. A double-blind placebo-controlled randomized trial. Radiotherapy and Oncology 1997;47(2):145-8.

\section{Li 2006 \{published data only\}}

Li Y, Yu Z, Liu F, Tan L, Wu B, Li J. Oral glutamine ameliorates chemotherapy-induced changes of intestinal permeability and does not interfere with the antitumor effect of chemotherapy in patients with breast cancer: a prospective randomized trial. Tumori 2006;92(5):396-401.

\section{Lievens 1998 \{published data only\}}

Lievens $Y$, Haustermans $K$, van den Weyngaert $D$, van den Bogaert W, Scalliet P, Hutsebaut L et al. Does sucralfate reduce the acute side-effects in head and neck cancer treated with radiotherapy? A double-blind randomized trial. Radiotherapy and Oncology 1998;47(2):149-53.

\section{Lilleby 2006 \{published data only\}}

Lilleby K, Garcia P, Gooley T, McDonnnell P, Taber R, Holmberg $L$ et al. A prospective, randomized study of cryotherapy during administration of high-dose melphalan to decrease the severity and duration of oral mucositis in patients with multiple myeloma undergoing autologous peripheral blood stem cell transplantation. Bone Marrow Transplantation 2006;37(11):1031-5.

\section{Lin 2006 \{published data only\}}

Lin J, Wang X, Fan Z. A study on quantizing evaluation on stomatitis of malignant tumor patients undergoing large dose of chemotherapy. Chinese Nursing Research 2008;22(2A):328-9.

* Lin LC, Que J, Lin LK, Lin FC. Zinc supplementation to improve mucositis and dermatitis in patients after radiotherapy for head-and-neck cancers: a double-blind, randomized study. International Journal of Radiation Oncology, Biology, Physics 2006;65(3):745-50

\section{Lockhart 2005 \{published data only\}}

Lockhart PB, Brennan MT, Kent ML, Packman CH, Norton HJ, Fox PC et al. Randomized controlled trial of pilocarpine 
hydrochloride for the moderation of oral mucositis during autologous blood stem cell transplantation. Bone Marrow Transplantation 2005;35(7):713-20.

\section{Loprinzi 1990 \{published and unpublished data\}}

Dose AM, Loprinzi CL, Cianflone S, Etzell P, Burnham N, Therneau T. A controlled evaluation of an allopurinol mouthwash as prophylaxis against 5-fluorouracil-induced stomatitis. A North Central Cancer Treatment Group and Mayo clinic study. In: Proceedings of the American Society of Clinical Oncology. Vol. 8. 1989:341 (Abstract 1328).

* Loprinzi CL, Cainflone SG, Dose AM, Etzell PS, Burnham NL, Therneau TM et al. A controlled evaluation of an allopurinol mouthwash as prophylaxis against 5 -fluorouracil-induced stomatitis. Cancer 1990;65(8):1879-82.

\section{Madan 2008 \{published data only\}}

Madan PD, Sequeira PS, Shenoy K, Shetty J. The effect of three mouthwashes on radiation-induced oral mucositis in patients with head and neck malignancies: a randomized control trial. Journal of Cancer Research and Therapeutics 2008;4(1):3-8.

\section{Mahood 1991 \{published data only\}}

Mahood DJ, Dose AM, Loprinzi CL, Veeder MH, Athmann LM, Thereau TM et al. Inhibition of fluorouracil-induced stomatitis by oral cryotherapy. Journal of Clinical Oncology 1991;9(3):449-52.

\section{Makkonen 1994 \{published data only\}}

Makkonen TA, Bostrom P, Vilja P, Joensuu H. Sucralfate mouth washing in the prevention of radiation-induced mucositis: A placebo-controlled double-blind randomized study. International Journal of Radiation Oncology, Biology, Physics 1994;30(1):177-82.

\section{Makkonen 2000 \{published data only\}}

* Makkonen TA, Minn H, Jekunen A, Vilja P, Tuominen J, Joeensuu H. Granulocyte Macrophage-colony stimulating factor (GM-CSF) and sucralfate in prevention of radiationinduced mucositis: a prospective randomized study. International Journal of Radiation Oncology, Biology, Physics 2000;46(3):525-34.

Minn HR, Makkonen TA, Jekunen A, Vilja P, Tuominen J, Joensuu $\mathrm{H}$. Granulocyte macrophage-colony stimulating factor (GM-CSF) and sucralfate in prevention of radiation-induced mucositis: a prospective randomized study. International Journal of Radiation Oncology, Biology, Physics 1999;45 Suppl 3:239.

\section{McAleese 2006 \{published data only\}}

McAleese JJ, Bishop KM, A'Hern R, Henk JM. Randomized phase II study of GM-CSF to reduce mucositis caused by accelerated radiotherapy of laryngeal cancer. The British Journal of Radiology 2006;79(943):608-13.

\section{McGaw 1985 \{published data only\}}

McGaw WT, Belch A. Oral complications of acute leukemia: prophylactic impact of a chlorhexidine mouth rinse regimen. Oral Surgery, Oral Medicine, and Oral Pathology 1985;60(3):275-80.

\section{Meropol 2003 \{published data only\}}

Meropol NJ, Somer RA, Gutheil J, Pelley RJ, Modiano MR, Rowinsky EK et al. Randomized phase I trial of recombinant human keratinocyte growth factor plus chemotherapy: potential role as mucosal protectant. Journal of Clinical Oncology 2003;21(8):1452-8.

Mills 1988 \{published data only\}

Mills EE. The modifying effect of beta-carotene on radiation and chemotherapy induced oral mucositis. British Journal of Cancer 1988;57(4):416-7.

\section{Motallebnejad 2008 \{published and unpublished data\}}

Motallebnejad M, Akram S, Moghadamnia A, Moulana Z, Omidi S. The effect of topical application of pure honey on radiation-induced mucositis: a randomized clinical trial. The Journal of Contemporary Dental Practice 2008;9(3):40-7.

\section{Nemunaitis 1995 \{published data only\}}

Nemunaitis J, Rosenfeld CS, Ash R, Freedman MH, Deeg HJ, Appelbaum $\mathrm{F}$ et al. Phase III randomized, double-blind placebo-controlled trial of rhGM-CSF following allogeneic bone marrow transplantation. Bone Marrow Transplantation 1995;15(6):949-54.

\section{Nottage 2003 \{published data only\}}

Nottage M, McLachlan SA, Brittain MA, Oza A, Hedley D, Feld $R$ et al. Sucralfate mouthwash for prevention and treatment of 5-fluorouracil-induced mucositis: a randomized, placebocontrolled trial. Supportive Care in Cancer 2003;11(1):41-7.

\section{Oberbaum 2001 \{published data only\}}

* Oberbaum M, Yaniv I, Ben-Gal Y, Stein J, Ben-Zvi N, Freedman LS et al. A randomized, controlled clinical trial of the homeopathic medication TRAUMEEL $S$ in the treatment of chemotherapy-induced stomatitis in children undergoing stem cell transplantation. American Cancer Society 2001;92(3):684-90.

Oberbaum M, Yaniv I, Ben-Gal Y, Stein J, Ben-Zvi N, Freedman LS et al. A randomized, controlled clinical trial of the homoeopathic medication Traumeel $\mathrm{S}$ in the treatment of chemotherapy-induced stomatitis in children undergoing stem cell transplantation. Biologische Medizin 2002;31(1):25-31.

\section{Okuno 1999 \{published data only\}}

Okuno SH, Swan L, Ebbert C. Phase III placebo-controlled clinical trial evaluation of glutamine for decreasing mucositis in patients receiving $5 \mathrm{FU}$ (Fluorouracil)-based chemotherapy. In: Proceedings of the Annual Meeting of the American Society of Clinical Oncology. 1998:256.

* Okuno SH, Woodhouse CO, Loprinzi CL, Sloan JA, LaVasseur BI, Clemens-Schutjer D et al. Phase III controlled evaluation of glutamine for decreasing stomatitis in patients receiving fluorouracil (5-FU)-based chemotherapy. American Journal of Clinical Oncology 1999;22(3):258-61.

Panahi 2009 \{published data only\}

Panahi Y, Ala S, Saeedi M, Okhovatian A, Bazzaz N, Naghizadeh MM. Allopurinol mouth rinse for prophylaxis of 
fluorouracil-induced mucositis. European Journal of Cancer Care 2010;19(3):308-12.

\section{Peterson 2009 \{published data only\}}

Barker NP, Peterson DE, Akhmadullina LI, Rodionova I, Sherman NZ, Gertner JM et al. Prophylaxis of recurrent chemotherapy-induced oral mucositis: a phase II multicenter, randomized, placebo-controlled trial of recombinant human intestinal trefoil factor (rhITF). Journal of Clinical Oncology 2008;26:505 (Abstract 9514).

* Peterson DE, Barker NP, Akhmadullina LI, Rodionova I, Sherman NZ, Davidenko IS et al. Phase II, randomized, double-blind, placebo-controlled study of recombinant human intestinal trefoil factor oral spray for prevention of oral mucositis in patients with colorectal cancer who are receiving fluorouracil-based chemotherapy. Journal of Clinical Oncology 2009;27(26):4333-8.

\section{Pfeiffer 1990 \{published data only\}}

Pfeiffer P, Hansen SO, Madsen EL, May O. Sucralfate prophylaxis of chemotherapy-induced stomatitis. In: Proceedings of the American Society of Clinical Oncology. Vol. 8. 1989:171 (Abstract 665).

* Pfeiffer P, Madsen EL, Hansen O, May O. Effect of prophylactic sucralfate suspension on stomatitis induced by cancer chemotherapy. Acta Oncologica 1990;29(2):171-3.

\section{Pillsbury 1986 \{published data only\}}

Pillsbury HC 3rd, Webster WP, Rosenman J. Prostaglandin inhibitor and radiotherapy in advanced head and neck cancers. Archives of Otolaryngology - Head \& Neck Surgery 1986;112(5):552-3.

\section{Pitten 2003 \{published data only\}}

Pitten FA, Kiefer T, Buth C, Doelken G, Kramer A. Do cancer patients with chemotherapy-induced leukopenia benefit from an antiseptic chlorhexidine-based oral rinse? A doubleblind, block-randomized, controlled study. Journal of Hospital Infection 2003;53(4):283-91.

\section{Prada 1987 \{published data only\}}

Prada A, Chiesa F. Effects of benzydamine on the oral mucositis during antineoplastic radiotherapy and/or intra-arterial chemotherapy. International Journal of Tissue Reaction 1987;9(2):115-9.

\section{Puataweepong 2009 \{published data only\}}

Puataweepong P, Dhanachai M, Dangprasert S, Sithatani C, Sawangsilp T, Narkwong $L$ et al. The efficacy of oral aloe vera for radiation induced mucositis in head and neck cancer patients: a double-blind placebo controlled study. Asian Biomedicine 2009;3(4):375-82.

\section{Qin 2007 \{published data only\}}

Qin WJ, Luo W, Lin SR, Sun Y, Li FM, Liu XQ et al. Sparing normal oral tissues with individual dental stent in radiotherapy for primary nasopharyngeal carcinoma patients. Ai Zheng 2007;26(3):285-9.
Rahn 1997 \{published data only\}

Adamietz IA, Rahn R, Bottcher HD, Reimer K, Fleischer W. Prophylaxis of radiation induced oral mucositis with povidone iodine. Supportive Care in Cancer 1997;5 Suppl:165 (Abstract 48).

Adamietz IA, Rahn R, Bottcher HD, Schafer V, Reimer K, Fleischer W. Prophylaxis of radiochemotherapy-induced mucositis. Efficacy of prophylactic oral rinsing with povidone iodine solution. Stranhlentherapie und Onkologie 1998;174(3):149-55.

Adamietz IA, Rhan R, Bottcher HD, Schafer V, Reimer K, Fleischer W. Prophylaxis with povidone-iodine against induction of oral mucositis by radiochemotherapy. Supportive Care in Cancer 1998;6(4):373-7.

* Rahn R, Adamietz IA, Boettcher HD, Schaefer V, Reimer K, Fleischer W. Povidone-iodine to prevent mucositis in patients during antineoplastic radiochemotherapy. Dermatology 1997;195 Suppl 2:57-61.

Rahn R Al, Bottcher HD, Reimer K, and Fleischer W. PVPiodine solution as a mucositis prophylaxis by radiotherapy. Deutsche Zeitschrift fur Mund-, Kiefer- und Gesichtschirurgie 1996;20(3):137-9.

\section{Rashad 2008 \{published data only\}}

Rashad UM, Al-Gezawy SM, El-Gezawy E, Azzaz AN. Honey as topical prophylaxis against radiochemotherapy-induced mucositis in head and neck cancer. The Journal of Laryngology and Otology 2009;123(2):223-8.

\section{Rocke 1993 \{published data only\}}

Dose AM, Mahood D, Loprinzi CL, Gainey D, Sorensen JM, Therneau T. A controlled trial of oral cryotherapy for preventing stomatitis in patients receiving 5 - fluorouracil (5FU) plus leucovorin (LV). A North Central Cancer Treatment Group and Mayo Clinic study. In: Proceedings of the American Society of Clinical Oncology. Vol. 9. 1990:321 (Abstract 1242).

* Rocke LK, Loprinzi CL, Lee JK, Kunselman SJ, Iverson RK, Finck $\mathrm{G}$ et al. A randomized clinical trial of two different durations or oral cryotherapy for prevention of 5-fluorouracilrelated stomatitis. Cancer 1993;72(7):2234-8.

\section{Rosen 2006 \{published data only\}}

Rosen LS, Abdi E, Davis ID, Gutheil J, Schnell FM, Zalcberg $J$ et al. Palifermin reduces the incidence of oral mucositis in patients with metastatic colorectal cancer treated with fluorouracil-based chemotherapy. Journal of Clinical Oncology 2006;24(33):5194-200.

\section{Saarilahti 2002 \{published data only\}}

Saarilahti K, Kajanti M, Joensuu T, Kouri M, Joensuu H. Comparison of granulocyte-macrophage colony-stimulating factor and sucralfate mouthwashes in the prevention of radiation-induced mucositis: a double-blind prospective randomized phase III study. International Journal of Radiation Oncology, Biology, Physics 2002;54(2):479-85. 
Scarantino 2006 \{published data only\}

* Scarantino C, LeVeque F, Swann RS, White R, Schulsinger A, Hodson DI et al. Effect of pilocarpine during radiation therapy: results of RTOG 97-09, a phase III randomized study in head and neck cancer patients. The Journal of Supportive Oncology 2006;4(5):252-8.

Scarantino CW, Leveque F, Scott C, White RL, Rotman M, Hodson DI. A Phase III study on the concurrent use of oral pilocarpine to reduce hyposalivation and mucositis associated with radiation therapy in head and neck cancer patients. Final results of RTOG 97-09. International Journal of Radiation Oncology, Biology, Physics 2001;51(3 Suppl 1):85-6.

Scarantino CW, LeVeque FG, Scott CB, White RL, Rotman M, Hodson DI. A phase III study of concomitant oral pilocarpine to reduce hypo-salivation and mucositis associated with curative radiation therapy (RT) in head and neck (H\&N) cancer patients. RTOG 9709. In: Proceedings of the American Society of Clinical Oncology. 2001:Abstract 897.

\section{Scherlacher 1990 \{published data only\}}

Scherlacher A, Beaufort-Spontin F. Radiotherapy of head-neck neoplasms: prevention of inflammation of the mucosa by sucralfate treatment. HNO 1990;38(1):24-8.

Schneider 1999 \{published data only\}

Schneider SB, Nishimura RD, Zimmerman RP, Tran L, Shiplacoff J, Tormey M et al. Filgrastim (r-metHuG-CSF) and its potential use in the reduction of radiation-induced oropharyngeal mucositis: an interim look at a randomized, double blind, placebo-controlled trial. Cytokines, Cellular and Molecular Therapy 1999;5(3):175-80.

\section{Schubert 2007 \{published data only\}}

Schubert MM, Eduardo FP, Guthrie KA, Franquin JC, Bensadoun RJ, Migliorati CA et al. A phase III randomized double-blind placebo-controlled clinical trial to determine the efficacy of low level laser therapy for the prevention of oral mucositis in patients undergoing hematopoietic cell transplantation. Supportive Care in Cancer 2007;15(10):1145-54.

\section{Shenep 1988 \{published and unpublished data\}}

Shenep JL, Kalwinsky DK, Hutson PR, George SL, Dodge RK, Blankenship KR et al. Efficacy of oral sucralfate suspension in prevention and treatment of chemotherapy-induced mucositis. Journal of Pediatrics 1988;113(4):758-63.

\section{Shieh 1997 \{published data only\}}

Shieh SH, Wang ST, Tsai ST, Tseng CC. Mouth care for nasopharyngeal cancer patients undergoing radiotherapy. Oral Oncology 1997;33(1):36-41.

\section{Sorensen 2008 \{published data only\}}

Sorensen J, Skovsgaard T, Bork E, Damstrup L, Ingeberg S. Double blind, placebo-controlled randomized study of chlorhexidine prophylaxis for chemotherapy-induced oral mucositis with nonblinded randomized comparison to oral cooling (cryotherapy). Journal of Clinical Oncology: ASCO annual meeting proceedings 2006;24(18S Part I):470.
* Sorensen JB, Skovsgaard T, Bork E, Damstrup L, Ingeberg S. Double-blind, placebo-controlled, randomized study of chlorhexidine prophylaxis for 5-fluorouracil-based chemotherapy-induced oral mucositis with nonblinded randomized comparison to oral cooling (cryotherapy) in gastrointestinal malignancies. Cancer 2008;112(7):1600-6.

\section{Sornsuvit 2008 \{published data only\}}

Sornsuvit C, Komindr S, Chuncharunee S, Wanikiat P, Archararit N, Santanirand P. Pilot Study: effects of parenteral glutamine dipeptide supplementation on neutrophil functions and prevention of chemotherapy-induced side-effects in acute myeloid leukaemia patients. The Journal of International Medical Research 2008;36(6):1383-91.

\section{Spencer 2005 \{published data only\}}

Spencer A, Horvath N, Gibson J, Prince HM, Herrmann R, Bashford $\mathrm{J}$ et al. Prospective randomised trial of amifostine cytoprotection in myeloma patients undergoing high-dose melphalan conditioned autologous stem cell transplantation. Bone Marrow Transplantation 2005;35(10):971-7.

\section{Spielberger 2004 \{published data only\}}

Spielberger R, Stiff P, Bensinger W, Gentile T, Weisdorf D, Kewalramani $T$ et al. Palifermin for oral mucositis after intensive therapy for hematologic cancers. The New England Journal of Medicine 2004;351(25):2590-8.

\section{Spijkervet 1989 \{published data only\}}

Spijkervet FK, van Saene HK, Panders AK, Vermey A, van Saene JJ, Mehta DM et al. Effect of chlorhexidine rinsing on the oropharyngeal ecology in patients with head and neck cancer who have irradiation mucositis. Oral Surgery, Oral Medicine, and Oral Pathology 1989;67(2):154-61.

\section{Stokman 2003 \{published data only\}}

Stokman MA, Spijkervet FK, Burlage FR, Dijkstra PU, Manson WL, de Vries EG et al. Oral mucositis and selective elimination of oral flora in head and neck cancer patients receiving radiotherapy: a double-blind randomised clinical trial. British Journal of Cancer 2003;88(7):1012-6.

\section{Su 2004 \{published data only\}}

Su C, Mehta V, Ravikumar L, Shah R, Pinto H, Halpern J et al. Phase II double-blind randomized study comparing oral aloe vera (AV) versus placebo to prevent radiation (RT)-related mucositis in patients with head and neck (HN) neoplasms. In: Proceedings of the Amercian Society of Clinical Oncology. 2004.

* Su C, Mehta V, Ravikumar L, Shah R, Pinto H, Halpern J et al. Phase II double-blind randomized study comparing oral aloe vera versus placebo to prevent radiation-related mucositis in patients with head-and-neck neoplasms. International Journal of Radiation Oncology, Biology, Physics 2004;60(1):171-7.

\section{Su 2006 \{published data only\}}

* Su YB, Vickers AJ, Zelefsky MJ, Kraus DH, Shaha AR, Shah JP et al. Double-blind, placebo-controlled, randomized trial of granulocyte-colony stimulating factor during postoperative radiotherapy for squamous head and neck cancer. Cancer Journal 2006;12(3):182-8. 
Su YB. Double-blind, randomized trial of granulocytecolony stimulating factor (GCSF) versus (v.) placebo during postoperative radiation (RT) for advanced resectable squamous cell head and neck cancer (SCCHN): impact on mucositis. Journal of Clinical Oncology 2004;22 Suppl:14S.

\section{Svanberg 2007 \{published data only\}}

Svanberg A, Öhrn K. Cryotherapy during chemotherapy - could it delay or alleviate the development of mucositis? Bone Marrow Transplantation 2004;33 Suppl 1:S292.

* Svanberg A, Birgegard G, Ohrn K. Oral cryotherapy reduces mucositis and opioid use after myeloablative therapy-a randomized controlled trial. Supportive Care in Cancer 2007;15(10):1155-61.

\section{Symonds 1996 \{published data only\}}

* Symonds RP, Mcllroy P, Khorrami J, Pyper E, Alcock SR, McCallum I et al. The reduction of radiation mucositis by selective decontamination antibiotic pastilles: a placebocontrolled double-blind trial. British Journal of Cancer 1996;74(2):312-7.

Symonds RP, Thomas M, Alcock SR, Khorrami J, McEllroy P, McMuray $A$. The reduction of radiation mucositis by antibiotic pastilles: a placebo-controlled double-blind trial. European Journal Surgery Oncology 1995;21:447.

\section{Trotti 2004 \{published data only\}}

* Trotti A, Garden A, Warde P, Symonds P, Langer C, Redman $R$ et al. A multinational, randomized phase III trial of iseganan $\mathrm{HCl}$ oral solution for reducing the severity of oral mucositis in patients receiving radiotherapy for head-and-neck malignancy. International Journal of Radiation Oncology, Biology, Physics 2004;58(3):674-81.

Trotti A, Garden AS, Warde P, Symonds P, Langer C, Fleming T et al. Phase III trial of iseganan $\mathrm{HCL}$ oral solution (iseganan) for reducing oral mucositis severity in patients receiving radiotherapy for head and neck malignancies (PROMPT-RT). In Proceedings of the Annual Meeting of the American Society of Clinical Oncology. 2002:Abstract 908.

\section{Tu 1998 \{published data only\}}

Tu Q, Tang J, Shen L, Lei Y, Yu S, Zhou J et al. The second phase clinical observation of anti-radiation effect by superoxide dismutase. Bulletin of Hunan Medical University 1998;23(3):308-10.

\section{Vacha 2003 \{published data only\}}

* Vacha P, Fehlauer F, Mahlmann B, Marx M, Hinke A, Sommer $\mathrm{K}$ et al. Randomized phase III trial of postoperative radiochemotherapy $+/$ - amifostine in head and neck cancer: Is there evidence for radioprotection? Strahlentherapie und Onkologie 2003;179(6):385-9.

Vacha P, Marx M, Engel A, Richter E, Feyerabend T. Side effects of postoperative radiochemotherapy with amisfostine versus radiotherapy alone in head and neck tumors. Preliminary results of a prospective randomized trial. Strahlentherapie und onkologie 1999;175 Suppl 4:18-22.

\section{Vadhan-Raj 2010 \{published data only\}}

* Vadhan-Raj S, Trent J, Patel S, Zhou X, Johnson MM, Araujo $D$ et al. Single-dose palifermin prevents severe oral mucositis during multicycle chemotherapy in patients with cancer: a randomised trial. Annals of Internal Medicine 2010;153(6):358-67.

Vadhan-Raj S, Trent JC, Patel SR, Araujo DM, Ludwig LA, Bailey $D$ et al. Randomised, double blind, placebo controlled study of palifermin for the prevention of mucositis in patients receiving doxorubicin chemotherapy. Journal of Clinical Oncology 2008:Abs No 9547.

\section{van der Lelie 2001 \{published data only\}}

van der Lelie $\mathrm{H}$, Thomas BL, van Oers $\mathrm{RH}$, Ek-Post M, Sjamsoedin SA, van Dijk-Overtoom ML et al. Effect of locally applied GM-CSF on oral mucositis after stem cell transplantation: a prospective placebo-controlled double-blind study. Annals of Hematology 2001;80(3):150-4.

\section{Veerasarn 2006 \{published data only\}}

Veerasarn V, Phromratanapongse P, Suntornpong N, Lorvidhaya V, Sukthomya V, Chitapanarux I et al. Effect of Amifostine to prevent radiotherapy-induced acute and late toxicity in head and neck cancer patients who had normal or mild impaired salivary gland function. Journal of the Medical Association of Thailand 2006;89(12):2056-67.

\section{Veness 2006 \{published data only\}}

Veness MJ, Foroudi F, Gebski V, Timms I, Sathiyaseelan Y, Cakir $B$ et al. Use of topical misoprostol to reduce radiation-induced mucositis: results of a randomized, double-blind, placebocontrolled trial. Australasian Radiology 2006;50(5):468-74.

\section{Vokurka 2005 \{published data only\}}

Vokurka S, Bystricka E, Koza V, Scudlova J, Pavlicova V, Valentova $D$ et al. The comparative effects of povidoneiodine and normal saline mouthwashes on oral mucositis in patients after high-dose chemotherapy and APBSCT--results of a randomized multicentre study. Supportive Care in Cancer 2005;13(7):554-8.

\section{Wahlin 1989 \{published and unpublished data\}}

Wahlin YB. Effects of chlorhexidine mouthrinse on the oral health in patients with acute leukemia. Oral Surgery, Oral Medicine, and Oral Pathology 1989;68(3):279-87.

\section{Wang 2002 \{published data only\}}

Wang J. Effect on Chinese herbs decoction gargling to treat and to prevent chemotherapy caused stomatitis. Chinese Nursing Research 2002;16(10):578-9.

\section{Watanabe 2010 \{published data only\}}

Watanabe T, Ishihara M, Matsuura K, Mizuta K, Itoh Y. Polaprezinc prevents oral mucositis associated with radiochemotherapy in patients with head and neck cancer. International Journal of Cancer 2010;127(8):1984-90.

\section{Wijers 2001 \{published data only\}}

Wijers OB, Levendag PC, Harms ER, Gan-Teng AM, Schmitz PI, Hendriks WD et al. Mucositis reduction by selective elimination 
of oral flora in irradiated cancers of the head and neck: a placebo-controlled double-blind randomized study. International Journal of Radiation Oncology, Biology, Physics 2001;50(2):343-52.

\section{Wu 2009 \{published data only\}}

Ahn YWH, Song S, Kim Y, Oh Y, Lee C et al. The therapeutic effect of recombinant human epidermal growth factor (rhEGF) on mucositis in patients with head and neck cancer undergoing radiotherapy with or without chemotherapy: a double-blind placebo-controlled prospective phase II multi-institutional study. Journal of Clinical Oncology 2008;26:Abstract 6021.

Lee S, Song S, Kim Y, Oh Y, Lee C, Keum K, et al. The therapeutic effect of recombinant human epidermal growth factor (rhEGF) on mucositis in patients with head and neck cancer undergoing radiotherapy with or without chemotherapy: a double blind placebo controlled prospective phase II multi-institutional clinical trial. International Journal of Radiation Oncology 2008;72(1):S32.

* Wu HG, Song SY, Kim YS, Oh YT, Lee CG, Keum KC et al. Therapeutic effect of recombinant human epidermal growth factor (RhEGF) on mucositis in patients undergoing radiotherapy, with or without chemotherapy, for head and neck cancer: a double-blind placebo-controlled prospective phase 2 multi-institutional clinical trial. Cancer 2009;115(16):3699-708.

\section{You 2009 \{published data only\}}

You WC, Hsieh CC, Huang JT. Effect of extracts from indigowood root (Isatis indigotica Fort.) on immune responses in radiationinduced mucositis. Journal of Alternative and Complementary Medicine 2009;15(7):771-8.

\section{Yuen 2001 \{published data only\}}

Yuen KY, Woo PCY, Tai JW, Lie AK, Luk J, Liang R. Effects of clarithromycin on oral mucositis in bone marrow transplant recipients. Haematologica 2001;86(5):554-5.

\section{References to studies excluded from this review}

\section{Abramoff 2008 \{published data only\}}

Abramoff MM, Lopes NN, Lopes LA, Dib LL, Guilherme A, Caran EM et al. Low-level laser therapy in the prevention and treatment of chemotherapy-induced oral mucositis in young patients. Photomedicine and Laser Surgery 2008;26(4):393-400.

\section{Aisa 2005 \{published data only\}}

Aisa Y, Mori T, Kudo M, Yashima T, Kondo S, Yokoyama A et al. Oral cryotherapy for the prevention of high-dose melphalan-induced stomatitis in allogeneic hematopoietic stem cell transplant recipients. Supportive Care in Cancer 2005;13(4):266-9.

\section{Altmann 1999 \{published data only\}}

Altmann S, Hoffmanns H. Cytoprotection with amifostine in radiotherapy or radio-chemotherapy of head and neck tumors. Strahlentherapie und Onkologie 1999;175 Suppl 4:30-3.

\section{Andersen 1987 \{published data only\}}

Andersen E, Pedersen H. Oral ftorafur versus intravenous 5fluorouracil. A comparative study in patients with colorectal cancer. Acta Oncologica 1987;26(6):433-6.

\section{Anderson 1998b \{published data only\}}

Anderson PM, Ramsay NKC, Shu XO, Rydholm N, Rogosheske J, Nicklow $R$ et al. Effect of low dose oral glutamine on painful stomatitis during bone marrow transplantation. Bone Marrow Transplantation 1998;22(4):339-44

\section{Antin 2002 \{published data only\}}

Antin JH, Lee SJ, Neuberg D, Alyea E, Soiffer RJ, Sonis S et al. A phase I/II double-blind, placebo-controlled study of recombinant human interleukin-11 for mucositis and acute GVHD prevention in allogeneic stem cell transplantation. Bone Marrow Transplantation 2002;29(5):373-7.

\section{Antonadou 1998 \{published data only\}}

Antonadou D, Athanassiou E, Synodinou M, Koliarakis N, Panoussaki K, Karageorgis P et al. Evaluation of the efficacy of granulocyte macrophage colony stimulating factor (GM-CSF) in the prevention of radiation induced mucositis. Radiotherapy Oncology 1998;48 Suppl 1:S39.

\section{Apaydin 1996 \{published data only\}} Apaydin A, Karadeniz AN, Aysigi G, Blige N. The effect and therapeutical use of benzydamine $\mathrm{HCL}$ on radiation-induced oral cavity and oropharyngeal mucositis. Medical Bulletin Istanbul 1996;29(1):59-63.

\section{Aquino 2005 \{published data only\}}

Aquino VM, Harvey AR, Garvin JH, Godder KT, Nieder ML, Adams $\mathrm{RH}$ et al. A double-blind randomized placebo-controlled study of oral glutamine in the prevention of mucositis in children undergoing hematopoietic stem cell transplantation: a pediatric blood and marrow transplant consortium study. Bone Marrow Transplantation 2005;36(7):611-6.

\section{Ardizzoni 2002 \{published data only\}}

Ardizzoni A, Tjan-Heijnen VC, Postmus PE, BuchholzE, Biesma B, Karnicka-Mlodkowska $\mathrm{H}$, et al. Standard versus intensified chemotherapy with granulocyte colony-stimulating factor support in small-cell lung cancer: a prospective European Organization for Research and Treatment of Cancer-Lung Cancer Group Phase III Trial-08923. Journal of Clinical Oncology 2002;20(19):3947-55.

\section{Arora 2008 \{published data only\}}

Arora H, Pai KM, Maiya A, Vidyasagar MS, Rajeev A. Efficacy of He-Ne Laser in the prevention and treatment of radiotherapyinduced oral mucositis in oral cancer patients. Oral Surgery, Oral Medicine, Oral Pathology, Oral Radiology, \& Endodontics 2008;105(2):180-6.

\section{Awada 2002 \{published data only\}}

Awada A, Biganzoli L, Cufer T, Beex L, Lohrisch C, Batter V et al. An EORTC-IDBBC phase I study of gemcitabine and continuous infusion 5 -fluorouracil in patients with metastatic breast cancer resistant to anthracyclines or pre-treated with 
both anthracyclines and taxanes. European Journal of Cancer 2002;38(6):773-8.

\section{Awada 2004 \{published data only\}}

Awada A, Gil T, Sales F, Dubuisson M, Vereecken P, Klastersky $J$ et al. Prolonged schedule of temozolomide (Temodal) plus liposomal doxorubicin (Caelyx) in advanced solid cancers. AntiCancer Drugs 2004;15(5):499-502.

\section{Awidi 2001 \{published data only\}}

Awidi A, Homsi U, Kakail RI, Mubarak A, Hassan A, Kelta M, Martinez P et al. Double-blind, placebo-controlled cross-over study of oral pilocarpine for the prevention of chemotherapyinduced oral mucositis in adult patients with cancer. European Journal of Cancer 2001;37(16):2010-4.

\section{Awwad 2002 \{published data only\}}

Awwad HK, Lotayef M, Shouman T, Begg AC, Wilson G, Bentzen SM et al. Accelerated hyperfractionation (AHF) compared to conventional fractionation (CF) in the postoperative radiotherapy of locally advanced head and neck cancer: influence of proliferation. British Journal of Cancer 2002;86(4):517-23.

\section{Barasch 1995 \{published data only\}}

Barasch A, Peterson DE, Tanzer JM, D'Ambrososio JA, Nuki K, Schubert MM et al. Helium-Neon laser effects on conditioninginduced oral mucositis in bone marrow transplantation patients. Cancer 1995;76(12):2550-6.

\section{Baydar 2005 \{published data only\}}

Baydar M, Dikilitas M, Sevinc A, Aydogdu I. Prevention of oral mucositis due to 5 -fluorouracil treatment with oral cryotherapy. Journal of the National Medical Association 2005;97(8):1161-4.

\section{Bensadoun 2006 \{published data only\}}

Bensadoun RJ, Benezery K, Dassonville O, Magne N, Poissonnet G, Ramaioli A et al. French multicenter phase III randomized study testing concurrent twice-a-day radiotherapy and cisplatin/5-fluorouracil chemotherapy (BiRCF) in unresectable pharyngeal carcinoma: Results at 2 years (FNCLCC-GORTEC). International Journal of Radiation Oncology, Biology, Physics 2006;64(4):983-94.

\section{Bentzen 2001 \{published data only\}}

Bentzen SM, Saunders MI, Dische S, Bond SJ. Radiotherapyrelated early morbidity in head and neck cancer: quantitative clinical radiobiology as deduced from the CHART trial. Radiotherapy Oncology 2001;60(2):123-35.

\section{Bleehen 1996 \{published data only\}}

Bleehen NM, Girling DJ, Hopwood P, Lallemand G, Machin D, Stephens RJ et al. Randomised trial of four-drug vs less intensive two-drug chemotherapy in the palliative treatment of patients with small-cell lung cancer (SCLC) and poor prognosis. British Journal of Cancer 1996;73:406-13.

\section{Bourhis 2006 \{published data only\}}

Bourhis J, Lapeyre M, Tortochaux J, Rives M, Aghili M, Bourdin $S$ et al. Phase III randomized trial of very accelerated radiation therapy compared with conventional radiation therapy in squamous cell head and neck cancer: a GORTEC trial. Journal of Clinical Oncology 2006;24(18):2873-8.

\section{Braaksma 2002 \{published data only\}}

Braaksma M, Levendag P. Tools for optimal tissue sparing in concomitant chemoradiation of advanced head and neck cancer: subcutaneous amifostine and computed tomographybased target delineation. Seminars in Oncology 2002;29(6 Supp 19):63-70.

\section{Buentzel 1999 \{published data only\}}

Buentzel J, Glatzel M, Weinaug R, Schuth J, Kuettner K, Froehlich $\mathrm{D}$. Amifostine in combined radio- and chemomodalities for head and neck cancer. European Journal of Cancer 1999;35(Suppl 4):363 (Abs No 1472).

\section{Calais 2000 \{published data only\}}

* Calais G, Alfonsi M, Bardet E, Sire C, Germain T, Bergerot P et al. Stage III and IV cancers of the oropharynx: results of a randomized study of Gortec comparing radiotherapy alone with concomitant chemotherapy. Bulletin du Cancer 2000;87 Spec No:48-53.

Calais GM, Alfonsi E, Bardet C, Sire H, Bourgeois C, Bergerot $B$ et al. Randomized study comparing radiation alone (RT) versus RT with concomitant chemotherapy (CT) in stages III and IV oropharynx carcinoma (ARCORO). Preliminary results of the 94.01 study from the French Group of radiation oncology for head and neck cancer (GORTEC). In: Proceedings of Annual Meeting of the American Society of Clinical Oncology. 1998:Abstract 1484.

\section{Calais 2004 \{published data only\}}

Calais G, Bardet E, Sire C, Alfonsi M, Bourhis J, Rhein B et al. Radiotherapy with concomitant weekly docetaxel for stages III/ IV oropharynx carcinoma. Results of the 98-02 GORTEC phase II trial. International Journal of Radiation, Oncology, Biology, Physics 2004;58(1):161-6.

\section{Cassidy 2002 \{published data only\}}

Cassidy J, Twelves C, Van Cutsem E, Hoff P, Bajetta E, Boyer M et al. First-line oral capecitabine therapy in metastatic colorectal cancer: a favorable safety profile compared with intravenous 5fluorouracil/leucovorin. Annals of Oncology 2002;13(4):566-75.

\section{Castro 2009 \{published data only\}}

Castro G Jr, de Lima AG, Lopes DR, Ortegosa MV, Rosalmeida MC, Gil E et al. Oral mucositis prevention by lowlevel laser therapy in head and neck cancer patients submitted to concurrent chemoradiation: a prospective randomized trial. Journal of Clinical Oncology 2009;27 Suppl:15S (Abstract 6019).

\section{Cella 2003 \{published data only\}}

Cella D, Pulliam J, Fuchs H, Miller C, Hurd D, Wingard JR et al. Evaluation of pain associated with oral mucositis during the acute period after administration of high-dose chemotherapy. Cancer 2003;98(2):406-12.

\section{Cheng 2001 \{published data only\}}

Cheng KK, Molassiotis A, Chang AM, Wai WC, Cheung SS. Evaluation of an oral care protocol intervention in the 
prevention of chemotherapy-induced oral mucositis in paediatric cancer patients. European Journal of Cancer 2001;37(16):2056-63.

\section{Cheng 2002 \{published data only\}}

Cheng KKF, Molassiotis A, Chang AM. An oral care protocol intervention to prevent chemotherapy-induced oral mucositis in paediatric cancer patients: a pilot study. European Journal of Oncology Nursing 2002;6(2):66-74.

\section{Cheng 2006 \{published data only\}}

Cheng KK-F, Yuen JKT. A pilot study of chlorhexidine and benzydamine oral rinses for the prevention and treatment of irradiation mucositis in patients with head and neck cancers. Cancer Nursing 2006;29(5):423-30.

\section{Clarke 2001 \{published data only\}}

Clarke SJ, Abdi E, Davis ID, Schnell FM, Zalcberg JR, Gutheil J et al. Recombinant human keratinocyte growth factor (rHuKGF) prevents chemotherapy-induced mucositis in patients with advanced colorectal cancer: a randomized phase II trial. In: Proceedings of the American Society of Clinical Oncology. Vol. 20 (Pt 1). 2001:383a (Abstract 1529).

\section{Colella 2010 \{published data only\}}

Colella G, Cannavale R, Vicidomini A, Rinaldi G, Compilato D, Campisi G. Efficacy of a spray compound containing a pool of collagen precursor synthetic aminoacids (l-proline, I-leucine, l-lysine and glycine) combined with sodium hyaluronate to manage chemo/radiotherapy-induced oral mucositis: preliminary data of an open trial. International Journal of Immunopathology and Pharmacology 2010;23(1):143-51.

\section{Collova 2004 \{published data only\}}

Collova E, Castagna L, Nozza A, Perfetti V, Patrone F, Danova M et al. New approaches for reduction of oral mucositis in patients undergoing high-dose chemotherapy with hematopoietic stem cell support. Bone Marrow Transplantation 2004;33 Suppl 1:S323-4.

\section{Colombat 1995 \{published data only\}}

Colombat P, Colin B. Comparison of fluconazole and amphotericin $B$ in the prevention of mucositis in patients with long term aplasia. Bone Marrow Transplantation 1995;15:178.

\section{Costa 1999 \{published data only\}}

Costa EMMB, Pinto LP, Fernandes MZ, Costa ALL. Preventing oral complications in leukemic children submitted to chemotherapy. Journal of Dental Research 1999;78:1021 (Abstract B-220).

\section{Costa 2003 \{published data only\}}

Costa EM, Fernandes MZ, Quinder LB, de Souza LB, Pinto LP. Evaluation of an oral preventive protocol in children with acute lymphoblastic leukemia. Pesquisa Odontologica Brasileira 2003;17(2):147-50.

\section{Cowen 1997 \{published data only\}}

Cowen D, Tardieu C, Resbeut M, Hannoun-Levi JM, Alzieu C, Schubert $\mathrm{M}$ et al. Low energy helium-neon laser presents oral mucositis after high-dose chemo-radiotherapy: results of a double-blind randomized trial. International Journal of
Radiation Oncology, Biology, Physics 1996;36 Suppl 1:264 (Abstract 1041).

* Cowen D, Tardieu C, Schubert M, Peterson D, Resbeut M, Faucher $\mathrm{C}$ et al. Low energy Helium-neon laser in the prevention of oral mucositis in patients undergoing bone marrow transplant: results of a double blind randomized trial. International Journal of Radiation Oncology, Biology, Physics 1997;38(4):697-703.

\section{Cunningham 1995 \{published data only\}}

Cunningham D, Zalcberg JR, Rath U, Olver I, van Cutsem EV, Sevensson C et al. 'Tomudex' (ZD1694): results of a randomised trial in advanced colorectal cancer demonstrate efficacy and reduced mucositis and leucopenia. European Journal of Cancer 1995;31A(12):1945-54.

\section{Damon 2004 \{published data only\}}

Damon LE, Johnston LJ, Ries CA, Rugo HS, Case D, Ault K et al. Treatment of acute leukemia with idarubicin, etoposide and cytarabine (IDEA). A randomized study of etoposide schedule. Cancer Chemotherapy and Pharmacology 2004;53(6):468-74.

\section{De Boer 2002 \{published data only\}}

De Boer RH, Eisen TG, Ellis PA, Johnston SR, Walsh G, Ashley $S$ et al. A randomised phase II study of conventional versus accelerated infusional chemotherapy with granulocyte colonystimulating factor support in advanced breast cancer. Annals of Oncology 2002;13(6):889-94.

\section{Denham 1999 \{published data only\}}

Denham JW, Peters LJ, Johansen J, Poulsen M, Lamb DS, Hindley $A$ et al. Do acute mucosal reactions lead to consequential late reactions in patients with head and neck cancer? Radiotherapy and Oncology 1999;52(2):157-64.

Djuric 2006 \{published data only\}

Djuric M, Hillier-Kolarov V, Belic A, Jankovic L. Mucositis prevention by improved dental care in acute leukemia patients. Supportive Care in Cancer 2006;14(2):137-46.

\section{Dobrowsky 1998 \{published data only\}}

Dobrowsky W, Naude J, Widder J, Dobrowsky E, Millesi W, Pavelka $R$ et al. Continuous hyperfractionated accelerated radiotherapy with/without mitomycin $\mathrm{C}$ in head and neck cancer. International Journal of Radiation Oncology, Biology, Physics 1998;42(4):803-6.

\section{Doroshow 1987 \{published data only\}}

Doroshow JH, Berthtand M, Newman E, Multhauf P, Leong L, Blayney $D$ et al. Preliminary analysis of a randomized comparison of 5-fluorouracil versus 5-fluorouracil and highdose continuous-infusion folinic acid in disseminated colorectal cancer. NCI Monographs 1987;5:171-4.

\section{Dreicer 1997 \{published data only\}}

Dreicer R, Propert KJ, Kuzel T, Kirkwood JM, O'Dwyer PJ, Loehrer PJ. A phase II trial of edatrexate in patients with advanced renal cell carcinoma. An Eastern Cooperative Oncology Group study. American Journal of Clinical Oncology 1997;20(3):251-3. 
Dudjak 1987 \{published data only\}

Dudjak LA. Mouth care for mucositis due to radiation therapy. Cancer Nursing 1987;10(3):131-40.

\section{Edelman 1998 \{published data only\}}

Edelman MJ, Gandara Dr, Perez EA, Lau D, Lauder I, Turrell C et al. Phase I trial of edatrexate plus carboplatin in advanced solid tumors: amelioration of dose-limiting mucositis by ice chip cryotherapy. Investigational New Drugs 1998;16(1):69-75.

\section{Eisen 2003 \{published data only\}}

Eisen D, Essel J, Broun ER, Sigmund D, DeVoe M. Clinical utility of oral valacyclovir compared with oral acyclovir for the prevention of herpes simplex virus mucositis following autologous bone marrow transplantation or stem cell rescue therapy. Bone Marrow Transplantation 2003;31(1):51-5.

\section{El-Sayed 2002a \{published data only\}}

* El-Sayed S, Epstein J, Minish E, Burns P, Hay J, Laukkanen E. A pilot study evaluating the safety and microbiologic efficacy of an economically viable antimicrobial lozenge in patients with head and neck cancer receiving radiation therapy. Head \& Neck 2002;24(1):6-15.

El-Sayed S, Nabid A, MacKenzie R, Gelinas M, Hay J, Shelley et al. Prophylaxis of radiation associated mucositis (RAM) in head and neck cancer, results of a double blind phase III trail evaluating the clinical efficacy of an antimicrobial lozenge utilizing a new validated mucositis scoring system. In: Proceedings of the 42nd Annual Meeting of the American Society for Therapeutic Radiology and Oncology. Vol. 321. 2000:Abstract 2115.

\section{Epstein 1992 \{published data only\}}

Epstein JB, Vickars L, Spinalli J, Reece D. Efficacy of chlorhexidine and nystatin rinses in prevention of oral complications in leukemia and bone marrow transplantation. Oral Surgery, Oral Medicine, and Oral Pathology 1992;73(6):682-9.

\section{Erkisi 1996 \{published data only\}}

Erkisi M, Erkurt E, Ozbarlas S, Burgut R, Doran F, Seyrek E. The use of recombinant human granulocyte colony-stimulating factor in combination with single or fractionated doses of ifosfamide and doxorubicin in patients with advanced soft tissue sarcoma. Journal of Chemotherapy 1996;8(3):224-8.

\section{Erlichman 1988 \{published data only\}}

* Erlichman C, Fine S, Wong A, Elhakim T. A randomized trial of fluorouracil and folonic acid in patients with metastatic colorectal carcinoma. Journal of Clinical Oncology 1988;6(3):469-75.

Erlichman C. Fluorouracil and leucovorin for metastatic colorectal cancer. Journal of Chemotherapy 1990;2 Suppl 1:38-40.

\section{Etiz 2000 \{published data only\}}

* Etiz D, Erkal HS, Serin M, Kucuk B, Hepari A, Elhan AH et al. Clinical and histopathological evaluation of sucralfate in prevention of oral mucositis induced by radiation therapy in patients with head and neck malignancies. Oral Oncology 2000;36(1):116-20.

Etiz M, Erkal HS, Serin M, Kucuk B, Hepari A, Tulunay O et al. Clinicohistopathological evaluation of effectiveness of sucralfate in prevention of severe radiation-induced mucositis in patients with head and neck malignancies. Radiotherapy Oncology 1998;48 Suppl 1:S68.

\section{Ezzat 2005 \{published data only\}}

Ezzat M, Shouman T, Zaza K, Safwat A, El-Khoudary A, ElSenosi $M$ et al. A randomized study of accelerated fractionation radiotherapy with and without mitomycin $\mathrm{C}$ in the treatment of locally advanced head and neck cancer. Journal of the Egyptian National Cancer Institute 2005;17(2):85-92.

Fahlke 1999 \{published data only\}

Fahlke J, Ridwelski K, Lippert H. High-dose therapy with combined 5-fluorouracil and folinic acid with and without amifostine in the treatment of patients with metastatic colorectal carcinoma. International Journal of Colorectal Disease 1999;14(2):128-30

\section{Falcone 2001 \{published data only\}}

Falcone A, Allergrini G, Masi G, Lencioni M, Panner E, Brunetti I. 5-fluorouracil administered as a 48-hour chronomodulated infusion in combination with leucovorin and cisplatin: a randomized phase II study in metastatic colorectal cancer. Oncology 2001;61(1):28-35.

Fay 1994 \{published data only\}

Fay JW, Lazarus H, Herzig R, Saez R, Stevens DA, Collins RH $J r$ et al. Sequential administration of recombinant human interleukin-3 and granulocyte-macrophage colony-stimulating factor after autologous bone marrow transplantation for malignant lymphoma: a phase I/II multicenter study. Blood 1994;84(7):2151-7.

\section{Feber 1995 \{published data only\}}

Feber T. Mouth care for patients receiving oral irradiation. Professional Nurse 1995;10(10):666-70.

\section{Feber 1996 \{published data only\}}

Feber T. Management of mucositis in oral irradiation. Clinical Oncology 1996;8(2):106-11.

\section{Ferreira 2004 \{published data only\}}

Ferreira PR, Fleck JF, Diehl A, Barletta D, Braga-Filho A, Barletta $A$ et al. Protective effect of alpha-tocopherol in head and neck cancer radiation-induced mucositis: a double-blind randomized trial. Head \& Neck 2004;26(4):313-21.

Ferreira RR, Fleck JF, Filho AB, Barletta D, Barletta A, Diehl A et al. Protective effect of vitamin $E(V E)$ in head and neck cancer radiation induced mucositis: a double-blind randomized trial. In: Proceedings of the American Society of Clinical Oncology. Vol. 21 (Pt 1). 2002:228a.

\section{Ferretti 1990 \{published and unpublished data\}}

Ferretti GA, Raybould TP, Brown AT, Macdonal JS, Greenwood M, Maruyama $Y$ et al. Chlorhexidine prophylaxis for chemotherapyand radiotherapy-induced stomatitis: a randomised double- 
blind trial. Oral Surgery, Oral Medicine, and Oral Pathology 1990;69(3):331-8.

\section{Foncuberta 2001 \{published data only\}}

Foncuberta MC, Cagnoni PJ, Brandts CH, Mandanas R, Fields K, Derigs $\mathrm{HG}$ et al. Topical transforming growth factor-beta3 in the prevention or alleviation of chemotherapy-induced oral mucositis in patients with lymphomas or solid tumors. Journal of Immunotherapy 2001;24(4):384-8.

Gabison 1995 \{published data only\}

Gabison R. Can zinc picolinate in patients receiving chemotherapy for metastatic colorectal carcinoma prevent stomatitis? European Journal of Cancer 1995;31 Suppl 6:S258 (Abstract 1234).

\section{Gandara 1997 \{published data only\}}

* Gandara DR, Edelman MJ, Crowley JJ, Lau DH, Livingston RB. Phase II trial of edatrexate plus carboplatin in metastatic nonsmall-cell lung cancer: a Southwest Oncology Group study. Cancer Chemotherapy and Pharmacology 1997;41(1):75-8.

\section{Genot-Klastersky 2008 \{published data only\}}

Genot-Klastersky MT, Klastersky J, Awada F, Awada A, Crombez P, Martinez MD et al. The use of low-energy laser (LEL) for the prevention of chemotherapy- and/or radiotherapy-induced oral mucositis in cancer patients: results from two prospective studies. Supportive Care in Cancer 2008;16(12):1381-7.

\section{Ghoreishi 2007 \{published data only\}}

Ghoreishi Z, Shidfar F, Iravani M, Esfahani A, Ghavamzadeh A. Effect of vitamin $E$ on chemotherapy-induced mucositis and neutropenia in leukemic patients undergoing bone marrow transplantation. Asia-Pacific Journal of Clinical Oncology 2007;3(3):113-8.

\section{Giles 2003a \{published data only\}}

Giles FJ, Miller CB, Hurd DD, Wingard JR, Fleming TR, Sonis ST et al. A phase III, randomized, double-blind, placebo-controlled, multinational trial of iseganan for the prevention of oral mucositis in patients receiving stomatotoxic chemotherapy (PROMPT-CT trial). Leukemia \& Lymphoma 2003;44(7):1165-72.

\section{Giles 2003b \{published data only\}}

Giles FJ, Faderl S, Thomas DA, Cortes JE, Garcia-Manero G, Douer $D$ et al. Randomized phase I/II study of troxacitabine combined with cytarabine, idarubicin, or topotecan in patients with refractory myeloid leukemias. Journal of Clinical Oncology 2003;21(6):1050-6.

\section{Gladkov 2007 \{published data only\}}

Gladkov OA, Vazhenin AV, Sharabura TM, Kandakova E, Galiatova lu V, Sychev VI et al. Effectiveness of different regimes of combined treatment (cisplatin+ radiotherapy) for intraoral and oropharyngeal cancer. Voprosy Onkologii 2007;53(5):575-7.

\section{Goldberg 2003 \{published data only\}}

Goldberg S. Safety and tolerability of en3247 in the prevention of oral mucositis associated with chemotherapy with or without total body irradiation: results of a randomized, double-blind, placebo-controlled trial. In: Proceedings of the American Society of Clinical Oncology. 2003:770.

Gordon 1993 \{published data only\}

Gordon B, Spadinger A, Hodges E, Coccia P. Effect of granulocyte macrophage colony stimulating factor (GMCSF) on oral mucositis after autologous bone marrow transplantation. In: Proceedings of the American Society of Clinical Oncology. Vol. 12. 1993:432 (Abstract 1489).

\section{Grotz 2001 \{published data only\}}

Grotz KA, Henneicke-Von Zepelin HH, Kohnen R, Kutzner J, Belz GG. Prophylaxis of mucositis and dry mouth after head and neck radiotherapy. A new treatment. Krankenhauspharmazie 2002;23(5):193-8.

* Grotz KA, Wustenberg P, Kohnen R, Al-Nawas B, Henneickevon Zepelin $\mathrm{HH}$, Bockisch A et al. Prophylaxis of radiogenic sialadenitis and mucositis by coumarin/troxerutine in patients with head and neck cancer- a prospective, randomized, placebo-controlled, double-blind study. The British Journal of Oral and Maxillofacial Surgery 2001;39(1):34-9.

\section{Gutierrez 1996 \{published data only\}}

Gutierrez AR, Boizas EC, Carreras PS, Rodriguez CS, Rodriguez OA, Chicote MJV et al. Fluconazol as prophylaxis of radioinduced oral mucositis. Preliminary study. Oncologia 1996;19(6):56-9.

\section{Harris 1995 \{published data only\}}

Harris JR, Russell NH, Hunter AE. Folinic acid mouthwashes do not reduce the degree of mucositis in patients undergoing allogeneic bone marrow transplantation. Bone Marrow Transplantation 1995;15(S2):S164.

He 2004 \{published data only\} He XY, Hu CS, Wu YR. Radioprotective effect of amifostine in nasopharyngeal carcinoma. Acta Academiae Medicinae Shanghai 2004;31(1).

\section{Hickey 1982 \{published data only\}}

Hickey AJ, Toth BB, Lindquist SB. Effect of intravenous hyperalimentation and oral care on the development of oral stomatitis during cancer chemotherapy. The Journal of Prosthetic Dentistry 1982;47(2):188-93.

\section{Horsley 2007 \{published data only\}}

Horsley P, Bauer JD, Mazkowiack R, Gardner R, Bashford J. Palifermin improves severe mucositis, swallowing problems, nutrition impact symptoms, and length of stay in patients undergoing hematopoietic stem cell transplantation. Supportive Care in Cancer 2007;15(1):105-9.

\section{Howell 1983 \{published data only\}}

Howell SB, Pfeifle CE, Wung WE. Effect of allopurinol on the toxicity of high-dose 5 -fluorouracil administered by intermittent bolus injection. Cancer 1983;51(2):220-5.

\section{Hu 2003 \{published data only\}}

Hu K, Ship JA, Harrison LB. Rationale for integrating high-dose rate intraoperative radiation (HDR-IORT) and postoperative 
external beam radiation with subcutaneous amifostine for the management of stage III/IV head and neck cancer. Seminars in Oncology 2003;30(6 Suppl 18):40-8.

\section{Hunter 2007 \{published data only\}}

Hunter A, Mahendra P, Wilson K, Fields P, Cook G, Peniker A et al. $A$ randomized, double-blind, placebo-controlled, multicenter trial of ATL-104, a swallowable mouthwash, in patients with oral mucositis following peripheral blood stem cell transplantation. Journal of Supportive Oncology 2007;5(4 Suppl 2):52-3.

\section{Hwang 2004 \{published data only\}}

Hwang WY, Koh LP, Ng HJ, Tan PH, Chuah CT, Fook SC et al. A randomized trial of amifostine as a cytoprotectant for patients receiving myeloablative therapy for allogeneic hematopoietic stem cell transplantation. Bone Marrow Transplantation 2004;34(1):51-6.

\section{Inagaki 2006 \{published data only\}}

Inagaki N. Report on the treatment of infections complicating hematological diseases. Case 2. Two cases of deep-seated mycosis developing during chemotherapy of leukaemia. Japanese Journal of Antibiotics 2007;60(5):317-8.

\section{Ito 2002 \{published data only\}}

Ito A, Hanawa T, Fujii E. The preventive effect of allopurinol spray on stomatitis induced by anti-cancer drugs. Gan To Kagaku Ryoho 2002;29(4):563-7.

\section{Jebb 1995 \{published data only\}}

Jebb SA, Marcus R, Elia M. A pilot study of oral glutamine supplementation in patients receiving bone marrow transplants. Clinical Nutrition 1995;14(3):162-5.

\section{Jham 2007 \{published data only\}}

Jham BC, Chen H, Carvalho AL, Freire AR. A randomized phase III prospective trial of bethanechol to prevent mucositis, candidiasis, and taste loss in patients with head and neck cancer undergoing radiotherapy: a secondary analysis. Journal of Oral Science 2009;51(4):565-72.

* Jham BC, Teixeira IV, Aboud CG, Carvalho AL, Coelho Mde M, Freire AR. A randomized phase III prospective trial of bethanechol to prevent radiotherapy-induced salivary gland damage in patients with head and neck cancer. Oral Oncology 2007;43(2):137-42.

\section{Johnson 2002 \{published data only\}}

Johnson DJ, Scott CB, Marks JE, Seay TE, Atkins JN, Berk LB et al. Assessment of quality of life and oral function of patients participating in a phase II study of radioprotection of oral and pharyngeal mucosa by the prostaglandin $E(1)$ analog misoprostol (RTOG 96-07). International Journal of Radiation Oncology, Biology, Physics 2002;54(5):1455-9.

\section{Ju 2009 \{published data only\}}

Ju G-JF, Lu P-H, Wang W-X, Jiao Y-H. Effect of systematic oropharyngeal managament in prevention of acute radiation mucositis. Chinese Journal of Cancer Prevention and Treatment 2009;16(13):1031-2.
Kante 1995 \{published data only\}

Kante V. Comparative study of two prophylactic regimes for the prevention of mucositis in autologous bone marrow transplants. Bone Marrow Transplantation 1995;15:253.

\section{Karacetin 2004 \{published data only\}}

Karacetin D, Yucel B, Leblebicioglu B, Aksakal O, Maral O, Incekara $O$. A randomized trial of amifostine as radioprotector in the radiotherapy of head and neck cancer. Journal of B.U.ON. 2004;9(1):23-6.

\section{Karthaus 1998 \{published data only\}}

Karthaus M, Rosenthal C, Huebner G, Paul H, Elser C, Hertenstein B et al. Effect of topical oral G-CSF on oral mucositis: a randomised placebo-controlled trial. Bone Marrow Transplantation 1998;22(8):781-5.

Kenny 1990 \{published data only\}

Kenny SA. Effect of two oral care protocols on the incidence of stomatitis in hematology patients. Cancer Nursing 1990;13(6):345-53.

\section{Khouri 2009 \{published data only\}}

Khouri VY, Stracieri AB, Rodrigues MC, Moraes DA, Pieroni F, Simoes BP et al. Use of therapeutic laser for prevention and treatment of oral mucositis. Brazilian Dental Journal 2009;20(3):215-20.

\section{Klocke 2006 \{published data only\}}

Klocke J, Cannon M, Gissinger D, Bayer R, Devoe C, John V. Prevention of mucositis in auto BMT/stem cell transplant patients. Oncology Nursing Forum 2006;33(2):454.

\section{Kuhn 2009 \{published data only\}}

Kuhn A, Porto FA, Miraglia P, Brunetto AL. Low-level infrared laser therapy in chemotherapy-induced oral mucositis: a randomized placebo-controlled trial in children. Journal of Pediatric Hematology/Oncology 2009;31(1):33-7.

\section{Kuriakose 2002 \{published data only\}}

Kuriakose P, Gandara DR, Perez EA. Phase I trial of edatrexate in advanced breast and other cancers. Cancer Investigation 2002;20(4):473-9.

\section{Labbate 2003 \{published data only\}}

Labbate R, Lehn CN, Denardin OVP. Effects of chlorhexidine mouthwash on radiation induced mucosistis in head and neck cancer. Revista Brasileira de Otorrinolaringologia 2003;69(3):349-54.

\section{Lanzos 2010 \{published data only\}}

Lanzos I, Herrera D, Santos S, O'Connor A, Pena C, Lanzos $E$ et al. Mucositis in irradiated cancer patients: effects of an antiseptic mouthrinse. Medicina Oral, Patologia Oral y Cirugia Bucal 2010;15(5):e732-8.

\section{Lavendag 1998 \{published data only\}}

Lavendag PC, Wijers OB, Harms RE, Schmitz PIM, Wilms BE, Visch LL. Mucositis prevention by selective elimination of oral flora in irradiated cancers of the head and neck: a prospective randomized study. Radiotherapy Oncology 1998;48:S10. 
Le 2008 \{published data only\}

Henke M, Alfonsi M, Foa P et al. Palifermin significantly reduces severe oral mucositis in subjects with resected locally advanced head and neck cancer undergoing post-operative concurrent radio-chemotherapy. Radiotherapy Oncology 2008;88 Suppl 2:S152.

* Le Q, Kim H, Schneider C, Muraközy G, Skladowski K, Reinisch $S$ et al. Palifermin reduces severe oral mucositis in subjects with locally advanced head and neck cancer undergoing chemoradiotherapy. International Journal of Radiation Oncology, Biology, Physics 2008;72 Suppl 1:S32.

\section{Lee 1989 \{published data only\}}

Lee DJ, Pajak TF, Stetz J, Order SE, Weissberg JB, Fischer JJ. A phase I/II study of the hypoxic cell sensitizer misonidazole as an adjunct to high fractional dose radiotherapy in patients with unresectable squamous cell carcinoma of the head and neck: a RTOG randomized study (\#79-04). International Journal of Radiation Oncology, Biology, Physics 1989;16(2):465-70.

\section{Leong 1995 \{published data only\}}

Leong L, Sakurai C, Sebastian W, Shaw N, Grant E, Grant M et al. Phase III trial assessing the use of oral thymidine (THY) for prevention of fluorouracil (5-FU)-induced mucositis. In: Proceedings of the Annual Meeting of the American Society of Clinical Oncology. Vol. 14. 1995:A334.

Levi 1997 \{published data only\}

Levi F, Zidani R, Misset JL. Randomised multicentre trial of chronotherapy with oxaliplatin, fluorouracil, and folinic acid in metastatic colorectal cancer. Lancet 1997;350(9079):681-6.

\section{Loo 2010 \{published data only\}}

Loo WT, Jin L, Chow LW, Cheung MN, Wang M. Rhodiola algida improves chemotherapy-induced oral mucositis in breast cancer patients. Expert Opinion on Investigational Drugs 2010;19 Suppl 1:S91-100.

\section{Lopez 1994 \{published data only\}}

Lopez I, Goudou C, Ribrag V, Sauvage C, Hazebroucq G, Dreyfus $F$. Treatment of mucositis with vitamin E during administration of neutropenic antineoplastic agents. Annales de Medecine Interne 1994;145(6):405-8.

\section{Lopez-Campo 2004 \{published data only\}}

Lopez-Campo JH. Chemotherapy induced stomatitis management using collagenase vs a liquid mixture. Pediatric Blood and Cancer 2004;43(4).

\section{Lorusso 2003 \{published data only\}}

Lorusso D, Ferrandina G, Greggi S, Gadducci A, Pignata S, Tateo S. Phase III multicenter randomized trial of amifostine as cytoprotectant in first-line chemotherapy in ovarian cancer patients. Annals of Oncology 2003;14(7):1086-93.

\section{Lozada 1998 \{published data only\}}

Lozada-Nur F, Schoelch M, Fu K, Muscoplat C, Trivedi M, Smith $C$ et al. A pilot study to evaluate the effect of pilocarpine tablets on salivary flow and mucositis in head and neck cancer patients during radiotherapy. In: Proceedings of the Annual Meeting of the Society of Clinical Oncology. 1998:1541.

Luglié 2002 \{published data only\}

Lugliè PF, Mura G, Mura A, Angius A, Soru G, Farris A. Prevention of periodontopathy and oral mucositis during antineoplastic chemotherapy. Clinical study. Minerva Stomatologica 2002;51(6):231-9.

Maddocks-Jennings 2009 \{published data only\}

Maddocks-Jennings W, Wilkinson JM, Cavanagh HM, Shillington D. Evaluating the effects of the essential oils Leptospermum scoparium (manuka) and Kunzea ericoides (kanuka) on radiotherapy induced mucositis: a randomized, placebo controlled feasibility study. European Journal of Oncology Nursing 2009;13(2):87-93.

\section{Madero 1999 \{published data only\}}

Madero L, Diaz MA, Ortega JJ, Olive T, Martinez A, Badell I et al. Recombinant human granulocyte-macrophage colonystimulating factor accelerates engraftment kinetics after allogeneic bone marrow transplantation for childhood acute lymphoblastic leukemia. Haematologica 1999;84(2):133-7.

\section{Mahmoud 1996 \{published data only\}}

Mahmoud HK SE, Kamel M, El HMA, Nassar A. Influence of folinic acid rescue on methotrexate-related toxicity and graft-versushost disease after allogeneic bone marrow transplantation. Tumor Diagnostik Und Therapie 1996;17(1):18-21.

\section{Malaker 1991 \{published data only\}}

Malaker K, Anderson BJ, Beecroft WA, Hodson DI. Management of oral mucosal dysplasia with beta-carotene retinoic acid: a pilot cross-over study. Cancer Detection and Prevention 1991;15(5):335-40.

\section{Mantovani 2003 \{published data only\}}

Mantovani G, Massa E, Astara G, Murgia V, Gramignano G, Lusso MR et al. Phase II clinical trial of local use of GM-CSF for prevention and treatment of chemotherapy- and concomitant chemoradiotherapy-induced severe oral mucositis in advanced head and neck cancer patients: an evaluation of effectiveness, safety and costs. Oncology Reports 2003;10(1):197-206.

\section{Marcial 1994 \{published data only\}}

Marcial F, Schubert M, Niccoli-Filho WD, Lloid ME, Kelly J, Franquin JC et al. A phase I/II nonblinded randomized trial to determine the efficacy of low-energy laser to prevent oral mucositis resulting from conditioning regimens for bone marrow transplantation. Oral Surgery, Oral Medicine, and Oral Pathology 1994;78(6):738.

\section{Martin 2006 \{published data only\}}

Martin M, Lluch A, Segui MA, Ruiz A, Ramos M, Adrover E et al. Toxicity and health-related quality of life in breast cancer patients receiving adjuvant docetaxel, doxorubicin, cyclophosphamide (TAC) or 5-fluorouracil, doxorubicin and cyclophosphamide (FAC): impact of adding primary prophylactic granulocyte-colony stimulating factor to the TAC regimen. Annals of Oncology 2006;17(8):1205-12. 
Masucci 2005 \{published data only\}

Masucci G, Broman P, Kelly C, Lindahl S, Malmberg L, Reizenstein $\mathrm{J}$ et al. Therapeutic efficacy by recombinant human granulocyte/monocyte-colony stimulating factor on mucositis occurring in patients with oral and oropharynx tumors treated with curative radiotherapy: a multicenter open randomized phase III study. Medical Oncology 2005;22(3):247-56.

Matejka 1990 \{published data only\}

Matejka M, Nell A, Kment G, Schein A, Leukauf M, Porteder H et al. Local benefit of prostaglandin E2 in radiochemotherapyinduced oral mucositis. The British Journal of Oral \& Maxillofacial Surgery 1990;28(2):89-91.

Mcltroy 1996 \{published data only\}

Mcllroy P. Radiation mucositis: a new approach to prevention and treatment. European Journal of Cancer Care 1996;5(3):153-8.

\section{Merte 1999 \{published data only\}}

Merte H, Wied R, Engenhart-Cabillic R. Der effekt von immunglobulinen in der behandlung der radiogenen dermatitis und mukositis bei patienten mit hals-nasen und rachentumoren. Strahlentherapy und Onkologie 1999;175(1):135.

\section{Mills 1995 \{published data only\}}

Mills W, Strang J, Goldstone AH, Linch DC. Dose intensification of etoposide in the BEAM ABMT protocol for malignant lymphoma. Leukemia \& Lymphoma 1995;17(3-4):263-70.

\section{Mori 2006 \{published data only\}}

Mori T, Yamazaki R, Aisa Y, Nakazato T, Kudo M, Yashima T et al. Brief oral cryotherapy for the prevention of high-dose melphalan-induced stomatitis in allogeneic hematopoietic stem cell transplant recipients. Supportive Care in Cancer 2006;14(4):392-5.

\section{Nicolatou-Galitis 2006 \{published data only\}}

Nicolatou-Galitis O, Velegraki A, Sotiropoulou-Lontou A, Dardoufas K, Kouloulias V, Kyprianou K et al. Effect of fluconazole antifungal prophylaxis on oral mucositis in head and neck cancer patients receiving radiotherapy. Supportive Care in Cancer 2006;14(1):44-51.

\section{Niibe 1985 \{published data only\}}

Niibe H, Takahashi I, Mitsuhashi N, Miyaishi K, Itoh J, Maehara $Y$ et al. An evaluation of the clinical usefulness of amifostine (YM-08310), radioprotective agent. A double-blind placebocontrolled study. 1. Head and neck tumors. Nippon Gan Chiryo Gakkai Shi 1985;20(5):984-93.

Niibe H, Takahashi I, Miyaishi K, Mitsuhashi N, Maehara Y, Nakajima $\mathrm{N}$ et al. An evaluation of the clinical usefulness of amifostine (YM-08310), radioprotective agent. A double-blind placebo-controlled study. 2. Abdominal and pelvic tumours. Nippon Gan Chiryo Gakkai Shi 1985;20(5):994-1001.

Nikoletti 2005 \{published data only\}

Nikoletti S, Hyde S, Shaw T, Myers H, Kristjanson LJ. Comparison of plain ice and flavoured ice for preventing oral mucositis associated with the use of 5 fluorouracil. Journal of Clinical Nursing 2005;14(6):750-3.

Okuno 1997 \{published data only\}

Okuno SH, Foote RL, Loprinzi CL, Gulavita S, Sloan JA, Earle $\mathrm{J}$ et al. A randomized trial of a nonabsorbable antibiotic lozenge given to alleviate radiation-induced mucositis. Cancer 1997;79(1):2193-9.

\section{Okutomi 2000 \{published data only\}}

Okutomi T, Kato Y, Ichihara H, Hyodo I, Fujitsuka H, Yasuda $S$ et al. Clinical effects of adjuvant therapy using Z-100 (Ancer 20 injection) for oral cancer--prevention of stomatitis and hematopoietic impairment. Gan To Kagaku Ryoho 2000;27(1):65-71.

\section{Papadeas 2007 \{published data only\}}

Papadeas E, Naxakis S, Riga M, Kalofonos Ch. Prevention of 5-fluorouracil-related stomatitis by oral cryotherapy: a randomized controlled study. European Journal Oncology Nursing 2007;11(1):60-5.

Papas 1984 \{published data only\}

Papas A, Johansen E. Prevention of mucositis in oncology patients undergoing radiation therapy. Journal of Dental Research 1984;63(Special Issue March):311 (Abs No 1267).

Papas 2003 \{published data only\}

Papas AS, Clark RE, Martuscelli G, O'Loughlin KT, Johansen E, Miller KB. A prospective, randomized trial for the prevention of mucositis in patients undergoing hematopoietic stem cell transplantation. Bone Marrow Transplantation 2003;31(8):705-12.

\section{Penpattanagul 2007 \{published data only\}}

Penpattanagul S. Reduced incidence and severity of acute radiation mucositis by WF10 (immunokine) as adjunct to standard of cure in the management of head \& neck cancer patients. Journal of the Medical Association of Thailand 2007;90(8):1590-600.

Peters 1993 \{published data only\}

Peters E, Antczak-Bouckoms A, Burdick E. Meta-analysis of chlorhexidine in the prevention of mucositis from chemotherapy. Journal of Dental Research 1993;Special Issue(259):1249.

Phillips 2002 \{published data only\}

Phillips GL 2nd. The potential of amifostine in high-dose chemotherapy and autologous hematopoietic stem cell transplantation. Seminars in Oncology 2002;29(6 Supp 19):53-6.

\section{Piccirillo 2003 \{published data only\}}

Piccirillo N, De Matteis S, Laurenti L, Chiusolo P, Sora F, Pittiruti $\mathrm{M}$ et al. Glutamine-enriched parenteral nutrition after autologous peripheral blood stem cell transplantation: effects on immune reconstitution and mucositis. Haematologica 2003;88(2):192-200. 


\section{Pouli 1999 \{published data only\}}

Pouli A, Nikiforakis E. A prospective randomized trial of GMCFS mouthwash versus sodium bicarbonate mouthwash in the treatment of stomatitis following allogeneic bone marrow transplantation. Bone Marrow Transplantation 1999;23:S166.

Prada 1985 \{published data only\}

Prada A, Lozza L, Moglia D, Sala L, Chiesa F. Effects of benzydamine on radio-polychemotherapeutic mucositis of the oral cavity. International Journal of Tissue Reaction $1985 ; 7(3): 237-9$

\section{Putwatana 2009 \{published data only\}}

Putwatana P, Sanmanowong P, Oonprasertpong L, Junda T, Pitiporn S, Narkwong L. Relief of radiation-induced oral mucositis in head and neck cancer. Cancer Nursing 2009;32(1):82-7.

\section{Pyrhonen 1995 \{published data only\}}

Pyrhonen S, Kuitunen T, Nyandoto P, Kouri M. Randomised comparison of fluorouracil, epidoxorubicin and methotrexate (FEMTX) plus supportive care with supportive care alone in patients with non-resectable gastric cancer. British Journal of Cancer 1995;71(3):587-91.

\section{Pytlik 2002 \{published data only\}}

Pytlik R, Benes P, Patorkova M, Chocenska E, Gregora E, Prochazka B et al. Standardized parenteral alanylglutamine dipeptide supplementation is not beneficial in autologous transplant patients: a randomized, double-blind, placebo controlled study. Bone Marrow Transplantation 2002;30(12):953-61.

\section{Rabinovitch 2006 \{published data only\}}

Rabinovitch R, Grant B, Berkey BA, Raben D, Ang KK, Fu KK et al. Impact of nutrition support on treatment outcome in patients with locally advanced head and neck squamous cell cancer treated with definitive radiotherapy: a secondary analysis of RTOG trial 90-03. Head \& Neck 2006;28(4):287-96.

\section{Rades 2004 \{published data only\}}

Rades D, Fehlauer F, Bajrovic A, Mahlmann B, Richter E, Alberti W. Serious adverse effects of amifostine during radiotherapy in head and neck cancer patients. Radiotherapy and Oncology 2004;70(3):261-4.

\section{Radmard 2002 \{published data only\}}

Radmard A, Niewohner-Desbordes U, Wagner W. rhGM-CSF in the treatment of radiogenic mucositis: prospective randomised phase-II study on the effectivity and tolerance of rhGM-CSF in the treatment of oral mucositis under radiotherapy of head and neck tumors. Strahlentherapie und Onkologie 2002;178 Suppl 1:24.

\section{Raether 1989 \{published data only\}}

Raether D, Walker PO, Bostrum B, Weisdorf D. Effectiveness of oral chlorhexidine for reducing stomatitis in a pediatric bone marrow transplant population. Pediatric Dentistry 1989;11(1):37-42.

\section{Robustelli 1999 \{published data only\}}

Robustelli della Cuna FS, Ucci G, Cuomo AM, Goglio AM. Galenic preparation for the prophylaxsis of oral mucositis induced by 5 fluororacil continous infusion. Supportive Care in Cancer 1999;7 Suppl:132 (Abs No P-67).

\section{Rocci 2005 \{published data only\}}

Rocci L, Vincenzi B, Santini D, Tonini G. Timing of 5-fluorouracile infusion: a randomized clinical trial. International Nursing Perspectives 2005;5(2):53-60.

\section{Rojas 2001 \{published data only\}}

Rojas de Morales T, Zambrano O, Rivera L, Navas R, Chaparro N, Bernardonni $\mathrm{C}$ et al. Oral-disease prevention in children with cancer: testing preventive protocol effectiveness. Medicina Oral 2001;6(5):326-34

Rothwell 1990 \{published data only\}

Rothwell BR. Palliation of radiation-related mucositis. Special Care in Dentistry 1990;10(1):21-5.

Rutkauskas 1993 \{published data only\} Rutkauskas JS, Davis JW. Effects of chlorhexidine during immunosuppressive chemotherapy: A preliminary report. Oral Surgery, Oral Medicine, and Oral Pathology 1993;76(4):441-8.

\section{Ryu 2007 \{published data only\}}

Ryu JK, Swann S, LeVeque F, Scarantino CW, Johnson D, Chen A et al. The impact of concurrent granulocyte macrophage-colony stimulating factor on radiation-induced mucositis in head and neck cancer patients: a double-blind placebo-controlled prospective phase III study by Radiation Therapy Oncology Group 9901. International Journal of Radiation Oncology, Biology, Physics 2007;67(3):643-50.

\section{Samaranayake 1988 \{published data only\}}

Samaranayake LP, Robertson AG, MacFarlane TW, Hunter IP, MacFarlane G, Soutar DS et al. The effect of chlorhexidine and benzydamine mouthwashes on mucositis induced by therapeutic irradiation. Clinical Radiology 1988;39(3):291-4.

\section{Sato 1997 \{published data only\}}

Sato A, Kumagai S, Sakaki K, Morikawa H, Song ST, Mori S. Inhibition of 5-fluorouracil-cisplatin-induced stomatitis by oral cryotherapy: use of an ice-bar containing fibrinolysin and deoxyribonuclease comiben (Elase). Gan to Kagaku Ryoho 1997;24(9):1135-9.

\section{Sato 2006 \{published data only\}}

Sato A, Saisho-Hattori T, Koizumi Y, Minegishi M, linuma K, Imaizumi M. Prophylaxis of mucosal toxicity by oral propantheline and cryotherapy in children with malignancies undergoing myeloablative chemo-radiotherapy. The Tohoku Journal of Experimental Medicine 2006;210(4):315-20.

\section{Schuster 2008 \{published data only\}}

Schuster MW, Anaissie E, Hurd D, Bensinger W, Mason J, McCarty $\mathrm{J}$ et al. Final analysis of the phase II, randomized, double-blind, placebo-controlled trial of single-dose velafermin (CG53135-05) for the prevention of oral mucositis. Journal of Supportive Oncology 2007;5(4 Suppl 2):58-9. 
* Schuster MW, Shore TB, Harpel JG, Greenberg J, Jalilizeinali B, Possley $S$ et al. Safety and tolerability of velafermin

(CG53135-05) in patients receiving high-dose chemotherapy and autologous peripheral blood stem cell transplant. Supportive Care in Cancer 2008;16(5):477-83.

\section{Schwerkoske 1999 \{published data only\}}

Schwerkoske J, Schwartzberg L, Weaver CH, Schwertschlag US, Goodfellow J, Bedrosian CL. A phase 1 double-masked, placebo-controlled study to evaluate tolerability of Neumega ${ }^{\circledR}$ (rhIL-11; oprelvekin) to reduce mucositis in patients with solid tumors or lymphoma receiving high-dose chemotherapy (CT) with autologous peripheral blood stem cell reinfusion (PBSCT). In: Proceedings of the American Society of Clinical Oncology. Vol. 18. 1999:584a (Abstract 2256).

\section{Shabanloei 2009 \{published data only\}}

Shabanloei R, Ahmadi F, Vaez J, Ansarin K, Hajizadeh E, Javadzadeh $Y$ et al. Allopurinol, chamomile and normal saline mouth washes for the prevention of chemotherapyinduced stomatitis. Journal of Clinical and Diagnostic Research 2009;3(3):1537-42

\section{Sharma 2009 \{published data only\}}

Sharma A, Rath GK, Choudhary SP, Thakar A, Mohanti BK, Bahadur $S$ et al. A randomized double-blind phase III study of efficacy of lactobacillus CD2 lozenges in preventing radiationand chemotherapy-induced oral mucositis in head and neck cancer patients: Interim analysis. Journal of Clinical Oncology 2009;27(15S):6008.

\section{Shea 2007 \{published data only\}}

Shea TC, Kewalramani T, Mun Y, Jayne G, Dreiling LK. Evaluation of single-dose palifermin to reduce oral mucositis (OM) in fractionated total body irradiation (fTBI) and high dose (HD) chemotherapy with autologous peripheral blood progenitor cell (PBPC) transplantation. Blood 2006;108(11 Part 1):875-6.

* Shea TC, Kewalramani T, Mun Y, Jayne G, Dreiling LK. Evaluation of single-dose palifermin to reduce oral mucositis in fractionated total-body irradiation and high-dose chemotherapy with autologous peripheral blood progenitor cell transplantation. Journal of Supportive Oncology 2007;5(4 Suppl 2):60-2.

\section{Shidfar 2008 \{published data only\}}

Shidfar F, Ghorayshi Z, Iravani M, Aghahosseini F. The effects of vitamin $E$ intakes on mucositis and neutropenia in patients with Leukamia. Pediatric Blood Cancer 2008;50 Suppl 5:165.

\section{Simoes 2009 \{published data only\}}

Simoes A, Eduardo FP, Luiz AC, Campos L, Sa PH, Cristofaro M et al. Laser phototherapy as topical prophylaxis against head and neck cancer radiotherapy-induced oral mucositis: comparison between low and high/low power lasers. Lasers in Surgery and Medicine 2009;41(4):264-70.

\section{Spadaro 1991 \{published data only\}}

Spadaro P, Buemi B, Ferraro G, Marabello G, Russi E, Pergolizzi S. Prophylaxis of chemotherapy-radiotherapy induced mucositis or oral fungal infection with vitamin E + vitamin A and Fluconazolo. European Journal of Cancer 1991;27 Suppl 2:S288.

\section{Spielberger 2001 \{published data only\}}

Spielberger RT, Stiff P, Emmanouilides C, Yanovich S, Bensinger W, Hedrick E et al. Efficacy of recombinant human keratinocyte growth factor (rHuKGF) in reducing mucositis in patients with hematologic malignancies undergoing autologous peripheral blood progenitor cell transplantation (auto-PBPCT) after radiation-based conditioning - results of a phase 2 trial. In: Proceedings of the American Society of Clinical Oncology. Vol. 20 (Pt 1). 2001:7a (Abstract 25).

Stokman 2004 \{published data only\}

Stokman MA, Wachters FM, Koopmans P, Burgerhof JG, Groen HJ, Spijkervet FK et al. Outcome of local application of amifostine (WR-1065) on epirubicin-induced oral mucositis. A phase II study. Anticancer Research 2004;24(5B):3263-7.

Teshima 1986 \{published data only\}

Teshima T. Clinical evaluation of kenalog ointment for radiation mucositis of patients with head and neck cancer. Yakuri to Chiryo 1986;14(11):7163-6.

\section{Thieblemont 2002 \{published data only\}}

Thieblemont C, Dumontet C, Saad H, Roch N, Bouafia F, Arnaud $P$ et al. Amifostine reduces mucosal damage after high-dose melphalan conditioning and autologous peripheral blood progenitor cell transplantation for patients with multiple myeloma. Bone Marrow Transplantation 2002;30(11):769-75.

\section{Throuvalas 1995 \{published data only\}}

Throuvalas N, Antonadou D, Pulizzi M, Sarris G. Evaluation of the efficacy and safety of GM-CSF in the prophylaxis of mucositis in patients with head and neck cancer treated with RT. European Journal of Cancer 1995;31 Suppl 5:S93 (Abstract 431).

\section{Tiemann 2006 \{published data only\}}

Tiemann P, Toelg M, Ramos FM. Administration of Ratanhiabased herbal oral care products for the prophylaxis of oral mucositis in cancer chemotherapy patients: a clinical trial. Evidence Based Complementary and Alternative Medicine 2007;4(3):361-6.

\section{Toubai 2003 \{published data only\}}

Toubai T, Tanaka J, Fujisawa F, Kondo Y, Imamura M, Ota S et al. Effect of prophylaxis against myocosis in patients with hematological malignancy disease: efficacy of dosage of itraconazole. Japanese Journal of Antibiotics 2003;56(1):61-5.

\section{Uchiyama 2005 \{published data only\}}

Uchiyama Y, Murakami S, Kakimoto N, Nakatani A, Furukawa S. Effectiveness of Cepharanthin in decreasing interruptions during radiation therapy for oral cancer. Oral Radiology 2005;21(1):41-4.

\section{Valcárcel 1997 \{published data only\}}

Valcárcel F, De la Torre A, Aragón G, Lanzós E, Rodríguez R, Veiras $C$. Double-blind randomized and pilot study on the potential of thymostimulin to reduce the incidence of mucositis 
in head and neck cancer patients with radical radiotherapy. In: Oncología IX Congreso Nacional de la Asociación Española de Radioterapia y Oncología. Vol. 20. 1997:161.

\section{Valcarcel 2002 \{published data only\}}

Valcarcel D, Sanz M, Sureda A, Sala M, Munoz L, Subira M et al. Topically applied recombinant human granulocyte-macrophage colony stimulating factor (rhGM-CSF) for oropharyngeal mucositis (OM) in stem cell transplantation recipients: a randomized double-blind placebo-controlled study. Bone Marrow Transplantation 2002;Suppl 2:S20.

* Valcarcel D, Sanz MA Jr, Sureda A, Sala M, Munoz L, Subira M et al. Mouth-washings with recombinant human granulocytemacrophage colony stimulating factor (rhGM-CSF) do not improve grade III-IV oropharyngeal mucositis (OM) in patients with hematological malignancies undergoing stem cell transplantation. Results of a randomized double-blind placebo-controlled study. Bone Marrow Transplantation 2002;29(9):783-7.

\section{van Zaanen 1994 \{published data only\}}

van Zaanen HC, van der Lelie H, Timmer JG, Furst P, Sauerwein HP. Parenteral glutamine dipeptide supplementation does not ameliorate chemotherapy-induced toxicity. Cancer 1994;74(10):2879-84.

\section{Verdi 1995 \{published data only\}}

Verdi CJ, Garewal HS, Koenig LM, Vaughn B, Burkhead T. A double-blind, randomized, placebo-controlled, crossover trial of pentoxiflline for the prevention of chemotherapy-induced oral mucositis. Osomopore 1995;80(1):36-42.

Vesole 1999 \{published data only\}

Vesole D, Fuchs HJ. IB-367 reduces the number of days of severe oral mucositis complicating myeloablative chemotherapy. Blood 1999;94(10 Suppl 1):154 (Abs No 675).

\section{Villar 2009 \{published data only\}}

Villar RC, de Lima AG, Junior GC, Gil E, Rosalmedia MC, Antequera $\mathrm{W}$ et al. Prophylactic low energy laser application to prevent chemoradiation-induced oral mucositis: a prospective and randomized trial. International journal of Oncology, Biology, Physics 2009;75(3):S30.

\section{Vitello 2000 \{published data only\}}

Vitello M, Cianio SG. A comparison of two mouthrinse agents used during head/neck radiation. Journal of Dental Research 2000;79(Special Issue):215 (Abs No 576).

\section{Wagner 2002 \{published data only\}}

Wagner W, Radmard A, Niewohner-Desbordes U, Haus U, Matt J. rhGM-CSF in the treatment of radiotherapy induced mucositisprospective randomized, double-blind study to investigate the feasibility and effectiveness of rhGM-CSF in patients with head and neck cancer. In: Proceedings of the American Society for Therapeutic Radiology and Oncology Meeting. 2002:311 (Abstract 2175).
Wang 2002a \{published data only\}

Wang HM, Wang CS, Chen JS, Chen IH, Liao CT, Chang TC. Cisplatin, tegafur, and leucovorin: a moderately effective and minimally toxic outpatient neoadjuvant chemotherapy for locally advanced squamous cell carcinoma of the head and neck. Cancer 2002;94(11):2989-95.

\section{Ward 2007 \{published data only\}}

Ward E, Smith M, Henderson M, Reid U, Lewis I, Kinsey S et al. The effect of high-dose enteral glutamine on the incidence and severity of mucositis in paediatric oncology patients. European Journal of Clinical Nutrition 2007;63(1):134-40.

\section{Warde 2002 \{published data only\}}

Warde P, O'Sullivan B, Aslanidis J, Kroll B, Lockwood G, Waldron $\mathrm{J}$ et al. A Phase III placebo-controlled trial of oral pilocarpine in patients undergoing radiotherapy for head-and-neck cancer. International Journal of Radiation Oncology, Biology, Physics 2002;54(1):9-13.

\section{Weisdorf 1989 \{published data only\}}

Weisdorf DJ, Bostrom B, Raether D, Mattingly M, Walker P, Pihlstrom B et al. Oropharyngeal mucositis complicating bone marrow transplantation: prognostic factors and the effect of chlorhexidine mouthrinse. Bone Marrow Transplantation 1989;4(1):89-95.

\section{Weiss 1990 \{published data only\}}

Weiss GR, Green S, Hannigan EV, Boutselis JG, Surwit EA, Wallace DL et al. A phase II trial of cisplatin and 5-fluorouracil with allopurinol for recurrent or metastatic carcinoma of the uterine cervix: a Southwest Oncology Group trial. Gynecologic Oncology 1990;37(3):354-8.

\section{Whelan 2002 \{published data only\}}

Whelan HT, Connelly JF, Hodgson BD, Barbeau L, Post AC, Bullard $G$ et al. NASA light-emitting diodes for the prevention of oral mucositis in pediatric bone marrow transplant patients. Journal of Clinical Laser Medicine \& Surgery 2002;20(6):319-24.

\section{Whelan 2004 \{published data only\}}

Whelan $\mathrm{H}$. Phase II randomized study of NASA-developed lightemitting diode therapy for the prevention of oral mucositis in children receiving a myeloablative conditioning regimen comprising chemotherapy with or without radiotherapy followed by first allogeneic bone marrow transplantation. http://www.clinicaltrials.gov (accessed 2003).

Wollina 2002 \{published data only\}

Wollina U, Christen N, Kostler E, Schorcht J. On prophylaxis and treatment of radiation-induced dermatitis and mucositis. Zeitschrift fur Hautkrankheiten 2002;77(9):418-23.

\section{Wymenga 1999 \{published data only\}}

* Wymenga AN, van der Graaf WT, Hofstra LS, Spijkervet FK, Timens W, Timmer-Bosscha $\mathrm{H}$ et al. Phase I study of transforming growth factor-beta3 mouthwashes for prevention of chemotherapy-induced mucositis. Clinical Cancer Research 1999;5(6):1363-8. 
Wymenga AN, van der Graaf WT, Hofstra LS, Timens W, Spijkervet FK, Hospers GAP et al. TGF-b3 mouthwashes aimed at prevention of chemotherapy induced mucositis, a phase-I study. Supportive Care in Cancer 1999;7 (Suppl):168 (Abstract 0-15).

\section{Yokomizo 2004 \{published data only\}}

Yokomizo H, Yoshimatsu K, Hashimoto M, Ishibashi K, Umehara A, Yoshida K et al. Prophylactic efficacy of allopurinol ice ball for leucovorin/5-fluorouracil therapy-induced stomatitis. Anticancer Research 2004;24(2C):1131-4.

\section{Zanin 2010 \{published data only\}}

Zanin T, Zanin F, Carvalhosa AA, Castro PH, Pacheco MT, Zanin IC et al. Use of 660-nm diode laser in the prevention and treatment of human oral mucositis induced by radiotherapy and chemotherapy. Photomedicine and Laser Surgery 2010;28(2):233-7.

\section{References to studies awaiting assessment}

\section{Cheng 2003 \{published data only\}}

Cheng KK, Chang AM, Yuen MP. Prevention of oral mucositis in paediatric patients treated with chemotherapy; a randomised crossover trial comparing two protocols of oral care. European Journal of Cancer 2004;40(8):1208-16.

Cheng KK, Chang AM. Palliation of oral mucositis symptoms in pediatric patients treated with cancer chemotherapy. Cancer Nursing 2003;26(6):476-84.

Cheng KK. Children's acceptance and tolerance of chlorhexidine and benzydamine oral rinses in the treatment of chemotherapyinduced oropharyngeal mucositis. European Journal of Oncology Nursing 2004;8(4):341-9.

\section{de Koning 2007 \{published data only\}}

de Koning BA, Philipsen-Geerling B, Hoijer M, Hahlen K, Buller HA, Pieters R. Protection against chemotherapy induced mucositis by TGF-beta(2) in childhood cancer patients: results from a randomized cross-over study. Paediatric Blood \& Cancer 2007;48(5):532-9.

\section{Grzegorczyk 2006 \{published data only\}}

Grzegorczyk-Jazwinska A, Dwilewicz-Trojaczek J, Kozak I, Karakulska-Prystupiuk E, Gorska R. Effect of locally applied G-CSF on oral mucositis after autogeneic and allogeneic stem cell transplantation. Acta Haematologica Polonica 2006;37(2):225-40.

\section{Jellema 2006 \{published data only\}}

Jellema AP, Slotman BJ, Muller MJ, Leemans CR, Smeele LE, Hoekman $\mathrm{K}$ et al. Radiotherapy alone, versus radiotherapy with amifostine 3 times weekly, versus radiotherapy with amifostine 5 times weekly: A prospective randomized study in squamous cell head and neck cancer. Cancer 2006;107(3):544-53.

\section{Peterson 2007 \{published data only\}}

* Peterson DE, Jones JB, Petit RG. Randomized, placebocontrolled trial of Saforis for prevention and treatment of oral mucositis in breast cancer patients receiving anthracyclinebased chemotherapy. Cancer 2007;109(2):322-31.

Peterson DE, Petit RG. AES-14 in chemotherapy patients at risk for mucositis. Phase III study. In: Proceedings of the American Society of Clinical Oncology. Vol. 725. 2003.

Petit RG, II, French C. Phase III clinical trial design considerations for oral treatments of chemotherapy - induced mucositis: AES-14 (uptake-facilitated L-glutamine) pivotal studies. In: Proceedings of the American Society of Clinical Oncology. Vol. 20 (Pt 2). 2001:301b (Abstract 2954).

\section{Wu 2010 \{published data only\}}

* Wu S, Cui T, Zhao C, Pan J, Xu B, Tian Y et al. A prospective, randomized, multi-center trial to investigate Actovegin in prevention and treatment of acute oral mucositis caused by chemoradiotherapy for nasopharyngeal carcinoma. Radiotherapy and Oncology 2010;97(1):113-8.

Wu S, Cui T, Zhao C, Pan J, Xu B, Tian Y et al. A randomised controlled multicentre trial of actovegin against acute oral mucositis induced by chemo-radiotherapy for nasopharyngeal carcinoma. International Journal of Radiation Oncology, Biology, Physics 2008;72 Suppl 1:S380.

\section{Yasuda 2011 \{published data only\}}

Preventive Effect of Rebamipide Gargle on ChemoradiotherpyInduced Oral Mucositis in Patients with Oral Cancer: a Pilot Study. J Oral Maxillofac Res 2011 (Oct-Dec);2(4):e3.

Zhe 2000 \{published data only\}

Zhe H, Ding Z, Guo QM, Cheng BQ. Prevention and treatment of oral mucositis caused by radiotherapy in patients with nasopharyngeal carcinoma. Journal of Ningxia Medical College 2000;22(2):99-100.

\section{Additional references}

\section{Andreassen 2003}

Andreassen CN, Grau C, Lindegaard JC. Chemical radioprotection: a critical review of amifostine as a cytoprotector in radiotherapy. Seminars in Radiation Oncology 2003;13(1):62-72.

\section{Begg 1996}

Begg C, Cho M, Eastwood S, Horton R, Moher D, Olkin I et al. Improving the quality of reporting of randomized controlled trials: the CONSORT statement. JAMA 1996;276(8):637-9.

\section{Bellm 2002}

Bellm LA, Cunningham G, Durnell L, Eilers J, Epstein JB, Fleming $T$ et al. Defining clinically meaningful outcomes in the evaluation of new treatments for oral mucositis: oral mucositis patient provider advisory board. Cancer Investigation 2002;20(5-6):793-800.

\section{Chang 2003}

Chang VT, Ingham J. Symptom control. Cancer Investigation 2003;21(4):564-78. 


\section{Clarkson 2007a}

Clarkson JE, Worthington HV, Eden TOB. Interventions for preventing oral candidiasis for patients with cancer receiving treatment. Cochrane Database of Systematic Reviews 2007, Issue 1. Art. No: CD003807. Art. No: CD003807. [DOI: Art. No.: CD003807. DOI: 10.1002/14651858.CD003807.pub3]

\section{Clarkson 2007b}

Clarkson JE, Worthington HV, Eden TOB. Interventions for treating oral mucositis for patients with cancer receiving treatment. Cochrane Database of Systematic Reviews 2007, Issue 2. Art. No: CD001973. Art. No: CD001973. [DOI: Art. No.: CD001973. DOI: 10.1002/14651858.CD001973.pub3]

\section{Clarkson 2010}

Clarkson JE, Worthington HV, Furness S, McCabe M, Khalid T, Meyer S. Interventions for treating oral mucositis for patients with cancer receiving treatment. Cochrane Database of Systematic Reviews 2010, Issue 8. Art. No: CD001973. Art. No: CD001973. [DOI: Art. No.: CD001973. DOI: 10.1002/14651858.CD001973.pub4]

\section{Denning 1992}

Denning DW, Donnelly JP, Hellreigel KP, Ito J, Martino P, van't Wout JW. Antifungal prophylaxis during neutropenia or allogeneic bone marrow transplantation: what is the state of the art? Chemotherapy 1992;38(S1):43-9.

\section{De Pauw 1997}

De Pauw BE. Practical modalities for prevention of fungal infections in cancer patients. European Journal of Clinical Microbiological Infectious Diseases 1997;16(1):32-41.

\section{Duncan 2003}

Duncan M, Grant G. Oral and intestinal mucositis - causes and possible treatments. Alimentary Pharmacology \& Therapeutics 2003;18(9):853-74

\section{Egger 1997}

Egger M, Davey Smith G, Schneider M, Minder C. Bias in meta-analysis detected by a simple, graphical test. $B M J$ 1997;315(7109):629-34.

\section{Eilers 1988}

Eilers J, Berger AM, Petersen MC. Development, testing, and application of the oral assessment guide. Oncology Nursing Forum 1988;15(3):325-30.

\section{Elbourne 2002}

Elbourne DR, Altman DG, Higgins JP, Curtin F, Worthington HV, Vail A. Meta-analyses involving cross-over trials. International Journal of Epidemiology 2002;31(1):140-9.

\section{Gibson 2010}

Gibson F, Auld EM, Bryan G, Coulson S, Craig JV, Glenny AM. A systematic review of oral assessment instruments: what can we recommend to practitioners in children's and young people's cancer care? Cancer Nursing 2010;33(4):E1-E19.

\section{Glenny 2004}

Glenny AM, Gibson F, Auld E, Coulson S, Clarkson JE, Craig JV et al. A survey of current practice with regard to oral care for children being treated for cancer. European Journal of Cancer 2004;40(8):1217-24.

\section{Glenny 2009}

Glenny AM, Fernandez Mauleffinch LM, Pavitt S, Walsh T. Interventions for the prevention and treatment of herpes simplex virus in patients treated for cancer. Cochrane Database of Systematic Reviews 2009, Issue 1. Art. No: CD006706. Art. No: CD006706. [DOI: Art. No.: CD006706. DOI: 10.1002/14651858.CD006706.pub2]

\section{Higgins 2009}

Higgins JPT, Green S (editors). Cochrane Handbook for Systematic Reviews of Interventions version 5.0.2 (updated September 2009). The Cochrane Collaboration, 2009. Available from www.cochrane-handbook.org.

\section{Kassab 2009}

Kassab S, Cummings M, Berkovitz S, van Haselen R, Fisher P. Homeopathic medicines for adverse effects of cancer treatments. Cochrane Database of Systematic Reviews 2009, Issue 1. Art. No: CD004845. Art. No: CD004845. [DOI: Art. No.: CD004845. DOI: 10.1002/14651858.CD004845.pub2]

\section{Keefe 2007}

Keefe DM, Schubert MM, Elting LS, Sonis ST, Epstein JB, Raber-Durlacher JE et al. Updated clinical practice guidelines for the prevention and treatment of mucositis. Cancer 2007;109(5):820-31.

\section{Kowanko 1998}

Kowanko I, Long L, Hodgkinson B, Evans D. The effectiveness of strategies for preventing and treating chemotherapy and radiation induced oral mucositis in patients with cancer. Joanna Briggs Institute for Evidence Based Nursing and Midwifery 1998:1-84.

\section{Lortholary 1997}

Lortholary O, Dupont B. Antifungal prophylaxis during neutropenia and immunodeficiency. Clinical Microbiological Review 1997;10(3):477-504.

\section{McDonnell 2007}

McDonnell AM, Lenz KL. Palifermin: role in the prevention of chemotherapy- and radiation-induced mucositis. Annals of Pharmacotherapy 2007;41(1):86-94.

\section{Merck Index 2010}

O'Neil, Maryadele J (editors). The Merck Index: an encyclopedia of chemicals, drugs and biologicals. MedicinesComplete. Available from:http:// www.medicinescomplete.com/mc/merck/2010/08591.htm? $q=\% 22$ dobell\%22\&t=search\&ss=text\&p=1\#_hit (accessed 4 November 2010).

\section{Moher 2001}

Moher D, Schulz KF, Altman DG. The CONSORT statement: revised recommendations for improving the quality of reports 
of parallel-group randomized trials. Annals of Internal Medicine 2001;134(8):657-62.

\section{Rubenstein 2004}

Rubestein EB, Peterson DE, Schubert M, Keefe D, McGuire D, Epstein J et al. Clinical practice guidelines for the prevention and treatment of cancer therapy-induced oral and gastrointestinal mucositis. Cancer Supplement 2004;100(9):2026-46.

\section{Sasse 2006}

Sasse AD, Clark LG, Sasse EC, Clark OA. Amifostine reduces side effects and improves complete response rate during radiotherapy: results of a meta-analysis. International Journal of Radiation Oncology, Biology, Physics 2006;64(3):784-91.

\section{Savarese 2003}

Savarese DM, Savy G, Vahdat L, Wischmeyer PE, Corey B. Prevention of chemotherapy and radiation toxicity with glutamine. Cancer Treatment Reviews 2003;29(6):501-13.

\section{Sonis 2004}

Sonis ST, Elting LS, Keefe D, Peterson ED, Schubert M, HauerJensen $M$ et al. Perspectives on cancer therapy-induced mucosal injury. Cancer Supplement 2004;100(9):1995-2025.

\section{Stevens 1995}

Stevens DA. Therapy for opportunistic fungal infections: past present and future. Indian Journal of Cancer 1995;32(1):1-9.

\section{Stokman 2006}

Stokman MA, Spijkervet FK, Boezen HM, Schouten JP, Roodenburg JL, de Vries EG. Preventive intervention possibilities in radiotherapy- and chemotherapy-induced oral mucositis: results of meta-analyses. Journal of Dental Research 2006;85(8):690-700.

\section{Sunderland 2001}

Sutherland SE, Browman GP. Prophylaxis of oral mucositis in irradiated head-and-neck cancer patients: a proposed classification scheme of interventions and meta-analysis of randomized controlled trials. International Journal of Radiation Oncology, Biology, Physics 2001;49(4):917-30.

\section{Symonds 1998}

Symonds RP. Treatment-induced mucositis: an old problem with new remedies. British Journal of Cancer 1998;77(10):1689-95.

\section{Tavender 2004}

Tavender E, Davies AN, Glenny AM. Pharmacological interventions for preventing salivary gland dysfunction following radiotherapy. Cochrane Database of Systematic Reviews 2004, Issue 3. Art. No: CD004940. [DOI: DOI: 10.1002/14651858.CD004940]

\section{Verdi 1993}

Verdi CJ. Cancer therapy and oral mucositis. Drug Safety 1993;9(3):185-95.

\section{White 1993}

White M. Antifungal prophylaxis. Current Opinion in Infectious Diseases 1993;6:737-43.

\section{Worthington 2004a}

Worthington HV, Clarkson JE, Eden OB. Interventions for treating oral mucositis for patients with cancer receiving treatment. Cochrane Database of Systematic Reviews 2004, Issue 2. Art. No: CD001973. Art. No: CD001973. [DOI: Art. No.: CD001973. DOI: 10.1002/14651858.CD001973.pub2]

\section{Worthington 2007a}

Worthington HV, Clarkson JE, Eden TOB. Interventions for treating oral candidiasis for patients with cancer receiving treatment. Cochrane Database of Systematic Reviews 2007, Issue 2. Art. No: CD001972. Art. No: CD001972. [DOI: Art. No.: CD001972. DOI: 10.1002/14651858.CD001972.pub3]

\section{Worthington 2015}

Worthington $\mathrm{H}$, Clarkson J, Weldon J. Priority oral health research identification for clinical decision-making. Evidencebased Dentistry 2015;16(3):69-71.

\section{Wright 2003}

Wright JR, McKenzie M, DeAngelis C, Foroudi F, Paul N, Rajaraman $M$ et al. Radiation induced mucositis: co-ordinating a research agenda. Clinical Oncology 2003;15(8):473-7.

\section{References to other published versions of this review \\ Clarkson 2000}

Clarkson JE, Worthington HV, Eden OB. Prevention of oral mucositis or oral candidiasis for patients with cancer receiving chemotherapy (excluding head and neck cancer). Cochrane Database of Systematic Reviews 2000, Issue 2.

\section{Clarkson 2003a}

Clarkson JE, Worthington HV, Eden OB. Interventions for preventing oral mucositis for patients with cancer receiving treatment. Cochrane Database of Systematic Reviews 2003, Issue 3. Art. No: CD000978. Art. No: CD000978. [DOI: Art. No.: CD000978. DOI: 10.1002/14651858.CD000978]

\section{Worthington 2006}

Worthington HV, Clarkson JE, Eden OB. Interventions for preventing oral mucositis for patients with cancer receiving treatment. Cochrane Database of Systematic Reviews 2006, Issue 2. Art. No: CD000978. Art. No: CD000978. [DOI: Art. No.: CD000978. DOI: 10.1002/14651858.CD000978.pub2]

\section{Worthington 2007}

Worthington HV, Clarkson JE, Eden TOB. Interventions for preventing oral mucositis for patients with cancer receiving treatment. Cochrane Database of Systematic Reviews 2007, Issue 4. Art. No: CD000978. [DOI: 10.1002/14651858.CD000978.pub3]

* Indicates the major publication for the study 
CHARACTERISTICS OF STUDIES

Characteristics of included studies [ordered by study ID]

Abbasi-Nazari 2007

\section{Study characteristics}

\begin{tabular}{ll}
\hline Methods & Randomised, parallel group multicentre study conducted in Iran. Unclear if dentist involved in the \\
study. Drop outs: unclear. Duration: 42 days.
\end{tabular}
study. Drop outs: unclear. Duration: 42 days.

\begin{tabular}{ll}
\hline Participants & $\begin{array}{l}\text { Adults with cancers of the oral cavity, nasopharynx or hypopharynx treated with radiotherapy or } \\
\text { chemoradiotherapy (Cisplatine). Data presented for } 24 \text { patients. No dates for start and finish of recruit- } \\
\text { ment. }\end{array}$ \\
\hline Interventions & $\begin{array}{l}2 \text { groups: placebo versus allopurinol mouthrinse. } 10 \mathrm{~mL} \text { of solution rinsed three times a day for three } \\
\text { minutes. Solution then discarded. }\end{array}$
\end{tabular}

Outcomes

Authors state that mucositis was graded weekly using the WHO instrument. However, the instrument reproduced in the publication is not the WHO instrument. Other reported outcomes: None.

Notes Funding source: pharmaceutical.

\section{Risk of bias}

Bias Authors' judgement Support for judgement

Random sequence genera- Unclear risk Quote: "A dynamic randomization procedure was utilized to divide patients to tion (selection bias) receive allopurinol mouthwash (treatment group) or placebo mouthwashes (control group)".

Comment: random component not described.

\begin{tabular}{lll}
\hline $\begin{array}{l}\text { Allocation concealment } \\
\text { (selection bias) }\end{array}$ & Unclear risk & Insufficient information to determine 'yes' or 'no'. \\
\hline $\begin{array}{l}\text { Blinding (performance } \\
\text { bias and detection bias) } \\
\text { Carers }\end{array}$ & Unclear risk & Insufficient information to determine 'yes' or 'no'
\end{tabular}

\begin{tabular}{lll}
\hline $\begin{array}{l}\text { Blinding (performance } \\
\text { bias and detection bias) } \\
\text { Patients }\end{array}$ & Low risk & $\begin{array}{l}\text { Quote: "double blind". } \\
\text { Comment: probably done. }\end{array}$ \\
\hline $\begin{array}{l}\text { Blinding (performance } \\
\text { bias and detection bias) } \\
\text { Outcome assessors }\end{array}$ & Low risk & Quote: "double blind". \\
\hline $\begin{array}{l}\text { Incomplete outcome data } \\
\text { (attrition bias) } \\
\text { All outcomes }\end{array}$ & Unclear risk & $\begin{array}{l}\text { Quote: "Patients who experienced hypersensitivity reaction or serious side ef- } \\
\text { fects were excluded from the study. Also patients who complained about pain } \\
\text { or other signs attributed to severe mucositis were excluded from the study." }\end{array}$ \\
& & $\begin{array}{l}\text { Comment: } 24 \text { patients included in analysis. However, it is unclear how many } \\
\text { patients were recruited. }\end{array}$
\end{tabular}

\begin{tabular}{ll}
\hline $\begin{array}{l}\text { Selective reporting (re- } \\
\text { porting bias) }\end{array}$ & $\begin{array}{l}\text { Data presented for } 24 \text { patients for grade of mucositis by grade of mucositis by } \\
\text { week for each arm of the study (figures } 1 \text { and 2). However, it is unclear how } \\
\text { many patients were initially recruited. }\end{array}$ \\
\hline
\end{tabular}


Ahmed 1993

\section{Study characteristics}

\begin{tabular}{ll}
\hline Methods & Randomised, parallel group study conducted in USA. Unclear whether dentist was involved in study. \\
\hline Participants & $\begin{array}{l}\text { Adults with haematological malignancies prior to BMT after conditioning with etoposide. } 12 \text { enrolled } \\
\text { and completed. }\end{array}$ \\
\hline Interventions & $\begin{array}{l}2 \text { groups, placebo versus propantheline (30 mg every } 6 \text { hours during infusion and } 12 \text { hours after, for to- } \\
\text { tal of } 6 \text { doses). }\end{array}$ \\
\hline Outcomes & $\begin{array}{l}\text { Mucositis graded with reference to previous publication. Data presented as number of patients de- } \\
\text { veloping mucositis in both groups. Assessment used: day 3. Other reported outcomes: blood counts } \\
\text { febrile episodes, survival, tumour response. }\end{array}$ \\
\hline Notes & $\begin{array}{l}\text { All patients received conditioning regimen of etoposide, cyclophosphamide and carmustine, together } \\
\text { with acyclovir, and nystatin or clotrimazole. } \\
\text { Funding source: unclear. }\end{array}$
\end{tabular}

\section{Risk of bias}

\begin{tabular}{|c|c|c|}
\hline Bias & Authors' judgement & Support for judgement \\
\hline $\begin{array}{l}\text { Random sequence genera- } \\
\text { tion (selection bias) }\end{array}$ & Unclear risk & $\begin{array}{l}\text { Quote: "patients were randomly assigned". } \\
\text { Comment: random component not described. }\end{array}$ \\
\hline $\begin{array}{l}\text { Allocation concealment } \\
\text { (selection bias) }\end{array}$ & Unclear risk & Insufficient information to determine 'yes' or 'no'. \\
\hline $\begin{array}{l}\text { Blinding (performance } \\
\text { bias and detection bias) } \\
\text { Carers }\end{array}$ & Unclear risk & Insufficient information to determine 'yes' or 'no'. \\
\hline $\begin{array}{l}\text { Blinding (performance } \\
\text { bias and detection bias) } \\
\text { Patients }\end{array}$ & Unclear risk & $\begin{array}{l}\text { Quote: "Trial drugs were administered blind". } \\
\text { Comment: unclear who was blind. }\end{array}$ \\
\hline $\begin{array}{l}\text { Blinding (performance } \\
\text { bias and detection bias) } \\
\text { Outcome assessors }\end{array}$ & Unclear risk & $\begin{array}{l}\text { Quote: "Assessment of mucositis severity was performed by two independent } \\
\text { observers". } \\
\text { Comment: unclear if they were blinded to allocation. }\end{array}$ \\
\hline $\begin{array}{l}\text { Incomplete outcome data } \\
\text { (attrition bias) } \\
\text { All outcomes }\end{array}$ & Unclear risk & $\begin{array}{l}12 \text { patients randomised. Authors do not give information about drop outs. Un- } \\
\text { clear how many patients in each arm. Unclear how many patients included in } \\
\text { results. }\end{array}$ \\
\hline $\begin{array}{l}\text { Selective reporting (re- } \\
\text { porting bias) }\end{array}$ & Unclear risk & $\begin{array}{l}\text { Brief mucositis data presented in text (enough for use in mucositis absent ver- } \\
\text { sus present dichotomy). }\end{array}$ \\
\hline Other bias & Low risk & Study appears to be free of other sources of bias. \\
\hline
\end{tabular}


Anderson 1998

\section{Study characteristics}

Methods Randomised, cross-over study conducted in USA. Unclear if dentist was involved in study. Duration 14 days. Recruitment May 1993 to April 1996.

\begin{tabular}{ll}
\hline Participants & $\begin{array}{l}\text { Children and adults with solid cancer (sarcoma/blastoma) who have previously had chemotherapy and } \\
\text { experienced mucositis. } 24 \text { patients eligible and enrolled, } 13 \text { completed. }\end{array}$ \\
\hline Interventions & $\begin{array}{l}2 \text { groups, glycine control (described as placebo) versus glutamine }\left(4 \mathrm{ml} / \mathrm{M}^{2} \text { twice daily swish and swal- }\right. \\
\text { low) for } 14 \text { days. }\end{array}$ \\
\hline Outcomes & $\begin{array}{l}\text { Mucositis (patient's description on } 0-4 \text { scale). Grade }>=2 \text { painful mucositis which altered food intake. } \\
\text { Assessment used: day } 14 . \text { Other reported outcomes: none. }\end{array}$ \\
\hline Notes & Funding source: charity/university.
\end{tabular}

\section{Risk of bias}

\begin{tabular}{lll}
\hline Bias & Authors' judgement & Support for judgement \\
\hline $\begin{array}{ll}\text { Random sequence genera- } \\
\text { tion (selection bias) }\end{array}$ & Unclear risk & $\begin{array}{l}\text { Quote: "Patients were assigned randomly to two courses of glutamine and two } \\
\text { courses of glycine". }\end{array}$ \\
& & Comment: random component not described. \\
\hline
\end{tabular}

\begin{tabular}{lll}
\hline $\begin{array}{l}\text { Allocation concealment } \\
\text { (selection bias) }\end{array}$ & Unclear risk & Insufficient information to determine 'yes' or 'no'. \\
\hline $\begin{array}{l}\text { Blinding (performance } \\
\text { bias and detection bias) } \\
\text { Carers }\end{array}$ & Low risk & $\begin{array}{l}\text { Quote: "In addition to the patients, the nurses and oncologists involved in the } \\
\text { care of these patients also were blinded". }\end{array}$ \\
& Comment: probably done.
\end{tabular}

\begin{tabular}{|c|c|c|}
\hline $\begin{array}{l}\text { Blinding (performance } \\
\text { bias and detection bias) } \\
\text { Patients }\end{array}$ & Low risk & $\begin{array}{l}\text { Quote: "double blind". } \\
\text { Comment: probably done. }\end{array}$ \\
\hline $\begin{array}{l}\text { Blinding (performance } \\
\text { bias and detection bias) } \\
\text { Outcome assessors }\end{array}$ & Low risk & $\begin{array}{l}\text { Quote: "double blind". } \\
\text { Comment: probably done. }\end{array}$ \\
\hline $\begin{array}{l}\text { Incomplete outcome data } \\
\text { (attrition bias) } \\
\text { All outcomes }\end{array}$ & High risk & $\begin{array}{l}24 \text { patients randomised. Paired outcome data available for } 13 \text { patients. Au- } \\
\text { thors give full reasons for attrition/exclusion. Potential for overall estimate to } \\
\text { be reversed if excluded patients were included. }\end{array}$ \\
\hline $\begin{array}{l}\text { Selective reporting (re- } \\
\text { porting bias) }\end{array}$ & Unclear risk & $\begin{array}{l}\text { Data presented for total days of mucositis compared to patient age and days } \\
\text { of mucositis > grade } 2 \text { by chemotherapy regime. }\end{array}$ \\
\hline Other bias & Low risk & Study appears to be free of other sources of bias. \\
\hline
\end{tabular}

\section{Study characteristics}


Antonadou 2002 (Continued)

Methods

Randomised, parallel group study conducted in Greece. Clear information on withdrawals: $3 / 26$ control, 2/24 intervention. Dentist not involved in study. Drop outs: 10\%. Duration 3 months.

$\begin{array}{ll}\text { Participants } & \text { Adults with head and neck cancer. Radiotherapy total 60-74 Gy } 2 \text { Gy fractions } 5 \text { days weekly. } \\ \text { Chemotherapy carboplatin ( } 90 \mathrm{mg} / \mathrm{m} 2 \text { once per week (no surgery before radiotherapy)). } 50 \text { patients } \\ \text { enrolled between January } 1997 \text { and January } 1998.45 \text { completed. }\end{array}$

$\begin{array}{ll}\text { Interventions } & \begin{array}{l}2 \text { groups, no treatment control versus amifostine } 300 \mathrm{mg} / \mathrm{m} 2 \text { 15-30 min before radiotherapy for 6-7 } \\ \text { weeks. }\end{array}\end{array}$

\begin{tabular}{ll}
\hline Outcomes & $\begin{array}{l}\text { Mucositis assessed weekly EORTC criteria. Assessment used: day 28. Other reported outcomes: dyspha- } \\
\text { gia, xerostomia, treatment interruptions, haematological changes, side effects (nausea, transient hypo- } \\
\text { tention). }\end{array}$ \\
\hline Notes & Funding source: unclear.
\end{tabular}

\section{Risk of bias}

Bias Authors' judgement Support for judgement

$\begin{array}{ll}\begin{array}{l}\text { Random sequence genera- } \\ \text { tion (selection bias) }\end{array} & \begin{array}{l}\text { Quote: "Eligible patients were randomized (1:1) to receive radiochemotherapy } \\ \text { plus amifostine (study group) or radiochemotherapy". }\end{array} \\ & \text { Comment: random component not described. }\end{array}$

\begin{tabular}{lll}
\hline $\begin{array}{l}\text { Allocation concealment } \\
\text { (selection bias) }\end{array}$ & Unclear risk & Insufficient information to determine 'yes' or 'no'. \\
\hline $\begin{array}{l}\text { Blinding (performance } \\
\text { bias and detection bias) } \\
\text { Carers }\end{array}$ & High risk & Comment: amifostine versus no intervention. No apparent blinding.
\end{tabular}

\begin{tabular}{lll}
\hline $\begin{array}{l}\text { Blinding (performance } \\
\text { bias and detection bias) } \\
\text { Patients }\end{array}$ & High risk & Comment: amifostine versus no intervention. No apparent blinding. \\
\hline $\begin{array}{l}\text { Blinding (performance } \\
\text { bias and detection bias) }\end{array}$ & High risk & Comment: amifostine versus no intervention. No apparent blinding. \\
$\begin{array}{l}\text { Outcome assessors } \\
\text { (attrition bias) } \\
\text { All outcomes }\end{array}$ & Low risk & $\begin{array}{l}50 \text { patients randomised. Assessable data from } 45 \text { patients. } 2 / 24 \text { in the amifos- } \\
\text { tine group and } 3 / 26 \text { in the control group. Authors give full reasons for attrition } \\
\text { and exclusion. }\end{array}$ \\
\hline
\end{tabular}

Selective reporting (re- Low risk Data presented for 45 patients by mucositis grade (table 4).

porting bias)

Other bias Low risk Study appears to be free from other sources of bias.

Antunes 2007

\section{Study characteristics}

Methods

Randomised, parallel group study conducted in Brazil. Study conducted between January 4th 2004 and May 20th 2005. Dentist involved in study. 
Antunes 2007 (Continued)

Participants Adults with leukaemia, lymphoma or myelodysplastic syndrome undergoing HSCT. 38 patients recruited and completed.

$\begin{array}{ll}\text { Interventions } & 2 \text { groups, lazer }(50 \mathrm{~mW} \text { InGaAlP diode laser, emitting continuous light at } 660 \mathrm{~nm} \text {, with a real power out- } \\ \text { put of } 46.7 \mathrm{~mW} \text { and energy density (ED) of } 4 \mathrm{~J} / \mathrm{cm} 2 \text {, measured at the fiberoptic end with } 0.196 \mathrm{~cm} 2 \text { of } \\ \text { section area) versus sham laser control. }\end{array}$

Outcomes

Mucositis incidence (OMAS, WHO), correlation between OMAS and WHO, mucositis free survival, ulcerative area extension, evaluator agreement, pain, clinical outcomes.

Notes Funding source: unclear.

\section{Risk of bias}

Bias Authors' judgement Support for judgement

Random sequence genera- Unclear risk tion (selection bias)

Quote: "Patients were randomised on the day of admission for the transplantation, between receiving laser therapy, or not receiving laser therapy".

Comment: random component not described.

Allocation concealment Unclear risk Insufficient information to determine 'yes' or 'no'.
(selection bias)

\begin{tabular}{|c|c|c|}
\hline $\begin{array}{l}\text { Blinding (performance } \\
\text { bias and detection bias) } \\
\text { Carers }\end{array}$ & Low risk & $\begin{array}{l}\text { Quote: "the dentists were the only members of the team who knew which } \\
\text { group the patient was randomized to". } \\
\text { Comment: probably done. }\end{array}$ \\
\hline $\begin{array}{l}\text { Blinding (performance } \\
\text { bias and detection bias) } \\
\text { Patients }\end{array}$ & Low risk & $\begin{array}{l}\text { Quote: "the dentists were the only members of the team who knew which } \\
\text { group the patient was randomized to". } \\
\text { Comment: probably done. }\end{array}$ \\
\hline $\begin{array}{l}\text { Blinding (performance } \\
\text { bias and detection bias) } \\
\text { Outcome assessors }\end{array}$ & High risk & $\begin{array}{l}\text { Quote: "one dentist and } 3 \text { nurses (blinded for the study) performed daily oral } \\
\text { evaluation of the patients". } \\
\text { Comment: one outcome assessor was not blind. }\end{array}$ \\
\hline $\begin{array}{l}\text { Incomplete outcome data } \\
\text { (attrition bias) } \\
\text { All outcomes }\end{array}$ & Low risk & 38 patients randomised. No missing outcome data. \\
\hline $\begin{array}{l}\text { Selective reporting (re- } \\
\text { porting bias) }\end{array}$ & Low risk & Data presented for all patients by mucositis grade (fig 1 ). \\
\hline Other bias & Low risk & Study appears to be free from other sources of bias. \\
\hline
\end{tabular}

Arun Maiya 2006

\section{Study characteristics}

Methods 
Arun Maiya 2006 (Continued)

\begin{tabular}{ll} 
Participants & Adults with carcinoma off the oral cavity receiving radiotherapy (66 Gy in 33 fractions). \\
\hline Interventions & $\begin{array}{l}\text { 2 groups, analgesics, anaesthetics, } 0.9 \% \text { saline and chlorhexidine versus laser (632.8 nm, } 10 \mathrm{~mW} \text { ) for } 3 \\
\text { minutes, } 5 \text { days per week. }\end{array}$ \\
\hline Outcomes & Mucositis assessed weekly using the WHO score. Other reported outcome measures: pain. \\
\hline Notes & Funding source: unclear.
\end{tabular}

\section{Risk of bias}

\begin{tabular}{lll}
\hline Bias & Authors' judgement & Support for judgement \\
\hline $\begin{array}{ll}\text { Random sequence genera- } \\
\text { tion (selection bias) }\end{array}$ & Low risk & $\begin{array}{l}\text { Quote: "the patients were divided based on computer generated randomiza- } \\
\text { tion into laser (study group) and control group with 25 patients in each group." } \\
\end{array}$ \\
& & Comment: computer generated randomisation. \\
\hline
\end{tabular}

$\begin{aligned} & \text { Allocation concealment } \\ & \text { (selection bias) }\end{aligned}$
Unclear risk Insufficient information to determine 'yes' or 'no'.

\begin{tabular}{|c|c|c|}
\hline $\begin{array}{l}\text { Blinding (performance } \\
\text { bias and detection bias) } \\
\text { Carers }\end{array}$ & High risk & $\begin{array}{l}\text { Neon laser versus oral analgesics, local application of anaesthetics, } 0.9 \% \\
\text { saline and povidine wash. No apparent blinding. }\end{array}$ \\
\hline
\end{tabular}

$\begin{array}{ll}\begin{array}{l}\text { Blinding (performance } \\ \text { bias and detection bias) } \\ \text { Patients }\end{array} & \text { High risk }\end{array} \quad \begin{aligned} & \text { Neon laser versus oral analgesics, local application of anaesthetics, } 0.9 \% \\ & \text { saline and povidine wash. No apparent blinding. }\end{aligned}$

\begin{tabular}{|c|c|c|}
\hline $\begin{array}{l}\text { Blinding (performance } \\
\text { bias and detection bias) } \\
\text { Outcome assessors }\end{array}$ & Low risk & $\begin{array}{l}\text { Quote: "Physician blinded to the type of treatment using WHO scale for mu- } \\
\text { cositis and visual analogue scale for pain evaluation recorded the objective as- } \\
\text { sessment of the degree of mucositis weekly". } \\
\text { Comment: probably done. }\end{array}$ \\
\hline $\begin{array}{l}\text { Incomplete outcome data } \\
\text { (attrition bias) } \\
\text { All outcomes }\end{array}$ & Low risk & 50 patients randomised. No missing outcome data. \\
\hline $\begin{array}{l}\text { Selective reporting (re- } \\
\text { porting bias) }\end{array}$ & Low risk & $\begin{array}{l}\text { Data presented for all patients by arm and grade of mucositis in text (page } \\
\text { 401). }\end{array}$ \\
\hline Other bias & Unclear risk & $\begin{array}{l}\text { No information given on characteristics of patients in each group at baseline. } \\
\text { Amount of analgesics used in each group not reported. }\end{array}$ \\
\hline
\end{tabular}

Attal 1993

\section{Study characteristics}

\begin{tabular}{ll}
\hline Methods & $\begin{array}{l}\text { Randomised, parallel group study conducted in France. Clear information on withdrawals: } 6 / 70 \text { control, } \\
6 / 70 \text { test. Unclear if dentist involved in study. Drop outs: } 0 \% \text {. Duration: day }-8 \text { to day }+100 .\end{array}$ \\
\hline Participants & $\begin{array}{l}\text { Adults with mixed blood cancers admitted to BMT unit. } 140 \text { patients enrolled } 6 \text { died in each group, but } \\
\text { all were evaluated. Recruited December } 1990 \text { to September } 1992 .\end{array}$ \\
\hline
\end{tabular}


Attal 1993 (Continued)

Interventions $\quad 2$ groups, no treatment control versus pentoxifylline (oral PTX $1600 \mathrm{mg} 1$ per day in 4 doses).

Outcomes Number requiring MSO4 for grade II or higher mucositis (by published criteria). Assessment used: day 100. Other reported outcomes: duration of stay in hospital, renal insufficiency, days morphine, fever, septicaemia, 100 day survival.

Notes

All patients received one of 4 possible standard regimens either; Cyclophosphamide +TBI, or cyclophosphamide + bisulfan, or melphalan + TBI or cyclophosphamide + etoposide + carmustine, prior

to autologous or allogenic BMT.

Funding source: not stated.

\section{Risk of bias}

\section{Bias}

\section{Authors' judgement Support for judgement}

Random sequence genera- Low risk tion (selection bias)

Quote: "patients were randomised to receive or not PTX. The treatment allocation for each patients was assigned by telephone by the biostatistics department, which had prepared before initiation of the trial a computer-generated sequence unknown to the physicians participating in the trial."

Comment: computer generated randomisation.

$\begin{array}{ll}\begin{array}{l}\text { Allocation concealment } \\ \text { (selection bias) }\end{array} & \text { Low risk } \\ & \begin{array}{l}\text { Quote: "The treatment allocation for each patient was assigned by telephone } \\ \text { by biostatistics department." }\end{array} \\ \text { Comment: central method of allocation. }\end{array}$

Blinding (performance High risk

PTX versus no treatment. No apparent blinding.

bias and detection bias)

Carers

Blinding (performance $\quad$ High risk PTX versus no treatment. No apparent blinding.
bias and detection bias)
Patients

\begin{tabular}{|c|c|c|}
\hline $\begin{array}{l}\text { Blinding (performance } \\
\text { bias and detection bias) } \\
\text { Outcome assessors }\end{array}$ & Unclear risk & $\begin{array}{l}\text { The authors state that the physicians participating in the trial were unaware } \\
\text { of the randomisation sequence. However, it is unclear who was doing the out- } \\
\text { come assessment. }\end{array}$ \\
\hline
\end{tabular}

Incomplete outcome data Low risk 140 patients randomised. No missing outcome data.

(attrition bias)

All outcomes

\begin{tabular}{|c|c|c|}
\hline $\begin{array}{l}\text { Selective reporting (re- } \\
\text { porting bias) }\end{array}$ & Low risk & $\begin{array}{l}\text { Data presented in the text for the number of patients with mucositis grade } 2 \text { or } \\
\text { higher in each study arm. }\end{array}$ \\
\hline
\end{tabular}

\begin{tabular}{ll}
\hline Other bias $\quad$ Low risk Study appears to be free of other sources of bias. \\
\hline
\end{tabular}

\section{Bensadoun 1999}

\section{Study characteristics}

$\begin{array}{ll}\text { Methods } & \text { Randomised, parallel multisite study conducted in France. Clear information about withdrawals: } 0 . \\ \text { Dentist involved in study. } 30 \text { patients recruited between September } 1994 \text { and March } 1998 . \text { Duration: } 5 \\ \text { consecutive days each week during the } 7 \text { weeks of radiotherapy. }\end{array}$


Bensadoun 1999 (Continued)

Participants Adults with head and neck cancers receiving radiotherapy (at least $65 \mathrm{~Gy}$ in total).

\begin{tabular}{ll}
\hline Interventions & 2 groups, sham laser versus laser (wavelength: $632.8 \mathrm{~nm}$; power: $60 \mathrm{~mW}$ in Nice and Mareilles, $25 \mathrm{~mW}$ in \\
Reims).
\end{tabular}

Mucositis assessed weekly using the WHO scale. Other outcome measures: pain, ability to swallow, in-
cidence and duration of treatment gaps.

Notes Funding source: unclear.

\section{Risk of bias}

Bias Authors' judgement Support for judgement

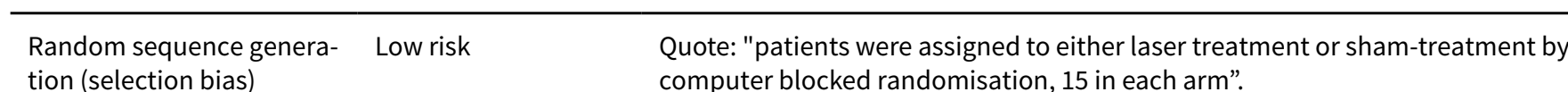
tion (selection bias) computer blocked randomisation, 15 in each arm".

Comment: computer generated randomisation.

Allocation concealment $\quad$ Unclear risk Insufficient information to determine 'yes' or 'no'.
(selection bias)

(selection bias)

\begin{tabular}{ll}
\hline $\begin{array}{l}\text { Blinding (performance } \\
\text { bias and detection bias) }\end{array}$ & Low risk \\
$\begin{array}{l}\text { Carers } \\
\text { was being sham treated, and did not participate in the evaluation and scoring } \\
\text { of mucositis". }\end{array}$
\end{tabular}

Comment: unlikely that nursing staff would know of allocation.

\begin{tabular}{|c|c|c|}
\hline $\begin{array}{l}\text { Blinding (performance } \\
\text { bias and detection bias) }\end{array}$ & Low risk & $\begin{array}{l}\text { Quote: "double blind". } \\
\text { Comment: probably done. }\end{array}$ \\
\hline
\end{tabular}

\begin{tabular}{|c|c|c|}
\hline $\begin{array}{l}\text { Blinding (performance } \\
\text { bias and detection bias) } \\
\text { Outcome assessors }\end{array}$ & Low risk & $\begin{array}{l}\text { Quote: "Objective assessment of degree of mucositis was recorded weekly by a } \\
\text { physician blinded to the type of treatment the patient received". } \\
\text { Comment: probably done. }\end{array}$ \\
\hline
\end{tabular}

\begin{tabular}{lll}
\hline $\begin{array}{l}\text { Incomplete outcome data } \\
\text { (attrition bias) } \\
\text { All outcomes }\end{array}$ & Low risk & 30 patients randomised. No missing outcome data. \\
\hline $\begin{array}{l}\text { Selective reporting (re- } \\
\text { porting bias) }\end{array}$ & Unclear risk & $\begin{array}{l}\text { Data presented for mean grade of mucositis by arm by week of treatment (ta- } \\
\text { ble } 3 / \text { fig } 3 \text { ) and distribution of mucositis grades, in number of weeks, for both } \\
\text { treatment weeks. }\end{array}$ \\
\hline Other bias & Unclear risk & $\begin{array}{l}\text { Possible imbalance of groups at baseline laser group older (mean } 62.7 \text { vs 58.1). } \\
\text { Also } 12 / 15 \text { of laser group vs. } 6 / 15 \text { of placebo group received laser treatment to } \\
\text { skin of neck ("possible distant laser effect"). Different power of laser used at } \\
\text { one study site (Relms). }\end{array}$ \\
\hline
\end{tabular}

Biswal 2003

\section{Study characteristics}

Rethods
Rentist was involved in study. Drop outs: $0 \%$. Duration: 49 days.


Biswal 2003 (Continued)

Participants Adults with head and neck cancer. 40 patients recruited and evaluated. Recruited November 2000 to October 2001.

Interventions

2 groups, rinse then swallow $20 \mathrm{ml}$ natural honey before radiotherapy, $20 \mathrm{ml}$ after and $20 \mathrm{ml} 6$ hours after that versus no treatment control.

\begin{tabular}{ll}
\hline Outcomes & Mucositis RTOG grading. Other reported outcomes: weight gain. \\
\hline Notes & Funding source: university. All patients received radiotherapy 60-70 Gy over 6-7 weeks.
\end{tabular}

\section{Risk of bias}

\section{Bias Authors' judgement Support for judgement}

Random sequence genera- Low risk Quote: "twenty patients were allocated equally to one study arm and another tion (selection bias) 20 to the control arm by computer generated random numbers".

Comment: computer generated random numbers.

\begin{tabular}{lll}
\hline $\begin{array}{l}\text { Allocation concealment } \\
\text { (selection bias) }\end{array}$ & Unclear risk & Insufficient information to determine 'yes' or 'no'. \\
\hline $\begin{array}{l}\text { Blinding (performance } \\
\text { bias and detection bias) }\end{array}$ & High risk & Honey versus no intervention. No apparent blinding. \\
Carers & &
\end{tabular}

Blinding (performance $\quad$ High risk $\quad$ Honey versus no intervention. No apparent blinding.
bias and detection bias)

Patients

Blinding (performance
bias and detection bias) High risk Honey versus no intervention. No apparent blinding.

bias and detection bias)

Incomplete outcome data Low risk 40 patients randomised. No missing outcome data.

(attrition bias)

All outcomes

\begin{tabular}{lll}
\hline $\begin{array}{l}\text { Selective reporting (re- } \\
\text { porting bias) }\end{array}$ & Low risk & $\begin{array}{l}\text { Data presented for number of patients with mucositis, number of patients with } \\
\text { grade 3/4 mucositis, mean grade, mean onset and mean total duration (all ta- } \\
\text { ble 2). }\end{array}$ \\
\hline Other bias & Low risk & Study appears to be free of other sources of bias.
\end{tabular}

Bjarnason 2009

\section{Study characteristics}

\begin{tabular}{ll}
\hline $\begin{array}{l}\text { Methods } \\
\text { Randomised parallel group multisite study conducted in Canada. Clear information about withdrawals. } \\
\text { Dentist involved in study. Recruitment of patients took place between August 1999 and November } \\
2004 .\end{array}$ \\
\hline Participants & Adults with head and neck cancers receiving radiotherapy (50-70 Gy). \\
\hline Interventions & 2 groups, radiotherapy in the morning (8am to 10am) versus radiotherapy in the evening (4pm to $6 \mathrm{pm})$. \\
\hline & \\
\hline Interventions for preventing oral mucositis for patients with cancer receiving treatment (Review) & $\mathbf{6 6}$ \\
Copyright $\odot 2011$ The Cochrane Collaboration. Published by John Wiley \& Sons, Ltd.
\end{tabular}

Copyright $\odot 2011$ The Cochrane Collaboration. Published by John Wiley \& Sons, Ltd. 
Bjarnason 2009 (Continued)

Outcomes Mucositis assessed weekly using the OMAS instrument. Other reported outcomes: disease reoccurrence, quality of life, compliance with treatment, death, smoking status, weight loss.

Notes

Funding source: National Cancer Institute of Canada.

\section{Risk of bias}

\section{Bias}

\section{Authors' judgement Support for judgement}

Random sequence genera- Unclear risk tion (selection bias)

Quote: "A minimization procedure was used to randomize patients".

Quote: "patients were stratified by treatment centre, pretreatment smoking behaviour...tobacco use questionnaire, and planned total radiation dose".

Comment: minimization.

Allocation concealment $\quad$ Unclear risk Insufficient information to determine 'yes' or 'no'.
(selection bias)

(selection bias)

High risk Morning versus evening radiation. No apparent blinding.

Blinding (performance

bias and detection bias)

Carers

Blinding (performance
bias and detection bias) High risk Morning versus evening radiation. No apparent blinding.

Patients

\begin{tabular}{lll}
\hline $\begin{array}{l}\text { Blinding (performance } \\
\text { bias and detection bias) } \\
\text { Outcome assessors }\end{array}$ & High risk & $\begin{array}{l}\text { Quote: "the oncologists performing the evaluations were aware of the treat- } \\
\text { ment arm for each patient". }\end{array}$ \\
\hline $\begin{array}{l}\text { Incomplete outcome data } \\
\text { (attrition bias) }\end{array}$ & Low risk & $\begin{array}{l}216 \text { patients recruited. } 7 \text { patients deemed ineligible }(4 / 108 \text { arm A, 3/108 arm } \\
\text { Bll outcomes }\end{array}$ \\
& $\begin{array}{l}\text { arm B did not have mucositis assessment. 205 patients included in final analy- } \\
\text { sis. }\end{array}$ \\
\hline $\begin{array}{l}\text { Selective reporting (re- } \\
\text { porting bias) }\end{array}$ & Unclear risk & $\begin{array}{l}\text { Data presented for number of patients with grade } 3 \text { or greater mucositis, me- } \\
\text { dian interval to mucositis and median grade of mucositis (all RTOG). Data col- } \\
\text { lected using OMAS instrument also presented (table 3). }\end{array}$
\end{tabular}

\begin{tabular}{ll}
\hline Other bias $\quad$ Low risk $\quad$ Study appears to be free from other sources of bias. \\
\hline
\end{tabular}

\section{Blazar 2006}

\section{Study characteristics}

\begin{tabular}{ll}
\hline Methods & $\begin{array}{l}\text { Randomised, parallel group, multisite study conducted in the USA. Clear information about with- } \\
\text { drawals: } 20 \text { (17 patients withdrew and were replaced). Unclear if dentist involved in study. }\end{array}$ \\
\hline Participants & $\begin{array}{l}\text { Adults and children with haematological malignancies (acute lymphoblastic leukaemia, acute } \\
\text { myelogenous leukaemia, chronic myelogenous leukaemia, myelodysplastic syndrome, non- } \\
\text { Hodgkin leukaemia, Hodgkin's disease, other) aged between } 3 \text { and } 65 \text { years old, receiving allogeneic } \\
\text { hematopoietic stem cell transplantation. Conditioning regimes: cyclophosphamide and total body irra- } \\
\text { diation or busulfan and cyclophosphamide. }\end{array}$ \\
\hline
\end{tabular}


Blazar 2006 (Continued)

Interventions
3 cohorts, cohort 1 received either palifermin ( $60 \mu \mathrm{g} / \mathrm{kg}$ in 6 doses), palifermin ( $40 \mu \mathrm{g} / \mathrm{kg}$ in 6 doses) or placebo. Cohort 2 received palifermin $(60 \mu \mathrm{g} / \mathrm{kg}$ in 9 doses) or placebo. Cohort 3 received palifermin (60 $\mu \mathrm{g} / \mathrm{kg}$ in 12 doses).

\begin{tabular}{ll} 
Outcomes & $\begin{array}{l}\text { Mucositis assessed weekly using the world health organisation and common toxicities criteria scales. } \\
\text { Other reported outcome measures: adverse events, GVHD, hematopoietic recovery, methotrexate dos- } \\
\text { ing, survival and relapse. }\end{array}$ \\
\hline Notes & Funding source: National Institute of Health grants and Amgen (pharmaceutical)
\end{tabular}

\section{Risk of bias}

\begin{tabular}{|c|c|c|}
\hline Bias & Authors' judgement & Support for judgement \\
\hline \multirow[t]{2}{*}{$\begin{array}{l}\text { Random sequence genera- } \\
\text { tion (selection bias) }\end{array}$} & Unclear risk & $\begin{array}{l}\text { Quote: "Randomisation was structured to achieve balance between the place- } \\
\text { bo and palifermin groups within each study site in each cohort". }\end{array}$ \\
\hline & & Comment: random component not described. \\
\hline $\begin{array}{l}\text { Allocation concealment } \\
\text { (selection bias) }\end{array}$ & Unclear risk & Insufficient information to determine 'yes' or 'no'. \\
\hline $\begin{array}{l}\text { Blinding (performance } \\
\text { bias and detection bias) } \\
\text { Carers }\end{array}$ & Unclear risk & Insufficient information to determine 'yes' or 'no'. \\
\hline Blinding (performance & Low risk & Quote: "double blind". \\
\hline Patients & & Comment: probably done. \\
\hline $\begin{array}{l}\text { Blinding (performance } \\
\text { bias and detection bias) }\end{array}$ & Low risk & \\
\hline Outcome assessors & & Comment: probably done. \\
\hline $\begin{array}{l}\text { Incomplete outcome data } \\
\text { (attrition bias) } \\
\text { All outcomes }\end{array}$ & Low risk & $\begin{array}{l}100 \text { patients randomised. } 17 \text { patients discontinued and replaced ( } 1 / 31 \text { placebo } \\
\text { group). } 3 \text { patients suffered SAE and were not replaced ( } 1 / 31 \text { placebo group). } \\
\text { Full reasons given for attrition/exclusion. }\end{array}$ \\
\hline $\begin{array}{l}\text { Selective reporting (re- } \\
\text { porting bias) }\end{array}$ & Low risk & $\begin{array}{l}\text { Data presented for all patients by mucositis grade. Palifermin doses combined } \\
\text { (table 4). }\end{array}$ \\
\hline Other bias & Low risk & Study appears to be free of other sources of bias. \\
\hline
\end{tabular}

Borowski 1994

\section{Study characteristics}

\begin{tabular}{ll}
\hline Methods & $\begin{array}{l}\text { Randomised, parallel group study conducted in France. Clear information on withdrawals: } 7 / 82 \text { control, } \\
9 / 84 \text { test. Dentist involved in study. Duration: } 30 \text { days. }\end{array}$ \\
\hline Participants & $\begin{array}{l}\text { Children and adults with mixed cancer and candidates for BMT. } 166 \text { eligible and enrolled between Feb- } \\
\text { ruary } 1986 \text { and November } 1989 \text { with } 150 \text { completing. }\end{array}$ \\
\hline Interventions & $\begin{array}{l}\text { 2 groups, limited oral hygiene versus intense oral hygiene (brushing } 3 \text { times per day after meals as in- } \\
\text { structed by dentist). }\end{array}$ \\
\hline
\end{tabular}


Borowski 1994 (Continued)

Outcomes
Moderate or severe mucositis with detailed description of each category. Assessment used: day 30. Other outcomes: plaque, fever, septicaemia.

Notes

Chlorhexidine mouthrinse used at least 5 times daily by both groups.

Funding source: unclear.

\section{Risk of bias}

\begin{tabular}{lll}
\hline Bias & Authors' judgement & Support for judgement \\
\hline $\begin{array}{l}\text { Random sequence genera- } \\
\text { tion (selection bias) }\end{array}$ & Unclear risk & $\begin{array}{l}\text { Quote: "Patients fulfilling the enrolment criteria were randomly allocated by } \\
\text { telephone". }\end{array}$ \\
& $\begin{array}{l}\text { Quote: "randomisation was balanced every } 4 \text { subjects and stratified on IOS." } \\
\text { Comment: random component not described. }\end{array}$
\end{tabular}

\begin{tabular}{ll}
\hline $\begin{array}{l}\text { Allocation concealment } \\
\text { (selection bias) }\end{array}$ & $\begin{array}{l}\text { Quote: "Patients fulfilling the enrolment criteria were randomly allocated by } \\
\text { telephone". }\end{array}$ \\
Comment: central allocation.
\end{tabular}

Blinding (performance $\quad$ High risk Intensive oral hygiene versus limited oral hygiene. No apparent blinding.
bias and detection bias)
Carers

Blinding (performance High risk Intensive oral hygiene versus limited oral hygiene. No apparent blinding. bias and detection bias) Patients

\begin{tabular}{ll}
\hline $\begin{array}{l}\text { Blinding (performance } \\
\text { bias and detection bias) } \\
\text { Outcome assessors }\end{array}$ & High risk
\end{tabular}$\quad \begin{aligned} & \text { Quote: "these evaluations could not be performed blindly because of dental } \\
& \text { plaque." }\end{aligned}$

\begin{tabular}{lll}
\hline $\begin{array}{l}\text { Incomplete outcome data } \\
\text { (attrition bias) } \\
\text { All outcomes }\end{array}$ & Low risk & $\begin{array}{l}166 \text { patients randomised. } 16 \text { patients excluded from analysis: } 9 / 84 \text { intensive } \\
\text { oral hygiene group, } 7 / 82 \text { limited oral hygiene group. Authors give complete } \\
\text { reasons for exclusion/attrition. }\end{array}$ \\
\hline $\begin{array}{l}\text { Selective reporting (re- } \\
\text { porting bias) }\end{array}$ & Unclear risk & $\begin{array}{l}\text { Data presented in the text for proportions of patients with moderate/severe } \\
\text { mucositis according to treatment allocation. Percentage of patients with mod- } \\
\text { erate or severe mucositis presented over time for both arms of the study (fig 2) } \\
\text { and patients receiving TBI/no TBI (fig 1). }\end{array}$ \\
\hline Other bias & Low risk & Study appears to be free of other sources of bias. \\
\hline
\end{tabular}

Bourhis 2000

\section{Study characteristics}

Methods

Randomised, parallel group study conducted in France. Unclear information on withdrawals: 1 died and 1 refused, unclear which group. Unclear if dentist involved in study. Drop outs: 8\%. Duration: unclear.

Participants

Adults with head and neck cancer, stage IV not amenable to conventional radiosurgical treatment. Karnofsky performance > 60. Radiotherapy $64 \mathrm{~Gy}$ in 22-23 days. 26 patients enrolled and randomised between May 1996 and February 1998. 24 were evaluated. 
Bourhis 2000 (Continued)

Interventions
2 groups, no treatment control versus amifostine (subcutaneous infusion $150 \mathrm{mg} / \mathrm{m}^{2}$ amifostine administered IV twice daily 15-30 minutes prior to each radiotherapy session).

Outcomes

Max WHO grade (I to IV). Assessment used: day 23. Other reported outcomes: duration of feeding tube, vomiting, liver function, erythema (tolerance of amifostine). Duration of feeding tube.

\section{Notes}

RTOG index also given with mean duration of at least grade 3 mucositis.

Funding source: pharmaceutical.

\section{Risk of bias}

Bias Authors' judgement Support for judgement

Random sequence genera- Unclear risk tion (selection bias)
Quote: "Patients were randomized to receive or not $150 \mathrm{mg} / \mathrm{m} 2$ amifostine 15-30 min prior to each radiation session."

Comment: random component not described.

\begin{tabular}{lll}
\hline $\begin{array}{l}\text { Allocation concealment } \\
\text { (selection bias) }\end{array}$ & Low risk & $\begin{array}{l}\text { Quote: "The randomisation procedure was done by telephone". } \\
\text { Comment: central allocation. Probably done. }\end{array}$ \\
\hline $\begin{array}{l}\text { Blinding (performance } \\
\text { bias and detection bias) } \\
\text { Carers }\end{array}$ & High risk & Comment: amifostine versus no intervention. No apparent blinding. \\
\hline
\end{tabular}

Blinding (performance
bias and detection bias) High risk Comment: amifostine versus no intervention. No apparent blinding.

bias and detection bias)

Patients

Blinding (performance High risk Comment: amifostine versus no intervention. No apparent blinding.
bias and detection bias)
Outcome assessors

Outcome assessors

Incomplete outcome data Low risk

(attrition bias)

All outcomes
26 patients randomised. 2 patients not included in mucositis assessment. Full reasons for drop outs.

\begin{tabular}{|c|c|c|}
\hline $\begin{array}{l}\text { Selective reporting (re- } \\
\text { porting bias) }\end{array}$ & Unclear risk & $\begin{array}{l}\text { Data presented WHO grades } 2 \text { to } 4 \text { and mean duration of }>\text { grade } 3 \text { mucositis } \\
\text { (days) (table } 1 \text { ). }\end{array}$ \\
\hline
\end{tabular}

Other bias High risk Study stopped early due to problems with the tolerance of amifostine.

Brizel 2000

\section{Study characteristics}

\begin{tabular}{ll}
\hline Methods & $\begin{array}{l}\text { Randomised, parallel group multisite study conducted in USA, Germany and France. Clear information } \\
\text { about withdrawals: none. Unclear if dentist involved in study. Drop outs: } 0 \% . \text { Duration: } 1 \text { year. }\end{array}$ \\
\hline Participants & $\begin{array}{l}\text { Adults with head and neck cancer. Newly diagnosed squamous cell radiation more than or equal to } \\
70 \% \text { both parotid glands more than or equal to } 40 \text { Gy - daily } 2 \text { Gy. } 315 \text { enrolled and randomised be- } \\
\text { tween October } 1995 \text { to October } 1997.12 \text { patients never received any treatment or follow-up. The re- } \\
\text { sults are presented for the remaining } 303 .\end{array}$ \\
\hline Interventions & 2 groups, no treatment control versus amifostine $200 \mathrm{mg} / \mathrm{m} 2$ daily $15-20$ minutes prior to radiation. \\
\hline \hline
\end{tabular}


Brizel 2000 (Continued)

Outcomes
Mucositis assessed weekly by physician. Radiation Therapy Oncology Group Scoring systems. Assessment used: day 90. Other reported outcomes: nausea, vomiting, xerostomia, saliva production, survival, local disease control.

Notes Funding source: pharmaceutical.

\section{Risk of bias}

\begin{tabular}{lll}
\hline Bias & Authors' judgement & Support for judgement \\
\hline $\begin{array}{l}\text { Random sequence genera- } \\
\text { tion (selection bias) }\end{array}$ & Low risk & $\begin{array}{l}\text { Quote: "three hundred fifteen patients were enrolled and randomised from } \\
\text { October } 1995 \text { to October 1997". }\end{array}$ \\
& Quote: "Patients were randomized using a dynamic allocation process." \\
& $\begin{array}{l}\text { Comment: random component not described, however, authors make refer- } \\
\text { ence to two articles on randomisation. Probably done. }\end{array}$
\end{tabular}

\begin{tabular}{ll}
\hline $\begin{array}{l}\text { Allocation concealment } \\
\text { (selection bias) }\end{array}$ & Low risk \\
& $\begin{array}{l}\text { Quote: "treatment assignment was determined by a phone call from the en- } \\
\text { rolling institution to the protocol sponsor". } \\
\text { Comment: central allocation. Probably done. }\end{array}$ \\
\hline
\end{tabular}

Blinding (performance $\quad$ High risk Quote: "open label".
bias and detection bias)
Carers

\begin{tabular}{lll}
\hline $\begin{array}{l}\text { Blinding (performance } \\
\text { bias and detection bias) } \\
\text { Patients }\end{array}$ & High risk & Quote: "open label". \\
\hline $\begin{array}{l}\text { Blinding (performance } \\
\text { bias and detection bias) } \\
\text { Outcome assessors }\end{array}$ & High risk & Quote: "open label". \\
\hline $\begin{array}{l}\text { Incomplete outcome data } \\
\text { (attrition bias) } \\
\text { All outcomes }\end{array}$ & Low risk & $\begin{array}{l}315 \text { patients randomised. } 12 \text { patients never received intervention. 22 patients } \\
\text { discontinued but included in efficacy analysis. 2/150 patients in amifostine } \\
\text { group missing from mucositis analysis. Observed event risk not sufficient to } \\
\text { have clinically relevant impact. }\end{array}$
\end{tabular}

\begin{tabular}{lll}
\hline $\begin{array}{l}\text { Selective reporting (re- } \\
\text { porting bias) }\end{array}$ & Low risk & Data presented for 301 patients by grade of mucositis. \\
\hline Other bias & Low risk & Study appears to be free of other sources of bias. \\
\hline
\end{tabular}

Brizel 2008

\section{Study characteristics}

Methods

Randomised, parallel group multisite study conducted in the USA, Canada and Australia. Withdrawals unclear (see ROB). Unclear if dentist involved in study.

Participants

Adults with stage III/IV or IV squamous carcinoma of the oral cavity, oropharynx, hypopharynx and larynx undergoing concurrent chemoradiotherapy. Radiotherapy given in 2 Gy fractions to 70 Gy, hyperfractionated radiotherapy given in 1.25 Gy fractions twice daily. Chemotherapy: cisplatin $20 \mathrm{mg} / \mathrm{m}^{2}$ for 4 days and fluorouracil $1000 \mathrm{mg} / \mathrm{m}^{2} / \mathrm{d}$ for 4 days (weeks 1 and 5 of radiotherapy). 
Brizel 2008 (Continued)

Interventions $\quad 2$ groups: placebo versus palifermin $60 \mu \mathrm{g}$ once weekly during radiotherapy for 9 consecutive weeks.

\begin{tabular}{ll}
\hline Outcomes & $\begin{array}{l}\text { Mucositis assessed weekly using CTCAE (version 2). Other reported outcomes: dysphagia, xerostomia, } \\
\text { radiotherapy breaks, supplemental nutrition, safety. }\end{array}$ \\
\hline Notes & Funding source: pharmaceutical.
\end{tabular}

\section{Risk of bias}

Bias Authors' judgement Support for judgement

Random sequence genera- Unclear risk tion (selection bias)

Quote: "A multicentre, double blind, randomised, placebo controlled study was conducted at 22 centres".

Comment: random component not described.

Allocation concealment $\quad$ Unclear risk
(selection bias)

(selection bias)

Blinding (performance Unclear risk Insufficient information to determine 'yes' or 'no'.
bias and detection bias)
Carers

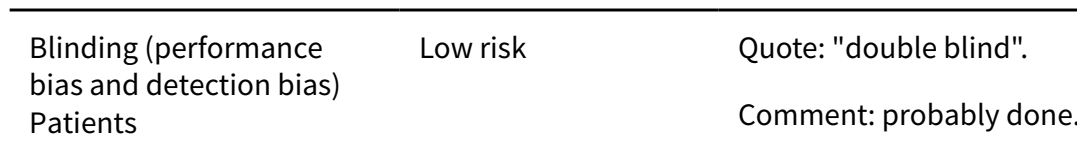

\begin{tabular}{|c|c|c|}
\hline $\begin{array}{l}\text { Blinding (performance } \\
\text { bias and detection bias) }\end{array}$ & Low risk & Quote: "double blind". \\
\hline Outcome assessors & & Comment: probably done. \\
\hline
\end{tabular}

\begin{tabular}{ll}
\hline $\begin{array}{l}\text { Incomplete outcome data } \\
\text { (attrition bias) } \\
\text { All outcomes }\end{array}$ & $\begin{array}{l}\text { Quote: "Ninety-nine of } 100 \text { patients who were randomly assigned (67 palifer- } \\
\text { min, } 32 \text { placebo received at least } 1 \text { dose of study treatment and were evaluat- } \\
\text { ed". }\end{array}$ \\
& $\begin{array}{l}\text { Comment: } 101 \text { patients stated as randomised in figure } 1 . \text { Table } 1 \text { gives base- } \\
\text { line data for } 99 \text { patients. }\end{array}$ \\
& $\begin{array}{l}\text { Comment: } 21 \text { patients discontinued. } 17 / 67 \text { in palifermin group, } 4 / 32 \text { in placebo } \\
\text { group. Authors give incomplete reasons for attrition/exclusion. }\end{array}$
\end{tabular}

Selective reporting (re- Unclear risk Data only presented for mucositis scores $>2$ and $>3$ (fig 2 ).
porting bias)

\begin{tabular}{ll}
\hline Other bias & High risk \\
& $\begin{array}{l}\text { Authors used NCI CTC tool to assess patients for first } 12 \text { weeks and then the } \\
\text { RTOG late onset tool at weeks } 14 / 16 / 18 / 20 . \text { This prevented direct comparisons } \\
\text { between the groups. }\end{array}$
\end{tabular}

Bubley 1989

\section{Study characteristics}

Methods

Randomised, parallel group study conducted in USA. Clear information about withdrawals: 0 . Unclear if dentist involved in study. 
Bubley 1989 (Continued)

Participants

Adults with head and neck cancer. Prior positive titre to Herpes Simplex. Results presented for 57 patients.

\begin{tabular}{ll}
\hline Interventions & 2 groups, placebo versus acyclovir $200 \mathrm{mg}$ tablets 12 hourly. \\
\hline Outcomes & $\begin{array}{l}\text { Mucositis assessed by nurse. Assessment used: unclear. Other reported outcomes: herpes simplex } \\
\text { virus. }\end{array}$ \\
\hline Notes & $\begin{array}{l}\text { Data presented separately for patients receiving chemo and radiotherapy. } \\
\text { Funding source: pharmaceutical. }\end{array}$ \\
\hline
\end{tabular}

\section{Risk of bias}

\begin{tabular}{|c|c|c|}
\hline Bias & Authors' judgement & Support for judgement \\
\hline $\begin{array}{l}\text { Random sequence genera- } \\
\text { tion (selection bias) }\end{array}$ & Low risk & $\begin{array}{l}\text { Quote: "Randomization occurred on the basis of computer-generated random } \\
\text { codes supplied by the sponsor of the study". } \\
\text { Comment: computer generated randomisation sequence. }\end{array}$ \\
\hline $\begin{array}{l}\text { Allocation concealment } \\
\text { (selection bias) }\end{array}$ & Unclear risk & Insufficient information to determine 'yes' or 'no'. \\
\hline $\begin{array}{l}\text { Blinding (performance } \\
\text { bias and detection bias) } \\
\text { Carers }\end{array}$ & Unclear risk & Insufficient information to determine 'yes' or 'no'. \\
\hline $\begin{array}{l}\text { Blinding (performance } \\
\text { bias and detection bias) } \\
\text { Patients }\end{array}$ & Low risk & $\begin{array}{l}\text { Quote: "double blind". } \\
\text { Comment: probably done. }\end{array}$ \\
\hline $\begin{array}{l}\text { Blinding (performance } \\
\text { bias and detection bias) } \\
\text { Outcome assessors }\end{array}$ & Low risk & $\begin{array}{l}\text { Quote: "double blind". } \\
\text { Comment: probably done. }\end{array}$ \\
\hline $\begin{array}{l}\text { Incomplete outcome data } \\
\text { (attrition bias) } \\
\text { All outcomes }\end{array}$ & Low risk & 57 patients recruited. All patients included analysis. \\
\hline $\begin{array}{l}\text { Selective reporting (re- } \\
\text { porting bias) }\end{array}$ & Unclear risk & Data presented for absent versus present dichtomy. \\
\hline Other bias & Low risk & Study appears to be free of other sources of bias. \\
\hline
\end{tabular}

Buentzel 2006

\section{Study characteristics}

\begin{tabular}{ll}
\hline Methods & Randomised, parallel group, multicentre study conducted in USA/Europe. Clear information on with- \\
drawals: none. Unclear if dentist involved in study. Drop outs: $22 \%$. Duration: up to 90 days.
\end{tabular}

Participants Adults with head and neck cancer. 132 enrolled and randomised between October 1996 to October 1998. 102 completed but ITT analysis presented. 
Buentzel 2006 (Continued)

Interventions

2 groups, placebo versus intravenous amifostine $(300 \mathrm{mg} / \mathrm{m} 2$ before carboplatin $70 \mathrm{mg} / \mathrm{m} 2$ and radiotherapy on days 1 to 5 and 21 to 25 , and intravenous amifostine $200 \mathrm{mg} / \mathrm{m} 2$ or placebo before radiotherapy on 6 to 20 and 26 to $30 / 35$ days).
Mucositis graded with reference to RTOG criteria on a 0-4 scale. Assessment used up to 90 days. Other reported outcomes: xerostomia, 1 yr locoregional failure, progression-free survival, overall survival, treatment related adverse events: vomiting, nausea, asthenia, allergic reaction, anaemia, phlebitis, leukopenia, hypotension, allergic reaction.

\begin{tabular}{ll}
\hline Notes & Funding source: industry. \\
& Pharmacological company provided drug and organised randomisation.
\end{tabular}

\section{Risk of bias}

\begin{tabular}{|c|c|c|}
\hline Bias & Authors' judgement & Support for judgement \\
\hline $\begin{array}{l}\text { Random sequence genera- } \\
\text { tion (selection bias) }\end{array}$ & Unclear risk & $\begin{array}{l}\text { Quote: "Patients were randomly assigned in a ratio of } 1: 1 " \text { ". } \\
\text { Comment: random component not described. }\end{array}$ \\
\hline $\begin{array}{l}\text { Allocation concealment } \\
\text { (selection bias) }\end{array}$ & Unclear risk & Insufficient information to determine "yes" or "no". \\
\hline $\begin{array}{l}\text { Blinding (performance } \\
\text { bias and detection bias) } \\
\text { Carers }\end{array}$ & Unclear risk & Insufficient information to determine "yes" or "no". \\
\hline $\begin{array}{l}\text { Blinding (performance } \\
\text { bias and detection bias) } \\
\text { Patients }\end{array}$ & Low risk & $\begin{array}{l}\text { Quote: "double blind". } \\
\text { Comment: probably done. }\end{array}$ \\
\hline $\begin{array}{l}\text { Blinding (performance } \\
\text { bias and detection bias) } \\
\text { Outcome assessors }\end{array}$ & Low risk & $\begin{array}{l}\text { Quote: "double blind". } \\
\text { Comment: probably done. }\end{array}$ \\
\hline $\begin{array}{l}\text { Incomplete outcome data } \\
\text { (attrition bias) } \\
\text { All outcomes }\end{array}$ & Low risk & $\begin{array}{l}132 \text { patients randomised. } 20 / 67 \text { missing from treatment group, } 9 / 65 \text { missing } \\
\text { from placebo group. } 1 \text { patient from each group not treated. Authors give full } \\
\text { reasons for exclusions and withdrawals. ITT analysis. Mucositis data presented } \\
\text { for } 129 \text { patients. }\end{array}$ \\
\hline $\begin{array}{l}\text { Selective reporting (re- } \\
\text { porting bias) }\end{array}$ & Low risk & Data presented for 129 patients by mucositis grade (table 2 ). \\
\hline Other bias & Low risk & Study appears to be free from other sources of bias. \\
\hline
\end{tabular}

Buntzel 1998

\section{Study characteristics}

\begin{tabular}{ll}
\hline Methods & $\begin{array}{l}\text { Randomised, parallel group study conducted in Germany. Clear information on withdrawals: none. Un- } \\
\text { clear if dentist involved in study. Drop outs: 0\%. Duration: } 6 \text { weeks. }\end{array}$ \\
\hline Participants & $\begin{array}{l}\text { Adults with head and neck cancer, hospitalised with stage III-IV tumour, no evidence of systemic infec- } \\
\text { tion, liver or renal impairment, tumour resected or excised before adjuvant radiotherapy. } 28 \text { patients } \\
\text { enrolled, } 28 \text { were evaluated. }\end{array}$ \\
\hline
\end{tabular}


Buntzel 1998 (Continued)

Interventions
2 groups, radiotherapy with or without amifostine ( $15 \mathrm{~min}$ infusion $500 \mathrm{mg}$ preceded by antiemetic regimen of $12 \mathrm{mg}$ dexamethasone and $8 \mathrm{mg}$ ondansetron).

Outcomes

WHO mucositis grades 3/4. Assessment used: day 42. Other reported outcomes: xerostomia, dysphagia, loss of taste, dermatitis, haematological side effects.

\begin{tabular}{ll}
\hline Notes & More data presented but included extra 11 patients in amifostine group who were not entered into \\
& study. \\
& Funding source: pharmaceutical.
\end{tabular}

Risk of bias

\begin{tabular}{|c|c|c|}
\hline Bias & Authors' judgement & Support for judgement \\
\hline $\begin{array}{l}\text { Random sequence genera- } \\
\text { tion (selection bias) }\end{array}$ & Unclear risk & $\begin{array}{l}\text { Quote: "eligible patients were randomised to receive RCT } \pm \text { amifostine". } \\
\text { Comment: random component not described. }\end{array}$ \\
\hline $\begin{array}{l}\text { Allocation concealment } \\
\text { (selection bias) }\end{array}$ & Unclear risk & Insufficient information to determine 'yes' or 'no'. \\
\hline $\begin{array}{l}\text { Blinding (performance } \\
\text { bias and detection bias) } \\
\text { Carers }\end{array}$ & High risk & Amifostine versus no intervention. No apparent blinding. \\
\hline $\begin{array}{l}\text { Blinding (performance } \\
\text { bias and detection bias) } \\
\text { Patients }\end{array}$ & High risk & Amifostine versus no intervention. No apparent blinding. \\
\hline $\begin{array}{l}\text { Blinding (performance } \\
\text { bias and detection bias) } \\
\text { Outcome assessors }\end{array}$ & High risk & Amifostine versus no intervention. No apparent blinding. \\
\hline $\begin{array}{l}\text { Incomplete outcome data } \\
\text { (attrition bias) } \\
\text { All outcomes }\end{array}$ & Low risk & $\begin{array}{l}28 \text { patients initially randomised. After positive results suggested an additional } \\
11 \text { patients were recruited to the amifostine arm. No missing outcome data. }\end{array}$ \\
\hline $\begin{array}{l}\text { Selective reporting (re- } \\
\text { porting bias) }\end{array}$ & Low risk & Data presented for all patients by mucositis grade (see table 2 ). \\
\hline Other bias & High risk & $\begin{array}{l}\text { Quote: "In view of these positive results, an additional } 11 \text { patients were subse- } \\
\text { quently accrued to the amifostine arm." }\end{array}$ \\
\hline
\end{tabular}

Cartee 1995

\section{Study characteristics}

Methods Randomised, parallel group study conducted in USA. Unclear information on withdrawals: 5 withdrew, unclear from which groups. Dentist involved in study. Drop outs: 10\%. Duration: 21 days.

Participants $\quad$ Adults with breast cancer stage IV, with combination of chemotherapy including 5-FU, adriamycin \& methotrexate. First cycle of chemotherapy. 50 patients were enrolled and 45 were evaluated. 
Cartee 1995 (Continued)

Interventions $\quad 5$ groups, $0.1 \%$ albumin (described as placebo, dose 0 ), GM-CSF (molgramostim, range of doses, 0.01 , $0.10,1.00,10.00 \mathrm{mcg} / \mathrm{ml}$. Mouthwash solutions administered 4 times daily starting 24 hours after chemotherapy initiation). Continuing until end of cycle.

Outcomes Mucositis (CALGB GRADE >= 3). Assessment used: day 15. Other reported outcomes: WBC, plasma GMCSF.

Notes

Doses $0.01,0.10,1.00,10.00$ were combined and compared with dose 0 (control).

Funding source: government.

\section{Risk of bias}

\begin{tabular}{lll}
\hline Bias & Authors' judgement & Support for judgement \\
\hline $\begin{array}{l}\text { Random sequence genera- } \\
\text { tion (selection bias) }\end{array}$ & Low risk & $\begin{array}{l}\text { Quote: "patients were randomised by the Duke Centre Protocol office accord- } \\
\text { ing to a block randomisation scheme and assigned a unique identifier number } \\
\text { which designated the GM-CSF dose level to be received". }\end{array}$ \\
& $\begin{array}{l}\text { Comment: random component not explicit. However, setting makes adequate } \\
\text { randomisation likely. }\end{array}$
\end{tabular}

\begin{tabular}{ll}
\hline $\begin{array}{l}\text { Allocation concealment } \\
\text { (selection bias) }\end{array}$ & $\begin{array}{l}\text { Quote: "The patient supply of mouthwash was labelled to correspond with the } \\
\text { assigned identifier number and dispensed by pharmacy. The patient assign- } \\
\text { ment information was maintained by the pharmacy to perverse the study dou- } \\
\text { ble blind". }\end{array}$ \\
& Comment: pharmacy controlled randomisation.
\end{tabular}

\begin{tabular}{|c|c|c|}
\hline $\begin{array}{l}\text { Blinding (performance } \\
\text { bias and detection bias) }\end{array}$ & Low risk & $\begin{array}{l}\text { Adequate allocation concealment. Unlikely that carers would know of alloca- } \\
\text { tion. }\end{array}$ \\
\hline
\end{tabular}

\begin{tabular}{|c|c|c|}
\hline $\begin{array}{l}\text { Blinding (performance } \\
\text { bias and detection bias) } \\
\text { Patients }\end{array}$ & Low risk & $\begin{array}{l}\text { Quote: "double blind". } \\
\text { Comment: probably done. }\end{array}$ \\
\hline
\end{tabular}

\begin{tabular}{ll}
\hline $\begin{array}{l}\text { Blinding (performance } \\
\text { bias and detection bias) } \\
\text { Outcome assessors }\end{array}$ & Low risk \\
\hline
\end{tabular}

$\begin{array}{ll}\begin{array}{l}\text { Incomplete outcome data } \\ \text { (attrition bias) }\end{array} & \text { Low risk } \\ \text { All outcomes } & \begin{array}{l}50 \text { patients randomised. } 5 \text { patients withdrew. Authors give full reasons for } \\ \text { withdrawals and exclusions, but do not state which arm patients were ran- } \\ \text { domised to. }\end{array}\end{array}$

\begin{tabular}{lll}
\hline $\begin{array}{l}\text { Selective reporting (re- } \\
\text { porting bias) }\end{array}$ & Unclear risk & Data presented for grade 3 mucositis by dose (table 1). \\
\hline Other bias & Low risk & Study appears to be free of other sources of bias. \\
\hline
\end{tabular}

Carter 1999

\section{Study characteristics}

Methods

Randomised, parallel group study conducted in USA. Clear information on withdrawals: none. Dentist Involvement unclear. Drop outs: $0 \%$. Duration: up to 4 months post radiotherapy. 
Carter 1999 (Continued)

Participants $\quad$ Adults with head and neck cancer receiving curative intent radiotherapy, Karnofsky performance $>60$. 102 patients enrolled and 102 completed.

\begin{tabular}{ll}
\hline Interventions & $\begin{array}{l}2 \text { groups, placebo versus sucralfate (added as suspension of } 1 \text { gm sucralfate/15 ml solution) swish } 2 \\
\text { minutes and swallow } 4 \text { times per day. }\end{array}$
\end{tabular}

\begin{tabular}{ll}
\hline Outcomes & RTOG graded mucositis. Assessment used: maximum during treatment at 60 Gy. Other reported out- \\
comes: pain, need for placement of feeding tube, use of narcotics, need for intravenous fluids, diet, \\
need for treatment break. All assessed weekly.
\end{tabular}

Notes Funding source: not stated.

\section{Risk of bias}

\begin{tabular}{lll}
\hline Bias & Authors' judgement & Support for judgement \\
\hline $\begin{array}{ll}\text { Random sequence genera- } \\
\text { tion (selection bias) }\end{array}$ & Unclear risk & $\begin{array}{l}\text { Quote: "Patients were randomly assigned to receive either sucralfate or place- } \\
\text { bo". }\end{array}$ \\
& & Comment: random component not described. \\
\hline
\end{tabular}

Allocation concealment $\quad$ Unclear risk $\quad$ Insufficient information to determine 'yes' or 'no'.
(selection bias)

\begin{tabular}{|c|c|c|}
\hline $\begin{array}{l}\text { Blinding (performance } \\
\text { bias and detection bias) } \\
\text { Carers }\end{array}$ & Unclear risk & Insufficient information to determine 'yes' or 'no'. \\
\hline $\begin{array}{l}\text { Blinding (performance } \\
\text { bias and detection bias) } \\
\text { Patients }\end{array}$ & Low risk & $\begin{array}{l}\text { Quote: "double blind". } \\
\text { Quote: "Both radiation oncology staff and patients were blinded to assigned } \\
\text { treatment". } \\
\text { Comment: probably done. }\end{array}$ \\
\hline $\begin{array}{l}\text { Blinding (performance } \\
\text { bias and detection bias) } \\
\text { Outcome assessors }\end{array}$ & Low risk & $\begin{array}{l}\text { Quote: "double blind". } \\
\text { Quote: "Both radiation oncology staff and patients were blinded to assigned } \\
\text { treatment". } \\
\text { Comment: probably done. }\end{array}$ \\
\hline $\begin{array}{l}\text { Incomplete outcome data } \\
\text { (attrition bias) } \\
\text { All outcomes }\end{array}$ & Low risk & $\begin{array}{l}102 \text { patients randomised. } 16 \text { patients withdrew. } 7 / 50 \text { placebo, 9/52 sucralfate. } \\
\text { Authors give reasons for attrition/exclusion. }\end{array}$ \\
\hline $\begin{array}{l}\text { Selective reporting (re- } \\
\text { porting bias) }\end{array}$ & Unclear risk & $\begin{array}{l}\text { Data presented for grade } 3 \text { mucositis (table } 3 \text { ), time to healing of mucositis } \\
\text { (figure } 3 \text { ) and cumulative fraction of patients with }>\text { grade } 3 \text { mucositis during } \\
\text { treatment. }\end{array}$ \\
\hline Other bias & Low risk & Study appears to be free of other sources of bias. \\
\hline
\end{tabular}

\section{Study characteristics}


Cascinu 1994 (Continued)

Methods

Randomised, parallel group study conducted in Italy. Clear information on withdrawals: none. Unclear if dentist involved in study. Drop outs: $0 \%$. Duration: unclear.

Participants

Adults with solid cancer (GI \& prostate). Chemotherapy: 5-FU. First course of chemotherapy. 84 patients eligible, enrolled and completed.

\begin{tabular}{ll}
\hline Interventions & $\begin{array}{l}\text { 2 groups, control (no treatment) versus ice chips (cryotherapy, } 5 \text { mins before 5-FU for } 30 \text { mins after). } \\
\text { Checked every week and judgement on mucositis performed on day of next chemotherapy course. }\end{array}$ \\
\hline Outcomes & $\begin{array}{l}\text { Mucositis (global assessment of physician's and patient's description on 0-4 scale). Assessment used: } \\
\text { unclear. }\end{array}$ \\
\hline Notes & $\begin{array}{l}\text { Statistical handling of data incorrect as all cycles included but used data from first cycle. } \\
\text { Funding source: unclear. }\end{array}$
\end{tabular}

\section{Risk of bias}

Bias Authors' judgement Support for judgement

Random sequence genera- Unclear risk
tion (selection bias)

Quote: "randomised to a control arm or to receive chemotherapy".

Comment: random component not described.

Allocation concealment $\quad$ Unclear risk
(selection bias)

Blinding (performance

High risk

Ice chips versus no intervention. Blinding impossible.

bias and detection bias)

Carers

Blinding (performance High risk Ice chips versus no intervention. Blinding impossible.
bias and detection bias)
Patients

\begin{tabular}{lll}
\hline $\begin{array}{l}\text { Blinding (performance } \\
\text { bias and detection bias) } \\
\text { Outcome assessors }\end{array}$ & High risk & Ice chips versus no intervention. No apparent blinding. \\
\hline $\begin{array}{l}\text { Incomplete outcome data } \\
\begin{array}{l}\text { (attrition bias) } \\
\text { All outcomes }\end{array}\end{array}$ & Low risk & $\begin{array}{l}84 \text { patients randomised. No patients discontinued over first cycle (data used in } \\
\text { meta-analysis). }\end{array}$ \\
\hline $\begin{array}{l}\text { Selective reporting (re- } \\
\text { porting bias) }\end{array}$ & Low risk & Data presented for all patients by mucositis grade for first cycle (see table 3). \\
\hline \begin{tabular}{l} 
Other bias \\
\hline
\end{tabular} & Low risk & Study appears to be free from other sources of bias.
\end{tabular}

Castagna 2001

\section{Study characteristics}

Methods Randomised, parallel group multicentre study conducted in France, Italy and Switzerland. Clear information about withdrawals: 2/53 sucralfate, $1 / 52$ placebo. Unclear if dentist involved in study. Drop outs: $2.8 \%$. 
Castagna 2001 (Continued)

Participants Adults with mixed cancer (hospitalised for allogenic or autologous BMT). 105 enrolled, 102 completed.

\begin{tabular}{ll}
\hline Interventions & $\begin{array}{l}2 \text { groups, placebo }(n=51) \text { versus } 2 \text { g sucralfate }(n=51) \text { every } 3 \text { hours daily, swish and swallow, for a } \\
\text { maximum of } 7 \text { mouthwashes. }\end{array}$
\end{tabular}

Outcomes Mucositis grade 3-4. Other reported outcomes: duration, diarrhoea, caloric intake by oral nutrition.

Notes Funding source: pharmaceutical.

\section{Risk of bias}

Bias Authors' judgement Support for judgement

Random sequence genera- Unclear risk tion (selection bias)

Quote: "patients fulfilling the enrolment criteria ... were randomly allocated to the sucralfate or the placebo group. Randomisation was stratified on TBI"

Comment: random component not described.

\begin{tabular}{|c|c|c|}
\hline $\begin{array}{l}\text { Allocation concealment } \\
\text { (selection bias) }\end{array}$ & Unclear risk & Insufficient information to determine 'yes' or 'no'. \\
\hline $\begin{array}{l}\text { Blinding (performance } \\
\text { bias and detection bias) } \\
\text { Carers }\end{array}$ & Unclear risk & Insufficient information to determine 'yes' or 'no'. \\
\hline $\begin{array}{l}\text { Blinding (performance } \\
\text { bias and detection bias) } \\
\text { Patients }\end{array}$ & Low risk & $\begin{array}{l}\text { Quote: "double blind". } \\
\text { Comment: probably done. }\end{array}$ \\
\hline $\begin{array}{l}\text { Blinding (performance } \\
\text { bias and detection bias) } \\
\text { Outcome assessors }\end{array}$ & Low risk & $\begin{array}{l}\text { Quote: "double blind". } \\
\text { Comment: probably done. }\end{array}$ \\
\hline $\begin{array}{l}\text { Incomplete outcome data } \\
\text { (attrition bias) } \\
\text { All outcomes }\end{array}$ & Low risk & $\begin{array}{l}105 \text { patients randomised. } 3 \text { patients withdrawn due to disease recurrence } \\
\text { ( } 2 / 53 \text { Sucralfate, } 1 / 52 \text { placebo). }\end{array}$ \\
\hline $\begin{array}{l}\text { Selective reporting (re- } \\
\text { porting bias) }\end{array}$ & Unclear risk & $\begin{array}{l}\text { Data presented in percentages for grades } 3 \text { and } 4 \text { mucositis, but stated that } 51 \\
\text { patients in each group were evaluated (text). }\end{array}$ \\
\hline Other bias & Low risk & Study appears to be free of other sources of bias. \\
\hline
\end{tabular}

\section{Cengiz 1999}

\section{Study characteristics}

\begin{tabular}{ll}
\hline Methods & $\begin{array}{l}\text { Randomised, parallel group study conducted in Turkey. Clear information on withdrawals: none. Den- } \\
\text { tist involved in study. Drop outs: } 0 \% \text {. Duration from beginning to end of radiotherapy. }\end{array}$ \\
\hline Participants & Adults with head and neck cancer. 28 patients enrolled and completed. \\
\hline Interventions & $\begin{array}{l}2 \text { groups, placebo versus sucralfate (6 g sucralfate suspension mouthwash } 4 \text { doses orally before meals } \\
\text { and bedtime). }\end{array}$ \\
\hline
\end{tabular}


Cengiz 1999 (Continued)

Outcomes

RTOG mucositis (0-IV). Topical and systemic analgesic use, weight loss, dry mouth. Assessment used: day 42. Other reported outcomes: pain, difficulty eating, constipation, analgesics, dry mouth.

Notes

Funding source: unclear.

\section{Risk of bias}

\begin{tabular}{|c|c|c|}
\hline Bias & Authors' judgement & Support for judgement \\
\hline $\begin{array}{l}\text { Random sequence genera- } \\
\text { tion (selection bias) }\end{array}$ & Unclear risk & $\begin{array}{l}\text { Quote: "patients were randomised". } \\
\text { Comment: random component not described. }\end{array}$ \\
\hline $\begin{array}{l}\text { Allocation concealment } \\
\text { (selection bias) }\end{array}$ & Unclear risk & Insufficient information to determine 'yes' or 'no'. \\
\hline $\begin{array}{l}\text { Blinding (performance } \\
\text { bias and detection bias) } \\
\text { Carers }\end{array}$ & Unclear risk & Insufficient information to determine 'yes' or 'no'. \\
\hline $\begin{array}{l}\text { Blinding (performance } \\
\text { bias and detection bias) } \\
\text { Patients }\end{array}$ & Low risk & $\begin{array}{l}\text { Quote: "double blind". } \\
\text { Comment: probably done. }\end{array}$ \\
\hline $\begin{array}{l}\text { Blinding (performance } \\
\text { bias and detection bias) } \\
\text { Outcome assessors }\end{array}$ & Low risk & $\begin{array}{l}\text { Quote: "double blind". } \\
\text { Comment: probably done. }\end{array}$ \\
\hline $\begin{array}{l}\text { Incomplete outcome data } \\
\text { (attrition bias) } \\
\text { All outcomes }\end{array}$ & Low risk & $\begin{array}{l}\text { Data presented for } 28 \text { patients ( } 18 \text { sucralfate, } 10 \text { placebo). All randomised pa- } \\
\text { tients included in analysis. }\end{array}$ \\
\hline $\begin{array}{l}\text { Selective reporting (re- } \\
\text { porting bias) }\end{array}$ & Low risk & $\begin{array}{l}\text { Data presented for } 28 \text { patients by treatment allocation and grades of mucosi- } \\
\text { tis. }\end{array}$ \\
\hline Other bias & Low risk & Study appears to be free from other sources of bias. \\
\hline
\end{tabular}

\section{Cerchietti 2006}

\section{Study characteristics}

$\begin{array}{ll}\text { Methods } & \text { Randomised, parallel group study conducted in Argentina. Clear information on withdrawals: none. } \\ \text { Dentist involvement unclear. Drop outs: 0\%. Duration: } 60 \text { days. }\end{array}$

Participants Adults with head and neck cancer. Chemoradiotherapy - radiotherapy 2 Gy /day up to total 70 Gy, plus cisplatin and 5-FU daily on days 1-5 repeated every 3 weeks. 32 enrolled 29 randomised and completed.

\begin{tabular}{|c|c|}
\hline Interventions & $\begin{array}{l}2 \text { groups, placebo versus glutamine. (patients intravenous L-alanyl-L-glutamine } 0.4 \mathrm{~g} / \mathrm{kg} \text { weight/day on } \\
\text { each day of chemo through a separate IV line). }\end{array}$ \\
\hline Outcomes & $\begin{array}{l}\text { Mucositis assessed by mean of } 3 \text { highest scores by Objective Mucositis Score (OMS) and the WHO grad- } \\
\text { ing system on a 0-4 scale. Mucositis graded once/week during chemo and every other day during CRT. } \\
\text { Assessment used up to } 60 \text { days. Other reported outcomes: pain, feeding tubes, mucositis related hospi- } \\
\text { talisation, adverse drug effects, body weight change, incidence of local infections, tumour response. }\end{array}$ \\
\hline
\end{tabular}


Cerchietti 2006 (Continued)

Notes

Funding source: industry and foundation. Pharmacological company provided drug and organised randomisation.

\section{Risk of bias}

\begin{tabular}{|c|c|c|}
\hline Bias & Authors' judgement & Support for judgement \\
\hline $\begin{array}{l}\text { Random sequence genera- } \\
\text { tion (selection bias) }\end{array}$ & Unclear risk & $\begin{array}{l}\text { Quote: "Patients were randomly assigned (in a 1:1 ratio in blocks of } 6 \text { ) to re- } \\
\text { ceive, in a double blind methodology, either intravenous L-alanyl-L-glutamine } \\
\text { or placebo". } \\
\text { Comment: random component not described. }\end{array}$ \\
\hline $\begin{array}{l}\text { Allocation concealment } \\
\text { (selection bias) }\end{array}$ & Unclear risk & Insufficient information to determine 'yes' or 'no' \\
\hline $\begin{array}{l}\text { Blinding (performance } \\
\text { bias and detection bias) } \\
\text { Carers }\end{array}$ & Unclear risk & Insufficient information to determine 'yes' or 'no' \\
\hline $\begin{array}{l}\text { Blinding (performance } \\
\text { bias and detection bias) } \\
\text { Patients }\end{array}$ & Low risk & $\begin{array}{l}\text { Quote: "double blind". } \\
\text { Comment: probably done. }\end{array}$ \\
\hline $\begin{array}{l}\text { Blinding (performance } \\
\text { bias and detection bias) } \\
\text { Outcome assessors }\end{array}$ & Low risk & $\begin{array}{l}\text { Quote: "double blind". } \\
\text { Comment: probably done. }\end{array}$ \\
\hline $\begin{array}{l}\text { Incomplete outcome data } \\
\text { (attrition bias) } \\
\text { All outcomes }\end{array}$ & Low risk & 29 patients randomised. No missing outcome data. \\
\hline $\begin{array}{l}\text { Selective reporting (re- } \\
\text { porting bias) }\end{array}$ & Unclear risk & $\begin{array}{l}\text { Data presented for intensity of objective mucositis developed (mean } 3 \text { highest } \\
\text { OMS), patients with severe objective mucositis, and patients with mucositis } \\
\text { WHO grade } 4 \text { (table } 2 \text { ). }\end{array}$ \\
\hline Other bias & Low risk & Study appears to be free of other sources of bias. \\
\hline
\end{tabular}

Chi 1995

\section{Study characteristics}

\begin{tabular}{ll}
\hline Methods & Randomised cross-over multisite study conducted in Taiwan. Clear information on withdrawals: 0. Un- \\
clear if dentist involved in study. Duration: 10 days (day 5 to day 14)
\end{tabular}

Participants Adults with head and neck cancer undergoing chemotherapy (two cycles of cisplatin $20 \mathrm{mg} / \mathrm{m}^{2} / \mathrm{day}$,
fluorouracil $800 \mathrm{mg} / \mathrm{m}^{2} /$ day and leucovorin $90 \mathrm{mg} / \mathrm{m}^{2} /$ day).

\begin{tabular}{ll}
\hline Interventions & 2 groups, no therapy versus GM-CSF $(4 \mu \mathrm{g} / \mathrm{kg} /$ day subcutaneously) crossed over for 2 nd cycle. \\
\hline Outcomes & $\begin{array}{l}\text { Mucositis assessed daily for } 17 \text { days }(0-4 \text { scale). Other outcome measures: tumour response rate, neu- } \\
\text { trophil and leukocyte counts, adverse events. }\end{array}$
\end{tabular}


Chi 1995 (Continued)

\section{Risk of bias}

\begin{tabular}{|c|c|c|}
\hline Bias & Authors' judgement & Support for judgement \\
\hline $\begin{array}{l}\text { Random sequence genera- } \\
\text { tion (selection bias) }\end{array}$ & Unclear risk & $\begin{array}{l}\text { Quote: "randomised". } \\
\text { Comment: random component not described. }\end{array}$ \\
\hline $\begin{array}{l}\text { Allocation concealment } \\
\text { (selection bias) }\end{array}$ & Unclear risk & Insufficent information to determine 'yes' or 'no'. \\
\hline $\begin{array}{l}\text { Blinding (performance } \\
\text { bias and detection bias) } \\
\text { Carers }\end{array}$ & Unclear risk & Insufficent information to determine 'yes' or 'no'. \\
\hline $\begin{array}{l}\text { Blinding (performance } \\
\text { bias and detection bias) } \\
\text { Patients }\end{array}$ & High risk & GM-CSF versus no intervention. No apparent blinding. \\
\hline $\begin{array}{l}\text { Blinding (performance } \\
\text { bias and detection bias) } \\
\text { Outcome assessors }\end{array}$ & High risk & GM-CSF versus no intervention. No apparent blinding. \\
\hline $\begin{array}{l}\text { Incomplete outcome data } \\
\text { (attrition bias) } \\
\text { All outcomes }\end{array}$ & Low risk & 20 patients randomised. No missing outcome data. \\
\hline $\begin{array}{l}\text { Selective reporting (re- } \\
\text { porting bias) }\end{array}$ & Unclear risk & $\begin{array}{l}\text { Data provided in text for percentage reduction in incidence of severe mucosi- } \\
\text { tis, the mean duration of severe mucositis. }\end{array}$ \\
\hline Other bias & Low risk & Study appears to be free from other sources of bias. \\
\hline
\end{tabular}

Choi 2007

\section{Study characteristics}

$\begin{array}{ll}\text { Methods } & \text { Randomised, parallel group study conducted in Korea. Clear information about withdrawals: } 0 . \text { Unclear } \\ \text { if dentist involved in study. Drop outs: } 0 \% \text {. Recruitment September } 2003 \text { to August } 2005 .\end{array}$

\begin{tabular}{ll}
\hline Participants & Adults with solid tumours receiving 5FU chemotherapy. 51 enrolled and randomised, all completed. \\
\hline Interventions & $\begin{array}{l}2 \text { groups, glutamine } 30 \mathrm{~g} / \text { day as supplement administered enterally for } 15 \text { days, versus best supportive } \\
\text { care. Patients in both groups received cryotherapy. }\end{array}$ \\
\hline Outcomes & $\begin{array}{l}\text { Mucositis severity evaluated using 0-4 scale, CTCAE criteria, any mucositis, } \geq \text { grade } 2 \text { mucositis, } \geq \text { grade } \\
\text { Nucositis, cost and adverse events. }\end{array}$ \\
\hline Notes & Funding source: not stated.
\end{tabular}

\section{Risk of bias}

\begin{tabular}{lll}
\hline Bias & Authors' judgement & Support for judgement \\
\hline $\begin{array}{l}\text { Random sequence genera- } \\
\text { tion (selection bias) }\end{array}$ & Low risk & $\begin{array}{l}\text { Quote: "patients were randomised by the clinical trials office, using stage of } \\
\text { therapy as the stratifying variable". }\end{array}$
\end{tabular}


Choi 2007 (Continued)

Comment: computer generated randomisation.

\begin{tabular}{ll}
\hline $\begin{array}{l}\text { Allocation concealment } \\
\text { (selection bias) }\end{array}$ & $\begin{array}{l}\text { Quote: "Packages containing anonymous treatment supplies for each patient } \\
\text { were provided by the clinical trials office". }\end{array}$ \\
Comment: unclear if packages were sequentially numbered.
\end{tabular}

\begin{tabular}{|c|c|c|}
\hline $\begin{array}{l}\text { Blinding (performance } \\
\text { bias and detection bias) } \\
\text { Carers }\end{array}$ & High risk & Quote: "open label trial". \\
\hline $\begin{array}{l}\text { Blinding (performance } \\
\text { bias and detection bias) } \\
\text { Patients }\end{array}$ & High risk & Quote: "open label trial". \\
\hline $\begin{array}{l}\text { Blinding (performance } \\
\text { bias and detection bias) } \\
\text { Outcome assessors }\end{array}$ & High risk & Quote: "open label trial". \\
\hline $\begin{array}{l}\text { Incomplete outcome data } \\
\text { (attrition bias) } \\
\text { All outcomes }\end{array}$ & Low risk & 51 patients recruited. No missing outcome data. \\
\hline $\begin{array}{l}\text { Selective reporting (re- } \\
\text { porting bias) }\end{array}$ & Low risk & Data presented for 51 patients by grade of mucositis and treatment arm. \\
\hline Other bias & Low risk & Study appears to be free of other sources of bias. \\
\hline
\end{tabular}

Chor 2010

\section{Study characteristics}

\begin{tabular}{ll}
\hline Methods & $\begin{array}{l}\text { Randomised parallel group study conducted in Brazil. Clear information about withdrawals: 0. Dentist } \\
\text { involved in study. Duration: } 7 \text { days (day -7 to day 0). }\end{array}$ \\
\hline Participants & 34 adults undergoing autologous transplantation. No disease or treatment information. \\
\hline Interventions & $\begin{array}{l}2 \text { groups, sham laser (led) versus laser (diode laser of } 50 \mathrm{~mW} \text { AsGaAl applied emitting continuous light } \\
\text { at } 660 \mathrm{~nm}) .\end{array}$ \\
\hline Outcomes & $\begin{array}{l}\text { Mucositis assessed daily from day-2 until discharge using the Tardieu scale. Other outcome measures: } \\
\text { febrile episodes, cumulative probability of developing mucositis, length of hospital stay. }\end{array}$ \\
\hline Notes & Funding Source: unclear.
\end{tabular}

\section{Risk of bias}

\begin{tabular}{lll}
\hline Bias & Authors' judgement & Support for judgement \\
\hline $\begin{array}{l}\text { Random sequence genera- } \\
\text { tion (selection bias) }\end{array}$ & Unclear risk & Quote: "randomised". \\
& & Comment: random component not described. \\
\hline $\begin{array}{l}\text { Allocation concealment } \\
\text { (selection bias) }\end{array}$ & Unclear risk & Insufficient information to determine 'yes' or 'no'. \\
\hline
\end{tabular}


Chor 2010 (Continued)

Blinding (performance Unclear risk Insufficient information to determine 'yes' or 'no'. bias and detection bias)

Carers

\begin{tabular}{|c|c|c|}
\hline $\begin{array}{l}\text { Blinding (performance } \\
\text { bias and detection bias) } \\
\text { Patients }\end{array}$ & Low risk & $\begin{array}{l}\text { Quote: "double blind". } \\
\text { Comment: probably done. }\end{array}$ \\
\hline $\begin{array}{l}\text { Blinding (performance } \\
\text { bias and detection bias) } \\
\text { Outcome assessors }\end{array}$ & Low risk & $\begin{array}{l}\text { Quote: "double blind". } \\
\text { Comment: probably done. }\end{array}$ \\
\hline $\begin{array}{l}\text { Incomplete outcome data } \\
\text { (attrition bias) } \\
\text { All outcomes }\end{array}$ & Low risk & 34 patients randomised. No missing outcome data. \\
\hline $\begin{array}{l}\text { Selective reporting (re- } \\
\text { porting bias) }\end{array}$ & Unclear risk & $\begin{array}{l}\text { Data presented in the text for the number of patients experiencing mucositis in } \\
\text { each arm. }\end{array}$ \\
\hline Other bias & Low risk & Study appears to be free of bias. \\
\hline
\end{tabular}

\section{Crawford 1999}

\section{Study characteristics}

\begin{tabular}{|c|c|c|}
\hline Methods & \multicolumn{2}{|c|}{$\begin{array}{l}\text { Randomised, parallel group multicentre study conducted in USA. Unclear information on withdrawals } \\
\text { (previously described): } 6 / 110 \text { placebo, } 6 / 101 \text { test. Dentist involvement unclear. Drop outs: } 9 \% \text {. Dura- } \\
\text { tion: from day } 4 \text { to day } 17 \text { of cycle. }\end{array}$} \\
\hline Participants & \multicolumn{2}{|c|}{ Adults with small cell lung cancer. 211 patients enrolled, 199 evaluated, 195 evaluated on first cycle. } \\
\hline Interventions & \multicolumn{2}{|c|}{2 groups: placebo (not described) versus filgrastim $\left(230 \mathrm{ug} / \mathrm{m}^{2}\right)$} \\
\hline Outcomes & \multicolumn{2}{|c|}{$\begin{array}{l}\text { WHO mucositis grades } 0-4 \text {. Assessment used: day } 21 \text {. Other reported outcomes: neutropenia, infections } \\
\text { complications. }\end{array}$} \\
\hline Notes & \multicolumn{2}{|c|}{$\begin{array}{l}\text { Used first cycle data. } \\
\text { Funding source: not stated. }\end{array}$} \\
\hline \multicolumn{3}{|l|}{ Risk of bias } \\
\hline Bias & Authors' judgement & Support for judgement \\
\hline $\begin{array}{l}\text { Random sequence genera- } \\
\text { tion (selection bias) }\end{array}$ & Unclear risk & $\begin{array}{l}\text { Quote: "randomised within each study centre to receive chemotherapy with } \\
\text { either filgrastim or the equivalent volume of placebo". } \\
\text { comment: random component not described. }\end{array}$ \\
\hline $\begin{array}{l}\text { Allocation concealment } \\
\text { (selection bias) }\end{array}$ & Unclear risk & Insufficient information to determine 'yes' or 'no'. \\
\hline $\begin{array}{l}\text { Blinding (performance } \\
\text { bias and detection bias) } \\
\text { Carers }\end{array}$ & Unclear risk & Insufficient information to determine 'yes' or 'no'. \\
\hline
\end{tabular}


Crawford 1999 (Continued)

Blinding (performance Low risk Quote: "patients remained on blinded study drug until the primary endpoint of bias and detection bias) the study, FN, was reached."

Patients

\begin{tabular}{|c|c|c|}
\hline $\begin{array}{l}\text { Blinding (performance } \\
\text { bias and detection bias) } \\
\text { Outcome assessors }\end{array}$ & Low risk & $\begin{array}{l}\text { Quote: "A blinded chart review confirmed the exclusion of dental and oral } \\
\text { problems related to mucositis". } \\
\text { Comment: outcome assessors presumed to be blind. }\end{array}$ \\
\hline $\begin{array}{l}\text { Incomplete outcome data } \\
\text { (attrition bias) } \\
\text { All outcomes }\end{array}$ & Low risk & $\begin{array}{l}211 \text { patients randomised. } 12 \text { patients excluded ( } 6 / 110 \text { placebo, } 6 / 101 \text { interven- } \\
\text { tion). } 199 \text { patients received at least one cycle of chemotherapy and were in- } \\
\text { cluded in the efficacy analysis. Authors provide reasons for exclusions in linked } \\
\text { paper. }\end{array}$ \\
\hline $\begin{array}{l}\text { Selective reporting (re- } \\
\text { porting bias) }\end{array}$ & Unclear risk & $\begin{array}{l}\text { Data presented for incidence of mucositis in percentages (present versus ab- } \\
\text { sent) for both treatment arms and time to first episode of mucositis. }\end{array}$ \\
\hline Other bias & Low risk & Study appears to be free of other sources of bias. \\
\hline
\end{tabular}

\section{Cruz 2007}

\section{Study characteristics}

\begin{tabular}{ll}
\hline Methods & Randomised parallel group study conducted in Brazil. Unclear information about withdrawals. Dentist \\
involved in study. Duration: 5 consecutive days from initiation of chemotherapy. Recruitment ran from \\
May 2003 to February 2005.
\end{tabular}
May 2003 to February 2005.

\begin{tabular}{ll}
\hline Participants & Children aged between 3 and 18 years old. 62 patients recruited. 56 patients evaluated on second visit, \\
& 59 patients evaluated at the 3rd evaluation. 35 patients had leukaemia or lymphoma, 25 patients had \\
solid tumours. All patients received chemotherapy, 24 patients also received a stem cell transplant.
\end{tabular}

Interventions

2 groups, no treatment control versus laser (continuous $780 \mathrm{~nm}$ wavelength, $60 \mathrm{~mW}$ power, fluence $4 \mathrm{~J}$ / $\mathrm{cm}^{2}$.

\begin{tabular}{ll}
\hline Outcomes & Oral assessments performed 3 times (days 1,8 and 15$)$ using the Common Toxicity Criteria Nation- \\
al Cancer Institute toxicity scale (0-4 scale). Other reported outcomes: use of drugs to treat infection, \\
food intake (kcal), nutritional status (BMI), buccal health (number of decayed, missing and filled teeth), \\
white cell count, number of teeth brushing sessions.
\end{tabular}

Notes Funding information: government.

\section{Risk of bias}

\begin{tabular}{lll}
\hline Bias & Authors' judgement & Support for judgement \\
\hline $\begin{array}{l}\text { Random sequence genera- } \\
\text { tion (selection bias) }\end{array}$ & Low risk & $\begin{array}{l}\text { Quote: “patients were randomized to receive or not laser treatment according } \\
\text { to group allocation”. }\end{array}$ \\
& $\begin{array}{l}\text { Comment: author contacted and replied that sequence was computer gener- } \\
\text { ated. }\end{array}$ \\
\hline $\begin{array}{l}\text { Allocation concealment } \\
\text { (selection bias) }\end{array}$ & Unclear risk & Insufficient information to determine 'yes' or 'no'. \\
\hline
\end{tabular}

Blinding (performance

High risk

Laser versus no intervention. No apparent blinding.

bias and detection bias) 
Cruz 2007 (Continued)

Carers

Blinding (performance

bias and detection bias)

High risk

Laser versus no intervention. No apparent blinding.

Patients

Blinding (performance Low risk

bias and detection bias)

Low risk

Outcome assessors

Quote: "oral mucositis was scored by the same investigator...who was blind to the randomisation allocation using the CTC NCI."

Comment: probably done.

$\begin{array}{ll}\begin{array}{l}\text { Incomplete outcome data } \\ \text { (attrition bias) }\end{array} & \text { Low risk } \\ \text { All outcomes } & \text { tion information. } 56 \text { patients evaluated at } 2^{\text {nd }} \text { assessment. } 59 \text { patients evalu- } \\ \text { ated at assessment 3. Authors give no reasons for omissions. }\end{array}$

ated at assessment 3 . Authors give no reasons for omissions.

Selective reporting (re- Unclear risk $\quad$ Data presented for 59 patients in text and fig 1.

porting bias)

Other bias Low risk Study appears to be free of other sources of bias.

Dai 2009

\section{Study characteristics}

\begin{tabular}{|c|c|}
\hline Methods & $\begin{array}{l}\text { Randomised, parallel group study conducted in China. Clear information about withdrawals: } 0 \text {. Unclear } \\
\text { if dentist involved in study. Drop outs: } 0 \% \text {. }\end{array}$ \\
\hline Participants & $\begin{array}{l}\text { Adults with head and neck cancer receiving radiotherapy. } 42 \text { enrolled and randomised between Janu- } \\
\text { ary } 2008 \text { to December 2008, all completed. }\end{array}$ \\
\hline Interventions & $\begin{array}{l}2 \text { groups, YHD Humo Decoction (honeysuckle flower } 15 \mathrm{~g} \text {, forsythia fruit } 9 \mathrm{~g} \text {, scullcap root } 15 \mathrm{~g} \text {, glehnia } \\
\text { root } 15 \mathrm{~g} \text {, lilyturf root } 15 \mathrm{~g} \text {, crude rehmannia root } 15 \mathrm{~g} \text {, figwort root } 15 \mathrm{~g} \text {, red peony root } 10 \mathrm{~g} \text {, red sage } \\
10 \mathrm{~g} \text {, milkvetch root } 10 \mathrm{~g} \text {, asiabell root } 10 \mathrm{~g} \text {, balloon flower root } 10 \mathrm{~g} \text {, arctium fruit } 10 \mathrm{~g} \text {, and liquorice } 6 \\
\mathrm{~g} \text { ). It was decocted in water, boiling down to } 150 \mathrm{~mL} \text { of decoction, one dose daily, administered in six } \\
\text { times by keeping it in the mouth for } 2 \text { min and then swallowed. No treatment control. All patients gar- } \\
\text { gled with } 2 \% \text { lidocaine before meals and at night. }\end{array}$ \\
\hline
\end{tabular}

Outcomes Mucositis severity evaluated daily using RTOG 0-4 scale and the highest grade reported. Unclear how often this was measured but results reported by grade of mucositis and as days to reach each RTOG grade.

Notes Funding source: government.

\section{Risk of bias}

\begin{tabular}{lll}
\hline Bias & Authors' judgement & Support for judgement \\
\hline $\begin{array}{l}\text { Random sequence genera- } \\
\text { tion (selection bias) }\end{array}$ & Unclear risk & Quote: "They were randomised equally into the test group and control group". \\
\hline $\begin{array}{l}\text { Allocation concealment } \\
\text { (selection bias) }\end{array}$ & Unclear risk & Insufficient information to determine 'yes' or 'no'. \\
\hline $\begin{array}{l}\text { Blinding (performance } \\
\text { bias and detection bias) }\end{array}$ & High risk & Yangyin Humo Decoction (YHD) versus no treatment. No apparent blinding.
\end{tabular}


Dai 2009 (Continued)

Carers

Blinding (performance bias and detection bias)

High risk

Yangyin Humo Decoction (YHD) versus no treatment. No apparent blinding.

Patients

Blinding (performance High risk

bias and detection bias)

Outcome assessors

\begin{tabular}{lll}
\hline $\begin{array}{l}\text { Incomplete outcome data } \\
\text { (attrition bias) } \\
\text { All outcomes }\end{array}$ & Low risk & \\
\hline $\begin{array}{l}\text { Selective reporting (re- } \\
\text { porting bias) }\end{array}$ & Low risk & Data presented for 42 patients by arm and grade of mucositis. \\
\hline Other bias & High risk & $\begin{array}{l}\text { Patients in the intervention group received a higher dose of radiation than } \\
\text { those in the control group (P }<0.05) .\end{array}$ \\
& $\begin{array}{l}\text { All Chinese medicine RCTs are now a cause for concern in light of the findings } \\
\text { of Taixiang et al, 2007. }\end{array}$ \\
\hline
\end{tabular}

\section{Dazzi 2003}

\section{Study characteristics}

\begin{tabular}{ll}
\hline Methods & $\begin{array}{l}\text { Randomised, parallel group study conducted in Italy. Clear information about withdrawals: } 0 . \text { Unclear if } \\
\text { dentist involved in study. Drop outs: } 0 \% .\end{array}$ \\
\hline Participants & $\begin{array}{l}\text { Adults with solid cancer. } 90 \text { enrolled and randomised between July } 1997 \text { and February } 2002,90 \text { com- } \\
\text { pleted. }\end{array}$ \\
\hline Interventions & $\begin{array}{l}2 \text { groups, placebo versus GM-CSF mouthwash (150 ug/day) in } 100 \mathrm{cl} 4 \text { times per day. Rinse } 1 \text { minute. All } \\
\text { patients } 0.2 \% \text { chlorhexidine and amphotericin B. }\end{array}$ \\
\hline Outcomes & $\begin{array}{l}\text { Mucositis severity evaluated daily using NCI CTC. Other reported outcomes: oral pain evaluated daily } \\
\text { using visual scale and pain requiring opioids. }\end{array}$ \\
\hline Notes & Funding source: none (c). \\
\hline
\end{tabular}

\section{Risk of bias}

\begin{tabular}{lll}
\hline Bias & Authors' judgement & Support for judgement \\
\hline $\begin{array}{l}\text { Random sequence genera- } \\
\text { tion (selection bias) }\end{array}$ & Unclear risk & $\begin{array}{l}\text { Quote: "were randomly allocated to the GM-CSF or the placebo group". } \\
\text { Comment: random component not described. }\end{array}$ \\
\hline $\begin{array}{l}\text { Allocation concealment } \\
\text { (selection bias) }\end{array}$ & Low risk & $\begin{array}{l}\text { Quote: "Study suspensions were prepared by the pharmacy unit and provided } \\
\text { to the bone marrow transplant patients." }\end{array}$ \\
\hline $\begin{array}{l}\text { Blinding (performance } \\
\text { bias and detection bias) }\end{array}$ & Low risk & $\begin{array}{l}\text { Comment: pharmacy controlled randomisation. } \\
\text { that carers would have knowledge of allocation. }\end{array}$
\end{tabular}


Dazzi 2003 (Continued)

Carers

\begin{tabular}{|c|c|c|}
\hline $\begin{array}{l}\text { Blinding (performance } \\
\text { bias and detection bias) } \\
\text { Patients }\end{array}$ & Low risk & $\begin{array}{l}\text { Quote: "double blind". } \\
\text { Comment: probably done. }\end{array}$ \\
\hline $\begin{array}{l}\text { Blinding (performance } \\
\text { bias and detection bias) } \\
\text { Outcome assessors }\end{array}$ & Low risk & $\begin{array}{l}\text { Quote: "double blind". } \\
\text { Comment: probably done. }\end{array}$ \\
\hline $\begin{array}{l}\text { Incomplete outcome data } \\
\text { (attrition bias) } \\
\text { All outcomes }\end{array}$ & Low risk & 90 patients randomised. ITT analysis used. No missing outcome data. \\
\hline $\begin{array}{l}\text { Selective reporting (re- } \\
\text { porting bias) }\end{array}$ & Unclear risk & $\begin{array}{l}\text { Data presented for incidence of stomatitis, incidence and duration of severe } \\
\text { stomatitis, and patients judged maximum mucositis score (table } 3 \text { ). }\end{array}$ \\
\hline Other bias & Low risk & Study appears to be free of other sources of bias. \\
\hline
\end{tabular}

Dickson 2000

\section{Study characteristics}

\begin{tabular}{ll}
\hline Methods & $\begin{array}{l}\text { Randomised, parallel group study conducted in USA. Clear information on withdrawals: none. Dentist } \\
\text { not involved in study. Drop outs: } 0 \% \text {. Duration: first day of treatment until discharge or max 28 days af- } \\
\text { ter transplant. Recruitment June } 1995 \text { to August } 1997 .\end{array}$ \\
\hline Participants & $\begin{array}{l}\text { Adults receiving bone marrow transplant (BMT) or peripheral blood progenitor cell transplant (PBPCT). } \\
58 \text { enrolled and evaluated with leukaemia or lymphoma. }\end{array}$ \\
\hline Interventions & $\begin{array}{l}2 \text { groups, powdered sugar added to food or drink (placebo) versus glutamine (10 g doses mixed with } \\
\text { food or liquid chosen by patient) } 3 \text { times daily (30 g/day). }\end{array}$ \\
\hline Outcomes & $\begin{array}{l}\text { Stamford University Hospital BMT toxicity scale for mucositis scale 0-4. Reported as grade 2+. Parenter- } \\
\text { al nutrition with TPN. Assessment used: day 28. Other reported outcomes: length of hospital stay. Days } \\
\text { in total, parenteral nutrition, diarrhoea, toxicity. }\end{array}$ \\
\hline Notes & $\begin{array}{l}\text { Funding source: pharmaceutical supply product/small grants programme of Stanford University Hospi- } \\
\text { tal's Nursing Management Department. }\end{array}$
\end{tabular}

\section{Risk of bias}

\section{Bias Authors' judgement Support for judgement}

\begin{tabular}{lll}
\hline Random sequence genera- & Unclear risk & Quote: "the BMT or PBPCT patients were registered with the data managers \\
tion (selection bias) & & and randomly assigned to receive glutamine".
\end{tabular}
tion (selection bias) and randomly assigned to receive glutamine".

Comment: random component not described.

\begin{tabular}{lll}
\hline $\begin{array}{l}\text { Allocation concealment } \\
\text { (selection bias) }\end{array}$ & Unclear risk & Insufficient information to determine 'yes' or 'no'. \\
\hline $\begin{array}{l}\text { Blinding (performance } \\
\text { bias and detection bias) } \\
\text { Carers }\end{array}$ & Unclear risk & Insufficient information to determine 'yes' or 'no'. \\
\hline
\end{tabular}


Dickson 2000 (Continued)
Blinding (performance
Low risk
Quote: "double blind".
bias and detection bias)
Comment: probably done.
Patients

\begin{tabular}{|c|c|c|}
\hline $\begin{array}{l}\text { Blinding (performance } \\
\text { bias and detection bias) }\end{array}$ & Low risk & $\begin{array}{l}\text { Quote: "double blind". } \\
\text { Comment: probably don }\end{array}$ \\
\hline
\end{tabular}

Incomplete outcome data Low risk 58 patients randomised. No missing outcome data.

(attrition bias)

All outcomes

\begin{tabular}{lll}
\hline $\begin{array}{l}\text { Selective reporting (re- } \\
\text { porting bias) }\end{array}$ & Unclear risk & $\begin{array}{l}\text { Data presented for median mucositis duration (days), median mucositis grade } \\
\text { and mucositis grades 2-4 (in percentages). }\end{array}$ \\
\hline Other bias & Low risk & Study appears to be free of other sources of bias. \\
\hline
\end{tabular}

\section{Dodd 1996}

\section{Study characteristics}

\begin{tabular}{|c|c|c|}
\hline Methods & \multicolumn{2}{|c|}{$\begin{array}{l}\text { Randomised, parallel group, multicentre study conducted in USA. Dentist involved in study. Duration: } \\
\text { up to } 3 \text { months. }\end{array}$} \\
\hline Participants & \multicolumn{2}{|c|}{$\begin{array}{l}\text { Adults with solid cancer receiving chemotherapy. Followed for } 3 \text { cycles of chemotherapy. } 303 \text { eligible, } \\
227 \text { enrolled and evaluated. }\end{array}$} \\
\hline Interventions & \multicolumn{2}{|c|}{$\begin{array}{l}2 \text { groups: water control (described as placebo) versus chlorhexidine mouthrinse }(0.12 \%, 20 \mathrm{ml} \text {, twice } \\
\text { per day). }\end{array}$} \\
\hline Outcomes & \multicolumn{2}{|c|}{$\begin{array}{l}\text { Oral assessment guide (OAG) } 0-24 \text {, scores over } 10 \text { were considered to be oral mucositis. Maximum of } 3 \\
\text { months. Assessment used: day } 90 \text {. Other reported outcomes: survival, cost, time to onset of mucositis, } \\
\text { severity of mucositis. }\end{array}$} \\
\hline Notes & \multicolumn{2}{|c|}{$\begin{array}{l}\text { Severity of mucositis at onset measured. ITT analysis. } \\
\text { Funding source: government and pharmaceutical. }\end{array}$} \\
\hline \multicolumn{3}{|l|}{ Risk of bias } \\
\hline Bias & Authors' judgement & Support for judgement \\
\hline \multirow[t]{2}{*}{$\begin{array}{l}\text { Random sequence genera- } \\
\text { tion (selection bias) }\end{array}$} & Unclear risk & $\begin{array}{l}\text { Quote: "Researchers used a randomised, double-blind, placebo controlled tri- } \\
\text { al design". }\end{array}$ \\
\hline & & Comment: random component not described. \\
\hline $\begin{array}{l}\text { Allocation concealment } \\
\text { (selection bias) }\end{array}$ & Unclear risk & Insufficient information to determine 'yes' or 'no'. \\
\hline \multirow{2}{*}{$\begin{array}{l}\text { Blinding (performance } \\
\text { bias and detection bias) } \\
\text { Carers }\end{array}$} & \multirow[t]{2}{*}{ Low risk } & Quote:"physicians and intervention nurses performed blinded assessments". \\
\hline & & Comment: probably done. \\
\hline \multirow{2}{*}{$\begin{array}{l}\text { Blinding (performance } \\
\text { bias and detection bias) }\end{array}$} & \multirow[t]{2}{*}{ Low risk } & Quote: "double blind". \\
\hline & & Comment: probably done. \\
\hline
\end{tabular}


Dodd 1996 (Continued)

Patients

\begin{tabular}{|c|c|c|}
\hline $\begin{array}{l}\text { Blinding (performance } \\
\text { bias and detection bias) }\end{array}$ & Low risk & Quote:"physicians and intervention nurses performed blinded assessments." \\
\hline Outcome assessors & & Comment: probably done. \\
\hline
\end{tabular}

\begin{tabular}{ll}
\hline Incomplete outcome data & Low risk \\
$\begin{array}{l}\text { (attrition bias) } \\
\text { All outcomes }\end{array}$ & $\begin{array}{l}227 \text { patients randomised. } 5 \text { patients were ineligible. Final sample of } 222 \text { pa- } \\
\text { tients. } 89 \text { patients }(40 \%) \text { did not finish } 3 \text { cycles of chemotherapy. ITT analysis } \\
\text { conducted. }\end{array}$
\end{tabular}

\begin{tabular}{|c|c|c|}
\hline $\begin{array}{l}\text { Selective reporting (re- } \\
\text { porting bias) }\end{array}$ & Unclear risk & $\begin{array}{l}\text { Data presented for } 222 \text { patients for mucositis incidence, time to onset of mu- } \\
\text { cositis and severity of mucositis (table } 3 \text { ). }\end{array}$ \\
\hline
\end{tabular}

\begin{tabular}{lll} 
porting bias) & cositis and severity of mucositis (table 3$).$ \\
\hline Other bias & Low risk & Study appears to be free of other sources of bias. \\
\hline
\end{tabular}

\section{Dorr 2007}

\section{Study characteristics}

\begin{tabular}{ll}
\hline Methods & $\begin{array}{l}\text { Randomised, parallel group multisite study conducted in Germany. Clear information about with- } \\
\text { drawals: } 8 \text { (4/36 wobe mugos; 4/33 placebo). Unclear if dentist involved in study. Duration: treatment } \\
\text { continued until } 5 \text { days after radiotherapy. Recruitment conducted between June } 1996 \text { and May } 2000 .\end{array}$ \\
\hline Participants & Adults with head and neck cancers undergoing radiotherapy (all patients received dose $>40$ Gy). \\
\hline Interventions & $\begin{array}{l}2 \text { groups, placebo versus wobe mugos (papain } 100 \mathrm{mg}, \text { trypsin } 40 \mathrm{mg} \text { and chymotrypsin } 40 \mathrm{mg}), 3 \times 4 \\
\text { tablets per day. }\end{array}$ \\
\hline Outcomes & $\begin{array}{l}\text { Mucositis assessed weekly using the RTOG/ EORTC classification. Other reported outcomes: side ef- } \\
\text { fects, pain on swallowing, dysphagia, skin erythema, skin desquamation. }\end{array}$ \\
\hline Notes & Funding source: unclear. Figure 1 data used.
\end{tabular}

\section{Risk of bias}

Bias Authors' judgement Support for judgement

Random sequence genera- Low risk tion (selection bias)

Quote: "randomisation was performed with the software 'Rancode plus' in randomly permuted blocks at a ratio of $1: 1 "$.

Comment: computer generated random numbers.

\begin{tabular}{lll}
\hline $\begin{array}{l}\text { Allocation concealment } \\
\text { (selection bias) }\end{array}$ & Unclear risk & Insufficient information to determine 'yes' or 'no'. \\
\hline $\begin{array}{l}\text { Blinding (performance } \\
\text { bias and detection bias) } \\
\text { Carers }\end{array}$ & Unclear risk & Quote: "triple blind". \\
\hline $\begin{array}{l}\text { Blinding (performance } \\
\text { bias and detection bias) }\end{array}$ & Low risk & Comment: unclear who the third blind party was. Nurse or statistician? \\
$\begin{array}{l}\text { Patients } \\
\begin{array}{l}\text { Blinding (performance } \\
\text { bias and detection bias) } \\
\text { Outcome assessors }\end{array}\end{array}$ & Low risk & Comment: probably done. \\
\hline \hline
\end{tabular}


Dorr 2007 (Continued)
Incomplete outcome data Low risk
69 patients randomised. 8 patients withdrew/excluded (4/36 wobe mugos; (attrition bias) 4/33 placebo).
All outcomes

\begin{tabular}{lll}
\hline $\begin{array}{l}\text { Selective reporting (re- } \\
\text { porting bias) }\end{array}$ & Unclear risk & $\begin{array}{l}\text { Data presented for frequency distribution of oral mucositis by grade (fig 1, } \\
\text { percentages, not clear if all participants included), mean values of maximum } \\
\text { scores (fig 2), and average mucositis score (fig 3). }\end{array}$ \\
\hline Other bias & Low risk & Study appears to be free of other sources of bias. \\
\hline
\end{tabular}

\section{Dozono 1989}

\section{Study characteristics}

\begin{tabular}{ll}
\hline Methods & $\begin{array}{l}\text { Randomised, cross-over study conducted in Japan. Clear information on withdrawals: none. Unclear if } \\
\text { dentist was involved. Drop outs: } 0 \% . \text { Duration: unclear. }\end{array}$ \\
\hline Participants & Adults with solid cancer receiving chemotherapy. 15 patients enrolled and completed both periods. \\
\hline Interventions & $\begin{array}{l}2 \text { groups: no treatment control versus allopurinol mouthwash (carboxymethylcellulose (CMC-Na) } 5 \mathrm{~g} \\
\text { and allopurinol } 500 \mathrm{mg}, \text { water to } 500 \mathrm{ml} \text { solution). }\end{array}$ \\
\hline Outcomes & Japan Society for Cancer Therapy criteria for stomatitis 0-4 scale. \\
\hline Notes & Funding source: unclear.
\end{tabular}

\section{Risk of bias}

\begin{tabular}{lll}
\hline Bias & Authors' judgement & Support for judgement \\
\hline $\begin{array}{l}\text { Random sequence genera- } \\
\text { tion (selection bias) }\end{array}$ & Unclear risk & $\begin{array}{l}\text { Quote: "the subject was randomised into allopurinol administration and con- } \\
\text { trol one by the envelope method". } \\
\end{array}$ \\
$\begin{array}{l}\text { Comment: unclear if envelopes were sequentially numbered or suffled. Ran- } \\
\text { dom component not described. }\end{array}$
\end{tabular}

\begin{tabular}{lll}
\hline $\begin{array}{l}\text { Allocation concealment } \\
\text { (selection bias) }\end{array}$ & Unclear risk & $\begin{array}{l}\text { Envelope method of randomisation. Unclear if envelopes were opaque and se- } \\
\text { quentially numbered. }\end{array}$ \\
\hline $\begin{array}{l}\text { Blinding (performance } \\
\text { bias and detection bias) } \\
\text { Carers }\end{array}$ & High risk & Allopurinol mouthwash versus no intervention. No apparent blinding. \\
\hline
\end{tabular}

Blinding (performance High risk

Allopurinol mouthwash versus no intervention. No apparent blinding.

bias and detection bias)

Patients

\begin{tabular}{lll}
\hline Blinding (performance & High risk $\quad$ Allopurinol mouthwash versus no intervention. No apparent blinding. \\
bias and detection bias) &
\end{tabular}

Outcome assessors

Incomplete outcome data Low risk 15 patients randomised into cross-over study. No missing outcome data.
(attrition bias)

(attrition bias)
All outcomes 
Dozono 1989 (Continued)

Selective reporting (re- Low risk Data presented for grade of stomatitis for control and treatment arms by treatporting bias) ment regimen.

Other bias

High risk

Risk of bias assessed from translation.

Duenas 1996

\section{Study characteristics}

\begin{tabular}{ll}
\hline Methods & $\begin{array}{l}\text { Randomised, parallel group study conducted in Mexico. Clear information on withdrawals: none. Un- } \\
\text { clear if dentist was involved in study. Drop outs: } 0 \% . \text { Duration: -4 to day } 16 .\end{array}$ \\
\hline Participants & $\begin{array}{l}\text { Adults with mixed cancer undergoing peripheral stem cell transplant, receiving high dose (ifosfamide, } \\
\text { carboplatin, etoposide). } 15 \text { patients enrolled (16 course of chemotherapy) and completed. }\end{array}$ \\
\hline Interventions & 2 groups, placebo versus misoprostol (racemic prostaglandin E1 analogue) $250 \mu \mathrm{gg} 3$ times per day. \\
\hline Outcomes & $\begin{array}{l}\text { WHO mucositis grades 0-4, candidiasis, days in hospital with range. Assessment used: day } 16 . \\
\text { Other reported outcomes: diarrohea, fever, days in hospital, duration of antibiotics. }\end{array}$ \\
\hline Notes & $\begin{array}{l}\text { All patients received fluconazole prophylaxis. Also received ranitidine, ketoconazole \& ciprofloxacin. } \\
\text { Severity of mucositis also given but no SD. Study stopped prematurely due to a significant finding at an } \\
\text { interim analysis, favouring the placebo. } \\
\text { Funding source: government, pharmaceutical. }\end{array}$ \\
\hline
\end{tabular}

\section{Risk of bias}

Bias Authors' judgement Support for judgement

Random sequence genera- Unclear risk tion (selection bias)

Quote: "...randomly assigned to receive misoprostol $250 \mathrm{mg}$ three times a day by mouth, or identical tablets of placebo in the same schedule".

Comment: random component not described.

Allocation concealment Unclear risk Insufficient information to determine 'yes' or 'no'.

(selection bias)

Blinding (performance
bias and detection bias) Unclear risk Insufficient information to determine 'yes' or 'no'.

bias and detection bias)

Carers

$\begin{array}{ll}\text { Blinding (performance } & \text { Quote: "double blind". } \\ \text { bias and detection bias) } & \text { Comment: probably done. } \\ \text { Patients } & \end{array}$

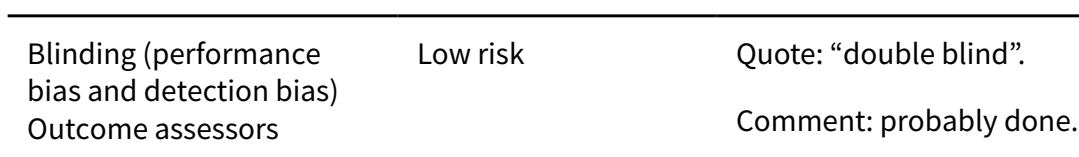

\begin{tabular}{ll}
\hline $\begin{array}{l}\text { Incomplete outcome data } \\
\text { (attrition bias) }\end{array}$ & Low risk \\
All outcomes & $\begin{array}{l}15 \text { patients randomised to receive } 16 \text { courses of chemotherapy. No missing } \\
\text { outcome data. }\end{array}$
\end{tabular}

\begin{tabular}{l}
$\begin{array}{l}\text { Selective reporting (re- } \\
\text { porting bias) }\end{array}$ \\
\hline
\end{tabular}


Duenas 1996 (Continued)

Other bias
15 patients received 16 courses of radiotherapy. Data presented for 16 patients.

Study ended prematurely: interim analysis demonstrated a significant difference favouring placebo in the incidence and severity of mucositis.

Elad 2006

\section{Study characteristics}

\begin{tabular}{ll}
\hline Methods & $\begin{array}{l}\text { Randomised, parallel group study conducted in Israel, from August } 2002 \text { to March 2003. Unclear infor- } \\
\text { mation on withdrawals. Dentist involvement unclear. Drop outs: 13\%. Duration: } 28 \text { days. }\end{array}$ \\
\hline Participants & $\begin{array}{l}\text { Adults with mixed cancer. BMT, total body irradiation, chemotherapy, chemoradiotherapy. } 45 \text { enrolled } \\
\text { and randomised } 39 \text { completed. }\end{array}$ \\
\hline Interventions & $\begin{array}{l}2 \text { groups, placebo versus topical histamine gel (a semi viscous solution containing } 0.12 \% \text { w/w HDC (his- } \\
\text { tamine dihydrochloride) in a carbomer-based vehicle). Patients instructed to use } 5 \mathrm{ml} \text { (1 teaspoon) } 4 \\
\text { times a day. }\end{array}$ \\
\hline Outcomes & $\begin{array}{l}\text { Mucositis measured twice weekly using the NCI CTC v2 scoring scale and the OMAS scale. Assessment } \\
\text { used up to } 28 \text { days. Other reported outcomes: oral pain and ability to swallow using } 10 \mathrm{~cm} \text { VAS, salivary } \\
\text { flow rate, adverse events nausea and vomiting. }\end{array}$ \\
\hline Notes & $\begin{array}{l}\text { Funding source: early part of study funded by industry, rest of funding unclear. All received standard } \\
\text { oral care: chlorhexidine mouthrinse } 2 / \text { day amphotericin B lozenges 4/day. Pharmacological company } \\
\text { provided drug and organised randomisation. }\end{array}$ \\
\hline
\end{tabular}

\section{Risk of bias}

\begin{tabular}{|c|c|c|}
\hline Bias & Authors' judgement & Support for judgement \\
\hline \multirow[t]{2}{*}{$\begin{array}{l}\text { Random sequence genera- } \\
\text { tion (selection bias) }\end{array}$} & Unclear risk & $\begin{array}{l}\text { Quote: "Patients were allocated at random to one of two treatment arms in a } \\
\text { blocked randomisation schedule." }\end{array}$ \\
\hline & & Comment: random component not described. \\
\hline $\begin{array}{l}\text { Allocation concealment } \\
\text { (selection bias) }\end{array}$ & Unclear risk & Insufficient information to determine 'yes' or 'no'. \\
\hline \multirow{2}{*}{$\begin{array}{l}\text { Blinding (performance } \\
\text { bias and detection bias) } \\
\text { Carers }\end{array}$} & Low risk & $\begin{array}{l}\text { Quote: "Patient, investigator and staff were blinded to the treatment assign- } \\
\text { ment." }\end{array}$ \\
\hline & & Comment: probably done. \\
\hline
\end{tabular}

\begin{tabular}{|c|c|c|}
\hline $\begin{array}{l}\text { Blinding (performance } \\
\text { bias and detection bias) } \\
\text { Patients }\end{array}$ & Low risk & $\begin{array}{l}\text { Quote: "Patient, investigator and staff were blinded to the treatment assign- } \\
\text { ment." } \\
\text { Comment: probably done. }\end{array}$ \\
\hline $\begin{array}{l}\text { Blinding (performance } \\
\text { bias and detection bias) } \\
\text { Outcome assessors }\end{array}$ & Low risk & $\begin{array}{l}\text { Quote: "Patient, investigator and staff were blinded to the treatment assign- } \\
\text { ment." } \\
\text { Comment: probably done. }\end{array}$ \\
\hline
\end{tabular}

\begin{tabular}{|c|c|c|}
\hline $\begin{array}{l}\text { Incomplete outcome data } \\
\text { (attrition bias) }\end{array}$ & Unclear risk & $\begin{array}{l}45 \text { patients randomised. } 39 \text { patients matched inclusion criteria for efficacy } \\
\text { analysis. No information given about } 6 \text { withdrawals. }\end{array}$ \\
\hline
\end{tabular}


Elad 2006 (Continued)

All outcomes

\begin{tabular}{|c|c|c|}
\hline $\begin{array}{l}\text { Selective reporting (re- } \\
\text { porting bias) }\end{array}$ & Unclear risk & $\begin{array}{l}\text { Data presented for maximum intensity, average intensity, and duration of mu- } \\
\text { cositis. Incidence of mucositis > grade } 2 \text { (table } 3 \text { ). }\end{array}$ \\
\hline
\end{tabular}

\begin{tabular}{ll}
\hline Other bias $\quad$ Low risk Study appears to be free of other sources of bias. \\
\hline
\end{tabular}

El Sayed 2002

\section{Study characteristics}

\begin{tabular}{ll}
\hline Methods & $\begin{array}{l}\text { Randomised, parallel group, multicentre study conducted in Canada. Clear information on with- } \\
\text { drawals. Dentist not involved in study. Drop outs: 0\%. Duration: over radiotherapy. }\end{array}$ \\
\hline Participants & $\begin{array}{l}\text { Adults with head and neck cancer treated with radiotherapy to the oral cavity, pharynx or larynx. } 137 \\
\text { enrolled randomised and completed. }\end{array}$ \\
\hline Interventions & $\begin{array}{l}2 \text { groups, placebo versus antimicrobial lozenge (bacitracin, clotrimazole and gentamicin (BCoG) } 1 \\
\text { lozenge qid, day } 1 \text { to end of radiotherapy). }\end{array}$ \\
\hline Outcomes & $\begin{array}{l}\text { Mucositis graded according to the OMAS scale extent of severe mucositis score, worst-ever grade of ul- } \\
\text { ceration/pseudomembrane. Assessment used: time to development of severe mucositis. Other report- } \\
\text { ed outcomes: number of treatment days lost, changes in body weight, worst-ever grade of oral toxicity } \\
\text { measured in patient diary, general non-mucosal toxicity assessed by the investigator. } \\
\text { Mucositis measured twice weekly using the NCI CTC v2 scoring scale and the OMAS scale. Assessment } \\
\text { used up to } 28 \text { days. Other reported outcomes: oral pain and ability to swallow using } 10 \mathrm{~cm} \text { VAS, salivary } \\
\text { flow rate, adverse events nausea and vomiting. }\end{array}$ \\
\hline Notes & \begin{tabular}{l} 
Funding source: National Cancer Institute. \\
\hline
\end{tabular}
\end{tabular}

\section{Risk of bias}

\begin{tabular}{|c|c|c|}
\hline Bias & Authors' judgement & Support for judgement \\
\hline $\begin{array}{l}\text { Random sequence genera- } \\
\text { tion (selection bias) }\end{array}$ & Unclear risk & $\begin{array}{l}\text { Quote: “enrolled patients were randomized". } \\
\text { Comment: random component not described. }\end{array}$ \\
\hline $\begin{array}{l}\text { Allocation concealment } \\
\text { (selection bias) }\end{array}$ & Unclear risk & Insufficient information to determine 'yes' or 'no'. \\
\hline $\begin{array}{l}\text { Blinding (performance } \\
\text { bias and detection bias) } \\
\text { Carers }\end{array}$ & Unclear risk & Insufficient information to determine 'yes' or 'no'. \\
\hline $\begin{array}{l}\text { Blinding (performance } \\
\text { bias and detection bias) } \\
\text { Patients }\end{array}$ & Low risk & $\begin{array}{l}\text { Quote: "double blind". } \\
\text { Comment: probably done. }\end{array}$ \\
\hline $\begin{array}{l}\text { Blinding (performance } \\
\text { bias and detection bias) } \\
\text { Outcome assessors }\end{array}$ & Low risk & $\begin{array}{l}\text { Quote: “double blind”. } \\
\text { Comment: probably done. }\end{array}$ \\
\hline $\begin{array}{l}\text { Incomplete outcome data } \\
\text { (attrition bias) } \\
\text { All outcomes }\end{array}$ & Low risk & $\begin{array}{l}138 \text { patients randomised. } 1 \text { patient ( } 1 / 68 \text { placebo) deemed ineligible. } 4 \text { pa- } \\
\text { tients removed from primary analysis due to missing data ( } 1 / 69 \mathrm{BCoG}, 3 / 68 \\
\text { placebo). } 137 \text { patients included in extent of severe mucositis analysis. }\end{array}$ \\
\hline
\end{tabular}


El Sayed 2002 (Continued)

Selective reporting (re- Low risk Data presented for severity of mucositis by grade of mucositis for all ranporting bias) domised patients (table 4).

Other bias

High risk

Variation in radiation protocols and standard care between sites.

Epstein 1989

\section{Study characteristics}

\begin{tabular}{ll}
\hline Methods & $\begin{array}{l}\text { Randomised, parallel group single site study conducted in Canada. Clear information on withdrawals: } \\
6 / 24 \text { placebo. Dentist involved in study. Drop outs: } 12 \% \text {. No information given about dates of recruit- } \\
\text { ment. Duration: unclear. }\end{array}$ \\
\hline Participants & $\begin{array}{l}\text { Adults with head and neck cancer receiving radiotherapy (25 patients received } 4500 \text { cGy in } 15 \text { daily } \\
\text { fractions over } 3 \text { weeks, } 18 \text { patients received } 6000 \text { cGy in } 25 \text { daily fractions over } 5 \text { weeks). } 49 \text { patients en- } \\
\text { rolled, } 43 \text { patients completed. }\end{array}$ \\
\hline Interventions & $\begin{array}{l}2 \text { groups, placebo (10\% alcohol) base versus benzydamine }(1.5 \mathrm{mg} / \mathrm{ml} \text { benzydamine hydrochloride in } \\
\text { a } 10 \% \text { alcohol base). Both groups asked to rinse } 15 \mathrm{ml} \text { for } 30 \text { seconds, } 4 \text { times daily, and then expecto- } \\
\text { rate. }\end{array}$ \\
\hline Outcomes & $\begin{array}{l}\text { Multivariable scale (area of involvement, severity of inflammation, severity of ulceration and maximum } \\
\text { size of ulceration each graded using a 0-3 scale. Scores then combined). Other outcomes measures: } \\
\text { pain (at rest and on eating), burning, anesthetic effect of benzydamine, salivary flow rate. }\end{array}$ \\
\hline Notes & Funding source: pharmaceutical. \\
\hline
\end{tabular}

\section{Risk of bias}

Bias Authors' judgement Support for judgement

Random sequence genera- Unclear risk tion (selection bias)

Quote: "the patients were selected randomly to receive drug (Bzd) or placebo rinse (carrier base only)".

Comment: random component not described.

$\begin{array}{ll}\begin{array}{l}\text { Allocation concealment } \\ \text { (selection bias) }\end{array} & \text { Unclear risk } \\ & \text { Comment: insufficient information to determine 'yes' or 'no'. }\end{array}$

Blinding (performance Unclear risk Insufficient information to determine 'yes' or 'no'.

bias and detection bias)

Carers

\begin{tabular}{|c|c|c|}
\hline $\begin{array}{l}\text { Blinding (performance } \\
\text { bias and detection bias) }\end{array}$ & Low risk & Quote: "double blind". \\
\hline Patients & & Comment: probably done. \\
\hline
\end{tabular}

\begin{tabular}{ll}
\hline $\begin{array}{l}\text { Blinding (performance } \\
\text { bias and detection bias) }\end{array}$ & Low risk \\
Outcome assessors & Comment: probably done.
\end{tabular}

$\begin{aligned} & \text { Incomplete outcome data } \\ & \text { (attrition bias) }\end{aligned}$
$\begin{aligned} & \text { Lllow risk } \\ & \text { drawn due to non-compliance. }\end{aligned}$

All outcomes 
Epstein 1989 (Continued)

Selective reporting (re- Unclear risk $\quad$ Data presented for maximum size of ulcerations, total area of ulcerations, avporting bias) erage ulceration size and area of reaction $x$ severity of inflammation/surfaces involved.

Other bias Low risk Study appears to be free of other sources of bias.

Epstein 1994

\section{Study characteristics}

\begin{tabular}{ll}
\hline Methods & $\begin{array}{l}\text { Randomised parallel group study conducted in Canada. Clear information about withdrawals: 0. Den- } \\
\text { tist involved in study. Duration: 5-7 weeks. }\end{array}$ \\
\hline Participants & $\begin{array}{l}\text { Adults with head and neck cancer receiving radiotherapy (either } 5000 \text { cGy in } 16 \text { fractions or } 6000 \text { cGy in } \\
25 \text { fractions). } 33 \text { patients randomised and completed study. }\end{array}$ \\
\hline Interventions & $\begin{array}{l}2 \text { groups, placebo versus sucralfate }(1 \mathrm{~g} / 5 \mathrm{ml}) . \text { Drug or placebo rinsed and swallowed for } 1 \text { or } 2 \text { minutes, } \\
4 \text { times daily. }\end{array}$ \\
\hline Outcomes & $\begin{array}{l}\text { Mucositis assessed weekly using a cumulative mucositis score (Epstein). Other reported outcome mea- } \\
\text { sures: compliance, pain, adverse events, dysphagia, xerostomia. }\end{array}$ \\
\hline Notes & Funding source: pharmaceutical.
\end{tabular}

\section{Risk of bias}

\begin{tabular}{|c|c|c|}
\hline Bias & Authors' judgement & Support for judgement \\
\hline $\begin{array}{l}\text { Random sequence genera- } \\
\text { tion (selection bias) }\end{array}$ & Unclear risk & $\begin{array}{l}\text { Quote: "following consent and randomisation". } \\
\text { Comment: random component not described. }\end{array}$ \\
\hline $\begin{array}{l}\text { Allocation concealment } \\
\text { (selection bias) }\end{array}$ & Unclear risk & Insufficient information to determine 'yes' or 'no'. \\
\hline $\begin{array}{l}\text { Blinding (performance } \\
\text { bias and detection bias) } \\
\text { Carers }\end{array}$ & Unclear risk & Insufficient information to determine 'yes' or 'no'. \\
\hline $\begin{array}{l}\text { Blinding (performance } \\
\text { bias and detection bias) } \\
\text { Patients }\end{array}$ & Low risk & $\begin{array}{l}\text { Quote: "double blind". } \\
\text { Comment: probably done. }\end{array}$ \\
\hline $\begin{array}{l}\text { Blinding (performance } \\
\text { bias and detection bias) } \\
\text { Outcome assessors }\end{array}$ & Low risk & $\begin{array}{l}\text { Quote: "double blind". } \\
\text { Comment: probably done. }\end{array}$ \\
\hline $\begin{array}{l}\text { Incomplete outcome data } \\
\text { (attrition bias) } \\
\text { All outcomes }\end{array}$ & Low risk & 33 patients randomised. No missing outcome data. \\
\hline $\begin{array}{l}\text { Selective reporting (re- } \\
\text { porting bias) }\end{array}$ & Unclear risk & Data presented for total mucositis score and total ulceration by arm. \\
\hline Other bias & Low risk & Study appears to be free from other sources of bias. \\
\hline
\end{tabular}


Epstein 2001

\section{Study characteristics}

\begin{tabular}{ll}
\hline Methods & $\begin{array}{l}\text { Randomised parallel group multisite study conducted in the USA and Canada. Clear information about } \\
\text { withdrawals. Unclear if dentist involved in study. Duration: until } 2 \text { weeks after completion of radiother- } \\
\text { apy. }\end{array}$ \\
\hline Participants & $\begin{array}{l}\text { Adults with head and neck cancers receiving radiotherapy (total planned dose of } 5000 \text { Gy) or concomi- } \\
\text { tant radiotherapy and chemotherapy (cisplatin, or 5-fluorouracil). }\end{array}$ \\
\hline Interventions & $\begin{array}{l}2 \text { groups, placebo versus benzydamine (0.15\%, } 1.5 \mathrm{mg} / \mathrm{ml}) . \text { Patients asked to rinse with } 15 \mathrm{ml} \text { of } \\
\text { mouthwash for } 2 \text { minutes, } 4-8 \text { times daily } 173 \text { patients randomised. }\end{array}$ \\
\hline Outcomes & $\begin{array}{l}\text { Mucositis assessed at every clinic visit using a multivariable scale (Epstein). Other reported outcome } \\
\text { measures: use of analgesics, mouth and throat pain, compliance, number of patients diluting rinses, } \\
\text { adverse events, risk of mucositis, weight loss, number of patients needing nasogastric or percutaneous } \\
\text { endoscopic gastrostomy tube feeds. }\end{array}$
\end{tabular}

Notes $\quad$ Funding source: pharmaceutical.

\section{Risk of bias}

\begin{tabular}{|c|c|c|}
\hline Bias & Authors' judgement & Support for judgement \\
\hline $\begin{array}{l}\text { Random sequence genera- } \\
\text { tion (selection bias) }\end{array}$ & Unclear risk & $\begin{array}{l}\text { Quote: "randomised". } \\
\text { Comment: random component not described. }\end{array}$ \\
\hline $\begin{array}{l}\text { Allocation concealment } \\
\text { (selection bias) }\end{array}$ & Unclear risk & Insufficient information to determine 'yes' or 'no'. \\
\hline $\begin{array}{l}\text { Blinding (performance } \\
\text { bias and detection bias) } \\
\text { Carers }\end{array}$ & Unclear risk & Insufficient information to determine 'yes' or 'no'. \\
\hline $\begin{array}{l}\text { Blinding (performance } \\
\text { bias and detection bias) } \\
\text { Patients }\end{array}$ & Unclear risk & Placebo controlled study, however no blinding information is given. \\
\hline $\begin{array}{l}\text { Blinding (performance } \\
\text { bias and detection bias) } \\
\text { Outcome assessors }\end{array}$ & Unclear risk & Placebo controlled study, however no blinding information is given. \\
\hline $\begin{array}{l}\text { Incomplete outcome data } \\
\text { (attrition bias) } \\
\text { All outcomes }\end{array}$ & Low risk & $\begin{array}{l}173 \text { patients randomised. } 172 \text { patients treated. } 165 \text { patients (who had receivec } \\
\text { at least } 1 \text { on-radiation evaluation) included in ITT analysis. }\end{array}$ \\
\hline $\begin{array}{l}\text { Selective reporting (re- } \\
\text { porting bias) }\end{array}$ & Unclear risk & Data presented for mean AUCs by radiotherapy interval. \\
\hline Other bias & Low risk & Study appears to be free from other sources of bias. \\
\hline
\end{tabular}


Ertekin 2004

\section{Study characteristics}

Methods $\quad$ Randomised, parallel group study conducted in Turkey, between May 2001 and May 2002. Clear information about withdrawals, 3 in placebo. Dentist not involved in study. Drop outs: $10 \%$.

\begin{tabular}{ll}
\hline Participants & Adults with head and neck cancer. 30 enrolled, 27 completed. \\
\hline Interventions & $\begin{array}{l}\text { 2 groups, zinc sulphate } 50 \mathrm{mg} \text { zinc capsules } 3 \text { times per day starting first day of radiotherapy until } 6 \\
\text { weeks after versus placebo. All patients access to local anaesthetic solutions and analgesic agents. }\end{array}$ \\
\hline Outcomes & Mucositis RTOG grading. Other reported outcomes: non-steroidal analgesics. \\
\hline Notes & Funding source: unclear.
\end{tabular}

\section{Risk of bias}

\begin{tabular}{lll}
\hline Bias & Authors' judgement & Support for judgement \\
\hline $\begin{array}{l}\text { Random sequence genera- } \\
\text { tion (selection bias) }\end{array}$ & Unclear risk & $\begin{array}{l}\text { Quote: randomly assigned to receive either zinc sulphate or placebo during } \\
\text { RT". } \\
\text { Comment: random component not described. }\end{array}$ \\
\hline $\begin{array}{l}\text { Allocation concealment } \\
\text { (selection bias) }\end{array}$ & Unclear risk & $\begin{array}{l}\text { Quote: "the placebos were empty capsules bought from the same medical firm } \\
\text { to be identical to the zinc sulphate capsules". }\end{array}$ \\
\hline $\begin{array}{l}\text { Blinding (performance } \\
\text { bias and detection bias) } \\
\text { Carers }\end{array}$ & Unclear risk & $\begin{array}{l}\text { Zinc versus placebo. } \\
\text { Reference made to the need for a "well-designed double-blind randomized } \\
\text { study to evaluate the reliability and effectiveness" of zinc. However, no infor- } \\
\text { mation on blinding provided. }\end{array}$
\end{tabular}

\begin{tabular}{|c|c|c|}
\hline $\begin{array}{l}\text { Blinding (performance } \\
\text { bias and detection bias) } \\
\text { Patients }\end{array}$ & Unclear risk & $\begin{array}{l}\text { Reference made to the need for a "well-designed double-blind randomized } \\
\text { study to evaluate the reliability and effectiveness" of zinc. However, no infor- } \\
\text { mation on blinding provided. }\end{array}$ \\
\hline
\end{tabular}

\begin{tabular}{|c|c|c|}
\hline $\begin{array}{l}\text { Blinding (performance } \\
\text { bias and detection bias) } \\
\text { Outcome assessors }\end{array}$ & Unclear risk & $\begin{array}{l}\text { Reference made to the need for a "well-designed double-blind randomized } \\
\text { study to evaluate the reliability and effectiveness" of zinc. However, no infor- } \\
\text { mation on blinding provided. }\end{array}$ \\
\hline
\end{tabular}

\begin{tabular}{lll}
\hline $\begin{array}{l}\text { Incomplete outcome data } \\
\text { (attrition bias) } \\
\text { All outcomes }\end{array}$ & Low risk & $\begin{array}{l}30 \text { patients randomised. } 3 \text { patients withdrew (3/15 placebo). Authors give no } \\
\text { information about which arm patients were randomised to. 27 patients includ- } \\
\text { ed in analysis. }\end{array}$ \\
\hline $\begin{array}{l}\text { Selective reporting (re- } \\
\text { porting bias) }\end{array}$ & Low risk & $\begin{array}{l}\text { Data presented in the text for grade of mucositis by treatment arm. Data also } \\
\text { presented for start of mucositis (week), severity of mucositis, dose of radio- } \\
\text { therapy at which mucositis developed (table 2), and mucositis levels } 6 \text { weeks } \\
\text { after radiotherapy (table 3). }\end{array}$ \\
\hline Other bias & Low risk & Study appears to be free of other sources of bias. \\
\hline
\end{tabular}

\section{Study characteristics}


Evensen 2001 (Continued)

Methods Randomised, parallel group study conducted in Norway. All randomised patients included in evaluation. Dentist involvement unclear. Recruitment September 1995-June 1998.

\begin{tabular}{ll}
\hline Participants & Adults with hand and neck cancer undergoing radiotherapy. 60 enrolled, 60 completed. \\
\hline Interventions & $\begin{array}{l}\text { 2 groups, patients randomised to sucralfate mouthrinse or placebo, swish and spit, } 5 \text { times daily and } \\
\text { same patients also received sucralfate gel to skin on one side of radiation field and placebo gel to other } \\
\text { side of the radiation field (i.e. all patients received some sucralfate gel). }\end{array}$ \\
\hline Outcomes & Mucositis \& skin reaction, RTOG grading. Other reported outcomes: food intake. \\
\hline Notes & Funding source: not stated.
\end{tabular}

\section{Risk of bias}

Bias Authors' judgement Support for judgement

\section{Random sequence genera- Unclear risk} tion (selection bias)
Quote: "The same patients were randomly allocated to receive either Na-SOS or placebo for the oral rinsing procedure".

Comment: random component not described.

\begin{tabular}{|c|c|c|}
\hline $\begin{array}{l}\text { Allocation concealment } \\
\text { (selection bias) }\end{array}$ & Unclear risk & Insufficient information to determine 'yes' or 'no'. \\
\hline $\begin{array}{l}\text { Blinding (performance } \\
\text { bias and detection bias) } \\
\text { Carers }\end{array}$ & Unclear risk & Insufficient information to determine 'yes' or 'no'. \\
\hline $\begin{array}{l}\text { Blinding (performance } \\
\text { bias and detection bias) } \\
\text { Patients }\end{array}$ & Low risk & $\begin{array}{l}\text { Quote: "double blind". } \\
\text { Comment: probably done. }\end{array}$ \\
\hline $\begin{array}{l}\text { Blinding (performance } \\
\text { bias and detection bias) } \\
\text { Outcome assessors }\end{array}$ & Low risk & $\begin{array}{l}\text { Quote: "double blind". } \\
\text { Comment: probably done. }\end{array}$ \\
\hline $\begin{array}{l}\text { Incomplete outcome data } \\
\text { (attrition bias) } \\
\text { All outcomes }\end{array}$ & Low risk & 60 patients randomised. No missing outcome data. \\
\hline $\begin{array}{l}\text { Selective reporting (re- } \\
\text { porting bias) }\end{array}$ & Low risk & Data presented for 60 patients by treatment allocation and grade of mucositis. \\
\hline Other bias & Unclear risk & $\begin{array}{l}\text { Difference between groups at baseline regarding tumour stage ( } 23 \% \text { sucralfate } \\
\text { group T3/4, 53\% placebo group). No P value presented. }\end{array}$ \\
\hline
\end{tabular}

\section{Ferretti 1988}

\section{Study characteristics}

$\begin{array}{ll}\text { Methods } & \text { Randomised, parallel group study conducted in USA. Unclear information on withdrawals: } 1 / 28 \text { control, } \\ 4 / 28 \text { test. Dentist involved in study. Drop outs: } 10 \% \text {. Recruitment period April } 1983 \text { to March } 1985 . \text { Dura- } \\ \text { tion: up to } 90 \text { days. }\end{array}$


Ferretti 1988 (Continued)

Participants
Children and adults (1-51 years) with mixed blood haematological and solid cancers receiving BMT. Pretransplant chemoradiotherapy and TBI. 56 patients enrolled and 51 completed, but variable numbers of patients evaluated at each time point (24-50).

\begin{tabular}{|c|c|}
\hline Interventions & 2 groups, placebo versus chlorhexidine gluconate mouthrinse ( $15 \mathrm{cc} 0.12 \%, 3$ times per day for $30 \mathrm{~s}$ ). \\
\hline Outcomes & $\begin{array}{l}\text { Mucositis (clinical scale } 0-3 \text {, but then dichotomised and measured at } 7,14,25,33,60 \& 90 \text { days). As- } \\
\text { sessment used: day } 33 \text {. Other reported outcomes: gross candida (clinical appearance + swab culture or } \\
\mathrm{KOH} \text { preparation), oral streptococus, yeast, gram -ve bacilli, death, morphine use, febrile episodes, use } \\
\text { of antibiotic, blood changes. }\end{array}$ \\
\hline Notes & $\begin{array}{l}\text { Candidemia (persistant candidiasis) also recorded, with } 3 \text { deaths due to candida in the control group. } \\
\text { Mean mucositis scores given graphically with bars for SE. Given oral nystatin suspension } 15 \mathrm{ml} 4 \text { times } \\
\text { daily or clotrimazole troches. Supplemental nystatin soaks or popsicles were used liberally. } \\
\text { Funding source: pharmaceutical and government. }\end{array}$ \\
\hline
\end{tabular}

\section{Risk of bias}

\begin{tabular}{lll}
\hline Bias & Authors' judgement & Support for judgement \\
\hline $\begin{array}{ll}\text { Random sequence genera- } \\
\text { tion (selection bias) }\end{array}$ & Unclear risk & $\begin{array}{l}\text { Quote: "By prospective randomisation, patients were assigned in a dou- } \\
\text { ble-blind fashion a mouthrinse containing 0.12\% chlorhexidine digluconate or } \\
\text { a control mouthrinse identical in composition but minus chlorhexidine". }\end{array}$ \\
& & Comment: random component not described. \\
\hline
\end{tabular}

Allocation concealment $\quad$ Unclear risk $\quad$ Insufficient information to determine 'yes' or 'no'.
(selection bias)

\begin{tabular}{ll}
\hline $\begin{array}{l}\text { Blinding (performance } \\
\text { bias and detection bias) } \\
\text { Carers }\end{array}$ & Unclear risk
\end{tabular} $\begin{aligned} & \begin{array}{l}\text { Quote: "Mouthrinse use was supervised by transplant unit nursing staff for the } \\
\text { duration of hospitalization". }\end{array} \\
& \text { Comment: insufficient information to determine 'yes' or 'no'. }\end{aligned}$

\begin{tabular}{|c|c|c|}
\hline $\begin{array}{l}\text { Blinding (performance } \\
\text { bias and detection bias) }\end{array}$ & Low risk & $\begin{array}{l}\text { Quote: "double blind". } \\
\text { Quote: "mouthrinse identical in composition but without chlorhexidine". }\end{array}$ \\
\hline
\end{tabular}

\begin{tabular}{|c|c|c|}
\hline $\begin{array}{l}\text { Blinding (performance } \\
\text { bias and detection bias) } \\
\text { Outcome assessors }\end{array}$ & Low risk & $\begin{array}{l}\text { Quote: "double Blind". } \\
\text { Comment: probably done. }\end{array}$ \\
\hline $\begin{array}{l}\text { Incomplete outcome data } \\
\text { (attrition bias) } \\
\text { All outcomes }\end{array}$ & Unclear risk & $\begin{array}{l}56 \text { patients randomised. } 5 \text { patients excluded. Authors give reasons for attri- } \\
\text { tion/exclusion but variable numbers are evaluated at each time point and rea- } \\
\text { sons for missing data are not provided. }\end{array}$ \\
\hline $\begin{array}{l}\text { Selective reporting (re- } \\
\text { porting bias) }\end{array}$ & Unclear risk & $\begin{array}{l}\text { Data presented for percentage of patients with mucositis and mean mucosi- } \\
\text { tis score in the form of graphs (figure } 1 \text { and figure } 2 \text { ). Different numbers of pa- } \\
\text { tients re-evaluated at each time point. }\end{array}$ \\
\hline
\end{tabular}

Other bias Low risk Study appears to be free of other sources of bias.


Fidler 1996

\section{Study characteristics}

\begin{tabular}{ll}
\hline Methods & Randomised, parallel group study conducted in USA. Unclear information on withdrawals: $1 / 165$ total. \\
Unlcear if dentist involved in study. Drop outs: $1 \%$. Duration: 14 days.
\end{tabular}

\begin{tabular}{ll}
\hline Participants & $\begin{array}{l}\text { Adults, cancer type not given. Chemotherapy: first course 5-FU based. } 165 \text { enrolled, } 164 \text { clinical evalua- } \\
\text { tion, } 135 \text { patient evaluation. }\end{array}$ \\
\hline Interventions & 2 groups, placebo versus camomile (30 drops in $100 \mathrm{ml}$ water, 3 times per day). \\
\hline Outcomes & $\begin{array}{l}\text { Mucositis (physician and patient scales 0-4). Score judged historically 4-5 weeks after chemothera- } \\
\text { py cycle initiation. Additionally patient form filled out on daily basis for first } 3 \text { weeks after first day of } \\
\text { chemotherapy. Assessment used: day 21. Other reported outcomes: toxicity. }\end{array}$
\end{tabular}

Notes Mean daily mucositis scores shown graphically but no SD. All patients used ice chips 5 mins before chemotherapy and for 30 minutes in total.

Patient's mucositis scores used.

Funding source: government.

\section{Risk of bias}

Bias Authors' judgement Support for judgement

Random sequence genera- Unclear risk tion (selection bias)

Quote: "Randomised in a double-blind manner to receive a chamomile mouthwash or an identical-appearing placebo."

Comment: random component not described.

\begin{tabular}{|c|c|c|}
\hline $\begin{array}{l}\text { Allocation concealment } \\
\text { (selection bias) }\end{array}$ & Unclear risk & Insufficient information to determine 'yes' or 'no'. \\
\hline $\begin{array}{l}\text { Blinding (performance } \\
\text { bias and detection bias) } \\
\text { Carers }\end{array}$ & Unclear risk & Insufficient information to determine 'yes' or 'no'. \\
\hline $\begin{array}{l}\text { Blinding (performance } \\
\text { bias and detection bias) } \\
\text { Patients }\end{array}$ & Low risk & $\begin{array}{l}\text { Quote: "double-blind". } \\
\text { Comment: probably done. }\end{array}$ \\
\hline $\begin{array}{l}\text { Blinding (performance } \\
\text { bias and detection bias) } \\
\text { Outcome assessors }\end{array}$ & Low risk & $\begin{array}{l}\text { Quote: "double-blind". } \\
\text { Comment: probably done. }\end{array}$ \\
\hline $\begin{array}{l}\text { Incomplete outcome data } \\
\text { (attrition bias) } \\
\text { All outcomes }\end{array}$ & Low risk & $\begin{array}{l}165 \text { patients randomised. } 1 \text { patient removed due to a major protocol violation. } \\
164 \text { patients had evaluable physician judged mucositis scores. Patient judged } \\
\text { mucositis scores evaluable in } 135 \text { patients. }\end{array}$ \\
\hline $\begin{array}{l}\text { Selective reporting (re- } \\
\text { porting bias) }\end{array}$ & Low risk & $\begin{array}{l}\text { Data presented for maximum severity of mucositis by grade for physician and } \\
\text { patients judged mucositis scores (table } 2 \text { ). }\end{array}$ \\
\hline Other bias & Low risk & Study appears to be free of other sources of bias. \\
\hline
\end{tabular}

\section{Study characteristics}


Foote 1994 (Continued)

Methods Randomised, parallel group, multicentre study conducted in USA and Canada. Clear information on withdrawals: none. Unclear if dentist involved in study. Drop outs: 0\%. Duration: 14 days.

\begin{tabular}{ll}
\hline Participants & Adults with head and neck cancer. 52 patients were eligible, enrolled and evaluated. \\
\hline Interventions & 2 groups, placebo versus chlorhexidine ( $15 \mathrm{ml} 4$ times per day for $130 \mathrm{~s})$. \\
\hline Outcomes & Mucositis scale $0-4$ by patient and clinician at weekly intervals. Assessment used: day unclear. \\
\hline Notes & Funding source: pharmaceutical and government.
\end{tabular}

\section{Risk of bias}

\begin{tabular}{|c|c|c|}
\hline Bias & Authors' judgement & Support for judgement \\
\hline $\begin{array}{l}\text { Random sequence genera- } \\
\text { tion (selection bias) }\end{array}$ & Unclear risk & $\begin{array}{l}\text { Quote: "Following randomisation, they were randomized in a double-blind } \\
\text { manner to receive a chlorhexidine mouthwash or a placebo mouthwash." } \\
\text { Comment: random component not described. }\end{array}$ \\
\hline $\begin{array}{l}\text { Allocation concealment } \\
\text { (selection bias) }\end{array}$ & Low risk & $\begin{array}{l}\text { Quote: "only a coded bottle was communicated to the treatment centre". } \\
\text { Comment: central allocation. Probably done. }\end{array}$ \\
\hline $\begin{array}{l}\text { Blinding (performance } \\
\text { bias and detection bias) } \\
\text { Carers }\end{array}$ & Low risk & $\begin{array}{l}\text { Adequate allocation concealment. Unlikely that carers would know alloca- } \\
\text { tions. }\end{array}$ \\
\hline $\begin{array}{l}\text { Blinding (performance } \\
\text { bias and detection bias) } \\
\text { Patients }\end{array}$ & Low risk & $\begin{array}{l}\text { Quote: "double Blind". } \\
\text { Comment: probably done. }\end{array}$ \\
\hline $\begin{array}{l}\text { Blinding (performance } \\
\text { bias and detection bias) } \\
\text { Outcome assessors }\end{array}$ & Low risk & $\begin{array}{l}\text { Quote: "double Blind". } \\
\text { Comment: probably done. }\end{array}$ \\
\hline $\begin{array}{l}\text { Incomplete outcome data } \\
\text { (attrition bias) } \\
\text { All outcomes }\end{array}$ & Low risk & 52 patients randomised. No incomplete outcome data. \\
\hline $\begin{array}{l}\text { Selective reporting (re- } \\
\text { porting bias) }\end{array}$ & Low risk & $\begin{array}{l}\text { Data presented for } 52 \text { patients for maximum mucositis severity score by grade } \\
\text { of mucositis and intervention. }\end{array}$ \\
\hline Other bias & High risk & $\begin{array}{l}\text { Quote: "Due to the significantly higher toxicity rates and the lack of evidence of } \\
\text { efficacy associated with chlorhexidine, the double-blinded portion of the trial } \\
\text { was permanently closed". }\end{array}$ \\
\hline
\end{tabular}

Franzen 1995

\section{Study characteristics}

\begin{tabular}{ll}
\hline Methods & Randomised, parallel group study conducted in Sweden. Unclear information on withdrawals: $2 / 50$ to- \\
tal. Unclear if dentist involved in study. Drop outs: $4 \%$. Duration of treatment: 6 weeks (starting 2 weeks \\
after start of radiotherapy).
\end{tabular}


Franzen 1995 (Continued)

Participants Adults with head and neck cancer. 50 patients were randomised and 48 evaluated.

Interventions 2 groups, placebo versus sucralfate (granules of sucralfate an alkaline aluminimum hydroxide of
suphated sucrose, swish with 1 dose package $1 \mathrm{~g}$ dissolved in water 6 times/day).

Outcomes Patient based assessment of mucositis on 0-3 scale, number with grades 2 or 3 reported. Assessement used: day 28. Other reported outcomes: mucosal reaction, pain, functional impairment. Mucositis evaluations from -2 to 14 weeks.

Notes Funding source: charity.

\section{Risk of bias}

\begin{tabular}{|c|c|c|}
\hline Bias & Authors' judgement & Support for judgement \\
\hline \multirow[t]{2}{*}{$\begin{array}{l}\text { Random sequence genera- } \\
\text { tion (selection bias) }\end{array}$} & Unclear risk & $\begin{array}{l}\text { Quote: "granules of sucralfate or placebo similar in taste, colour, and consis- } \\
\text { tency were dispensed randomly". }\end{array}$ \\
\hline & & Comment: random component not described. \\
\hline $\begin{array}{l}\text { Allocation concealment } \\
\text { (selection bias) }\end{array}$ & Unclear risk & Insufficient information to determine 'yes' or 'no'. \\
\hline $\begin{array}{l}\text { Blinding (performance } \\
\text { bias and detection bias) } \\
\text { Carers }\end{array}$ & Unclear risk & Insufficient information to determine 'yes' or 'no'. \\
\hline $\begin{array}{l}\text { Blinding (performance } \\
\text { bias and detection bias) }\end{array}$ & Low risk & \\
\hline Patients & & Comment: probably done. \\
\hline $\begin{array}{l}\text { Blinding (performance } \\
\text { bias and detection bias) }\end{array}$ & Low risk & \\
\hline Outcome assessors & & Comment: probably done. \\
\hline $\begin{array}{l}\text { Incomplete outcome data } \\
\text { (attrition bias) } \\
\text { All outcomes }\end{array}$ & Unclear risk & $\begin{array}{l}50 \text { patients randomised. } 2 \text { patients excluded from analysis. Authors give full } \\
\text { reasons for attrition/exclusion. Numbers of patients reported in outcome as- } \\
\text { sessments not reported information only given in percentages. }\end{array}$ \\
\hline $\begin{array}{l}\text { Selective reporting (re- } \\
\text { porting bias) }\end{array}$ & Unclear risk & $\begin{array}{l}\text { Data presented in a graph for mucosal reaction over time (figure 1). Figures } \\
\text { given in percentages. }\end{array}$ \\
\hline Other bias & Low risk & Study appears to be free of other sources of bias. \\
\hline
\end{tabular}

Freytes 2004

\section{Study characteristics}

$\begin{array}{ll}\text { Methods } & \text { Randomised, parallel group, multicentre study conducted in USA. Clear information on withdrawals: } \\ \text { none. Dentist not involved in study. Drop outs: } 0 \% \text {. Duration: } 28 \text { days after last dose of intervention. }\end{array}$

Participants Adults with mixed cancer. BMT. 42 enrolled, randomised and evaluated. 
Freytes 2004 (Continued)

Interventions $\quad 3$ groups, placebo versus repifermin $25 \mathrm{mug} / \mathrm{kg}$ and repifermin $50 \mathrm{mug} / \mathrm{kg}$ (patients received intravenous repifermin or placebo for 3 days before their autologous haematopoietic stem cell transplantation (auto-HSCT) conditioning regimen and for up to 10 days after auto-HSCT).

Notes Funding source: unclear.

Mucositis measured 3/week until mucositis resolved using the NCI CTC mucositis toxicity scale for bone marrow transplant studies (on a scale of 0-4). Mucositis was also assessed by the OMAS scale. Assessment used: up to day 28. Other reported outcomes: severity and duration of ambient oral and oropharyngeal pain and pain on swallowing, an ability to eat score, narcotic pain medication use, adverse events incuded the frequency, severity and duration of diarrhoea.

\begin{tabular}{|c|c|c|}
\hline \multicolumn{3}{|l|}{ Risk of bias } \\
\hline Bias & Authors' judgement & Support for judgement \\
\hline $\begin{array}{l}\text { Random sequence genera- } \\
\text { tion (selection bias) }\end{array}$ & Unclear risk & $\begin{array}{l}\text { Quote: "This study was a multicentre randomised, double-blinded, placebo } \\
\text { controlled, phase I/II study." }\end{array}$ \\
\hline & & Comment: random component not described. \\
\hline $\begin{array}{l}\text { Allocation concealment } \\
\text { (selection bias) }\end{array}$ & Unclear risk & Insufficient information to determine 'yes' or 'no'. \\
\hline $\begin{array}{l}\text { Blinding (performance } \\
\text { bias and detection bias) } \\
\text { Carers }\end{array}$ & Unclear risk & Insufficient information to determine 'yes' or 'no'. \\
\hline $\begin{array}{l}\text { Blinding (performance } \\
\text { bias and detection bias) }\end{array}$ & Low risk & Quote: “double blind”. \\
\hline Patients & & Comment: probably done. \\
\hline $\begin{array}{l}\text { Blinding (performance } \\
\text { bias and detection bias) }\end{array}$ & Low risk & \\
\hline Outcome assessors & & Comment: probably done. \\
\hline $\begin{array}{l}\text { Incomplete outcome data } \\
\text { (attrition bias) } \\
\text { All outcomes }\end{array}$ & Low risk & 42 patients recruited. No missing outcome data. \\
\hline $\begin{array}{l}\text { Selective reporting (re- } \\
\text { porting bias) }\end{array}$ & Unclear risk & $\begin{array}{l}\text { Data only presented in percentages for mucositis grades between } 2 \text { and } 4 \text { (fig- } \\
\text { ure 1). }\end{array}$ \\
\hline Other bias & High risk & $\begin{array}{l}\text { Authors highlight possible bias because of the multiplicity of conditioning reg- } \\
\text { imens used. }\end{array}$ \\
\hline
\end{tabular}

Gandemer 2007

\section{Study characteristics}

\begin{tabular}{ll}
\hline Methods & $\begin{array}{l}\text { Randomised, parallel multicentre study conducted in France. Clear information about withdrawals: } \\
3 / 73 \text { intervention, } 2 / 72 \text { control. Duration: from first day of chemotherapy to } 3 \text { days after the end of } \\
\text { chemotherapy. Recruitment conducted between March } 1999 \text { and December } 2002 .\end{array}$ \\
\hline Participants & $\begin{array}{l}\text { Children aged between } 5 \text { and } 18 \text { years old undergoing chemotherapy. Mix of diseases (osteosarcoma, } \\
\text { Hodgkin lymphoma, acute lymphoblastic leukaemia, acute myeloblastic leukaemia, rhabdomysarco- }\end{array}$
\end{tabular}


Gandemer 2007 (Continued)

ma, lymphoma, Ewing sarcoma). all chemotherapy regimens were associated with at least a $30 \%$ rate of grade $3 / 4$ mucositis.

\begin{tabular}{ll}
\hline Interventions & groups, no treatment control versus chewing gum. Patients in the chewing gum arm were asked to \\
chew 5-6 pieces of gum per day. All patients received standard oral care (brushing with a soft tooth- \\
brush and rinsing with sodium bicarbonate).
\end{tabular}

Outcomes

Mucositis assessed daily using the WHO score and a detailed instrument designed by the authors. Other reported outcome measures: pain, abdominal disorders, use of parenteral nutrition, adverse events, infection, factors associated with severe mucositis (multivariate analysis).

Notes Funding source: publicly funded research grant and a national clinical research grant.

\begin{tabular}{|c|c|c|}
\hline \multicolumn{3}{|l|}{ Risk of bias } \\
\hline Bias & Authors' judgement & Support for judgement \\
\hline $\begin{array}{l}\text { Random sequence genera- } \\
\text { tion (selection bias) }\end{array}$ & Low risk & $\begin{array}{l}\text { Quote: "Eligible patients were randomised by the study randomisation cen- } \\
\text { tre..." }\end{array}$ \\
\hline & & Quote: "A minimization procedure was used..." \\
\hline & & Comment: minimization. \\
\hline $\begin{array}{l}\text { Allocation concealment } \\
\text { (selection bias) }\end{array}$ & Low risk & $\begin{array}{l}\text { Quote: "the study centres and the randomisation centres communicated by } \\
\text { fax". }\end{array}$ \\
\hline $\begin{array}{l}\text { Blinding (performance } \\
\text { bias and detection bias) } \\
\text { Carers }\end{array}$ & High risk & Chewing gum versus no intervention. Blinding impossible. \\
\hline $\begin{array}{l}\text { Blinding (performance } \\
\text { bias and detection bias) } \\
\text { Patients }\end{array}$ & High risk & Chewing gum versus no intervention. Blinding impossible. \\
\hline $\begin{array}{l}\text { Blinding (performance } \\
\text { bias and detection bias) } \\
\text { Outcome assessors }\end{array}$ & High risk & Chewing gum versus no intervention. \\
\hline $\begin{array}{l}\text { Incomplete outcome data } \\
\text { (attrition bias) } \\
\text { All outcomes }\end{array}$ & Low risk & $\begin{array}{l}145 \text { patients randomised. Primary end point (WHO score) was evaluable in } 140 \\
\text { patients. Excluded patients equally distributed ( } 3 / 73 \text { intervention, } 2 / 72 \text { con- } \\
\text { trol). Authors do not give reasons for withdrawals/exclusions. }\end{array}$ \\
\hline $\begin{array}{l}\text { Selective reporting (re- } \\
\text { porting bias) }\end{array}$ & Unclear risk & $\begin{array}{l}\text { Data presented in percentages for } 140 \text { patients for mucositis grades } 1 \text { and } 2 \\
\text { combined and mucositis grades } 3 \text { and } 4 \text { combined (fig } 2 A \text { ). }\end{array}$ \\
\hline Other bias & Low risk & Study appears to be free of other sources of bias. \\
\hline
\end{tabular}

Giles 2004

\section{Study characteristics}

Methods
Randomised, parallel group, multicentre study conducted in USA between November 2001 and June
2002. Clear information on withdrawals: none. Dentist not involved in study. Drop outs: $0 \%$. Duration:


Giles 2004 (Continued)

Participants Adults and children with mixed cancer. BMT. 502 randomised and completed.

\begin{tabular}{|c|c|}
\hline Interventions & $\begin{array}{l}2 \text { groups, placebo versus iseganan (patients received an oral rinse, consisting of iseganan } 9 \mathrm{mg} \text { or } \\
\text { placebo, to be swished/swallowed } 6 \text { times daily, for up to } 21 \text { days). }\end{array}$ \\
\hline Outcomes & $\begin{array}{l}\text { Mucositis assessed } 3 / \text { weekly by the proportion of patients who did not develop a peak NCI CTC stom- } \\
\text { atitis grade } 2 \text { or above. Assessment used up to } 21 \text { days. Other reported outcomes: mouth pain, diffi- } \\
\text { culty swallowing, incidence of ulcerative oral mucositis (UOM), opioid use, adverse events included fa- } \\
\text { tigue, anxiety, sore throat, dermatitis, insomnia and erythema. }\end{array}$ \\
\hline
\end{tabular}

Notes

Funding source: unclear. Pharmacological company provided drug and organised randomisation. Correspondence with Dr D Peterson: clinical trials with iseganan were discontinued approximately 6 years ago. Approval of the drug for oral mucositis was not obtained in the United States.

\section{Risk of bias}

\begin{tabular}{lll}
\hline Bias & Authors' judgement & Support for judgement \\
\hline $\begin{array}{l}\text { Random sequence genera- } \\
\text { tion (selection bias) }\end{array}$ & Unclear risk & $\begin{array}{l}\text { Quote: "A randomised, double blind, placebo controlled study". } \\
\text { Comment: random component not described. }\end{array}$ \\
\hline $\begin{array}{l}\text { Allocation concealment } \\
\text { (selection bias) }\end{array}$ & Unclear risk & $\begin{array}{l}\text { Quote: "all study drugs were packaged in identical white opaque plastic bot- } \\
\text { tles, each containing a 5 day supply." }\end{array}$ \\
& $\begin{array}{l}\text { Comment: authors do not state whether drugs were sequentially numbered. } \\
\text { Insufficient information to determine 'yes'. }\end{array}$
\end{tabular}

Blinding (performance Unclear risk Insufficient information to determine 'yes' or 'no'.

bias and detection bias)

Carers

\begin{tabular}{ll}
\hline $\begin{array}{l}\text { Blinding (performance } \\
\text { bias and detection bias) }\end{array}$ & Quote: "double blind". \\
$\begin{array}{ll}\text { Patients } & \text { Quote: "Patients, study personnel, and the sponsor were blinded to whether } \\
& \end{array}$ & an individual patient received iseganan or placebo".
\end{tabular}

Comment: probably done.

\begin{tabular}{|c|c|c|}
\hline Outcome assessors & & $\begin{array}{l}\text { Quote: "Patients, study personnel, and the sponsor were blinded to whether } \\
\text { an individual patient received iseganan or placebo". }\end{array}$ \\
\hline
\end{tabular}

Comment: probably done.

\begin{tabular}{lll}
\hline $\begin{array}{l}\text { Incomplete outcome data } \\
\text { (attrition bias) } \\
\text { All outcomes }\end{array}$ & Unclear risk & $\begin{array}{l}\text { 502 patients randomised. 56\% of Iseganan group and 66\% of placebo group } \\
\text { completed study. Authors give incomplete reasons for exclusion/attrition. }\end{array}$ \\
\hline $\begin{array}{l}\text { Selective reporting (re- } \\
\text { porting bias) }\end{array}$ & Unclear risk & $\begin{array}{l}\text { Data presented for percentage without mucositis, peak mucositis grade, mean } \\
\text { mucositis grade, and incidence (percentage) of ulcerative mucositis. }\end{array}$ \\
\hline Other bias & Low risk & Study appears to be free of other sources of bias. \\
\hline
\end{tabular}


Gori 2007

\section{Study characteristics}

Methods Randomised, parallel multisite study conducted in Italy between October 2004 and January 2006. Clear information on withdrawals. Unclear if dentist involved in study.

Participants Adults and children with haematological malignancies undergoing allogeneic stem cell transplantation. All patients received methotrexate $\left(20 \mathrm{mg} / \mathrm{m}^{2}\right.$ on day $+1,5 \mathrm{mg} / \mathrm{m}^{2}$ on days $+3,+6$ and +11$)$. 130 patients were randomised. 8 patients were excluded. 50 patients received folinic acid rescue.

\begin{tabular}{ll}
\hline Interventions & 2 groups, no treatment control versus cryotherapy (1 hour, ice chips or popsicles). \\
\hline Outcomes & $\begin{array}{l}\text { Mucositis assessed daily using the WHO score. Other reported outcome measures: multivariate analysis } \\
\text { of factors affecting mucositis development (lack of folinic acid rescue and use of TBI). }\end{array}$
\end{tabular}

Notes Funding source: Italian HSCT Nurses Group.

\section{Risk of bias}

\begin{tabular}{lll}
\hline Bias & Authors' judgement & Support for judgement \\
\hline $\begin{array}{l}\text { Random sequence genera- } \\
\text { tion (selection bias) }\end{array}$ & Unclear risk & $\begin{array}{l}\text { Quote: "After giving their informed consent, patients were included in a pre- } \\
\text { formed randomization list that was updated by the co-ordinating centre. Ran- } \\
\text { domization was performed at the ratio of 1 patient per arm with no further } \\
\text { stratification." }\end{array}$ \\
& Comment: random component not described.
\end{tabular}

\begin{tabular}{|c|c|c|}
\hline $\begin{array}{l}\text { Allocation concealment } \\
\text { (selection bias) }\end{array}$ & Unclear risk & $\begin{array}{l}\text { Co-ordinating centre described in text, however, unclear who held the sched- } \\
\text { ules. Therefore, there is insufficient information to determine 'yes' or 'no'. }\end{array}$ \\
\hline $\begin{array}{l}\text { Blinding (performance } \\
\text { bias and detection bias) } \\
\text { Carers }\end{array}$ & High risk & Ice chips versus no intervention. Blinding impossible. \\
\hline $\begin{array}{l}\text { Blinding (performance } \\
\text { bias and detection bias) } \\
\text { Patients }\end{array}$ & High risk & Ice chips versus no intervention. Blinding impossible. \\
\hline $\begin{array}{l}\text { Blinding (performance } \\
\text { bias and detection bias) } \\
\text { Outcome assessors }\end{array}$ & High risk & Ice chips versus no intervention. \\
\hline $\begin{array}{l}\text { Incomplete outcome data } \\
\text { (attrition bias) } \\
\text { All outcomes }\end{array}$ & Low risk & $\begin{array}{l}130 \text { patients were randomised. } 8 \text { patients were excluded. Authors give com- } \\
\text { plete reasons for exclusions/withdrawals but do not state which arm patients } \\
\text { were randomised to. }\end{array}$ \\
\hline $\begin{array}{l}\text { Selective reporting (re- } \\
\text { porting bias) }\end{array}$ & Low risk & Data presented for 122 patients by mucositis grade and arm. \\
\hline Other bias & Low risk & Study appears to be free of other sources of bias. \\
\hline
\end{tabular}

\section{Study characteristics}


Goyal 2009 (Continued)

Methods Randomised, parallel group study conducted in India. All patients underwent oro-dental prophylaxis prior to randomisation. Recruitment conducted from July 2006 until July 2007.

Participants

Adults with head and neck cancer (non-metastatic carcinoma of the oral cavity, pharynx or larynx) receiving radiotherapy. 212 patients randomised. 35 patients excluded.

\begin{tabular}{ll}
\hline Interventions & Morning radiotherapy (8am-11am) versus evening radiotherapy (3pm-6pm). \\
\hline Outcomes & $\begin{array}{l}\text { Oral mucositis assessed weekly using RTOG instrument (0-4) for } 7 \text { weeks. Week 4 data used (table 3). } \\
\text { Other reported outcomes: highest grade of mucositis, response to radiation, dysgeusia, dysphagia, xe- } \\
\text { rostomia, skin reaction. }\end{array}$ \\
\hline Notes & Funding source unclear. \\
\hline
\end{tabular}

Risk of bias

\begin{tabular}{lll}
\hline Bias & Authors' judgement & Support for judgement \\
\hline $\begin{array}{ll}\text { Random sequence genera- } \\
\text { tion (selection bias) }\end{array}$ & Unclear risk & $\begin{array}{l}\text { Quote: "All patients were hospitalised during the course of treatment and were } \\
\text { randomised to arm 1, receiving radiation in the morning and arm 2, receiving } \\
\text { radiation in the evening." } \\
\text { Comment: random component not described. }\end{array}$ \\
& & \\
\hline
\end{tabular}

\begin{tabular}{lll}
\hline $\begin{array}{l}\text { Allocation concealment } \\
\text { (selection bias) }\end{array}$ & Unclear risk & Insufficient information to determine 'yes' or 'no'. \\
\hline $\begin{array}{l}\text { Blinding (performance } \\
\text { bias and detection bias) } \\
\text { Carers }\end{array}$ & High risk & Morning versus evening radiation. Blinding impossible. \\
\hline
\end{tabular}

Blinding (performance High risk Morning versus evening radiation. Blinding impossible.

bias and detection bias)

Patients

\begin{tabular}{|c|c|c|}
\hline $\begin{array}{l}\text { Blinding (performance } \\
\text { bias and detection bias) } \\
\text { Outcome assessors }\end{array}$ & Low risk & $\begin{array}{l}\text { Quote: "Radiation reactions were assessed weekly by a blinded observer ac- } \\
\text { cording by RTOG criteria". } \\
\text { Comment: probably done. }\end{array}$ \\
\hline $\begin{array}{l}\text { Incomplete outcome data } \\
\text { (attrition bias) } \\
\text { All outcomes }\end{array}$ & High risk & $\begin{array}{l}212 \text { patients randomised. } 35 \text { patients excluded. Authors give incomplete rea- } \\
\text { sons for drop outs/exclusions and no information about which arms these pa- } \\
\text { tients were allocated. }\end{array}$ \\
\hline $\begin{array}{l}\text { Selective reporting (re- } \\
\text { porting bias) }\end{array}$ & Low risk & $\begin{array}{l}\text { Data presented for grade of mucositis by arm and week of treatment (table } 3 \text { ). } \\
\text { Data also presented for grades I and II and grades III and IV in percentages (ta- } \\
\text { ble 2). }\end{array}$ \\
\hline Other bias & Low risk & Study appears to be free from other sources of bias. \\
\hline
\end{tabular}

Gujral 2001

\section{Study characteristics}

\begin{tabular}{ll}
\hline Methods & Randomised, parallel group study conducted in India. Unclear information about withdrawals. Dentist \\
no involved in study. Drop outs: $1 \%$. Duration: 6 months.
\end{tabular}


Gujral 2001 (Continued)

Participants Adults with head and neck cancer. T3 and T4 squamous cell cancer, 100 enrolled, 99 evaluated.

\begin{tabular}{ll}
\hline Interventions & 2 groups, no treatment versus hydrolytic enzymes, papain $100 \mathrm{mg}$, trypsin 40 mg and chymotrypsin 40 \\
$\mathrm{mg} .3$ tablets 3 times a day -3 until +5.
\end{tabular}

Outcomes RTOG/EORTC scoring. Assessment used: day 54. Other reported outcomes: dysphagia, dermatitis.

Notes No oral care except toothbrushing. Funding source: pharmaceutical.

\section{Risk of bias}

Bias Authors' judgement Support for judgement

Random sequence genera- Unclear risk tion (selection bias)
Quote: "patient randomisation was carried out by the sealed envelope method."

Quote: "The patients were enrolled in chronological order. They were assigned consecutive patient numbers, and received either radiation therapy, or radiation therapy together with enzyme therapy".

Comment: unclear if envelopes were shuffled. Random component not described.

\begin{tabular}{ll}
\hline $\begin{array}{l}\text { Allocation concealment } \\
\text { (selection bias) }\end{array}$ & Unclear risk \\
& $\begin{array}{l}\text { Comment: unclear whether envelopes were sequentially numbered and } \\
\text { opaque. }\end{array}$ \\
\hline
\end{tabular}

Blinding (performance High risk Quote: "randomised, open trial".

bias and detection bias)

Carers

\begin{tabular}{lll}
\hline $\begin{array}{l}\text { Blinding (performance } \\
\text { bias and detection bias) } \\
\text { Patients }\end{array}$ & High risk & Quote: "randomised, open trial". \\
\hline $\begin{array}{l}\text { Blinding (performance } \\
\text { bias and detection bias) } \\
\text { Outcome assessors }\end{array}$ & High risk & Quote: "randomised, open trial". \\
\hline
\end{tabular}

\begin{tabular}{|c|c|c|}
\hline $\begin{array}{l}\text { Incomplete outcome data } \\
\text { (attrition bias) } \\
\text { All outcomes }\end{array}$ & Low risk & $\begin{array}{l}100 \text { patients randomised. Outcome data given for } 99 \text { patients. } 53 \text { : interven- } \\
\text { tion, } 46 \text { : control. } 2 \text { patients died during study } 2 / 53 \text { intervention. Missing pa- } \\
\text { tient from control group. No information given. Observed event risk not suffi- } \\
\text { cient to have clinically relevant impact on result. }\end{array}$ \\
\hline
\end{tabular}

\begin{tabular}{ll}
\hline $\begin{array}{l}\text { Selective reporting (re- } \\
\text { porting bias) }\end{array}$ & Low risk \\
& $\begin{array}{l}\text { Data presented for } 99 \text { patients by mucositis grade (table 3). AUC data present- } \\
\text { ed for } 93 \text { patients with complete data (table 4). Minimum and maximum, mean }\end{array}$ \\
& (SD) grades given for 99 patients (table 2). Data presented for time to mucositis \\
& grade 2 (table 5).
\end{tabular}

Other bias Low risk Study appears to be free from other sources of bias.

\section{Study characteristics}


Haddad 2009 (Continued)

Methods

Randomised, parallel group, 1 site study conducted in USA. Clear information on withdrawals: none. Unclear if dentist involved in study. Drop outs: $0 \%$. Duration: up to 43 days.
Adults with head and neck cancer. 58 patients enrolled and randomised between May 2003 and April 2006, all completed.

\begin{tabular}{ll}
\hline Interventions & 2 groups, no amifostine versus intravenous amifostine $\left(500 \mathrm{mg} / \mathrm{m}^{2}\right.$ concomitant with 4 weekly doses of \\
carboplatin (area under the curve, 1.5$)$ and paclitaxel $\left(45 \mathrm{mg} / \mathrm{m}^{2}\right)$ and boost radiation 72 Gy in 42 frac- \\
tions).
\end{tabular}

Outcomes

Mucositis secondary outcome as determined by Common Terminology Criteria for Adverse Events, version 3.0), assessment every 4 weeks and the worst grade recorded. Only percent of patients with grades 3 and 4 reported.

Other reported outcomes: xerostomia, locoregional failure, progression-free survival, overall survival (all up to 60 months), treatment related adverse events: cytokine level, feeding tubes, swallowing function, breaks in treatment, allergic reaction.

Notes Funding source: industry.

\section{Risk of bias}

\section{Bias Authors' judgement Support for judgement}

Random sequence genera- Low risk Quote: "the randomisation process was centralised and managed through the tion (selection bias) Dana-Farber Cancer Institute protocol office".

Comment: random component not explicit. However, setting makes adequate randomisation likely.

\begin{tabular}{|c|c|c|}
\hline $\begin{array}{l}\text { Allocation concealment } \\
\text { (selection bias) }\end{array}$ & Unclear risk & $\begin{array}{l}\text { Quote: "central method of allocation". } \\
\text { Insufficient information to determine 'yes' or 'no'. }\end{array}$ \\
\hline $\begin{array}{l}\text { Blinding (performance } \\
\text { bias and detection bias) } \\
\text { Carers }\end{array}$ & High risk & Radiotherapy with or without subcutaneous amifostine. No apparent blinding. \\
\hline $\begin{array}{l}\text { Blinding (performance } \\
\text { bias and detection bias) } \\
\text { Patients }\end{array}$ & High risk & Radiotherapy with or without subcutaneous amifostine. No apparent blinding. \\
\hline $\begin{array}{l}\text { Blinding (performance } \\
\text { bias and detection bias) } \\
\text { Outcome assessors }\end{array}$ & High risk & Radiotherapy with or without subcutaneous amifostine. No apparent blinding. \\
\hline $\begin{array}{l}\text { Incomplete outcome data } \\
\text { (attrition bias) } \\
\text { All outcomes }\end{array}$ & Low risk & 58 patients randomised. No missing outcome data. \\
\hline $\begin{array}{l}\text { Selective reporting (re- } \\
\text { porting bias) }\end{array}$ & Unclear risk & $\begin{array}{l}\text { Data presented in percentages for number of patients experiencing grade } 3 \\
\text { and } 4 \text { mucositis. }\end{array}$ \\
\hline Other bias & High risk & $\begin{array}{l}\text { The study was stopped before the completion of planned accrual because IM- } \\
\text { RT was becoming the de facto standard technique in treating head and neck } \\
\text { cancer. }\end{array}$ \\
\hline
\end{tabular}


Hanson 1995

\section{Study characteristics}

\begin{tabular}{ll}
\hline Methods & $\begin{array}{l}\text { Randomised, parallel group multisite study conducted in the USA. Clear information about with- } \\
\text { drawals: 0. Unclear if dentist involved in study. Duration: 5-7 weeks. }\end{array}$ \\
\hline Participants & $\begin{array}{l}\text { Adults with head and neck cancer undergoing radiotherapy (daily fractions of } 2 \text { Gy/day, total dose: } \\
50-70 \text { Gy over 5-7 weeks). }\end{array}$ \\
\hline Interventions & $\begin{array}{l}2 \text { groups, placebo tablets or misoprostol tablets (200 } \mu \text { g) dissolved in } 15 \text { ml tap water. Patient asked to } \\
\text { swish and gargle without swallowing. }\end{array}$ \\
\hline Outcomes & $\begin{array}{l}\text { Mucositis assessed weekly using a 0-4 scale. Other reported outcome measures: plasma values of miso- } \\
\text { number of patients receiving antifungals, nasogastric tubes and parotid sparing. }\end{array}$ \\
\hline Notes & \begin{tabular}{l} 
Funding source: pharmaceutical. \\
\hline
\end{tabular}
\end{tabular}

\section{Risk of bias}

\begin{tabular}{|c|c|c|}
\hline Bias & Authors' judgement & Support for judgement \\
\hline $\begin{array}{l}\text { Random sequence genera- } \\
\text { tion (selection bias) }\end{array}$ & Unclear risk & $\begin{array}{l}\text { Quote: "randomized". } \\
\text { Comment: random component not described. }\end{array}$ \\
\hline $\begin{array}{l}\text { Allocation concealment } \\
\text { (selection bias) }\end{array}$ & Unclear risk & $\begin{array}{l}\text { Quote: } 35 \text { tablets containing } 200 \mu \mathrm{g} \text { each of MP of } 35 \text { placebo tablets contain- } \\
\text { ing the vehicle alone were supplied by Searle in coded bottles". } \\
\text { Comment: unclear if bottles were sequentially numbered. }\end{array}$ \\
\hline $\begin{array}{l}\text { Blinding (performance } \\
\text { bias and detection bias) } \\
\text { Carers }\end{array}$ & Low risk & $\begin{array}{l}\text { Quote: "each patient was assigned a bottle of tablets without knowledge of the } \\
\text { content (MP or placebo), nor did the attending physician, nursing or adminis- } \\
\text { trative staff knew the content or coding". } \\
\text { Comment: probably done. }\end{array}$ \\
\hline
\end{tabular}

Blinding (performance Low risk

bias and detection bias)

Patients
Quote: "each patient was assigned a bottle of tablets without knowledge of the content (MP or placebo), nor did the attending physician, nursing or administrative staff knew the content or coding".

Comment: probably done.

$\begin{array}{ll}\begin{array}{l}\text { Blinding (performance } \\ \text { bias and detection bias) }\end{array} & \text { Low risk } \\ \text { Outcome assessors } & \begin{array}{l}\text { Quote: "each patient was assigned a bottle of tablets without knowledge of the } \\ \text { content (MP or placebo), nor did the attending physician, nursing or adminis- } \\ \text { trative staff knew the content or coding". }\end{array}\end{array}$

Comment: probably done.

Incomplete outcome data Low risk 69 patients randomised. No missing outcome data.

(attrition bias)

All outcomes

\begin{tabular}{lll}
\hline $\begin{array}{l}\text { Selective reporting (re- } \\
\text { porting bias) }\end{array}$ & Unclear risk & Data presented for mean mucositis score over time for both hospital sites. \\
\hline Other bias & High risk & $\begin{array}{l}\text { Significant difference seen between the } 2 \text { investigative sites in this study } \\
\text { (1 showed an effect, the other did not). Authors have no definitive explana- } \\
\text { tion but there is a suggestion that there may have been differences in the }\end{array}$
\end{tabular}


Hartmann 2001

\section{Study characteristics}

\begin{tabular}{ll}
\hline Methods & $\begin{array}{l}\text { Randomised, parallel group study conducted in Germany. Clear information about withdrawals: } 0 . \text { Un- } \\
\text { clear if dentist involved in study. Drop outs: } 0 \% .\end{array}$ \\
\hline Participants & Adults with solid cancer. 40 enrolled between August 1997 and January 1999,40 completed. \\
\hline Interventions & $\begin{array}{l}2 \text { groups, amifostine } 910 \mathrm{mg} / \mathrm{m}^{2}, 15 \text { minute IV infusion before carboplatin and ifosfamide for } 3 \text { consecu- } \\
\text { tive days versus no amifostine control. }\end{array}$ \\
\hline Outcomes & $\begin{array}{l}\text { Mucositis WHO percentage patients grade 3-4. Other reported outcomes nausea/vomiting, costs of to- } \\
\text { tal care, diarrhoea. }\end{array}$ \\
\hline Notes & Funding source: pharmaceutical.
\end{tabular}

\section{Risk of bias}

Bias Authors' judgement Support for judgement

Random sequence genera- Unclear risk tion (selection bias)
Quote: "Patients had given informed consent for the treatment with HD-VIC and for the randomization to pre-treatment with or without amifostine."

Comment: random component not described.

Allocation concealment $\quad$ Unclear risk
(selection bias)

High risk

Blinding (performance bias and detection bias)

Carers

\begin{tabular}{|c|c|c|}
\hline $\begin{array}{l}\text { Blinding (performance } \\
\text { bias and detection bias) } \\
\text { Patients }\end{array}$ & High risk & Amifostine versus no intervention. No apparent blinding. \\
\hline $\begin{array}{l}\text { Blinding (performance } \\
\text { bias and detection bias) } \\
\text { Outcome assessors }\end{array}$ & High risk & Amifostine versus no intervention. No apparent blinding. \\
\hline
\end{tabular}

\begin{tabular}{lll}
\hline $\begin{array}{l}\text { Incomplete outcome data } \\
\text { (attrition bias) } \\
\text { All outcomes }\end{array}$ & Low risk & 40 patients randomised. No missing outcome data. \\
\hline $\begin{array}{l}\text { Selective reporting (re- } \\
\text { porting bias) }\end{array}$ & Unclear risk & $\begin{array}{l}\text { Data presented for median WHO grade and for percentage of patients with } \\
\text { mucositis grades }>3 \text { and } 4 .\end{array}$ \\
\hline Other bias & Low risk & Study appears to be free of other sources of bias. \\
\hline
\end{tabular}


He 2008

\section{Study characteristics}

Methods Randomised, parallel group study conducted in China. Clear information about withdrawals: 0 . Unclear if dentist involved in study. Drop outs: $0 \%$. Recruitment period: unclear.

Participants Adults with oesophageal and cardiac cancer receiving chemotherapy. 48 enrolled and randomised, all completed.

\begin{tabular}{ll}
\hline Interventions & 2 groups, 20 g glutamine daily versus a placebo (compound amino acid) given by 'injection' possibly in- \\
to parenteral nutrition solution.
\end{tabular}

\begin{tabular}{ll}
\hline Outcomes & $\begin{array}{l}\text { Mucositis severity evaluated using 0-4 scale NCI CTCAE criteria, grade 0, 1, 2 versus grade 3, 4, nau- } \\
\text { sea/vomiting, diarrhoea, leucopenia, weight loss. }\end{array}$
\end{tabular}
sea/vomiting, diarrhoea, leucopenia, weight loss.

Notes

Funding source: government. All above information obtained from Chinese translation.

\section{Risk of bias}

\begin{tabular}{|c|c|c|}
\hline Bias & Authors' judgement & Support for judgement \\
\hline $\begin{array}{l}\text { Random sequence genera- } \\
\text { tion (selection bias) }\end{array}$ & Unclear risk & $\begin{array}{l}\text { Quote "randomization table". } \\
\text { Comment: random component not described. }\end{array}$ \\
\hline $\begin{array}{l}\text { Allocation concealment } \\
\text { (selection bias) }\end{array}$ & Unclear risk & $\begin{array}{l}\text { Quote "randomization table". } \\
\text { Comment: method of concealment unclear. }\end{array}$ \\
\hline $\begin{array}{l}\text { Blinding (performance } \\
\text { bias and detection bias) } \\
\text { Carers }\end{array}$ & Unclear risk & $\begin{array}{l}\text { Parenteral amino acid solution with or without glutamine. No apparent blind- } \\
\text { ing. }\end{array}$ \\
\hline $\begin{array}{l}\text { Blinding (performance } \\
\text { bias and detection bias) } \\
\text { Patients }\end{array}$ & Unclear risk & $\begin{array}{l}\text { Parenteral amino acid solution with or without glutamine. No apparent blind- } \\
\text { ing. }\end{array}$ \\
\hline $\begin{array}{l}\text { Blinding (performance } \\
\text { bias and detection bias) } \\
\text { Outcome assessors }\end{array}$ & Unclear risk & $\begin{array}{l}\text { Parenteral amino acid solution with or without glutamine. No apparent blind- } \\
\text { ing. }\end{array}$ \\
\hline $\begin{array}{l}\text { Incomplete outcome data } \\
\text { (attrition bias) } \\
\text { All outcomes }\end{array}$ & Low risk & 48 patients randomised. No missing outcome data. \\
\hline $\begin{array}{l}\text { Selective reporting (re- } \\
\text { porting bias) }\end{array}$ & Unclear risk & $\begin{array}{l}\text { Data presented for number of patients with grades } 0-2 \text { mucositis and grades } \\
3-4 \text { mucositis for both arms. }\end{array}$ \\
\hline Other bias & High risk & ROB assessed from a translation. \\
\hline
\end{tabular}

Hu 2005

\section{Study characteristics}

$\begin{array}{ll}\text { Methods } & \text { Randomised, parallel group study conducted in China. Clear information about withdrawals: } 0 . \text { Unclear } \\ \text { if dentist involved in study. Drop outs: } 0 \% .\end{array}$


Hu 2005 (Continued)

Participants Adults with head and neck cancer receiving radiotherapy. 140 enrolled and randomised, all completed.

\begin{tabular}{ll}
\hline Interventions & 2 groups, Shenqi Fanghou recipe (author named) Chinese herb decoction containing 22 specifically se- \\
lected herbs such as codonopsis pilosula $30 \mathrm{~g}$, raidx astragali $30 \mathrm{~g}$, Indian buead $30 \mathrm{~g}$, etc. altogether \\
$406 \mathrm{~g}$ as a dosage for a day. All the herbs were put into water for boiling then removing the herbs and \\
$400 \mathrm{ml}$ of solution obtained. The patients were asked to intake the solution orally, $200 \mathrm{ml}$ a time and \\
twice a day. No treatment control. All patients gargled with $2 \%$ lidocaine before meals and at night.
\end{tabular}

Outcomes Mucositis severity evaluated using 0-4 scale and the highest grade throughout radiotherapy course re-
ported. Unclear how often this was measured but results reported by grade of mucositis.

Notes $\quad$ Funding source: unclear. All above information obtained from Chinese translation.

\section{Risk of bias}

\begin{tabular}{|c|c|c|}
\hline Bias & Authors' judgement & Support for judgement \\
\hline $\begin{array}{l}\text { Random sequence genera- } \\
\text { tion (selection bias) }\end{array}$ & Unclear risk & Quote: "randomised". \\
\hline $\begin{array}{l}\text { Allocation concealment } \\
\text { (selection bias) }\end{array}$ & Unclear risk & Insufficient information to determine 'yes' or 'no'. \\
\hline $\begin{array}{l}\text { Blinding (performance } \\
\text { bias and detection bias) } \\
\text { Carers }\end{array}$ & High risk & Shenqi Fanghou recipe versus no treatment. No apparent blinding. \\
\hline $\begin{array}{l}\text { Blinding (performance } \\
\text { bias and detection bias) } \\
\text { Patients }\end{array}$ & High risk & Shenqi Fanghou recipe versus no treatment. No apparent blinding. \\
\hline $\begin{array}{l}\text { Blinding (performance } \\
\text { bias and detection bias) } \\
\text { Outcome assessors }\end{array}$ & High risk & Shenqi Fanghou recipe versus no treatment. No apparent blinding. \\
\hline $\begin{array}{l}\text { Incomplete outcome data } \\
\text { (attrition bias) } \\
\text { All outcomes }\end{array}$ & Low risk & 140 patients randomised. No missing outcome data. \\
\hline $\begin{array}{l}\text { Selective reporting (re- } \\
\text { porting bias) }\end{array}$ & Low risk & Data presented for 140 patients by grade and treatment arm. \\
\hline Other bias & High risk & Risk of bias assessed from translation. \\
\hline
\end{tabular}

Huang 2000

\section{Study characteristics}

Randomised, parallel group study conducted in Taiwan. Clear information about withdrawals: none.
Dentist not involved in study. Drop outs: $0 \%$. Duration: beginning of radiation treatment until 25 fac-
tions ( 5 weeks). Recruitment July 1997 to June 1998.

Participants Adults with head and neck cancer. 17 patients were enrolled and evaluated. 
Huang 2000 (Continued)

Interventions
2 groups, placebo (30 $\mathrm{ml}$ saline) versus glutamine $(2 \mathrm{~g}$ in $30 \mathrm{ml}$ saline, swish $30 \mathrm{ml} 3$ mins then expectorate).

Outcomes

Clinicians assessed subjective mucositis on 0-4 scale and objective RTOG/EORTC 0-4 scale. WHO step of analgesic drugs. Assessment used: day unclear.

Notes

Subjective mucositis scale used. Funding source: not stated.

\section{Risk of bias}

\begin{tabular}{|c|c|c|}
\hline Bias & Authors' judgement & Support for judgement \\
\hline $\begin{array}{l}\text { Random sequence genera- } \\
\text { tion (selection bias) }\end{array}$ & Unclear risk & $\begin{array}{l}\text { Quote: "patients were sequentially randomised to two treatment arms". } \\
\text { Comment: random component not described. }\end{array}$ \\
\hline $\begin{array}{l}\text { Allocation concealment } \\
\text { (selection bias) }\end{array}$ & Unclear risk & Insufficient information to determine 'yes' or 'no'. \\
\hline $\begin{array}{l}\text { Blinding (performance } \\
\text { bias and detection bias) } \\
\text { Carers }\end{array}$ & Unclear risk & Insufficient information to determine 'yes' or 'no'. \\
\hline $\begin{array}{l}\text { Blinding (performance } \\
\text { bias and detection bias) } \\
\text { Patients }\end{array}$ & Low risk & $\begin{array}{l}\text { Quote: "single blind randomised study". } \\
\text { Comment: probably done. }\end{array}$ \\
\hline $\begin{array}{l}\text { Blinding (performance } \\
\text { bias and detection bias) } \\
\text { Outcome assessors }\end{array}$ & High risk & $\begin{array}{l}\text { Quote: "due to manpower problems, not all physicians who evaluated patients } \\
\text { were blind to test solutions". } \\
\text { Comment: assessors not blind. }\end{array}$ \\
\hline $\begin{array}{l}\text { Incomplete outcome data } \\
\text { (attrition bias) } \\
\text { All outcomes }\end{array}$ & Low risk & 17 patients randomised. No missing outcome data. \\
\hline $\begin{array}{l}\text { Selective reporting (re- } \\
\text { porting bias) }\end{array}$ & Low risk & Maximum grade of mucositis by grade and treatment arm (table 2). \\
\hline Other bias & Low risk & Study appears to be free of other sources of bias. \\
\hline
\end{tabular}

Huang 2003

\section{Study characteristics}

Methods

Randomised, parallel group study conducted in China. Clear information on withdrawals. Unclear whether dentist involved in study. Drop outs: $0 \%$. Duration: average radiotherapy 50 days.

\section{Participants}

Adults with head and neck cancer treated with chemotherapy cisplatin (DDP $30 \mathrm{mg} / \mathrm{m}^{2}$ ) with concomitant radiotherapy. 101 patients recruited and evaluated.

Interventions

$$
\begin{aligned}
& 2 \text { groups, Dobell's solution (unclear what this is) gargled 5-8 times daily versus Chinese medicine } \\
& \text { (sucked and swallowed) } 6 \text { times from first to sixth week of radiotherapy. Patients received either Chi- } \\
& \text { nese medicine or Dobell's solution 5-8 times daily. } \\
& \text { The decoction is made as solution by cooking the } 11 \text { herbs together with water. Doses of the herbs for } \\
& 1 \text { day are: coastal glehnia } 30 \mathrm{~g} \text {, dwarf lilyturf tuber root } 30 \mathrm{~g} \text {, rehmannia dried root } 30 \mathrm{~g} \text {, figwort rood } 15
\end{aligned}
$$


Huang 2003 (Continued)

$\mathrm{g}$, spreading hedyotis herb $30 \mathrm{~g}$, belamcauda rhizome $15 \mathrm{~g}$, platycodon root $15 \mathrm{~g}$, shinyleaf pricklyoash root $15 \mathrm{~g}$, honeysuckle flower $15 \mathrm{~g}$, licorice root $3 \mathrm{~g}$, lalanggrass rhizome $20 \mathrm{~g}$.

The authors follow theoretical principles of Chinese medicine: treatment should be modified in adapting the changes of the diagnosis. So, if the patients with symptoms of rhinorrhagia or blood clot in the sputum, adding hairy vein agrimony herb $20 \mathrm{~g}$, hyacinth bletilla tuber $15 \mathrm{~g}$; with nausea and vomiting adding red ochre $15 \mathrm{~g}$, magnolis bark of Sichuan $15 \mathrm{~g}$, bamboo shaving $15 \mathrm{~g}$; with obstruction of the nose, adding sibirian cocklebur fruit $15 \mathrm{~g}$, magnolia flower $15 \mathrm{~g}$; with malaise and poor appetite, adding pseudostellaria root $30 \mathrm{~g}$, bighead atractylodes rhizome $15 \mathrm{~g}$, malt $30 \mathrm{~g}$, millet sprout $30 \mathrm{~g}$; with the tongue in dark pink colour, adding root of red rooted salvia $15 \mathrm{~g}$, powder of notoginsen $3 \mathrm{~g}$.

\begin{tabular}{ll}
\hline Outcomes & Mucositis assessed according to acute oropharyngeal mucositis grade on a 0-4 scale. \\
\hline Notes & $\begin{array}{l}\text { Pharmacological company provided drug and organised randomisation. This information was provid- } \\
\text { ed by Chinese translation. }\end{array}$
\end{tabular}

\section{Risk of bias}

\begin{tabular}{lll}
\hline Bias & Authors' judgement & Support for judgement \\
\hline $\begin{array}{l}\text { Random sequence genera- } \\
\text { tion (selection bias) }\end{array}$ & Unclear risk & $\begin{array}{l}\text { Quote: "Randomisation were randomly assigned by random numbers generat- } \\
\text { ed from random number table". }\end{array}$ \\
\hline $\begin{array}{l}\text { Allocation concealment } \\
\text { (selection bias) }\end{array}$ & Unclear risk & Comment: random number table. \\
\hline
\end{tabular}

\begin{tabular}{|c|c|c|}
\hline $\begin{array}{l}\text { Blinding (performance } \\
\text { bias and detection bias) }\end{array}$ & High risk & $\begin{array}{l}\text { Difference between intervention and control in the mode of application (gar- } \\
\text { gle versus suck and swallow). Blinding impossible. }\end{array}$ \\
\hline
\end{tabular}

Carers ed by Chinese translation.

\begin{tabular}{lll}
\hline $\begin{array}{l}\text { Blinding (performance } \\
\text { bias and detection bias) } \\
\text { Patients }\end{array}$ & High risk & $\begin{array}{l}\text { Difference between intervention and control in the mode of application (gar- } \\
\text { gle versus suck and swallow). Blinding impossible. }\end{array}$ \\
\hline $\begin{array}{l}\text { Blinding (performance } \\
\text { bias and detection bias) } \\
\text { Outcome assessors }\end{array}$ & Unclear risk & Insufficient information to determine 'yes' or 'no'. \\
\hline $\begin{array}{l}\text { Incomplete outcome data } \\
\begin{array}{l}\text { (attrition bias) } \\
\text { All outcomes }\end{array}\end{array}$ & Low risk & 101 patients randomised. No withdrawals/exclusions. \\
\hline $\begin{array}{l}\text { Selective reporting (re- } \\
\text { porting bias) }\end{array}$ & Low risk & Data presented for 101 patients for mucositis incidence by grade and treat- \\
\hline $\begin{array}{l}\text { Other bias } \\
\text { ment. }\end{array}$ \\
\hline
\end{tabular}

Ifrah 1999

\section{Study characteristics}

Methods

Randomised, parallel group study conducted in France. Unclear information about drop outs. Unclear if dentist involved in study.

Participants

Adults with blood cancer. 67 enrolled and randomised between November 1990 and April 1992, results given on 64 . 
Ifrah 1999 (Continued)

\begin{tabular}{ll} 
Interventions & 2 groups, rGM-CSF $5 \mathrm{ug} / \mathrm{kg}$ as a 6 hour IV infusion versus placebo. \\
\hline Outcomes & WHO mucositis score $(>3)$. \\
\hline Notes & Funding source: none.
\end{tabular}

\section{Risk of bias}

\begin{tabular}{lll}
\hline Bias & Authors' judgement & Support for judgement \\
\hline $\begin{array}{l}\text { Random sequence genera- } \\
\text { tion (selection bias) }\end{array}$ & Unclear risk & $\begin{array}{l}\text { Quote: "At admission, patients were randomised to receive either rGM-CSF or } \\
\text { placebo } 24 \text { hours after induction treatment was completed." }\end{array}$ \\
& $\begin{array}{l}\text { Quote: "the randomisation sequences were generated by the co-ordinating } \\
\text { centre and were balanced with each centre". }\end{array}$
\end{tabular}

\begin{tabular}{|c|c|c|}
\hline $\begin{array}{l}\text { Allocation concealment } \\
\text { (selection bias) }\end{array}$ & Unclear risk & $\begin{array}{l}\text { Quote: "the randomisation sequences were generated by the co-ordinating } \\
\text { centre and were balanced with each centre". }\end{array}$ \\
\hline & & $\begin{array}{l}\text { Comment: unclear if allocation remained with the co-ordinating centre. Insuf- } \\
\text { ficient information to determine 'yes' or 'no'. }\end{array}$ \\
\hline
\end{tabular}

\begin{tabular}{|c|c|c|}
\hline $\begin{array}{l}\text { Blinding (performance } \\
\text { bias and detection bias) } \\
\text { Carers }\end{array}$ & Unclear risk & Insufficient information to determine 'yes' or 'no'. \\
\hline $\begin{array}{l}\text { Blinding (performance } \\
\text { bias and detection bias) } \\
\text { Patients }\end{array}$ & Low risk & $\begin{array}{l}\text { Quote: "double blind". } \\
\text { Comment: probably done. }\end{array}$ \\
\hline $\begin{array}{l}\text { Blinding (performance } \\
\text { bias and detection bias) } \\
\text { Outcome assessors }\end{array}$ & Low risk & $\begin{array}{l}\text { Quote: "double blind". } \\
\text { Comment: probably done. }\end{array}$ \\
\hline $\begin{array}{l}\text { Incomplete outcome data } \\
\text { (attrition bias) } \\
\text { All outcomes }\end{array}$ & Low risk & $\begin{array}{l}67 \text { patients randomised. } 3 \text { patients withdrew ( } 1 \text { patient was ineligible, } 2 \text { pa- } \\
\text { tients withdrawn due to major dose errors). Authors give full reasons for attri- } \\
\text { tion/exclusion but do not state which arms patients were randomised too. }\end{array}$ \\
\hline $\begin{array}{l}\text { Selective reporting (re- } \\
\text { porting bias) }\end{array}$ & Unclear risk & $\begin{array}{l}\text { Data presented for mucositis grade }>3 \text { (WHO score) (table } 2 \text { ) and duration of } \\
\text { mucositis grade }>2 \text { (median values in days) (table } 4 \text { ) for patients receiving au- } \\
\text { tologous transplantation. }\end{array}$ \\
\hline Other bias & High risk & $\begin{array}{l}\text { Patients randomised to the rGM-CSF arm were older (median age } 36 \text { years ver- } \\
\text { sus } 28 \text { years, } P=0.04 \text { ). } \\
\text { More patients randomised to the rGM-CSF arm had Philadelphia chromosome, } \\
P=0.026 \text {. }\end{array}$ \\
\hline
\end{tabular}

Jebb 1994

\section{Study characteristics}

Methods

Randomised, cross-over study conducted in UK. Unclear information about withdrawals: 11/28 in total. Dentist not involved in study. recruitment period: not stated.

Drop outs: $39 \%$. Duration: (1st part) 8 days. 
Jebb 1994 (Continued)

Participants Adults with gastrointestinal cancer undergoing 5-FU \& folic acid daily for 5 days and repeated 4 weeks from start. 28 patients enrolled and 17 completed 2 cycles.

Interventions

2 groups, glucose polymer (Polycal) (described as placebo) versus glutamine (16 mg daily divided into 4 equal doses and dissolved in $150 \mathrm{ml}$ water before consumption), swish and swallow.

\begin{tabular}{ll}
\hline Outcomes & WHO mucositis score, mouth comfort, ease of eating. Assessment used: day 8. \\
\hline Notes & Funding source: not stated.
\end{tabular}

\section{Risk of bias}

\section{Bias Authors' judgement Support for judgement}

Random sequence genera- Unclear risk tion (selection bias)

Quote: "Patients were randomised to receive either glutamine or placebo with the first cycle of treatment and the alternative supplement with cycle 2, such that each patient could act as his or her control".

Comment: random component not described.

\begin{tabular}{|c|c|c|}
\hline $\begin{array}{l}\text { Allocation concealment } \\
\text { (selection bias) }\end{array}$ & Unclear risk & $\begin{array}{l}\text { Quote: "Patients and investigator were unaware of the randomisation order } \\
\text { for each subject". }\end{array}$ \\
\hline
\end{tabular}

Comment: insufficient information to determine 'yes' or 'no'.

Blinding (performance Unclear risk Insufficient information to determine 'yes' or 'no'.

bias and detection bias)

Carers

\begin{tabular}{|c|c|c|}
\hline $\begin{array}{l}\text { Blinding (performance } \\
\text { bias and detection bias) } \\
\text { Patients }\end{array}$ & Low risk & $\begin{array}{l}\text { Quote: "double blind". } \\
\text { Comment: probably done. }\end{array}$ \\
\hline $\begin{array}{l}\text { Blinding (performance } \\
\text { bias and detection bias) } \\
\text { Outcome assessors }\end{array}$ & Low risk & $\begin{array}{l}\text { Quote: "double blind". } \\
\text { Comment: probably done. }\end{array}$ \\
\hline $\begin{array}{l}\text { Incomplete outcome data } \\
\text { (attrition bias) } \\
\text { All outcomes }\end{array}$ & High risk & $\begin{array}{l}28 \text { patients randomised. Paired outcome data available for } 17 \text { patients who } \\
\text { completed } 2 \text { courses of treatment. Authors give full reasons for attrition/exclu- } \\
\text { sion. However, there is the potential for the overall estimate to be reversed if } \\
\text { excluded patients included. }\end{array}$ \\
\hline $\begin{array}{l}\text { Selective reporting (re- } \\
\text { porting bias) }\end{array}$ & Low risk & $\begin{array}{l}\text { Data presented for maximum WHO mucositis grade for } 17 \text { patients ( } 34 \text { scores) } \\
\text { (figure } 1 \mathrm{a} \text { and figure } 1 \mathrm{~b} \text { ). }\end{array}$ \\
\hline Other bias & Low risk & Study appears to be free of other sources of bias. \\
\hline
\end{tabular}

Katano 1995

\section{Study characteristics}

Methods

Randomised, parallel group study conducted in Japan. Clear information about withdrawals: none. Unclear if dentist involved in study. Drop outs: $0 \%$. Duration: administration ceased when leukocyte exceeded $8000 / \mathrm{mm}^{3}$. 
Katano 1995 (Continued)

Participants $\quad$ Adults with solid (breast cancer). 14 patients enrolled and evaluated. Recruitment January 1992 to December 1996.

\begin{tabular}{ll}
\hline Interventions & 2 groups, no treatment versus G-CSF (by injection $125 \mathrm{ug})$. \\
\hline Outcomes & WHO mucositis score (0-4) by clinician. Other reported outcomes: alopecia, fever. Assessment used: day \\
& 8. \\
\hline Notes & Funding source: pharmaceutical supply product.
\end{tabular}

\section{Risk of bias}

\begin{tabular}{|c|c|c|}
\hline Bias & Authors' judgement & Support for judgement \\
\hline $\begin{array}{l}\text { Random sequence genera- } \\
\text { tion (selection bias) }\end{array}$ & Unclear risk & $\begin{array}{l}\text { Quote: "they were randomised into two groups of } 7 \text { patients each". } \\
\text { Comment: random component not described. }\end{array}$ \\
\hline $\begin{array}{l}\text { Allocation concealment } \\
\text { (selection bias) }\end{array}$ & Unclear risk & Insufficient information to determine 'yes' or 'no'. \\
\hline $\begin{array}{l}\text { Blinding (performance } \\
\text { bias and detection bias) } \\
\text { Carers }\end{array}$ & High risk & G-CSF versus no intervention. No apparent blinding. \\
\hline $\begin{array}{l}\text { Blinding (performance } \\
\text { bias and detection bias) } \\
\text { Patients }\end{array}$ & High risk & G-CSF versus no intervention. No apparent blinding. \\
\hline $\begin{array}{l}\text { Blinding (performance } \\
\text { bias and detection bias) } \\
\text { Outcome assessors }\end{array}$ & High risk & G-CSF versus no intervention. No apparent blinding. \\
\hline $\begin{array}{l}\text { Incomplete outcome data } \\
\text { (attrition bias) } \\
\text { All outcomes }\end{array}$ & Low risk & 14 patients randomised. No missing outcome data. \\
\hline $\begin{array}{l}\text { Selective reporting (re- } \\
\text { porting bias) }\end{array}$ & Unclear risk & Data presented for incidence and duration (days) of mucositis. \\
\hline Other bias & Low risk & Study appears to be free of other sources of bias. \\
\hline
\end{tabular}

Kaul 1999

\section{Study characteristics}

\begin{tabular}{ll}
\hline Methods & $\begin{array}{l}\text { Randomised, parallel group study conducted in India. Unclear information about withdrawals. Dentist } \\
\text { not involved in study. Drop outs unclear. Duration unclear. }\end{array}$ \\
\hline Participants & Adults with head and neck cancer radiotherapy 50-60 Gy/5-6 weeks. 50 patients enrolled. \\
\hline Interventions & $\begin{array}{l}2 \text { groups, no treatment control versus wobe-mugos enzyme preparation } 3 \text { tablets/day } 3 \text { days prior to } \\
\text { RT until } 1 \text { week after. }\end{array}$ \\
\hline
\end{tabular}


Kaul 1999 (Continued)

Outcomes Mucositis. Assessment used: day 28. Other reported outcomes: xerostomia, skin changes, dysphagia, hospitalisation.

Notes Funding source: none.

\section{Risk of bias}

Bias Authors' judgement Support for judgement

Random sequence genera- Unclear risk Quote: "A prospective randomised phase III clinical trial".

tion (selection bias)

Quote: "A randomisation of 50 patients fulfilling inclusion criteria".

Comment: random component not described.

Allocation concealment $\quad$ Unclear risk Insufficient information to determine 'yes' or 'no'.
(selection bias)

Blinding (performance
bias and detection bias) High risk intervention versus 9 tablets. No apparent blinding.

Carers

Blinding (performance $\quad$ High risk No intervention versus 9 tablets. No apparent blinding.
bias and detection bias)
Patients

Patients

Blinding (performance $\quad$ High risk No intervention versus 9 tablets. No apparent blinding.
bias and detection bias)
Outcome assessors

Outcome assessors

\begin{tabular}{|c|c|c|}
\hline $\begin{array}{l}\text { Incomplete outcome data } \\
\text { (attrition bias) } \\
\text { All outcomes }\end{array}$ & High risk & $\begin{array}{l}50 \text { patients randomised. } 1 \text { patient died during study. } 69.4 \% \text { of patients com- } \\
\text { pleted the study without a treatment gap. However, authors presented data } \\
\text { for } 25 \text { patients ( } 50 \%) \text { at week } 11 \text { of the study. Authors do not give full reasons } \\
\text { for attrition/exclusion. }\end{array}$ \\
\hline
\end{tabular}

\begin{tabular}{lll}
\hline $\begin{array}{l}\text { Selective reporting (re- } \\
\text { porting bias) }\end{array}$ & Unclear risk & $\begin{array}{l}\text { Data presented for oral mucositis by grade for radiotherapy and radiotherapy } \\
\text { plus wobe-mugos for } 11 \text { weeks of treatment. Data only presented for } 50 \% \text { of } \\
\text { sample at week } 11 .\end{array}$ \\
\hline Other bias & Low risk & Study appears to be free of other sources of bias. \\
\hline
\end{tabular}

Kazemian 2009

\section{Study characteristics}

\begin{tabular}{ll}
\hline Methods & $\begin{array}{l}\text { Randomised, parallel group study conducted in Iran between } 2004 \text { and 2005. Full information given on } \\
\text { withdrawals. Dentist involved in study. Drop outs: } 19 \% .\end{array}$ \\
\hline Participants & $\begin{array}{l}\text { Adults with head and neck cancer receiving radiotherapy. } 100 \text { enrolled in study, } 81 \text { were evaluated, } 39 \\
\text { in the benzydamine group and } 42 \text { in the placebo group. }\end{array}$ \\
\hline Interventions & $\begin{array}{l}2 \text { groups, placebo versus benzydamine (0.15 benzydamine oral rinse). Participants rinsed with } 15 \text { ml for } \\
2 \text { minutes, } 4 \text { times per day from the first day of radiotherapy treatment to the end. }\end{array}$ \\
\hline Outcomes & $\begin{array}{l}\text { Assessment on the RTOG grading system for oral mucositis, assessment carried out weekly. Other re- } \\
\text { ported outcomes: effects of smoking, effects of chemoradiotherapy. }\end{array}$ \\
\hline \hline
\end{tabular}


Kazemian 2009 (Continued)

Notes Funding source: unclear.

\section{Risk of bias}

\begin{tabular}{|c|c|c|}
\hline Bias & Authors' judgement & Support for judgement \\
\hline $\begin{array}{l}\text { Random sequence genera- } \\
\text { tion (selection bias) }\end{array}$ & Unclear risk & $\begin{array}{l}\text { Quote: "one hundred patients were randomised into this study". } \\
\text { Comment: random component not described. }\end{array}$ \\
\hline $\begin{array}{l}\text { Allocation concealment } \\
\text { (selection bias) }\end{array}$ & Unclear risk & Insufficient information to determine 'yes' or 'no'. \\
\hline $\begin{array}{l}\text { Blinding (performance } \\
\text { bias and detection bias) } \\
\text { Carers }\end{array}$ & Unclear risk & Insufficient information to determine 'yes' or 'no'. \\
\hline $\begin{array}{l}\text { Blinding (performance } \\
\text { bias and detection bias) } \\
\text { Patients }\end{array}$ & Low risk & $\begin{array}{l}\text { Quote: "double blind". } \\
\text { Comment: probably done. }\end{array}$ \\
\hline $\begin{array}{l}\text { Blinding (performance } \\
\text { bias and detection bias) } \\
\text { Outcome assessors }\end{array}$ & Low risk & $\begin{array}{l}\text { Quote: "double blind". } \\
\text { Comment: probably done. }\end{array}$ \\
\hline $\begin{array}{l}\text { Incomplete outcome data } \\
\text { (attrition bias) } \\
\text { All outcomes }\end{array}$ & Low risk & $\begin{array}{l}100 \text { patients randomised. } 81 \text { patients included in the analysis. } 19 \text { cases exclud- } \\
\text { ed. Exclusions equally distributed. } 17 / 19 \text { stopped due to side effects. Authors } \\
\text { provide full reasons for withdrawals/drop outs. }\end{array}$ \\
\hline $\begin{array}{l}\text { Selective reporting (re- } \\
\text { porting bias) }\end{array}$ & Unclear risk & Data presented for grade $>3$ mucositis (in text). \\
\hline Other bias & Low risk & Study appears to be free of other sources of bias. \\
\hline
\end{tabular}

Koukourakis 2000

\section{Study characteristics}

\begin{tabular}{|c|c|}
\hline Methods & $\begin{array}{l}\text { Randomised, parallel group study conducted in Greece. Unclear information on withdrawals 0/20 con- } \\
\text { trol, } 1 / 20 \text { test. Unclear if dentist involved in study. Drop outs: } 3 \% \text {. Duration 6-7 weeks. }\end{array}$ \\
\hline Participants & $\begin{array}{l}\text { Adults with } 3 \text { cancer types: thoracic, pelvic, RT postoperative or inoperable dose 64-70 Gy. } 140 \text { patients } \\
\text { enrolled between July } 1997 \text { and May 1999, } 130 \text { completed. }\end{array}$ \\
\hline Interventions & 2 groups, no treatment control versus amifostine $500 \mathrm{mg}$ daily before RT. \\
\hline Outcomes & $\begin{array}{l}\text { Mucositis 0-4 scale combined categories. Assessment used: unclear. Other reported outcomes RT de- } \\
\text { lay, side effects. }\end{array}$ \\
\hline Notes & $\begin{array}{l}\text { Patients selected from other types of cancer because mucositis data available. Funding source: govern- } \\
\text { ment \& pharmaceutical. }\end{array}$ \\
\hline \multicolumn{2}{|l|}{ Risk of bias } \\
\hline Bias & Authors' judgement Support for judgement \\
\hline
\end{tabular}


Koukourakis 2000 (Continued)

Random sequence genera- Low risk Quote: "patients were randomly assigned to undergo radiotherapy or radiotion (selection bias) therapy supported with subcutaneous administration of Amifostine, according to a table of random numbers ( 0 V 1 )."

Comment: authors used random number table.

\begin{tabular}{|c|c|c|}
\hline $\begin{array}{l}\text { Allocation concealment } \\
\text { (selection bias) }\end{array}$ & High risk & Comment: open random table. \\
\hline $\begin{array}{l}\text { Blinding (performance } \\
\text { bias and detection bias) } \\
\text { Carers }\end{array}$ & High risk & Amifostine versus no intervention. No apparent blinding. \\
\hline $\begin{array}{l}\text { Blinding (performance } \\
\text { bias and detection bias) } \\
\text { Patients }\end{array}$ & High risk & Amifostine versus no intervention. No apparent blinding. \\
\hline $\begin{array}{l}\text { Blinding (performance } \\
\text { bias and detection bias) } \\
\text { Outcome assessors }\end{array}$ & High risk & Amifostine versus no intervention. No apparent blinding. \\
\hline $\begin{array}{l}\text { Incomplete outcome data } \\
\text { (attrition bias) } \\
\text { All outcomes }\end{array}$ & Unclear risk & $\begin{array}{l}140 \text { patients randomised. Interruption of treatment in } 10 \text { patients. } 10 / 70 \text { ami- } \\
\text { fostine. Mucositis data presented for } 130 \text { patients. }\end{array}$ \\
\hline $\begin{array}{l}\text { Selective reporting (re- } \\
\text { porting bias) }\end{array}$ & Unclear risk & Data presented for 130 patients for grades $0 / 1$, grade 2 , and grade $3 / 4$ (table 4 ). \\
\hline Other bias & Low risk & Study appears to be free of other sources of bias. \\
\hline
\end{tabular}

Labar 1993

\section{Study characteristics}

\begin{tabular}{|c|c|c|}
\hline Methods & \multicolumn{2}{|c|}{$\begin{array}{l}\text { Randomised, parallel group study conducted in Croatia. Clear information about withdrawals: none. } \\
\text { Dentist not involved in study. Drop outs: } 0 \% \text {. Duration: }+7 \text { to day }+21 \text {. }\end{array}$} \\
\hline Participants & \multicolumn{2}{|c|}{$\begin{array}{l}\text { Children and adults ( } 5-43 \text { years) with blood cancers, undergoing BMT. } 60 \text { patients eligible, enrolled and } \\
\text { evaluated. }\end{array}$} \\
\hline Interventions & \multicolumn{2}{|c|}{2 groups, placebo versus prostaglandin E2 ( $0.5 \mathrm{mg} 3$ times per day). } \\
\hline Outcomes & \multicolumn{2}{|c|}{$\begin{array}{l}\text { Clinical and culture fungal measurement. Mucositis (WHO scale for 0-II vs III+, and } 0 \text { vs } 1+\text { ). Severity } \\
\text { over }-7 \text { to }+35 \text { days. Severity of mucositis also measured but no SD given. Assessment used: day } 35 \text {. } \\
\text { Other reported outcomes: HSV infection, microbiology, vomiting, diarrhoea, fever, death, GVHD (c). }\end{array}$} \\
\hline Notes & \multicolumn{2}{|l|}{ Funding source: none. } \\
\hline \multicolumn{3}{|l|}{ Risk of bias } \\
\hline Bias & Authors' judgement & Support for judgement \\
\hline \multirow[t]{2}{*}{$\begin{array}{l}\text { Random sequence genera- } \\
\text { tion (selection bias) }\end{array}$} & Low risk & $\begin{array}{l}\text { Quote: "the patients were randomised to receive either prophylactic regimen A } \\
\text { or B according to the Pocock and Simon method". }\end{array}$ \\
\hline & & Comment: minimization. \\
\hline
\end{tabular}


Labar 1993 (Continued)

\begin{tabular}{lll}
$\begin{array}{l}\text { Allocation concealment } \\
\text { (selection bias) }\end{array}$ & Unclear risk & Insufficient information to determine 'yes' or 'no'. \\
\hline $\begin{array}{l}\text { Blinding (performance } \\
\text { bias and detection bias) }\end{array}$ & Unclear risk & Insufficient information to determine 'yes' or 'no'.
\end{tabular}

Carers

\begin{tabular}{|c|c|c|}
\hline $\begin{array}{l}\text { Blinding (performance } \\
\text { bias and detection bias) } \\
\text { Patients }\end{array}$ & Low risk & $\begin{array}{l}\text { Quote: "double blind". } \\
\text { Comment: probably done. }\end{array}$ \\
\hline
\end{tabular}

\begin{tabular}{|c|c|c|}
\hline $\begin{array}{l}\text { Blinding (performance } \\
\text { bias and detection bias) }\end{array}$ & Low risk & Quote: "double blind". \\
\hline Outcome assessors & & Comment: probably done. \\
\hline
\end{tabular}

\begin{tabular}{lll}
\hline $\begin{array}{l}\text { Incomplete outcome data } \\
\text { (attrition bias) } \\
\text { All outcomes }\end{array}$ & Unclear risk & $\begin{array}{l}60 \text { patients randomised. Authors give outcome data in percentages making it } \\
\text { difficult to assess the possibility of incomplete outcome data. }\end{array}$ \\
\hline $\begin{array}{l}\text { Selective reporting (re- } \\
\text { porting bias) }\end{array}$ & Unclear risk & $\begin{array}{l}\text { Data presented in percentages in a piechart for grades I and II vs grades III and } \\
\text { IV (figure 1) and severity of OM over time (figure 2). }\end{array}$ \\
\hline Other bias & Low risk & Study appears to be free of other sources of bias. \\
\hline
\end{tabular}

Leborgne 1997

\section{Study characteristics}

\begin{tabular}{|c|c|c|}
\hline Methods & \multicolumn{2}{|c|}{$\begin{array}{l}\text { Randomised, parallel group study conducted in Uruguay. Unclear information about withdrawals. Un- } \\
\text { clear whether dentist involved in study. Drop outs: } 4 \% \text {. Duration } 90 \text { days. }\end{array}$} \\
\hline Participants & \multicolumn{2}{|c|}{ Adults with head and neck cancer radical RT. 69 enrolled, 66 completed. } \\
\hline Interventions & \multicolumn{2}{|c|}{2 groups, placebo versus prednisone $40 \mathrm{mg}$ once daily through day 28 reduced dose to day 43.} \\
\hline Outcomes & \multicolumn{2}{|c|}{$\begin{array}{l}\text { Mucositis WHO. Assessment used: unclear. Other reported outcomes: duration of treatment, treatment } \\
\text { interruptions, parenteral nutrition, hospital stay, weight loss, locoregional control, survival. }\end{array}$} \\
\hline Notes & \multicolumn{2}{|c|}{ Funding source: not stated. Mucositis data for all grades of severity obtained after writing to authors. } \\
\hline \multicolumn{3}{|l|}{ Risk of bias } \\
\hline Bias & Authors' judgement & Support for judgement \\
\hline $\begin{array}{l}\text { Random sequence genera- } \\
\text { tion (selection bias) }\end{array}$ & Unclear risk & $\begin{array}{l}\text { Quote: "69 patients were randomized". } \\
\text { Comment: random component not described. }\end{array}$ \\
\hline \multirow[t]{2}{*}{$\begin{array}{l}\text { Allocation concealment } \\
\text { (selection bias) }\end{array}$} & Unclear risk & $\begin{array}{l}\text { Quote: "The codes were broken after the mucosal reactions in the last patient } \\
\text { were scored." }\end{array}$ \\
\hline & & Comment: insufficient information to determine 'yes' or 'no'. \\
\hline $\begin{array}{l}\text { Blinding (performance } \\
\text { bias and detection bias) }\end{array}$ & Unclear risk & Insufficient information to determine 'yes' or 'no'. \\
\hline
\end{tabular}


Leborgne 1997 (Continued)

Carers

\begin{tabular}{lll}
\hline $\begin{array}{l}\text { Blinding (performance } \\
\text { bias and detection bias) } \\
\text { Patients }\end{array}$ & Low risk & Quote: “double blind”. \\
& Comment: probably done. \\
\hline $\begin{array}{l}\text { Blinding (performance } \\
\text { bias and detection bias) } \\
\text { Outcome assessors }\end{array}$ & Low risk & Quote: "double blind". \\
\hline
\end{tabular}

\begin{tabular}{|c|c|c|}
\hline $\begin{array}{l}\text { Incomplete outcome data } \\
\text { (attrition bias) } \\
\text { All outcomes }\end{array}$ & Low risk & $\begin{array}{l}69 \text { patients randomised. } 3 \text { patients were excluded due to major protocol viola- } \\
\text { tions. Authors give full reasons for exclusions but do not state which arms pa- } \\
\text { tients were randomised to. }\end{array}$ \\
\hline
\end{tabular}

\begin{tabular}{lll}
\hline $\begin{array}{l}\text { Selective reporting (re- } \\
\text { porting bias) }\end{array}$ & Low risk & Mucositis data for all grades of severity obtained after writing to authors. \\
\hline Other bias & High risk & $\begin{array}{l}\text { Baseline differences: significantly more patients in the treatment arm had } \\
\text { stage 3 disease compared to placebo }(\mathrm{P}=0.02) .\end{array}$
\end{tabular}

Li 2006

\section{Study characteristics}

$\begin{array}{ll}\text { Methods } & \text { Randomised, parallel group study conducted in China. Clear information about withdrawals: } 1 \text { from } \\ \text { glutamine group. Unclear if dentist involved in study. Drop outs: } 2 \% \text {. Recruitment March } 2001 \text { to De- } \\ \text { cember } 2002 .\end{array}$

\begin{tabular}{ll}
\hline Participants & Adults with breast cancer receiving 5-FU chemotherapy. 60 enrolled and randomised, 59 completed. \\
\hline Interventions & $\begin{array}{l}2 \text { groups, } 30 \text { received } 30 \text { g oral glutamine per day for } 12 \text { days prior to chemotherapy, } 29 \text { received place- } \\
\text { bo. }\end{array}$ \\
\hline Outcomes & $\begin{array}{l}\text { Mucositis severity evaluated using 0-4 scale (NCI CTCAE) (grade 3-4). Other reported outcomes: intesti- } \\
\text { nal permeability, intestinal toxicity, plasma glutamine levels. }\end{array}$ \\
\hline Notes & Funding source: government. \\
\hline
\end{tabular}

\section{Risk of bias}

\begin{tabular}{lll}
\hline Bias & Authors' judgement & Support for judgement \\
\hline $\begin{array}{l}\text { Random sequence genera- } \\
\text { tion (selection bias) }\end{array}$ & Unclear risk & $\begin{array}{l}\text { Quote: "Eligible study patients were randomly assigned to a placebo ( } \mathrm{n}=30 \text { ) or } \\
\text { a glutamine group ( }=30) . "\end{array}$ \\
& Comment: random component not described. \\
\hline $\begin{array}{l}\text { Allocation concealment } \\
\text { (selection bias) }\end{array}$ & Unclear risk & Insufficient information to determine 'yes' or 'no'. \\
\hline $\begin{array}{l}\text { Blinding (performance } \\
\text { bias and detection bias) } \\
\text { Carers }\end{array}$ & Unclear risk & Insufficient information to determine 'yes' or 'no'. \\
\hline $\begin{array}{l}\text { Blinding (performance } \\
\text { bias and detection bias) }\end{array}$ & Unclear risk & Glutamine versus placebo (glycerine). \\
\hline
\end{tabular}


Li 2006 (Continued)

Patients

\begin{tabular}{lll}
\hline $\begin{array}{l}\text { Blinding (performance } \\
\text { bias and detection bias) } \\
\text { Outcome assessors }\end{array}$ & Unclear risk & Glutamine versus placebo (glycerine). \\
\hline $\begin{array}{l}\text { Incomplete outcome data } \\
\text { (attrition bias) } \\
\text { All outcomes }\end{array}$ & Low risk & $\begin{array}{l}60 \text { patients randomised. 1 patient (1/30 glutamine) excluded from analysis due } \\
\text { to lack of toxicity data. }\end{array}$ \\
\hline $\begin{array}{l}\text { Selective reporting (re- } \\
\text { porting bias) }\end{array}$ & Unclear risk & $\begin{array}{l}\text { Data presented in a graph for grade of stomatitis (grade 0, grade 1-2, grade 3-4) } \\
\text { by arm in percentages. }\end{array}$ \\
\hline Other bias & Low risk & Study appears to be free of other sources of bias. \\
\hline
\end{tabular}

\section{Lievens 1998}

\section{Study characteristics}

\begin{tabular}{ll}
\hline Methods & $\begin{array}{l}\text { Randomised, parallel group study conducted in Belgium. Clear information about withdrawals: } 19 \text { (12 } \\
\text { sucralfate and 7 placebo). Unclear if dentist involved in study. Duration: 25-33 days (entire duration of } \\
\text { therapy). }\end{array}$ \\
\hline Participants & $\begin{array}{l}102 \text { adults with head and neck cancers receiving radiotherapy ( } 5 \text { fractions per week, doses ranged from } \\
55 \text { Gy in } 25 \text { daily fractions of } 2.2 \text { Gy to } 66 \text { Gy in } 33 \text { daily fractions of } 2 \text { Gy). }\end{array}$ \\
\hline Interventions & 2 groups, placebo versus sucralfate (1 g 6 times daily). \\
\hline Outcomes & $\begin{array}{l}\text { Mucositis scored once weekly using 0-6 scale. Other reported outcome measures: subjective intoler- } \\
\text { ance to radiotherapy treatment, dysphagia, nausea, dermatitis, weight loss, side effects. }\end{array}$ \\
\hline Notes & Funding source: unclear.
\end{tabular}

\section{Risk of bias}

\begin{tabular}{|c|c|c|}
\hline Bias & Authors' judgement & Support for judgement \\
\hline $\begin{array}{l}\text { Random sequence genera- } \\
\text { tion (selection bias) }\end{array}$ & Unclear risk & $\begin{array}{l}\text { Quote: "Randomised". } \\
\text { Comment: random component not described. }\end{array}$ \\
\hline $\begin{array}{l}\text { Allocation concealment } \\
\text { (selection bias) }\end{array}$ & Unclear risk & Insufficient information to determine 'yes' or 'no'. \\
\hline $\begin{array}{l}\text { Blinding (performance } \\
\text { bias and detection bias) } \\
\text { Carers }\end{array}$ & Unclear risk & Insufficient information to determine 'yes' or 'no'. \\
\hline $\begin{array}{l}\text { Blinding (performance } \\
\text { bias and detection bias) } \\
\text { Patients }\end{array}$ & Low risk & $\begin{array}{l}\text { Quote: "double blind". } \\
\text { Comment: probably done. }\end{array}$ \\
\hline $\begin{array}{l}\text { Blinding (performance } \\
\text { bias and detection bias) } \\
\text { Outcome assessors }\end{array}$ & Low risk & $\begin{array}{l}\text { Quote: "double blind". } \\
\text { Comment: probably done. }\end{array}$ \\
\hline
\end{tabular}


Lievens 1998 (Continued)

Incomplete outcome data Unclear risk 102 patients randomised. 19 patients withdrew (12 sucralfate, 7 placebo). (attrition bias)

All outcomes

\begin{tabular}{lll}
$\begin{array}{l}\text { Selective reporting (re- } \\
\text { porting bias) }\end{array}$ & Unclear risk & Data presented for mean peak mucositis. \\
\hline Other bias & Low risk & Study appears to be free from other sources of bias. \\
\hline
\end{tabular}

Lilleby 2006

\section{Study characteristics}

\begin{tabular}{ll}
\hline Methods & Randomised, parallel group study conducted in USA. Clear information on withdrawals: 1 in saline \\
group withdrew consent because wanted ice chips. Dentist not involved in study. Drop outs: $2 \%$. Dura- \\
tion: -2 to 28 days post-transplant.
\end{tabular}

\begin{tabular}{ll}
\hline Participants & $\begin{array}{l}\text { Adults with blood cancer - multiple myeloma scheduled to receive melphalan } 200 \mathrm{mg} / \mathrm{m}^{2} \text { followed by } \\
\text { BMT- autologous stem cell transplantation (ASCT). } 41 \text { enrolled and randomised, } 40 \text { completed. }\end{array}$ \\
\hline Interventions & $\begin{array}{l}2 \text { groups, room temperature normal saline rinse versus ice chips (oral cryotherapy) } 30 \text { minutes before } \\
\text { and } 6 \text { hours after high-dose therapy. }\end{array}$
\end{tabular}

\begin{tabular}{ll}
\hline Outcomes & Mucositis was assessed as part of routine care using the NCI CTC grades 0-4. Assessment used: -2 to 28 \\
days. Other reported outcomes: days of total parenteral nutrition (TNP), narcotic use, hospitalisation, \\
weight loss and resumption of oral caloric intake for 28 days after transplant.
\end{tabular}

\begin{tabular}{ll}
\hline Notes & Funding source: charity. \\
\hline Risk of bias &
\end{tabular}

\begin{tabular}{lll}
\hline Bias & Authors' judgement & Support for judgement \\
\hline $\begin{array}{ll}\text { Random sequence genera- } \\
\text { tion (selection bias) }\end{array}$ & Unclear risk & $\begin{array}{l}\text { Quote: "Patients were randomised to receive either ice-chips or room temper- } \\
\text { ature normal saline rinses." }\end{array}$ \\
& & Comment: random component not described. \\
\hline
\end{tabular}

Allocation concealment $\quad$ Unclear risk $\quad$ Insufficient information to determine 'yes' or 'no'.
(selection bias)

\begin{tabular}{lll}
\hline $\begin{array}{l}\text { Blinding (performance } \\
\text { bias and detection bias) } \\
\text { Carers }\end{array}$ & High risk & Ice chips versus saline. Blinding impossible. \\
\hline $\begin{array}{l}\text { Blinding (performance } \\
\text { bias and detection bias) }\end{array}$ & High risk & Ice chips versus saline. Blinding impossible. \\
$\begin{array}{l}\text { Patients } \\
\text { Blinding (performance } \\
\text { bias and detection bias) } \\
\text { Outcome assessors }\end{array}$ & High risk & Ice chips versus saline. No apparent blinding. \\
\hline
\end{tabular}

\begin{tabular}{ll}
\hline $\begin{array}{l}\text { Incomplete outcome data } \\
\text { (attrition bias) }\end{array}$ & Low risk
\end{tabular}$\quad \begin{aligned} & 41 \text { patients randomised. } 1 \text { patient withdrew: 1/20 saline group. Authors give } \\
& \text { reasons for attrition/ exclusion. }\end{aligned}$


Lilleby 2006 (Continued)

All outcomes

Selective reporting (re- Low risk Data presented for all patients by arm and mucositis grade (table 3).
porting bias)

Other bias Low risk Study appears to be free of other sources of bias.

Lin 2006

\section{Study characteristics}

\begin{tabular}{|c|c|}
\hline Methods & $\begin{array}{l}\text { Randomised, parallel, multisite study conducted in Taiwan. Clear information on withdrawals: } 3 \text { ( } 2 \\
\text { placebo, } 1 \text { intervention). Unclear if dentist involved in study. Recruitment conducted from January } \\
2003 \text { until August 2004. Duration: during radiotherapy treatment (approximately } 2 \text { months). }\end{array}$ \\
\hline Participants & $\begin{array}{l}\text { Adults with head and neck cancers receiving radiotherapy ( } 180 \text { cGy to } 200 \text { cGy in } 5 \text { weekly fractions) } \\
\text { with or without concurrent chemotherapy (no extra information). } 100 \text { randomised, } 97 \text { completed. }\end{array}$ \\
\hline Interventions & 2 groups, soya bean oil placebo versus oral zinc ( 25 mg Pro-Z) (3 capsules a day). \\
\hline Outcomes & $\begin{array}{l}\text { Mucositis assessed weekly using the RTOG criteria for acute morbidity. Other reported outcome mea- } \\
\text { sures: dermatitis, weight loss, interruption of radiotherapy, adverse events. }\end{array}$ \\
\hline Notes & e: Chi-Mei Foundation Medical Centre. \\
\hline
\end{tabular}

\section{Risk of bias}

\begin{tabular}{lll}
\hline Bias & Authors' judgement & Support for judgement \\
\hline $\begin{array}{ll}\text { Random sequence genera- } \\
\text { tion (selection bias) }\end{array}$ & Low risk & $\begin{array}{l}\text { Quote: "Blocked randomisation was used for all subjects to achieve balanced } \\
\text { assignment. We adapted the RV.Uniform }(0,1) \text { function in SPSS for windows to } \\
\text { generate random numbers and to assign distinct random permuted blocks to } \\
\text { subjects". } \\
\text { Comment: computer generated randomisation. }\end{array}$ \\
& &
\end{tabular}

Allocation concealment Unclear risk
$\begin{aligned} & \text { (selection bias) } \\ & \text { tor until the end of the experiment". }\end{aligned}$

Comment: insufficient information to determine 'yes' or 'no'.

\begin{tabular}{|c|c|c|}
\hline $\begin{array}{l}\text { Blinding (performance } \\
\text { bias and detection bias) }\end{array}$ & Unclear risk & $\begin{array}{l}\text { Comment: authors state that serum zinc levels were checked biweekly, staff } \\
\text { who checked these levels would presumably have knowledge of allocation. }\end{array}$ \\
\hline
\end{tabular}

Carers

\begin{tabular}{ll} 
Blinding (performance & Low risk \\
$\begin{array}{l}\text { bias and detection bias) } \\
\text { Patients }\end{array}$ & Quote: "double blind". \\
\hline
\end{tabular}

\begin{tabular}{ll}
\hline $\begin{array}{l}\text { Blinding (performance } \\
\text { bias and detection bias) }\end{array}$ & Unclear risk
\end{tabular}$\quad \begin{aligned} & \text { Comment: authors state that serum zinc levels were checked biweekly, staff } \\
& \text { who checked these levels would presumably have knowledge of allocation. }\end{aligned}$

Outcome assessors

\begin{tabular}{ll}
\hline $\begin{array}{l}\text { Incomplete outcome data } \\
\text { (attrition bias) }\end{array}$ & Low risk \\
& $\begin{array}{l}100 \text { patients randomised. } 3 \text { patients dropped out (1/50 intervention, } 2 / 50 \\
\text { placebo group). Authors give reasons for withdrawals/drop outs. }\end{array}$
\end{tabular}

(attrition bias)

placebo group). Authors give reasons for withdrawals/drop outs. 
Lin 2006 (Continued)

\begin{tabular}{|c|c|c|}
\hline $\begin{array}{l}\text { Selective reporting (re- } \\
\text { orting bias) }\end{array}$ & Unclear risk & $\begin{array}{l}\text { Data presented for time to grade } 2 \text { and } 3 \text { mucositis in text. Mean scores for mu- } \\
\text { cositis plotted over time by treatment arm in fig } 3 \text {. }\end{array}$ \\
\hline
\end{tabular}

Other bias Low risk Study appears to be free from other sources of bias.

Lockhart 2005

\section{Study characteristics}

\begin{tabular}{ll}
\hline Methods & $\begin{array}{l}\text { Randomised, parallel group study conducted in USA. Clear information on withdrawals: none. Unclear } \\
\text { whether dentist involved in study. Drop outs: } 0 \% \text {. Duration: unclear. }\end{array}$ \\
\hline Participants & $\begin{array}{l}\text { Adults with mixed cancer. BMT - autologous blood stem cell transplant (ABSCT). 36 enrolled, ran- } \\
\text { domised and completed. }\end{array}$ \\
\hline Interventions & $\begin{array}{l}2 \text { groups, placebo versus pilocarpine (patients were randomised to receive a } 5 \text { mg tablet of pilocarpine, } \\
\text { or a placebo, during and following chemotherapy). }\end{array}$ \\
\hline Outcomes & $\begin{array}{l}\text { Mucositis assessed every other day using the WHO mucositis score and the authors' own developed } \\
\text { data entry forms to capture subjective and objective data, including toxicity criteria. This new tool is } \\
\text { a highly modified version of the Southwest Oncology Group (SWOG) toxicity scale. We used the high- } \\
\text { est score mucositis score recorded, supplied by author. Assessment used: up to day } 10 . \text { Other report- } \\
\text { ed outcomes: problems with nutrition, oral infection, use of narcotics for mucosal pain, problems with } \\
\text { oral hygiene, gingival bleeding, eating, speaking and sleeping (ordinal variables), pain at rest or with } \\
\text { swallowing, mouth dryness (VAS scale). }\end{array}$ \\
\hline Fotes & \begin{tabular}{l} 
Funding source: charity/foundation. \\
\hline
\end{tabular}
\end{tabular}

\section{Risk of bias}

Bias Authors' judgement Support for judgement

Random sequence genera- Low risk tion (selection bias)

Quote: "Subjects were stratified according to initial diagnosis and randomized by computer generated numbering scheme to receive either pilocarpine or an identical-appearing placebo".

Comment: computer generated randomisation.

\begin{tabular}{lll}
\hline $\begin{array}{l}\text { Allocation concealment } \\
\text { (selection bias) }\end{array}$ & Unclear risk & Insufficient information to determine 'yes' or 'no'. \\
\hline $\begin{array}{l}\text { Blinding (performance } \\
\text { bias and detection bias) } \\
\text { Carers }\end{array}$ & Unclear risk & Insufficient information to determine 'yes' or 'no'. \\
\hline
\end{tabular}

\begin{tabular}{|c|c|c|}
\hline $\begin{array}{l}\text { Blinding (performance } \\
\text { bias and detection bias) } \\
\text { Patients }\end{array}$ & Low risk & $\begin{array}{l}\text { Quote: "double blind". } \\
\text { Comment: probably done. }\end{array}$ \\
\hline $\begin{array}{l}\text { Blinding (performance } \\
\text { bias and detection bias) } \\
\text { Outcome assessors }\end{array}$ & Low risk & $\begin{array}{l}\text { Quote: "double blind”. } \\
\text { Comment: probably done. }\end{array}$ \\
\hline
\end{tabular}

Incomplete outcome data Low risk $\quad 36$ patients randomised. No missing outcome data.
(attrition bias)


Lockhart 2005 (Continued)

All outcomes

\section{Selective reporting (re- Unclear risk} porting bias)
Data presented for incidence and duration of oral mucositis, gingival mucositis and oropharyngeal mucositis (days) (Table 3); highest grade of mucositis by treatment arms, average mucositis score between days 4 and 8 by treatment arm and average mucositis score between days 6 and 8 (separated into oral, gingival and oropharyngeal) (fig 1).

Other bias Low risk Study appears to be free of other sources of bias.

Loprinzi 1990

\section{Study characteristics}

\begin{tabular}{ll}
\hline Methods & $\begin{array}{l}\text { Randomised cross-over trial conducted in USA. Clear information on withdrawals: none. Dentist was } \\
\text { not involved. Drop outs: } 0 \% \text {. Duration: } 5 \text { days. }\end{array}$ \\
\hline Participants & $\begin{array}{l}\text { Adults with colorectal cancer receiving first } 5 \text { day course of 5-FU. } 77 \text { patients enrolled, and completed } \\
1 \text { st period, only } 20 \text { completed } 2 \mathrm{nd} \text { period. }\end{array}$ \\
\hline Interventions & $\begin{array}{l}2 \text { groups, placebo versus allupurinol mouthrinse } 1 \mathrm{mg} / \mathrm{ml} \mathrm{made} \text { from } 450 \mathrm{mg}+150 \mathrm{ml} \text { cologel (450 } \\
\mathrm{mg} / 5 \mathrm{mg} \text { methylcellulose with } 5 \% \text { alcohol) }+450 \mathrm{ml} \text { flavouring agent. } 20 \mathrm{ml} \text { used for } 30 \mathrm{~s} \text { immediately } \\
\text { after treatment then at } 1,2,3 \text { hours). }\end{array}$ \\
\hline Outcomes & Mucositis (physician and patient scales 0-4). Assessed used: day 30. \\
\hline Notes & $\begin{array}{l}\text { Data cross-tabulated in a form suitable for meta-analysis provided by authors. } \\
\text { Funding source: none. }\end{array}$ \\
\hline
\end{tabular}

\section{Risk of bias}

Bias Authors' judgement Support for judgement

Random sequence genera- Unclear risk Quote: "a dynamic randomization procedure was utilized for assigning pation (selection bias) tients to initially receive either the allopurinol or the placebo mouthwash."

Comment: random component not described.

\begin{tabular}{lll}
\hline $\begin{array}{l}\text { Allocation concealment } \\
\text { (selection bias) }\end{array}$ & Unclear risk & Insufficient information to determine 'yes' or 'no'. \\
\hline $\begin{array}{l}\text { Blinding (performance } \\
\text { bias and detection bias) } \\
\text { Carers }\end{array}$ & Unclear risk & Insufficient information to determine 'yes' or 'no'. \\
\hline $\begin{array}{l}\text { Blinding (performance } \\
\text { bias and detection bias) }\end{array}$ & Low risk & Quote: "double blind". \\
$\begin{array}{l}\text { Patients } \\
\begin{array}{l}\text { Blinding (performance } \\
\text { bias and detection bias) } \\
\text { Outcome assessors }\end{array}\end{array}$ & Low risk & Comment: probably done. \\
\hline
\end{tabular}

Incomplete outcome data Low risk

77 patients recruited. Data from all patients included in analysis.

(attrition bias)

All outcomes 
Loprinzi 1990 (Continued)

Selective reporting (re- Low risk $\quad$ Data presented for 77 patients for physician judged mucositis (table 2) and 71 porting bias) patients for patient judged mucositis grade (table 3 ).

Other bias

High risk

Study aimed to recruit 120 patients but was terminated early after 77 patients were recruited after the power calculation was re-run and the results found to favour the intervention.

Madan 2008

\section{Study characteristics}

Methods Randomised, parallel study conducted in India. Clear information on withdrawals: 4. Unclear if dentist
involved in study. Duration: 6 weeks.

\begin{tabular}{ll}
\hline Participants & Adults with head and neck cancer receiving radiotherapy (2 Gy daily dose, total dose 60 Gy). \\
\hline Interventions & $\begin{array}{l}\text { 4 groups, } 0.12 \% \text { chlorhexidine versus } 1 \% \text { povidone-iodine versus salt/sodium bicarbonate versus plain } \\
\text { water. All mouthwashes given in doses of } 10 \mathrm{ml} \text { twice a day for } 6 \text { weeks. }\end{array}$ \\
\hline Outcomes & Mucositis assessed weekly using WHO scale. Other reported outcome measures: none. \\
\hline Notes & Funding source: Manipal University, India.
\end{tabular}

\section{Risk of bias}

\begin{tabular}{lll}
\hline Bias & Authors' judgement & Support for judgement \\
\hline $\begin{array}{l}\text { Random sequence genera- } \\
\text { tion (selection bias) }\end{array}$ & Unclear risk & Quote: "randomly assigned". \\
& & Comment: random component not described.
\end{tabular}

\begin{tabular}{ll}
\hline $\begin{array}{l}\text { Allocation concealment } \\
\text { (selection bias) }\end{array}$ & Quote: "the mouthwashes were numbered randomly from 1 to 80 by the \\
mouthwash manufacturer. The coding was done by the manufacturer and was \\
known only to him. It was revealed to the investigator only at the end of the \\
study. Mouthwashes were dispensed in identical 500 ml coded glass bottles".
\end{tabular}

Comment: sequentially numbered drugs containers of identical appearance.

\begin{tabular}{|c|c|c|}
\hline $\begin{array}{l}\text { Blinding (performance } \\
\text { bias and detection bias) } \\
\text { Carers }\end{array}$ & Low risk & $\begin{array}{l}\text { Double blind study with adequate allocation concealment. Unlikely that carers } \\
\text { would have knowledge of allocations. }\end{array}$ \\
\hline
\end{tabular}

\begin{tabular}{ll}
\hline $\begin{array}{l}\text { Blinding (performance } \\
\text { bias and detection bias) }\end{array}$ & Quote: "double blind". \\
Patients & Comment: probably done. \\
\hline
\end{tabular}

\begin{tabular}{|c|c|c|}
\hline $\begin{array}{l}\text { Blinding (performance } \\
\text { bias and detection bias) } \\
\text { Outcome assessors }\end{array}$ & Low risk & $\begin{array}{l}\text { Quote: "double blind". } \\
\text { Comment: probably done. }\end{array}$ \\
\hline $\begin{array}{l}\text { Incomplete outcome data } \\
\text { (attrition bias) } \\
\text { All outcomes }\end{array}$ & Low risk & $\begin{array}{l}80 \text { patients randomised. } 4 \text { patients dropped out ( } 1 / 20 \text { chlorhexidine group, } \\
1 / 20 \text { povidone, } 2 / 20 \text { salt and bicarbonate). Authors give reasons for with- } \\
\text { drawals. }\end{array}$ \\
\hline
\end{tabular}

\begin{tabular}{|c|c|c|}
\hline $\begin{array}{l}\text { Selective reporting (re- } \\
\text { porting bias) }\end{array}$ & Unclear risk & $\begin{array}{l}\text { Data presented for mean mucositis scores by arm by week of treatment (fig } 2 \\
\text { and table } 2 \text { ). }\end{array}$ \\
\hline
\end{tabular}


Madan 2008 (Continued)

Other bias Low risk Study appears to be free from other sources of bias.

Mahood 1991

\section{Study characteristics}

\begin{tabular}{ll}
\hline Methods & Randomised, cross-over study conducted in USA. Unclear information on withdrawals: $2 / 45$ control, \\
$0 / 50$ treatment in first cycle. Dentists not involved in study. Drop outs $2 \%$. Duration from 5 mins before \\
5-FU and for 30 mins after.
\end{tabular}

\begin{tabular}{ll}
\hline Participants & Adults mostly over 40 years with cancer of the colon (solid cancer). Chemotherapy first 5 day course of \\
5-FU. 95 patients eligible and enrolled and 93 completed first cycle, however, only 82 patients assessed \\
mucositis.
\end{tabular}

\begin{tabular}{ll}
\hline Interventions & $\begin{array}{l}\text { 2 groups, no treatment control versus ice chips (cryotherapy) placed in the mouth } 5 \text { mins before each } \\
\text { dose of 5-FU and replenished over } 30 \text { mins. }\end{array}$ \\
\hline Outcomes & $\begin{array}{l}\text { Mucositis (physician \& patients scales 0-4) and historical } 1 \text { month after treatment. Assessment used: } \\
\text { day } 28 .\end{array}$ \\
\hline Notes & $\begin{array}{l}\text { Data cross-tabulated in a form suitable for meta-analysis provided by authors. } \\
\text { Funding source: government. }\end{array}$ \\
\hline
\end{tabular}

\section{Risk of bias}

\begin{tabular}{lll}
\hline Bias & Authors' judgement & Support for judgement \\
\hline $\begin{array}{ll}\text { Random sequence genera- } \\
\text { tion (selection bias) }\end{array}$ & Unclear risk & $\begin{array}{l}\text { Quote: "prior to therapy, patients were stratified by age and whether or not } \\
\text { they had denture. They were then randomised to a control arm or to receive } \\
\text { cryotherapy". } \\
\text { Comment: random component not described. }\end{array}$ \\
\hline
\end{tabular}

\begin{tabular}{lll}
\hline $\begin{array}{l}\text { Allocation concealment } \\
\text { (selection bias) }\end{array}$ & Unclear risk & Insufficient information to determine 'yes' or 'no'. \\
\hline $\begin{array}{l}\text { Blinding (performance } \\
\text { bias and detection bias) } \\
\text { Carers }\end{array}$ & High risk & Ice chips versus saline. Blinding impossible. \\
\hline
\end{tabular}

\begin{tabular}{|c|c|c|}
\hline $\begin{array}{l}\text { Blinding (performance } \\
\text { bias and detection bias) } \\
\text { Patients }\end{array}$ & High risk & Ice chips versus saline. Blinding impossible. \\
\hline $\begin{array}{l}\text { Blinding (performance } \\
\text { bias and detection bias) } \\
\text { Outcome assessors }\end{array}$ & Unclear risk & $\begin{array}{l}\text { Quote: "the attending physician who judged the mucositis grade was frequent- } \\
\text { ly not aware of whether the patient had received cryotherapy or not". } \\
\text { Comment: insufficient information to determine 'yes' or 'no'. }\end{array}$ \\
\hline $\begin{array}{l}\text { Incomplete outcome data } \\
\text { (attrition bias) } \\
\text { All outcomes }\end{array}$ & Unclear risk & $\begin{array}{l}95 \text { patients randomised. } 2 \text { patients not included in final analysis due to lack } \\
\text { of data. Authors do not state which arms missing were randomised. Patient } \\
\text { judged mucositis scores collected from } 85 \text { patients. Authors do not state to } \\
\text { which arms missing were randomised. }\end{array}$ \\
\hline $\begin{array}{l}\text { Selective reporting (re- } \\
\text { porting bias) }\end{array}$ & Low risk & $\begin{array}{l}\text { Physician judged mucositis scales presented for } 93 \text { patients (table 2). Patient } \\
\text { judged mucositis scales presented for } 82 \text { patients (table } 3 \text { ). }\end{array}$ \\
\hline
\end{tabular}


Mahood 1991 (Continued)

Other bias Low risk Study appears to be free of other sources of bias.

Makkonen 1994

\section{Study characteristics}

\begin{tabular}{ll}
\hline Methods & Randomised, parallel group study conducted in Finland. Clear information about withdrawals: none \\
mentioned. Dentist involved in study. Drop outs: $0 \%$. Duration: during therapy (9 weeks). Recruitment \\
November 1989 to December 1991.
\end{tabular}

\begin{tabular}{ll}
\hline Participants & Adults with head and neck cancer. 40 patients eligible, enrolled and evaluated. \\
\hline Interventions & $\begin{array}{l}2 \text { groups, placebo versus sucralfate (suspension } 1 \mathrm{~g} 6 \text { times per day orally, patients mix granules with } \\
100 \mathrm{ml} \text { water rinse for } 1 \mathrm{~min} \text { then swallow). Rinsed throughout radiotherapy, dose } 45-73 \mathrm{~Gy} .\end{array}$ \\
\hline Outcomes & $\begin{array}{l}\text { Mucositis on scale } 0-2(0=\text { no mucositis, } 1=\text { moderate, } 2=\text { severe), at } 9 \text { weekly evaluation visits. Assess- } \\
\text { ment used: day } 28 . \text { Other reported outcomes: salivary lactoferrin, salivary albumin, amount of anaes- } \\
\text { thetic mouthwash, radiotherapy interrupted, toxicity. }\end{array}$
\end{tabular}

\begin{tabular}{ll}
\hline Notes & Visit at week 4 taken. Antifungal agents given to 29 patients during study. \\
& Funding source: government.
\end{tabular}

\section{Risk of bias}

Bias Authors' judgement Support for judgement

Random sequence genera- Unclear risk tion (selection bias)

Quote: "The sealed envelope method was used in randomization, and the envelopes were opened only after all clinical information for each patient had been collected."

Comment: unclear if envelopes were shuffled. Random component not described.

\begin{tabular}{|c|c|c|}
\hline $\begin{array}{l}\text { Allocation concealment } \\
\text { (selection bias) }\end{array}$ & Unclear risk & $\begin{array}{l}\text { Quote: "All drugs prepared by the manufacturer, } 1 \mathrm{~g} \text { sucralfate or identically } \\
\text { looking placebo granules were sealed in coded paper bags". }\end{array}$ \\
\hline & & $\begin{array}{l}\text { Sealed envelope method of randomisation. However, authors do not state } \\
\text { whether envelopes or bags were sequentially numbered. }\end{array}$ \\
\hline
\end{tabular}

Blinding (performance Unclear risk Insufficient information to determine 'yes' or 'no'.

bias and detection bias)

Carers

\begin{tabular}{|c|c|c|}
\hline $\begin{array}{l}\text { Blinding (performance } \\
\text { bias and detection bias) } \\
\text { Patients }\end{array}$ & Low risk & $\begin{array}{l}\text { Quote: “double blind”. } \\
\text { Comment: probably done. }\end{array}$ \\
\hline $\begin{array}{l}\text { Blinding (performance } \\
\text { bias and detection bias) } \\
\text { Outcome assessors }\end{array}$ & Low risk & $\begin{array}{l}\text { Quote: “double blind”. } \\
\text { Comment: probably done. }\end{array}$ \\
\hline $\begin{array}{l}\text { Incomplete outcome data } \\
\text { (attrition bias) } \\
\text { All outcomes }\end{array}$ & Low risk & $\begin{array}{l}40 \text { patients recruited. Authors give mucositis data for } 40 \text { patients after } 3 \text { weeks } \\
\text { of treatment. }\end{array}$ \\
\hline
\end{tabular}


Makkonen 1994 (Continued)

Selective reporting (re- Low risk Data presented for grade of mucositis at week 3 for all patients (text), and for porting bias) percentage of patients with radiation mucositis in each group at each evaluation visit (fig 1).
Significant differences between the group for sex $(P=0.05)$ and age $(P=0.04)$ of patients at randomisation. Both have been suggested as independent variables for mucositis severity.

3 patients had a buccal mucosa resection as part of their treatment. Authors provide no information about allocation of these patients.

Dentate patients (10 sucralfate \& 6 placebo) also received weekly fluoride treatments.

Makkonen 2000

\section{Study characteristics}

\begin{tabular}{ll}
\hline Methods & $\begin{array}{l}\text { Randomised, parallel group study conducted in Finland. Clear information about withdrawals: none. } \\
\text { Dentist involved in study. Drop outs: 0\%. Duration: during therapy (9 weeks). }\end{array}$ \\
\hline Participants & $\begin{array}{l}\text { Adults with head and neck cancer. } 40 \text { patients eligible, enrolled between November } 1994 \text { and August } \\
1996, \text { all were evaluated. }\end{array}$ \\
\hline Interventions & $\begin{array}{l}2 \text { groups, no treatment control versus GM-CSF (150 to } 300 \text { ug given subcutaneously daily until last day } \\
\text { of irradiation. Dose depends on body weight). }\end{array}$ \\
\hline Outcomes & $\begin{array}{l}\text { Mucositis on scale 0-2 ( } 0=\text { no mucositis, } 1 \text { = moderate, } 2 \text { = severe). Assessment used: day } 28 . \text { Other re- } \\
\text { ported outcomes: oral pain on scale 1-4, and patient VAS scale for pain. Evaluated weekly during treat- } \\
\text { ment then } 1 \text { and } 6 \text { months after therapy, use of analgesic, weight loss, toxicity, survival. }\end{array}$ \\
\hline Notes & $\begin{array}{l}\text { All patients used sucralfate suspension } 1 \mathrm{~g} 6 \text { times daily. } \\
\text { Funding source: pharmaceutical. }\end{array}$ \\
\hline
\end{tabular}

\section{Risk of bias}

\section{Bias Authors' judgement Support for judgement}

Random sequence genera- Low risk Quote: "after obtaining an oral informed consent, assignment to the treatment tion (selection bias) groups were carried out via a phone call to the randomisation centre at the Finnish Cancer registry, Helsinki."

Comment: random component not explicit. However, setting makes adequate randomisation likely.

Allocation concealment Low risk

(selection bias)
Quote: "after obtaining an oral informed consent, assignment to the treatment groups were carried out via a phone call to the randomisation centre at the Finnish Cancer registry, Helsinki."

Comment: central method of allocation.

\begin{tabular}{lll}
\hline $\begin{array}{l}\text { Blinding (performance } \\
\text { bias and detection bias) } \\
\text { Carers }\end{array}$ & High risk & Quote: "open, prospective, randomised study". \\
& & Comment: no blinding. \\
\hline $\begin{array}{l}\text { Blinding (performance } \\
\text { bias and detection bias) }\end{array}$ & High risk & Quote: "open, prospective, randomised study".
\end{tabular}


Makkonen 2000 (Continued)

Patients

Comment: no blinding.

\begin{tabular}{|c|c|c|}
\hline $\begin{array}{l}\text { Blinding (performance } \\
\text { bias and detection bias) }\end{array}$ & High risk & Quote: "open, prospective, randomised study". \\
\hline Outcome assessors & & Comment: no blir \\
\hline
\end{tabular}

Outcome assessors

40 patients recruited. No missing outcome data.

Incomplete outcome data Low risk

(attrition bias)

All outcomes Selective reporting (re- Unclear risk
porting bias)
Data presented in graphs showing percentages of patients with mucositis (fig 1) and mucosal pain (fig 2). Figures given in the text for percentage of patients with mucositis at weeks 1 and 3.

Other bias Low risk Study appears to be free of other sources of bias.

McAleese 2006

\section{Study characteristics}

\begin{tabular}{ll}
\hline Methods & $\begin{array}{l}\text { Randomised, parallel group study single centre study conducted in the UK. Clear information about } \\
\text { withdrawals: } 2 / 29 . \text { Unclear if dentist involved in study. Drop outs: } 7 \% . \text { Duration: } 10 \text { weeks. }\end{array}$ \\
\hline Participants & $\begin{array}{l}\text { Adults with head and neck cancer to be treated with radiotherapy. } 29 \text { patients eligible, enrolled be- } \\
\text { tween September } 1997 \text { and October } 2000.27 \text { patients evaluated. }\end{array}$ \\
\hline Interventions & $\begin{array}{l}2 \text { groups, GM-CSF at dose of } 150 \text { ug subcutaneous injection once daily for } 14 \text { days beginning at the end } \\
\text { of second week of radiotherapy. Compared to no treatment. }\end{array}$ \\
\hline Outcomes & RTOG rating for mucositis on 0-4 scale. \\
\hline Notes & Maximum value of mucositis taken. Funding unclear. \\
\hline
\end{tabular}

\section{Risk of bias}

Bias Authors' judgement Support for judgement

Random sequence genera- Unclear risk tion (selection bias)

Quote: "29 patients agreed to enter and were randomly assigned to the active or control arms."

Comment: random component not described.

\begin{tabular}{|c|c|c|}
\hline $\begin{array}{l}\text { Allocation concealment } \\
\text { (selection bias) }\end{array}$ & Unclear risk & Insufficient information to determine 'yes' or 'no'. \\
\hline $\begin{array}{l}\text { Blinding (performance } \\
\text { bias and detection bias) } \\
\text { Carers }\end{array}$ & Unclear risk & Insufficient information to determine 'yes' or 'no'. \\
\hline $\begin{array}{l}\text { Blinding (performance } \\
\text { bias and detection bias) } \\
\text { Patients }\end{array}$ & High risk & $\begin{array}{l}\text { Quote: "A placebo injection was not used because it was not considered ethi- } \\
\text { cally justifiable". } \\
\text { Comment: GM-CSF versus no intervention. }\end{array}$ \\
\hline $\begin{array}{l}\text { Blinding (performance } \\
\text { bias and detection bias) }\end{array}$ & Low risk & $\begin{array}{l}\text { Quote: "At each visit one of two independent observers, blinded to group allo- } \\
\text { cation, scored mucositis by the RTOG system?" }\end{array}$ \\
\hline
\end{tabular}


McAleese 2006 (Continued)

Outcome assessors

$\begin{array}{ll}\begin{array}{l}\text { Incomplete outcome data } \\ \text { (attrition bias) }\end{array} & \text { Low risk } \\ \text { All outcomes } & \begin{array}{l}29 \text { patients recruited. } 2 \text { patients withdrew (2/15 intervention group). Authors } \\ \text { give full reasons for exclusions and withdrawals. ITT analysis performed. Mu- } \\ \text { cositis data given for } 29 \text { patients. }\end{array}\end{array}$
$\begin{array}{ll}\text { Selective reporting (re- } \quad \text { Low risk } & \text { Maximum mucositis grades given for } 29 \text { patients by arm in text. Data also pre- } \\ \text { porting bias) } & \text { sented for the proportion of patients with each grade by arm in graphs (fig } 1\end{array}$

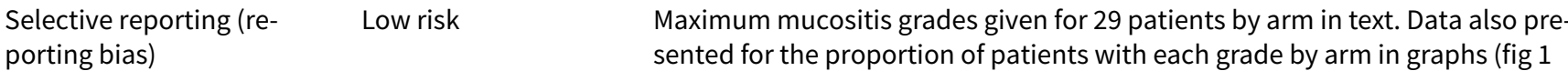
and fig 2).

Other bias Low risk Study appears to be free of other sources of bias.

\section{McGaw 1985}

\section{Study characteristics}

\begin{tabular}{ll}
\hline Methods & $\begin{array}{l}\text { Randomised, parallel group single site study conducted in Canada. Dentist involved in study. Drop outs: } \\
\text { 0\%. Duration: } 28 \text { days. No enrolment dates. }\end{array}$ \\
\hline Participants & $\begin{array}{l}16 \text { patients with acute myeloblative leukaemia aged between } 17 \text { and } 54 \text { years old. All patients received } \\
\text { conditioning with cytosine-arabinoside }\left(200 \mathrm{mg} / \mathrm{m}^{2} \text { daily for } 5 \text { days), adriamycin }\left(40 \mathrm{mg} / \mathrm{m}^{2} \text { on day } 1\right.\right. \\
\text { and } 2) \text { and amsacrine }\left(100 \mathrm{mg} / \mathrm{m}^{2} \text { daily for } 5 \text { days) chemotherapy. }\right.\end{array}$ \\
\hline
\end{tabular}

Interventions 2 groups, intervention group received $10 \mathrm{ml}$ of $0.1 \%$ aqueous solution of chlorhexidine gluconate (corsodyl), placebo group received a identically coloured and flavoured solution. Both groups rinsed twice daily for 2 minutes.

Hickey instrument used (0-3 scale). Other outcome measures: dental plaque scores, gingivitis scores,
numbers of patients developing candidiasis, number of patients requiring antibiotics, average number
of febrile days, level of tooth staining and discolouration.

of febrile days, level of tooth staining and discolouration.

Notes Funding source: not stated.

\section{Risk of bias}

\begin{tabular}{|c|c|c|}
\hline Bias & Authors' judgement & Support for judgement \\
\hline $\begin{array}{l}\text { Random sequence genera- } \\
\text { tion (selection bias) }\end{array}$ & Unclear risk & $\begin{array}{l}\text { Quote: "patients randomised into two experimental groups". } \\
\text { Comment: random component not described. }\end{array}$ \\
\hline $\begin{array}{l}\text { Allocation concealment } \\
\text { (selection bias) }\end{array}$ & Unclear risk & Insufficient information to determine 'yes' or 'no'. \\
\hline $\begin{array}{l}\text { Blinding (performance } \\
\text { bias and detection bias) } \\
\text { Carers }\end{array}$ & Unclear risk & Insufficient information to determine 'yes' or 'no'. \\
\hline $\begin{array}{l}\text { Blinding (performance } \\
\text { bias and detection bias) } \\
\text { Patients }\end{array}$ & Low risk & $\begin{array}{l}\text { Quote: "double blind". } \\
\text { Comment: probably done. }\end{array}$ \\
\hline $\begin{array}{l}\text { Blinding (performance } \\
\text { bias and detection bias) } \\
\text { Outcome assessors }\end{array}$ & Low risk & $\begin{array}{l}\text { Quote: "double blind". } \\
\text { Comment: probably done. }\end{array}$ \\
\hline
\end{tabular}


McGaw 1985 (Continued)
Incomplete outcome data
Low risk
16 patients randomised. No incomplete outcome data.
(attrition bias)

All outcomes

\begin{tabular}{lll}
$\begin{array}{l}\text { Selective reporting (re- } \\
\text { porting bias) }\end{array}$ & Unclear risk & Data presented for mean mucositis score by week for both study arms. \\
\hline Other bias & Low risk & Study appears to be free from other sources of bias. \\
\hline
\end{tabular}

Meropol 2003

\section{Study characteristics}

\begin{tabular}{ll}
\hline Methods & Randomised, parallel group, multicentre study conducted in USA. Clear information about with- \\
drawals: 0 . Dentist not involved in study. Drop outs: $0 \%$ Duration: 28 days.
\end{tabular}

\begin{tabular}{ll}
\hline Participants & Adults with solid cancer treated with 5-FU. Patients enrolled, 81 completed. \\
\hline Interventions & $\begin{array}{l}2 \text { groups, KGF IV injection patient cohorts treated with escalating doses of KGF 1,10, 20, 40, 60 and } 80 \\
\text { micrograms/kg per day versus placebo control. }\end{array}$ \\
\hline Outcomes & $\begin{array}{l}\text { Mucositis WHO grading evaluated by examination on day } 1,4,8,15 \text { and } 28 . \text { Other reported outcomes: } \\
\text { nausea, vomiting, blood changes. }\end{array}$ \\
\hline Notes & Funding source: unclear.
\end{tabular}

\section{Risk of bias}

Bias Authors' judgement Support for judgement

Random sequence genera- Unclear risk Quote: "This study was a multicentre, randomized, double blinded, placebo tion (selection bias) controlled, phase I study".

Comment: random component not described.

\begin{tabular}{|c|c|c|}
\hline $\begin{array}{l}\text { Allocation concealment } \\
\text { (selection bias) }\end{array}$ & Unclear risk & Insufficient information to determine 'yes' or 'no'. \\
\hline
\end{tabular}

\begin{tabular}{|c|c|c|}
\hline $\begin{array}{l}\text { Blinding (performance } \\
\text { bias and detection bias) } \\
\text { Carers }\end{array}$ & Unclear risk & Insufficient information to determine 'yes' or 'no'. \\
\hline $\begin{array}{l}\text { Blinding (performance } \\
\text { bias and detection bias) } \\
\text { Patients }\end{array}$ & Low risk & $\begin{array}{l}\text { Quote: "double blind". } \\
\text { Comment: probably done. }\end{array}$ \\
\hline $\begin{array}{l}\text { Blinding (performance } \\
\text { bias and detection bias) } \\
\text { Outcome assessors }\end{array}$ & Low risk & $\begin{array}{l}\text { Quote: "double blind". } \\
\text { Comment: probably done. }\end{array}$ \\
\hline $\begin{array}{l}\text { Incomplete outcome data } \\
\text { (attrition bias) } \\
\text { All outcomes }\end{array}$ & Low risk & 81 patients recruited. No missing outcome data. \\
\hline
\end{tabular}


Meropol 2003 (Continued)

Selective reporting (re- Unclear risk Data only presented in graphical form for incidence of grade 2 to 4 mucositis porting bias)

(as percentage), duration of mucositis (days) and patient reports of mucositis.

Full data not presented.

Other bias Low risk Study appears to be free of other sources of bias.

Mills 1988

\section{Study characteristics}

\begin{tabular}{ll}
\hline Methods & $\begin{array}{l}\text { Randomised, parallel group study conducted in South Africa. Clear information about withdrawals: } 0 . \\
\text { Dentist not involved in study. Drop outs: } 0 \% \text {. Duration: unclear. }\end{array}$ \\
\hline Participants & Adults with head and neck cancer. 10 enrolled, 10 completed. \\
\hline Interventions & 2 groups, beta carotene $(250 \mathrm{mg} /$ day for 21 days, $75 \mathrm{mg}$ daily after this) versus no treatment control. \\
\hline Outcomes & Mucositis. \\
\hline Notes & Funding source: pharmaceutical.
\end{tabular}

\section{Risk of bias}

\begin{tabular}{|c|c|c|}
\hline Bias & Authors' judgement & Support for judgement \\
\hline $\begin{array}{l}\text { Random sequence genera- } \\
\text { tion (selection bias) }\end{array}$ & Unclear risk & $\begin{array}{l}\text { Quote: "...randomised to receive standard diet with supplemental beta } \\
\text { carotene (study patients) or standard diet only with no placebo (control pa- } \\
\text { tients)." } \\
\text { Comment: random component not described. }\end{array}$ \\
\hline $\begin{array}{l}\text { Allocation concealment } \\
\text { (selection bias) }\end{array}$ & Unclear risk & Insufficient information to determine 'yes' or 'no'. \\
\hline $\begin{array}{l}\text { Blinding (performance } \\
\text { bias and detection bias) } \\
\text { Carers }\end{array}$ & High risk & Beta-carotene versus no intervention. No apparent blinding. \\
\hline $\begin{array}{l}\text { Blinding (performance } \\
\text { bias and detection bias) } \\
\text { Patients }\end{array}$ & High risk & Beta-carotene versus no intervention. No apparent blinding. \\
\hline $\begin{array}{l}\text { Blinding (performance } \\
\text { bias and detection bias) } \\
\text { Outcome assessors }\end{array}$ & High risk & Beta-carotene versus no intervention. No apparent blinding. \\
\hline $\begin{array}{l}\text { Incomplete outcome data } \\
\text { (attrition bias) } \\
\text { All outcomes }\end{array}$ & Low risk & 20 patients randomised. No missing outcome data. \\
\hline $\begin{array}{l}\text { Selective reporting (re- } \\
\text { porting bias) }\end{array}$ & Low risk & Data presented by mucositis grade by weeks of treatment (table 2 ). \\
\hline Other bias & Low risk & Study appears to be free of other sources of bias. \\
\hline
\end{tabular}


Motallebnejad 2008

\section{Study characteristics}

\begin{tabular}{ll}
\hline Methods & $\begin{array}{l}\text { Randomised, parallel group study conducted in Iran. Clear information about withdrawals. Unclear if } \\
\text { dentist involved in study. Duration unclear (5-6 weeks?). }\end{array}$ \\
\hline Participants & Adults with head and neck cancer receiving radiotherapy (1.8 Gy to 2 Gy per day, total dose 50-60 Gy). \\
\hline Interventions & $\begin{array}{l}2 \text { groups, saline ( } 20 \mathrm{ml} \text { saline } 0.09 \% \text { before and after radiotherapy) versus honey (20 ml pure honey, } 15 \\
\text { minutes before and } 15 \text { minutes after radiotherapy, and } 6 \text { hours after radiotherapy). }\end{array}$ \\
\hline Outcomes & Mucositis assessed using the OMAS instrument weekly. Other reported outcomes: weight loss. \\
\hline Notes & Funding source: university.
\end{tabular}

\section{Risk of bias}

\begin{tabular}{|c|c|c|}
\hline Bias & Authors' judgement & Support for judgement \\
\hline $\begin{array}{l}\text { Random sequence genera- } \\
\text { tion (selection bias) }\end{array}$ & Unclear risk & $\begin{array}{l}\text { Quote: "randomised". } \\
\text { Comment: random component not described. }\end{array}$ \\
\hline $\begin{array}{l}\text { Allocation concealment } \\
\text { (selection bias) }\end{array}$ & Unclear risk & Insufficient information to determine 'yes' or 'no'. \\
\hline $\begin{array}{l}\text { Blinding (performance } \\
\text { bias and detection bias) } \\
\text { Carers }\end{array}$ & Unclear risk & Insufficient information to determine 'yes' or 'no'. \\
\hline $\begin{array}{l}\text { Blinding (performance } \\
\text { bias and detection bias) } \\
\text { Patients }\end{array}$ & High risk & Honey versus saline. Single blind study. \\
\hline $\begin{array}{l}\text { Blinding (performance } \\
\text { bias and detection bias) } \\
\text { Outcome assessors }\end{array}$ & Low risk & $\begin{array}{l}\text { Quote: "evaluator was blinded to the group assignments of the patients". } \\
\text { Comment: probably done. }\end{array}$ \\
\hline $\begin{array}{l}\text { Incomplete outcome data } \\
\text { (attrition bias) } \\
\text { All outcomes }\end{array}$ & Low risk & 40 patients randomised. No missing outcome data. \\
\hline $\begin{array}{l}\text { Selective reporting (re- } \\
\text { porting bias) }\end{array}$ & Unclear risk & $\begin{array}{l}\text { Data presented for mean rank of OMAS (table 1), end of week OMAS score (fig } \\
\text { 1) and change in OMAS score (fig 2) for both arms of the study. }\end{array}$ \\
\hline Other bias & Low risk & Study appears to be free from other sources of bias. \\
\hline
\end{tabular}

Nemunaitis 1995

\section{Study characteristics}

Methods Randomised, parallel group, multicentre study conducted in USA and Canada. Clear information about withdrawals: none. Unclear if dentist involved in study. Drop outs: 0\%. Duration: 1 year. 
Nemunaitis 1995 (Continued)

Participants $\quad$ Adults with mixed cancer receiving BMT, chemotherapy cyclosporine \& prednisolone. 109 patients enrolled between November 1990 and July 1993. 109 completed.

Interventions

2 groups, placebo versus RhGM-CSF (human granulocyte macrophage colony-stimulating factor) 250 $\mathrm{ug} / \mathrm{m}^{2} /$ day IV day $0-20$.

\section{Outcomes}

Mucositis scored by nurse 3 grades (categorised according to WHO criteria for analysis). Assessment used: day 28. Other reported outcomes: infection, anorexia, diarrhoea, hypertension, stomatitis. Mucositis reported on all 109 patients.

Notes Funding source: pharmaceutical.

\section{Risk of bias}

Bias Authors' judgement Support for judgement

Random sequence genera- Unclear risk tion (selection bias)

Quote: "Assignment to treatment was made via a randomisation schema prepared by Almedica Corporation (Waldwick, NJ)".

Comment: random component not described.

\begin{tabular}{ll}
\hline $\begin{array}{l}\text { Allocation concealment } \\
\text { (selection bias) }\end{array}$ & Unclear risk
\end{tabular}

Comment: unclear whether these vials were sequentially numbered.

\begin{tabular}{|c|c|c|}
\hline $\begin{array}{l}\text { Blinding (performance } \\
\text { bias and detection bias) } \\
\text { Carers }\end{array}$ & Low risk & $\begin{array}{l}\text { Quote: "The pharmacists, principal investigators, patients, support care per- } \\
\text { sonnel and sponsoring company were blinded to the study medication for the } \\
\text { entire course of the study". }\end{array}$ \\
\hline
\end{tabular}

\begin{tabular}{|c|c|c|}
\hline $\begin{array}{l}\text { Blinding (performance } \\
\text { bias and detection bias) } \\
\text { Patients }\end{array}$ & Low risk & $\begin{array}{l}\text { Quote: "The pharmacists, principal investigators, patients, support care per- } \\
\text { sonnel and sponsoring company were blinded to the study medication for the } \\
\text { entire course of the study". }\end{array}$ \\
\hline
\end{tabular}

\begin{tabular}{lll}
\hline $\begin{array}{l}\text { Blinding (performance } \\
\text { bias and detection bias) } \\
\text { Outcome assessors }\end{array}$ & Low risk & $\begin{array}{l}\text { Quote: "The pharmacists, principal investigators, patients, support care per- } \\
\text { sonnel and sponsoring company were blinded to the study medication for the } \\
\text { entire course of the study". }\end{array}$ \\
\hline $\begin{array}{l}\text { Incomplete outcome data } \\
\text { (attrition bias) } \\
\text { All outcomes }\end{array}$ & Low risk & $\begin{array}{l}109 \text { patients recruited. } 21 \text { patients withdrew }(13 / 53 \text { intervention, 8/56 place- } \\
\text { bo). Authors provide full reasons for drop outs/withdrawals. All patients in- } \\
\text { cluded in efficacy and toxicity analyses. }\end{array}$ \\
\hline $\begin{array}{l}\text { Selective reporting (re- } \\
\text { porting bias) }\end{array}$ & Unclear risk & $\begin{array}{l}\text { Data given in the text for percentage of patients with > grade } 2 \text { mucositis and } \\
\text { grade } 3 / 4 \text { mucositis. }\end{array}$ \\
\hline $\begin{array}{l}\text { Other bias } \\
\text { nigh risk }\end{array}$ & $\begin{array}{l}5 \text { patients in placebo arm also received cytokines off study during the first } 42 \\
\text { days post-transplant. }\end{array}$ \\
\hline
\end{tabular}

Nottage 2003

\section{Study characteristics}

Rethods
bo. Dentists not involved in study. Drop outs: $1.2 \%$.

Participants Adults with solid cancer treated with 5-FU. 81 enrolled 80 completed.


Nottage 2003 (Continued)

Interventions
2 groups, placebo versus sucralfate mouthwash ( $10 \mathrm{ml}$ mouthwash for 2 minutes then swallow 4 times per day).

Outcomes

Mucositis severity (patient daily diary scores). Other reported outcomes: pain eating/drinking difficulty, quality of life score, weight loss, nausea and vomiting.

Notes Funding source: unclear.

\section{Risk of bias}

\begin{tabular}{lll}
\hline Bias & Authors' judgement & Support for judgement \\
\hline $\begin{array}{l}\text { Random sequence genera- } \\
\text { tion (selection bias) }\end{array}$ & Unclear risk & $\begin{array}{l}\text { Quote: "permuted block randomisation was used to allocate patients to the } \\
\text { treatment with sucralfate suspension or placebo with identical appearance". }\end{array}$ \\
& Comment: random component not described. \\
\hline
\end{tabular}

Allocation concealment Unclear risk Insufficient information to determine 'yes' or 'no'.
(selection bias)

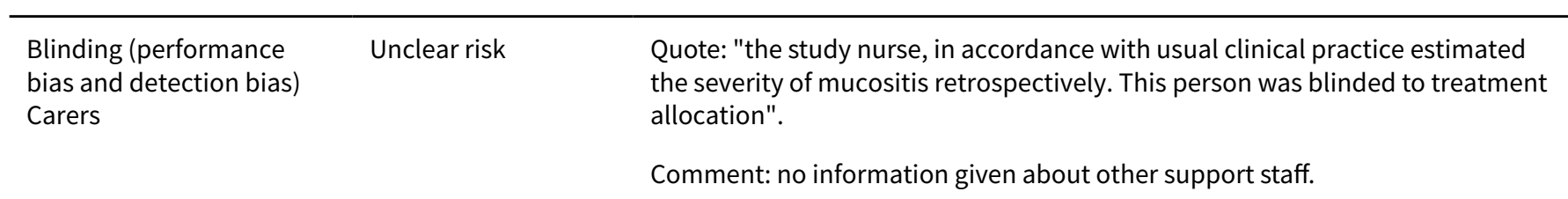

\begin{tabular}{|c|c|c|}
\hline $\begin{array}{l}\text { Blinding (performance } \\
\text { bias and detection bias) } \\
\text { Patients }\end{array}$ & Low risk & $\begin{array}{l}\text { Quote: "Investigators, treating physicians, and study subjects were all blinded } \\
\text { to study allocation". } \\
\text { Comment: probably done. }\end{array}$ \\
\hline $\begin{array}{l}\text { Blinding (performance } \\
\text { bias and detection bias) } \\
\text { Outcome assessors }\end{array}$ & Unclear risk & $\begin{array}{l}\text { Quote: "Investigators, treating physicians, and study subjects were all blinded } \\
\text { to study allocation". } \\
\text { Comment: probably done. }\end{array}$ \\
\hline
\end{tabular}

$\begin{array}{ll}\begin{array}{l}\text { Incomplete outcome data } \\ \text { (attrition bias) }\end{array} & \text { Low risk } \\ \text { All outcomes } & \begin{array}{l}81 \text { patients randomised. } 1 \text { patient was excluded from the placebo group } 1 / 40 . \\ \text { Remaining randomised patients included in outcome assessment. } 89 \text { missing } \\ \text { data days (14\%) in sucralfate group and } 63 \text { (11\%) in placebo. Method of assign- } \\ \text { ing values for missing data to give conservative outcome estimate clearly de- } \\ \text { scribed. }\end{array}\end{array}$

\begin{tabular}{|c|c|c|}
\hline $\begin{array}{l}\text { Selective reporting (re- } \\
\text { porting bias) }\end{array}$ & Unclear risk & $\begin{array}{l}81 \text { patients randomised. } 1 \text { patient was excluded from the placebo group 1/40. } \\
\text { Remaining randomised patients included in outcome assessment. } 89 \text { missing } \\
\text { data days (14\%) in sucralfate group and } 63(11 \%) \text { in placebo. Method of assign- } \\
\text { ing values for missing data to give conservative outcome estimate clearly de- } \\
\text { scribed. }\end{array}$ \\
\hline
\end{tabular}

\begin{tabular}{ll}
\hline Other bias & Unclear risk
\end{tabular}$\quad \begin{aligned} & \text { Authors suggest underreporting of mucositis by study staff due to the retro- } \\
& \text { spective method of assessment. }\end{aligned}$

\section{Oberbaum 2001}

\section{Study characteristics}


Oberbaum 2001 (Continued)

Methods

Randomised, parallel group study conducted in Israel. Clear information about withdrawals: 1/16 control, 1/16 test. Unclear if dentist involved in study. Drop outs: 6\%. Duration: unclear.

Participants

Children and adults with mixed cancer receiving a BMT. 32 consecutive patients enrolled, 30 completed.

\begin{tabular}{ll}
\hline Interventions & 2 groups, placebo versus traumeel (homeopathic) rinse vigorously 30 sec before swallowing $5 /$ day for a \\
minimum 14 days.
\end{tabular}
minimum 14 days.

Outcomes Mucositis WHO scale evaluated every 2 days. Assessment used: day 7. Other reported outcomes: sub-
jective symptom score for dry mouth, oral pain and difficulty in eating.

Notes All patients twice daily chlorhexidine, oral amphotericin B, gentle toothbrushing.

Funding source: unclear.

\section{Risk of bias}

Bias Authors' judgement Support for judgement

Random sequence genera- Unclear risk tion (selection bias)
Quote: "The randomisation code was prepared by the manufacturer (HEEL) and was revealed only on completion of the study."

Comment: random component not described.
Allocation concealment Low risk (selection bias)
Quote: "packages of Traumeel S and placebo were prepared by the HEEL company and were identified by serial number only".

Comment: adequate.

\begin{tabular}{lll}
\hline $\begin{array}{l}\text { Blinding (performance } \\
\text { bias and detection bias) } \\
\text { Carers }\end{array}$ & Unclear risk & Insufficient information to d \\
\hline $\begin{array}{l}\text { Blinding (performance } \\
\text { bias and detection bias) }\end{array}$ & Low risk & Quote: "double blind". \\
Patients & & Comment: probably done.
\end{tabular}

\begin{tabular}{ll}
\hline $\begin{array}{l}\text { Blinding (performance } \\
\text { bias and detection bias) } \\
\text { Outcome assessors }\end{array}$ & Low risk
\end{tabular}$\quad \begin{aligned} & \text { Quote: "all evaluations were performed blind by the same observer (the study } \\
& \text { nurse)". } \\
& \end{aligned}$

\begin{tabular}{|c|c|c|}
\hline $\begin{array}{l}\text { Incomplete outcome data } \\
\text { (attrition bias) } \\
\text { All outcomes }\end{array}$ & Low risk & $\begin{array}{l}32 \text { patients randomised. } 2 \text { patients ( } 1 / 15 \text { placebo and } 1 / 15 \text { traumeel } S) \text {, re- } \\
\text { ceived a single dose of study drug and then refused further treatment. Patients } \\
\text { not included in analysis. }\end{array}$ \\
\hline
\end{tabular}

\begin{tabular}{lll}
\hline $\begin{array}{l}\text { Selective reporting (re- } \\
\text { porting bias) }\end{array}$ & Unclear risk & $\begin{array}{l}\text { Data presented for individual AUC scores (table 3), and mean AUC scores for } \\
\text { each group. }\end{array}$ \\
\hline Other bias & Low risk & No other sources of bias identified. \\
\hline
\end{tabular}

\section{Okuno 1999}

\section{Study characteristics}


Okuno 1999 (Continued)

Methods

Randomised, parallel group study conducted in USA. Clear information about withdrawals: none. Dentist not involved in study. Drop outs: $0 \%$. Duration: up to 5 weeks after initial chemotherapy. Dentist involvement unclear.

\begin{tabular}{ll}
\hline Participants & $\begin{array}{l}\text { Adults with cancer (type unclear) receiving chemotherapy with 5-FU, 134 eligible, enrolled and } 134 \\
\text { evaluated by physician, but patient assessment only completed by } 124 \text { patients. }\end{array}$ \\
\hline Interventions & 2 groups, placebo versus glutamine (4 g twice a day, swish for 10 seconds, then swallow). \\
\hline Outcomes & $\begin{array}{l}\text { Maximum severity of mucositis over } 14 \text { days using 0-4 scale, both physician and patient assessment. } \\
\text { Other reported outcomes: toxicity (no detail). Assessment used: day } 14 .\end{array}$ \\
\hline Notes & $\begin{array}{l}\text { All patients used ice chips } 5 \text { minutes before 5-FU for } 30 \text { minutes. } \\
\text { Funding source: government. }\end{array}$
\end{tabular}

\section{Risk of bias}

Bias Authors' judgement Support for judgement

Random sequence genera- Unclear risk tion (selection bias)

Quote: "patients were subsequently randomised to receive $4 \mathrm{~g}$ of glutamine or an identical appearing placebo twice daily for 14 days".

Comment: random component not described.

Allocation concealment $\quad$ Unclear risk $\quad$ Insufficient information to determine 'yes' or 'no'.
(selection bias)

Blinding (performance $\quad$ Unclear risk Insufficient information to determine 'yes' or 'no'.
bias and detection bias)
Carers

\begin{tabular}{|c|c|c|}
\hline $\begin{array}{l}\text { Blinding (performance } \\
\text { bias and detection bias) }\end{array}$ & Low risk & $\begin{array}{l}\text { Quote: "double blind". } \\
\text { Comment: probably done. }\end{array}$ \\
\hline
\end{tabular}

\begin{tabular}{|c|c|c|}
\hline $\begin{array}{l}\text { Blinding (performance } \\
\text { bias and detection bias) } \\
\text { Outcome assessors }\end{array}$ & Low risk & $\begin{array}{l}\text { Quote: "double blind". } \\
\text { Comment: probably done. }\end{array}$ \\
\hline $\begin{array}{l}\text { Incomplete outcome data } \\
\text { (attrition bias) } \\
\text { All outcomes }\end{array}$ & Low risk & 134 patients randomised. No missing outcome data. \\
\hline $\begin{array}{l}\text { Selective reporting (re- } \\
\text { porting bias) }\end{array}$ & Low risk & $\begin{array}{l}\text { Physician judged mucositis scales presented for } 134 \text { patients by grade (table } \\
\text { 3). Patient judged scores presented for } 124 \text { patients (table 4). }\end{array}$ \\
\hline Other bias & High risk & $\begin{array}{l}\text { Statistically significant age difference between placebo and intervention } \\
\text { group }(P=0.01) \text {. }\end{array}$ \\
\hline
\end{tabular}

Panahi 2009

\section{Study characteristics}

$\begin{array}{ll}\text { Methods } & \text { Randomised, parallel group study conducted in Iran. Clear information on withdrawals. Unclear if den- } \\ \text { tist involved in study. Duration: } 3 \text { days. }\end{array}$


Panahi 2009 (Continued)

Participants Adults with solid tumours (colon, breast, stomach, pancreas, rectum, esophagus and other) receiving chemotherapy.

\begin{tabular}{ll}
\hline Interventions & $\begin{array}{l}2 \text { groups, placebo versus allopurinol ( } 1 \mathrm{mg} / \mathrm{ml}), \text { patients asked to swish } 20 \text { ml of mouthwash for } 30 \text { sec- } \\
\text { onds at } 1 \mathrm{hr}, 2 \text { hrs and } 3 \text { hrs after chemotherapy. }\end{array}$ \\
\hline Outcomes & $\begin{array}{l}\text { Mucositis assessed } 3 \text { times (day } 1 \text {, day } 3 \text { and day } 7 \text { ) using the WHO scale. Other reported outcome mea- } \\
\text { sures: use of dentures and education (multiple logistic regression). }\end{array}$ \\
\hline Notes & Funding source: unclear.
\end{tabular}

\section{Risk of bias}

\begin{tabular}{|c|c|c|}
\hline Bias & Authors' judgement & Support for judgement \\
\hline \multirow[t]{2}{*}{$\begin{array}{l}\text { Random sequence genera- } \\
\text { tion (selection bias) }\end{array}$} & Unclear risk & $\begin{array}{l}\text { Quote: "patients were divided randomly into two groups and received allop- } \\
\text { urinol mouthwash }(1 \mathrm{mg} / \mathrm{ml}) \text { or placebo in a double blind fashion". }\end{array}$ \\
\hline & & Comment: random component not described. \\
\hline $\begin{array}{l}\text { Allocation concealment } \\
\text { (selection bias) }\end{array}$ & Unclear risk & Insufficient information to determine 'yes' or 'no'. \\
\hline $\begin{array}{l}\text { Blinding (performance } \\
\text { bias and detection bias) } \\
\text { Carers }\end{array}$ & Unclear risk & Insufficient information to determine 'yes' or 'no'. \\
\hline $\begin{array}{l}\text { Blinding (performance } \\
\text { bias and detection bias) }\end{array}$ & Low risk & \\
\hline Patients & & Quote: probably done. \\
\hline $\begin{array}{l}\text { Blinding (performance } \\
\text { bias and detection bias) }\end{array}$ & Low risk & \\
\hline Outcome assessors & & Quote: probably done. \\
\hline $\begin{array}{l}\text { Incomplete outcome data } \\
\text { (attrition bias) } \\
\text { All outcomes }\end{array}$ & Low risk & $\begin{array}{l}33 \text { patients recruited. } 3 \text { patients excluded due to inappropriate use of the } \\
\text { mouthwash. Authors do not state which arm excluded patients were ran- } \\
\text { domised to. }\end{array}$ \\
\hline $\begin{array}{l}\text { Selective reporting (re- } \\
\text { porting bias) }\end{array}$ & Low risk & $\begin{array}{l}\text { Data presented in the text (and in figure 1) for the distribution of mucositis } \\
\text { grades by arm. }\end{array}$ \\
\hline Other bias & Low risk & Study appears to be free of other sources of bias. \\
\hline
\end{tabular}

Peterson 2009

\section{Study characteristics}

\begin{tabular}{ll}
\hline Methods & $\begin{array}{l}\text { Parallel group study. Duration } 14 \text { days treatment from the beginning of cycle } 2 \text { of chemotherapy, final } \\
\text { follow-up at day } 21+/-2 \text {. Dentist involvement - unclear. }\end{array}$ \\
\hline Participants & $\begin{array}{l}\text { Inclusion criteria: aged }>18 \text { years with colorectal cancer, undergoing chemotherapy \& having experi- } \\
\text { enced grade } 2 \text { or greater OM in cycle } 1 . \text { Patients had to have WHO grade } 0 \text { OM at study entry and ECOG } \\
\text { performance status }</=2 .\end{array}$
\end{tabular}


Exclusion: pregnancy, lactation, administration of other investigational drugs within 14 days of start of study or plans to use topical or systemic treatments for OM during study, radiotherapy to head \& neck, alcohol or drug abuse, active fungal or herpetic infection.

Number randomised 99; number completed 98.

\begin{tabular}{ll}
\hline Interventions & groups: low dose $(\mathrm{n}=33) 10 \mathrm{mg} / \mathrm{ml}$ recombinant human intestinal trefoil factor (rhITF) in aqueous \\
& solution dispensed as $3.5 \mathrm{ml}$ spray vial. Patients (all outpatients) administered 3 puffs (approx 100 \\
& ul each) to oral mucosa 8 times daily for 14 days. High dose $(n=33) 80 \mathrm{mg} / \mathrm{ml}$ rhlTF, administered as \\
& above. Placebo $(\mathrm{n}=33)$ water packaged and administered as above.
\end{tabular}

\begin{tabular}{ll}
\hline Outcomes & Incidence of grade 2 or greater OM, duration of grade 2 or greater OM. \\
\hline Notes & Funding source: the GI company (private pharma). \\
& All patients received analgesia as required but dose was low and comparable between groups. \\
\hline
\end{tabular}

\section{Risk of bias}

\section{Bias Authors' judgement Support for judgement}

Random sequence genera- Unclear risk tion (selection bias)

Quote: "eligible patients who had developed WHO grade $>2$ OM in the first cycle of chemotherapy were randomised in a 1:1:1 ratio to receive one of two doses of rhITF or a matched placebo oral spray during the second cycle of chemotherapy".

Comment: random component not described.

\begin{tabular}{lll}
\hline $\begin{array}{l}\text { Allocation concealment } \\
\text { (selection bias) }\end{array}$ & Unclear risk & Insufficient information to determine 'yes' or 'no'. \\
\hline $\begin{array}{l}\text { Blinding (performance } \\
\text { bias and detection bias) } \\
\text { Carers }\end{array}$ & Low risk & Quote: "The placebo oral sprays were manufactured by the GI company." \\
& & $\begin{array}{l}\text { Intervention was manufactured in the US and conducted in Russia. Therefore, } \\
\text { carers likely to be blinded. }\end{array}$ \\
\hline $\begin{array}{l}\text { Blinding (performance } \\
\text { bias and detection bias) }\end{array}$ & Low risk & Quote: "double blind". \\
$\begin{array}{l}\text { Patients } \\
\begin{array}{l}\text { Blinding (performance } \\
\text { bias and detection bias) } \\
\text { Outcome assessors }\end{array}\end{array}$ & Low risk & Comment: probably done. \\
\hline
\end{tabular}

$\begin{array}{ll}\begin{array}{l}\text { Incomplete outcome data } \\ \text { (attrition bias) }\end{array} & \text { Low risk } \\ \text { Alloutconts randomised. } 1 \text { patient (1/33 low dose rhITF) lost to follow-up on } \\ \text { day 21. Patient included in overall incidence of OM incidence data. }\end{array}$

All outcomes

Selective reporting (re- Low risk $\quad$ Data presented for all patients by grade and treatment arm (fig 2).
porting bias)

porting bias)

\begin{tabular}{ll}
\hline Other bias $\quad$ Low risk $\quad$ Study appears to be free of other sources of bias. \\
\hline
\end{tabular}

\section{Pfeiffer 1990}

\section{Study characteristics}


Pfeiffer 1990 (Continued)

Methods

Randomised, cross-over study conducted in Denmark. Unclear information about withdrawals. Dentist not involved in study. Drop outs: $43 \%$. Duration: 14 days.

\section{Participants}

Adults with head and neck cancer. 40 patients enrolled, 23 evaluable.

Interventions

2 groups, placebo versus sulcralfate $(1 \mathrm{~g} 15 \mathrm{ml}$ suspension, swish for $2 \mathrm{~min}$ then spit out or swallow).
Ulceration or not.

Assessment used: day 14. Other reported outcomes: pain, problems eating.

Notes

Funding source: pharmaceutical support for product.

\section{Risk of bias}

\begin{tabular}{lll}
\hline Bias $\quad$ Authors' judgement Support for judgement \\
\hline
\end{tabular}

Random sequence genera- Unclear risk tion (selection bias)

Quote: "The patients were randomly assigned to receive either sucralfate-placebo or placebo-sucralfate".

Comment: random component not described.

\begin{tabular}{|c|c|c|}
\hline $\begin{array}{l}\text { Allocation concealment } \\
\text { (selection bias) }\end{array}$ & Unclear risk & Insufficient information to determine 'yes' or 'no'. \\
\hline $\begin{array}{l}\text { Blinding (performance } \\
\text { bias and detection bias) } \\
\text { Carers }\end{array}$ & Unclear risk & Insufficient information to determine 'yes' or 'no'. \\
\hline $\begin{array}{l}\text { Blinding (performance } \\
\text { bias and detection bias) } \\
\text { Patients }\end{array}$ & Low risk & $\begin{array}{l}\text { Quote: "double blind". } \\
\text { Comment: probably done. }\end{array}$ \\
\hline $\begin{array}{l}\text { Blinding (performance } \\
\text { bias and detection bias) } \\
\text { Outcome assessors }\end{array}$ & Low risk & $\begin{array}{l}\text { Quote: "double blind. } \\
\text { Comment: probably done. }\end{array}$ \\
\hline $\begin{array}{l}\text { Incomplete outcome data } \\
\text { (attrition bias) } \\
\text { All outcomes }\end{array}$ & High risk & $\begin{array}{l}40 \text { patients randomised. Only } 23 \text { patients ( } 58 \% \text { ) included in the outcome as- } \\
\text { sessment. } 5 \text { due to change to chemotherapy regimen, } 2 \text { died, } 10 \text { not evaluable } \\
\text { due to 'swishing' ( } 7 \text { had increased nausea and } 3 \text { excluded due to poor compli- } \\
\text { ance). Authors give no information about which arms excluded patients were } \\
\text { allocated. }\end{array}$ \\
\hline $\begin{array}{l}\text { Selective reporting (re- } \\
\text { porting bias) }\end{array}$ & Unclear risk & $\begin{array}{l}\text { Data presented for numbers of patients in each treatment arm experiencing } \\
\text { erythema, edema, erosion and ulceration (table } 2 \text { ). }\end{array}$ \\
\hline Other bias & High risk & $\begin{array}{l}\text { Mode of application changed after } 18 \text { patients (next } 22 \text { patients were asked to } \\
\text { swish and expectorate the solution rather than swallowing). }\end{array}$ \\
\hline
\end{tabular}

Pillsbury 1986

\section{Study characteristics}

\begin{tabular}{ll}
\hline Methods & Randomised, parallel study conducted in USA. Clear information about withdrawals, 2/10 control, 0/10 \\
test. Dentist involved in study. Drop outs: $10 \%$. \\
Duration: until treatment was completed.
\end{tabular}


Pillsbury 1986 (Continued)

\begin{tabular}{ll} 
Participants & Adults with head and neck cancer. 20 enrolled, 18 completed. \\
\hline Interventions & 2 groups, placebo versus prostaglandin inhibitor (25 mg of indomethacin 4 times per day). \\
\hline Outcomes & Mucositis grade at day 1,2 and 3. \\
\hline Notes & Funding source: none.
\end{tabular}

\section{Risk of bias}

\begin{tabular}{lll}
\hline Bias & Authors' judgement & Support for judgement \\
\hline $\begin{array}{ll}\text { Random sequence genera- } \\
\text { tion (selection bias) }\end{array}$ & Unclear risk & $\begin{array}{l}\text { Quote: “Ten patients received indomethacin, 25 mg four times a day, where- } \\
\text { as the others received placebo during the entire course of treatment in a dou- } \\
\text { ble-blind fashion”. } \\
\text { Comment: random component not described. }\end{array}$ \\
\hline
\end{tabular}

\begin{tabular}{lll}
\hline $\begin{array}{l}\text { Allocation concealment } \\
\text { (selection bias) }\end{array}$ & Unclear risk & Insufficient information to determine 'yes' or 'no'. \\
\hline $\begin{array}{l}\text { Blinding (performance } \\
\text { bias and detection bias) } \\
\text { Carers }\end{array}$ & Unclear risk & Insufficient information to determine 'yes' or 'no'. \\
\hline
\end{tabular}

\begin{tabular}{|c|c|c|}
\hline $\begin{array}{l}\text { Blinding (performance } \\
\text { bias and detection bias) } \\
\text { Patients }\end{array}$ & Low risk & $\begin{array}{l}\text { Quote: "double blind". } \\
\text { Comment: probably done. }\end{array}$ \\
\hline
\end{tabular}

\begin{tabular}{|c|c|c|}
\hline $\begin{array}{l}\text { Blinding (performance } \\
\text { bias and detection bias) } \\
\text { Outcome assessors }\end{array}$ & Low risk & $\begin{array}{l}\text { Quote: “double blind”. } \\
\text { Comment: probably done. }\end{array}$ \\
\hline $\begin{array}{l}\text { Incomplete outcome data } \\
\text { (attrition bias) } \\
\text { All outcomes }\end{array}$ & Low risk & $\begin{array}{l}20 \text { patients recruited. } 1 \text { patient withdrew from control group. Authors give } \\
\text { complete reasons for withdrawal. In addition, } 1 \text { patient in control group was } \\
\text { excluded because they had not yet completed treatment. Mucositis data pre- } \\
\text { sented for } 18 \text { patients. }\end{array}$ \\
\hline $\begin{array}{l}\text { Selective reporting (re- } \\
\text { porting bias) }\end{array}$ & Unclear risk & Data presented for mucositis grade at days $1-3$ for 18 patients (table 1 ). \\
\hline Other bias & Low risk & Study appears to be free of other sources of bias. \\
\hline
\end{tabular}

Pitten 2003

\section{Study characteristics}

\begin{tabular}{ll}
\hline Methods & $\begin{array}{l}\text { Randomised, parallel group study conducted in Germany. Clear information about withdrawals: none. } \\
\text { Dentist involved in study. Drop outs: } 0 \% .\end{array}$ \\
\hline Participants & Adults with mixed cancer treated with chemotherapy, 47 enrolled, 47 completed. \\
\hline Interventions & $\begin{array}{l}2 \text { groups, placebo versus chlorhexidine } 100 \mathrm{ml} 0.3 \% \text { chlorhexidine, } 10.4 \mathrm{~g} \text { ethanol, } 1.67 \mathrm{~g} \text { hydrogen per- } \\
\text { oxide versus stannous fluoride. }\end{array}$ \\
\hline
\end{tabular}


Pitten 2003 (Continued)

Outcomes

Mucositis WHO grading. Other reported outcomes: systemic infection, febrile episodes, blood changes, microbial counts.

Notes

Funding source: external.

\section{Risk of bias}

\section{Bias}

Authors' judgement Support for judgement

Random sequence genera- Low risk tion (selection bias)

Quote: "the patients were assigned to one of the two treatment groups by stratified block randomisation; the blocks were selected using a set of random sampling numbers".

Comment: probably done.

\begin{tabular}{|c|c|c|}
\hline $\begin{array}{l}\text { Allocation concealment } \\
\text { (selection bias) }\end{array}$ & Low risk & $\begin{array}{l}\text { Quote: "the rinses were filled into brown glass bottles by the pharmacy of the } \\
\text { University of Greifswald, which was responsible for randomisation". }\end{array}$ \\
\hline $\begin{array}{l}\text { Blinding (performance } \\
\text { bias and detection bias) } \\
\text { Carers }\end{array}$ & Low risk & $\begin{array}{l}\text { Quote: "Neither the patient, nor the dentist knew whether the patient received } \\
\text { the chlorhexidine based product or the control medication. In addition, none } \\
\text { of the nurses, physicians, or oncologists knew the specific drug used for oral } \\
\text { rinsing". }\end{array}$ \\
\hline
\end{tabular}

Blinding (performance Low risk

bias and detection bias)

Quote: "Neither the patient, nor the dentist knew whether the patient received

Patients the chlorhexidine based product or the control medication. In addition, none of the nurses, physicians, or oncologists knew the specific drug used for oral rinsing".

\begin{tabular}{ll}
\hline $\begin{array}{l}\text { Blinding (performance } \\
\text { bias and detection bias) }\end{array}$ & $\begin{array}{l}\text { Quote: "Neither the patient, nor the dentist knew whether the patient received } \\
\text { the chlorhexidine based product or the control medication. In addition, none } \\
\text { of the nurses, physicians, or oncologists knew the specific drug used for oral } \\
\text { rinsing". }\end{array}$
\end{tabular}

Incomplete outcome data Low risk 47 patients randomised. No incomplete outcome data.

(attrition bias)

All outcomes

$\begin{aligned} & \text { Selective reporting (re- } \quad \text { Unclear risk } \\ & \text { porting bias) }\end{aligned}$

Other bias High risk Data from unplanned interim analysis.

Prada 1987

\section{Study characteristics}

\begin{tabular}{ll}
\hline Methods & $\begin{array}{l}\text { Randomised, parallel group study conducted in Italy. Unclear information about withdrawals. Dentist } \\
\text { not involved in study. Drop outs: } 10 \% \text {. Duration: } 10 \text { days. }\end{array}$ \\
\hline Participants & Adults with head and neck cancer. 40 patients eligible and enrolled, 36 evaluated. \\
\hline Interventions & $\begin{array}{l}2 \text { groups, placebo versus benzydamine }(120 \mathrm{ml} \text { solution of } 0.15 \% \text { benzydamine, } 15 \mathrm{ml} \text { mouthwash for } 5 \\
\text { mins every } 3 \text { hours up to max of } 6 \text { times daily). }\end{array}$ \\
\hline
\end{tabular}


Prada 1987 (Continued)

Outcomes
Physician evaluation of mucositis on 0 (absent) to 3 (intense or remarkable) scale every day for 10 days. Assessment used: day 10. Other reported outcomes: global clinical symptomatology, burning, chewing pain, dysphasia and odynophasia assessed.

Notes Funding source: none.

\section{Risk of bias}

\begin{tabular}{|c|c|c|}
\hline Bias & Authors' judgement & Support for judgement \\
\hline $\begin{array}{l}\text { Random sequence genera- } \\
\text { tion (selection bias) }\end{array}$ & Unclear risk & $\begin{array}{l}\text { Quote:."...according to the randomization code". } \\
\text { Comment: random component not described. }\end{array}$ \\
\hline $\begin{array}{l}\text { Allocation concealment } \\
\text { (selection bias) }\end{array}$ & Unclear risk & $\begin{array}{l}\text { Quote: "8 anonymous and indistinguishable bottles... " } \\
\text { Comment: unclear if bottles were sequentially numbered. }\end{array}$ \\
\hline $\begin{array}{l}\text { Blinding (performance } \\
\text { bias and detection bias) } \\
\text { Carers }\end{array}$ & Unclear risk & Insufficient information to determine 'yes' or 'no'. \\
\hline $\begin{array}{l}\text { Blinding (performance } \\
\text { bias and detection bias) } \\
\text { Patients }\end{array}$ & Low risk & $\begin{array}{l}\text { Quote: "double blind". } \\
\text { Comment: probably done. }\end{array}$ \\
\hline $\begin{array}{l}\text { Blinding (performance } \\
\text { bias and detection bias) } \\
\text { Outcome assessors }\end{array}$ & Low risk & $\begin{array}{l}\text { Quote: "double blind". } \\
\text { Comment: probably done. }\end{array}$ \\
\hline $\begin{array}{l}\text { Incomplete outcome data } \\
\text { (attrition bias) } \\
\text { All outcomes }\end{array}$ & Unclear risk & $\begin{array}{l}40 \text { patients randomised. } 4 \text { patients withdrew ( } 1 / 20 \text { benzydamine, } 3 / 20 \text { con- } \\
\text { trol). Authors give no reasons for withdrawal. }\end{array}$ \\
\hline $\begin{array}{l}\text { Selective reporting (re- } \\
\text { porting bias) }\end{array}$ & Unclear risk & $\begin{array}{l}\text { Data presented for onset of mucositis (probability analysis) (fig } 1 \text { ) and the } \\
\text { number of patients with mucositis in each arm (text). }\end{array}$ \\
\hline Other bias & High risk & $\begin{array}{l}\text { Not all patients had an oral mucositis score of } 0 \text { when entering the study. Dou- } \\
\text { ble blind study. However, placebo patients also received paracetamol for pain } \\
\text { control. }\end{array}$ \\
\hline
\end{tabular}

\section{Puataweepong 2009}

\section{Study characteristics}

\begin{tabular}{ll} 
Methods & $\begin{array}{l}\text { Parallel group study. Duration } 8 \text { weeks (throughout 3-4 weeks of radiotherapy and until } 8 \text { week fol- } \\
\text { low-up. Dentist involvement - unclear. }\end{array}$ \\
\hline Participants & $\begin{array}{l}\text { Inclusion criteria: stage } 2-4 \text { histologically confirmed head and neck cancer planning to undergo adju- } \\
\text { vant or definitive radiotherapy. Karnofsky performance status }>70 \% .\end{array}$ \\
& Exclusions: prior RT, history of allergy to aloe vera, underlying diabetes mellitus, HIV positive. \\
& Number randomised $61 ;$ completed 60 ; evaluated 61.
\end{tabular}


Puataweepong 2009 (Continued)

Interventions $\quad 2$ groups: $A(n=30) 15 \mathrm{ml}$ aloe vera solution 3 times daily beginning on day 1 of RT. B ( $\mathrm{n}=31) 15 \mathrm{ml}$ of placebo (identical in taste and appearance) 3 times daily beginning on day 1 of RT.

Outcomes

Onset \& incidence of severe mucositis, weight loss, number of patients \& duration of radiotherapy interruption, adverse events, requirement for analgesics, antibiotics, antifungals.

\section{Notes}

Funding source: The Thailand Research Fund.

All patients received daily supportive care including rinsing mouth with water, saline or viscous lidocaine. Analgesic drugs and antibiotics were allowed and feeding tubes were used as required.

\section{Risk of bias}

Bias Authors' judgement Support for judgement

Random sequence genera- Unclear risk

tion (selection bias)

Quote: "double blind randomised placebo controlled trial".

Quote: "Stratified block randomisation".

Comment: insufficient information to determine 'yes' or 'no'.

\begin{tabular}{ll}
\hline $\begin{array}{l}\text { Allocation concealment } \\
\text { (selection bias) }\end{array}$ & Unclear risk \\
& Comment: insufficient information to determine 'yes' or 'no'.
\end{tabular}

Blinding (performance Unclear risk Insufficient information to determine 'yes' or 'no'.

bias and detection bias)

Carers

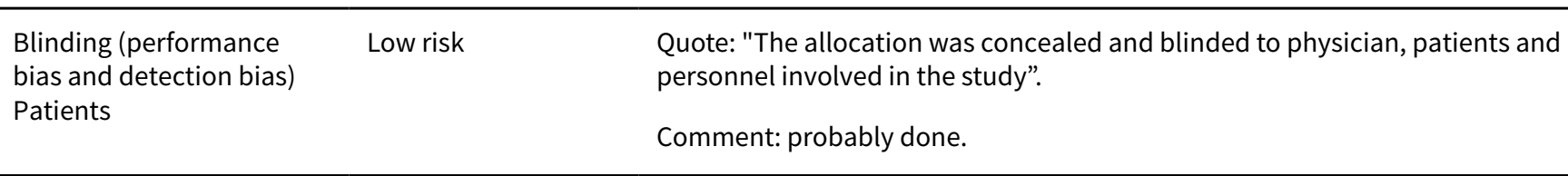

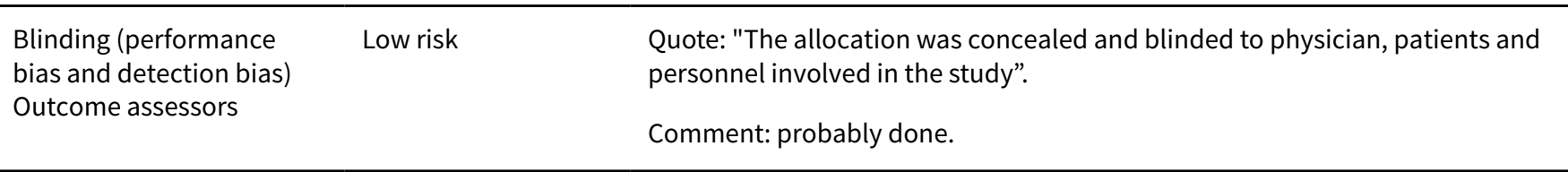

$\begin{array}{ll}\begin{array}{l}\text { Incomplete outcome data } \\ \text { (attrition bias) }\end{array} & \text { Low risk } \\ \text { Alloutconts recruited. } 1 \text { patient (1/31 placebo group) discontinued but was in- } \\ \text { cluded in mucositis data. }\end{array}$

All outcomes cluded in mucositis data.

\begin{tabular}{lll}
\hline $\begin{array}{l}\text { Selective reporting (re- } \\
\text { porting bias) }\end{array}$ & Low risk & $\begin{array}{l}\text { Data presented in percentages for mucositis incidence by grade and arm. Data } \\
\text { also presented for the incidence of severe mucositis by arm. }\end{array}$ \\
\hline Other bias & High risk & $\begin{array}{l}\text { Significant baseline imbalances between the study arms: gender }(P=0.03), \\
\text { previous smoking }(P=0.056), \text { previous surgery }(P=0.04) .\end{array}$ \\
\hline
\end{tabular}

Qin 2007

\section{Study characteristics}

$\begin{array}{ll}\text { Methods } & \text { Randomised, parallel group study conducted in China. Withdrawals: } 0 . \text { Unclear if dentist involved in } \\ \text { study, duration: duration of therapy. }\end{array}$


Qin 2007 (Continued) Participants $\begin{aligned} & \text { Adults and children aged } 16 \text { to } 70 \text { with nasogastric carcinoma receiving radiotherapy (total dose } 50-78 \\ & \text { Gy). }\end{aligned}$

\begin{tabular}{ll}
\hline Interventions & 2 groups, no treatment control versus dental stent (worn by patients during radiotherapy). \\
\hline Outcomes & Mucositis assessed using a 0-4 scale. Other reported outcome measures: weight loss, taste disruption. \\
\hline Notes & Funding source: unclear.
\end{tabular}

\section{Risk of bias}

\begin{tabular}{|c|c|c|}
\hline Bias & Authors' judgement & Support for judgement \\
\hline $\begin{array}{l}\text { Random sequence genera- } \\
\text { tion (selection bias) }\end{array}$ & Unclear risk & Comment: random component not described. \\
\hline $\begin{array}{l}\text { Allocation concealment } \\
\text { (selection bias) }\end{array}$ & Unclear risk & Insufficient information to determine 'yes' or 'no'. \\
\hline $\begin{array}{l}\text { Blinding (performance } \\
\text { bias and detection bias) } \\
\text { Carers }\end{array}$ & Unclear risk & Insufficient information to determine 'yes' or 'no'. \\
\hline $\begin{array}{l}\text { Blinding (performance } \\
\text { bias and detection bias) } \\
\text { Patients }\end{array}$ & Unclear risk & Insufficient information to determine 'yes' or 'no'. \\
\hline $\begin{array}{l}\text { Blinding (performance } \\
\text { bias and detection bias) } \\
\text { Outcome assessors }\end{array}$ & Unclear risk & Insufficient information to determine 'yes' or 'no'. \\
\hline $\begin{array}{l}\text { Incomplete outcome data } \\
\text { (attrition bias) } \\
\text { All outcomes }\end{array}$ & Low risk & 43 patients randomised. No missing outcome data. \\
\hline $\begin{array}{l}\text { Selective reporting (re- } \\
\text { porting bias) }\end{array}$ & Low risk & Data presented for all patients by grade of mucositis and arm. \\
\hline Other bias & High risk & $\begin{array}{l}\text { ROB assessed from translation. } \\
\text { Baseline imbalance: control group experienced more taste dysfunction at } \\
\text { baseline. }\end{array}$ \\
\hline
\end{tabular}

Rahn 1997

\section{Study characteristics}

\begin{tabular}{ll}
\hline Methods & $\begin{array}{l}\text { Randomised, parallel group study conducted in Germany. Clear information about withdrawals: none. } \\
\text { Dentist involvement unclear. Drop outs: } 0 \% . \text { Duration: until } 1 \text { week after end of radiotherapy. }\end{array}$ \\
\hline Participants & Adults with head and neck cancer. 40 patients eligible, enrolled. 2 died but all 40 were evaluated. \\
\hline Interventions & $\begin{array}{l}2 \text { groups, control (sterile water) versus povidone iodine rinse (rinsing for } 3 \text { mins with } 100 \mathrm{ml} \text { solution } 4 \\
\text { times daily). }\end{array}$ \\
\hline
\end{tabular}


Rahn 1997 (Continued)

Outcomes
WHO assessment of mucositis on 0-4 scale. During therapy and at 2, 6 weeks after therapy. Assessment used: day 28.

Notes

All patients received nystatin, dexpanthenol, ratoside and immunoglobin.

Funding source: unclear.

\section{Risk of bias}

\begin{tabular}{|c|c|c|}
\hline Bias & Authors' judgement & Support for judgement \\
\hline \multirow[t]{2}{*}{$\begin{array}{l}\text { Random sequence genera- } \\
\text { tion (selection bias) }\end{array}$} & Unclear risk & $\begin{array}{l}\text { Quote: " } 40 \text { patients were enrolled in the study and randomly assigned to a } \\
\text { treatment or control group". }\end{array}$ \\
\hline & & Comment: random component not described. \\
\hline $\begin{array}{l}\text { Allocation concealment } \\
\text { (selection bias) }\end{array}$ & Unclear risk & Insufficient information to determine 'yes' or 'no'. \\
\hline $\begin{array}{l}\text { Blinding (performance } \\
\text { bias and detection bias) } \\
\text { Carers }\end{array}$ & High risk & Quote: "Open, placebo controlled and randomised clinical trial". \\
\hline $\begin{array}{l}\text { Blinding (performance } \\
\text { bias and detection bias) } \\
\text { Patients }\end{array}$ & High risk & Quote: "Open, placebo controlled and randomised clinical trial". \\
\hline $\begin{array}{l}\text { Blinding (performance } \\
\text { bias and detection bias) } \\
\text { Outcome assessors }\end{array}$ & High risk & Quote: "Open, placebo controlled and randomised clinical trial". \\
\hline $\begin{array}{l}\text { Incomplete outcome data } \\
\text { (attrition bias) } \\
\text { All outcomes }\end{array}$ & Low risk & $\begin{array}{l}40 \text { patients recruited. } 37 \text { patients completed the study. Authors give incom- } \\
\text { plete reasons for attrition/exclusion. Mucositis data presented for } 40 \text { patients. }\end{array}$ \\
\hline $\begin{array}{l}\text { Selective reporting (re- } \\
\text { porting bias) }\end{array}$ & Low risk & Data presented for grades of mucositis for 40 patients (figure 3). \\
\hline Other bias & Low risk & Study appears to be free of other sources of bias. \\
\hline
\end{tabular}

Rashad 2008

\section{Study characteristics}

\begin{tabular}{ll}
\hline Methods & Randomised parallel group trial conducted in Egypt. Duration of follow-up 7 week.s \\
\hline Participants & $\begin{array}{l}\text { Adults with histologically confirmed SCCHN T1-4, N0-3, m0, KPS } \geq 50 \% .40 \text { randomised and evaluated. } \\
\text { Recruited April } 2005 \text { to July } 2006 .\end{array}$ \\
\hline Interventions & $\begin{array}{l}\text { Honey (from Trifolium Alexandrenum) versus no treatment. } 15 \text { min before, } 15 \text { min after and } 6 \text { hours af- } \\
\text { ter radiotherapy patients smeared mouth with honey, and then swallowed slowly to smear honey on } \\
\text { mucosa. }\end{array}$ \\
\hline
\end{tabular}

\begin{tabular}{ll}
\hline Outcomes & WHO mucositis grade, weekly during therapy (7 weeks) 4-week data used. \\
\hline Notes & All patients received chemoradiotherapy (60-66 Gy plus cisplatin $20 \mathrm{mg} / \mathrm{m}^{2}$ weekly) for 6-7 weeks. \\
\hline
\end{tabular}


Rashad 2008 (Continued)

Risk of bias

\begin{tabular}{lll}
\hline Bias & Authors' judgement & Support for judgement \\
\hline $\begin{array}{l}\text { Random sequence genera- } \\
\text { tion (selection bias) }\end{array}$ & $\begin{array}{l}\text { Unclear risk } \\
\text { Quote: "enrolled patients were randomised to either the treatment group, } \\
\text { to receive concomitant chemotherapy and radiotherapy plus topical appli- } \\
\text { cation of pure natural honey, or the control group, to receive concomitant } \\
\text { chemotherapy and radiotherapy without honey". }\end{array}$ \\
Comment: random component not described.
\end{tabular}

\begin{tabular}{lll}
\hline $\begin{array}{l}\text { Allocation concealment } \\
\text { (selection bias) }\end{array}$ & Unclear risk & \\
\hline $\begin{array}{l}\text { Blinding (performance } \\
\text { bias and detection bias) }\end{array}$ & High risk & Honey versus no intervention. Blinding impossible. \\
Carers & &
\end{tabular}

Blinding (performance

High risk

Honey versus no intervention. Blinding impossible.

bias and detection bias)

Patients

Blinding (performance High risk Honey versus no intervention. No apparent blinding.

bias and detection bias)

Outcome assessors

Incomplete outcome data Low risk $\quad 40$ patients randomised. No missing outcome data.
(attrition bias)

(attrition bias)

All outcomes

Selective reporting (re- Low risk $\quad$ Data presented for grade of mucositis by arm for 40 patients.
porting bias)

Other bias Unclear risk Insufficient information to determine 'yes' or 'no'.

Rocke 1993

\section{Study characteristics}

\begin{tabular}{ll}
\hline Methods & $\begin{array}{l}\text { Randomised parallel group study conducted in USA. Clear explanation of withdrawals: } 1 \text { in } 30 \text { min arm. } \\
\text { Drop outs: }<1 \% \text {. Duration: } 5 \text { days. }\end{array}$ \\
\hline Participants & Adults receiving first course of 5-FU, cancer type unclear. 179 eligible, and randomised, 178 evaluated. \\
\hline Interventions & $\begin{array}{l}2 \text { groups, } 30 \text { versus } 60 \text { minute cryotherapy. Ice chips placed in mouth } 5 \text { min before } 5 \text {-FU and then } \\
\text { swished round during treatment and replenished as ice melted. }\end{array}$ \\
\hline
\end{tabular}

Outcomes $\quad$ Physician and patient assessment of mucositis on 0-4 scale.

$\begin{array}{ll}\text { Notes } & \begin{array}{l}\text { Some cross-over data were included in paper. We have not included this as only patients with mild mu- } \\ \text { cositis crossed-over. }\end{array}\end{array}$

\begin{tabular}{ll} 
Risk of bias & Authors' judgement Support for judgement \\
\hline Bias & \\
\hline
\end{tabular}


Rocke 1993 (Continued)

Random sequence genera- Unclear risk Quote: "Patients were randomised to receive cryotherapy for either 30 or 60 tion (selection bias)

minutes".

Comment: random component not described.

Allocation concealment $\quad$ Unclear risk Insufficient information to determine 'yes' or 'no'.
(selection bias)

Blinding (performance

High risk

30 minutes versus 60 minutes of cryotherapy. Blinding impossible.

bias and detection bias)

Carers

\section{Blinding (performance \\ bias and detection bias) \\ Patients}

High risk

30 minutes versus 60 minutes of cryotherapy. Blinding impossible.

Blinding (performance $\quad$ High risk $\quad 30$ minutes versus 60 minutes of cryotherapy. No apparent blinding.
bias and detection bias)

Outcome assessors

$\begin{array}{ll}\begin{array}{l}\text { Incomplete outcome data } \\ \text { (attrition bias) }\end{array} & \text { Low risk } \\ \text { All outcomes } & \begin{array}{l}179 \text { patients recruited. } 1 \text { patient withdrawn. 1/90 30-minute cryotherapy. Au- } \\ \text { thors give reason for attrition. }\end{array}\end{array}$

All outcomes

\begin{tabular}{lll}
\hline $\begin{array}{l}\text { Selective reporting (re- } \\
\text { porting bias) }\end{array}$ & Low risk & $\begin{array}{l}\text { Physician judged mucositis scores presented for 178 patients (table 2). Patient } \\
\text { judged scores presented for 163 patients (table 3). }\end{array}$ \\
\hline Other bias & Low risk & Study appears to be free of other sources of bias. \\
\hline
\end{tabular}

\section{Rosen 2006}

\section{Study characteristics}

\begin{tabular}{ll}
\hline Methods & $\begin{array}{l}\text { Randomised, parallel group multisite study conducted in the USA and Australia. Clear information on } \\
\text { withdrawals. Unclear if dentist involved in study. }\end{array}$
\end{tabular}

Participants $\begin{aligned} & \text { Adults with tumours of the colon and rectum receiving chemotherapy or chemoradiotherapy. All pa- } \\ & \text { tients received leucovorin } 20 \mathrm{mg} / \mathrm{m}^{2} / \text { day and fluorouracil } 425 \mathrm{mg} / \mathrm{m}^{2} / \text { day for } 5 \text { consecutive days. }\end{aligned}$

\begin{tabular}{ll}
\hline Interventions & 2 groups, placebo versus palifermin $(40 \mathrm{\mu g} / \mathrm{kg})$ for 3 days before chemotherapy administration. \\
\hline Outcomes & $\begin{array}{l}\text { Mucositis assessed on days } 1,4,8,12, \text { and } 15 \text { and day } 28 \text { using the WHO score. Patients completed the } \\
\text { oral mucositis daily questionnaire daily between days } 1 \text { and } 27 . \text { Other reported outcomes: diarrhoea, } \\
\text { patient reported mouth and throat soreness, safety, laboratory assessments, disease outcomes, anti- } \\
\text { body assessments. }\end{array}$
\end{tabular}

Notes $\quad$ Funding source: pharmaceutical (Amgen).

\section{Risk of bias}

\begin{tabular}{lll}
\hline Bias & Authors' judgement & Support for judgement \\
\hline $\begin{array}{ll}\text { Random sequence genera- } \\
\text { tion (selection bias) }\end{array}$ & Unclear risk & $\begin{array}{l}\text { Quote: "patients were randomly assigned (by centre and prior chemotherapy) } \\
\text { in a 1:1 ratio to receive palifermin or placebo". }\end{array}$
\end{tabular}


Rosen 2006 (Continued)

Comment: random component not described.

\begin{tabular}{|c|c|c|}
\hline $\begin{array}{l}\text { Allocation concealment } \\
\text { (selection bias) }\end{array}$ & Unclear risk & Insufficient information to determine 'yes' or 'no'. \\
\hline $\begin{array}{l}\text { Blinding (performance } \\
\text { bias and detection bias) } \\
\text { Carers }\end{array}$ & Unclear risk & Insufficient information to determine 'yes' or 'no'. \\
\hline $\begin{array}{l}\text { Blinding (performance } \\
\text { bias and detection bias) } \\
\text { Patients }\end{array}$ & Low risk & $\begin{array}{l}\text { Quote: "double blind". } \\
\text { Comment: probably done. }\end{array}$ \\
\hline $\begin{array}{l}\text { Blinding (performance } \\
\text { bias and detection bias) } \\
\text { Outcome assessors }\end{array}$ & Low risk & $\begin{array}{l}\text { Quote: "double blind". } \\
\text { Comment: probably done. }\end{array}$ \\
\hline $\begin{array}{l}\text { Incomplete outcome data } \\
\text { (attrition bias) } \\
\text { All outcomes }\end{array}$ & Low risk & $\begin{array}{l}65 \text { patients recruited. } 64 \text { patients received study drugs. No patients discontin- } \\
\text { ued during } 1^{\text {st }} \text { cycle (data used in meta-analysis). } 10 \text { patients withdrew during } \\
2^{\text {nd }} \text { cycle of chemotherapy. } 8 / 28 \text { palifermin and } 2 / 36 \text { placebo. }\end{array}$ \\
\hline $\begin{array}{l}\text { Selective reporting (re- } \\
\text { porting bias) }\end{array}$ & Low risk & Data presented in percentages for all patients by mucositis grade (figure $2 a$ ). \\
\hline Other bias & Low risk & Study appears to be free of other sources of bias. \\
\hline
\end{tabular}

Saarilahti 2002

\section{Study characteristics}

\begin{tabular}{ll}
\hline Methods & $\begin{array}{l}\text { Randomised, parallel group study conducted in Finland. Clear information about withdrawals: none. } \\
\text { Unclear if dentist involved in study. Drop outs: } 0 \% . \text { Duration: } 10 \text { weeks. }\end{array}$ \\
\hline Participants & $\begin{array}{l}\text { Adults with head and neck cancer. } 40 \text { patients eligible, enrolled between October } \\
1999 \text { and April 2001, and evaluated. }\end{array}$ \\
\hline Interventions & $\begin{array}{l}\text { 2 groups, GM-CSF mouthwash made by dissolving } 150 \mathrm{mg} \text { of dried powder in } 100 \mathrm{ml} \text { sterile water ver- } \\
\text { sus mouthwash of } 4 \mathrm{~g} \text { sucralfate with } 100 \mathrm{ml} \text { sterile water. } 4 \text { doses x } 25 \mathrm{ml} \text { per day after meals. }\end{array}$ \\
\hline Outcomes & RTOG rating for mucositis on 0-4 scale. Author provided data in right form for the review. \\
\hline Notes & Maximum value of mucositis taken. \\
\hline
\end{tabular}

\section{Risk of bias}

\begin{tabular}{lll}
\hline Bias & Authors' judgement & Support for judgement \\
\hline $\begin{array}{l}\text { Random sequence genera- } \\
\text { tion (selection bias) }\end{array}$ & Low risk & Quote: "Randomisation was done using computer generated digits". \\
\hline $\begin{array}{l}\text { Allocation concealment } \\
\text { (selection bias) }\end{array}$ & Low risk & $\begin{array}{l}\text { Quote: "After patients provided written consent, they were assigned to a treat- } \\
\text { ment group by way of a telephone call to the randomisation office". }\end{array}$ \\
$\begin{array}{l}\text { Quote: "The drug vials were marked with a study code that prevented identifi- } \\
\text { cation of the allocation group". }\end{array}$
\end{tabular}


Saarilahti 2002 (Continued)

Comment: central method of randomisation.

\begin{tabular}{|c|c|c|}
\hline $\begin{array}{l}\text { Blinding (performance } \\
\text { bias and detection bias) }\end{array}$ & Low risk & $\begin{array}{l}\text { Comment: double blind study with adequate allocation concealment, drugs } \\
\text { prepared by pharmacy. }\end{array}$ \\
\hline
\end{tabular}

Carers

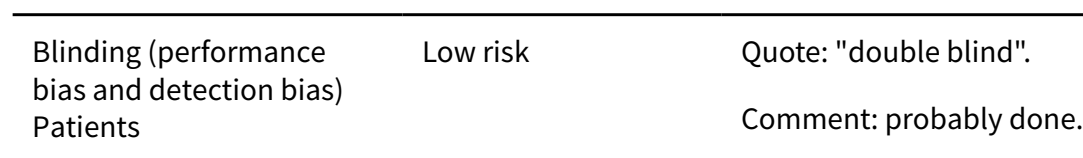

\begin{tabular}{|c|c|c|}
\hline $\begin{array}{l}\text { Blinding (performance } \\
\text { bias and detection bias) } \\
\text { Outcome assessors }\end{array}$ & Low risk & $\begin{array}{l}\text { Quote: "double blind". } \\
\text { Comment: probably done. }\end{array}$ \\
\hline $\begin{array}{l}\text { Incomplete outcome data } \\
\text { (attrition bias) } \\
\text { All outcomes }\end{array}$ & Low risk & 40 patients randomised. No missing outcome data. \\
\hline $\begin{array}{l}\text { Selective reporting (re- } \\
\text { porting bias) }\end{array}$ & Unclear risk & $\begin{array}{l}\text { Data presented for mean mucositis score over time (fig } 1 \text { ) and mean mucosal } \\
\text { pain scores (fig 2). }\end{array}$ \\
\hline Other bias & Low risk & Study appears to be free of other sources of bias. \\
\hline
\end{tabular}

Scarantino 2006

\section{Study characteristics}

\begin{tabular}{ll}
\hline Methods & $\begin{array}{l}\text { Randomised, parallel group study conducted in USA. Clear information on withdrawals: } 1 \text { in pilo- } \\
\text { carpine and } 2 \text { in placebo group refused protocol treatment. Dentist not involved in study. Drop outs: } \\
1 \% \text {. Duration: } 13 \text { weeks. }\end{array}$ \\
\hline Participants & $\begin{array}{l}\text { Adults with head and neck cancer. Planned radiotherapy to include have } 50 \% \text { of the volume of the ma- } \\
\text { jor salivary glands receive } 50 \mathrm{~Gy} .249 \text { enrolled, } 4 \text { ineligible, } 245 \text { randomised, } 242 \text { completed. }\end{array}$ \\
\hline Interventions & 2 groups, placebo versus pilocarpine 5 mg 4 times per day. \\
\hline Outcomes & $\begin{array}{l}\text { Mucositis graded } 3 \text { times per week according to the RTOG acute mucositis toxicity scale (0-4). Assess- } \\
\text { ment used: unclear. We used the highest RTOG score recoded. Other reported outcomes: sialometry of } \\
\text { unstimulated and stimulated whole saliva, eating, taste swallowing, pain, adverse events included nau- } \\
\text { sea and vomiting. }\end{array}$
\end{tabular}

Notes

Funding source: government. Pharmacological company provided drug and organised randomisation.

\section{Risk of bias}

Bias Authors' judgement Support for judgement

Random sequence genera- Unclear risk tion (selection bias)

Quote: "249 patients were randomised: 124 to receive $5 \mathrm{mg}$ of pilocarpine four times daily and 125 to receive a placebo on the same schedule".

Comment: random component not described.

Allocation concealment $\quad$ Unclear risk $\quad$ Insufficient information to determine 'yes' or 'no'.
(selection bias)

(selection bias) 
Scarantino 2006 (Continued)
Blinding (performance
Unclear risk
Insufficient information to determine 'yes' or 'no'.

bias and detection bias)

Carers

\begin{tabular}{|c|c|c|}
\hline $\begin{array}{l}\text { Blinding (performance } \\
\text { bias and detection bias) } \\
\text { Patients }\end{array}$ & Low risk & $\begin{array}{l}\text { Quote: "double blind". } \\
\text { Comment: probably done. }\end{array}$ \\
\hline $\begin{array}{l}\text { Blinding (performance } \\
\text { bias and detection bias) } \\
\text { Outcome assessors }\end{array}$ & Low risk & $\begin{array}{l}\text { Quote: "double blind". } \\
\text { Comment: probably done. }\end{array}$ \\
\hline $\begin{array}{l}\text { Incomplete outcome data } \\
\text { (attrition bias) } \\
\text { All outcomes }\end{array}$ & Low risk & $\begin{array}{l}249 \text { patients randomised. } 4 \text { patients were later deemed ineligible. A further } 3 \\
\text { patients withdrew ( } 1 / 121 \text { pilocarpine, } 2 / 124 \text { placebo). Authors give full reasons } \\
\text { for exclusions/withdrawals. }\end{array}$ \\
\hline $\begin{array}{l}\text { Selective reporting (re- } \\
\text { porting bias) }\end{array}$ & Unclear risk & Data presented for 242 patients by grade of mucositis for grades 0,1 and $2+$. \\
\hline Other bias & Unclear risk & $\begin{array}{l}\text { Baseline imbalance: more patients with a KPS of } 90-100 \text { were in the pilo- } \\
\text { carpine group }(P+0.03) \text {. However, it is unclear how this would affect mucositis } \\
\text { development. }\end{array}$ \\
\hline
\end{tabular}

\section{Scherlacher 1990}

\section{Study characteristics}

\begin{tabular}{ll}
\hline Methods & $\begin{array}{l}\text { Randomised, parallel group study conducted in Germany. Clear description of withdrawals: none. Un- } \\
\text { clear if dentist involved in study. Drop outs: 0\%. Duration 6-7 weeks. }\end{array}$ \\
\hline Participants & Adults with head and neck cancer. 45 eligible. \\
\hline Interventions & 2 groups: usual care control versus sucralfate suspension (1 g orally 4 times per day for 5 mins). \\
\hline Outcomes & Mucositis scored on 1-5 scale and number with mucositis 3-5 given. \\
\hline Notes & $\begin{array}{l}\text { Both groups received standard oral hygiene, frequent tooth cleaning and disinfection of oral and pha- } \\
\text { ryngeal mucosa. } \\
\text { Funding source: unclear. }\end{array}$
\end{tabular}

\section{Risk of bias}

\begin{tabular}{lll}
\hline Bias & Authors' judgement & Support for judgement \\
\hline $\begin{array}{l}\text { Random sequence genera- } \\
\text { tion (selection bias) }\end{array}$ & Unclear risk & Quote: "random allocation to test and control group". \\
& & Comment: random component not described. \\
\hline $\begin{array}{l}\text { Allocation concealment } \\
\text { (selection bias) }\end{array}$ & Unclear risk & Insufficient information to determine 'yes' or 'no'. \\
\hline $\begin{array}{l}\text { Blinding (performance } \\
\text { bias and detection bias) } \\
\begin{array}{l}\text { Carers } \\
\end{array}\end{array}$ & Unclear risk & Insufficient information to determine 'yes' or 'no'. \\
\hline
\end{tabular}


Scherlacher 1990 (Continued)

Blinding (performance Unclear risk Insufficient information to determine 'yes' or 'no'. bias and detection bias)

Patients

\begin{tabular}{lll}
\hline $\begin{array}{l}\text { Blinding (performance } \\
\text { bias and detection bias) } \\
\text { Outcome assessors }\end{array}$ & Unclear risk & Insufficient information to determine 'yes' or 'no'. \\
\hline $\begin{array}{l}\text { Incomplete outcome data } \\
\begin{array}{l}\text { (attrition bias) } \\
\text { All outcomes }\end{array}\end{array}$ & Unclear risk & 45 patients recruited. Outcomes given in percentages. \\
\hline $\begin{array}{l}\text { Selective reporting (re- } \\
\text { porting bias) }\end{array}$ & Unclear risk & Data presented for number of patients with mucositis grades 3-5. \\
\hline \begin{tabular}{l} 
Other bias \\
\hline
\end{tabular} & High risk & Risk of bias assessed from translation. \\
\hline
\end{tabular}

\section{Schneider 1999}

\section{Study characteristics}

Methods Randomised, parallel group study conducted in USA. Clear information about withdrawals: none. Den-
tist involved in study. Drop outs: $0 \%$.

\begin{tabular}{ll}
\hline Participants & $\begin{array}{l}\text { Adults with head and neck cancer. } 14 \text { patients enrolled and evaluated. Recruitment January } 1995 \text { to } \\
\text { April } 1996 .\end{array}$ \\
\hline Interventions & $\begin{array}{l}2 \text { groups, placebo versus filgrastim (subcutaneous injections daily throughout treatment titrated to } \\
\text { keep neutrophil count between 10x 109/l and 30x 109/l). }\end{array}$
\end{tabular}

\section{Outcomes}

WHO mucositis 0-4 scale, and Hickey mucositis scores. Proportion of patients greater than WHO mucositis grade 3 presented. Assessment used: week 10.

\begin{tabular}{|c|c|c|}
\hline Notes & \multicolumn{2}{|c|}{ All patients had oral hygiene instruction. Funding source: pharmaceutical. } \\
\hline \multicolumn{3}{|l|}{ Risk of bias } \\
\hline Bias & Authors' judgement & Support for judgement \\
\hline \multirow[t]{2}{*}{$\begin{array}{l}\text { Random sequence genera- } \\
\text { tion (selection bias) }\end{array}$} & Unclear risk & $\begin{array}{l}\text { Quote: "The patients were randomised equally between the two treatment } \\
\text { groups to receive either subcutaneous injections of filgrastim or placebo start- } \\
\text { ing concurrently with the first day of radiation and continuing daily". }\end{array}$ \\
\hline & & Comment: random component not described. \\
\hline \multirow[t]{2}{*}{$\begin{array}{l}\text { Allocation concealment } \\
\text { (selection bias) }\end{array}$} & Low risk & $\begin{array}{l}\text { Quote: "Amgen Inc. prepared and packaged all drug and placebo in identical } \\
\text { containers, with the only designator being the randomisation number. The } \\
\text { study material and randomisation list were held by the UCLA pharmacy for the } \\
\text { duration of the study". }\end{array}$ \\
\hline & & Comment: pharmacy controlled randomisation. \\
\hline $\begin{array}{l}\text { Blinding (performance } \\
\text { bias and detection bias) } \\
\text { Carers }\end{array}$ & Low risk & $\begin{array}{l}\text { Pharmacy controlled randomisation. Unlikely that carers would know alloca- } \\
\text { tions. }\end{array}$ \\
\hline
\end{tabular}


Schneider 1999 (Continued)
Blinding (performance
Low risk
Quote: "double Blind".
bias and detection bias)
Patients
Comment: probably done.

\begin{tabular}{|c|c|c|}
\hline $\begin{array}{l}\text { Blinding (performance } \\
\text { bias and detection bias) }\end{array}$ & Low risk & Quote: "double Blind". \\
\hline
\end{tabular}

\begin{tabular}{lll}
\hline $\begin{array}{l}\text { Incomplete outcome data } \\
\text { (attrition bias) } \\
\text { All outcomes }\end{array}$ & Low risk & $\begin{array}{l}\text { 14 patients randomised. } 1 \text { patient withdrew, however, results were included in } \\
\text { analysis. No missing outcome data. }\end{array}$ \\
\hline $\begin{array}{l}\text { Selective reporting (re- } \\
\text { porting bias) }\end{array}$ & Unclear risk & $\begin{array}{l}\text { Data presented for mean worst Hickey mucositis score by week (fig 1) and } \\
\text { mean worst WHO mucositis by week (fig 2) and the proportion of patients } \\
\text { whose scores remained below } 3 \text { by week (fig } 3 \text { and fig 4). }\end{array}$ \\
\hline Other bias & High risk & $\begin{array}{l}\text { Study was stopped after an interim analysis. Authors state that "owing to ad- } \\
\text { ministrative obstacles completion of the trial is not possible". Authors do not } \\
\text { meet either of their previously stated early stopping rules. }\end{array}$ \\
\hline
\end{tabular}

Schubert 2007

\begin{tabular}{ll}
\hline Study characteristics & \\
\hline Methods & $\begin{array}{l}\text { Randomised, parallel group study conducted in the USA. Clear information about withdrawals. Dura- } \\
\text { tion: 7-13 days. }\end{array}$ \\
\hline
\end{tabular}
Participants Adults (children over 12 could be recruited, however, youngest participant appears to have been 18) undergoing transplantation (both allogeneic and autologous). Conditioning: busulfan and cytoxan, TBI and cytoxan, fludarabine and busulfan, and other.

\begin{tabular}{ll}
\hline Interventions & $\begin{array}{l}3 \text { groups, sham laser versus laser }(650 \mathrm{~nm},(40 \mathrm{~mW})) \text { laser, versus laser }(780 \mathrm{~nm}(60 \mathrm{~mW})) \text {. Laser therapy } \\
\text { started on the first day of conditioning and continued for } 3 \text { days post-transplant. }\end{array}$ \\
\hline
\end{tabular}

Mucositis assessed using the oral mucositis index on days $0,4,7,11,14,18$, and 21. Other reported out-
comes: oral pain, adverse events (death).

\begin{tabular}{ll}
\hline Notes & Funding source: unclear. \\
\hline Risk of bias &
\end{tabular}

\begin{tabular}{lll}
\hline Bias & Authors' judgement & Support for judgement \\
\hline $\begin{array}{l}\text { Random sequence genera- } \\
\text { tion (selection bias) }\end{array}$ & Unclear risk & $\begin{array}{l}\text { Quote: "subjects who consented were randomised into one of two laser treat- } \\
\text { ment arms or a placebo therapy group". }\end{array}$ \\
\hline $\begin{array}{l}\text { Allocation concealment } \\
\text { (selection bias) }\end{array}$ & Unclear risk & Insufficient information to determine 'yes' or 'no'. \\
\hline $\begin{array}{l}\text { Blinding (performance } \\
\text { bias and detection bias) } \\
\text { Carers }\end{array}$ & Unclear risk & Insufficient information to determine 'yes' or 'no'. \\
\hline
\end{tabular}


Schubert 2007 (Continued) bias and detection bias)

Patients

Low risk Quote: "double blind".

Quote: "by having subjects wear both laser safety goggles and a soft cloth blindfold, it was physically impossible for them to see the tip of the laser emitting device or the control panel of the unit, thus ensuring that subjects were blinded as to whether they were receiving actual laser".

Comment: probably done.

Blinding (performance Low risk

bias and detection bias)

Outcome assessors

Quote: "double blind".

Quote: "mucositis examinations were carried out by trained and calibrated oral medicine personnel who were blind to the subjects treatment arm assignment".

Comment: probably done.

\begin{tabular}{lll}
\hline $\begin{array}{l}\text { Incomplete outcome data } \\
\text { (attrition bias) } \\
\text { All outcomes }\end{array}$ & Low risk & $\begin{array}{l}70 \text { patients randomised. } 2 \text { patients died during study. 67\% had scores for all } \\
\text { time points and a similar number in each group had missing data. Self assess- } \\
\text { ment of pain was only completed by 17/70 patients. }\end{array}$ \\
\hline $\begin{array}{l}\text { Selective reporting (re- } \\
\text { porting bias) }\end{array}$ & Unclear risk & $\begin{array}{l}\text { Data presented for mean mucositis scores over time (fig 1) and mean mucositis } \\
\text { scores by arm (table } 2) .\end{array}$ \\
\hline Other bias & High risk & $\begin{array}{l}\text { Patients in the } 650 \text { nm laser arm were significantly more likely to have received } \\
\text { a conditioning regimen which included TBl. }\end{array}$
\end{tabular}

Shenep 1988

\section{Study characteristics}

\begin{tabular}{ll}
\hline Methods & Randomised, parallel group study conducted in USA. Clear information about withdrawals: none. Den- \\
tist not involved in study. Drop outs: $0 \%$. Duration: 50 days.
\end{tabular}

\begin{tabular}{ll}
\hline Participants & $\begin{array}{l}\text { Children with leukaemia. Chemotherapy- remission induction multiagent ANLL-83. } 48 \text { patients enrolled } \\
\text { and evaluated. }\end{array}$
\end{tabular}

\begin{tabular}{ll}
\hline Interventions & 2 groups, placebo versus sucralfate $(0.75 \mathrm{mg} / \mathrm{kg}$ daily, suspension swished every 6 hours). \\
\hline Outcomes & $\begin{array}{l}\text { Mucositis (clinical and patients scales given, 0-4), gram-ve, gram+ve, fungal, all organisms. Assessment } \\
\text { used: day 50. Other reported outcomes: gastroenteritis, gingival bleeding, nutrition, fever, infection, } \\
\text { rash. }\end{array}$
\end{tabular}

\begin{tabular}{ll}
\hline Notes & Clinician's mucositis score used. \\
& Funding source: government.
\end{tabular}

\section{Risk of bias}

\begin{tabular}{lll}
\hline Bias & Authors' judgement & Support for judgement \\
\hline $\begin{array}{ll}\text { Random sequence genera- } \\
\text { tion (selection bias) }\end{array}$ & Unclear risk & $\begin{array}{l}\text { Quote: "randomisation of treatment for patients was performed by the hospi- } \\
\text { tal pharmacist according to a scheme obtained from Biostatics Division." }\end{array}$ \\
& & Comment: random component not described. \\
\hline
\end{tabular}


Shenep 1988 (Continued)

$\begin{aligned} & \text { Allocation concealment } \\ & \text { (selection bias) }\end{aligned} \quad$ Low risk Pharmacy controlled randomisation.

Blinding (performance Low risk Double blind study with adequate allocation concealment.

bias and detection bias)

Carers

\begin{tabular}{|c|c|c|}
\hline $\begin{array}{l}\text { Blinding (performance } \\
\text { bias and detection bias) } \\
\text { Patients }\end{array}$ & Low risk & $\begin{array}{l}\text { Quote: "double blind". } \\
\text { Comment: probably done. }\end{array}$ \\
\hline
\end{tabular}

\begin{tabular}{|c|c|c|}
\hline $\begin{array}{l}\text { Blinding (performance } \\
\text { bias and detection bias) }\end{array}$ & Low risk & Quote: "double blind". \\
\hline
\end{tabular}

\begin{tabular}{lll}
\hline $\begin{array}{l}\text { Incomplete outcome data } \\
\text { (attrition bias) } \\
\text { All outcomes }\end{array}$ & Low risk & \\
\hline $\begin{array}{l}\text { Selective reporting (re- } \\
\text { porting bias) }\end{array}$ & Unclear risk & $\begin{array}{l}\text { Data presented for observed mucositis and patient reports of mucositis at } \\
\text { grades } 0,1 \text { and }>2 \text { (table } 3) .\end{array}$ \\
\hline Other bias & Low risk & Study appears to be free of other sources of bias. \\
\hline
\end{tabular}

\section{Shieh 1997}

\section{Study characteristics}

\begin{tabular}{|c|c|c|}
\hline Methods & \multicolumn{2}{|c|}{$\begin{array}{l}\text { Randomised, parallel group study conducted in China. Clear information about withdrawals: none. } \\
\text { Dentist involved in study. Drop outs: } 0 \% \text {. Duration: } 5 \text { weeks. }\end{array}$} \\
\hline Participants & \multicolumn{2}{|c|}{$\begin{array}{l}\text { Adults with head and neck cancer. } 30 \text { patients were enrolled between June } 1994 \text { and May } 1995 \text { and all } \\
\text { evaluated. }\end{array}$} \\
\hline Interventions & \multicolumn{2}{|c|}{$\begin{array}{l}3 \text { groups (oral care protocols), control given no instructions, E1 given protocol to follow } 1 \text { day before } \\
\text { radiotherapy, E2 given protocol to follow } 1 \text { week before radiotherapy. Oral care protocol included in- } \\
\text { structions on how to brush teeth. Data from E1 and E2 combined as oral care intervention. }\end{array}$} \\
\hline Outcomes & \multicolumn{2}{|c|}{$\begin{array}{l}\text { Stomatitis free survival (graph). Also means and standard deviations of oral assessment guide (OAG) in- } \\
\text { dex, which includes multiple factors including voice and teeth. Assessment used: day } 28 \text {. }\end{array}$} \\
\hline Notes & \multicolumn{2}{|c|}{ Funding source: government. } \\
\hline \multicolumn{3}{|l|}{ Risk of bias } \\
\hline Bias & Authors' judgement & Support for judgement \\
\hline \multirow[t]{2}{*}{$\begin{array}{l}\text { Random sequence genera- } \\
\text { tion (selection bias) }\end{array}$} & Low risk & $\begin{array}{l}\text { Quote: "to achieve an equal number of study subjects in each group, every } \\
3 \text { consecutive entries of eligible patients over time were treated as a block } \\
\text { wherein a simple randomisation was performed". }\end{array}$ \\
\hline & & $\begin{array}{l}\text { Comment: random component not described. However, reference made to } \\
\text { randomisation article. }\end{array}$ \\
\hline
\end{tabular}


Shieh 1997 (Continued)

\begin{tabular}{lll}
$\begin{array}{l}\text { Allocation concealment } \\
\text { (selection bias) }\end{array}$ & Unclear risk & Insufficient information to determine 'yes' or 'no'. \\
\hline $\begin{array}{l}\text { Blinding (performance } \\
\text { bias and detection bias) } \\
\text { Carers }\end{array}$ & High risk & 2 different methods of oral care (E1/ E2) versus control. Blinding impossible. \\
\hline
\end{tabular}

Blinding (performance $\quad$ High risk 2 different methods of oral care (E1/ E2) versus control. Blinding impossible.
bias and detection bias)
Patients

Blinding (performance $\quad$ High risk 2 different methods of oral care (E1/ E2) versus control. No apparent blinding.
bias and detection bias)
Outcome assessors

Outcome assessors

Incomplete outcome data Low risk 30 patients randomised. No missing outcome data.

(attrition bias)

All outcomes

Selective reporting (re- Unclear risk
porting bias)

Data presented in the text for the percentage of patients with mucositis at week 2. Data also presented for onset time of stomatitis (figure 1), percentage incidence of stomatitis by treatment day (figure 2), mean OAG scores compared to days of treatment (figure 3), and increases in mean OAG score by treatment day (figure 4).

Other bias High risk
Baseline OAG score was 1.5 point higher for the $\mathrm{E} 1$ group due to random allo- cation of 3 patients with history of betel nut chewing to this group. Authors state that conclusions regarding the mean onset of mucositis did not change after these patients were excluded from the analysis. However, mean OAG scores are not provided for comparison.

Sorensen 2008

\section{Study characteristics}

\begin{tabular}{ll}
\hline Methods & $\begin{array}{l}\text { Randomised, parallel group study conducted in Denmark. Clear information about withdrawals. Un- } \\
\text { clear if dentis involved in study. Drop outs: } 8 \% .\end{array}$ \\
\hline Participants & $\begin{array}{l}\text { Adults with gastric or colorectal cancer treated with 5-FU containing chemotherapy, } 225 \text { enrolled, } 206 \\
\text { completed. }\end{array}$ \\
\hline Interventions & $\begin{array}{l}3 \text { groups, placebo (saline mouthrinse } 3 \text { times/day) versus chlorhexidine mouthrinse (3 times/day) ver- } \\
\text { sus crushed ice. }\end{array}$ \\
\hline Outcomes & $\begin{array}{l}\text { CTC v2 grading of mucositis. Assessment used: day 28. Other reported outcomes: patient reporting of } \\
\text { severity and duration of mucositis, compliance. }\end{array}$ \\
\hline Notes & Funding source: government.
\end{tabular}

\section{Risk of bias}

\begin{tabular}{lll}
\hline Bias & Authors' judgement & Support for judgement \\
\hline $\begin{array}{l}\text { Random sequence genera- } \\
\text { tion (selection bias) }\end{array}$ & Unclear risk & Quote: "randomised after informed consent to 1 of 3 prophylactic regimens". \\
\hline
\end{tabular}


Sorensen 2008 (Continued)

Comment: random component not described.

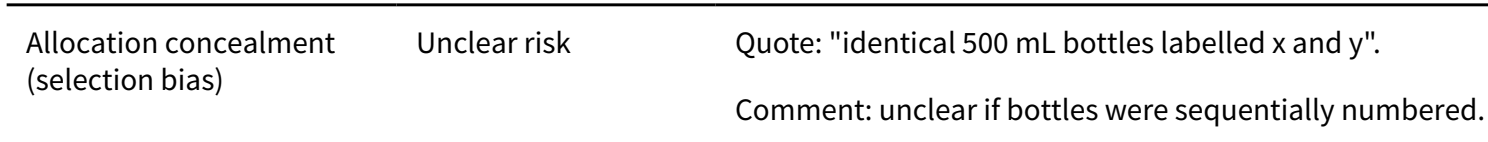

Blinding (performance
bias and detection bias) Unclear risk Insufficient information to determine 'yes' or 'no'.

Carers

\begin{tabular}{|c|c|c|}
\hline $\begin{array}{l}\text { Blinding (performance } \\
\text { bias and detection bias) } \\
\text { Patients }\end{array}$ & Low risk & $\begin{array}{l}\text { Quote: "double blind". } \\
\text { Comment: probably done. }\end{array}$ \\
\hline $\begin{array}{l}\text { Blinding (performance } \\
\text { bias and detection bias) } \\
\text { Outcome assessors }\end{array}$ & Low risk & $\begin{array}{l}\text { Quote: "double blind". } \\
\text { Comment: probably done. }\end{array}$ \\
\hline
\end{tabular}

\begin{tabular}{|c|c|c|}
\hline $\begin{array}{l}\text { Incomplete outcome data } \\
\text { (attrition bias) } \\
\text { All outcomes }\end{array}$ & Low risk & $\begin{array}{l}150 \text { patients randomised to double blind arms. } 11 \text { patients withdrew }(2 / 75 \\
\text { chlorhexidine, } 9 / 75 \text { placebo). } 139 \text { patients included in final analysis. } \\
75 \text { patients randomised to cryotherapy arm. } 8 \text { patients did not return ques- } \\
\text { tionnaire on side effects and compliance and were removed from final analy- } \\
\text { sis. } 67 \text { patients included in final analysis. }\end{array}$ \\
\hline
\end{tabular}

\begin{tabular}{lll}
$\begin{array}{l}\text { Selective reporting (re- } \\
\text { porting bias) }\end{array}$ & Low risk & Data presented for mucositis by grade and treatment arm. \\
\hline Other bias & Low risk & Study appears to be free of other sources of bias. \\
\hline
\end{tabular}

Sornsuvit 2008

\section{Study characteristics}

\begin{tabular}{ll}
\hline Methods & $\begin{array}{l}\text { Randomised, parallel group study conducted in Thailand. No withdrawals, losses to follow-up de- } \\
\text { scribed. Unclear if dentist involved in study. Duration: } 5 \text { days concurrently with each chemotherapy cy- } \\
\text { cle. Recruitment period: not stated. }\end{array}$ \\
\hline Participants & Adults with acute myeloid leukaemia. 16 patients eligible, and evaluated. \\
\hline Interventions & $\begin{array}{l}\text { 2 groups, glutamine } 30 \mathrm{~g} / \text { day IV or and equivalent quantity of standard amino acid mixture (control) } \\
\text { each day on days } 1-5 \text { of each chemotherapy cycle. }\end{array}$ \\
\hline Outcomes & Grades for mucositis on 0-4 scale, blood changes, infection, weight loss, adverse effects. \\
\hline Notes & Any mucositis, $\geq$ grade 2 mucositis, $\geq$ grade 3 mucositis.
\end{tabular}

\section{Risk of bias}

\begin{tabular}{lll}
\hline Bias & Authors' judgement & Support for judgement \\
\hline $\begin{array}{ll}\text { Random sequence genera- } \\
\text { tion (selection bias) }\end{array}$ & Unclear risk & $\begin{array}{l}\text { Quote: "randomised to receive intravenous supplementation with either } 30 \mathrm{~g} / \\
\text { day Gln or an equivalent quantity of a standard amino acid mixture". }\end{array}$ \\
& & Comment: random component not described. \\
\hline
\end{tabular}


Sornsuvit 2008 (Continued)

Allocation concealment Unclear risk Insufficient information to determine 'yes' or 'no'. (selection bias)

Blinding (performance

Unclear risk

Insufficient information to determine 'yes' or 'no'.

bias and detection bias)

Carers

Blinding (performance Unclear risk Glutamine versus standard amino acids.

bias and detection bias)

Patients

Blinding (performance Unclear risk Glutamine versus standard amino acids.

bias and detection bias)

Outcome assessors

Incomplete outcome data Low risk 16 patients randomised. No missing outcome data.

(attrition bias)

All outcomes

Selective reporting (re- Unclear risk
porting bias)

porting bias)

Data presented for mean severity grade, number of patients with mucositis $>2$ and number of patients with mucositis $>3$ (table 2 ).

Other bias Low risk Study appears to be free of other sources of bias.

Spencer 2005

\section{Study characteristics}

\begin{tabular}{|c|c|c|}
\hline Methods & \multicolumn{2}{|c|}{$\begin{array}{l}\text { Randomised, parallel group, multicentre study conducted in Australia. Clear information on with- } \\
\text { drawals: none. Unclear if dentist involved in study. Drop outs: } 0 \% \text {. Duration: up to } 46 \text { months. }\end{array}$} \\
\hline Participants & \multicolumn{2}{|c|}{$\begin{array}{l}\text { Adults blood cancer - multiple myeloma undergoing BMT high dose melphalan conditioned autolo- } \\
\text { gous stem cell transplantation (ASCT). Between May } 1999 \text { and November 2000, } 90 \text { patients were ran- } \\
\text { domised, with } 82 \text { evaluable at end of trial. }\end{array}$} \\
\hline Interventions & \multicolumn{2}{|c|}{$\begin{array}{l}2 \text { groups, no treatment control versus amifostine (patients undergoing ASCT were randomised to re- } \\
\text { ceive or not receive amifostine } 910 \mathrm{mg} / \mathrm{m}^{2} \text { prior to melphalan } 200 \mathrm{mg} / \mathrm{m}^{2} \text { ). }\end{array}$} \\
\hline Outcomes & \multicolumn{2}{|c|}{$\begin{array}{l}\text { Mucositis graded according to the adapted WHO toxicity scale. Assessment used: time unclear. Other } \\
\text { reported outcomes: parenteral nutrition, analgesic use, complete remission, adverse events included: } \\
\text { toxicity, nausea (grade 1), vomiting and hypotention. }\end{array}$} \\
\hline Notes & \multicolumn{2}{|c|}{$\begin{array}{l}\text { Funding source: industry and charity. All participants received antibacterial prophylaxis and flucona- } \\
\text { zole. Pharmacological company provided drug and organised randomisation. }\end{array}$} \\
\hline \multicolumn{3}{|l|}{ Risk of bias } \\
\hline Bias & Authors' judgement & Support for judgement \\
\hline \multirow[t]{2}{*}{$\begin{array}{l}\text { Random sequence genera- } \\
\text { tion (selection bias) }\end{array}$} & Unclear risk & $\begin{array}{l}\text { Quote: "patients were randomised to receive Mel200 with or without amifos- } \\
\text { tine } 910 \mathrm{mg} / \mathrm{m} 2 \text { pretreatment 15-30 mins prior to melphalan infusion." }\end{array}$ \\
\hline & & Comment: random component not described. \\
\hline
\end{tabular}


Spencer 2005 (Continued)

$\begin{aligned} & \text { Allocation concealment } \\ & \text { (selection bias) }\end{aligned} \quad$ Unclear risk Insufficient information to determine 'yes' or 'no'.

\begin{tabular}{lll}
$\begin{array}{l}\text { Blinding (performance } \\
\text { bias and detection bias) } \\
\text { Carers }\end{array}$ & High risk & Quote: "open label”. \\
\hline $\begin{array}{l}\text { Blinding (performance } \\
\text { bias and detection bias) }\end{array}$ & High risk & Quote: "open label". \\
Patients & & \\
\hline
\end{tabular}

Blinding (performance
bias and detection bias) High risk Quote: "open label".

Outcome assessors

$\begin{array}{ll}\begin{array}{l}\text { Incomplete outcome data } \\ \text { (attrition bias) }\end{array} & \text { Low risk } \\ \text { All outcomes } & \begin{array}{l}90 \text { patients randomised. } 82 \text { patients were evaluable at the end of the trial. Au- } \\ \text { thors do not denote which group withdrawals were from. ITT analysis per- } \\ \text { formed. }\end{array}\end{array}$

All outcomes

Selective reporting (re- Unclear risk

porting bias)

Data presented for percentage of patients with grade 0 , grades $1 / 2$ and $3 / 4$ mucositis (figure 1), median mucositis grade, median duration (table 5) and percentage of patients with no mucositis.

Other bias Low risk Study appears to be free of other sources of bias.

Spielberger 2004

\section{Study characteristics}

\begin{tabular}{ll}
\hline Methods & $\begin{array}{l}\text { Randomised, parallel group, multicentre study conducted in USA. Clear information on withdrawals: } \\
\text { none. Dentist involved in study. Drop outs: } 0 \% \text {. Duration: } 28 \text { days. }\end{array}$ \\
\hline Participants & $\begin{array}{l}\text { Adults with mixed cancer. BMT. Treated with fractionated total-body irradiation plus high-dose } \\
\text { chemotherapy and auto-HSCT. } 212 \text { enrolled, randomised and completed. }\end{array}$ \\
\hline Interventions & $\begin{array}{l}2 \text { groups, placebo versus palifermin (recombinant human keratinocyte growth factor) } 60 \text { micrograms } \\
\text { per kilogram of body weight per day iv for } 3 \text { consecutive days immediately before the initiation of con- } \\
\text { ditioning therapy. }\end{array}$ \\
\hline Outcomes & $\begin{array}{l}\text { Mucositis assessed daily using } 3 \text { scales: the WHO oral-toxicity scale (0-4) (primary scale), RTOG (0-4) } \\
\text { tium for Cancer Nursing Research (WCCNR) revised staging system for oral mucositis. Assessment used: } \\
-8 \text { up to day } 28 . \text { Other reported outcomes: soreness of the mouth and throat, swallowing limitations, } \\
\text { opioid use, incidence of febrile neutropenia, incidence of infections, incidence of the use of total par- } \\
\text { enteral nutrition. Adverse events: included rash, purities, erythema, taste alteration. }\end{array}$ \\
\hline
\end{tabular}

Notes

Funding source: industry. Pharmacological company provided drug and organised randomisation.

\section{Risk of bias}

\begin{tabular}{lll}
\hline Bias & Authors' judgement & Support for judgement \\
\hline $\begin{array}{l}\text { Random sequence genera- } \\
\text { tion (selection bias) }\end{array}$ & Unclear risk & $\begin{array}{l}\text { Quote: "Patients were randomised in a 1:1 (stratified according to centre and } \\
\text { type of hematologic cancer) to receive Palifermin or placebo". }\end{array}$
\end{tabular}


Spielberger 2004 (Continued)

Comment: random component not described.

\begin{tabular}{|c|c|c|}
\hline $\begin{array}{l}\text { Allocation concealment } \\
\text { (selection bias) }\end{array}$ & Unclear risk & Insufficient information to determine 'yes' or 'no'. \\
\hline $\begin{array}{l}\text { Blinding (performance } \\
\text { bias and detection bias) } \\
\text { Carers }\end{array}$ & Unclear risk & Insufficient information to determine 'yes' or 'no'. \\
\hline $\begin{array}{l}\text { Blinding (performance } \\
\text { bias and detection bias) } \\
\text { Patients }\end{array}$ & Low risk & $\begin{array}{l}\text { Quote: "double blind". } \\
\text { Comment: probably done. }\end{array}$ \\
\hline $\begin{array}{l}\text { Blinding (performance } \\
\text { bias and detection bias) } \\
\text { Outcome assessors }\end{array}$ & Low risk & $\begin{array}{l}\text { Quote: "double blind". } \\
\text { Comment: probably done. }\end{array}$ \\
\hline $\begin{array}{l}\text { Incomplete outcome data } \\
\text { (attrition bias) } \\
\text { All outcomes }\end{array}$ & Low risk & $\begin{array}{l}214 \text { patients randomised. } 212 \text { patients received at least } 1 \text { dose of palifermin. } 7 \\
\text { patients did not complete the study: } 2 / 106 \text { palifermin, } 4 / 106 \text { placebo. Authors } \\
\text { give no reasons for non-completion. Mucositis data given for } 212 \text { patients. }\end{array}$ \\
\hline $\begin{array}{l}\text { Selective reporting (re- } \\
\text { porting bias) }\end{array}$ & Low risk & Data presented in percentages for 212 patients by mucositis grade (figure 2 ). \\
\hline Other bias & Low risk & Study appears to be free of other sources of bias. \\
\hline
\end{tabular}

\section{Spijkervet 1989}

\section{Study characteristics}

\begin{tabular}{|c|c|c|}
\hline Methods & \multicolumn{2}{|c|}{$\begin{array}{l}\text { Randomised, parallel group study conducted in The Netherlands. Clear information about withdrawals: } \\
\text { none. Dentist involved in study. Drop outs: } 0 \% \text {. Duration: } 5 \text { weeks. }\end{array}$} \\
\hline Participants & \multicolumn{2}{|c|}{$\begin{array}{l}\text { Adults with head and neck cancer treated with radiotherapy. } 30 \text { patients eligible, enrolled and evaluat- } \\
\text { ed. }\end{array}$} \\
\hline Interventions & \multicolumn{2}{|c|}{$\begin{array}{l}2 \text { groups, placebo versus chlorhexidine spray/rinse }(0.1 \% \text { chlorhexidine } 100 \mathrm{ml} \text { per day (spray } 50 \mathrm{ml} \text { ) } \\
\text { rinsing } 3 \text { times with } 15 \mathrm{ml}) \text {. }\end{array}$} \\
\hline Outcomes & \multicolumn{2}{|c|}{$\begin{array}{l}\text { Semiquantitative scoring of mucositis in "described elsewhere". Assessed thrice weekly until end of } \\
\text { treatment (at least } 50 \mathrm{~Gy} \text { ). Assessment used: day 35. Other reported outcomes: microflora. }\end{array}$} \\
\hline Notes & \multicolumn{2}{|c|}{$\begin{array}{l}\text { Used data from text: } 24 \text { patients showed the most severe stage of pseudomembrane formation (12 in } \\
\text { placebo and } 12 \text { in test). During radiotherapy daily cleaning of teeth by hygienist. } \\
\text { Funding source: government. }\end{array}$} \\
\hline \multicolumn{3}{|l|}{ Risk of bias } \\
\hline Bias & Authors' judgement & Support for judgement \\
\hline \multirow[t]{2}{*}{$\begin{array}{l}\text { Random sequence genera- } \\
\text { tion (selection bias) }\end{array}$} & Unclear risk & $\begin{array}{l}\text { Quote: "This study was a prospective, double-blind, randomised placebo con- } \\
\text { trolled program." }\end{array}$ \\
\hline & & Comment: random component not described. \\
\hline
\end{tabular}


Spijkervet 1989 (Continued)

$\begin{aligned} & \text { Allocation concealment } \\ & \text { (selection bias) }\end{aligned}$
Unclear risk Insufficient information to determine 'yes' or 'no'.

Blinding (performance
bias and detection bias)

Carers

\begin{tabular}{|c|c|c|}
\hline $\begin{array}{l}\text { Blinding (performance } \\
\text { bias and detection bias) }\end{array}$ & Low risk & Quote: "double blind". \\
\hline
\end{tabular}

\begin{tabular}{ll}
\hline $\begin{array}{l}\text { Blinding (performance } \\
\text { bias and detection bias) } \\
\text { Outcome assessors }\end{array}$ & Quote: "double blind". \\
\hline
\end{tabular}

\begin{tabular}{lll}
\hline $\begin{array}{l}\text { Incomplete outcome data } \\
\text { (attrition bias) } \\
\text { All outcomes }\end{array}$ & Low risk & 30 patients randomised. No missing outcome data. \\
\hline $\begin{array}{l}\text { Selective reporting (re- } \\
\text { porting bias) }\end{array}$ & Unclear risk & $\begin{array}{l}\text { Data presented for number of patients with severe mucositis (pseudomem- } \\
\text { brane formation) in text. }\end{array}$ \\
\hline Other bias & Low risk & Study appears to be free of other sources of bias. \\
\hline
\end{tabular}

Stokman 2003

\section{Study characteristics}

\begin{tabular}{|c|c|c|}
\hline Methods & \multicolumn{2}{|c|}{$\begin{array}{l}\text { Randomised, parallel group study conducted in The Netherlands. Clear information on withdrawals: } \\
2 / 32 \text { placebo, } 5 / 33 \text { test. Unclear whether dentist involved in study. Drop outs: } 10.7 \% \text {. }\end{array}$} \\
\hline Participants & \multicolumn{2}{|c|}{ Adults with head and neck cancer. 65 enrolled, 58 completed. } \\
\hline Interventions & \multicolumn{2}{|c|}{$\begin{array}{l}2 \text { groups, placebo versus active lozenges (containing polymyxin } \mathrm{E} 2 \mathrm{mg} \text {, tobramycin } 1.8 \mathrm{mg} \text { and ampho- } \\
\text { tericin B } 10 \mathrm{mg}(\mathrm{PTA}) \text { ). }\end{array}$} \\
\hline Outcomes & \multicolumn{2}{|c|}{ Percentage developing mucositis (WHO 3-4). Other reported outcomes: weight loss. } \\
\hline Notes & \multicolumn{2}{|c|}{ Funding source: unclear. } \\
\hline \multicolumn{3}{|l|}{ Risk of bias } \\
\hline Bias & Authors' judgement & Support for judgement \\
\hline \multirow[t]{2}{*}{$\begin{array}{l}\text { Random sequence genera- } \\
\text { tion (selection bias) }\end{array}$} & Low risk & $\begin{array}{l}\text { Quote: "Randomisation was performed by the hospital pharmacist according } \\
\text { to a computer-generated, randomised allocation schedule". }\end{array}$ \\
\hline & & Comment: computer generated randomisation. \\
\hline $\begin{array}{l}\text { Allocation concealment } \\
\text { (selection bias) }\end{array}$ & Low risk & Pharmacy controlled randomisation. \\
\hline $\begin{array}{l}\text { Blinding (performance } \\
\text { bias and detection bias) } \\
\text { Carers }\end{array}$ & Low risk & $\begin{array}{l}\text { Adequate allocation concealment. Unlikely that carers would know of alloca- } \\
\text { tions. }\end{array}$ \\
\hline
\end{tabular}


Stokman 2003 (Continued)

Blinding (performance Low risk Quote: "Patients, clinicians, dental hygienists and microbiologists were blind bias and detection bias) for who was taking antibiotics".

Patients

$\begin{array}{ll}\begin{array}{l}\text { Blinding (performance } \\ \text { bias and detection bias) }\end{array} \quad \text { Low risk } & \begin{array}{l}\text { Quote: "Patients, clinicians, dental hygienists and microbiologists were blind } \\ \text { for who was taking antibiotics". }\end{array}\end{array}$

Outcome assessors

for who was taking antibiotics".

$\begin{array}{ll}\begin{array}{l}\text { Incomplete outcome data } \\ \text { (attrition bias) }\end{array} & \text { Low risk } \\ \text { All outcomes } & \begin{array}{l}65 \text { patients randomised. } 7 \text { patients withdrew (5/33 PTA, 2/32 placebo). ITT } \\ \text { analysis performed. }\end{array}\end{array}$

All outcomes

\begin{tabular}{|c|c|c|}
\hline $\begin{array}{l}\text { Selective reporting (re- } \\
\text { porting bias) }\end{array}$ & Unclear risk & $\begin{array}{l}\text { Data presented for mean mucositis score by weeks of radiation in a graph (fig } \\
\text { 1) and a table (table 2). Percentages of patients with grades } 3 \text { and } 4 \text { mucositis } \\
\text { presented in the text. }\end{array}$ \\
\hline
\end{tabular}

Other bias Low risk Study appears to be free of other sources of bias.

Su 2004

\section{Study characteristics}

\begin{tabular}{ll}
\hline Methods & $\begin{array}{l}\text { Randomised, parallel group study conducted in USA. Clear information about withdrawals: } 0 . \text { Unclear if } \\
\text { dentist involved in study. Drop outs: } 0 \% .\end{array}$ \\
\hline Participants & Adults with head and neck cancer. 58 enrolled, 58 completed. \\
\hline Interventions & 2 groups, placebo versus aloe vera solution (AV). 20 cc aloe vera a day during radiotherapy. \\
\hline Outcomes & Mucositis RTOG grade 3-4. Other reported outcomes: mean overall health, mean soreness score. \\
\hline Notes & Funding source: none.
\end{tabular}

\section{Risk of bias}

Bias Authors' judgement Support for judgement

Random sequence genera- Low risk tion (selection bias)

Quote: "the assignment procedure was termed "biased coin" randomization and ensures that the number of subjects assigned to aloe vera would be roughly equal to those receiving chemotherapy and those with the same primary care site."

Comment: biased coin randomisation.

\begin{tabular}{lll}
\hline $\begin{array}{l}\text { Allocation concealment } \\
\text { (selection bias) }\end{array}$ & Unclear risk & Insufficient information to determine 'yes' or 'no'. \\
\hline $\begin{array}{l}\text { Blinding (performance } \\
\text { bias and detection bias) } \\
\text { Carers }\end{array}$ & Unclear risk & Insufficient information to determine 'yes' or 'no'. \\
\hline $\begin{array}{l}\text { Blinding (performance } \\
\text { bias and detection bias) }\end{array}$ & Low risk & Quote: "double blind". \\
$\begin{array}{l}\text { Patients } \\
\text { Quote: "To minimize biases, both study physicians and patients were unaware }\end{array}$
\end{tabular}




\begin{tabular}{ll}
$\begin{array}{l}\text { Blinding (performance } \\
\text { bias and detection bias) } \\
\text { Outcome assessors }\end{array}$ & Quote: "double blind". \\
& $\begin{array}{l}\text { Quote: "To minimize biases, both study physicians and patients were unaware } \\
\text { of the results of randomisation". } \\
\text { Comment: probably done. }\end{array}$ \\
\hline
\end{tabular}

\begin{tabular}{lll}
\hline $\begin{array}{l}\text { Incomplete outcome data } \\
\text { (attrition bias) } \\
\text { All outcomes }\end{array}$ & Unclear risk & $\begin{array}{l}58 \text { patients recruited. All patients included in analysis. Mucositis data (table 2) } \\
\text { presented in percentages. }\end{array}$ \\
\hline $\begin{array}{l}\text { Selective reporting (re- } \\
\text { porting bias) }\end{array}$ & Unclear risk & $\begin{array}{l}\text { Data presented for grade 2-3 mucositis in percentages (table 2) and maximum } \\
\text { toxicity grade (table 3). }\end{array}$ \\
\hline Other bias & Low risk & Study appears to be free of other sources of bias. \\
\hline
\end{tabular}

\section{Study characteristics}

\begin{tabular}{ll}
\hline Methods & $\begin{array}{l}\text { Randomised double blind placebo controlled parallel group study conducted in USA. Dentist involve- } \\
\text { ment unclear. }\end{array}$ \\
\hline Participants & $\begin{array}{l}\text { Adults with stage 2-4 M0 SCCHN recruited January } 92 \text { to December } 96.19 \text { in G-CSF and } 22 \text { in placebo, all } \\
\text { but } 1 \text { patient in placebo group completed treatment and were evaluable. }\end{array}$ \\
\hline Interventions & $\begin{array}{l}\text { G-CSF } 3 \mu \mathrm{g} / \mathrm{kg} \text { daily SC, } 7 \text { times/week. Placebo equal volume } 5 \% \text { dextrose in water. Treatment start- } \\
\text { ed } 3 \text { days prior to radiotherapy and continued throughout. Planned dose reductions if white blood cell } \\
\text { count exceeded set limits, assessed by investigator who communicated directly with pharmacist to } \\
\text { maintain blinding. }\end{array}$ \\
\hline Outcomes & $\begin{array}{l}\text { Primary: incidence of percutaneous endoscopic gastrostomy placement. Also mucositis grade, level of } \\
\text { mucositis treatment required, overall survival, progression free survival, locoregional control. }\end{array}$ \\
\hline Notes & Funding source: NCl grant. Median duration of follow-up 7.25 years. \\
\hline
\end{tabular}

\section{Risk of bias}

\begin{tabular}{lll}
\hline Bias & Authors' judgement & Support for judgement \\
\hline $\begin{array}{l}\text { Random sequence genera- } \\
\text { tion (selection bias) }\end{array}$ & Low risk & $\begin{array}{l}\text { Quote: "Patients were randomised to either G-CSF or placebo by randomly } \\
\text { permuted blocks, after stratification by primary disease site". }\end{array}$ \\
& $\begin{array}{l}\text { Comment: random component not explicit. However, setting makes adequate } \\
\text { randomisation likely. }\end{array}$ \\
\hline $\begin{array}{l}\text { Allocation concealment } \\
\text { (selection bias) }\end{array}$ & Low risk & $\begin{array}{l}\text { Quote: "a randomization list was prepared by the Memorial Sloan-Kettering } \\
\text { Cancer centre biostatics service and held by the pharmacy. Investigators did } \\
\text { not have access to this list". }\end{array}$ \\
\hline $\begin{array}{l}\text { Blinding (performance } \\
\text { bias and detection bias) } \\
\begin{array}{l}\text { Carers } \\
\hline \hline\end{array}\end{array}$ & Low risk & $\begin{array}{l}\text { Adequate allocation concealment. Unlikely that carers would know of alloca- } \\
\text { tion. }\end{array}$ \\
\hline
\end{tabular}


Su 2006 (Continued)
Blinding (performance
Low risk
Quote: "double blind".
bias and detection bias)
Patients
Comment: probably done.

\begin{tabular}{ll}
\hline $\begin{array}{l}\text { Blinding (performance } \\
\text { bias and detection bias) } \\
\text { Outcome assessors }\end{array}$ & Low risk \\
\hline
\end{tabular}

\begin{tabular}{|c|c|c|}
\hline $\begin{array}{l}\text { Incomplete outcome data } \\
\text { (attrition bias) } \\
\text { All outcomes }\end{array}$ & Low risk & $\begin{array}{l}41 \text { patients recruited. } 1 \text { patient ( } 1 / 22 \text { placebo) withdrew. Authors do not give } \\
\text { reason for withdrawal. }\end{array}$ \\
\hline $\begin{array}{l}\text { Selective reporting (re- } \\
\text { porting bias) }\end{array}$ & Low risk & Data presented for 40 patients by grade of mucositis and arm. \\
\hline Other bias & Low risk & Study appears to be free of other sources of bias. \\
\hline
\end{tabular}

Svanberg 2007

\section{Study characteristics}

\begin{tabular}{ll}
\hline Methods & $\begin{array}{l}\text { Randomised, parallel group study conducted in Sweden. Clear information about withdrawals: 0. Den- } \\
\text { tist involved in study. Duration: during chemotherapy administration. Recruitment between January } \\
2002 \text { and August 2004. }\end{array}$ \\
\hline Participants & $\begin{array}{l}\text { Adults with a mix of testicular cancer and haematological malignancies undergoing myeloablative } \\
\text { therapy prior to bone marrow or stem cell transplantation. }\end{array}$ \\
\hline Interventions & 2 groups, no treatment versus cryotherapy. \\
\hline Outcomes & $\begin{array}{l}\text { Mucositis assessed daily using the OMAS instrument. Other reported outcome measures: blood counts, } \\
\text { c-reactive protein, compliance, adverse events. Days of intravenous opioids. }\end{array}$ \\
\hline Notes & $\begin{array}{l}\text { 45 staff members assessed mucositis using the OMAS instrument. Unclear if inter-rater reliability had } \\
\text { been conducted before starting data collection. Probably not due to the number of staff involved. }\end{array}$ \\
Funding: government.
\end{tabular}

\section{Risk of bias}

Bias Authors' judgement Support for judgement

Random sequence genera- Unclear risk tion (selection bias)
Quote: "The study was a randomised controlled trial with a random assignment to experimental (EXP) or control (CTR) group".

Comment: random component not described.

\begin{tabular}{lll}
\hline $\begin{array}{l}\text { Allocation concealment } \\
\text { (selection bias) }\end{array}$ & Unclear risk & Insufficient information to determine 'yes' or 'no'. \\
\hline $\begin{array}{l}\text { Blinding (performance } \\
\text { bias and detection bias) } \\
\text { Carers }\end{array}$ & High risk & Cryotherapy versus standard treatment. Blinding impossible. \\
\hline
\end{tabular}


Svanberg 2007 (Continued)

Patients

Blinding (performance
bias and detection bias) High risk Cryotherapy versus standard treatment. No apparent blinding.

bias and detection bias)

Outcome assessors

Incomplete outcome data $\quad$ Low risk
(attrition bias)

All outcomes

\begin{tabular}{|c|c|c|}
\hline $\begin{array}{l}\text { Selective reporting (re- } \\
\text { porting bias) }\end{array}$ & Unclear risk & $\begin{array}{l}\text { Data presented in the text for mucositis scores on day } 10 \text { (autologous pa- } \\
\text { tients), day } 16 \text { (allogeneic patients), days of mucositis. }\end{array}$ \\
\hline
\end{tabular}

\begin{tabular}{ll}
\hline Other bias $\quad$ Low risk $\quad$ Study appears to be free from other sources of bias. \\
\hline
\end{tabular}

Symonds 1996

\section{Study characteristics}

\begin{tabular}{ll}
\hline Methods & $\begin{array}{l}\text { Randomised, parallel group study conducted in Scotland. Clear information about withdrawals: 30/139 } \\
\text { control, 24/136 test. Unclear if dentist involved in study. Drop outs: 20\%. Duration: until radiation reac- } \\
\text { tion settled, } 8 \text { weeks. }\end{array}$ \\
\hline Participants & Adults with head and neck cancer. 275 patients enrolled and 221 evaluated. \\
\hline Interventions & $\begin{array}{l}2 \text { groups, placebo versus antibiotic pastille (polymyxin E } 2 \mathrm{mg}, \text { tobramycin } 1.8 \text { mg and amphotericin B } \\
10 \mathrm{mg}, 4 \text { times daily from start of radiotherapy). }\end{array}$ \\
\hline Outcomes & $\begin{array}{l}\text { Physician assessment of mucositis (none, patchy confluent). Assessment used: day } 56 . \text { Other reported } \\
\text { outcomes: patients asked about pain on swallowing and dysphagia, weight loss and compliance. }\end{array}$ \\
\hline Notes & Funding source: none.
\end{tabular}

\section{Risk of bias}

\begin{tabular}{lll}
\hline Bias & Authors' judgement & Support for judgement \\
\hline $\begin{array}{ll}\text { Random sequence genera- } \\
\text { tion (selection bias) }\end{array}$ & Unclear risk & $\begin{array}{l}\text { Quote: "Patients were randomised to receive either a placebo or active } \\
\text { pastilles containing polymyxin E } 2 \mathrm{mg}, \text { tobramycin } 1.8 \mathrm{mg} \text { and amphotericin B } \\
10 \mathrm{mg} \text {. }\end{array}$ \\
& & Comment: random component not described.
\end{tabular}

\begin{tabular}{|c|c|c|}
\hline $\begin{array}{l}\text { Allocation concealment } \\
\text { (selection bias) }\end{array}$ & Unclear risk & Insufficient information to determine 'yes' or 'no'. \\
\hline \multirow[t]{3}{*}{$\begin{array}{l}\text { Blinding (performance } \\
\text { bias and detection bias) } \\
\text { Carers }\end{array}$} & Low risk & $\begin{array}{l}\text { Quote: "The active and placebo pastilles were identical and neither the pa- } \\
\text { tients, clinicians, nurses nor microbiologists were aware who were taking an- } \\
\text { tibiotics". }\end{array}$ \\
\hline & & Quote: “double blind”. \\
\hline & & Comment: probably done. \\
\hline $\begin{array}{l}\text { Blinding (performance } \\
\text { bias and detection bias) } \\
\text { Patients }\end{array}$ & Low risk & $\begin{array}{l}\text { Quote: "The active and placebo pastilles were identical and neither the pa- } \\
\text { tients, clinicians, nurses nor microbiologists were aware who were taking an- } \\
\text { tibiotics". }\end{array}$ \\
\hline
\end{tabular}


Quote: "double blind".

Comment: probably done.

$\begin{array}{ll}\text { Blinding (performance } & \text { Low risk } \\ \begin{array}{l}\text { bias and detection bias) } \\ \text { Outcome assessors }\end{array} & \begin{array}{l}\text { Quote: "The active and placebo pastilles were identical and neither the pa- } \\ \text { tients, clinicians, nurses nor microbiologists were aware who were taking an- } \\ \text { tibiotics". }\end{array}\end{array}$

Quote: "double blind".

Comment: probably done.

Incomplete outcome data High risk (attrition bias)

All outcomes
275 patients randomised. 54 patients were unevaluable ( 24 pastilles, 30 placebo). Authors do not give full reasons for withdrawal/drop out.

\begin{tabular}{lll}
\hline $\begin{array}{l}\text { Selective reporting (re- } \\
\text { porting bias) }\end{array}$ & Unclear risk & $\begin{array}{l}\text { Data presented for erythema of mucosa for 220 patients (nil/slight/moder- } \\
\text { ate/severe), mucositis distribution for 221 patients (none/patchy/confluent) } \\
\text { and mucositis area (median/IQ range/range). }\end{array}$ \\
\hline Other bias & Low risk & Study appears to be free of other sources of bias. \\
\hline
\end{tabular}

Trotti 2004

\section{Study characteristics}

$\begin{array}{ll}\text { Methods } & \text { Randomised, parallel group, multicentre study conducted in USA, Canada, Germany, France and UK be- } \\ \text { tween July } 2000 \text { and December 2001. Clear information about withdrawals: } 0 \text {. Dentist involvement un- } \\ \text { clear. Drop outs: } 0 \% .\end{array}$

\begin{tabular}{ll}
\hline Participants & Adults with head and neck cancer receiving chemoradiotherapy. 545 enrolled, 511 results reported. \\
\hline Interventions & 3 groups, placebo plus SOC, iseganan (9 mg as 0.3\% aqueous solution) plus SOC, SOC alone. \\
\hline Outcomes & $\begin{array}{l}\text { Percentage mucositis NCI CTC grade 2-4. Other reported outcomes: completion of radiotherapy and } \\
\text { chemotherapy up to } 28 \text { days after radiotherapy. }\end{array}$ \\
\hline Notes & $\begin{array}{l}\text { Funding source: pharmaceutical. } \\
\text { Correspondence with Dr D Peterson: clinical trials with iseganan were discontinued approximately } 6 \\
\text { years ago. Approval of the drug for oral mucositis was not obtained in the United States. }\end{array}$ \\
\hline
\end{tabular}

\section{Risk of bias}

\begin{tabular}{|c|c|c|}
\hline Bias & Authors' judgement & Support for judgement \\
\hline \multirow{3}{*}{$\begin{array}{l}\text { Random sequence genera- } \\
\text { tion (selection bias) }\end{array}$} & Unclear risk & Quote: "randomised double blind". \\
\hline & & $\begin{array}{l}\text { Quote: "patients were randomised to receive } 9 \mathrm{mg} \text { doses of iseganan formulat- } \\
\text { ed as a } 0.3 \% \text { aqueous vehicle solution plus institute specific standard-of-care } \\
\text { (SOC) management of oral hygiene, or placebo (vehicle solution) plus SOC, or } \\
\text { SOC alone in a 3:2:1 distribution". }\end{array}$ \\
\hline & & Comment: random component not described. \\
\hline $\begin{array}{l}\text { Allocation concealment } \\
\text { (selection bias) }\end{array}$ & Unclear risk & $\begin{array}{l}\text { Quote: "all study drugs were packaged in identical multidose, white, opaque } \\
\text { plastic bottles". }\end{array}$ \\
\hline
\end{tabular}


Trotti 2004 (Continued)

Blinding (performance Unclear risk Insufficient information to determine 'yes' or 'no'.

bias and detection bias)

Carers

\begin{tabular}{|c|c|c|}
\hline $\begin{array}{l}\text { Blinding (performance } \\
\text { bias and detection bias) } \\
\text { Patients }\end{array}$ & Low risk & $\begin{array}{l}\text { Quote: "double blind". } \\
\text { Quote: "Patients, study personnel, and the sponsor were blinded as to whether } \\
\text { an individual received iseganan or placebo". } \\
\text { Comment: probably done. }\end{array}$ \\
\hline $\begin{array}{l}\text { Blinding (performance } \\
\text { bias and detection bias) } \\
\text { Outcome assessors }\end{array}$ & Low risk & $\begin{array}{l}\text { Quote: "double blind". } \\
\text { Quote: "Patients, study personnel, and the sponsor were blinded as to whether } \\
\text { an individual received iseganan or placebo". } \\
\text { Comment: probably done. }\end{array}$ \\
\hline $\begin{array}{l}\text { Incomplete outcome data } \\
\text { (attrition bias) } \\
\text { All outcomes }\end{array}$ & Low risk & $\begin{array}{l}545 \text { patients randomised. } 27 \text { patients were potentially affected by randomi- } \\
\text { sation error and were subsequently excluded from the efficacy analysis. } 7 \text { pa- } \\
\text { tients additionally excluded because they did not receive the study drug/base- } \\
\text { line assessment. Authors do not state which arms patients were randomised } \\
\text { to. }\end{array}$ \\
\hline
\end{tabular}

\begin{tabular}{lll}
\hline $\begin{array}{l}\text { Selective reporting (re- } \\
\text { porting bias) }\end{array}$ & Unclear risk & $\begin{array}{l}\text { Data presented for mucositis grades 0/1, 2 and 3/4 in percentages, mean peak } \\
\text { severity of OM, and average OM. }\end{array}$ \\
\hline Other bias & Low risk & Study appears to be free of other sources of bias. \\
\hline
\end{tabular}

Tu 1998

\section{Study characteristics}

\begin{tabular}{ll}
\hline Methods & $\begin{array}{l}\text { Randomised, parallel group multisite study conducted in China. Unclear if dentist involved in study. } \\
\text { Drop outs: } 0 \% \text {. Duration: } 4 \text { to } 6 \text { weeks. }\end{array}$ \\
\hline Participants & Data presented for 159 patients with mixed cancers receiving radiotherapy. \\
\hline Interventions & $\begin{array}{l}2 \text { groups, placebo group (intramuscular injection of lactose liquid) versus copper zinc super oxide dis- } \\
\text { mutase (SOD) (40000 units by intramuscular injection). Both groups received } 1 \text { injection a day, } 5 \text { days } \\
\text { per week. }\end{array}$ \\
\hline Outcomes & $\begin{array}{l}\text { Oral mucositis graded as slight, moderate and severe. Other outcome measures: skin pelvic visceral } \\
\text { and systemic adverse events. }\end{array}$ \\
\hline Notes & Funding source: unclear. \\
\hline
\end{tabular}

\section{Risk of bias}

\begin{tabular}{lll}
\hline Bias & Authors' judgement & Support for judgement \\
\hline $\begin{array}{l}\text { Random sequence genera- } \\
\text { tion (selection bias) }\end{array}$ & Unclear risk & Comment: random component not described. \\
\hline $\begin{array}{l}\text { Allocation concealment } \\
\text { (selection bias) }\end{array}$ & Unclear risk & Insufficient information to determine 'yes' or 'no'. \\
\hline
\end{tabular}


Tu 1998 (Continued)
Blinding (performance
Unclear risk
Insufficient information to determine 'yes' or 'no'.
bias and detection bias)

Carers

\begin{tabular}{|c|c|c|}
\hline $\begin{array}{l}\text { Blinding (performance } \\
\text { bias and detection bias) } \\
\text { Patients }\end{array}$ & Low risk & $\begin{array}{l}\text { Quote: "double blind". } \\
\text { Comment: probably done. }\end{array}$ \\
\hline $\begin{array}{l}\text { Blinding (performance } \\
\text { bias and detection bias) } \\
\text { Outcome assessors }\end{array}$ & Low risk & $\begin{array}{l}\text { Quote: "double blind". } \\
\text { Comment: probably done. }\end{array}$ \\
\hline $\begin{array}{l}\text { Incomplete outcome data } \\
\text { (attrition bias) } \\
\text { All outcomes }\end{array}$ & Low risk & 159 patients randomised. No missing outcome data. \\
\hline $\begin{array}{l}\text { Selective reporting (re- } \\
\text { porting bias) }\end{array}$ & Unclear risk & Data presented for mild and moderate to severe mucositis. \\
\hline Other bias & High risk & ROB assessed from translation. \\
\hline
\end{tabular}

\section{Vacha 2003}

\section{Study characteristics}

\begin{tabular}{ll}
\hline Methods & $\begin{array}{l}\text { Randomised, parallel group study conducted in Germany. Clear information on withdrawals. Unclear if } \\
\text { dentist involved in study. Duration: during radiotherapy. }\end{array}$ \\
\hline Participants & $\begin{array}{l}\text { Adults with cancers of the larynx, oropharynx and hypopharynx receiving radiotherapy (60 Gy /70 Gy) } \\
\text { and chemotherapy }\left(70 \mathrm{mg} / \mathrm{m}^{2}\right) .\end{array}$ \\
\hline Interventions & $\begin{array}{l}2 \text { groups, no treatment versus amifostine (250 mg). Amifostine given over short infusion (10-15 min- } \\
\text { utes). }\end{array}$ \\
\hline Outcomes & $\begin{array}{l}\text { Mucositis assessed weekly using the CTC criteria. Other reported outcome measures: xerostomia, skin } \\
\text { toxicity, body weight, performance status. }\end{array}$ \\
\hline Notes & Funding source: unclear.
\end{tabular}

\section{Risk of bias}

\begin{tabular}{lll}
\hline Bias & Authors' judgement & Support for judgement \\
\hline $\begin{array}{l}\text { Random sequence genera- } \\
\text { tion (selection bias) }\end{array}$ & Unclear risk & $\begin{array}{l}\text { Quote: "randomised". } \\
\text { Comment: random component not described. }\end{array}$ \\
\hline $\begin{array}{l}\text { Allocation concealment } \\
\text { (selection bias) }\end{array}$ & Unclear risk & Insufficient information to determine 'yes' or 'no'. \\
\hline $\begin{array}{l}\text { Blinding (performance } \\
\text { bias and detection bias) }\end{array}$ & High risk & $\begin{array}{l}\text { Chemotherapy and radiotherapy with or without amifostine. No apparent } \\
\text { Carers }\end{array}$ \\
\hline $\begin{array}{l}\text { Blinding (performance } \\
\text { bias and detection bias) }\end{array}$ & High risk & $\begin{array}{l}\text { Chemotherapy and radiotherapy with or without amifostine. No apparent } \\
\text { blinding. }\end{array}$ \\
\hline
\end{tabular}


Vacha 2003 (Continued)

Patients

\begin{tabular}{|c|c|c|}
\hline $\begin{array}{l}\text { Blinding (performance } \\
\text { bias and detection bias) }\end{array}$ & High risk & $\begin{array}{l}\text { Chemotherapy and radiotherapy with or without amifostine. No apparent } \\
\text { blinding. }\end{array}$ \\
\hline
\end{tabular}

Outcome assessors

$\begin{array}{ll}\text { Incomplete outcome data } & \text { Low risk } \\ \text { (attrition bias) } & 56 \text { patients randomised. } 6 \text { patients excluded. Authors do not state which arm } \\ \text { All outcomes } & \text { these patients were randomised to but do give full reasons for exclusion. }\end{array}$

All outcomes

\begin{tabular}{|c|c|c|}
\hline $\begin{array}{l}\text { Selective reporting (re- } \\
\text { porting bias) }\end{array}$ & Unclear risk & $\begin{array}{l}\text { Data presented for mean mucositis scores by week of treatment for both arms } \\
\text { of the study. }\end{array}$ \\
\hline
\end{tabular}

\begin{tabular}{ll}
\hline Other bias $\quad$ Low risk $\quad$ Study appears to be free from other sources of bias. \\
\hline
\end{tabular}

Vadhan-Raj 2010

\title{
Study characteristics
}

\begin{tabular}{ll}
\hline Methods & Parallel group study, but 2 very different randomisation schedules used within this study. Duration: \\
planned to be 6 cycles of chemotherapy but results reported based on 2 "blinded cycles" only. Dentist \\
involvement: unclear.
\end{tabular}
involvement: unclear.

\begin{abstract}
Participants
Inclusion criteria: patients with sarcoma who were planned to undergo multicycle chemotherapy aged 15-65 years with Karnofsky performance status $>/=80 \%$ \& adequate bone marrow, hepatic and renal function.

Exclusion criteria: patients with history of pelvic radiation or clinically significant cardiac disease or those who had undergone surgery in previous 2 weeks were excluded.

Number randomised 48. Number completed (6 cycles) 25.

Interventions
16) placebo single dose IV 3 days prior to chemotherapy.
\end{abstract}

Outcomes Moderate to severe, severe mucositis according to WHO grades, adverse effects.

$\begin{array}{ll}\text { Notes } & \text { Funding source: Amgen provided the palifermin and placebo, provided a grant to partially fund the } \\ \text { study, and the principal investigator is a member of the Amgen board. }\end{array}$

\section{Risk of bias}

Bias Authors' judgement Support for judgement

Random sequence genera- Unclear risk tion (selection bias)

\begin{abstract}
Quote: "Two distinct computer-generated randomization lists were prepared by the Dept of Biostatistics, University of Texas MD Anderson Cancer Centre, one for the 20 patients who consented to pharmacokinetic sampling and the other for the 28 patients who did not. For the pharmacokinetics cohort the treatment allocation ratio was 4:1 palifermin:placebo in 4 blocks of 5; for the other cohort the ratio was 4:3 palifermin to placebo in 2 blocks of $14 . "$

Comment: the clinical research team would have known that $4 / 5$ of the pharmacokinetic group were receiving active treatment.

Comment: random component not described.
\end{abstract}


Vadhan-Raj 2010 (Continued)

Allocation concealment Low risk Both randomisation lists were held by the pharmacy who assigned the patient (selection bias) to the next sequential slot and treatment on the basis of whether or not there was consent for pharmacokinetic sampling.

Blinding (performance High risk bias and detection bias) Carers
Quote: "the patient and the clinical research team (who assessed outcomes) were blinded to the study treatment".

Comment: however paper states that "blinding might not have been maintained due to the adverse effects of palifermin (pronounced leukoedema of buccal mucosa \& gingival)", and describes cycles $1 \& 2$ as 'blinded cycles'. Preand post-administration biopsies in ' 8 consenting patients' would have also revealed who was allocated to active treatment. Those patients consenting to the pharmacokinetic study had a 4/5 chance of receiving active treatment.

Comment: we consider it likely that none of the treatment cycles were truly blinded.

\section{Blinding (performance Unclear risk} bias and detection bias) Patients
Quote: "the patient and the clinical research team (who assessed outcomes) were blinded to the study treatment".

Comment: however paper states that "blinding might not have been maintained due to the adverse effects of palifermin (pronounced leukoedema of buccal mucosa \& gingival)", and describes cycles $1 \& 2$ as 'blinded cycles'. Preand post-administration biopsies in ' 8 consenting patients' would have also revealed who was allocated to active treatment. Those patients consenting to the pharmacokinetic study had a $4 / 5$ chance of receiving active treatment.

Comment: we consider it likely that none of the treatment cycles were truly blinded.

\section{Blinding (performance High risk} bias and detection bias) Outcome assessors
Quote: "the patient and the clinical research team (who assessed outcomes) were blinded to the study treatment".

Comment: however paper states that "blinding might not have been maintained due to the adverse effects of palifermin (pronounced leukoedema of buccal mucosa \& gingival)", and describes cycles $1 \& 2$ as 'blinded cycles'. Preand post-administration biopsies in ' 8 consenting patients' would have also revealed who was allocated to active treatment. Those patients consenting to the pharmacokinetic study had a 4/5 chance of receiving active treatment.

Comment: we consider it likely that none of the treatment cycles were truly blinded.

\section{Incomplete outcome data Unclear risk} (attrition bias)

All outcomes
$12 / 32(38 \%)$ and $12 / 16(75 \%)$ patients in the palifermin and placebo groups respectively discontinued treatment. Some reasons are given. The reported rates of disease progression, chemotoxicity \& surgery are similar in each group, but the rate of switching to open label treatment is much higher in placebo group and there is some mismatch between information in figures 1 \& 3.

Outcomes are reported as percentages only, and for the 'blinded cycles' 1 \& 2 the numbers evaluated in each group are unclear

Selective reporting (re- Unclear risk porting bias)
Reported outcomes of moderate/severe \& severe mucositis. However all reported outcomes are expressed as percentages together with a statement that "all patients were evaluable for toxicity and response to palifermin".

Planned outcomes also included duration of oral mucositis, patient reported outcomes, use of narcotic analgesics, weight loss \& dose reductions/delays in chemotherapy. These outcomes are not reported in the paper. 
Vadhan-Raj 2010 (Continued)

Other bias Unclear risk Use of granulocyte macrophage colony-stimulating factor is listed as not permitted, but patients received Pegfilgrastim which is a pegylated form of human granulocyte colony-stimulating factor.

van der Lelie 2001

\section{Study characteristics}

\begin{tabular}{ll}
\hline Methods & $\begin{array}{l}\text { Randomised, parallel group study conducted in The Netherlands. Clear information about withdrawals: } \\
\text { none. Dentist involved in study. Drop outs: 0\%. Duration: until neutrophil recovery. }\end{array}$ \\
\hline Participants & $\begin{array}{l}\text { Adults with mixed cancer receiving BMT or cell stem. } 39 \text { patients eligible, } 36 \text { enrolled between May } 1997 \\
\text { and August 1999, all evaluated. }\end{array}$ \\
\hline Interventions & $\begin{array}{l}2 \text { groups, placebo versus GM-CSF (300 ug of GM-CSF daily dose in } 2 \% \text { methylocellulose gel, } 5 \mathrm{ml} \text { gel } \\
\text { twice daily, keep in oral cavity as long as possible then swallow). }\end{array}$ \\
\hline Outcomes & $\begin{array}{l}\text { WHO mucositis scale 0-4. Assessment used: day 14. Other reported outcomes: VAS mucositis pain, OAS } \\
\text { mucositis, required morphine or not, fever, infection treated with antibiotics, duration of netropenia, } \\
\text { days in hospital. }\end{array}$
\end{tabular}

Notes All rinsed with $0.9 \%$ saline and in case of inflamation $0.12 \%$ chlorhexidine 6 times daily. Funding source: university, pharmaceutical for intervention.

\section{Risk of bias}

\begin{tabular}{|c|c|c|}
\hline Bias & Authors' judgement & Support for judgement \\
\hline $\begin{array}{l}\text { Random sequence genera- } \\
\text { tion (selection bias) }\end{array}$ & Unclear risk & $\begin{array}{l}\text { Quote: "After giving their informed consent, the patients were randomised to } \\
\text { receive GM-CSF or placebo". } \\
\text { Comment: random component not described. }\end{array}$ \\
\hline $\begin{array}{l}\text { Allocation concealment } \\
\text { (selection bias) }\end{array}$ & Unclear risk & Insufficient information to determine 'yes' or 'no'. \\
\hline $\begin{array}{l}\text { Blinding (performance } \\
\text { bias and detection bias) } \\
\text { Carers }\end{array}$ & Unclear risk & Insufficient information to determine 'yes' or 'no'. \\
\hline $\begin{array}{l}\text { Blinding (performance } \\
\text { bias and detection bias) } \\
\text { Patients }\end{array}$ & Low risk & $\begin{array}{l}\text { Quote: "double blind". } \\
\text { Comment: probably done. }\end{array}$ \\
\hline $\begin{array}{l}\text { Blinding (performance } \\
\text { bias and detection bias) } \\
\text { Outcome assessors }\end{array}$ & Low risk & $\begin{array}{l}\text { Quote: "double blind". } \\
\text { Comment: probably done. }\end{array}$ \\
\hline $\begin{array}{l}\text { Incomplete outcome data } \\
\text { (attrition bias) } \\
\text { All outcomes }\end{array}$ & Low risk & $\begin{array}{l}36 \text { patients randomised. } 8 \text { patients withdrew. } 4 / 18 \mathrm{GM}-\mathrm{CSF}, 4 / 18 \text { placebo. Au- } \\
\text { thors give full reasons for attrition/ exclusion. }\end{array}$ \\
\hline $\begin{array}{l}\text { Selective reporting (re- } \\
\text { porting bias) }\end{array}$ & Unclear risk & $\begin{array}{l}\text { Data presented for average WHO score, OAS and pains scores by days for both } \\
\text { intervention and placebo group. Number of patients with grade } 3 \text { and grade } 4 \\
\text { mucositis presented in text. }\end{array}$ \\
\hline
\end{tabular}


van der Lelie 2001 (Continued)

Other bias Low risk Study appears to be free of other sources of bias.

Veerasarn 2006

\section{Study characteristics}

\begin{tabular}{ll}
\hline Methods & $\begin{array}{l}\text { Randomised, parallel group, multicentre study conducted in Thailand. Clear information on with- } \\
\text { drawals: none. Unclear if dentist involved in study. Drop outs: } 7 \% \text {. Duration: up to } 90 \text { days. }\end{array}$ \\
\hline Participants & $\begin{array}{l}\text { Adults with head and neck cancer. } 67 \text { enrolled and randomised between February } 1999 \text { and September } \\
2001.62 \text { completed. }\end{array}$ \\
\hline Interventions & $\begin{array}{l}2 \text { groups, no amifostine control versus intravenous amifostine with radiotherapy }\left(200 \mathrm{mg} / \mathrm{m}^{2} 50 \mathrm{ml} \text { in- }\right. \\
\text { fusion daily } 30 \text { minutes prior to radiation treatment) (radiotherapy: } 66-70 \mathrm{~Gy} \text { or postoperative } 50-60 \mathrm{~Gy} \\
\text { both in } 2 \text { Gy fractions). }\end{array}$
\end{tabular}

\begin{tabular}{ll}
\hline Outcomes & $\begin{array}{l}\text { Mucositis graded with reference to RTOG criteria on a 0-4 scale. Assessed at 1-6 weeks during treat- } \\
\text { ment, } 4 \text { week data used for mucositis } \geq 2 .\end{array}$ \\
& $\begin{array}{l}\text { Other reported outcomes: xerostomia, dysphasia; treatment related adverse events: vomiting, nausea, } \\
\text { allergic reaction, haematologic, hypotension, hot flushes, somnolence, sneezing, hiccup. }\end{array}$ \\
\hline Notes & Funding source: pharmaceutical company.
\end{tabular}

\section{Risk of bias}

Bias Authors' judgement Support for judgement

Random sequence genera- Unclear risk tion (selection bias)
Quote: "...were randomised to receive radiotherapy or radiotherapy plus amifostine".

Comment: random component not described.

Allocation concealment $\quad$ Unclear risk $\quad$ Insufficient information to determine 'yes' or 'no'.
(selection bias)

High risk Quote: "open label".

Blinding (performance

bias and detection bias)

Carers

\begin{tabular}{|c|c|c|}
\hline $\begin{array}{l}\text { Blinding (performance } \\
\text { bias and detection bias) } \\
\text { Patients }\end{array}$ & High risk & Quote: "open label". \\
\hline $\begin{array}{l}\text { Blinding (performance } \\
\text { bias and detection bias) } \\
\text { Outcome assessors }\end{array}$ & High risk & Quote: "open label". \\
\hline $\begin{array}{l}\text { Incomplete outcome data } \\
\text { (attrition bias) } \\
\text { All outcomes }\end{array}$ & Unclear risk & $\begin{array}{l}67 \text { patients randomised. } 5 \text { patients ( } 5 / 35 \text { patients control group) excluded be- } \\
\text { cause they were missing baseline data. }\end{array}$ \\
\hline $\begin{array}{l}\text { Selective reporting (re- } \\
\text { porting bias) }\end{array}$ & Unclear risk & $\begin{array}{l}\text { Data presented in percentages for number of patients with mucositis (> grade } \\
\text { 2). }\end{array}$ \\
\hline Other bias & Low risk & Study appears to be free of other sources of bias. \\
\hline
\end{tabular}


Veness 2006

\section{Study characteristics}

\begin{tabular}{|c|c|}
\hline Methods & $\begin{array}{l}\text { Randomised, parallel group study conducted in Australia. Clear information on withdrawals: } 10 \text { (4/42 } \\
\text { misoprostol, } 6 / 41 \text { placebo). Dentist involved in study. Duration: until grade } 1 \text { or less mucositis was } \\
\text { recorded. }\end{array}$ \\
\hline Participants & $\begin{array}{l}\text { Adults with head and neck cancer radiotherapy }(n=52) \text { or concomitant chemotherapy and radiothera- } \\
\text { py }(n=31) \text {. All patients had }>50 \% \text { of the oral /oropharyngeal mucosa in the radiation field and received } \\
>50 \mathrm{~Gy} \text {. }\end{array}$ \\
\hline Interventions & $\begin{array}{l}2 \text { groups, placebo tablets versus misoprostol tablets }(200 \mu \mathrm{g}) \text { dissolved in } 15 \mathrm{ml} \text { of water. Patients } \\
\text { asked to swish liquid around the oral cavity for } 2 \text { minutes and gargled before being swallowed. }\end{array}$ \\
\hline Outcomes & $\begin{array}{l}\text { Mucositis assessed weekly using a 0-4 scale. Other reported outcomes: quality of life, weight loss, hos- } \\
\text { pital admission, pain, }\end{array}$ \\
\hline \multirow[t]{2}{*}{ Notes } & $\begin{array}{l}\text { Data used from table } 3 \text { (incidence of mucositis). Data treated as provided the wrong way round, as the } \\
\text { text suggests that } 42 \text { patients were received into the misoprostol group and } 41 \text { into the placebo group, } \\
\text { while the table provides data for } 42 \text { placebo patients and } 41 \text { misoprostol patients. }\end{array}$ \\
\hline & Funding source: government. \\
\hline
\end{tabular}

\section{Risk of bias}

\begin{tabular}{lll}
\hline Bias & Authors' judgement & Support for judgement \\
\hline $\begin{array}{ll}\text { Random sequence genera- } \\
\text { tion (selection bias) }\end{array}$ & Unclear risk & Quote: "randomisation was carried out using stratified minimization". \\
& & $\begin{array}{l}\text { Comment: minimization. Authors give information about which factors used } \\
\text { for stratification. }\end{array}$ \\
\hline
\end{tabular}

\begin{tabular}{l}
$\begin{array}{l}\text { Allocation concealment } \\
\text { (selection bias) }\end{array}$ \\
\hline
\end{tabular}

Blinding (performance
bias and detection bias) Unclear risk Insufficient information to determine 'yes' or 'no'.

bias and detection bias)

Carers

$\begin{array}{ll}\text { Blinding (performance } & \text { Low risk } \\ \begin{array}{l}\text { bias and detection bias) } \\ \text { Patients }\end{array} & \text { Comment: probably done. }\end{array}$

Blinding (performance Low risk

bias and detection bias)

Outcome assessors
Quote: "the patient's mucositis grade was scored by an experienced head and neck clinic nurse on a weekly basis. She had no prior knowledge of patient randomisation".

Comment: probably done.

83 patients randomised. 10 patients withdrew (4/42 misoprostol, 6/41 placebo). Mucositis data presented for 83 patients.

$\begin{array}{ll}\text { Incomplete outcome data } & \text { Low risk } \\ \text { (attrition bias) } & \text { bo). Mucositis data presented for } 83 \text { patients. }\end{array}$

All outcomes

\begin{tabular}{lll}
\hline $\begin{array}{l}\text { Selective reporting (re- } \\
\text { porting bias) }\end{array}$ & Low risk & $\begin{array}{l}\text { Data presented for incidence of mucositis by grade and arm (table 3) for 83 pa- } \\
\text { tients. }\end{array}$ \\
\hline Other bias & Low risk & Study appears to be free from other sources of bias. \\
\hline
\end{tabular}


Vokurka 2005

\section{Study characteristics}

\begin{tabular}{ll}
\hline Methods & $\begin{array}{l}\text { Randomised, parallel group, multicentre study conducted in Czech/Slovak Republics between January } \\
2002 \text { and June 2004. Unclear whether assessors blind. Unclear information on withdrawals: } 3 \text { refused } \\
\text { after start, } 2 \text { lost. Unclear if dentist involved in study. Drop outs: } 4 \% \text {. Duration: } 28 \text { days, total in-patient } \\
\text { stay. }\end{array}$ \\
\hline Participants & $\begin{array}{l}\text { Adults. Disease unclear. BMT. High dose chemotherapy followed by autologous peripheral stem cell } \\
\text { transplantation. } 137 \text { enrolled and randomised, } 132 \text { completed. }\end{array}$ \\
\hline Interventions & $\begin{array}{l}2 \text { groups, placebo (saline) versus povidone iodine (betadine } 1 \mathrm{ml} \text { and } 100 \text { ml water freshly made every } \\
\text { morning) (1:100 mouthwashes after high-dose chemotherapy comprising BEAM or HD-L-PAM), patients } \\
\text { gargled } 4 \text { times a day. }\end{array}$
\end{tabular}

Outcomes

Mucositis assessed once daily using the WHO grading on a scale of 0-4. Assessment used: up to 28 days. Other reported outcomes: oral pain, tolerability of mouthwashes, occurrence of infections, fever and oral microbiology in patients with clinical suspicion of local infection.

Notes Funding source: unclear.

\section{Risk of bias}

\begin{tabular}{|c|c|c|}
\hline Bias & Authors' judgement & Support for judgement \\
\hline $\begin{array}{l}\text { Random sequence genera- } \\
\text { tion (selection bias) }\end{array}$ & Unclear risk & $\begin{array}{l}\text { Quote: "prospective, randomised, multicentre study". } \\
\text { Comment: random component not described. }\end{array}$ \\
\hline $\begin{array}{l}\text { Allocation concealment } \\
\text { (selection bias) }\end{array}$ & Unclear risk & Insufficient information to determine 'yes' or 'no'. \\
\hline $\begin{array}{l}\text { Blinding (performance } \\
\text { bias and detection bias) } \\
\text { Carers }\end{array}$ & High risk & $\begin{array}{l}\text { Only patients were blinded to the treatment allocation. Authors give no infor- } \\
\text { mation on who made up the solutions each morning. }\end{array}$ \\
\hline $\begin{array}{l}\text { Blinding (performance } \\
\text { bias and detection bias) } \\
\text { Patients }\end{array}$ & Unclear risk & $\begin{array}{l}\text { Quote: "their composition was blinded to the patients." } \\
\text { Comment: normal saline versus povidone-iodine. Likely that patients would } \\
\text { be able to tell the difference between the treatments. Presumably iodine solu- } \\
\text { tion would be orange. }\end{array}$ \\
\hline
\end{tabular}

Blinding (performance Unclear risk Insufficient information to determine 'yes' or 'no'.

bias and detection bias)

Outcome assessors

\begin{tabular}{lll}
\hline $\begin{array}{l}\text { Incomplete outcome data } \\
\text { (attrition bias) } \\
\text { All outcomes }\end{array}$ & Low risk & $\begin{array}{l}132 \text { patients recruited. } 5 \text { patients excluded. Authors give reasons for attrition/ } \\
\text { exclusion, but do not state which arms patients were allocated to. }\end{array}$ \\
\hline $\begin{array}{l}\text { Selective reporting (re- } \\
\text { porting bias) }\end{array}$ & Low risk & $\begin{array}{l}\text { Data presented in percentages for grades of mucositis for both arms of the } \\
\text { study (fig 1), and for incidence of maximum mucositis severity (fig 2/3). }\end{array}$ \\
\hline
\end{tabular}

Other bias High risk
$0.01)$. 
Wahlin 1989

\section{Study characteristics}

\begin{tabular}{ll}
\hline Methods & $\begin{array}{l}\text { Randomised, parallel group study conducted in Sweden. Clear information about withdrawals: } 4 / 14 \\
\text { control, 3/14 test. Dentist involved in study. Drop outs: 0\%. Duration: 21 days. }\end{array}$ \\
\hline Participants & $\begin{array}{l}\text { Children and adults with acute leukaemia at start of chemotherapy. } 28 \text { patients enrolled, } 14 \text { patients } \\
\text { completed (although mucositis data presented on } 28) .\end{array}$ \\
\hline Interventions & 2 groups: no treatment versus chlorhexidine (0.2\% $10 \mathrm{ml}$ twice daily). \\
\hline Outcomes & $\begin{array}{l}\text { Mucositis scored at the level of ulceration. Assessment used: day 28. Other reported outcomes: candidi- } \\
\text { asis verified by detecting pseudohypae in smears, days fever, plaque, gingival bleeding, burning sensa- } \\
\text { tion. }\end{array}$ \\
\hline Notes & Funding source: government.
\end{tabular}

\section{Risk of bias}

\begin{tabular}{lll}
\hline Bias & Authors' judgement & Support for judgement \\
\hline $\begin{array}{l}\text { Random sequence genera- } \\
\text { tion (selection bias) }\end{array}$ & Unclear risk & $\begin{array}{l}\text { Quote: "28 patients were randomly divided into 2 groups". } \\
\text { Quote: "randomisation was performed by means of the closed envelope } \\
\text { method in blocks of 6". }\end{array}$ \\
& $\begin{array}{l}\text { Comment: unclear if envelopes were shuffled. Random component not de- } \\
\text { scribed. }\end{array}$ \\
\hline $\begin{array}{l}\text { Allocation concealment } \\
\text { (selection bias) }\end{array}$ & Unclear risk & Quote: "Closed envelope method". \\
& & Comment: unclear if envelopes were sequentially numbered.
\end{tabular}

Blinding (performance
bias and detection bias) High risk Chlorhexidine versus no intervention. No apparent blinding.

Carers

\begin{tabular}{|c|c|c|}
\hline $\begin{array}{l}\text { Blinding (performance } \\
\text { bias and detection bias) } \\
\text { Patients }\end{array}$ & High risk & Chlorhexidine versus no intervention. No apparent blinding. \\
\hline $\begin{array}{l}\text { Blinding (performance } \\
\text { bias and detection bias) } \\
\text { Outcome assessors }\end{array}$ & High risk & Chlorhexidine versus no intervention. No apparent blinding. \\
\hline $\begin{array}{l}\text { Incomplete outcome data } \\
\text { (attrition bias) } \\
\text { All outcomes }\end{array}$ & Unclear risk & $\begin{array}{l}28 \text { patients randomised. Data from } 7 \text { patients excluded. } 3 / 14 \text { chlorhexidine, } \\
4 / 14 \text { control group. Authors give reasons for withdrawals and exclusions. }\end{array}$ \\
\hline $\begin{array}{l}\text { Selective reporting (re- } \\
\text { porting bias) }\end{array}$ & Unclear risk & Ulceration data presented for 17 patients (table 4). \\
\hline Other bias & High risk & Blocked randomisation in an unblinded study. \\
\hline
\end{tabular}


Wang 2002

\section{Study characteristics}

$\begin{array}{ll}\text { Methods } & \text { Randomised, parallel group study conducted in China. Unclear information about withdrawals, al- } \\ \text { though there appeared to be none. Dentist not involved in study. Drop outs: } 0 \% \text {. Duration: } 1 \text { week after } \\ \text { course of chemotherapy. }\end{array}$
course of chemotherapy.

\begin{tabular}{ll}
\hline Participants & $\begin{array}{l}\text { Adults with solid cancer (breast, lung and lymphoma). CHOP for malignant lymphoma, CMF for breast } \\
\text { cancer and CAP for lung cancer. } 147 \text { eligible and enrolled, and with data. }\end{array}$ \\
\hline Interventions & $\begin{array}{l}2 \text { groups, Dobell's solution as control ( } 30 \mathrm{ml} \text { for } 3 \mathrm{~min} \text {, gargling } 5 \text { times per day). Concoction of Chinese } \\
\text { medicine including } 5 \text { herbs (corktree bark, Chinese gaul, European vebena herb, catechu, forsythia } \\
\text { fruit) and borneol (sucked and gargled } 5 \text { times per day). }\end{array}$
\end{tabular}

\begin{tabular}{ll}
\hline Outcomes & Mucositis scored on 4-point scale. Time of healing ulcers. \\
\hline Notes & Funding source: none. All information is from translation from Chinese.
\end{tabular}

\section{Risk of bias}

\begin{tabular}{|c|c|c|}
\hline Bias & Authors' judgement & Support for judgement \\
\hline $\begin{array}{l}\text { Random sequence genera- } \\
\text { tion (selection bias) }\end{array}$ & Unclear risk & $\begin{array}{l}\text { Quote: "randomised". } \\
\text { Comment: random component not described. }\end{array}$ \\
\hline $\begin{array}{l}\text { Allocation concealment } \\
\text { (selection bias) }\end{array}$ & Unclear risk & Insufficient information to determine 'yes' or 'no'. \\
\hline $\begin{array}{l}\text { Blinding (performance } \\
\text { bias and detection bias) } \\
\text { Carers }\end{array}$ & High risk & $\begin{array}{l}\text { Intervention and control were different in terms of colour, smell, and style of } \\
\text { packaging. }\end{array}$ \\
\hline $\begin{array}{l}\text { Blinding (performance } \\
\text { bias and detection bias) } \\
\text { Patients }\end{array}$ & High risk & $\begin{array}{l}\text { Intervention and control were different in terms of colour, smell, and style of } \\
\text { packaging. }\end{array}$ \\
\hline $\begin{array}{l}\text { Blinding (performance } \\
\text { bias and detection bias) } \\
\text { Outcome assessors }\end{array}$ & Unclear risk & Insufficient information to determine 'yes' or 'no'. \\
\hline $\begin{array}{l}\text { Incomplete outcome data } \\
\text { (attrition bias) } \\
\text { All outcomes }\end{array}$ & Low risk & 147 patients randomised. No missing outcome data. \\
\hline $\begin{array}{l}\text { Selective reporting (re- } \\
\text { porting bias) }\end{array}$ & Unclear risk & $\begin{array}{l}\text { Data presented for } 147 \text { patients by grade and arm. However, it is unclear over } \\
\text { what time interval. }\end{array}$ \\
\hline Other bias & High risk & Risk of bias assessed from translation. \\
\hline
\end{tabular}

Watanabe 2010

\section{Study characteristics}

\begin{tabular}{ll}
\hline Methods & $\begin{array}{l}\text { Randomised parallel group study conducted in Japan. Open study. No blinding. Clear information } \\
\text { about withdrawals: none. }\end{array}$ \\
\hline
\end{tabular}


Watanabe 2010 (Continued)

Participants

31 adults with head and neck cancer. Recruitment ran from January 2009 until October 2009. 21 patients received chemoradiotherapy. Remaining 9 patients received radiotherapy only. Difference between arms non-significant.
2 groups. Polaprezinc (zinc-L-carnosine) granules ( $0.5 \mathrm{~g}$ dissolved in $20 \mathrm{ml}$ of $5 \%$ sodium alginate solution) compared to azulene oral rinse ( 7 drops of $4 \%$ liquid in $100 \mathrm{ml}$ water). Patients rinsed with solution for 3 minutes 4 times daily. Polaprezinc solution swallowed.

Outcomes Mucositis assessed weekly using Common Terminology Criteria for Adverse Events (CTCAE). Other reported outcomes: pain, xerostomia, taste disturbances, reduction in the use of analgesics, number of patients experiencing inability to intake orally, reduction in daily meals.

Notes $\quad$ Funding source: no information (e-publication ahead of print).

\section{Risk of bias}

\begin{tabular}{|c|c|c|}
\hline Bias & Authors' judgement & Support for judgement \\
\hline $\begin{array}{l}\text { Random sequence genera- } \\
\text { tion (selection bias) }\end{array}$ & Unclear risk & $\begin{array}{l}\text { Quote: "randomly assigned". } \\
\text { Comment: random component not described. }\end{array}$ \\
\hline $\begin{array}{l}\text { Allocation concealment } \\
\text { (selection bias) }\end{array}$ & Unclear risk & Insufficient information to determine 'yes' or 'no'. \\
\hline $\begin{array}{l}\text { Blinding (performance } \\
\text { bias and detection bias) } \\
\text { Carers }\end{array}$ & High risk & $\begin{array}{l}\text { Quote: "open trial". } \\
\text { Comment: polaprezinc compared to azulene control. }\end{array}$ \\
\hline $\begin{array}{l}\text { Blinding (performance } \\
\text { bias and detection bias) } \\
\text { Patients }\end{array}$ & High risk & $\begin{array}{l}\text { Quote: "open trial". } \\
\text { Comment: polaprezinc compared to azulene control. }\end{array}$ \\
\hline $\begin{array}{l}\text { Blinding (performance } \\
\text { bias and detection bias) } \\
\text { Outcome assessors }\end{array}$ & High risk & $\begin{array}{l}\text { Quote: "open trial". } \\
\text { Comment: polaprezinc compared to azulene control. }\end{array}$ \\
\hline $\begin{array}{l}\text { Incomplete outcome data } \\
\text { (attrition bias) } \\
\text { All outcomes }\end{array}$ & Low risk & 31 patients recruited. No missing outcome data. \\
\hline $\begin{array}{l}\text { Selective reporting (re- } \\
\text { porting bias) }\end{array}$ & Low risk & Data presented for 31 patients by treatment arm and grade of mucositis. \\
\hline Other bias & High risk & $\begin{array}{l}\text { Baseline imbalance: mean serum creatinine values lower in the control arm } \\
\text { compared to the polaprezinc arm }(P=0.006) \text {. }\end{array}$ \\
\hline
\end{tabular}

Wijers 2001

\section{Study characteristics}

\begin{tabular}{ll}
\hline Methods & $\begin{array}{l}\text { Randomised, parallel group study conducted in The Netherlands. Unclear information about with- } \\
\text { drawals. Dentist involvement unclear. Drop outs: } 32 \% . \text { Duration: } 3 \text { weeks after radiation. }\end{array}$ \\
\hline Participants & Adults with head and neck cancer. 114 patients enrolled, 37 refused to continue, 77 completed. \\
\hline
\end{tabular}


Wijers 2001 (Continued)

Interventions $\quad 2$ groups, placebo versus PTA paste containing antibiotics, polymyxin E, tobramycin, amphotericin.

\begin{tabular}{ll}
\hline Outcomes & $\begin{array}{l}\text { Mucositis scored weekly, } 5 \text { point scale, Van der Schneren system. Assessment used: day } 28 \text { min. Other } \\
\text { reported outcomes: pain, microflora. }\end{array}$ \\
\hline Notes & Funding source: unclear.
\end{tabular}

\section{Risk of bias}

\begin{tabular}{|c|c|c|}
\hline Bias & Authors' judgement & Support for judgement \\
\hline $\begin{array}{l}\text { Random sequence genera- } \\
\text { tion (selection bias) }\end{array}$ & Unclear risk & $\begin{array}{l}\text { Quote: "Patients were randomised to PTA or placebo paste". } \\
\text { Comment: random component not described. }\end{array}$ \\
\hline $\begin{array}{l}\text { Allocation concealment } \\
\text { (selection bias) }\end{array}$ & Unclear risk & Insufficient information to determine 'yes' or 'no'. \\
\hline $\begin{array}{l}\text { Blinding (performance } \\
\text { bias and detection bias) } \\
\text { Carers }\end{array}$ & Unclear risk & Insufficient information to determine 'yes' or 'no'. \\
\hline $\begin{array}{l}\text { Blinding (performance } \\
\text { bias and detection bias) } \\
\text { Patients }\end{array}$ & Low risk & $\begin{array}{l}\text { Quote: "double blind". } \\
\text { Comment: probably done. }\end{array}$ \\
\hline $\begin{array}{l}\text { Blinding (performance } \\
\text { bias and detection bias) } \\
\text { Outcome assessors }\end{array}$ & Low risk & $\begin{array}{l}\text { Quote: "double blind". } \\
\text { Comment: probably done. }\end{array}$ \\
\hline $\begin{array}{l}\text { Incomplete outcome data } \\
\text { (attrition bias) } \\
\text { All outcomes }\end{array}$ & Unclear risk & $\begin{array}{l}114 \text { patients randomised. } 37 \text { patients withdrew during the first } 4 \text { weeks of the } \\
\text { trial ( } 32.5 \%) \text {. Authors give incomplete randomisation and withdrawal informa- } \\
\text { tion. } 77 \text { patients included in efficacy analysis. }\end{array}$ \\
\hline $\begin{array}{l}\text { Selective reporting (re- } \\
\text { porting bias) }\end{array}$ & Low risk & $\begin{array}{l}\text { Data presented for mucositis grade at week } 4 \text { ( } 77 \text { patients) by grade for both } \\
\text { groups (table } 2 \text { ). Authors also present data for max mucositis grade and mo- } \\
\text { ment of max mucositis grade (table } 2 \text { ). }\end{array}$ \\
\hline Other bias & Low risk & Study appears to be free of other sources of bias. \\
\hline
\end{tabular}

Wu 2009

\section{Study characteristics}

\begin{tabular}{ll} 
Methods & $\begin{array}{l}\text { Randomised, parallel group study conducted in Korea between January } 2007 \text { and August 2007. Unclear } \\
\text { if dentist involved in study. Withdrawal information included. }\end{array}$ \\
\hline Participants & $\begin{array}{l}\text { Adults with head and neck cancer receiving radiotherapy. } 116 \text { patients were screened. } 3 \text { refused to par- } \\
\text { ticipate, } 113 \text { were randomised. } 13 \text { patients dropped out before the 5th week of radiotherapy so the } \\
\text { endpoint evaluation was only done on } 100 \text { patients, } 6 \text { because of interruption of radiotherapy for more } \\
\text { than } 2 \text { consecutive days, } 3 \text { for receiving prohibitive drug treatments, } 2 \text { for refusal to participate, } 1 \text { be- } \\
\text { cause of adverse effects of radiotherapy, } 1 \text { for not being treated with the test drug. }\end{array}$ \\
\hline
\end{tabular}


Wu 2009 (Continued)

Interventions

Patients were randomised to 1 of 4 arms: placebo, epidermal growth factor $10 \mu \mathrm{g} / \mathrm{mL}, 50 \mu \mathrm{g} / \mathrm{mL}$ or 100 $\mu \mathrm{g} / \mathrm{mL}$. Epidermal growth factor and placebo both administered as a spray over the entire oral mucosa, twice daily with patients swallowing the residual. Treatment from day 1 to day 5 of radiotherapy.

Outcomes Mucositis scored weekly using RTOG scoring criteria. Assessment used: day 28. Other reported outcomes: WHO oral toxicity grade, patient weight, pain score, opioid analgesia use and time to develop mucositis.

Notes $\quad$ Funding source: grant from the National R\&D Program for Cancer Central, Ministry of Health, Welfare
and Family Affairs, Republic of Korea.

\section{Risk of bias}

Bias Authors' judgement Support for judgement

Random sequence genera- Unclear risk Quote: "We randomised patients to institution and concurrent use of tion (selection bias) chemotherapy".

Comment: random component not described.

Allocation concealment $\quad$ Unclear risk Insufficient information to determine 'yes' or 'no'.
(selection bias)

\begin{tabular}{|c|c|c|}
\hline $\begin{array}{l}\text { Blinding (performance } \\
\text { bias and detection bias) } \\
\text { Carers }\end{array}$ & High risk & $\begin{array}{l}\text { Quote: "double blind". } \\
\text { Comment: possible patient knowledge of allocation. Therefore all blinding } \\
\text { deemed inadequate. }\end{array}$ \\
\hline $\begin{array}{l}\text { Blinding (performance } \\
\text { bias and detection bias) } \\
\text { Patients }\end{array}$ & High risk & $\begin{array}{l}\text { Quote: "double blind". } \\
\text { Comment: authors state that } 1 \text { patient dropped out because they were not } \\
\text { randomised to the test drug. Patient knowledge of allocation. Therefore blind- } \\
\text { ing judged to be inadequate. }\end{array}$ \\
\hline
\end{tabular}

\begin{tabular}{lll}
\hline $\begin{array}{l}\text { Blinding (performance } \\
\text { bias and detection bias) } \\
\text { Outcome assessors }\end{array}$ & High risk & Quote: "double blind". \\
& $\begin{array}{l}\text { Comment: possible patient knowledge of allocation. Therefore all blinding } \\
\text { deemed inadequate. }\end{array}$
\end{tabular}

\begin{tabular}{|c|c|c|}
\hline $\begin{array}{l}\text { Incomplete outcome data } \\
\text { (attrition bias) }\end{array}$ & Low risk & $\begin{array}{l}70 \text { patients randomised ( } 1 / 28 \text { control group, } 3 / 2910 \mu \mathrm{g} / \mathrm{mL} \text { arm, } 3 / 2950 \mu \mathrm{g} / \\
\mathrm{mL} \text { arm, } 5 / 27100 \mu \mathrm{g} / \mathrm{mL} \text { arm). No missing outcome data. }\end{array}$ \\
\hline
\end{tabular}

(attrition bias) $\quad \mathrm{mL}$ arm, $5 / 27100 \mu \mathrm{g} / \mathrm{mL}$ arm). No missing outcome data.

\begin{tabular}{|c|c|c|}
\hline $\begin{array}{l}\text { Selective reporting (re- } \\
\text { porting bias) }\end{array}$ & Unclear risk & $\begin{array}{l}\text { Data presented in text for percentage of patients with oral mucositis > RTOG } \\
\text { grade } 3 \text {. Data also presented for average grade of mucositis by week for pa- } \\
\text { tient treated with } 50 \mathrm{mg} / \mathrm{mL} \text { compared with placebo (fig 4). }\end{array}$ \\
\hline
\end{tabular}

\begin{tabular}{ll}
\hline Other bias $\quad$ Low risk Study appears to be free of other sources of bias. \\
\hline
\end{tabular}

You 2009

\begin{tabular}{ll}
\hline Study characteristics & \\
\hline Methods & $\begin{array}{l}\text { Randomised, parallel group study conducted in Taiwan. Clear information about withdrawals. Unclear } \\
\text { if dentist involved in study. Drop outs: } 9 \% \text {. Duration: } 1 \text { week after course of chemotherapy. }\end{array}$ \\
\hline
\end{tabular}


You 2009 (Continued)

Participants Adults with head and neck cancer receiving radiotherapy. 22 patients randomised to 2 groups enrolled between October 2005 and May 2006. 2 patients in control withdrew due to refusal to give blood sample.

\begin{tabular}{ll}
\hline Interventions & 2 groups, saline and indigo wood root (IR) (Isatis indigotica called Ban-Lan-Gen in Chinese is a medici- \\
& nal plant belonging to the Brassicacaee family). Patients gargled with $30-\mathrm{mL}$ solution of either saline or \\
IR for 3 minutes and then swallowed before meals daily.
\end{tabular}

$\begin{array}{ll}\text { Outcomes } & \text { Mucositis scored on 4-point scale. Time of healing ulcers. Also reported difficulty swallowing, anorexia, } \\ \text { rest from treatment, blood changes. }\end{array}$

\begin{tabular}{ll}
\hline Notes & Funding source: none. \\
\hline
\end{tabular}

\section{Risk of bias}

Bias Authors' judgement Support for judgement

Random sequence genera- Unclear risk tion (selection bias)

Quote: "Patients were sequentially randomised into two treatment arms: (I) indigowood root group: $0.5 \mathrm{~g}$ IR powder in $30 \mathrm{~mL}$ double distilled water; (II) Control group: placebo with $30 \mathrm{~mL}$ normal saline".

Comment: random component not described.

\begin{tabular}{lll}
\hline $\begin{array}{l}\text { Allocation concealment } \\
\text { (selection bias) }\end{array}$ & Unclear risk & Insufficient information to determine 'yes' or 'no'. \\
\hline $\begin{array}{l}\text { Blinding (performance } \\
\text { bias and detection bias) }\end{array}$ & Unclear risk & Insufficient information to determine 'yes' or 'no'. \\
Carers & & \\
\hline
\end{tabular}

\begin{tabular}{|c|c|c|}
\hline $\begin{array}{l}\text { Blinding (performance } \\
\text { bias and detection bias) } \\
\text { Patients }\end{array}$ & Unclear risk & Indigo wood root or placebo. No apparent blinding. \\
\hline $\begin{array}{l}\text { Blinding (performance } \\
\text { bias and detection bias) } \\
\text { Outcome assessors }\end{array}$ & Unclear risk & Indigo wood root or placebo. No apparent blinding. \\
\hline $\begin{array}{l}\text { Incomplete outcome data } \\
\text { (attrition bias) } \\
\text { All outcomes }\end{array}$ & Low risk & $\begin{array}{l}22 \text { patients were randomised. } 2 \text { patients withdrew from the placebo group. } 20 \\
\text { patients included in analysis. }\end{array}$ \\
\hline $\begin{array}{l}\text { Selective reporting (re- } \\
\text { porting bias) }\end{array}$ & Low risk & Data presented for 20 patients for mucositis incidence by arm and treatment. \\
\hline Other bias & High risk & $\begin{array}{l}\text { All Chinese medicine RCTs are now a cause for concern in light of the findings } \\
\text { of Taixiang et al } 2007 \text {. }\end{array}$ \\
\hline
\end{tabular}

Yuen 2001

\section{Study characteristics}

Methods

Randomised, parallel group study conducted in Hong Kong. Clear information on withdrawals: none.

Unclear if dentist involved in study. Drop outs: $0 \%$. Duration: 60 days after BMT. 
Yuen 2001 (Continued)

Participants Adults with mixed cancer receiving BMT, 70 enrolled between October 1996 to February 1998.70 evaluated.

\begin{tabular}{ll}
\hline Interventions & 2 groups no treatment versus clarithromycin oral $500 \mathrm{mg}$ twice daily or IV 500 mg 12 hourly. Start day \\
-7.
\end{tabular}
-7 .

\begin{tabular}{ll}
\hline Outcomes & Mucositis scoring system not clear. Grade 2 data used. Assessment used: unclear. Other reported out- \\
comes: toxicity (rash, diarrhoea, liver function), infection, duration of fever, neutropenic fever, use of \\
antibiotics, parenteral nutrition, growth factors.
\end{tabular}

Notes Funding source: none.

\section{Risk of bias}

\begin{tabular}{lll}
\hline Bias & Authors' judgement & Support for judgement \\
\hline $\begin{array}{ll}\text { Random sequence genera- } \\
\text { tion (selection bias) }\end{array}$ & Low risk & $\begin{array}{l}\text { Quote: "The } 70 \text { patients were randomly divided into 2 subgroups by comput- } \\
\text { er". }\end{array}$ \\
& & Comment: computer generated randomisation. \\
\hline
\end{tabular}

Allocation concealment Unclear risk Insufficient information to determine 'yes' or 'no'.

(selection bias)

$\begin{array}{lll}\begin{array}{l}\text { Blinding (performance } \\ \text { bias and detection bias) } \\ \text { Carers }\end{array} & \text { High risk } & \text { Quote: "open-label". } \\ \text { Comment: no blinding. }\end{array}$

\begin{tabular}{|c|c|c|}
\hline $\begin{array}{l}\text { Blinding (performance } \\
\text { bias and detection bias) } \\
\text { Outcome assessors }\end{array}$ & High risk & $\begin{array}{l}\text { Quote: "open-label". } \\
\text { Comment: no blinding. }\end{array}$ \\
\hline $\begin{array}{l}\text { Incomplete outcome data } \\
\text { (attrition bias) } \\
\text { All outcomes }\end{array}$ & Low risk & 70 patients randomised. No missing outcome data. \\
\hline $\begin{array}{l}\text { Selective reporting (re- } \\
\text { porting bias) }\end{array}$ & Unclear risk & Data presented for grade $0-1$ and grade 2 mucositis (table 2 ). \\
\hline Other bias & Low risk & Study appears to be free of other sources of bias. \\
\hline
\end{tabular}

ASTC $=$ autologous stem cell transplantation

$\mathrm{BMT}=$ bone marrow transplant

EORTC = European Organization for Research and Treatment of Oral Cancer

$\mathrm{GI}=$ glycaemic index

GM-CSF = granulocyte/macrophage colony-stimulating factor

GVHD = graft-versus-host disease

HSCT = haematopoietic stem cell transplant

$\mathrm{HSV}=$ herpes simplex virus

ITT = intention-to-treat analysis

IV = intravenous

$\mathrm{KGF}=$ keratinocyte growth factor

$\mathrm{NCI} \mathrm{CTC}=$ National Cancer Institute Common Toxicity Criteria

$\mathrm{OAG}=$ oral assessment guide 
$\mathrm{OM}=$ oral mucositis

OMAS = oral mucosa assessment scale

OMS = objective mucositis score

$\mathrm{ROB}=$ risk of bias

$\mathrm{RT}=$ radiotherapy

RTOG = Radiation Therapy Oncology Group

$\mathrm{SD}=$ standard deviation

SOC $=$ standard oral care

$\mathrm{TBI}=$ total body irradiation

TPN = total parenteral nutrition

$\mathrm{UOM}=$ ulcerative oral mucositis

VAS = visual analogue scale

WBC - white blood count

WHO $=$ World Health Organization

5-FU = 5-fluorouracil

(c) indicates from correspondence with authors.

Characteristics of excluded studies [ordered by study ID]

\begin{tabular}{|c|c|}
\hline Study & Reason for exclusion \\
\hline Abramoff 2008 & Patients considered new case and re-randomised for each CT cycle (laser versus no treatment). \\
\hline Aisa 2005 & Not RCT (cryotherapy). \\
\hline Altmann 1999 & Not RCT (amifostine). \\
\hline Andersen 1987 & Cancer treatments comparing toxic effects. \\
\hline Anderson 1998b & Mucositis at baseline in some patients (glutamine versus placebo). \\
\hline Antin 2002 & $\begin{array}{l}\text { Study stopped early due to adverse event triggering preset stopping rule - data only for } 10 \text { patients } \\
\text { in rhIL group and } 3 \text { placebo (rhIL-11 versus placebo). }\end{array}$ \\
\hline Antonadou 1998 & Abstract, insufficient information (radiotherapy with or without GM-CSF). \\
\hline Apaydin 1996 & Unclear whether allocation is randomised. \\
\hline Aquino 2005 & $\begin{array}{l}\text { Composite score for mucositis including teeth with plaque (Walsh). Unable to use mucositis out- } \\
\text { come outcomes (oral glutamine). }\end{array}$ \\
\hline Ardizzoni 2002 & Cancer treatments comparing toxic effects and confounded by cancer (G-CSF). \\
\hline Arora 2008 & Not RCT (laser). \\
\hline Awada 2002 & Cancer treatment comparing toxic effects. \\
\hline Awada 2004 & Not RCT (temozolomide plus liposomal doxorubicin). \\
\hline Awidi 2001 & $\begin{array}{l}\text { Episodes not patients. Type of cross-over study but some patients were included in more than } 2 \\
\text { 'courses' (pilocarpine versus placebo). }\end{array}$ \\
\hline Awwad 2002 & $\begin{array}{l}\text { Cancer treatments comparing toxic effects (conventional fractionation versus accelerated hyper- } \\
\text { fractionation radiotherapy). }\end{array}$ \\
\hline Barasch 1995 & $\begin{array}{l}\text { As patients had already received some chemotherapy before intervention started, some patients, } \\
\text { but not all, have some mucositis. The trial is therefore a combination of prevention and treatment } \\
\text { (He-Ne laser versus no treatment). }\end{array}$ \\
\hline
\end{tabular}




\begin{tabular}{|c|c|}
\hline Study & Reason for exclusion \\
\hline Baydar 2005 & Not RCT (cryotherapy). \\
\hline Bensadoun 2006 & Comparison of different cancer treatment regimens, not primary outcome. \\
\hline Bentzen 2001 & Comparing different chemotherapy regimens. \\
\hline Bleehen 1996 & Different chemotherapy regimens. \\
\hline Bourhis 2006 & Comparing 2 radiotherapy regimens but looking at toxicity. \\
\hline Braaksma 2002 & Email sent to author requesting further information; no reply received by March 2011 . \\
\hline Buentzel 1999 & Abstract - insufficient information (amifostine). \\
\hline Calais 2000 & Trial of cancer treatments. \\
\hline Calais 2004 & Not RCT (chemotherapy). \\
\hline Cassidy 2002 & Cancer treatments comparing toxic effects. \\
\hline Castro 2009 & Abstract. \\
\hline Cella 2003 & $\begin{array}{l}\text { Emailed authors Nov } 172010 \text { requesting data to include this study in review. Authors replied stat- } \\
\text { ing that data held by pharma company and no longer available. }\end{array}$ \\
\hline Cheng 2001 & Not RCT (oral care protocol). \\
\hline Cheng 2002 & Not RCT (oral care protocol). \\
\hline Cheng 2006 & $\begin{array}{l}\text { Grade } 2 \text { mucositis was an exclusion criteria. However, unclear how many patients had grade } 1 \text { mu- } \\
\text { cositis at baseline. Email sent to authors. No reply. }\end{array}$ \\
\hline Clarke 2001 & Abstract, insufficient information (rHuKGF). \\
\hline Colella 2010 & Open non-randomised trial. \\
\hline Collova 2004 & Abstract - insufficient information. \\
\hline Colombat 1995 & Abstract - insufficient information (fluconazole versus amphotericin B). \\
\hline Costa 1999 & Abstract, not RCT (chlorhexidine versus no treatment). \\
\hline Costa 2003 & Not RCT (chlorhexidine versus control). \\
\hline Cowen 1997 & $\begin{array}{l}\text { Daily mucositis index used and summed across all categories (including voice, saliva). A cumulative } \\
\text { oral mucositis score generated for both nursing and patient assessments was used and categorised } \\
\text { into a } 0-3 \text { mucositis scale. Daily mucositis index ranging from } 0-48 \text { used, with means (SD) presented } \\
\text { but excluded as composite scale (He-Ne laser versus no treatment). }\end{array}$ \\
\hline Cunningham 1995 & Investigating new cancer treatment, tomudex, with oral mucositis as one of the minor side effects. \\
\hline Damon 2004 & Trial investigating 2 different methods of administering etoposide. \\
\hline De Boer 2002 & $\begin{array}{l}\text { Cancer treatments comparing toxic effects (conventional versus accelerated infusional chemother- } \\
\text { apy). }\end{array}$ \\
\hline
\end{tabular}




\begin{tabular}{|c|c|}
\hline Study & Reason for exclusion \\
\hline Denham 1999 & Cancer treatments comparing toxic effects (conventional versus accelerated fractionation). \\
\hline Djuric 2006 & Some mucositis present at baseline. \\
\hline Dobrowsky 1998 & Added to speed up radiotherapy, not radio-protection-toxic (mitomycin). \\
\hline Doroshow 1987 & Cancer treatments comparing toxic effects. \\
\hline Dreicer 1997 & Not RCT(edatrexate). \\
\hline Dudjak 1987 & $\begin{array}{l}\text { Uses Beck's OAG mucositis score (includes ability to swallow, saliva, diet and patient ability to self } \\
\text { care) ( } 2 \text { oral care protocols). }\end{array}$ \\
\hline Edelman 1998 & Not RCT (cryotherapy). \\
\hline Eisen 2003 & Not RCT (valacyclovir versus acyclovir). \\
\hline El-Sayed 2002a & Not RCT (antimicrobial lozenge). \\
\hline Epstein 1992 & $\begin{array}{l}\text { Sum of composite self-reported scale including mouth pain and its effect on oral intake, and the } \\
\text { absence or presence of stomatitis. Unable to use in review ( } 3 \text { groups: chlorhexidine rinse, nystatin } \\
\text { suspension and saline solution). }\end{array}$ \\
\hline Erkisi 1996 & $\begin{array}{l}\text { Patients randomised to different cancer treatments and where given G-CSF when clinically indicat- } \\
\text { ed, not randomly allocated (G-CSF versus no treatment). }\end{array}$ \\
\hline Erlichman 1988 & Comparing different chemotherapy regimens. \\
\hline Etiz 2000 & $\begin{array}{l}\text { Multicomponent scale of mucositis including pain, dysphasia and use of systemic analgesics (su- } \\
\text { cralfate versus placebo). }\end{array}$ \\
\hline Ezzat 2005 & Comparing 3 different radiotherapy regimens, survival not mucositis is primary outcome. \\
\hline Fahlke 1999 & Not RCT (amifostine). \\
\hline Falcone 2001 & Comparing different radiotherapy regimens. \\
\hline Fay 1994 & Not RCT (GM-CSF). \\
\hline Feber 1995 & $\begin{array}{l}\text { Oral assessment guide not just mucositis but includes plaque and voice changes (hydrogen perox- } \\
\text { ide versus sodium chloride rinses). }\end{array}$ \\
\hline Feber 1996 & $\begin{array}{l}\text { Oral assessment guide not just mucositis but includes plaque and voice changes ( } 2 \text { oral care proto- } \\
\text { cols). }\end{array}$ \\
\hline Ferreira 2004 & $\begin{array}{l}\text { Email sent to authors Nov } 2010 \text { requesting sufficient information to include study in this review. No } \\
\text { reply received March } 2011 .\end{array}$ \\
\hline Ferretti 1990 & Patients had mucositis at baseline. \\
\hline Foncuberta 2001 & Patients assigned sequentially not RCT (GF-B3). \\
\hline Gabison 1995 & Abstract - insufficient information (zinc picolinate). \\
\hline Gandara 1997 & Not RCT (edatrexate). \\
\hline
\end{tabular}




\begin{tabular}{|c|c|}
\hline Study & Reason for exclusion \\
\hline Genot-Klastersky 2008 & Some patients had grade 1 mucositis in prevention trial (laser versus placebo). \\
\hline Ghoreishi 2007 & $\begin{array}{l}\text { Email sent to authors Nov } 2010 \text { requesting further information to enable this study to be included. } \\
\text { No reply received by March } 2011 \text {. }\end{array}$ \\
\hline Giles 2003a & Comparing chemotherapy regimens not mucositis interventions. \\
\hline Giles 2003b & Cancer treatment toxicity (troxacitabine). \\
\hline Gladkov 2007 & Comparing different radio-chemo regimes for oral cancer. \\
\hline Goldberg 2003 & Abstract - insufficient information (en3247). \\
\hline Gordon 1993 & Abstract, insufficient information (GM-CSF). \\
\hline Grotz 2001 & $\begin{array}{l}\text { Index not in suitable form. Total RTOG scores including salivary glands, mucosa, skin (co- } \\
\text { marin/troxerutine versus placebo). }\end{array}$ \\
\hline Gutierrez 1996 & Not RCT (fluconazole). \\
\hline Harris 1995 & Abstract, insufficient information (folinic acid mouthwash versus placebo). \\
\hline He 2004 & Abstract - insufficient information (amifostine). \\
\hline Hickey 1982 & $\begin{array}{l}\text { Problems with data. } 21 \text { patients in total, unclear how many patients per group, but data presented } \\
\text { as } 67 \text { courses of chemotherapy (oral hygiene protocols). }\end{array}$ \\
\hline Horsley 2007 & Not RCT (keratinocyte). \\
\hline Howell 1983 & $\begin{array}{l}\text { Unclear if randomised. Cross-over study provided } 59 \text { paired course of treatment in } 23 \text { patients (al- } \\
\text { lopurinol). }\end{array}$ \\
\hline Hu 2003 & Not RCT (amifostine). \\
\hline Hunter 2007 & $\begin{array}{l}\text { Not RCT. This study combines patients who were in cohorts with increasing doses of mouthrinse to } \\
\text { assess safety, with an RCT (ATL-104 mouthwash versus placebo). }\end{array}$ \\
\hline Hwang 2004 & $\begin{array}{l}\text { Email sent to authors Nov } 2010 \text { requesting further details concerning this study. No reply was re- } \\
\text { ceived by March } 2011 .\end{array}$ \\
\hline Inagaki 2006 & Not RCT (cryotherapy). \\
\hline Ito 2002 & Not RCT (allopurinol spray). \\
\hline Jebb 1995 & Index of mucositis had multiple components other than mucositis (glutamine versus placebo). \\
\hline Jham 2007 & Study for prevention of xerostomia (bethanechol versus saliva supplement). \\
\hline Johnson 2002 & Not RCT (prostaglandin e1). \\
\hline Ju 2009 & Quasi-randomised study. Patients alternatively allocated to intervention and placebo. \\
\hline Kante 1995 & Abstract - insufficient information (oral care regimens). \\
\hline
\end{tabular}




\begin{tabular}{|c|c|}
\hline Study & Reason for exclusion \\
\hline Karacetin 2004 & $\begin{array}{l}\text { Patients were 'randomised' to intervention or control according to file number (amifostine versus } \\
\text { no treatment). }\end{array}$ \\
\hline Karthaus 1998 & $\begin{array}{l}\text { Problems with the data. } 8 \text { patients, } 32 \text { chemo cycles and results presented assuming independent } \\
\text { (G-CSF versus placebo). }\end{array}$ \\
\hline Kenny 1990 & $\begin{array}{l}\text { Oral assessment guide not only mucositis but includes plaque and voice changes ( } 2 \text { oral care proto- } \\
\text { cols). }\end{array}$ \\
\hline Khouri 2009 & $\begin{array}{l}\text { Quasi-randomised study. Patients allocated to intervention and placebo alternatively based on } \\
\text { date of hospitalisation. }\end{array}$ \\
\hline Klocke 2006 & Abstract - insufficient information. \\
\hline Kuhn 2009 & Children had mucositis grades $2+$ on entry into trial. \\
\hline Kuriakose 2002 & Not RCT (edatrexate). \\
\hline Labbate 2003 & Not RCT. \\
\hline Lanzos 2010 & 7 patients had mucositis at baseline (including 2 patients with grade 4 mucositis). \\
\hline Lavendag 1998 & Abstract, insufficient information (polyenes versus placebo). \\
\hline Le 2008 & Abstract (keratinocyte growth factor). \\
\hline Lee 1989 & Intervention given as part of cancer treatment, not to prevent mucositis. \\
\hline Leong 1995 & Abstract, insufficient information (thymidine versus no treatment). \\
\hline Levi 1997 & $\begin{array}{l}\text { Comparison of } 2 \text { cancer treatments where the primary outcome was maximum tumour response to } \\
\text { therapy. }\end{array}$ \\
\hline Loo 2010 & 130 of the 139 patients recruited into the study had mucositis at baseline. \\
\hline Lopez 1994 & $\begin{array}{l}\text { Data presented as number of days patients suffered for each grade of mucositis. Cannot be used in } \\
\text { meta-analysis unless we obtain further information from authors. Unable to contact authors. }\end{array}$ \\
\hline Lopez-Campo 2004 & $\begin{array}{l}\text { Abstract only. Insufficient information to include in review. No subsequent publication identified } \\
\text { (March 2011). }\end{array}$ \\
\hline Lorusso 2003 & Episodes not patients considered in analysis (amifostine). \\
\hline Lozada 1998 & Abstract with insufficent information given (pilocarpine). \\
\hline Luglié 2002 & Not RCT. \\
\hline Maddocks-Jennings 2009 & $\begin{array}{l}\text { Not RCT (alternate allocation and if patient could not gargle they were re-allocated to other } \\
\text { groups) (essential oils). }\end{array}$ \\
\hline Madero 1999 & No response to query whether patients were randomised to groups (rhGM-CFS). \\
\hline Mahmoud 1996 & Comparison of 2 cancer treatments where the primary outcome was survival (folinic acid). \\
\hline Malaker 1991 & Not RCT (B-Carotene retinoic acid). \\
\hline
\end{tabular}




\begin{tabular}{|c|c|}
\hline Study & Reason for exclusion \\
\hline Mantovani 2003 & Not randomised. \\
\hline Marcial 1994 & $\begin{array}{l}\text { Abstract, insufficient information. It states it is an RCT but mentions historical control group (low } \\
\text { energy laser versus no treatment). }\end{array}$ \\
\hline Martin 2006 & Not RCT (G-CSF). \\
\hline Masucci 2005 & Treatment of mucositis not prevention. \\
\hline Matejka 1990 & Not RCT (prostaglandin E2). \\
\hline Mcllroy 1996 & $\begin{array}{l}\text { Scoring system incorporated visible signs of mucositis with pain dysphasia and weight loss. Quali- } \\
\text { tative assessment with no data given (polyenes versus placebo). }\end{array}$ \\
\hline Merte 1999 & Abstract (German). \\
\hline Mills 1995 & Not RCT. \\
\hline Mori 2006 & Not RCT (cryotherapy). \\
\hline Nicolatou-Galitis 2006 & Not an RCT. Patients who received the intervention were compared to a control cohort. \\
\hline Niibe 1985 & $\begin{array}{l}\text { Report in Japanese. Translator describes outcome as oral mucous symptoms, time of assessment } \\
\text { unclear (based on radiation dose delivered) and reported as percentages per group with no de- } \\
\text { nominators or estimate of precision. Insufficient information to include and study to old to be able } \\
\text { to contact authors (amifostine versus placebo). }\end{array}$ \\
\hline
\end{tabular}

Nikoletti $2005 \quad$ Cross-over study, some doubt as to whether patients had any mucositis at baseline and outcomes
used OAG assessment scale which is an exclusion criterion for this review.

\begin{tabular}{|c|c|}
\hline Okuno 1997 & $\begin{array}{l}\text { Major change to protocol half way through study (antibiotic lozenge versus placebo). Data from } \\
\text { blinded and unblinded patients combined. Chlorhexidine for first part included as study by Foote } \\
\text { 1994. Data from first part comparing antibiotic lozenge with placebo mouthrinse have not been in- } \\
\text { cluded as we feel this is an inappropriate control. }\end{array}$ \\
\hline
\end{tabular}

\begin{tabular}{ll}
\hline Okutomi 2000 & Not RCT (Z-100 injections). \\
\hline Papadeas 2007 & CCT (cryotherapy). \\
\hline Papas 1984 & Abstract (patient management system). \\
\hline Papas 2003 & $\begin{array}{l}\text { The interventions were calcium phosphate rinses plus fluoride tray applications versus fluoride } \\
\text { rinses + placebo tray applications. The individual interventions were confounded. }\end{array}$ \\
\hline Penpattanagul 2007 & $\begin{array}{l}\text { Not RCT. "Patients were assigned to their treatment groups at the discretion of the investigator } \\
\text { with an attempt to achieve equal distribution of patient demographics." }\end{array}$ \\
\hline Peters 1993 & CCT. Paper states "Randomisation procedure was done according to day of birth." \\
\hline Phillips 2002 & Not RCT (amifostine). \\
\hline Piccirillo 2003 & $\begin{array}{l}\text { Excluded as mucositis index inappropriate for review. Mucositis index included pain and difficulty } \\
\text { in swallowing (response from authors). }\end{array}$ \\
\hline Pouli 1999 & Abstract, insufficient information (GM-CSF versus sodium bicarbonate mouthwash).
\end{tabular}




\begin{tabular}{|c|c|}
\hline Study & Reason for exclusion \\
\hline Prada 1985 & Mucositis present at baseline (benzydamine versus placebo mouthwash). \\
\hline Putwatana 2009 & $\begin{array}{l}\text { Quasi-randomised trial. Patients allocated to the intervention (glycerin payayor) or control (benzy- } \\
\text { damine) by alternative allocation. }\end{array}$ \\
\hline Pyrhonen 1995 & $\begin{array}{l}\text { Mucositis not primary outcome. Only presents data for test arm as adverse event (chemotherapy } \\
\text { agents). }\end{array}$ \\
\hline Pytlik 2002 & Inappropriate mucositis index includes voice quality and teeth (glutamine versus placebo). \\
\hline Rabinovitch 2006 & Trial of radiotherapy for head and neck cancer looking at cancer treatment. \\
\hline Rades 2004 & $\begin{array}{l}\text { Study halted when preset stopping rules were triggered due to adverse effects of amifostine. No } \\
\text { mucositis outcomes reported (amifostine). }\end{array}$ \\
\hline Radmard 2002 & Abstract - insufficient information (rhGM-CSF). \\
\hline Raether 1989 & $\begin{array}{l}\text { Average mucosal rating presented without standard deviation. Cannot be used in meta-analysis } \\
\text { unless we obtain further information from authors. Unable to contact authors. }\end{array}$ \\
\hline Robustelli 1999 & Abstract - insufficient information (galenic preparation). \\
\hline Rocci 2005 & $\begin{array}{l}\text { Not eligible since it is not dealing with prevention or treatment of mucositis, but uses mucositis to } \\
\text { measure side effect of } 2 \text { different ways to deliver an antitumoural drug for the treatment of gas- } \\
\text { trointestinal tumours. }\end{array}$ \\
\hline Rojas 2001 & Episodes not patients. \\
\hline Rothwell 1990 & Mucositis scores presented as means. Oral screening tool includes moniliasis (candidiasis). \\
\hline Rutkauskas 1993 & $\begin{array}{l}\text { No data for mucositis presented by randomised group, just line graph of all patients with no P val- } \\
\text { ues (chlorhexidine versus placebo). }\end{array}$ \\
\hline Ryu 2007 & $6 \%$ of patients had oral mucositis at baseline. \\
\hline Samaranayake 1988 & $\begin{array}{l}\text { Average mucosal rating presented without standard deviation. Cannot be used in meta-analysis } \\
\text { unless we obtain further information from authors. Unable to contact authors. }\end{array}$ \\
\hline Sato 1997 & Unsure if RCT and author has not responded to letter requesting further information. \\
\hline Sato 2006 & Not RCT (cryotherapy). \\
\hline Schuster 2008 & Not RCT (velafermin). \\
\hline Schwerkoske 1999 & Abstract, insufficient information (rhIL11). \\
\hline Shabanloei 2009 & $\begin{array}{l}\text { Quasi-randomised study. "Patients selected based on their ID code and by choosing from the box } \\
\text { and were divided into three groups." }\end{array}$ \\
\hline Sharma 2009 & Abstract. \\
\hline Shea 2007 & Abstracts only, insufficient information (palifermin). \\
\hline Shidfar 2008 & Abstract. \\
\hline
\end{tabular}




\begin{tabular}{|c|c|}
\hline Study & Reason for exclusion \\
\hline Simoes 2009 & Not RCT (laser). \\
\hline Spadaro 1991 & Abstract, insufficient information (vitamin $\mathrm{E}+$ vitamin $\mathrm{A}+$ fluconazole versus no treatment). \\
\hline Spielberger 2001 & Abstract, insufficient information (keratinocyte). \\
\hline Stokman 2004 & Not RCT. This was a cross-over study but not randomised. All patients had control cycle first. \\
\hline Teshima 1986 & $\begin{array}{l}\text { Japanese paper. Unclear information as to whether this was randomised. Written to authors but no } \\
\text { reply. }\end{array}$ \\
\hline Thieblemont 2002 & Not RCT. \\
\hline Throuvalas 1995 & Abstract, probably not RCT described as comparative study (GM-CSF). \\
\hline Tiemann 2006 & Not RCT (herbs). \\
\hline Toubai 2003 & Probably not RCT, only 12 patients in total? (itraconazole). \\
\hline Uchiyama 2005 & Not RCT. \\
\hline Valcárcel 1997 & Abstract - insufficient information (thymostimulin). \\
\hline Valcarcel 2002 & Participants had mucositis at baseline. \\
\hline van Zaanen 1994 & $\begin{array}{l}\text { Patients randomised per treatment cycle, } 15 \text { patients and } 20 \text { treatments cycles. Patients ran- } \\
\text { domised up to } 3 \text { times, data treated as independent but not reported per patient (glutamine + TPN } \\
\text { versus standard TPN). }\end{array}$ \\
\hline
\end{tabular}

Verdi 1995 Mucositis measured by OAG which includes teeth. Only in 10 patients (pentoxifylline versus place-
bo).
bo).

\begin{tabular}{ll}
\hline Vesole 1999 & Abstract insufficient information (IB-367). \\
\hline Villar 2009 & Abstract. \\
\hline Vitello 2000 & Abstract, insufficient information (lidocaine versus dyclone mouthrinses). \\
\hline Wagner 2002 & Abstract for treatment of mucositis review (GM-CSF). \\
\hline Wang 2002a & Not RCT. \\
\hline Ward 2007 & CCT (glutamine). \\
\hline Warde 2002 & $\begin{array}{l}\text { Maximal toxicity during treatment presented as percentages. Cannot be used in meta-analysis } \\
\text { unless we obtain further information from authors. Email sent 17 Nov 2010, no reply received by } \\
\text { March 2011. }\end{array}$ \\
\hline Weisdorf 1989 & $\begin{array}{l}\text { Outcome data presented as graph with standard deviations. Cannot be used in meta-analysis un- } \\
\text { less we obtain further information from authors. Unable to contact authors. }\end{array}$ \\
\hline Weiss 1990 & \begin{tabular}{l} 
Not randomised. Cross-over trial and data in wrong form for review (allopurinol). \\
\hline Whelan 2002
\end{tabular} \\
\hline
\end{tabular}




\begin{tabular}{ll}
\hline Study & Reason for exclusion \\
\hline Whelan 2004 & Not RCT (from author). \\
\hline Wollina 2002 & Not RCT (dexpanthenol). \\
\hline Wymenga 1999 & Not RCT (TGF-B3 mouthrinse versus no treatment). \\
\hline Yokomizo 2004 & Not RCT. \\
\hline Zanin 2010 & Mucositis data presented as mean values. Unclear if randomised. Authors contacted - no reply. \\
\hline
\end{tabular}

$\mathrm{CCT}=$ controlled clinical trial; $\mathrm{CT}=$ chemotherapy; $\mathrm{RCT}=$ randomised controlled trial $; \mathrm{SD}=$ standard deviation.

Characteristics of studies awaiting classification [ordered by study ID]

\begin{tabular}{ll} 
Cheng $\mathbf{2 0 0 3}$ & Randomised cross-over comparison of chlorhexidine versus benzydamine oral care protocols. \\
\hline Participants & Children aged 6-17 undergoing chemotherapy recruited between April 2000 and April 2001. \\
\hline Interventions & $\begin{array}{l}2 \text { groups, oral care protocol based on chlorhexidine mouthrinse twice daily during chemotherapy } \\
\text { compared to an oral care protocol based on benzydamine twice daily. }\end{array}$ \\
\hline Outcomes & $\begin{array}{l}\text { WHO mucositis scores, oral symptoms (eating, chewing, swallowing, speaking, mouth dryness on } \\
\text { VAS scale), pain, use of analgesics, concomitant medications. }\end{array}$ \\
\hline Notes & $\begin{array}{l}3 \text { publications relating to the same study. Unclear whether any patients had oral mucositis at base- } \\
\text { line. Email sent to authors requesting clarification. }\end{array}$
\end{tabular}

de Koning 2007

\begin{tabular}{ll}
\hline Methods & Randomised, cross-over study conducted in The Netherlands. \\
\hline Participants & Children with haematological malignancies receiving chemotherapy. \\
\hline Interventions & 2 groups, placebo feeds versus TGF-2 enriched feeds (dose dependant on patient weight). \\
\hline Outcomes & $\begin{array}{l}\text { Mucositis assessed daily using the WHO scale. Other reported outcomes: diarrhoea, pain, use of } \\
\text { analgesics, administration of antibiotics, frequency of blood cultures. }\end{array}$ \\
\hline Notes & $\begin{array}{l}\text { Discrepancy between data presented in tables } 2 \text { \& } 3 \text { in the paper. Awaiting clarification of data } \\
\text { from authors. }\end{array}$ \\
\hline
\end{tabular}

Grzegorczyk 2006

\begin{tabular}{ll}
\hline Methods & Randomised, parallel group study conducted in Poland. \\
\hline Participants & Adults undergoing stem cell transplantation. \\
\hline Interventions & 2 groups, placebo (methylcellulose) versus G-CSF ( $300 \mu \mathrm{g}$ in $2 \%$ methylcellulose). \\
\hline
\end{tabular}


Grzegorczyk 2006 (Continued)

Outcomes
Mucositis assessed using the WHO score. Other reported outcomes: granulocytes, patient report of pain.

Notes

Translation provided insufficient information. Discrepancy between graph legends and descriptions. Awaiting more information from translators.

Jellema 2006

\section{Methods}

Randomised, parallel group study conducted in The Netherlands. Clear information about withdrawals: 0. Unclear if dentist involved in study. Recruitment took place between August 1999 and August 2003.

\begin{tabular}{ll}
\hline Participants & Adults with head and neck cancer undergoing radiotherapy. \\
\hline Interventions & $\begin{array}{l}3 \text { groups, no treatment control versus amifostine }\left(200 \mathrm{mg} / \mathrm{m}^{2}\right) 5 \text { times weekly versus amifos- } \\
\text { tine }\left(200 \mathrm{mg} / \mathrm{m}^{2}\right) 3 \text { times weekly. Amifostine administered } 15-30 \text { minutes before irradiation. }\end{array}$ \\
\hline Outcomes & $\begin{array}{l}\text { Unclear how mucositis was assessed. Other reported outcomes: xerostomia, patient quality of life, } \\
\text { sticky saliva, locoregional control and survival. }\end{array}$ \\
\hline Notes & $\begin{array}{l}\text { Discrepancy between legend for Figure } 2 \text { and the text in this paper. Email sent. Awaiting clarifica- } \\
\text { tion from authors. }\end{array}$ \\
\hline
\end{tabular}

Peterson 2007

Methods Randomised, multicentre cross-over study conducted in Russia. Dentist involved in study. Duration: randomised to glutamine versus placebo in cycle 1 and then crossed over to alternative treatment in cycle 2.

\begin{tabular}{ll}
\hline Participants & Adults with breast cancer receiving chemotherapy. \\
\hline Interventions & Glutamine versus placebo. \\
\hline Outcomes & $\begin{array}{l}\text { Mucositis on OMAS scale. Mean score calculated as mean ulceration score across all sites. Mean ery- } \\
\text { thema score similarly calculated. Also WHO score assessed. Other outcomes: nausea, vomiting, dry } \\
\text { mouth. }\end{array}$ \\
\hline Notes & $\begin{array}{l}\text { Eligible if experienced WHO mucositis } \geq 2 \text { during screening cycle. Percentage of patients with WHO } \\
\text { scores } \geq 2 \text { presented } 1 \text { to } 21 \text { days in graph for each group during cycle } 1 \text {. Significant carry-over ef- } \\
\text { fect from cycle } 1 \text { to cycle } 2 \text {. Need to obtain further information from authors. }\end{array}$ \\
\hline
\end{tabular}

\section{Wu 2010}

\begin{tabular}{ll}
\hline Methods & $\begin{array}{l}\text { Randomised, parallel group study conducted in China. Recruited between February } 2006 \text { and May } \\
2007 .\end{array}$ \\
\hline Participants & Patients with nasopharyngeal carcinoma undergoing chemoradiotherapy. \\
\hline Interventions & $\begin{array}{l}\text { 3 groups; actovegin from start of chemo, actovegin from time of grade } 2 \text { mucositis, versus no treat- } \\
\text { ment. }\end{array}$ \\
\hline
\end{tabular}


Wu 2010 (Continued)

Outcomes $\quad \mathrm{NCl}-\mathrm{CTC}$ mucositis scale, pain, weight loss, adverse events.

Notes $\quad$ Full text paper published October 2010. To be included in next update.

\section{Yasuda 2011}

Methods

\section{Participants}

Interventions

Outcomes

Notes

Zhe 2000

Methods

\section{Participants}

Interventions

\section{Outcomes}

Notes

BMT = bone marrow transplant; G-CSF = granulocyte colony-stimulating factor; $\mathrm{NCl}-\mathrm{CTC}=$ National Cancer Institute - Common Toxicity Criteria; OMAS = oral mucosa assessment scale; RT = radiotherapy; RTOG = Radiation Therapy Oncology Group; VAS = visual analogue scale; WHO $=$ World Health Organization .

\section{DATA AND ANALYSES}

\section{Comparison 1. Allopurinol versus placebo/no treatment}

\begin{tabular}{lllll}
\hline Outcome or subgroup title & No. of studies & $\begin{array}{l}\text { No. of partici- } \\
\text { pants }\end{array}$ & Statistical method & Effect size \\
\hline 1.1 Mucositis (any) & 4 & & Risk Ratio (IV, Random, 95\% Cl) & $0.77[0.50,1.19]$ \\
\hline $\begin{array}{l}1.2 \text { Mucositis (moderate plus } \\
\text { severe) }\end{array}$ & 2 & 54 & Risk Ratio (M-H, Fixed, 95\% Cl) & $0.66[0.50,0.86]$ \\
\hline 1.3 Mucositis (severe) & 2 & 54 & Risk Ratio (M-H, Fixed, 95\% Cl) & $0.81[0.63,1.04]$ \\
\hline
\end{tabular}


Analysis 1.1. Comparison 1: Allopurinol versus placebo/no treatment, Outcome 1: Mucositis (any)

Risk Ratio

Study or Subgroup $\quad \log [R R] \quad$ SE $\quad$ Weight $\quad$ IV, Random, 95\% CI
Risk Ratio

IV, Random, 95\% CI

\begin{tabular}{lrrrr}
\hline Dozono 1989 & -1.2518 & 0.463 & $15.1 \%$ & $0.29[0.12,0.71]$ \\
Loprinzi 1990 & 0.167 & 0.205 & $31.6 \%$ & $1.18[0.79,1.77]$ \\
Abbasi-Nazari 2007 & -0.14 & 0.13 & $37.7 \%$ & $0.87[0.67,1.12]$ \\
Panahi 2009 & -0.46 & 0.45 & $15.6 \%$ & $0.63[0.26,1.52]$
\end{tabular}

Total (95\% CI)

$100.0 \%$

$0.77[0.50,1.19]$

Heterogeneity: $\mathrm{Tau}^{2}=0.11 ; \mathrm{Chi}^{2}=8.51, \mathrm{df}=3(\mathrm{P}=0.04) ; \mathrm{I}^{2}=65 \%$

Test for overall effect: $\mathrm{Z}=1.17(\mathrm{P}=0.24)$

Test for subgroup differences: Not applicable

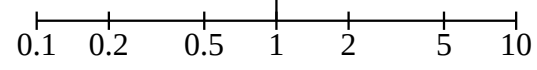

Favours allopurinol

Favours control

Analysis 1.2. Comparison 1: Allopurinol versus placebo/no treatment, Outcome 2: Mucositis (moderate plus severe)

\begin{tabular}{|c|c|c|c|c|c|c|c|}
\hline \multirow{2}{*}{ Study or Subgroup } & \multicolumn{2}{|c|}{ Allopurinol } & \multicolumn{2}{|c|}{ Control } & \multicolumn{2}{|r|}{ Risk Ratio } & Risk Ratio \\
\hline & Events & Total & Events & Total & Weight & M-H, Fixed, 95\% CI & M-H, Fixed, 95\% CI \\
\hline
\end{tabular}

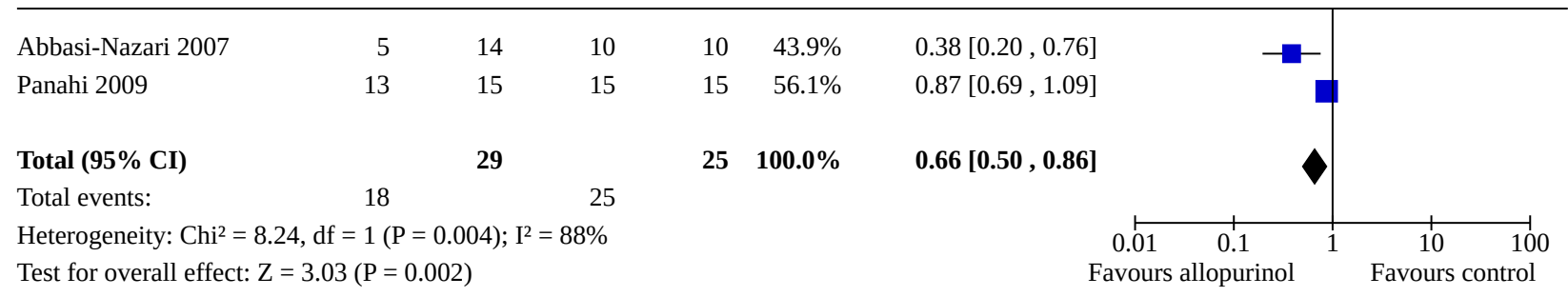

Test for subgroup differences: Not applicable

Analysis 1.3. Comparison 1: Allopurinol versus placebo/no treatment, Outcome 3: Mucositis (severe)

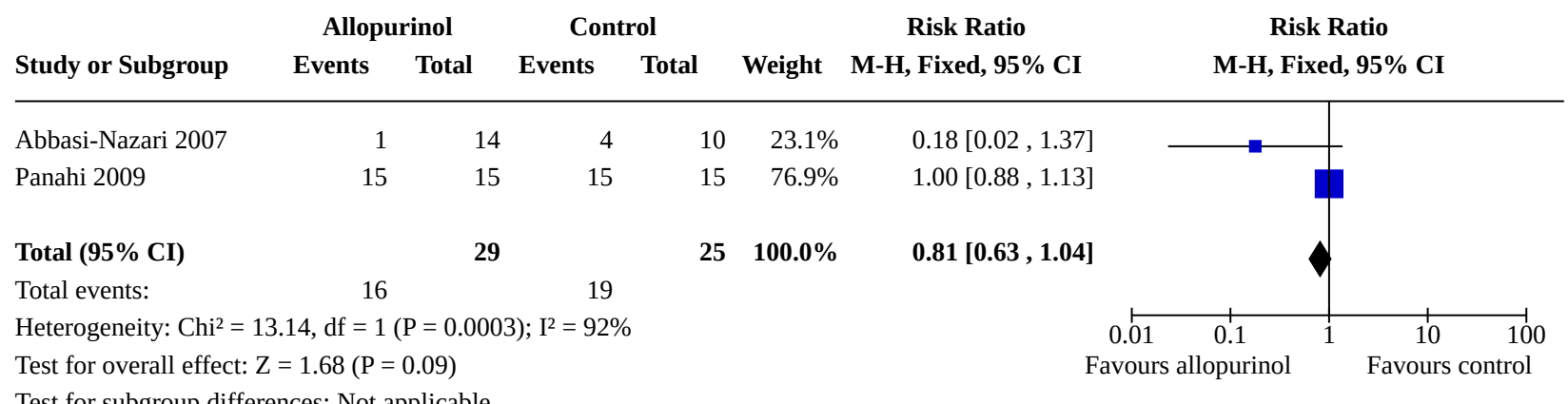

\section{Comparison 2. Aloe vera versus placebo}

\begin{tabular}{lllll}
\hline Outcome or subgroup title & No. of studies & $\begin{array}{l}\text { No. of partici- } \\
\text { pants }\end{array}$ & Statistical method & Effect size \\
\hline 2.1 Mucositis (moderate plus severe) & 2 & 119 & $\begin{array}{l}\text { Risk Ratio (M-H, Fixed, 95\% } \\
\text { Cl) }\end{array}$ & $0.74[0.58,0.96]$ \\
\hline
\end{tabular}




\section{Analysis 2.1. Comparison 2: Aloe vera versus placebo, Outcome 1: Mucositis (moderate plus severe)}

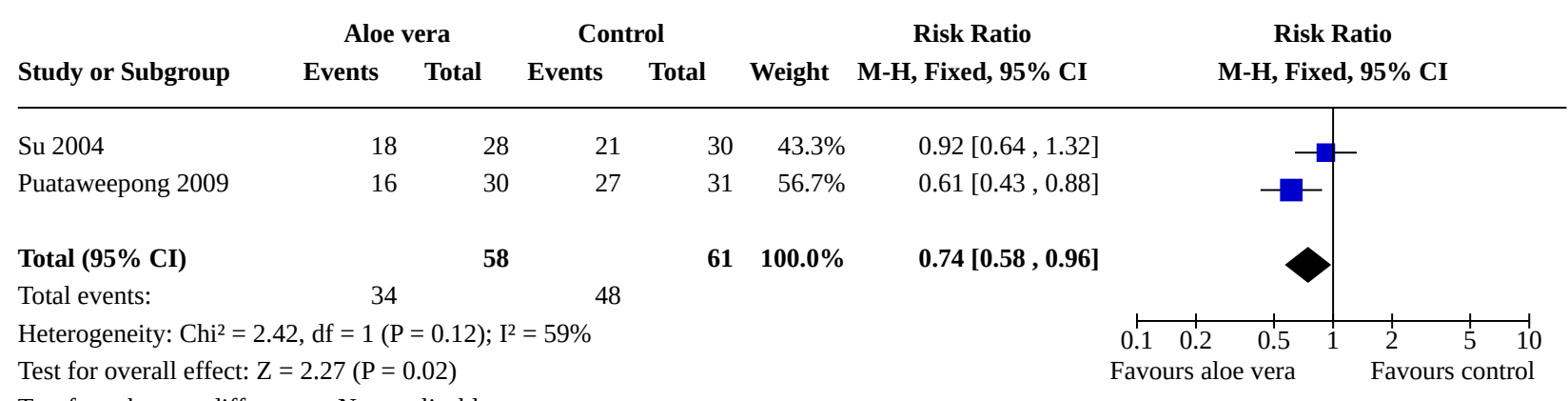

Test for subgroup differences: Not applicable

Comparison 3. Amifostine versus placebo/no treatment

\begin{tabular}{lllll}
\hline Outcome or subgroup title & No. of studies & $\begin{array}{l}\text { No. of partici- } \\
\text { pants }\end{array}$ & Statistical method & Effect size \\
\hline 3.1 Mucositis (any) & 3 & 430 & Risk Ratio (M-H, Random, 95\% Cl) & $0.95[0.91,0.99]$ \\
\hline $\begin{array}{l}3.2 \text { Mucositis (moderate plus } \\
\text { severe) }\end{array}$ & 6 & 757 & Risk Ratio (M-H, Random, 95\% Cl) & $0.75[0.58,0.96]$ \\
\hline 3.3 Mucositis (severe) & 9 & 845 & Risk Ratio (M-H, Random, 95\% Cl) & $0.68[0.45,1.03]$ \\
\hline
\end{tabular}

Analysis 3.1. Comparison 3: Amifostine versus placebo/no treatment, Outcome 1: Mucositis (any)

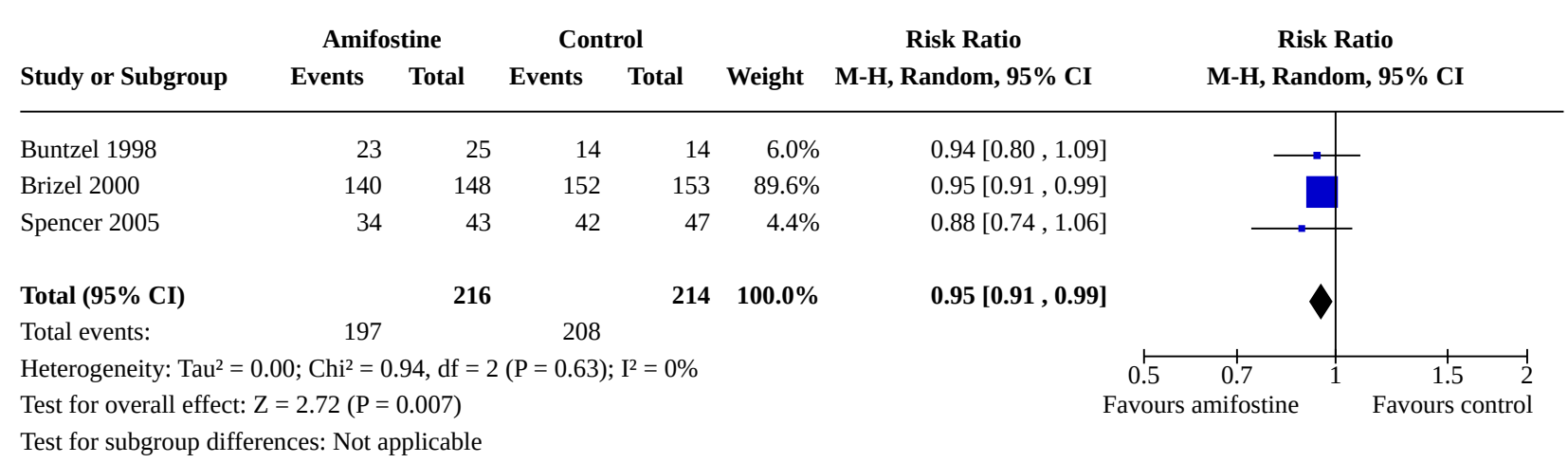


Analysis 3.2. Comparison 3: Amifostine versus placebo/no treatment, Outcome 2: Mucositis (moderate plus severe)

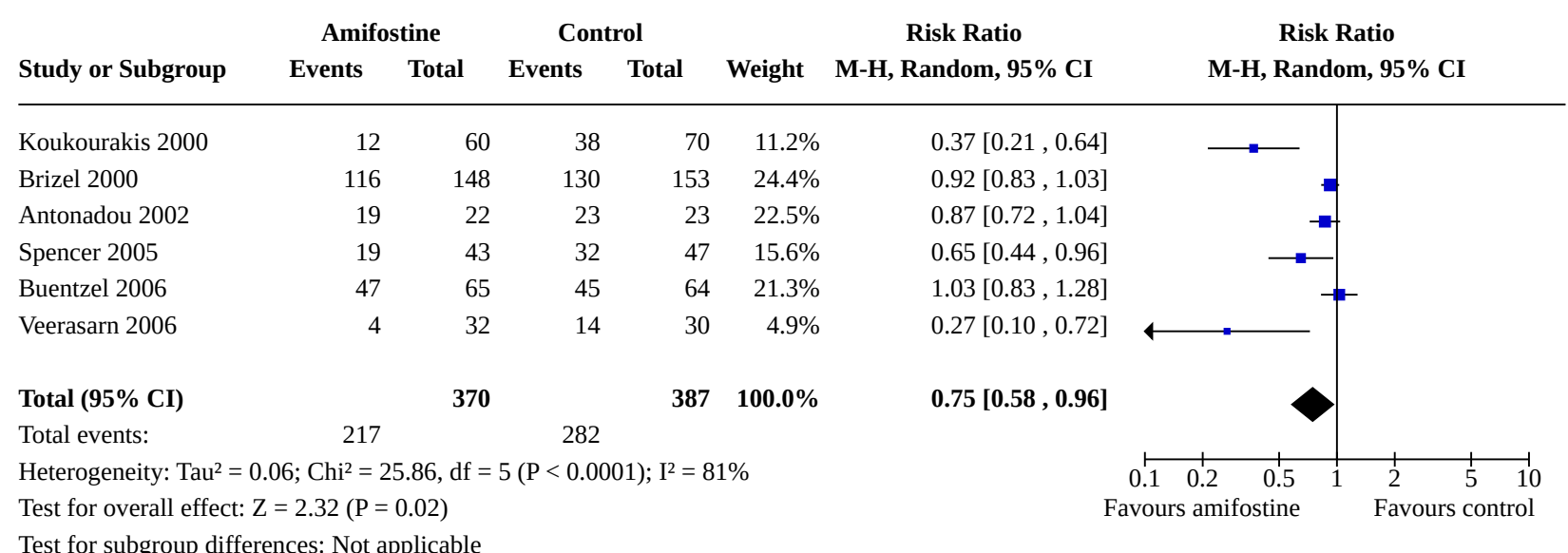

Analysis 3.3. Comparison 3: Amifostine versus placebo/no treatment, Outcome 3: Mucositis (severe)

\begin{tabular}{lcccccc} 
& \multicolumn{2}{c}{ Amifostine } & \multicolumn{2}{c}{ Control } & Risk Ratio & Risk Ratio \\
Study or Subgroup & Events & Total & Events $\quad$ Total & Weight & M-H, Random, 95\% CI & M-H, Random, 95\% CI
\end{tabular}

\begin{tabular}{|c|c|c|c|c|c|c|c|c|}
\hline Buntzel 1998 & 0 & 14 & 12 & 14 & $2.0 \%$ & $0.04[0.00,0.62]$ & $\vdash$ & \\
\hline Brizel 2000 & 52 & 148 & 60 & 153 & $16.7 \%$ & $0.90[0.67,1.20]$ & & - \\
\hline Bourhis 2000 & 11 & 12 & 11 & 12 & $17.2 \%$ & $1.00[0.79,1.27]$ & & \\
\hline Koukourakis 2000 & 1 & 60 & 15 & 70 & $3.5 \%$ & $0.08[0.01,0.57]$ & $\leftarrow$ & \\
\hline Hartmann 2001 & 5 & 20 & 10 & 20 & $10.0 \%$ & $0.50[0.21,1.20]$ & & - \\
\hline Antonadou 2002 & 5 & 22 & 18 & 23 & $10.8 \%$ & $0.29[0.13,0.65]$ & $\Rightarrow$ & \\
\hline Spencer 2005 & 5 & 43 & 15 & 47 & $9.6 \%$ & $0.36[0.14,0.92]$ & & \\
\hline Buentzel 2006 & 25 & 65 & 14 & 64 & $13.7 \%$ & $1.76[1.01,3.07]$ & & \\
\hline Haddad 2009 & 22 & 29 & 20 & 29 & $16.5 \%$ & $1.10[0.80,1.51]$ & & $=$ \\
\hline Total $(95 \% \mathrm{CI})$ & & 413 & & 432 & $100.0 \%$ & $0.68[0.45,1.03]$ & & \\
\hline Total events: & 126 & & 175 & & & & & \\
\hline \multicolumn{7}{|c|}{ Heterogeneity: $\mathrm{Tau}^{2}=0.24 ; \mathrm{Chi}^{2}=40.39, \mathrm{df}=8(\mathrm{P}<0.00001) ; \mathrm{I}^{2}=80 \%$} & $\begin{array}{ccc}\qquad & 1 & 1 \\
0.1 & 0.2 & 0.5\end{array}$ & $\begin{array}{lll}1 & 1 & 1 \\
2 & 5 & 10\end{array}$ \\
\hline
\end{tabular}

\section{Comparison 4. Chlorhexidine versus placebo/no treatment}

\begin{tabular}{lllll}
\hline Outcome or subgroup title & No. of studies & $\begin{array}{l}\text { No. of partici- } \\
\text { pants }\end{array}$ & Statistical method & Effect size \\
\hline 4.1 Mucositis (any) & 4 & 454 & Risk Ratio (M-H, Random, 95\% Cl) & $0.76[0.47,1.24]$ \\
\hline $\begin{array}{l}4.2 \text { Mucositis (moderate plus } \\
\text { severe) }\end{array}$ & 3 & 233 & Risk Ratio (M-H, Fixed, 95\% Cl) & $0.93[0.72,1.21]$ \\
\hline 4.3 Mucositis (severe) & 4 & 244 & Risk Ratio (M-H, Random, 95\% Cl) & $0.82[0.54,1.23]$ \\
\hline
\end{tabular}


Analysis 4.1. Comparison 4: Chlorhexidine versus placebo/no treatment, Outcome 1: Mucositis (any)

\begin{tabular}{|c|c|c|c|c|c|c|c|c|}
\hline \multirow[b]{2}{*}{ Study or Subgroup } & \multicolumn{2}{|c|}{ Chlorhexidine } & \multicolumn{2}{|c|}{ Control } & \multirow[b]{2}{*}{ Weight } & \multirow{2}{*}{$\begin{array}{c}\text { Risk Ratio } \\
\text { M-H, Random, 95\% CI }\end{array}$} & \multirow{2}{*}{$\begin{array}{c}\text { Risk Ratio } \\
\text { M-H, Random, 95\% CI }\end{array}$} & \\
\hline & Events & Total & Events & Total & & & & \\
\hline Ferretti 1988 & 4 & 23 & 13 & 23 & $14.2 \%$ & $0.31[0.12,0.80]$ & & \\
\hline Foote 1994 & 25 & 25 & 26 & 27 & $31.5 \%$ & $1.04[0.93,1.15]$ & J & \\
\hline Dodd 1996 & 26 & 112 & 28 & 110 & $24.8 \%$ & $0.91[0.57,1.45]$ & & \\
\hline Sorensen 2008 & 39 & 70 & 49 & 64 & $29.5 \%$ & $0.73[0.57,0.93]$ & $=$ & \\
\hline Total (95\% CI) & & 230 & & 224 & $100.0 \%$ & $0.76[0.47,1.24]$ & & \\
\hline Total events: & 94 & & 116 & & & & & \\
\hline \multicolumn{6}{|c|}{ Heterogeneity: $\mathrm{Tau}^{2}=0.19 ; \mathrm{Chi}^{2}=30.49, \mathrm{df}=3(\mathrm{P}<0.00001) ; \mathrm{I}^{2}=90 \%$} & 0.01 & 10 & 100 \\
\hline \multicolumn{6}{|c|}{ Test for overall effect: $\mathrm{Z}=1.10(\mathrm{P}=0.27)$} & Favours cl & orhexidine & trol \\
\hline
\end{tabular}

Test for subgroup differences: Not applicable

Analysis 4.2. Comparison 4: Chlorhexidine versus placebo/ no treatment, Outcome 2: Mucositis (moderate plus severe)

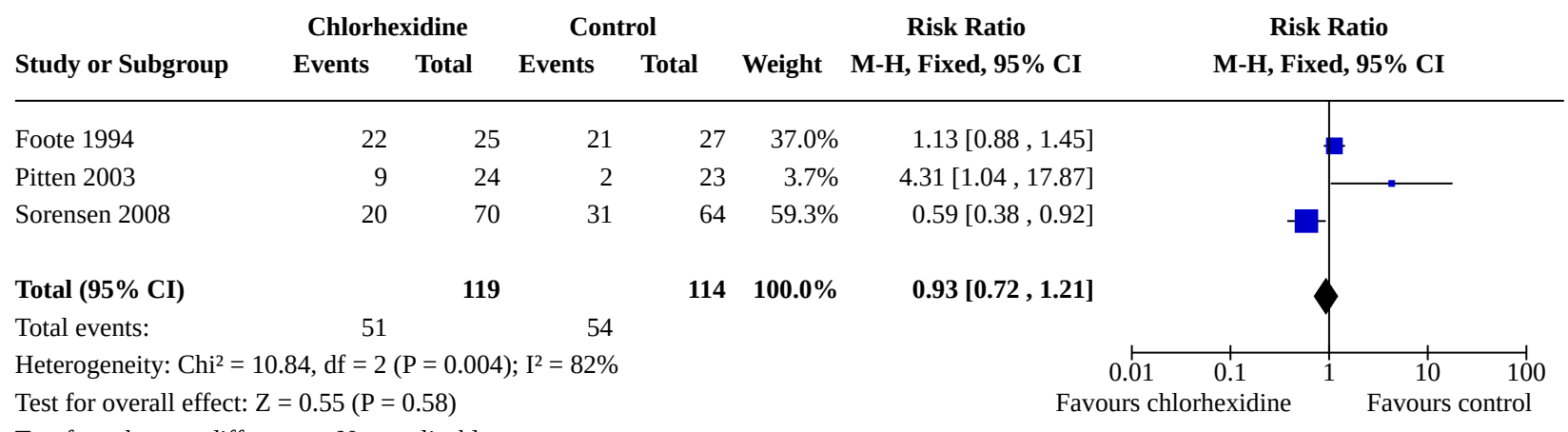

Test for subgroup differences: Not applicable

\section{Analysis 4.3. Comparison 4: Chlorhexidine versus placebo/no treatment, Outcome 3: Mucositis (severe)}

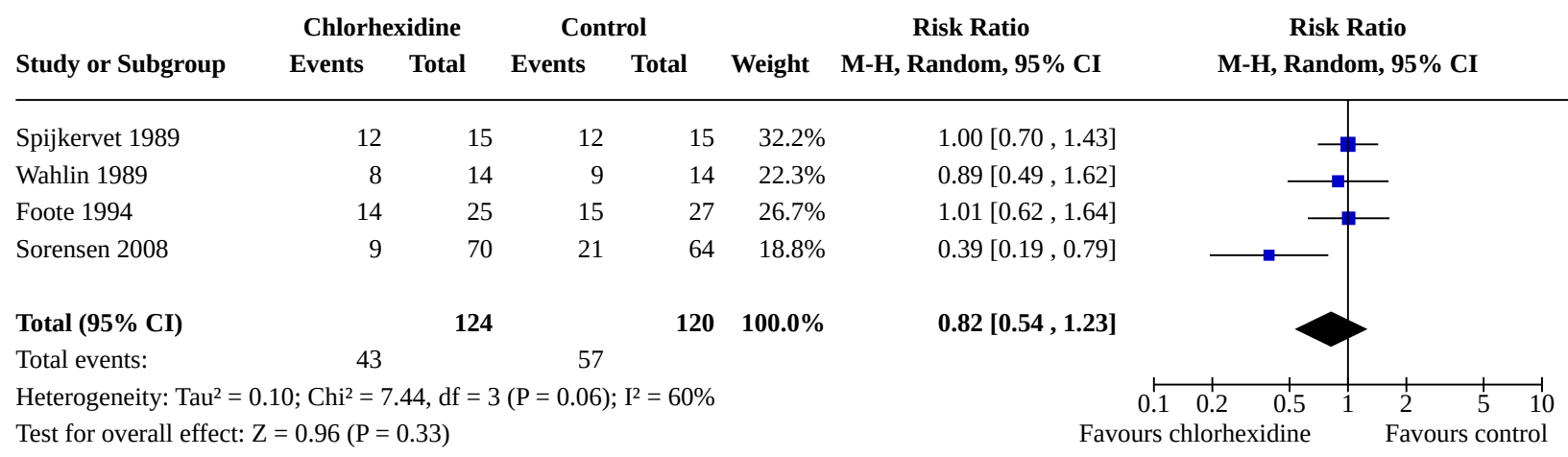


Comparison 5. Cryotherapy versus no treatment

\begin{tabular}{lllll}
\hline Outcome or subgroup title & No. of studies & $\begin{array}{l}\text { No. of partici- } \\
\text { pants }\end{array}$ & Statistical method & Effect size \\
\hline 5.1 Mucositis (any) & 5 & Risk Ratio (IV, Random, 95\% Cl) & $0.74[0.57,0.95]$ \\
\hline $\begin{array}{l}5.2 \text { Mucositis (moderate plus } \\
\text { severe) }\end{array}$ & 5 & Risk Ratio (IV, Random, 95\% Cl) & $0.53[0.31,0.91]$ \\
\hline 5.3 Mucositis (severe) & 5 & Risk Ratio (IV, Random, 95\% Cl) & $0.36[0.17,0.77]$ \\
\hline
\end{tabular}

Analysis 5.1. Comparison 5: Cryotherapy versus no treatment, Outcome 1: Mucositis (any)

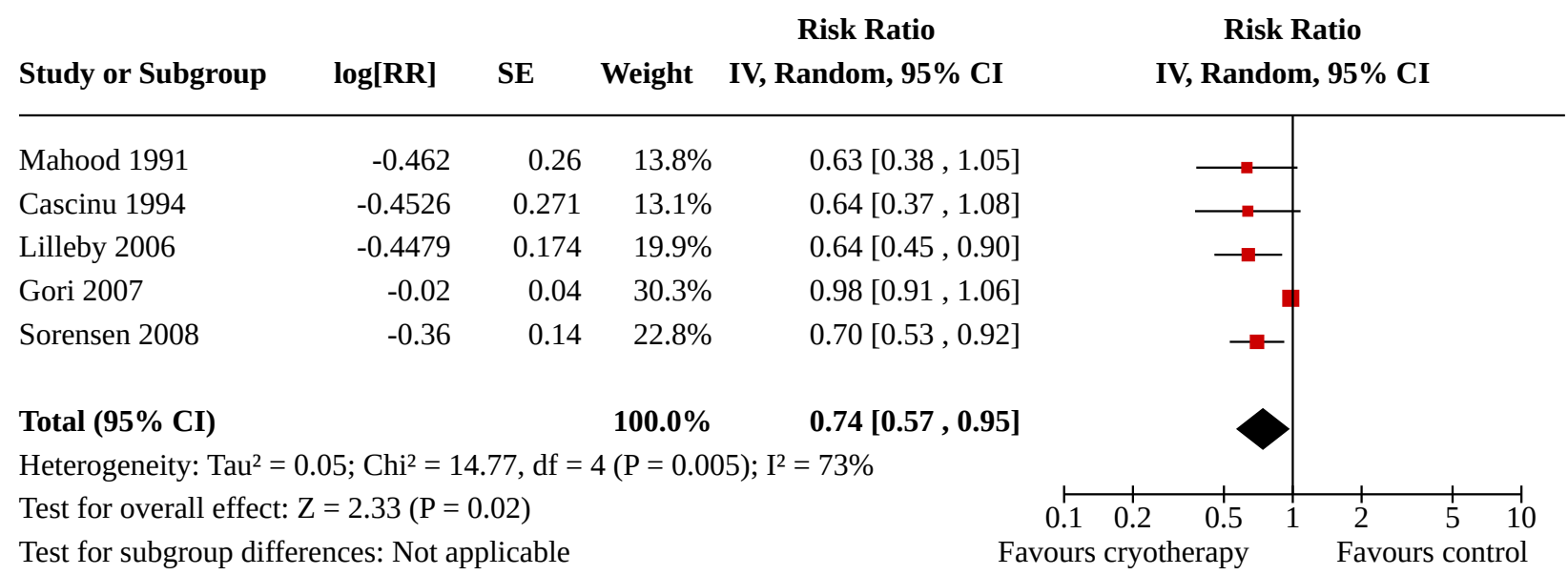

\section{Analysis 5.2. Comparison 5: Cryotherapy versus no treatment, Outcome 2: Mucositis (moderate plus severe)}

Risk Ratio

Study or Subgroup $\quad \log [R R] \quad$ SE $\quad$ Weight $\quad$ IV, Random, 95\% CI
Risk Ratio

IV, Random, 95\% CI

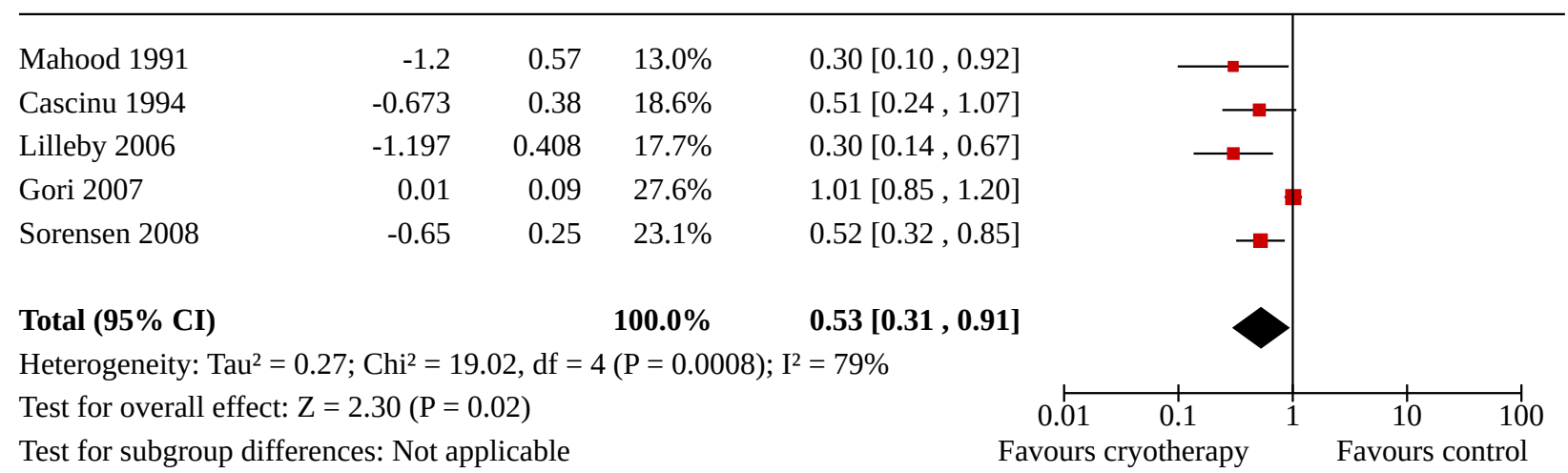




\section{Analysis 5.3. Comparison 5: Cryotherapy versus no treatment, Outcome 3: Mucositis (severe)}

Risk Ratio

Study or Subgroup $\quad \log [R R] \quad$ SE $\quad$ Weight $\quad$ IV, Random, 95\% CI
Risk Ratio

IV, Random, 95\% CI

\begin{tabular}{lrrrr}
\hline Mahood 1991 & -2.04 & 0.9 & $11.3 \%$ & $0.13[0.02,0.76]$ \\
Cascinu 1994 & -1.022 & 0.55 & $18.7 \%$ & $0.36[0.12,1.06]$ \\
Lilleby 2006 & -1.6399 & 0.552 & $18.6 \%$ & $0.19[0.07,0.57]$ \\
Gori 2007 & -0.13 & 0.18 & $28.8 \%$ & $0.88[0.62,1.25]$ \\
Sorensen 2008 & -1.08 & 0.41 & $22.6 \%$ & $0.34[0.15,0.76]$
\end{tabular}

Total (95\% CI)

$100.0 \%$

$0.36[0.17,0.77]$

Heterogeneity: $\mathrm{Tau}^{2}=0.47 ; \mathrm{Chi}^{2}=14.31, \mathrm{df}=4(\mathrm{P}=0.006) ; \mathrm{I}^{2}=72 \%$

Test for overall effect: $\mathrm{Z}=2.66(\mathrm{P}=0.008)$

Test for subgroup differences: Not applicable

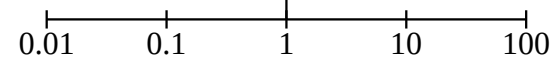

Favours cryotherapy

\section{Comparison 6. Glutamine versus placebo}

\begin{tabular}{|c|c|c|c|c|}
\hline Outcome or subgroup title & No. of studies & $\begin{array}{l}\text { No. of partici- } \\
\text { pants }\end{array}$ & Statistical method & Effect size \\
\hline 6.1 Mucositis (any) & 6 & & Risk Ratio (IV, Random, 95\% CI) & Subtotals only \\
\hline $\begin{array}{l}\text { 6.1.1 Oral suspension/supple- } \\
\text { mentation }\end{array}$ & 5 & & Risk Ratio (IV, Random, 95\% CI) & $0.78[0.57,1.08]$ \\
\hline 6.1.2 IV supplementation & 1 & & Risk Ratio (IV, Random, 95\% CI) & $0.33[0.04,2.63]$ \\
\hline $\begin{array}{l}6.2 \text { Mucositis (moderate plus se- } \\
\text { vere) }\end{array}$ & 6 & & Risk Ratio (IV, Random, 95\% CI) & Subtotals only \\
\hline $\begin{array}{l}\text { 6.2.1 Oral suspension/supple- } \\
\text { mentation }\end{array}$ & 5 & & Risk Ratio (IV, Random, 95\% Cl) & $0.88[0.69,1.12]$ \\
\hline 6.2.2 IV supplementation & 1 & & Risk Ratio (IV, Random, 95\% Cl) & $0.33[0.04,2.63]$ \\
\hline 6.3 Mucositis (severe) & 8 & & Risk Ratio (IV, Random, 95\% CI) & Subtotals only \\
\hline $\begin{array}{l}\text { 6.3.1 Oral suspension/supple- } \\
\text { mentation }\end{array}$ & 5 & & Risk Ratio (IV, Random, 95\% CI) & $0.69[0.37,1.29]$ \\
\hline 6.3.2 IV supplementation & 3 & & Risk Ratio (IV, Random, 95\% Cl) & $0.25[0.10,0.62]$ \\
\hline
\end{tabular}


Analysis 6.1. Comparison 6: Glutamine versus placebo, Outcome 1: Mucositis (any)

Risk Ratio

Study or Subgroup $\quad \log [R R] \quad$ SE $\quad$ Weight $\quad$ IV, Random, 95\% CI

\subsubsection{Oral suspension/supplementation}

$\begin{array}{lrrrr}\text { Jebb 1994 (1) } & -0.201 & 0.38 & 12.0 \% & 0.82[0.39,1.72] \\ \text { Anderson 1998 } & -0.478 & 0.22 & 20.9 \% & 0.62[0.40,0.95] \\ \text { Okuno 1999 } & 0.077 & 0.12 & 28.3 \% & 1.08[0.85,1.37] \\ \text { Li 2006 } & -0.05 & 0.14 & 26.9 \% & 0.95[0.72,1.25] \\ \text { Choi 2007 (2) } & -1.11 & 0.38 & 12.0 \% & 0.33[0.16,0.69] \\ \text { Subtotal (95\% CI) } & & & \mathbf{1 0 0 . 0} \% & \mathbf{0 . 7 8}[\mathbf{0 . 5 7}, \mathbf{1 . 0 8}]\end{array}$

Heterogeneity: $\mathrm{Tau}^{2}=0.08 ; \mathrm{Chi}^{2}=12.39, \mathrm{df}=4(\mathrm{P}=0.01) ; \mathrm{I}^{2}=68 \%$

Test for overall effect: $\mathrm{Z}=1.51(\mathrm{P}=0.13)$

\subsubsection{IV supplementation}

Sornsuvit 2008

$-1.11$

$1.06 \quad 100.0 \%$
$\mathbf{1 0 0 . 0} \%$

$100.0 \%$

$0.33[0.04,2.63]$

Subtotal (95\% CI)

Heterogeneity: Not applicable

Test for overall effect: $\mathrm{Z}=1.05(\mathrm{P}=0.30)$

\section{Footnotes}
(1) $15 \mathrm{~g} /$ day
(2) control = 'best supportive care'

Risk Ratio

IV, Random, 95\% CI 
Analysis 6.2. Comparison 6: Glutamine versus placebo, Outcome 2: Mucositis (moderate plus severe)

Risk Ratio

Study or Subgroup $\quad \log [R R] \quad$ SE $\quad$ Weight $\quad$ IV, Random, 95\% CI

\begin{tabular}{lrrrr}
\hline 6.2.1 Oral suspension/supplementation & & \\
Jebb $1994(1)$ & -0.3567 & 0.2 & $25.5 \%$ & $0.70[0.47,1.04]$ \\
Okuno 1999 & -0.0202 & 0.27 & $16.5 \%$ & $0.98[0.58,1.66]$ \\
Dickson 2000 & 0.058 & 0.2 & $25.5 \%$ & $1.06[0.72,1.57]$ \\
Huang $2000(2)$ & -0.02 & 0.18 & $29.1 \%$ & $0.98[0.69,1.39]$ \\
Choi $2007(3)$ & -1.24 & 0.66 & $3.4 \%$ & $0.29[0.08,1.06]$ \\
Subtotal (95\% CI) & & & $\mathbf{1 0 0 . 0 \%}$ & $\mathbf{0 . 8 8}[\mathbf{0 . 6 9}, \mathbf{1 . 1 2}]$
\end{tabular}

Heterogeneity: $\mathrm{Tau}^{2}=0.02 ; \mathrm{Chi}^{2}=5.52, \mathrm{df}=4(\mathrm{P}=0.24) ; \mathrm{I}^{2}=27 \%$

Test for overall effect: $\mathrm{Z}=1.02(\mathrm{P}=0.31)$

\subsubsection{IV supplementation}

Sornsuvit 2008

$-1.11$

$1.06 \quad 100.0 \%$

$100.0 \%$

$0.33[0.04,2.63]$

Subtotal (95\% CI)

Heterogeneity: Not applicable

Test for overall effect: $\mathrm{Z}=1.05(\mathrm{P}=0.30)$

\section{Footnotes}
(1) $15 \mathrm{~g} /$ day
(2) swish \& expectorate oral suspension
(3) control = 'best supportive care'

\section{Risk Ratio}

IV, Random, 95\% CI

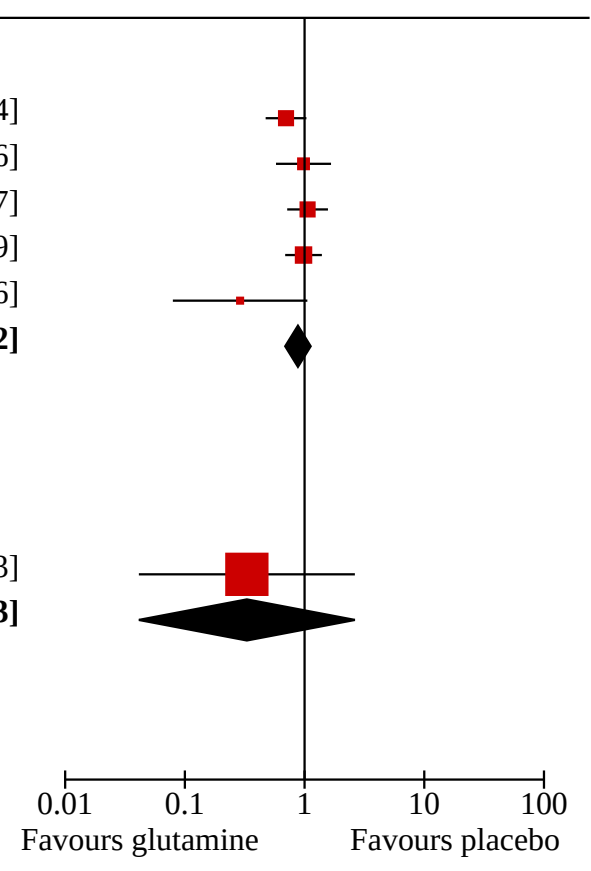




\section{Analysis 6.3. Comparison 6: Glutamine versus placebo, Outcome 3: Mucositis (severe)}

Risk Ratio

Study or Subgroup $\quad \log [R R] \quad$ SE $\quad$ Weight $\quad$ IV, Random, 95\% CI
Risk Ratio

IV, Random, 95\% CI

\subsubsection{Oral suspension/supplementation}

$\begin{array}{lrrrr}\text { Jebb 1994 (1) } & 0.2231 & 0.23 & 33.0 \% & 1.25[0.80,1.96] \\ \text { Anderson 1998 } & -1.109 & 0.46 & 21.9 \% & 0.33[0.13,0.81] \\ \text { Okuno 1999 } & -0.198 & 0.65 & 15.1 \% & 0.82[0.23,2.93] \\ \text { Huang 2000 } & -2.12 & 1.35 & 5.0 \% & 0.12[0.01,1.69] \\ \text { Li 2006 } & -0.29 & 0.39 & 25.0 \% & 0.75[0.35,1.61] \\ \text { Subtotal (95\% CI) } & & & \mathbf{1 0 0 . 0 \%} & \mathbf{0 . 6 9}[\mathbf{0 . 3 7}, \mathbf{1 . 2 9}]\end{array}$

Heterogeneity: $\mathrm{Tau}^{2}=0.26 ; \mathrm{Chi}^{2}=9.24, \mathrm{df}=4(\mathrm{P}=0.06) ; \mathrm{I}^{2}=57 \%$

Test for overall effect: $\mathrm{Z}=1.17(\mathrm{P}=0.24)$

\subsubsection{IV supplementation}

$\begin{array}{lrrrr}\text { Cerchietti } 2006 & -1.542 & 0.68 & 44.7 \% & 0.21[0.06,0.81] \\ \text { He 2008 } & -1.17 & 0.67 & 46.1 \% & 0.31[0.08,1.15] \\ \text { Sornsuvit 2008 } & -1.61 & 1.5 & 9.2 \% & 0.20[0.01,3.78] \\ \text { Subtotal (95\% CI) } & & & \mathbf{1 0 0 . 0 \%} & \mathbf{0 . 2 5}[\mathbf{0 . 1 0}, \mathbf{0 . 6 2}]\end{array}$

Heterogeneity: $\mathrm{Tau}^{2}=0.00 ; \mathrm{Chi}^{2}=0.18, \mathrm{df}=2(\mathrm{P}=0.91) ; \mathrm{I}^{2}=0 \%$

Test for overall effect: $\mathrm{Z}=3.03(\mathrm{P}=0.002)$

Footnotes

(1) $15 \mathrm{~g} /$ day crossover design

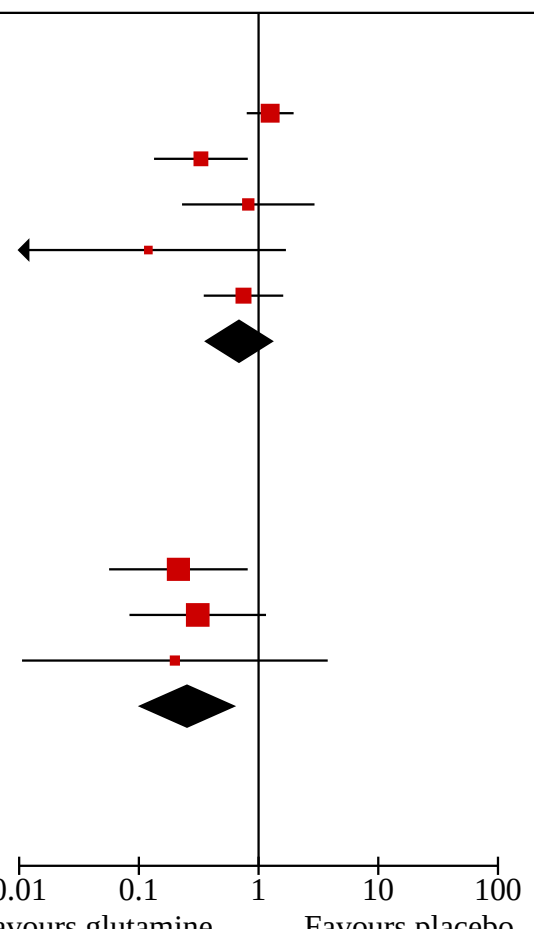

\begin{tabular}{lllll}
\hline Outcome or subgroup title & No. of studies & $\begin{array}{l}\text { No. of partici- } \\
\text { pants }\end{array}$ & Statistical method & Effect size \\
\hline 7.1 Mucositis (any) & 4 & 263 & Risk Ratio (M-H, Random, 95\% Cl) & $0.77[0.48,1.23]$ \\
\hline 7.2 Mucositis (severe) & 2 & 54 & Risk Ratio (M-H, Fixed, 95\% Cl) & $0.36[0.15,0.86]$ \\
\hline
\end{tabular}


Analysis 7.1. Comparison 7: G-CSF versus placebo or no treatment, Outcome 1: Mucositis (any)

\begin{tabular}{|c|c|c|c|c|c|c|c|c|c|}
\hline \multirow{3}{*}{$\begin{array}{l}\text { Study or Subgroup } \\
\text { Katano } 1995\end{array}$} & \multicolumn{2}{|c|}{ G-CSF } & \multicolumn{2}{|c|}{ Control } & \multirow[b]{2}{*}{ Weight } & \multirow{3}{*}{$\begin{array}{c}\text { Risk Ratio } \\
\text { M-H, Random, 95\% CI } \\
0.33[0.12,0.95]\end{array}$} & \multirow{2}{*}{\multicolumn{3}{|c|}{$\begin{array}{c}\text { Risk Ratio } \\
\text { M-H, Random, 95\% CI }\end{array}$}} \\
\hline & \multirow{2}{*}{$\begin{array}{r}\text { Events } \\
2\end{array}$} & \multirow{2}{*}{$\begin{array}{l}\text { Total } \\
7\end{array}$} & \multirow{2}{*}{$\begin{array}{r}\text { Events } \\
7\end{array}$} & \multirow{2}{*}{$\begin{array}{l}\text { Total } \\
7\end{array}$} & & & & & \\
\hline & & & & & $12.6 \%$ & & $\longmapsto$ & & \\
\hline Schneider 1999 & 8 & 8 & 6 & 6 & $30.0 \%$ & $1.00[0.77,1.30]$ & & & \\
\hline Crawford 1999 & 26 & 93 & 48 & 102 & $27.0 \%$ & $0.59[0.40,0.87]$ & & & \\
\hline Su 2006 & 17 & 19 & 18 & 21 & $30.5 \%$ & $1.04[0.83,1.32]$ & & & \\
\hline Total (95\% CI) & & 127 & & 136 & $100.0 \%$ & $0.77[0.48,1.23]$ & & & \\
\hline Total events: & 53 & & 79 & & & & & & \\
\hline Heterogeneity: $\mathrm{Tau}^{2}=$ & 17; $\mathrm{Chi}^{2}=2$ & $.48, \mathrm{df}=$ & $3(\mathrm{P}=0.00$ & $01) ; I^{2}=85$ & & & $0.2 \quad 1.5$ & 1 & 5 \\
\hline Test for overall effect & $=1.11(\mathrm{P}=$ & $0.27)$ & & & & & Favours G-CSF & Favours $c$ & trol \\
\hline
\end{tabular}

Test for subgroup differences: Not applicable

\section{Analysis 7.2. Comparison 7: G-CSF versus placebo or no treatment, Outcome 2: Mucositis (severe)}

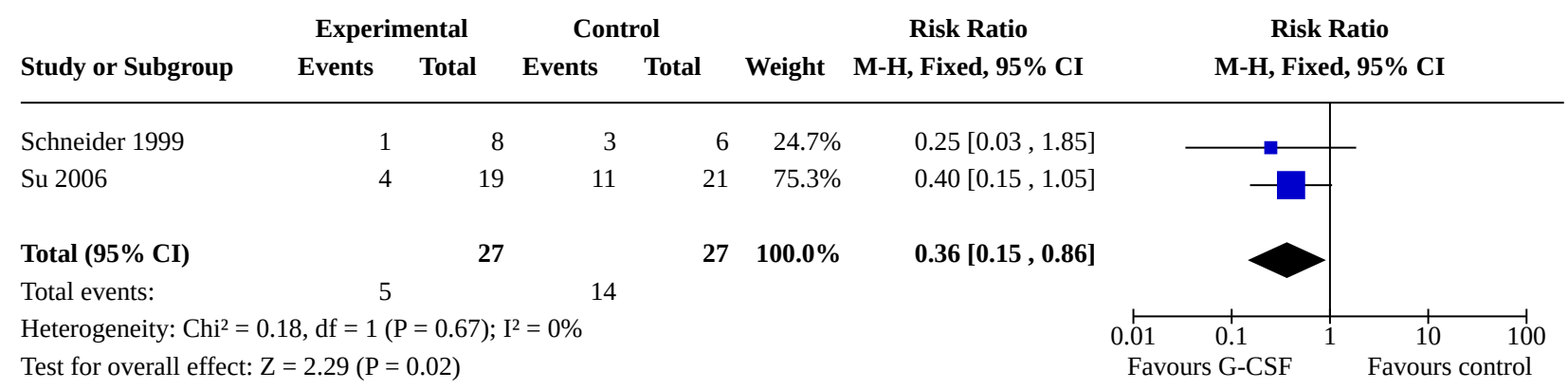

Test for subgroup differences: Not applicable

\section{Comparison 8. GM-CSF versus no treatment/placebo}

\begin{tabular}{lllll}
\hline Outcome or subgroup title & No. of studies & $\begin{array}{l}\text { No. of partici- } \\
\text { pants }\end{array}$ & Statistical method & Effect size \\
\hline 8.1 Mucositis (any) & 2 & 119 & Risk Ratio (M-H, Fixed, 95\% Cl) & $0.93[0.84,1.04]$ \\
\hline $\begin{array}{l}8.2 \text { Mucositis (moderate plus } \\
\text { severe) }\end{array}$ & 2 & 138 & Risk Ratio (M-H, Fixed, 95\% Cl) & $0.89[0.76,1.05]$ \\
\hline 8.3 Mucositis (severe) & 6 & 373 & Risk Ratio (M-H, Random, 95\% Cl) & $0.73[0.39,1.40]$ \\
\hline
\end{tabular}


Analysis 8.1. Comparison 8: GM-CSF versus no treatment/placebo, Outcome 1: Mucositis (any)

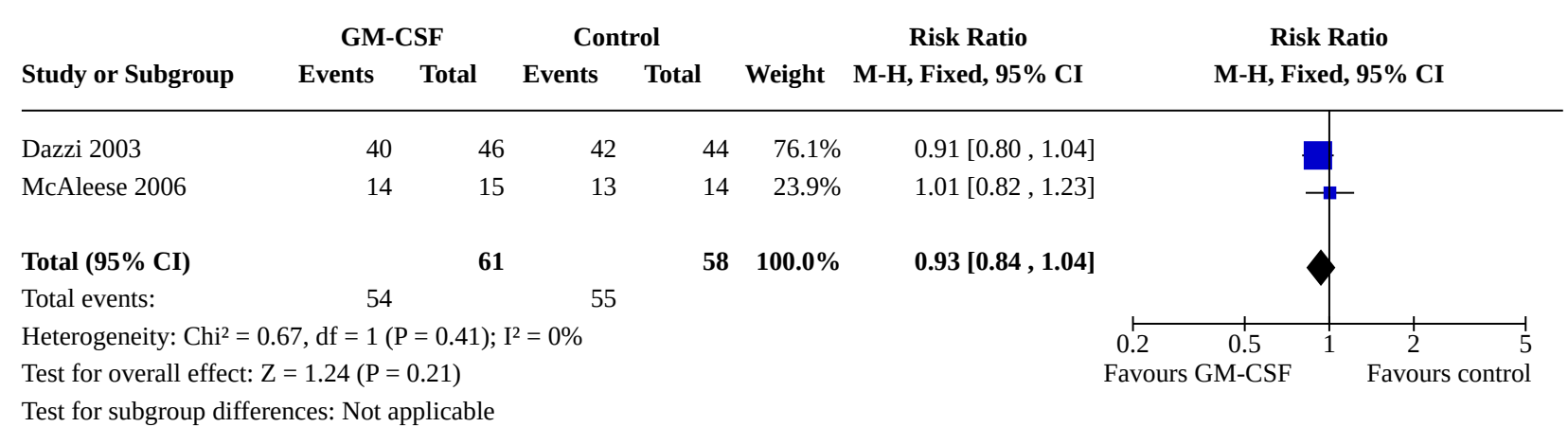

Analysis 8.2. Comparison 8: GM-CSF versus no treatment/placebo, Outcome 2: Mucositis (moderate plus severe)

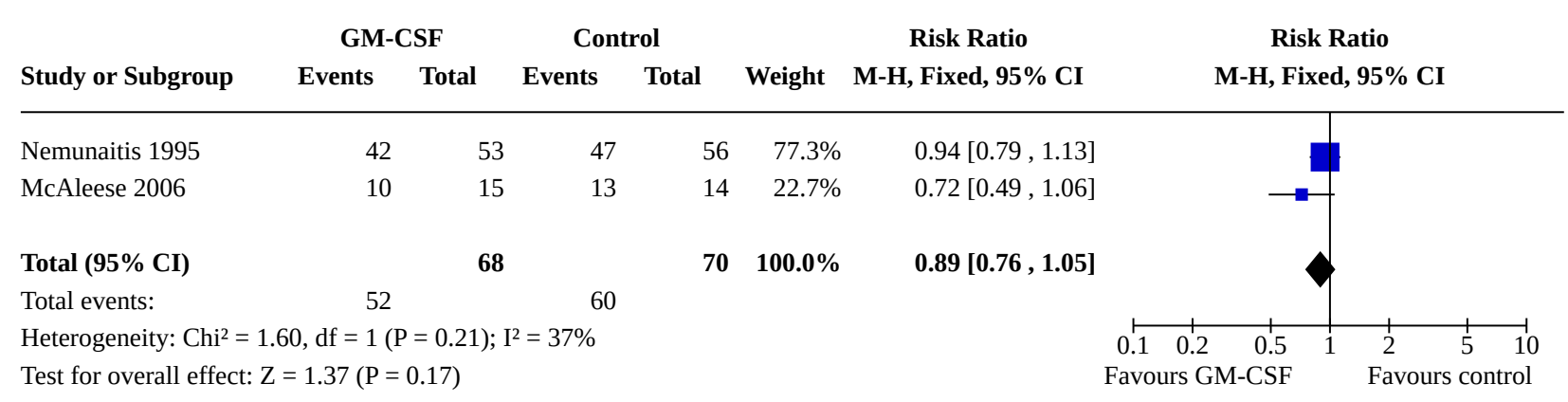

Test for subgroup differences: Not applicable

Analysis 8.3. Comparison 8: GM-CSF versus no treatment/placebo, Outcome 3: Mucositis (severe)

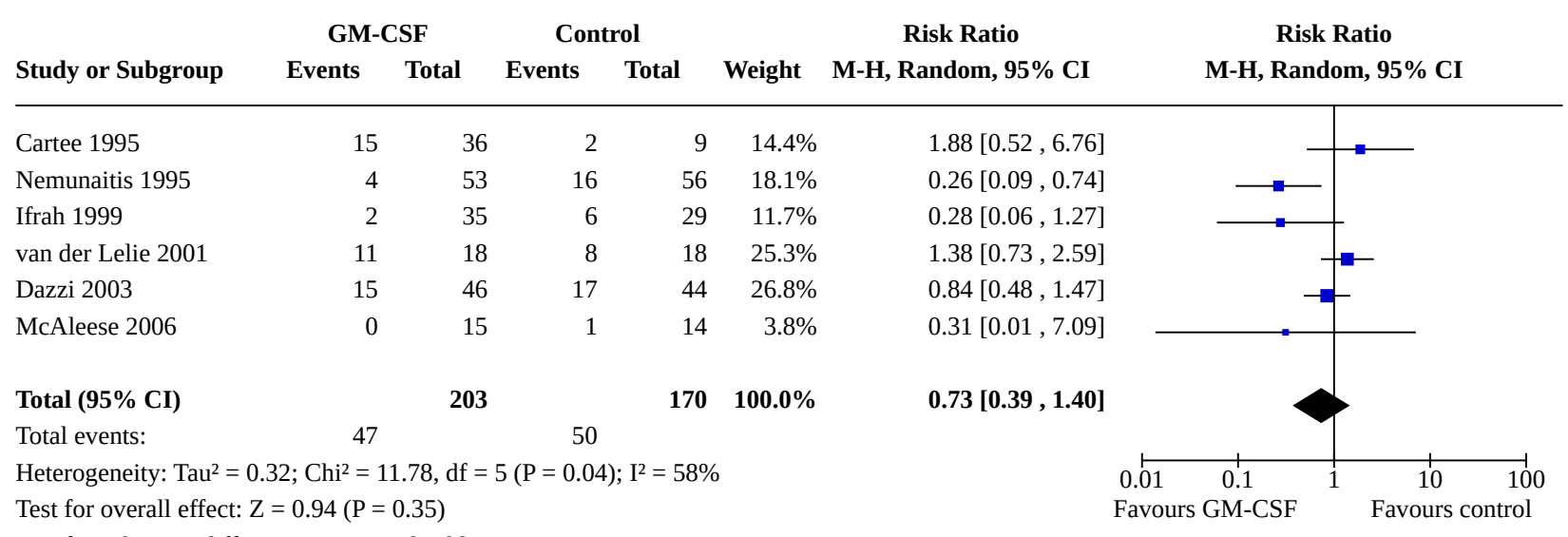

\section{Comparison 9. Honey versus control}

\begin{tabular}{lllll}
\hline Outcome or subgroup title & No. of studies & $\begin{array}{l}\text { No. of partici- } \\
\text { pants }\end{array}$ & Statistical method & Effect size \\
\hline 9.1 Mucositis (any) & 3 & 120 & Risk Ratio (M-H, Fixed, 95\% Cl) & $0.70[0.56,0.88]$ \\
\hline
\end{tabular}




\begin{tabular}{llllll}
\hline Outcome or subgroup title & No. of studies & $\begin{array}{l}\text { No. of partici- } \\
\text { pants }\end{array}$ & Statistical method & Effect size \\
\hline $\begin{array}{l}\text { 9.2 Mucositis (moderate plus } \\
\text { severe) }\end{array}$ & 2 & 80 & Risk Ratio (M-H, Fixed, 95\% Cl) & $0.48[0.31,0.74]$ \\
\hline 9.3 Mucositis (severe) & 2 & 80 & Risk Ratio (M-H, Fixed, 95\% Cl) & $0.26[0.13,0.52]$ \\
\hline
\end{tabular}

\section{Analysis 9.1. Comparison 9: Honey versus control, Outcome 1: Mucositis (any)}

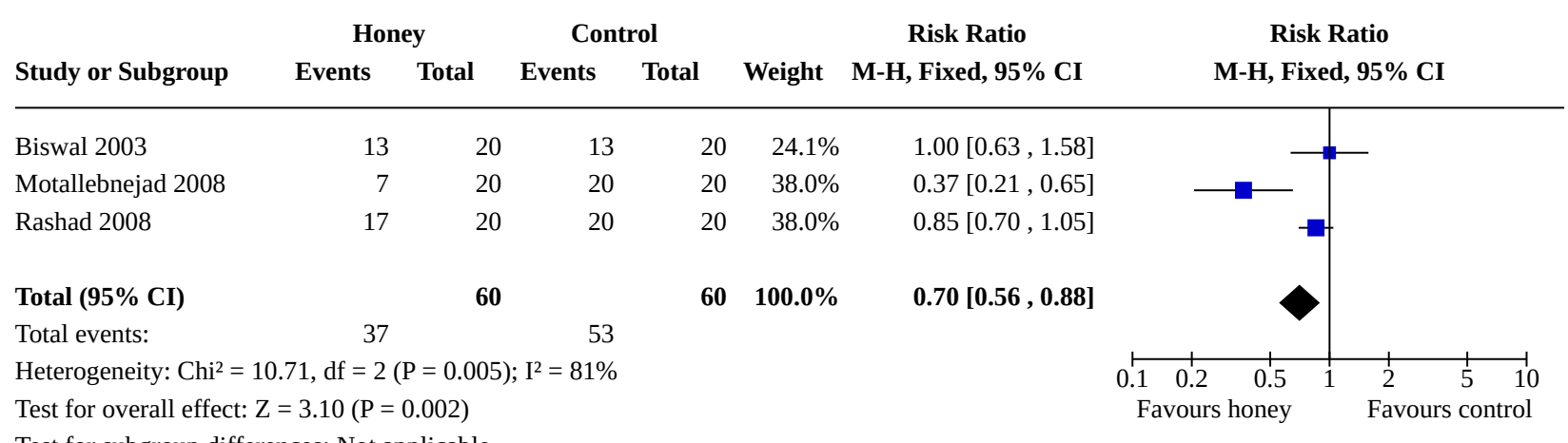

Test for subgroup differences: Not applicable

\section{Analysis 9.2. Comparison 9: Honey versus control, Outcome 2: Mucositis (moderate plus severe)}

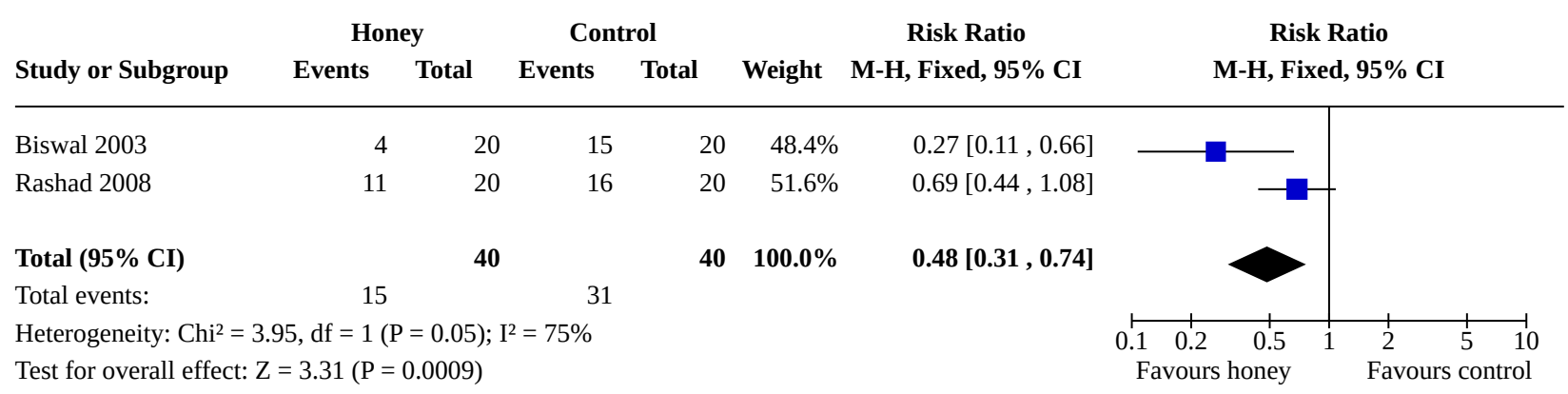

Test for subgroup differences: Not applicable

\section{Analysis 9.3. Comparison 9: Honey versus control, Outcome 3: Mucositis (severe)}

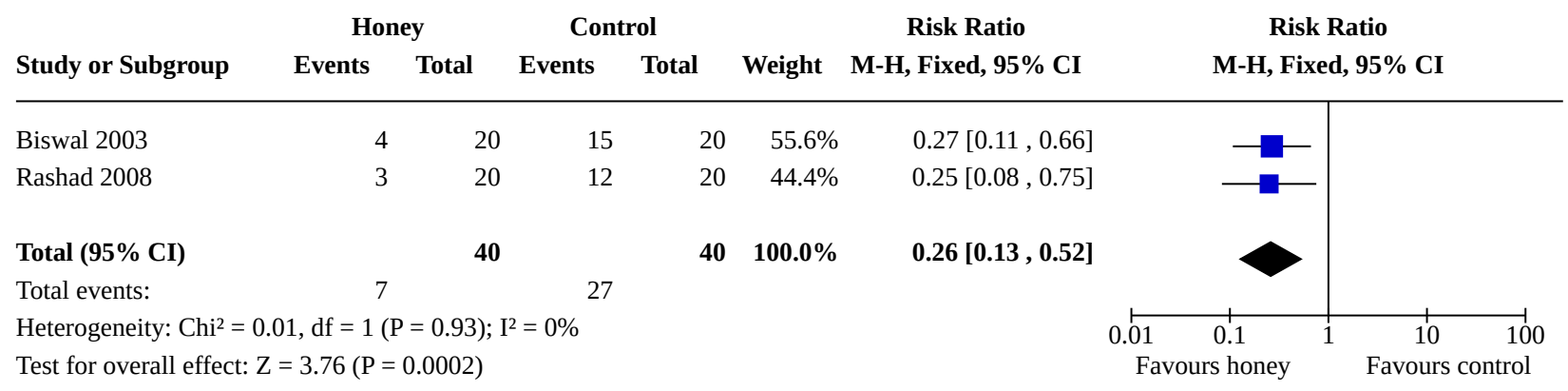


Comparison 10. Hydrolytic enzymes versus no treatment

\begin{tabular}{lllll}
\hline Outcome or subgroup title & No. of studies & $\begin{array}{l}\text { No. of partici- } \\
\text { pants }\end{array}$ & Statistical method & Effect size \\
\hline 10.1 Mucositis (any) & 2 & Risk Ratio (M-H, Fixed, 95\% Cl) & Totals not selected \\
\hline $\begin{array}{l}10.2 \text { Mucositis (moderate plus } \\
\text { severe) }\end{array}$ & 3 & Risk Ratio (M-H, Fixed, 95\% Cl) & Totals not selected \\
\hline
\end{tabular}

Analysis 10.1. Comparison 10: Hydrolytic enzymes versus no treatment, Outcome 1: Mucositis (any)

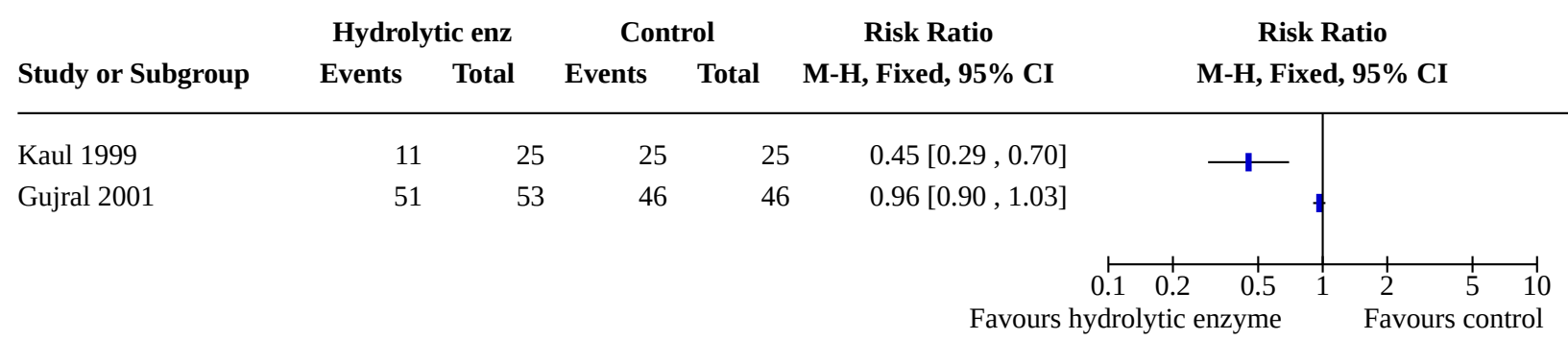

Analysis 10.2. Comparison 10: Hydrolytic enzymes versus no treatment, Outcome 2: Mucositis (moderate plus severe)

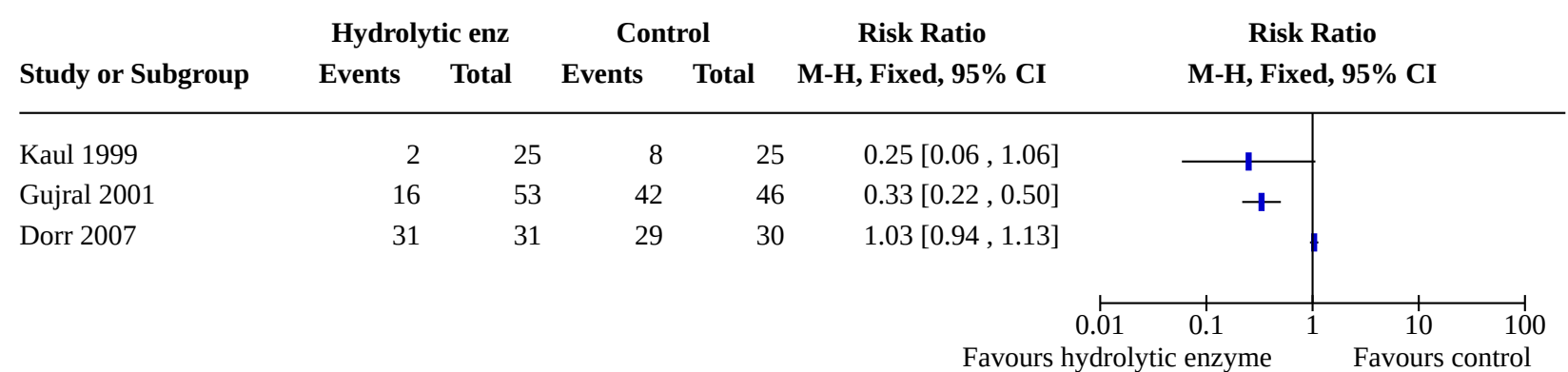

\section{Comparison 11. Iseganan versus placebo}

\begin{tabular}{lllll}
\hline Outcome or subgroup title & No. of studies & $\begin{array}{l}\text { No. of partici- } \\
\text { pants }\end{array}$ & Statistical method & Effect size \\
\hline $\begin{array}{l}11.1 \text { Mucositis (moderate plus se- } \\
\text { vere) }\end{array}$ & 2 & 926 & Risk Ratio (M-H, Fixed, 95\% Cl) & $0.95[0.89,1.03]$ \\
\hline 11.2 Mucositis (severe) & 2 & 926 & Risk Ratio (M-H, Fixed, 95\% Cl) & $0.99[0.89,1.10]$ \\
\hline
\end{tabular}


Analysis 11.1. Comparison 11: Iseganan versus placebo, Outcome 1: Mucositis (moderate plus severe)

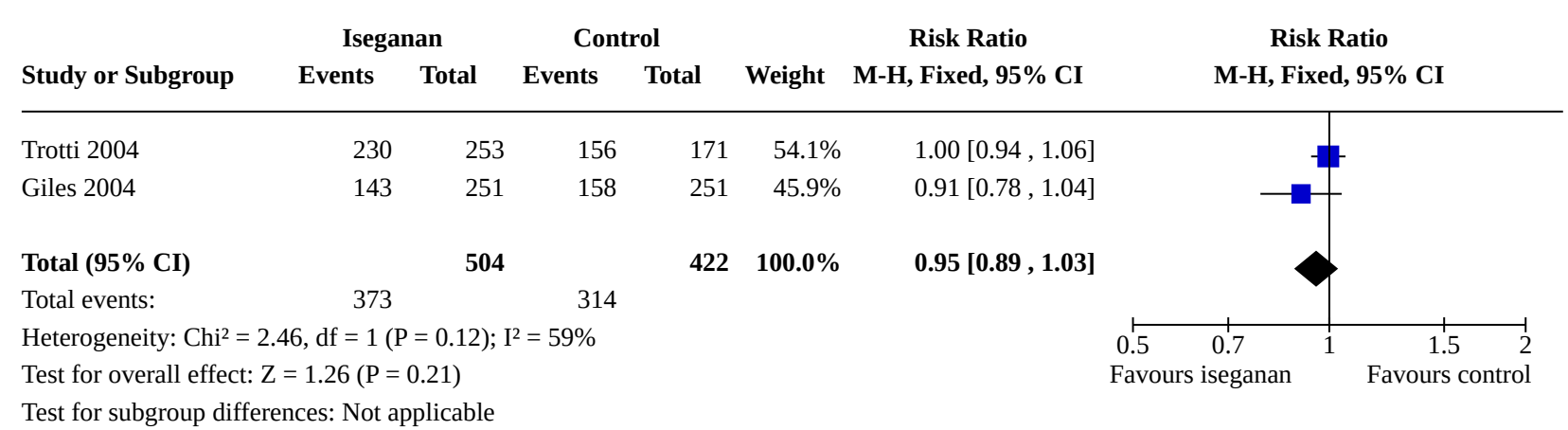

\section{Analysis 11.2. Comparison 11: Iseganan versus placebo, Outcome 2: Mucositis (severe)}

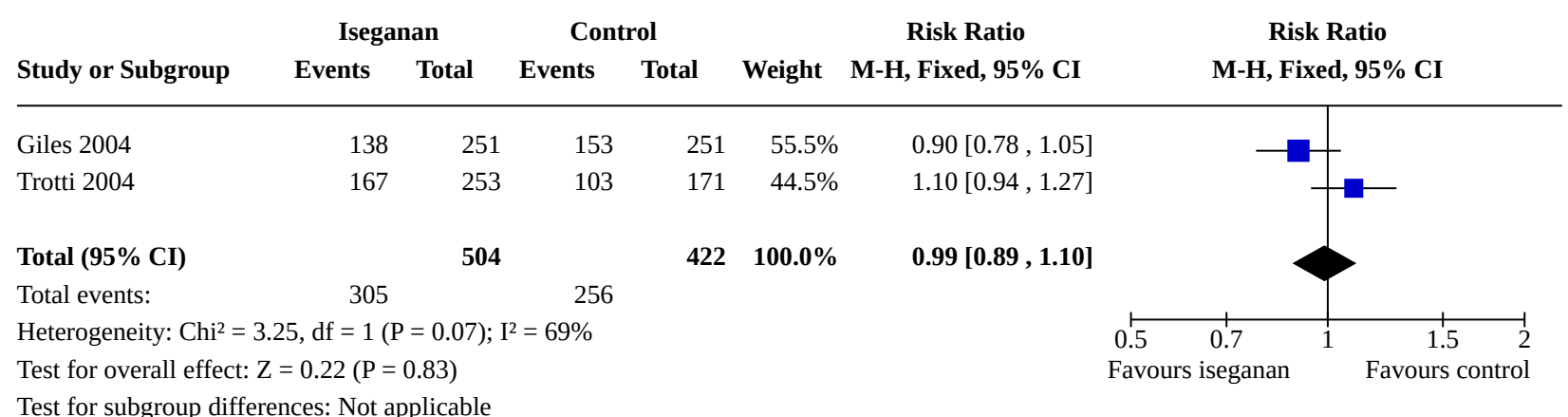

\section{Comparison 12. Keratinocyte GF versus placebo}

\begin{tabular}{|c|c|c|c|c|}
\hline Outcome or subgroup title & No. of studies & $\begin{array}{l}\text { No. of partici- } \\
\text { pants }\end{array}$ & Statistical method & Effect size \\
\hline 12.1 Mucositis (any) & 2 & 160 & Risk Ratio (M-H, Fixed, 95\% Cl) & $0.82[0.71,0.94]$ \\
\hline $\begin{array}{l}12.2 \text { Mucositis (moderate plus } \\
\text { severe) }\end{array}$ & 7 & 640 & Risk Ratio (M-H, Random, 95\% Cl) & $0.74[0.62,0.89]$ \\
\hline 12.3 Mucositis (severe) & 6 & 559 & Risk Ratio (M-H, Random, 95\% Cl) & $0.72[0.58,0.90]$ \\
\hline
\end{tabular}


Analysis 12.1. Comparison 12: Keratinocyte GF versus placebo, Outcome 1: Mucositis (any)

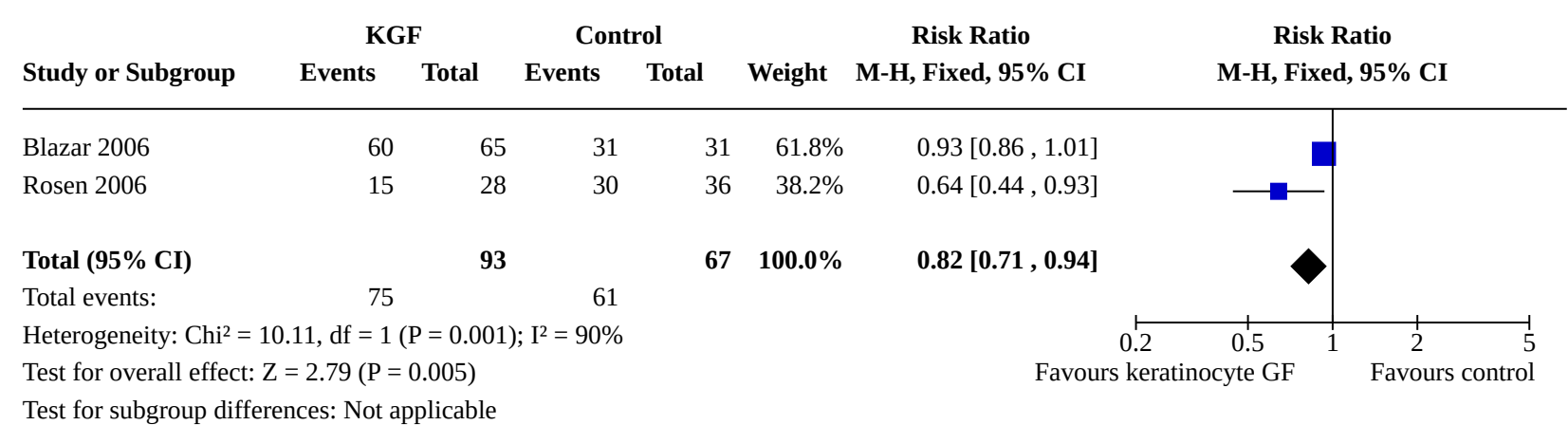

Analysis 12.2. Comparison 12: Keratinocyte GF versus placebo, Outcome 2: Mucositis (moderate plus severe)

\begin{tabular}{|c|c|c|c|c|c|c|c|c|}
\hline \multirow[b]{2}{*}{ Study or Subgroup } & \multicolumn{2}{|c|}{ KGF } & \multicolumn{2}{|c|}{ Control } & \multirow[b]{2}{*}{ Weight } & Risk Ratio & \multirow{2}{*}{\multicolumn{2}{|c|}{$\begin{array}{c}\text { Risk Ratio } \\
\text { M-H, Random, 95\% CI }\end{array}$}} \\
\hline & Events & Total & Events & Total & & M-H, Random, 95\% CI & & \\
\hline Meropol 2003 & 23 & 54 & 18 & 27 & $10.5 \%$ & $0.64[0.42,0.96]$ & & \\
\hline Freytes 2004 & 16 & 28 & 14 & 14 & $12.8 \%$ & $0.59[0.42,0.82]$ & $\longrightarrow$ & \\
\hline Spielberger 2004 & 98 & 106 & 106 & 106 & $21.3 \%$ & $0.92[0.87,0.98]$ & 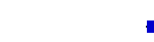 & \\
\hline Blazar 2006 & 53 & 65 & 31 & 31 & $19.7 \%$ & $0.82[0.73,0.93]$ & $=$ & \\
\hline Rosen 2006 & 8 & 28 & 22 & 36 & $6.0 \%$ & $0.47[0.25,0.89]$ & & \\
\hline Brizel 2008 & 60 & 65 & 31 & 32 & $20.6 \%$ & $0.95[0.87,1.05]$ & & \\
\hline Vadhan-Raj 2010 & 13 & 32 & 14 & 16 & $9.2 \%$ & $0.46[0.29,0.73]$ & & \\
\hline Total $(95 \% \mathrm{CI})$ & & 378 & & 262 & $100.0 \%$ & $0.74[0.62,0.89]$ & & \\
\hline Total events: & 271 & & 236 & & & & & \\
\hline \multicolumn{7}{|c|}{ Heterogeneity: $\mathrm{Tau}^{2}=0.04 ; \mathrm{Chi}^{2}=50.75, \mathrm{df}=6(\mathrm{P}<0.00001) ; \mathrm{I}^{2}=88 \%$} & 0.5 & 2 \\
\hline \multicolumn{6}{|c|}{ Test for overall effect: $\mathrm{Z}=3.15(\mathrm{P}=0.002)$} & Favours & tinocyte GF & Favour \\
\hline
\end{tabular}

Test for subgroup differences: Not applicable

Analysis 12.3. Comparison 12: Keratinocyte GF versus placebo, Outcome 3: Mucositis (severe)

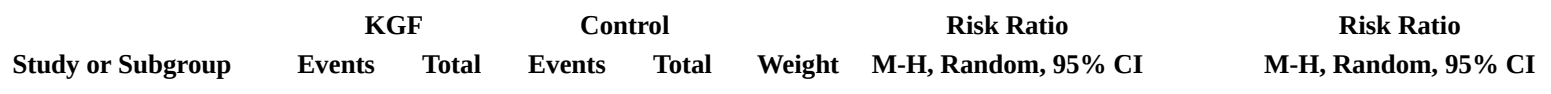

\begin{tabular}{|c|c|c|c|c|c|c|c|c|}
\hline Freytes 2004 & 4 & 28 & 1 & 14 & $1.1 \%$ & $2.00[0.25,16.26]$ & & \\
\hline Spielberger 2004 & 67 & 106 & 104 & 106 & $36.8 \%$ & $0.64[0.56,0.75]$ & - & \\
\hline Blazar 2006 & 43 & 65 & 24 & 31 & $27.7 \%$ & $0.85[0.66,1.11]$ & $\Rightarrow$ & \\
\hline Rosen 2006 & 1 & 28 & 4 & 36 & $1.1 \%$ & $0.32[0.04,2.72]$ & & \\
\hline Brizel 2008 & 43 & 65 & 26 & 32 & $29.1 \%$ & $0.81[0.64,1.04]$ & $\Rightarrow$ & \\
\hline Vadhan-Raj 2010 & 4 & 32 & 8 & 16 & $4.2 \%$ & $0.25[0.09,0.71]$ & $\longrightarrow$ & \\
\hline Total $(95 \%$ CI $)$ & & 324 & & 235 & $100.0 \%$ & $0.72[0.58,0.90]$ & $\Delta$ & \\
\hline Total events: & 162 & & 167 & & & & & \\
\hline \multicolumn{6}{|c|}{$\begin{array}{l}\text { Heterogeneity: } \mathrm{Tau}^{2}=0.03 ; \mathrm{Chi}^{2}=10.37, \mathrm{df}=5(\mathrm{P}=0.07) ; \mathrm{I}^{2}=52 \% \\
\text { Test for overall effect: } \mathrm{Z}=2.86(\mathrm{P}=0.004)\end{array}$} & $\begin{array}{r}0 \\
\text { Favours }\end{array}$ & $\begin{array}{cc}1 & 1 \\
0.1 & 1 \\
\text { inocyte GF }\end{array}$ & $\begin{array}{c}10 \quad 50 \\
\text { Favours control }\end{array}$ \\
\hline
\end{tabular}


Comparison 13. Laser versus no treatment

\begin{tabular}{|c|c|c|c|c|}
\hline Outcome or subgroup title & No. of studies & $\begin{array}{l}\text { No. of partici- } \\
\text { pants }\end{array}$ & Statistical method & Effect size \\
\hline 13.1 Mucositis (any) & 3 & 131 & Risk Ratio (M-H, Fixed, 95\% Cl) & $0.91[0.71,1.17]$ \\
\hline $\begin{array}{l}13.2 \text { Mucositis (moderate plus } \\
\text { severe) }\end{array}$ & 2 & 97 & Risk Ratio (M-H, Fixed, 95\% Cl) & $0.64[0.38,1.08]$ \\
\hline 13.3 Mucositis (severe) & 2 & 97 & Risk Ratio (M-H, Fixed, 95\% Cl) & $0.20[0.06,0.62]$ \\
\hline
\end{tabular}

Analysis 13.1. Comparison 13: Laser versus no treatment, Outcome 1: Mucositis (any)

\begin{tabular}{lcccccc} 
& \multicolumn{2}{c}{ Laser } & \multicolumn{2}{c}{ Control } & Risk Ratio & Risk Ratio \\
Study or Subgroup & Events & Total & Events $\quad$ Total & Weight & M-H, Fixed, 95\% CI & M-H, Fixed, 95\% CI
\end{tabular}

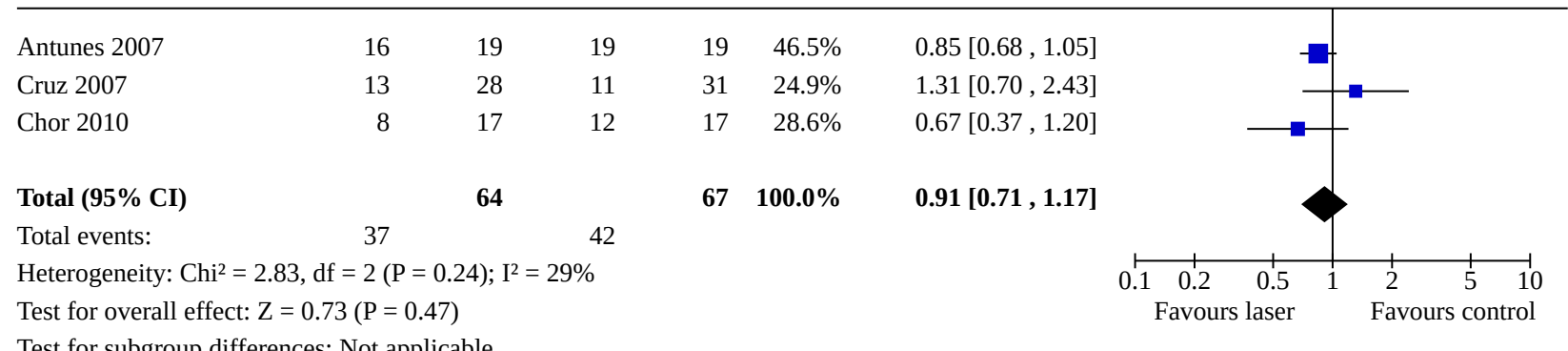

Test for subgroup differences: Not applicable

\section{Analysis 13.2. Comparison 13: Laser versus no treatment, Outcome 2: Mucositis (moderate plus severe)}

\begin{tabular}{|c|c|c|c|c|c|c|c|}
\hline \multirow{2}{*}{ Study or Subgroup } & \multicolumn{2}{|c|}{ Laser } & \multicolumn{2}{|c|}{ Control } & \multicolumn{2}{|r|}{ Risk Ratio } & \multirow{2}{*}{$\begin{array}{c}\text { Risk Ratio } \\
\text { M-H, Fixed, 95\% CI }\end{array}$} \\
\hline & Events & Total & Events & Total & Weight & M-H, Fixed, 95\% CI & \\
\hline
\end{tabular}

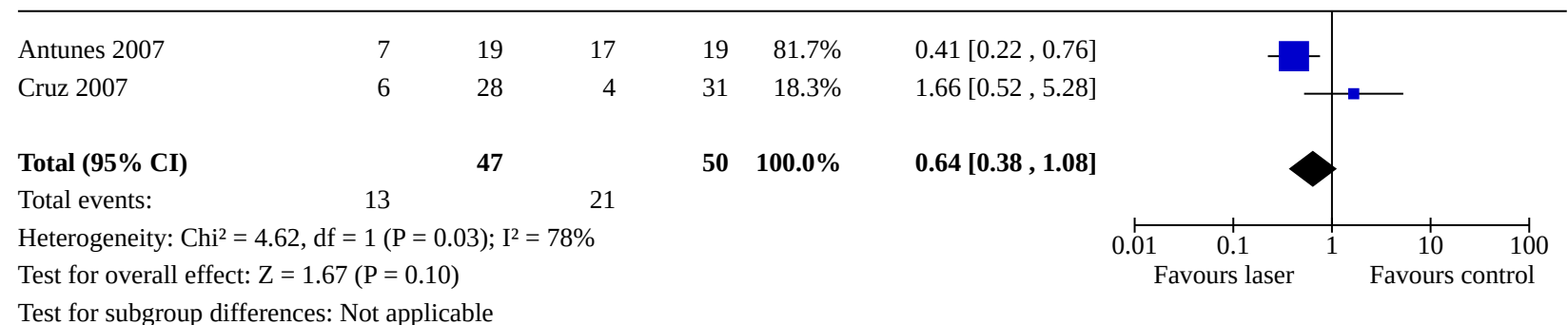


Analysis 13.3. Comparison 13: Laser versus no treatment, Outcome 3: Mucositis (severe)

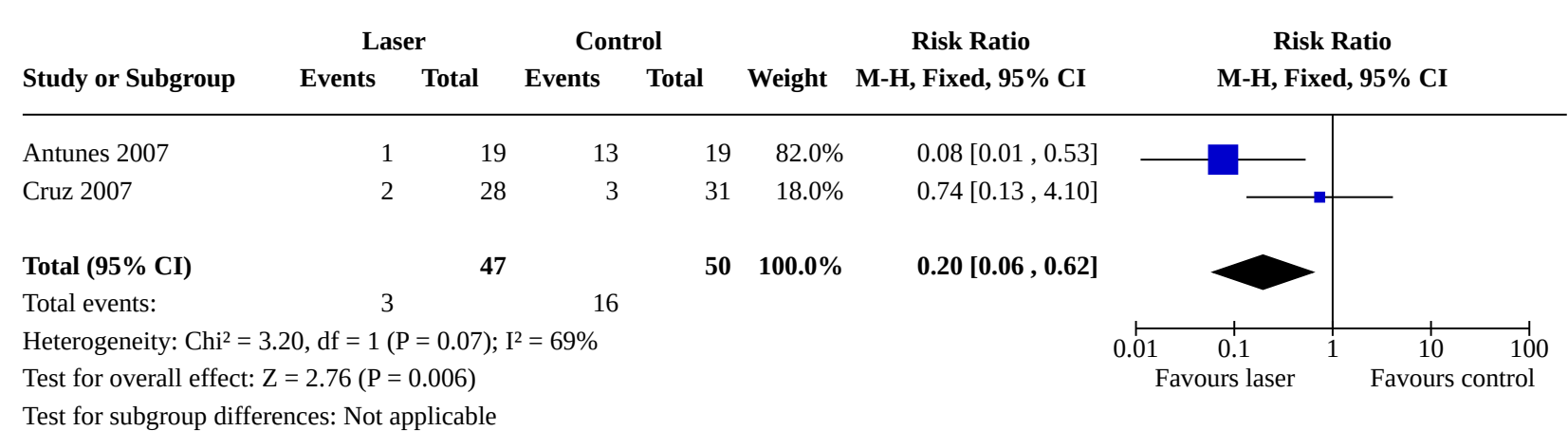

\section{Comparison 14. Pilocarpine versus placebo}

\begin{tabular}{lllll}
\hline Outcome or subgroup title & No. of studies & $\begin{array}{l}\text { No. of partici- } \\
\text { pants }\end{array}$ & Statistical method & Effect size \\
\hline 14.1 Mucositis (any) & 2 & 276 & Risk Ratio (M-H, Fixed, 95\% Cl) & $1.05[1.00,1.10]$ \\
\hline $\begin{array}{l}14.2 \text { Mucositis (moderate plus se- } \\
\text { vere) }\end{array}$ & 2 & 276 & Risk Ratio (M-H, Fixed, 95\% Cl) & $1.05[0.94,1.16]$ \\
\hline
\end{tabular}

Analysis 14.1. Comparison 14: Pilocarpine versus placebo, Outcome 1: Mucositis (any)

\begin{tabular}{|c|c|c|c|c|c|c|c|c|c|}
\hline \multirow{3}{*}{$\begin{array}{l}\text { Study or Subgroup } \\
\text { Lockhart } 2005\end{array}$} & \multicolumn{2}{|c|}{ Pilocarpine } & \multicolumn{2}{|c|}{ Control } & \multirow[b]{2}{*}{ Weight } & \multirow{2}{*}{$\begin{array}{c}\text { Risk Ratio } \\
\text { M-H, Fixed, 95\% CI }\end{array}$} & \multirow{2}{*}{\multicolumn{2}{|c|}{$\begin{array}{c}\text { Risk Ratio } \\
\text { M-H, Fixed, 95\% CI }\end{array}$}} & \\
\hline & Events & Total & Events & Total & & & & & \\
\hline & 17 & 18 & 16 & 16 & $13.3 \%$ & $0.95[0.81,1.11]$ & - & - & \\
\hline Scarantino 2006 & 119 & 120 & 114 & 122 & $86.7 \%$ & $1.06[1.01,1.12]$ & & & \\
\hline Total (95\% CI) & & 138 & & 138 & $100.0 \%$ & $1.05[1.00,1.10]$ & & & \\
\hline Total events: & 136 & & 130 & & & & & & \\
\hline \multicolumn{4}{|c|}{ Heterogeneity: $\mathrm{Chi}^{2}=1.83, \mathrm{df}=1(\mathrm{P}=0.18) ; \mathrm{I}^{2}=45 \%$} & & & & 0.7 & 1.5 & \\
\hline \multicolumn{4}{|c|}{ Test for overall effect: $\mathrm{Z}=1.86(\mathrm{P}=0.06)$} & & & & Favours pilocarpine & Favours & \\
\hline
\end{tabular}

\section{Analysis 14.2. Comparison 14: Pilocarpine versus placebo, Outcome 2: Mucositis (moderate plus severe)}

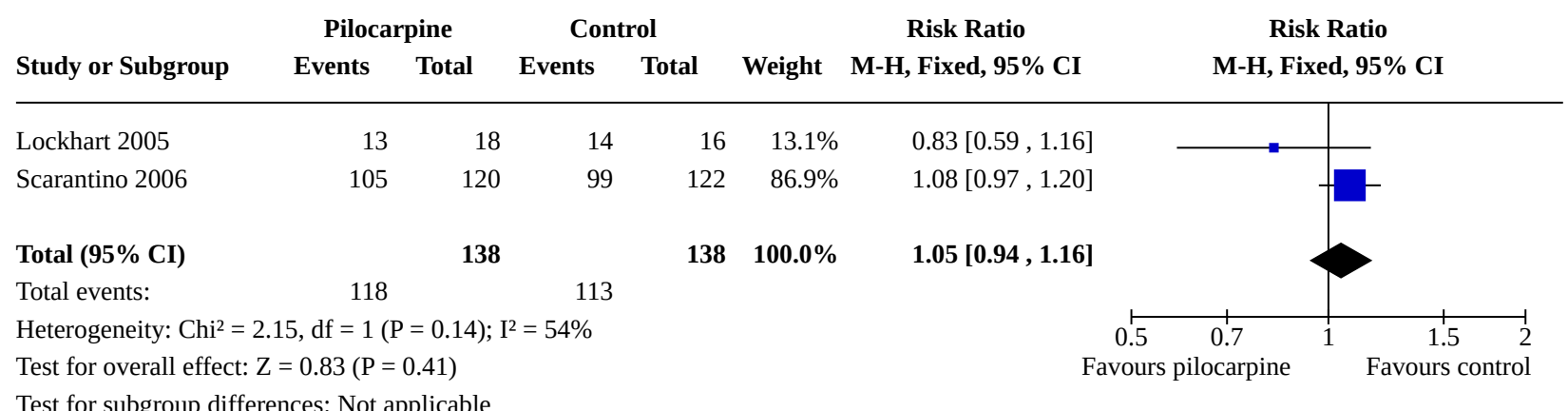


Comparison 15. Povidone versus water

\begin{tabular}{llllll}
\hline Outcome or subgroup title & No. of studies & $\begin{array}{l}\text { No. of partici- } \\
\text { pants }\end{array}$ & Statistical method & Effect size \\
\hline 15.1 Mucositis (any) & 2 & 172 & Risk Ratio (M-H, Fixed, 95\% Cl) & $0.90[0.76,1.08]$ \\
\hline $\begin{array}{l}15.2 \text { Mucositis (moderate plus } \\
\text { severe) }\end{array}$ & 2 & 172 & Risk Ratio (M-H, Fixed, 95\% Cl) & $0.82[0.62,1.10]$ \\
\hline \begin{tabular}{l}
15.3 Mucositis (severe) \\
\hline
\end{tabular} & 2 & 172 & Risk Ratio (M-H, Fixed, 95\% Cl) & $0.65[0.40,1.06]$ \\
\hline
\end{tabular}

Analysis 15.1. Comparison 15: Povidone versus water, Outcome 1: Mucositis (any)

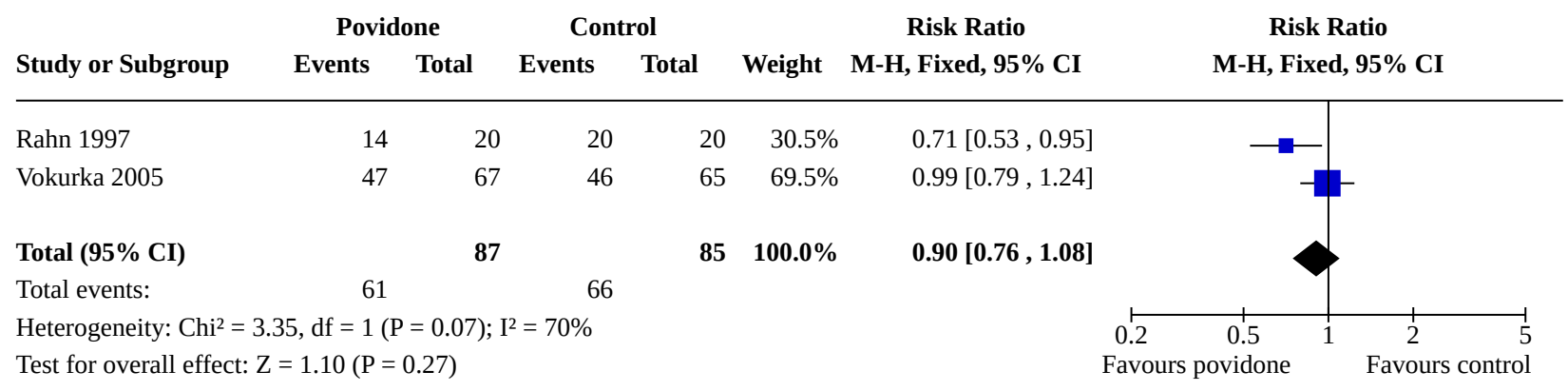

Test for subgroup differences: Not applicable

\section{Analysis 15.2. Comparison 15: Povidone versus water, Outcome 2: Mucositis (moderate plus severe)}

$\begin{array}{llll}\text { Povidone Control Risk Ratio Ratio } & \text { Risk Rel }\end{array}$

Study or Subgroup $\quad$ Events $\quad$ Total $\quad$ Events $\quad$ Total $\quad$ Weight $\quad$ M-H, Fixed, 95\% CI $\quad$ M-H, Fixed, 95\% CI

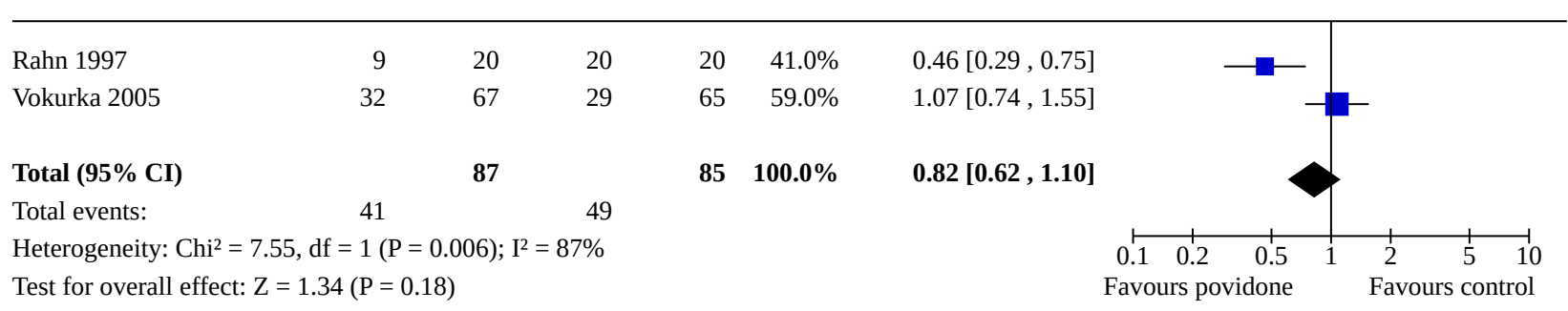


Analysis 15.3. Comparison 15: Povidone versus water, Outcome 3: Mucositis (severe)

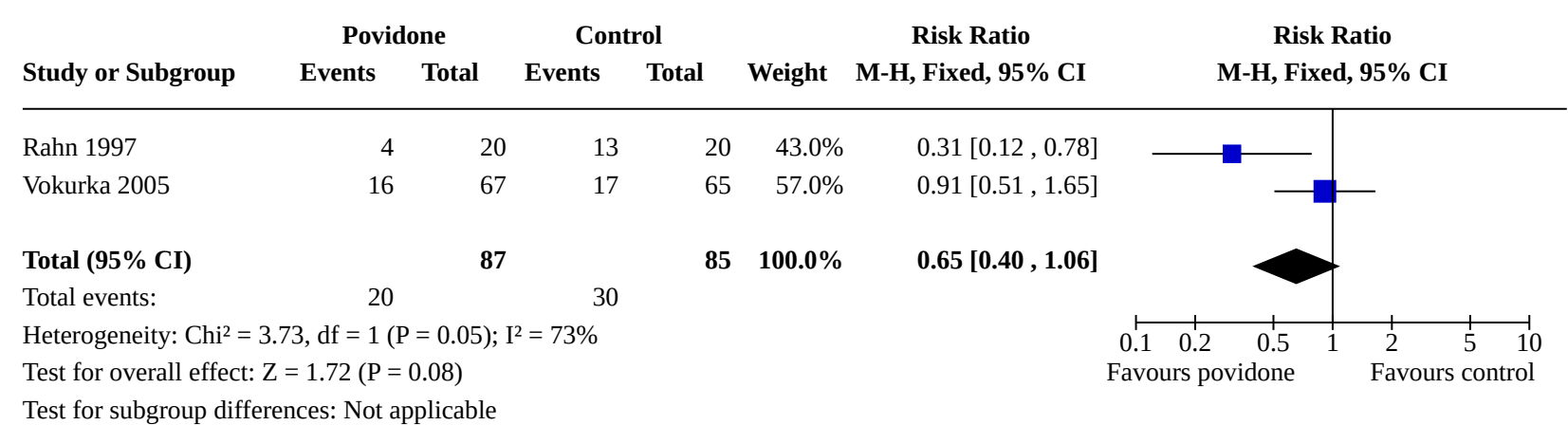

Comparison 16. Prostaglandin versus placebo

\begin{tabular}{llllll}
\hline Outcome or subgroup title & No. of studies & $\begin{array}{l}\text { No. of partici- } \\
\text { pants }\end{array}$ & Statistical method & Effect size \\
\hline 16.1 Mucositis (any) & 3 & 159 & Risk Ratio (M-H, Fixed, 95\% Cl) & $1.03[0.94,1.12]$ \\
\hline 16.2 Mucositis (severe) & 2 & 143 & Risk Ratio (M-H, Fixed, 95\% Cl) & $1.01[0.72,1.43]$ \\
\hline
\end{tabular}

Analysis 16.1. Comparison 16: Prostaglandin versus placebo, Outcome 1: Mucositis (any)

\begin{tabular}{|c|c|c|c|c|c|c|c|c|}
\hline \multirow[b]{2}{*}{ Study or Subgroup } & \multicolumn{2}{|c|}{ Prostaglandin } & \multicolumn{2}{|c|}{ Control } & \multirow[b]{2}{*}{ Weight } & \multirow{2}{*}{$\begin{array}{c}\text { Risk Ratio } \\
\text { M-H, Fixed, 95\% CI }\end{array}$} & \multirow{2}{*}{$\begin{array}{c}\text { Risk Ratio } \\
\text { M-H, Fixed, 95\% CI }\end{array}$} & \\
\hline & Events & Total & Events & Total & & & & \\
\hline Labar 1993 & 29 & 31 & 29 & 29 & $40.8 \%$ & $0.94[0.84,1.05]$ & & \\
\hline Duenas 1996 & 8 & 9 & 2 & 7 & $3.0 \%$ & $3.11[0.94,10.27]$ & & $\rightarrow$ \\
\hline Veness 2006 & 41 & 42 & 41 & 41 & $56.2 \%$ & $0.98[0.91,1.04]$ & & \\
\hline Total $(95 \%$ CI) & & 82 & & 77 & $100.0 \%$ & $1.03[0.94,1.12]$ & 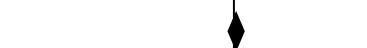 & \\
\hline Total events: & 78 & & 72 & & & & & \\
\hline \multicolumn{4}{|c|}{ Heterogeneity: $\mathrm{Chi}^{2}=7.87, \mathrm{df}=2(\mathrm{P}=0.02) ; \mathrm{I}^{2}=75 \%$} & & & & 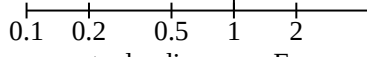 & $\begin{array}{ll}1 \\
5 & 10\end{array}$ \\
\hline Test for overall effect: & $=0.58(\mathrm{P}=$ & $0.57)$ & & & & Favo & urs prostaglandin & ss control \\
\hline
\end{tabular}

Test for subgroup differences: Not applicable

Analysis 16.2. Comparison 16: Prostaglandin versus placebo, Outcome 2: Mucositis (severe)

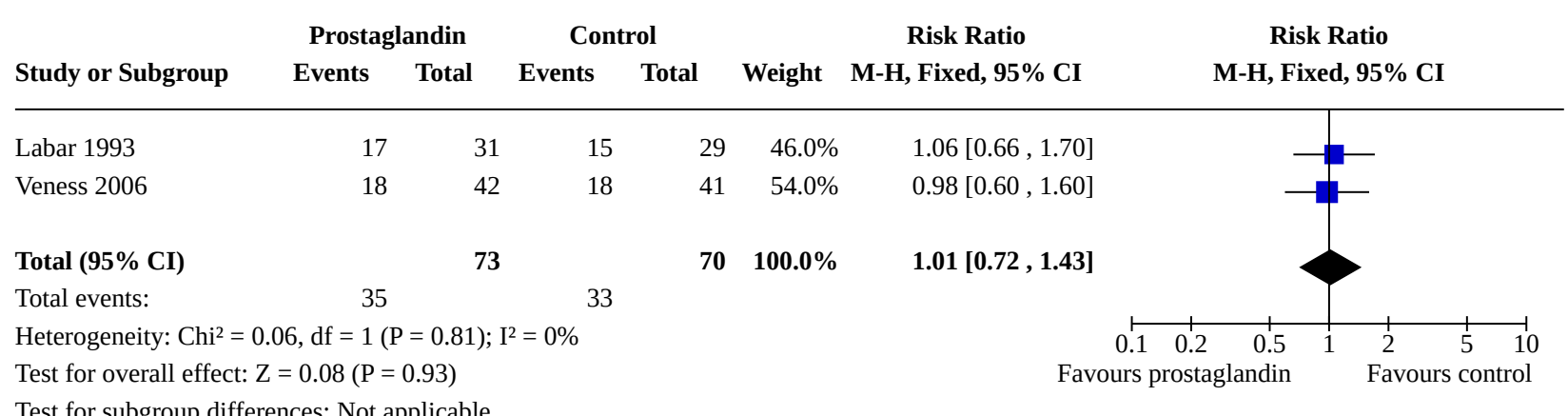


Comparison 17. PTA antibiotic pastille or paste versus placebo/no treatment

\begin{tabular}{lllll}
\hline Outcome or subgroup title & No. of studies & $\begin{array}{l}\text { No. of partici- } \\
\text { pants }\end{array}$ & Statistical method & Effect size \\
\hline 17.1 Mucositis (any) & 2 & 298 & Risk Ratio (M-H, Fixed, 95\% Cl) & $0.87[0.78,0.96]$ \\
\hline 17.2 Mucositis (severe) & 2 & 135 & Risk Ratio (M-H, Fixed, 95\% Cl) & $0.85[0.66,1.09]$ \\
\hline
\end{tabular}

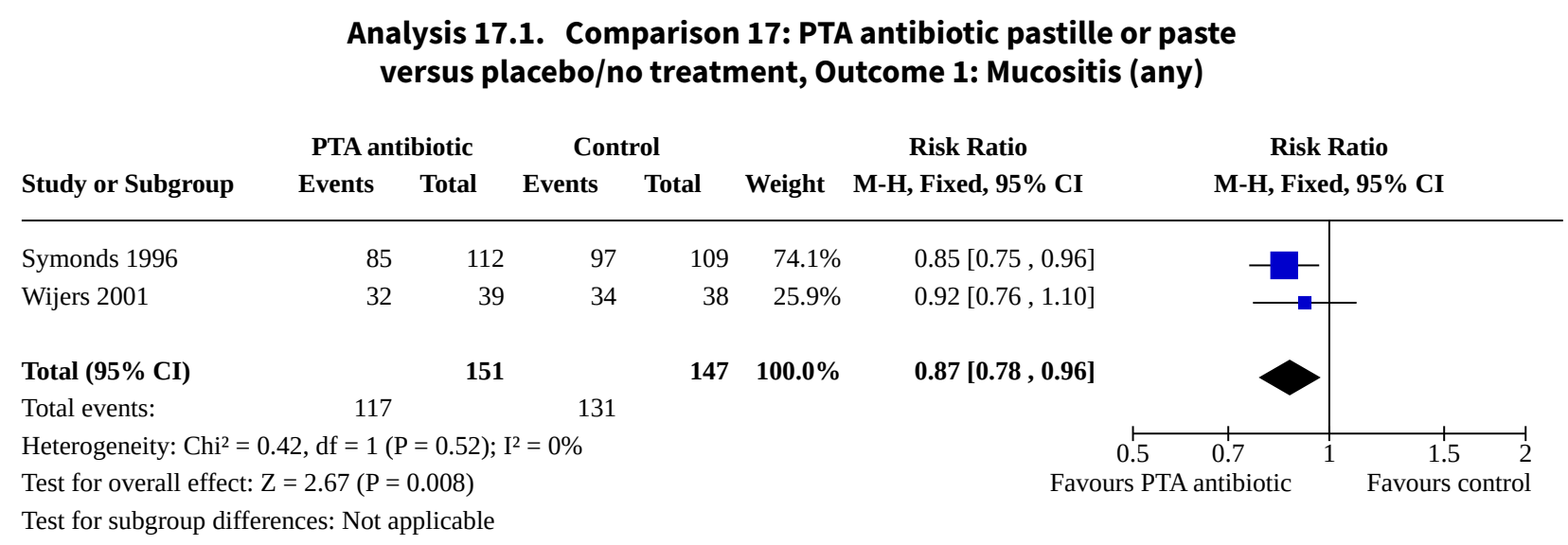

\section{Analysis 17.2. Comparison 17: PTA antibiotic pastille or paste versus placebo/no treatment, Outcome 2: Mucositis (severe)}

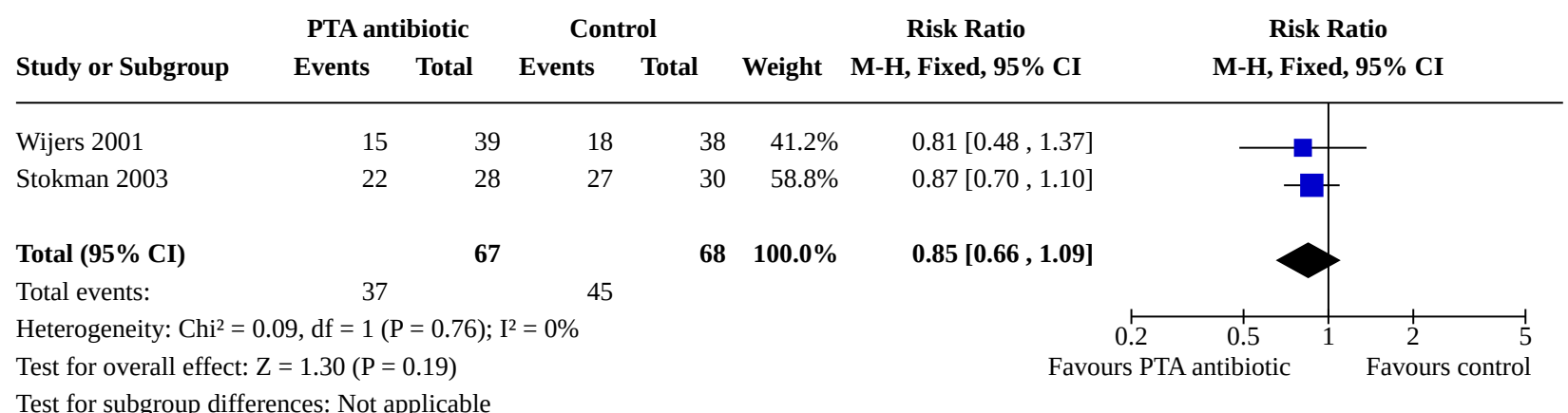

\section{Comparison 18. Radiotherapy: am versus pm}

\begin{tabular}{lllll}
\hline Outcome or subgroup title & No. of studies & $\begin{array}{l}\text { No. of partici- } \\
\text { pants }\end{array}$ & Statistical method & Effect size \\
\hline 18.1 Mucositis (severe) & 2 & 382 & Risk Ratio (M-H, Fixed, 95\% Cl) & $1.07[0.85,1.36]$ \\
\hline
\end{tabular}




\section{Analysis 18.1. Comparison 18: Radiotherapy: am versus pm, Outcome 1: Mucositis (severe)}

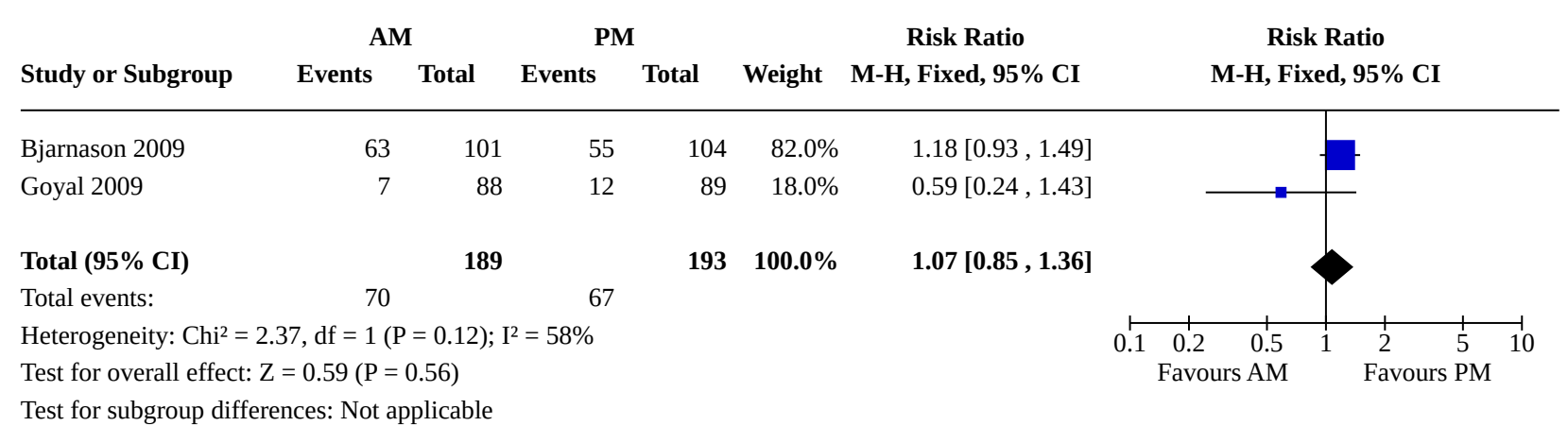

Comparison 19. Sucralfate versus placebo/usual care

\begin{tabular}{lllll}
\hline Outcome or subgroup title & No. of studies & $\begin{array}{l}\text { No. of partici- } \\
\text { pants }\end{array}$ & Statistical method & Effect size \\
\hline 19.1 Mucositis (any) & 3 & 222 & Risk Ratio (M-H, Fixed, 95\% Cl) & $0.98[0.88,1.10]$ \\
\hline $\begin{array}{l}19.2 \text { Mucositis (moderate plus } \\
\text { severe) }\end{array}$ & 4 & 164 & Risk Ratio (M-H, Random, 95\% Cl) & $0.75[0.54,1.04]$ \\
\hline 19.3 Mucositis (severe) & 7 & & Risk Ratio (IV, Random, 95\% Cl) & $0.67[0.48,0.92]$ \\
\hline
\end{tabular}

Analysis 19.1. Comparison 19: Sucralfate versus placebo/usual care, Outcome 1: Mucositis (any)

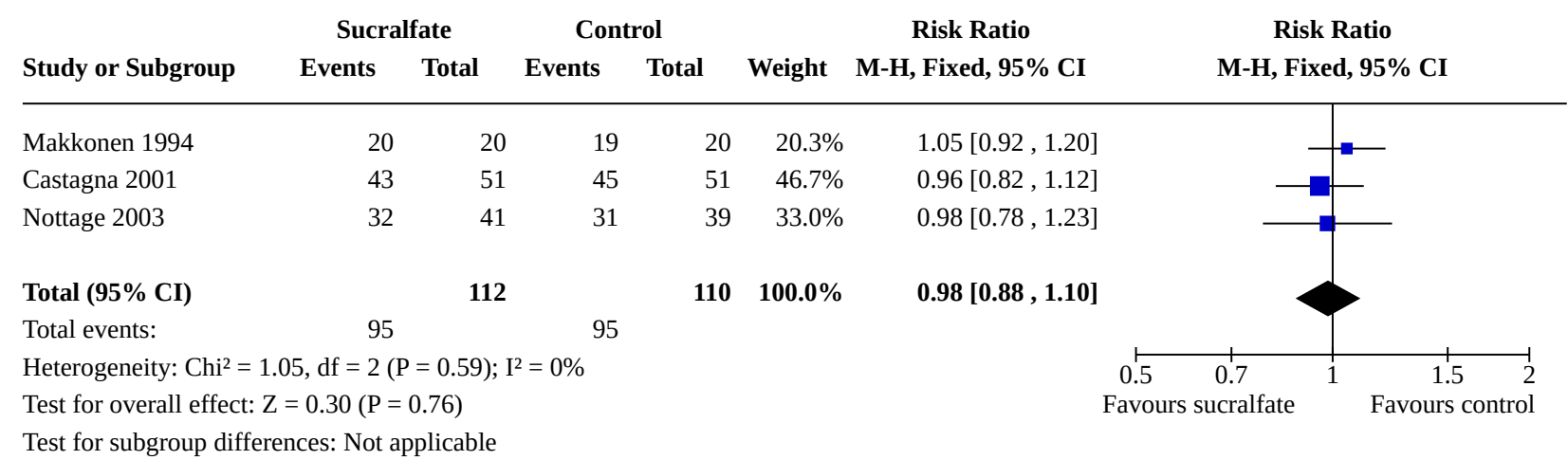


Analysis 19.2. Comparison 19: Sucralfate versus placebo/usual care, Outcome 2: Mucositis (moderate plus severe)

\begin{tabular}{|c|c|c|c|c|c|c|c|c|}
\hline \multirow[b]{2}{*}{ Study or Subgroup } & \multicolumn{2}{|c|}{ Sucralfate } & \multicolumn{2}{|c|}{ Control } & \multirow[b]{2}{*}{ Weight } & Risk Ratio & \multirow{2}{*}{\multicolumn{2}{|c|}{$\begin{array}{c}\text { Risk Ratio } \\
\text { M-H, Random, 95\% CI }\end{array}$}} \\
\hline & Events & Total & Events & Total & & M-H, Random, 95\% CI & & \\
\hline Shenep 1988 & 17 & 24 & 18 & 24 & $32.1 \%$ & $0.94[0.67,1.33]$ & & \\
\hline Makkonen 1994 & 14 & 20 & 15 & 20 & $29.7 \%$ & $0.93[0.64,1.37]$ & & \\
\hline Franzen 1995 & 7 & 24 & 15 & 24 & $15.3 \%$ & $0.47[0.23,0.94]$ & & \\
\hline Cengiz 1999 & 9 & 18 & 9 & 10 & $22.8 \%$ & $0.56[0.33,0.92]$ & & \\
\hline Total (95\% CI) & & 86 & & 78 & $100.0 \%$ & $0.75[0.54,1.04]$ & & \\
\hline Total events: & 47 & & 57 & & & & & \\
\hline \multicolumn{7}{|c|}{ Heterogeneity: $\mathrm{Tau}^{2}=0.06 ; \mathrm{Chi}^{2}=6.16, \mathrm{df}=3(\mathrm{P}=0.10) ; \mathrm{I}^{2}=51 \%$} & 0.2 & 2 \\
\hline Test for overall effect & $=1.73(\mathrm{P}=$ & $0.08)$ & & & & & Favours sucralfate & Favours \\
\hline
\end{tabular}

\section{Analysis 19.3. Comparison 19: Sucralfate versus placebo/usual care, Outcome 3: Mucositis (severe)}

Risk Ratio

Study or Subgroup $\quad \log [R R] \quad$ SE $\quad$ Weight $\quad$ IV, Random, 95\% CI

\begin{tabular}{lrrrr}
\hline Shenep 1988 & -1.11 & 0.6 & $6.4 \%$ & $0.33[0.10,1.07]$ \\
Pfeiffer 1990 & -0.1748 & 0.2 & $27.3 \%$ & $0.84[0.57,1.24]$ \\
Scherlacher 1990 & -1.5187 & 0.572 & $6.9 \%$ & $0.22[0.07,0.67]$ \\
Carter 1999 & -0.1625 & 0.22 & $25.1 \%$ & $0.85[0.55,1.31]$ \\
Cengiz 1999 & -2.12 & 1.48 & $1.2 \%$ & $0.12[0.01,2.18]$ \\
Castagna 2001 & -0.47 & 0.263 & $21.0 \%$ & $0.63[0.37,1.05]$ \\
Nottage 2003 & -0.1555 & 0.401 & $12.2 \%$ & $0.86[0.39,1.88]$
\end{tabular}

Total (95\% CI)

$100.0 \%$

$0.67[0.48,0.92]$

Heterogeneity: $\mathrm{Tau}^{2}=0.06 ; \mathrm{Chi}^{2}=9.13, \mathrm{df}=6(\mathrm{P}=0.17) ; \mathrm{I}^{2}=34 \%$

Test for overall effect: $\mathrm{Z}=2.50(\mathrm{P}=0.01)$

Test for subgroup differences: Not applicable
Risk Ratio

IV, Random, 95\% CI 


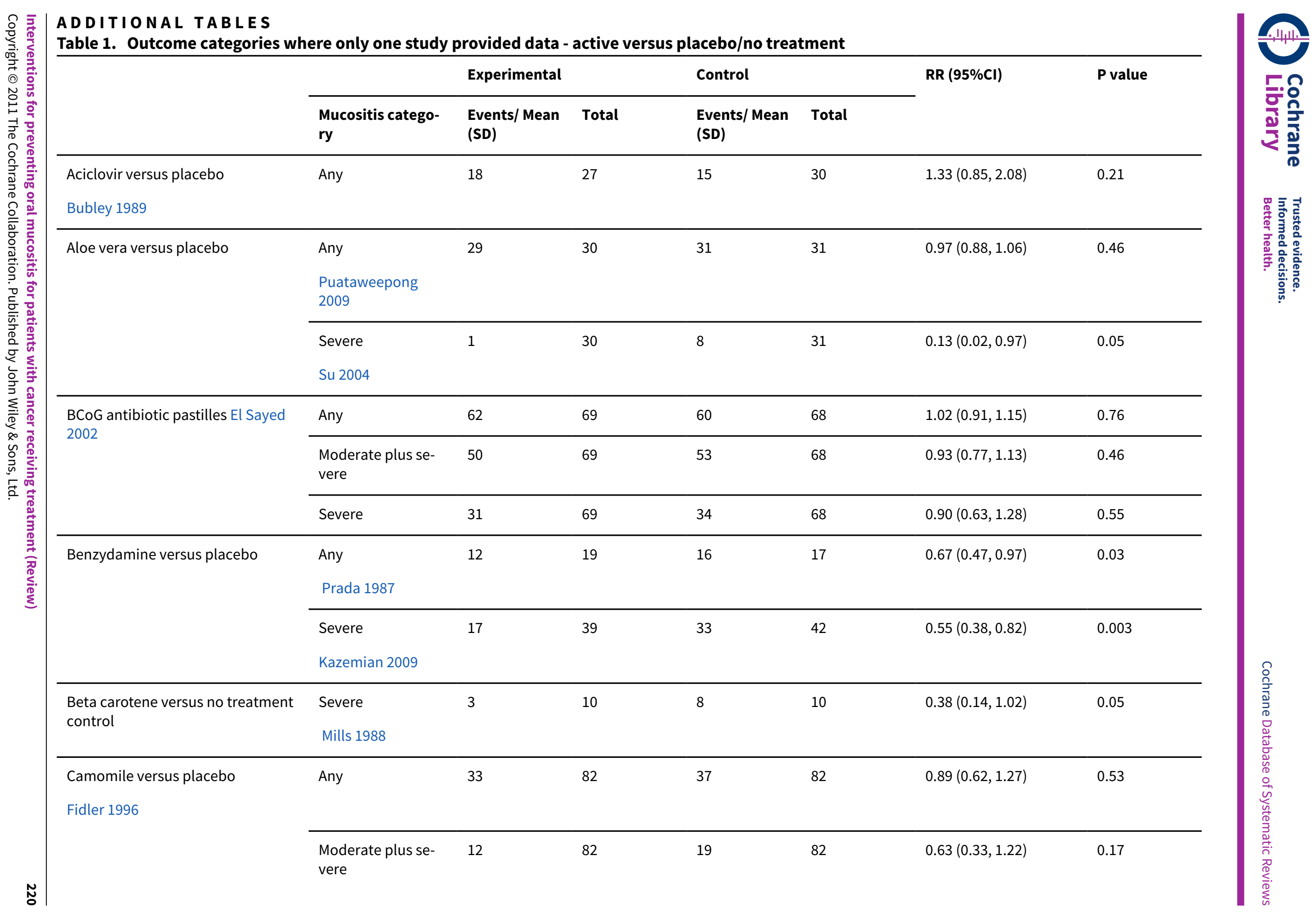




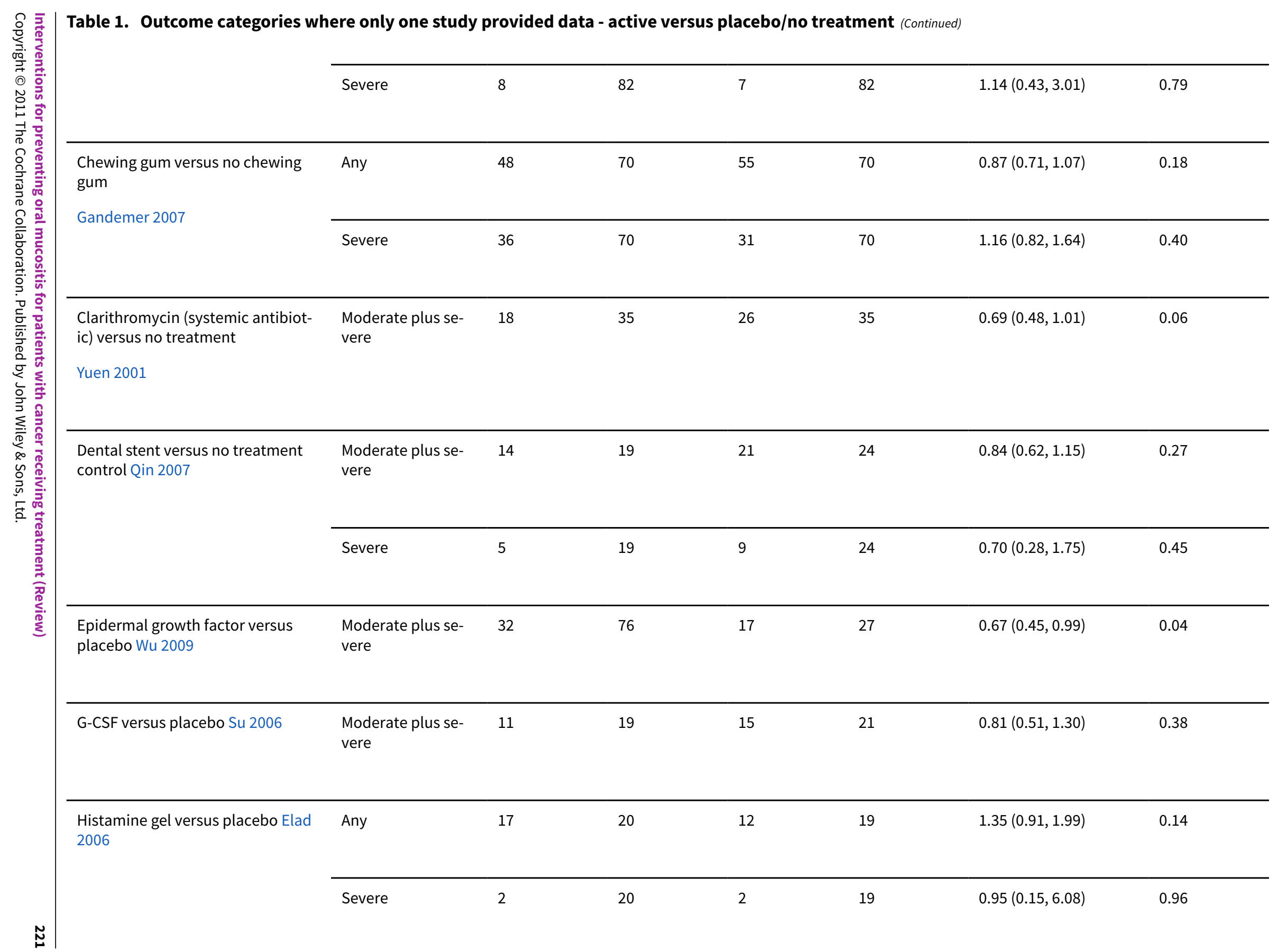




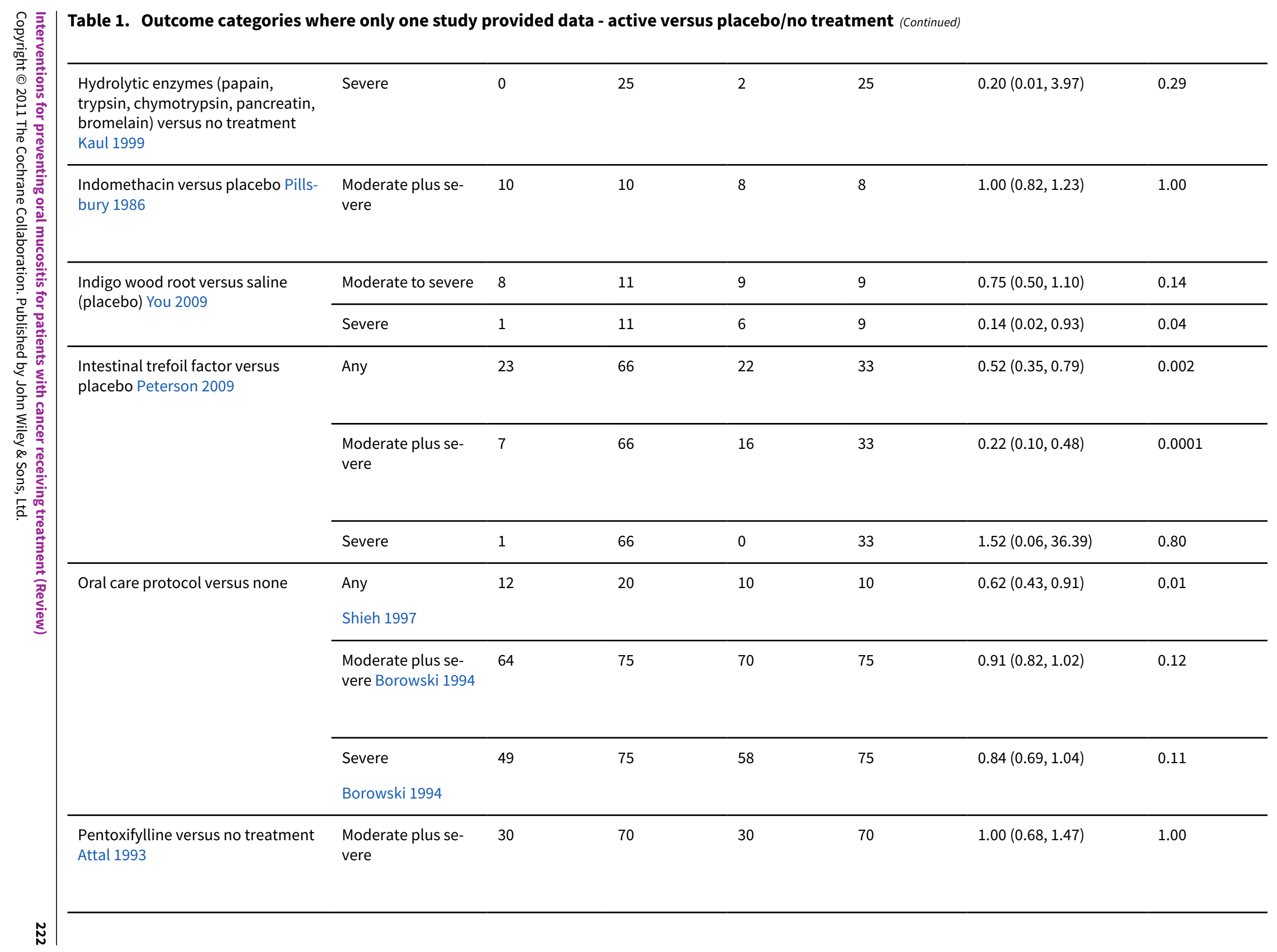




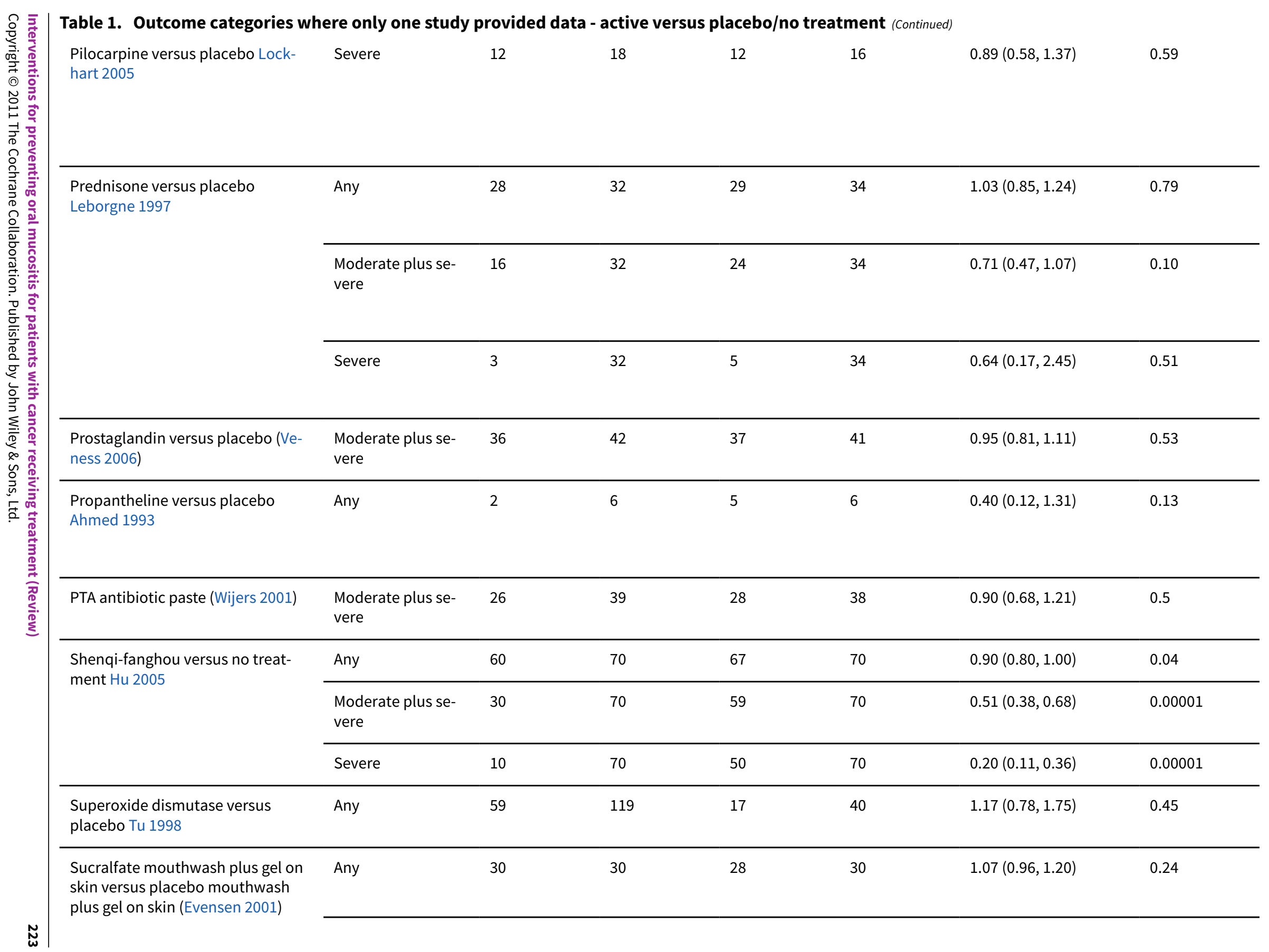




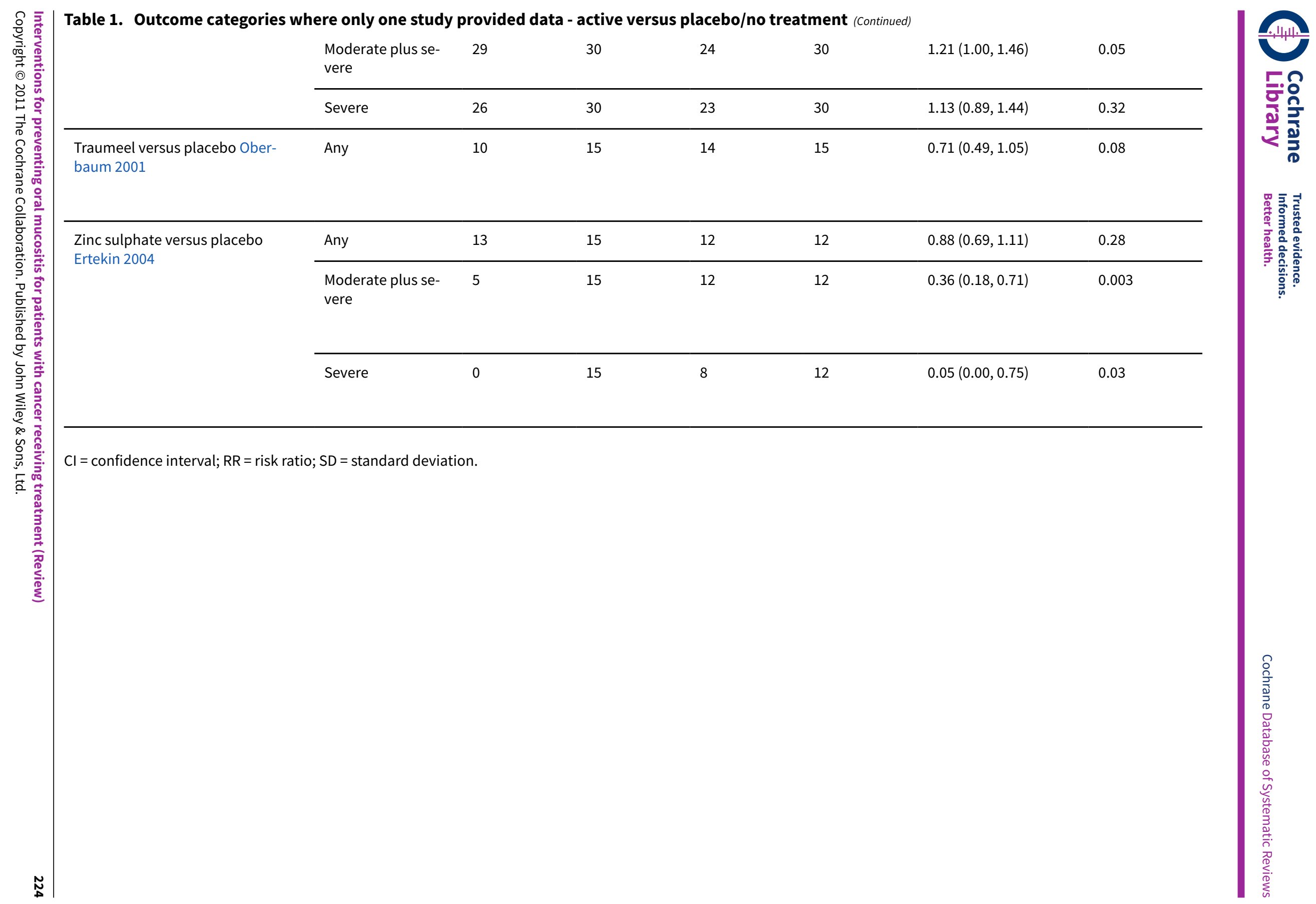


Table 2. Text only inclusions

\begin{tabular}{lll}
\hline Intervention & Study & Text \\
\hline $\begin{array}{l}\text { Amifostine versus no } \\
\text { treatment }\end{array}$ & Vacha 2003 & $\begin{array}{l}\text { CTC mucositis index used. Results presented as weekly means for both arms } \\
\text { with standard deviations. Text indicated statistically significant difference in } \\
\text { favour of amifostine at } 2 \text { weeks but does not mention overall result. }\end{array}$ \\
\hline $\begin{array}{l}\text { Benzydamine versus } \\
\text { placebo }\end{array}$ & Epstein 1989 & $\begin{array}{l}\text { Signs of mucositis were recorded by area of involvement, severity of inflam- } \\
\text { mation, severity of ulceration and maximum size of ulceration for each region } \\
\text { of the oral cavity. Results in Table } 3 \text { indicate borderline statistically significant } \\
\text { differences in favour of benzydamine. Maximum size of ulcerations }(P=0.04) ; \\
\text { total area of ulcerations }(P=0.05) ; \text { average area of mucositis }(P=0.050) .\end{array}$
\end{tabular}

\begin{tabular}{ll}
\hline $\begin{array}{l}\text { Benzydamine versus } \\
\text { placebo }\end{array}$ & Epstein 2001 \\
& $\begin{array}{l}\text { Area under the curve of mean mucositis cores presented for different radio- } \\
\text { therapy intervals. Overall there was a statistically significant difference in } \\
\text { favour of benzydamine }(P=0.006), \text { Table } 4 .\end{array}$
\end{tabular}

\begin{tabular}{ll}
\hline $\begin{array}{l}\text { Chlorhexidine versus } \\
\text { placebo }\end{array}$ & McGaw 1985 \\
& $\begin{array}{l}\text { Hickey (0-3 scale) index for mucositis used over 4-week period. During the } \\
\text { third and fourth weeks the average mucositis scores were significantly higher } \\
\text { in the control group. }\end{array}$
\end{tabular}

\begin{tabular}{lll}
\hline $\begin{array}{l}\text { Chlorhexidine versus } \\
\text { povidone-iodine, salt/ } \\
\text { soda versus water }\end{array}$ & Madan 2008 & $\begin{array}{l}\text { After } 4 \text { weeks there was a statistically significant decrease in mean mucositis } \\
\text { scores in each of the active treatment groups compared to placebo. }\end{array}$ \\
\hline $\begin{array}{l}\text { Cryotherapy versus no } \\
\text { treatment control }\end{array}$ & Svanberg 2007 & $\begin{array}{l}\text { "The results demonstrated that oral cryotherapy alleviated the development } \\
\text { of mucositis and oral pain, which resulted in a reduction in the number of days } \\
\text { of iv opioids for patients treated with autologous BMT." }\end{array}$
\end{tabular}

\begin{tabular}{lll}
\hline $\begin{array}{l}\text { GM-CSF versus no treat- } \\
\text { ment control }\end{array}$ & Chi 1995 & $\begin{array}{l}\text { Cross-over study showing period effect but indicating GM-CSF significantly } \\
\text { prevents mucositis }(\mathrm{P}<0.001) .\end{array}$ \\
\hline $\begin{array}{l}\text { Laser versus placebo } \\
\text { light treatment }\end{array}$ & Bensadoun 1999 & $\begin{array}{l}\text { Parallel group study mucositis measured on } 0-4 \text { scale. Mean calculated for } \\
\text { each patient over } 7 \text { weeks. Quote "the mean grade of mucositis during ra- } \\
\text { diotherapy was } 2.1+/ 0.26 \text { for the group without laser and } 1.7+/-0.26 \text { for the } \\
\text { group with laser }(P=0.01) . "\end{array}$ \\
\hline
\end{tabular}

Laser versus sham laser Schubert $2007 \quad$ OMI appropriate index (Schubert 1992).
treatment

Quote: "Figure 1 shows the mean OMI over time by treatment group. The placebo patient scores are higher on average than the laser patient scores at nearly every time point, signifying more severe mucositis over the course of the study.." The authors then present day 11 data and statistical test for that day $(P=0.06)$.

"The peak severity of mucositis that generally occurs during the second week of transplant was reduced in the 650 nm laser group."

The results of the overall burden over time in Table 2 showed the differences in the unadjusted model to be non-significant. Only one difference comparing low-level laser with placebo was significant in the adjusted model $(P=0.03)$.

\begin{tabular}{lll}
\hline $\begin{array}{l}\text { Prostaglandin versus } \\
\text { placebo }\end{array}$ & Hanson 1995 & $\begin{array}{l}\text { Data from } 2 \text { centres reported separately. Overall ANOVA for } 1 \text { centre showed } \\
\text { no significant difference. The other centre found statistically significant differ- } \\
\text { ences for weeks } 4 \text { and } 5 \text { with less mucositis in the intervention group }(P<0.05) .\end{array}$ \\
\hline $\begin{array}{l}\text { Sucralfate versus place- } \\
\text { bo }\end{array}$ & Epstein 1994 & $\begin{array}{l}\text { Signs of mucositis were recorded by area of involvement, severity of inflamma- } \\
\text { tion, severity of ulceration and maximum size of ulceration for each region of }\end{array}$
\end{tabular}


Table 2. Text only inclusions (Continued)

the oral cavity. No statistically significant difference was seen in mucositis ulceration or the composite mucositis score (Table 3).

Total mucositis score:

Placebo $(n=17)$ mean $=18.7+/-21.3$

Sucralfate $(n=16)$ mean $=22.3+/-31.2$

Total mucosal ulceration:

Placebo $(n=17)$ mean $=15.3+/-17.6$

Sucralfate $(n=16)$ mean $=19.4+/-19.8$.

Sucralfate versus place- Lievens 1998 bo
Mucositis scores on 0-6 ECOG scale. Graph (fig 1) displays mean mucositis scores for each week 1-7. Quote: "Comparing the time course of the mean scores for ... mucositis. . . no statistically significant differences between the two treatment arms were observed."

Quote: "At 5 week when the mucosal reaction tends to be most severe a clear but not statistically significant advantage is seen for sucralfate as opposed to placebo."

RTOG mucositis index used. Results presented as graphs. Quote: "This study no significant difference was found in the improvement of radiation mucositis and dermatitis during the 2 weeks between the patients with zinc supplement and those without."

ANOVA = analysis of variance; BMT = bone marrow transplant; CTC = Common Toxicity Criteria; ECOG = Eastern Cooperative Oncology Group; GM-CSF = granulocyte/macrophage colony-stimulating factor; OMI = oral mucositis index; RTOG = Radiation Therapy Oncology Group. 


\begin{tabular}{|c|c|c|c|c|c|c|c|}
\hline & & Experimental & & $\operatorname{RR}(95 \% \mathrm{Cl})$ & & RR $(95 \% \mathrm{Cl})$ & $P$ value \\
\hline & $\begin{array}{l}\text { Mucositis cate- } \\
\text { gory }\end{array}$ & $\begin{array}{l}\text { Events/Mean } \\
\text { (SD) }\end{array}$ & Total & $\begin{array}{l}\text { Events/Mean } \\
\text { (SD) }\end{array}$ & Total & & \\
\hline \multirow{2}{*}{$\begin{array}{l}\text { Chinese herbs (coastal glenhnia, dwarf } \\
\text { lilyturf tuber root, rehmannia dried root, } \\
\text { figwort root, spreading hedyotis herb, } \\
\text { belamcaude rhizome, platycodom root, } \\
\text { shinyleaf pricklyoash root, honeysuck- } \\
\text { le flower, licorice root, lalang grass rhi- } \\
\text { zome) versus Dobell's solution Huang } \\
2003\end{array}$} & Moderate & 23 & 52 & 47 & 49 & $0.46(0.34,0.63)$ & 0.00001 \\
\hline & Severe & 5 & 52 & 30 & 49 & $0.16(0.07,0.37)$ & 0.0001 \\
\hline \multirow{3}{*}{$\begin{array}{l}\text { Chinese herbs (corktree bark, Chinese } \\
\text { gall, European vebena herb, catechu, } \\
\text { weeping forsythia fruit and burneol) ver- } \\
\text { sus Dobell's solution Wang } 2002\end{array}$} & Any & 8 & 76 & 17 & 71 & $0.44(0.20,0.95)$ & 0.04 \\
\hline & $\begin{array}{l}\text { Moderate plus } \\
\text { severe }\end{array}$ & 4 & 76 & 14 & 71 & $0.27(0.09,0.77)$ & 0.01 \\
\hline & Severe & 0 & 76 & 5 & 71 & $0.09(0.00,1.51)$ & 0.09 \\
\hline \multirow{3}{*}{$\begin{array}{l}\text { Chlorhexidine versus cryotherapy } \\
\text { Sorensen } 2008\end{array}$} & Any & 39 & 70 & 34 & 63 & $1.03(0.76,1.41)$ & 0.84 \\
\hline & $\begin{array}{l}\text { Moderate plus } \\
\text { severe }\end{array}$ & 20 & 70 & 16 & 63 & $1.13(0.64,1.97)$ & 0.68 \\
\hline & Severe & 9 & 70 & 7 & 63 & $1.16(0.46,2.92)$ & 0.76 \\
\hline \multirow[t]{3}{*}{$\begin{array}{l}\text { Cryotherapy } 30 \text { versus } 60 \text { minutes Rocke } \\
1993\end{array}$} & Any & 33 & 89 & 37 & 89 & $0.89(0.62,1.29)$ & 0.54 \\
\hline & $\begin{array}{l}\text { Moderate plus } \\
\text { severe }\end{array}$ & 13 & 89 & 19 & 89 & $0.68(0.36,1.30)$ & 0.25 \\
\hline & Severe & 6 & 89 & 10 & 89 & $0.60(0.23,1.58)$ & 0.30 \\
\hline $\begin{array}{l}\text { GM-CSF versus sucralfate } \\
\text { Saarilahti } 2002\end{array}$ & $\begin{array}{l}\text { Moderate plus } \\
\text { severe }\end{array}$ & 19 & 21 & 18 & 19 & $0.96(0.80,1.14)$ & 0.61 \\
\hline
\end{tabular}




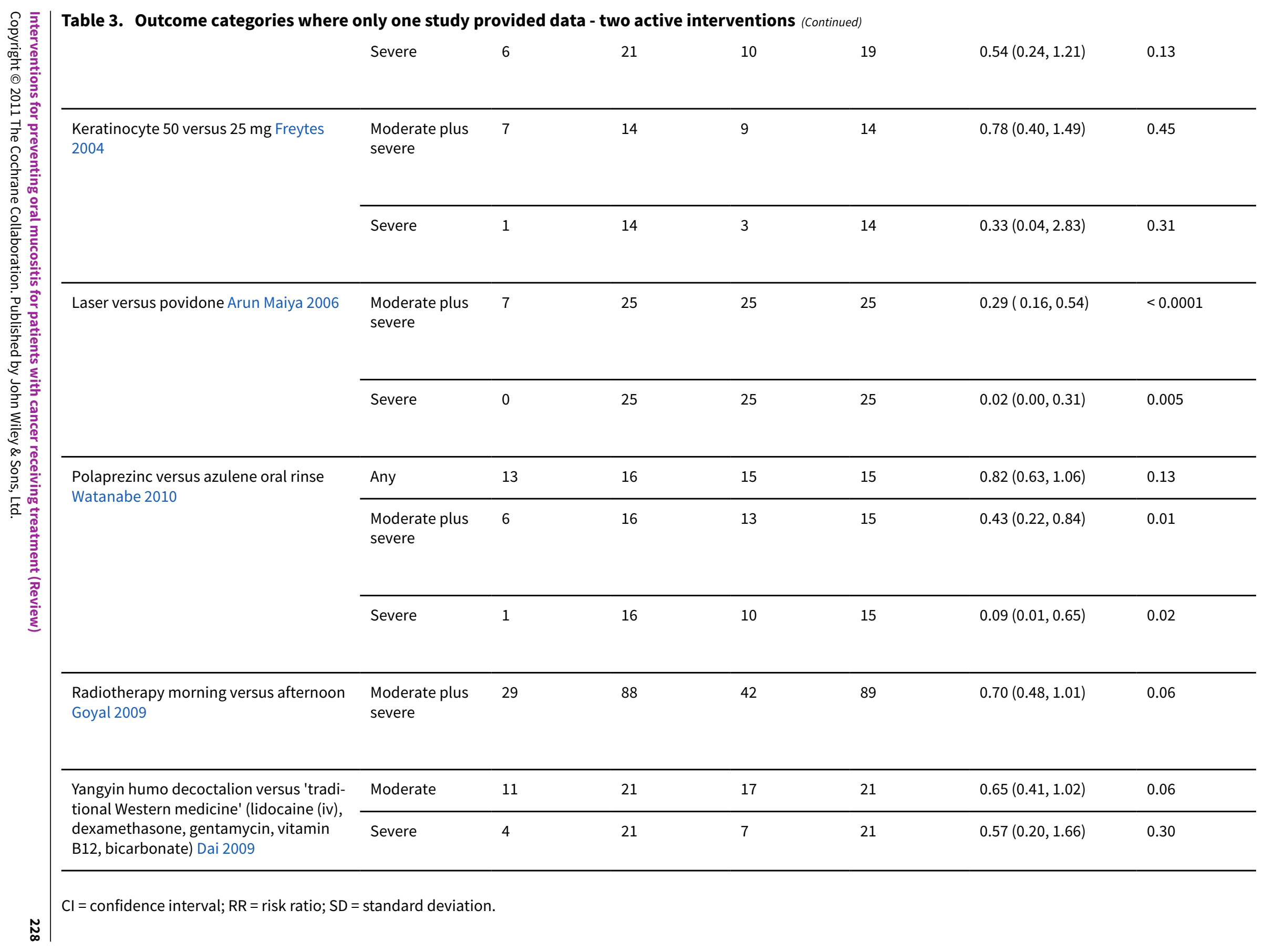




\section{AP PE N DICES}

\section{Appendix 1. Cochrane Oral Health Group Trials Register search strategy}

((neoplasm* OR leukemia OR leukaemia OR leukaemia OR lymphoma* OR plasmacytoma OR "histiocytosis malignant" OR reticuloendotheliosis OR "sarcoma mast cell" OR "Letterer Siwe disease" OR "immunoproliferative small intestine disease" OR "Hodgkin disease" OR "histiocytosis malignant" OR "bone marrow transplant" OR cancer* Or tumor* OR tumour* OR malignan* OR neutropeni* OR carcino* OR adenocarcinoma* OR radioth* OR radiat* OR radiochemo* OR irradiat* OR chemo*) AND (stomatitis OR "Stevens Johnson syndrome" OR "candidiasis oral" OR mucositis OR (oral AND (cand* OR mucos* OR fung*)) OR mycosis OR mycotic OR thrush))

\section{Appendix 2. CENTRAL search strategy}

1. Exp NEOPLASMS

2. Exp LEUKEMIA

3. EXP LYMPHOMA

4. EXP RADIOTHERAPY

5. Exp BONE MARROW TRANSPLANTATION

6. neoplasm* or cancer* or carcino* or malignan*

7. leukemi* or leukaemia*

8. tumour ${ }^{\star}$ or tumor ${ }^{\star}$

9. neutropeni ${ }^{\star}$

10.adenocarcinoma*

11.lymphoma*

12. (radioth* ${ }^{\star}$ or radiat ${ }^{\star}$ or irradiat* ${ }^{\star}$ or radiochemo*)

13. (bone next marrow next transplant ${ }^{\star}$ )

14.chemo* or radiochemo*

15. (\#1 or \#2 or \#3 or \#4 or \#5 or \#6 or \#7 or \#8 or \#9 or \#10 or \#11 or \#12 or \#13 or \#14)

16. Exp STOMATITIS

17.MUCOSITIS

18.CANDIDIASIS ORAL

19.stomatitis

20.(stevens next johnson next syndrome)

21. mucositis

22. oral near cand ${ }^{*}$

23. mouth near cand*

24.oral and fung*

25.mouth and fung*

26. (mycosis or mycotic or thrush)

27 . \#16 or \#17 or \#18 or \#19 or \#20 or \#21 or \#22 or \#23 or \#24 or \#25 or \#26

28.\#15 AND \#27

\section{Appendix 3. MEDLINE via OVID search strategy}

\section{1. $\exp$ NEOPLASMS/}

2. $\exp$ LEUKEMIA/

3. $\exp$ LYMPHOMA/

4. exp RADIOTHERAPY/

5. Bone Marrow Transplantation/

6. neoplasm\$.mp. [mp=title, abstract, subject headings, drug trade name, original title, device manufacturer, drug manufacturer name, device trade name]

7. cancer\$.mp. [mp=title, abstract, subject headings, drug trade name, original title, device manufacturer, drug manufacturer name, device trade name]

8. (leukaemi\$ or leukemi\$).mp. [mp=title, abstract, subject headings, drug trade name, original title, device manufacturer, drug manufacturer name, device trade name]

9. (tumour\$ or tumor\$).mp. [mp=title, abstract, subject headings, drug trade name, original title, device manufacturer, drug manufacturer name, device trade name] 
10. malignan\$.mp. [mp=title, abstract, subject headings, drug trade name, original title, device manufacturer, drug manufacturer name, device trade name]

11. neutropeni\$.mp. [mp=title, abstract, subject headings, drug trade name, original title, device manufacturer, drug manufacturer name, device trade name]

12. carcino\$.mp. [mp=title, abstract, subject headings, drug trade name, original title, device manufacturer, drug manufacturer name, device trade name]

13. adenocarcinoma\$.mp. [mp=title, abstract, subject headings, drug trade name, original title, device manufacturer, drug manufacturer name, device trade name]

14. lymphoma\$.mp. [mp=title, abstract, subject headings, drug trade name, original title, device manufacturer, drug manufacturer name, device trade name]

15. (radioth\$ or radiat\$ or irradiat\$).mp. [mp=title, abstract, subject headings, drug trade name, original title, device manufacturer, drug manufacturer name, device trade name]

16. (bone adj marrow adj5 transplant\$).mp. [mp=title, abstract, subject headings, drug trade name, original title, device manufacturer, drug manufacturer name, device trade name]

17. chemo\$.mp. [mp=title, abstract, subject headings, drug trade name, original title, device manufacturer, drug manufacturer name, device trade name]

18. or/1-17

19. exp STOMATITIS/

20. Candidiasis, Oral/

21. stomatitis.mp. [mp=title, abstract, subject headings, drug trade name, original title, device manufacturer, drug manufacturer name, device trade name]

22. mucositis.mp. [mp=title, abstract, subject headings, drug trade name, original title, device manufacturer, drug manufacturer name, device trade name]

23. (oral and cand\$).mp. [mp=title, abstract, subject headings, drug trade name, original title, device manufacturer, drug manufacturer name, device trade name]

24. (oral adj6 mucos\$).mp. [mp=title, abstract, subject headings, drug trade name, original title, device manufacturer, drug manufacturer name, device trade name]

25. (oral and fung\$).mp. [mp=title, abstract, subject headings, drug trade name, original title, device manufacturer, drug manufacturer name, device trade name]

26. (mycosis or mycotic).mp. [mp=title, abstract, subject headings, drug trade name, original title, device manufacturer, drug manufacturer name, device trade name]

27. or/19-26

28. 18 and 27

\section{Search filter for MEDLINE via OVID}

Cochrane Highly Sensitive Search Strategy (CHSSS) for identifying randomised trials in MEDLINE: sensitivity maximising version (September 2009 revision) as referenced in Chapter 6 and detailed in box 6.4.c of the Cochrane Handbook for Systematic Reviews of Interventions version 5.0.2 (updated September 2008):

1. randomized controlled trial.pt.

2. controlled clinical trial.pt.

3. randomized.ab.

4. placebo.ab.

5. drug therapy.fs.

6. randomly.ab.

7. trial.ab.

8. groups.ab.

9. or/1-8

10. animals.sh. not (humans.sh. and animals.sh.)

11.9 not 10

\section{Appendix 4. EMBASE via OVID search strategy}

1. $\exp$ NEOPLASM/

2. $\operatorname{exp~LEUKEMIA/~}$

3. exp LYMPHOMA/

4. exp RADIOTHERAPY/

5. exp bone marrow transplantation/

6. (neoplasm\$ or cancer $\$$ or leukemi\$ or leukaemi\$ or tumour $\$$ or tumor $\$$ or malignan\$ or neutropeni\$ or carcino $\$$ or adenocarcinoma\$ or lymphoma\$).mp. [mp=title, abstract, subject headings, drug trade name, original title, device manufacturer, drug manufacturer name] 7. (radioth\$ or radiat\$ or irradiat\$ or radiochemo\$).mp. [mp=title, abstract, subject headings, drug trade name, original title, device manufacturer, drug manufacturer name] 
8. (bone marrow adj3 transplant\$).mp. [mp=title, abstract, subject headings, drug trade name, original title, device manufacturer, drug manufacturer name]

9. chemo\$.mp. [mp=title, abstract, subject headings, drug trade name, original title, device manufacturer, drug manufacturer name]

10. or/1-9

11. exp Stomatitis/

12. Thrush/

13. (stomatitis or mucositis or (oral and candid\$) or (oral adj4 mucositis) or (oral and fung\$) or mycosis or mycotic or thrush).mp. [mp=title, abstract, subject headings, drug trade name, original title, device manufacturer, drug manufacturer name]

14. or $/ 11-13$

15. 10 and 14

\section{Filter for EMBASE via OVID}

1. random\$.ti,ab.

2. factorial\$.ti,ab.

3. (crossover\$ or cross over\$ or cross-over\$).ti,ab.

4. placebo\$.ti,ab.

5. (doubl\$ adj blind\$).ti,ab.

6. (singl\$ adj blind\$).ti,ab.

7. assign\$.ti,ab.

8. allocat\$.ti,ab.

9. volunteer\$.ti,ab.

10. CROSSOVER PROCEDURE.sh.

11. DOUBLE-BLIND PROCEDURE.sh.

12. RANDOMIZED CONTROLLED TRIAL.sh.

13. SINGLE BLIND PROCEDURE.sh.

14. or/1-13

15. ANIMAL/ or NONHUMAN/ or ANIMAL EXPERIMENT/

16. HUMAN/

17. 16 and 15

18. 15 not 17

19. 14 not 18

\section{Appendix 5. CANCERLIT (PubMed Cancer Subset) search strategy}

((neoplasm* OR leukemia OR leukaemia OR leukaemia OR lymphoma* OR plasmacytoma OR "histiocytosis malignant" OR reticuloendotheliosis OR "sarcoma mast cell" OR "Letterer Siwe disease" OR "immunoproliferative small intestine disease" OR "Hodgkin disease" OR "histiocytosis malignant" OR "bone marrow transplant*" OR cancer* Or tumor* OR tumour* OR malignan* OR neutropeni* OR carcino* OR adenocarcinoma* OR radioth* OR radiat* OR radiochemo* OR irradiat* OR chemotherap*) AND (stomatitis OR "Stevens Johnson syndrome" OR "candidiasis oral" OR mucositis OR (oral AND (candid* OR mucos* OR fung*)) OR mycosis OR mycotic OR thrush)) AND

(randomized controlled trial [pt] OR controlled clinical trial [pt] OR randomized controlled trials [mh] OR random allocation [mh] OR double-blind method [mh] OR single-blind method [mh] OR clinical trial [pt] OR clinical trials [mh] OR ("clinical trial" [tw] OR ((singl ${ }^{\star}[\mathrm{tw}]$

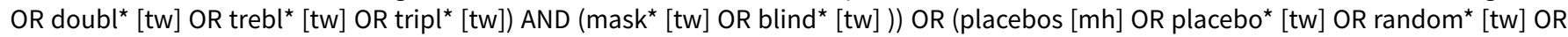
research design [mh:noexp]) NOT (animals [mh] NOT human $[\mathrm{mh}]))$

\section{Appendix 6. SIGLE search strategy}

((neoplasm* OR leukemia OR leukaemia OR leukaemia OR lymphoma* OR plasmacytoma OR histiocytosis malignant OR reticuloendotheliosis OR sarcoma mast cell OR Letterer Siwe disease OR immunoproliferative small intestine disease OR Hodgkin disease OR histiocytosis malignant OR bone marrow transplant ${ }^{\star}$ OR cancer ${ }^{\star}$ Or tumor ${ }^{\star}$ OR tumour ${ }^{\star}$ OR malignan ${ }^{\star}$ OR neutropeni ${ }^{\star}$ OR carcino ${ }^{\star}$ OR adenocarcinoma* $\mathrm{OR}$ radioth* ${ }^{\star} \mathrm{R}$ radiat ${ }^{\star} \mathrm{OR}$ radiochemo* $\mathrm{OR}$ irradiat ${ }^{\star} \mathrm{OR}$ chemo*$^{\star}$ )

AND

(stomatitis OR Stevens Johnson syndrome OR candidiasis oral OR mucositis OR (oral AND (cand* OR mucos* OR fung*)) OR mycosis OR mycotic OR thrush)

Not updated after 2005

\section{Appendix 7. LILACS search strategy}

(www.bireme.org)

((Pt randomized controlled trial OR Pt controlled clinical trial OR Mh randomized controlled trials OR Mh random allocation OR Mh double-blind method OR Mh single-blind method) AND NOT (Ct animals AND NOT (Ct human and Ct animal)) OR (Pt clinical trial OR Ex E05.318.760.535\$ OR (Tw clin\$ AND (Tw trial\$ OR Tw ensa\$ OR Tw estud\$ OR Tw experim\$ OR Tw investiga\$)) OR ((Tw singl\$ OR Tw simple 
\$ OR Tw doubl\$ OR Tw doble\$ OR Tw duplo\$ OR Tw trebl\$ OR Tw trip\$) AND (Tw blind\$ OR Tw cego\$ OR Tw ciego\$ OR Tw mask\$ OR Tw mascar\$)) OR Mh placebos OR Tw placebo\$ OR (Tw random\$ OR Tw randon\$ OR Tw casual\$ OR Tw acaso\$ OR Tw azar OR Tw aleator\$) OR Mh research design) AND NOT (Ct animals AND NOT (Ct human and Ct animals)) OR (Ct comparative study OR Ex E05.337\$ OR Mh followup studies OR Mh prospective studies OR Tw control\$ OR Tw prospectiv\$ OR Tw volunt\$ OR Tw volunteer\$) AND NOT (Ct animals AND NOT (Ct human and Ct animals)))

\section{AND}

Mh NEOPLASMS OR Tw neoplasm\$ OR Tw cancer\$ OR Tw carcinoma\$ OR Tw tumour\$ OR Tw tumor\$ OR Tw malignan\$ OR Tw carcino\$ OR Tw nuetropeni\$ OR Tw adenocarcinoma\$ OR Mh leukemia OR Tw leukaemia\$ OR Tw leukemi\$ OR Tw lymphoma\$ OR Tw "bone marrow transplantation" OR Tw "bone marrow transplant\$" OR Tw radiotherapy OR Tw radioth\$ OR Tw radiat\$ OR Tw irradiat\$ OR Tw radiochemo \$ OR Tw chemo\$

AND

Mh stomatitis OR Tw stomatitis OR Mh Candidiasis-Oral OR Tw "oral candidiasis" OR (Tw candida\$ AND (Tw mouth OR Tw oral)) OR Tw mucositis OR ((Tw oral OR mouth) AND Tw fung\$) OR (Tw oral AND Tw candidiasis\$)

\section{Appendix 8. CINAHL via EBSCO search strategy}

S1 (MH "Neoplasms+")

S2 (MH "Leukemia+")

S3 (MH "Lymphoma+")

S4 (MH "Radiotherapy+")

S5 (MH "Bone Marrow Transplantation")

S6 neoplasm*

S7 cancer*

S8 (leukemi* or leukaemi ${ }^{\star}$ )

S9 (tumour* or tumor*)

S10 malignan*

S11 neutropeni ${ }^{\star}$

S12 carcino*

S13 adenocarcinoma*

S14 lymphoma*

S15 (radioth* ${ }^{\star}$ or radiat ${ }^{\star}$ or irradiat ${ }^{\star}$ )

S16 (bone N1 marrow N5 transplant* ${ }^{\star}$ )

S17 chemo*

$\mathrm{S} 18 \mathrm{~S} 1$ or $\mathrm{S} 2$ or S3 or S4 or S5 or S6 or S7 or S8 or S9 or S10 or S11 or S12 or S13 or S14 or S15 or S16 or S17

S19 MH "Stomatitis+"

S20 MH "Candidiasis, Oral"

S21 stomatitis

S22 mucositis

S23 (oral and cand ${ }^{*}$ )

S24 (oral N6 mucos*)

S25 (oral and fung*)

S26 (mycosis or mycotic)

$\mathrm{S} 27 \mathrm{~S} 19$ or S20 or S21 or S22 or S23 or S24 or S25 or S26

S28 S18 AND S27

\section{Filter for CINAHL search}

S1 MH Random Assignment or MH Single-blind Studies or MH Double-blind Studies or MH Triple-blind Studies or MH Crossover design or MH Factorial Design

S2 TI ("multicentre study" or "multicenter study" or "multi-centre study" or "multi-center study") or AB ("multicentre study" or "multicenter study" or "multi-centre study" or "multi-center study") or SU ("multicentre study" or "multicenter study" or "multi-centre study" or "multi-center study")

S3 $\mathrm{TI}$ random* or $\mathrm{AB}$ random*

S4 AB "latin square" or TI "latin square"

S5 TI (crossover or cross-over) or AB (crossover or cross-over) or SU (crossover or cross-over)

S6 MH Placebos

S7 AB (singl* or doubl* or trebl* or tripl*) or TI (singl ${ }^{\star}$ or doubl ${ }^{\star}$ or trebl ${ }^{\star}$ or tripl ${ }^{\star}$ )

S8 TI blind $^{\star}$ or AB mask* or AB blind ${ }^{\star}$ or TI mask ${ }^{\star}$

S9 S7 and S8

S10 TI Placebo* or AB Placebo* or SU Placebo* 
S11 MH Clinical Trials

S12 TI (Clinical AND Trial) or AB (Clinical AND Trial) or SU (Clinical AND Trial)

$\mathrm{S} 13 \mathrm{~S} 1$ or $\mathrm{S} 2$ or $\mathrm{S} 3$ or $\mathrm{S} 4$ or $\mathrm{S} 5$ or $\mathrm{S} 6$ or $\mathrm{S} 9$ or $\mathrm{S} 10$ or $\mathrm{S} 11$ or $\mathrm{S} 12$

\section{WHAT'S NEW}

\begin{tabular}{lll}
\hline Date & Event & Description \\
\hline 16 March 2021 & Review declared as stable & $\begin{array}{l}\text { This review has been divided according to the category of inter- } \\
\text { vention and will not be further updated in this form. }\end{array}$ \\
\hline
\end{tabular}

\section{HISTOR Y}

Protocol first published: Issue 1, 1998

Review first published: Issue 1, 2000

\begin{tabular}{|c|c|c|}
\hline Date & Event & Description \\
\hline 31 January 2013 & Amended & Corrected error in summary of findings table 1 \\
\hline 8 March 2011 & $\begin{array}{l}\text { New citation required and conclusions } \\
\text { have changed }\end{array}$ & $\begin{array}{l}\text { Results and conclusions changed and five summary of findings } \\
\text { tables added. }\end{array}$ \\
\hline 8 March 2011 & New search has been performed & Updated search. \\
\hline 10 November 2010 & New search has been performed & $\begin{array}{l}42 \text { new studies and } 14 \text { new interventions added. Risk of bias as- } \\
\text { sessments incorporated. }\end{array}$ \\
\hline 10 November 2010 & $\begin{array}{l}\text { New citation required and conclusions } \\
\text { have changed }\end{array}$ & $\begin{array}{l}\text { Nine interventions found to be beneficial for the prevention of } \\
\text { mucositis. Conclusions changed. }\end{array}$ \\
\hline 16 June 2008 & Amended & Converted to new review format. \\
\hline 21 August 2007 & $\begin{array}{l}\text { New citation required and conclusions } \\
\text { have changed }\end{array}$ & $\begin{array}{l}\text { Substantive amendment. This substantial update with a search } \\
\text { only } 14 \text { months after the previous one includes } 18 \text { new included } \\
\text { studies, bringing the total of number of studies up to } 89 \text {. There } \\
\text { are four new interventions included, bringing the total number } \\
\text { of interventions to } 33 \text {. }\end{array}$ \\
\hline
\end{tabular}

\section{CONTRIBUTIONS OF AUTHORS}

Helen Worthington (HW) and Jan Clarkson (JC) wrote the protocol and 2000, 2003, 2006 and 2007 updates of the review.

The 2010 update was co-ordinated by Gemma Bryan (GB) and HW. GB, HW, JC independently and in duplicate assessed the eligibility of the trials. GB, HW, JC, Susan Furness (SF), Anne-Marie Glenny (A-MG), and Anne Littlewood (AL) independently and in duplicate extracted the information to complete the characteristics of included studies, and assessed the risk of bias of the trials. Data extraction was done by HW, GB, JC and AL and HW conducted the statistical analysis. GB, HW, JC, SF, A-MG, AL, Martin McCabe (MMcC) wrote the review. MMcC, Stefan Meyer (SM) and Tasneem Khalid (TK) provided a clinical perspective on the cancer, cancer treatments and interventions for preventing mucositis.

\section{DECLARATIONS OF INTEREST}

None known. 


\section{SOURCES OF SUPPORT}

\section{Internal sources}

- The University of Manchester, UK

- Chief Scientists Office, Scottish Executive, UK

- NHS Education for Scotland, UK

- University of Dundee, UK

- Manchester Academic Health Sciences Centre (MAHSC) and NIHR Manchester Biomedical Research Centre, UK

\section{External sources}

- NIDCR grant ref 1 DE016950-01, USA

\section{DIFFERENCES BETWEEN PROTOCOLANDREVIEW}

Clarification of the reason for exclusion of trials which report only multicomponent oral health indices.

\section{NOTES}

The title of the protocol was originally 'Oral care for patients with cancer treated with chemotherapy (excluding head and neck cancer).' This review has been divided according to the category of intervention and will not be further updated in this form.

\section{INDEX TERMS}

\section{Medical Subject Headings (MeSH)}

Antineoplastic Agents [ ${ }^{*}$ adverse effects]; Candidiasis, Oral [etiology] [ ${ }^{*}$ prevention \& control]; Neoplasms [ ${ }^{\star}$ therapy]; Oral Ulcer [etiology] [ ${ }^{\star}$ prevention \& control]; Randomized Controlled Trials as Topic; Stomatitis [etiology] [ ${ }^{*}$ prevention \& control]

\section{MeSH check words}

Humans 